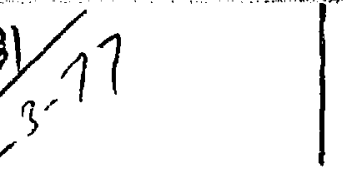

LA-6261-M

Manual

J. L. Norton

H. M. Ruppel uc-34 as 674

Issued: /December 1976

\title{
YAQUI User's Mariual for
}

\section{Firebali Calculations}

\author{
by

\section{MASTER}

An Aflirmative Action/Equal Opportunity Employer 
This work was supported by the Defense Nuclear Agency.

Printed in tire Linited States of America. Avalable fotn National Teclurical information Setrice

U.S. Deportunent of Commerce

5295 Port Royal Royd

Springfield, VA 2216

Price: Printed Copy $\$ 9.25$ bficm ficthe $\$ 3.00$

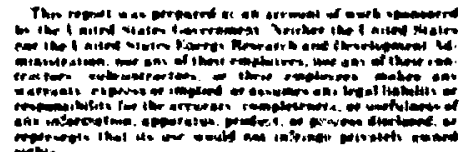

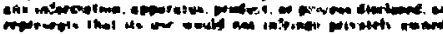

rate 
1. DESChtPTION of conf. . . . . . . . . . . . . . . . . . . . . . . . . . 1

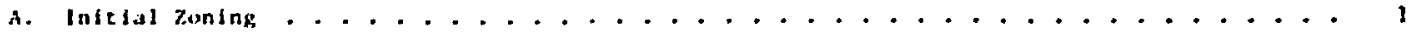

B. Fircball Inltialization ............................... 2

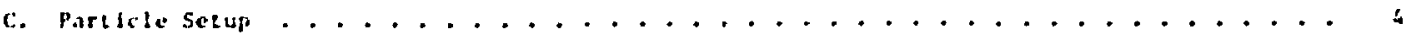

๖. Partile Movement . . . . . . . . . . . . . . . . . . . . . . . 5

f. Turbularace . . . . . . . . . . . . . . . . . . . . . . . . . . 6

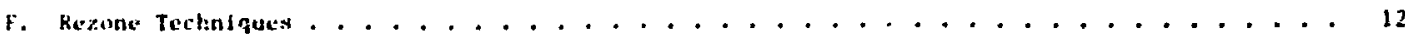

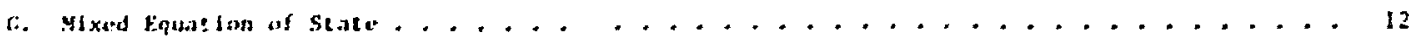

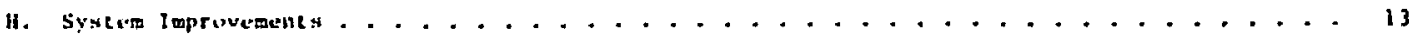

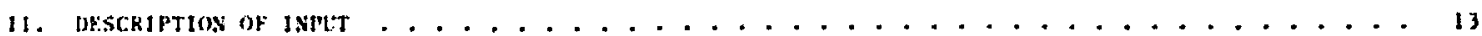

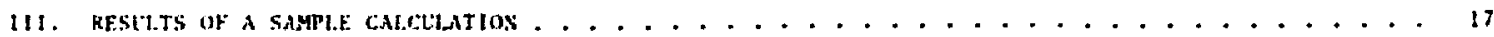

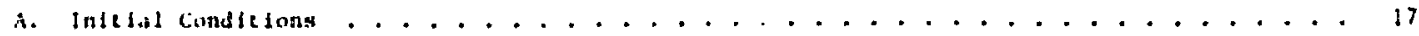

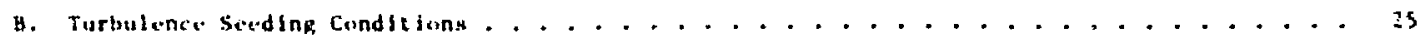

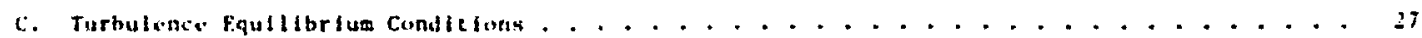

b. Maderate? late-tian Conditions

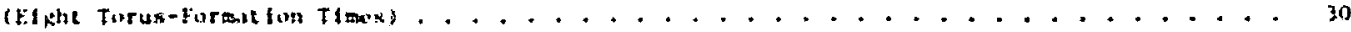

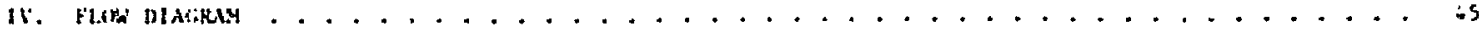

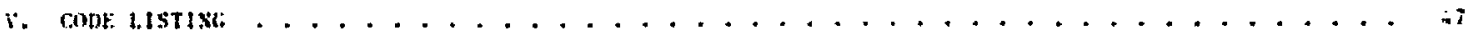

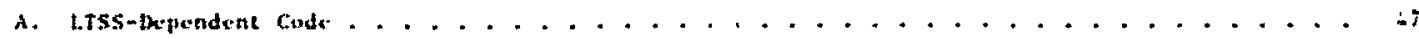

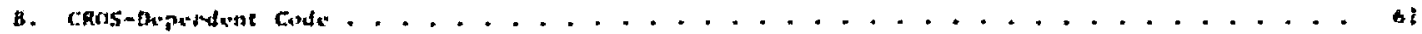

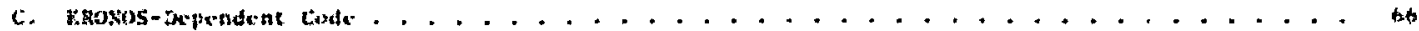

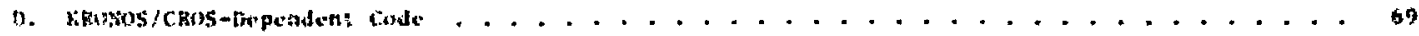

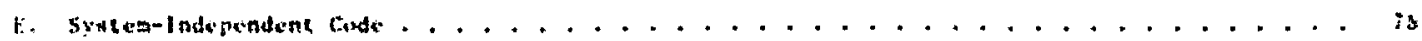

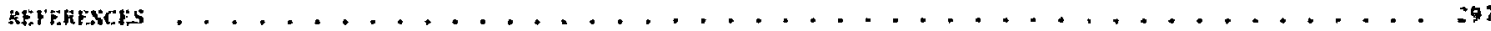

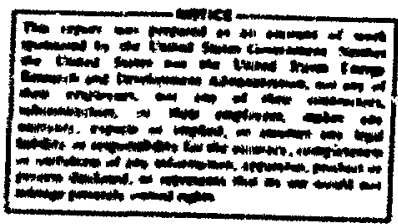




\author{
YAQYI LISER': MNUAI. FOK \\ FIREBAIL CALCULATIINS \\ by \\ I. I. Norton and H. M. Ruppel
}

\begin{abstract}
ABSTHAT

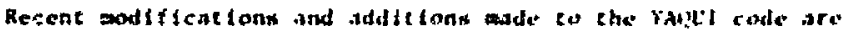

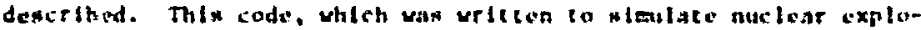
when in the atmosphere. hax bern laproved to tarlude the effects of turbulence. In addlelon. It now sllaws input data to ter opalined by direct interpalat ton in the one-disenutanal results of

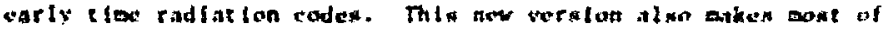

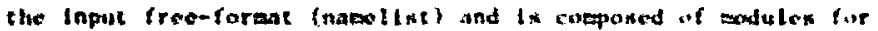

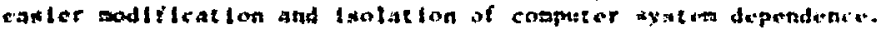

\section{DESCRIPTION of COD:}

The rapt eade ix a cosplation of two fluld-

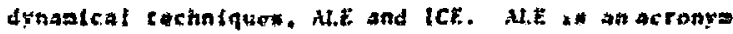

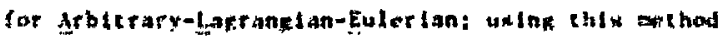
the finte difference wh polnts can be woved with the Cluld (lakrankian), hold xtatlonary (tulerlan). or soved ty kote prowertibed rezono alkoritho

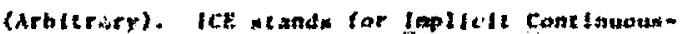
Indd Eulecian: becaune the hydrodynabse rquat fons

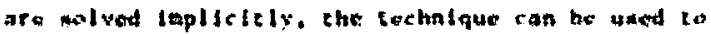
nolve for flow al all npedu. The analyxen of thene

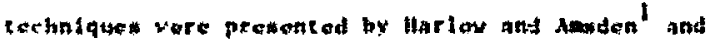

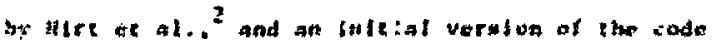
way deacrlow by tenden and Hire.

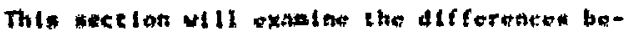
ween the Inictal version of the cate and the wad tied verwion wed to do the caleulatione in this report.

\section{A. Inlelal Zonin:}

An Intelal trout zonfing we to wown in Fits. 1. The ialeial urld la deterwiced by the porabeters ph.

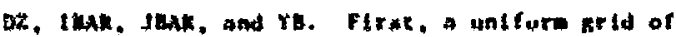

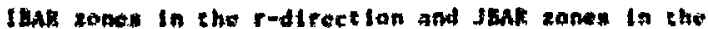
z-dicection with the botos at 2 - Vt i* kenetsced. The eones are all on ca vide by $D z$ ca hith. Then the

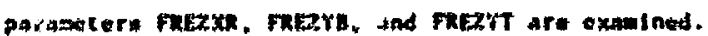

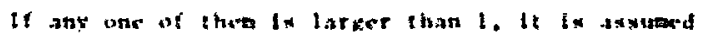

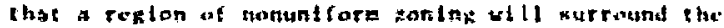

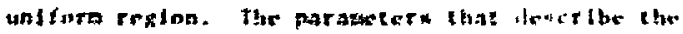

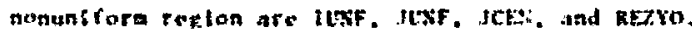

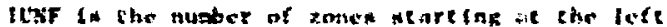

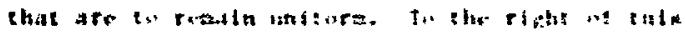

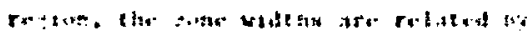

$$
\operatorname{mR}(1+1)=\operatorname{pas}(1)+\operatorname{matz} t a t
$$

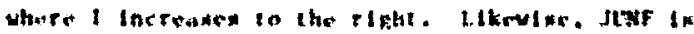
the nuber of zeses in the a-direston that vill

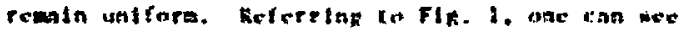
that the ropion of unf fore zont:e will be rentered on the line JCEs zones ahove the botson of the krla

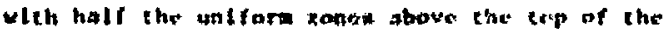
ICFith tone ard half bolow. The hulthe of the

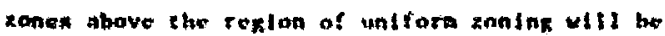
rolated by the equation

$$
\text { bz }(t+1)=\mathrm{mz}(s)-\text { Fugzrt }
$$

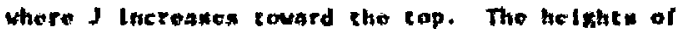

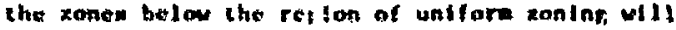
be related by the equation 


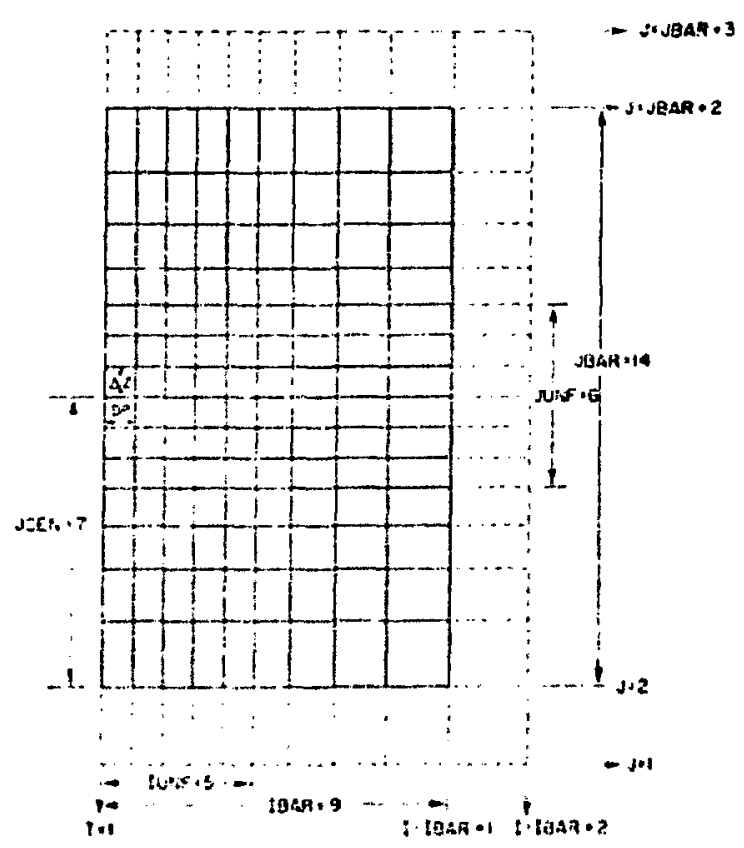

51.5. 1. Samplo inictal zontalg soctup.

$D \%(5+1)=1 \%(3)^{4 F R F T B}$.

The cop of the JCExth zone is redefined to be at the puint $a$ - aEtro. Becauge enezrs will arove tee botwa of the nowh. It is necensury to recalculace ya

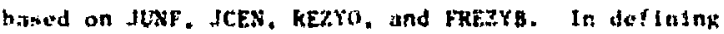
grics for probleses wh the ground at the iwt ton.

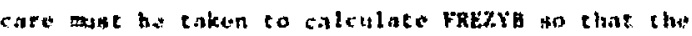
boteor of the $J=2$ kone colfeldes edith $r=0$.

the gatd is wurrounded on three wides by lingerm of Claciclous cells, hhows as doted ifnew in fin. 1 . Thwo allow a yarlety of boundary candtelass to he appllad. The boteon laver of fictitlous cells catures the firat row of rall zones to be at $f$ ? rather than at : 1 . Thls fact can be confussing if one is not aware of the convention. The grid lines are knom as I and I lines: I I It at the exerame left: 1 - IBNA + 2 In at the extresthe of the

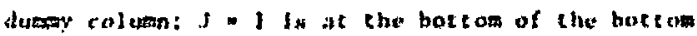

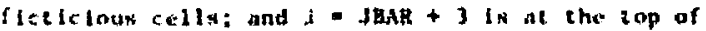
the cop fleticloun cells. The tonet whone lougr. lufe corngy Is at the Interswetion of the lines t and I Is known as une $(t, j)$.

\section{B. Firehall Initializat fon}

The Initial verston of the code read in data that had been Interpolated from one-dimensional spherical form to a two-dinenstonal grid with veluclties centored at cell edges as in MAC. However. In YAQUI. Veloctties appear at vertices: therefore. a seconv laberpotalion was required. To avoid this unnecessary step and the resultant smoothlng, the code was modifled in perult inputilng data in chedimensfonal form. The data is then interpolated directy anco the inupl grid.

The incerpoiacion cechntque is as follows. The 1j) data is Input inv zone per card. Card I contalns che radlus of the outor boundary of zone $i\left(r_{1}\right)$. the relocity of the outer boundary $\left(\dot{r}_{1}\right)$, and the spectific internal energy and density of the zone (e, and $f$. respectively) in the format $4 E 15.0$. Cards arc read untll a blanix card or thend-of-flle Is encountered. The inner radlus of the first zone is aswamed to be zero $\left(r_{0}-0\right)$ an is the velocity at the concer $\left(\dot{r}_{a}=0\right)$. The desilly and energy ire cell-eantered quanticles. A sample lo setup fo showt in Fig. 2. The in data is superimposed on the ID Yapte grid as shown in Tig. 3.

To tarry out the interpolation, one divides each spheriral sluell into subzones uning both radial and angular tegments. Conslder a portion of a ID nono is shmon on Flg. 4. Of courge, in practice

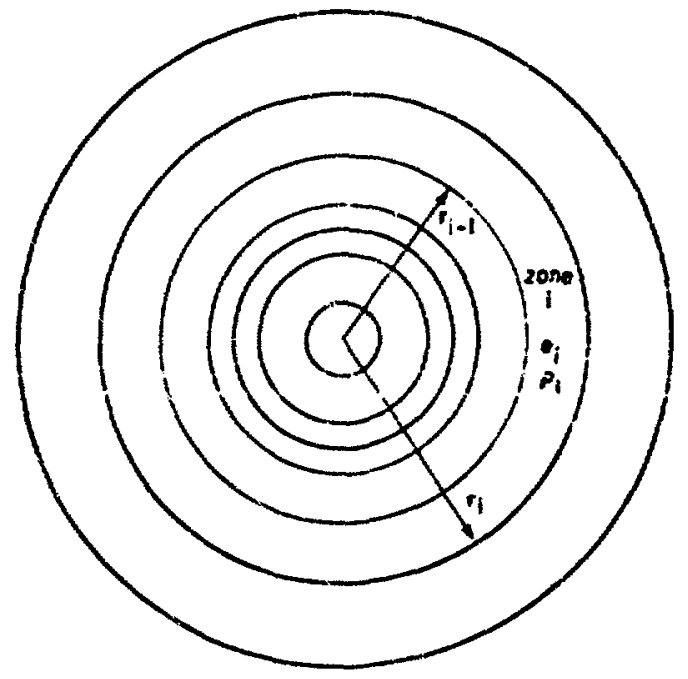

Fig. 2. Sample in firubsll Initiol data configurstion. 


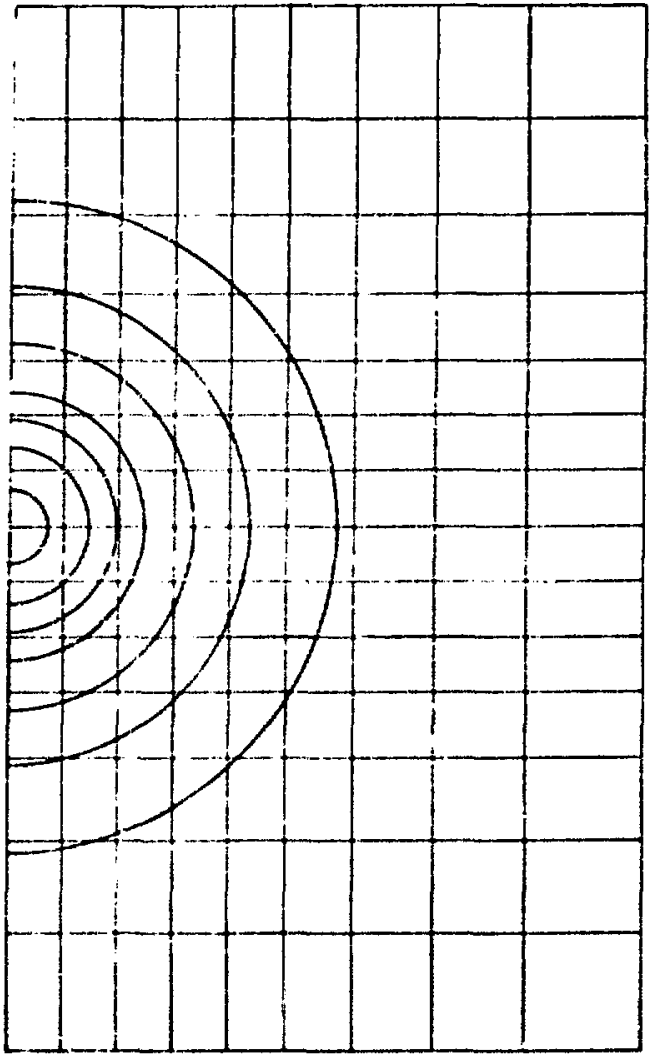

Fik. F. Supespostelon of li fireball data on the 2i) rewi: arid.

${ }_{1}$ to $0^{\circ}$ and ${ }_{2}$ 1s $180^{\circ}, \quad \because "$ is determined from $180^{\circ} /$ NTH, whe NTH it an Input quant liy: it is de-

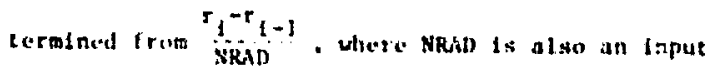
quancley. STH and NRAD Ir. held constane for all zones. Tho center of a subzone is deflned as shown in fig. 5. The Interpolation procedure, then. Is ass foilins. Constder a stingle subzone of a splserical shell. Find into which Yaqui zone the cenzer of the subronc falls. Assian nll the mass, momentum, and Internal cnergy of the subzone to the YaQUl zone. onat can estimite the accuracy of the procedure by accubalat Ing the voluses of the subzones that are assigned to an Individunl YaQu zone, When all of the subizones have been ansigned, the volume of the YNQU Jone and the sum of the volumes of the subzones itsslgned to the YaGUI zone should be nearly the satse except for those Yaqui zones only partlally within the outermost sshorical shell.

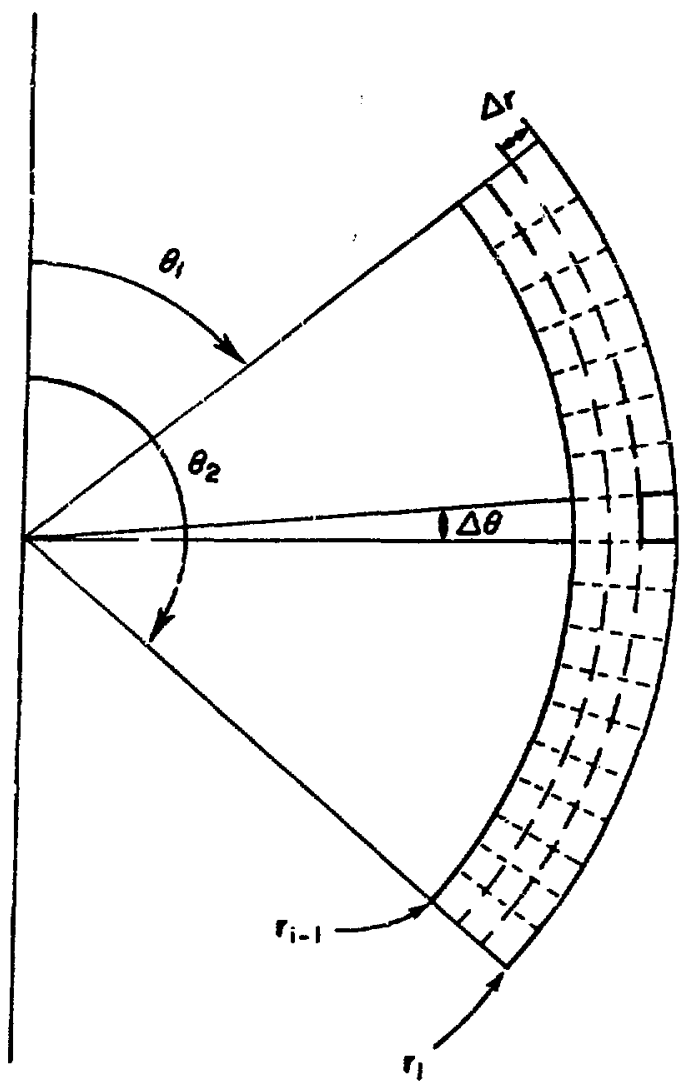

Fig. 4. viviston of lo fireball daca inco subzones for interpolation purposes.

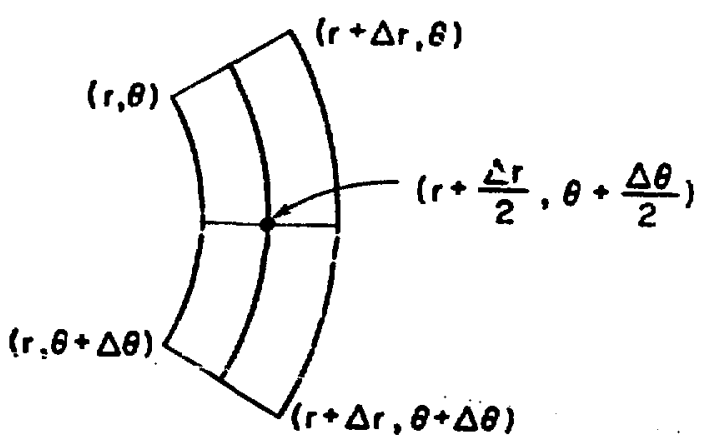

Fig. 5. A typical 1D interpolation subzone. 
To handle the latter, the sum of the subzone volumes is also used as a lag. If the volume crror

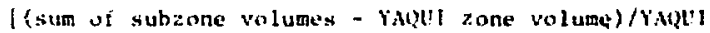
zone volumel is greater than 1 ? then the five nearest colls on the top. botlom. Ind right are examined c see if any are within the tirmall. (5ee Fig. 6.)

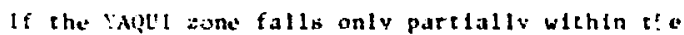
ifreball, at least one of the five netghbors will not bo within the freball at all. If all of the five golshbors are ftraball alls, then there is an Internal $\because 9$ ume Inaccuracs and the Interpolas ion

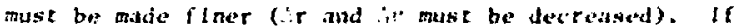
a nofitraball notghbor is found, then the spactif intersal energy and donsity of this nelghtor are used to establish the most and laternal enargy uf the part of the VAQL t zone that is not within the firehall.

To understind this betert. comolder the example shown In Fig. 6 . I.se $t_{\text {max }}$ he the outer radiug of the last 10 zone. The hor bontally crosstuateled purtion of zone ( $f, j)$ ls whin the forbill and the

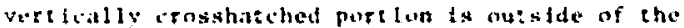
firebail. The relative voluse error will cortalnds be preater than $1 \%$ of the five netghors shown.

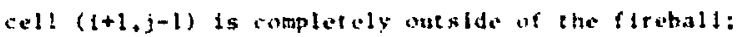
its specifle internal enerny and donstev would be usted fo astablish the laternal encery and fass of the Vutetially cenishatehed puretion.

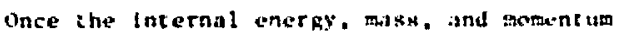
romponents are established fo. all ragt l zones thilt iall completely or partially within the flraball

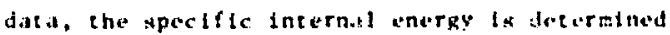
by alktang the zone Internal chergy by the zone

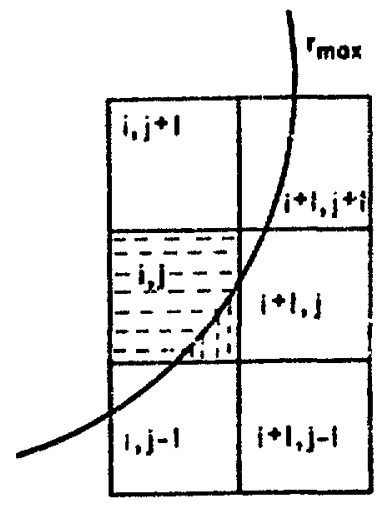

Fig. 6. Technique for handling YAQUI zones only partially within the fireball.

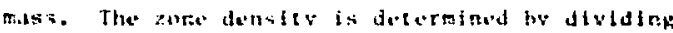

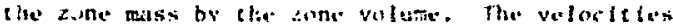

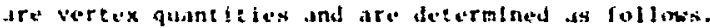

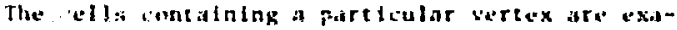

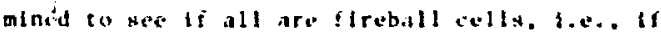
the vertax lise withen the firelkall. If any ire

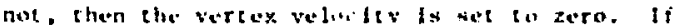

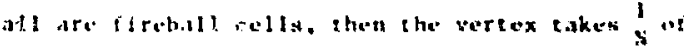

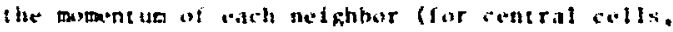

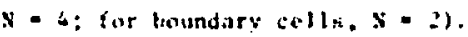

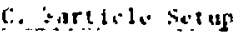

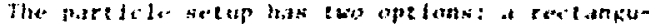

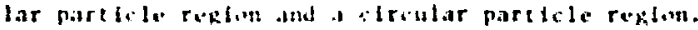
Buretangulats Reglan

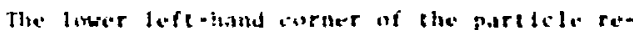

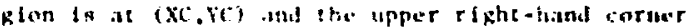

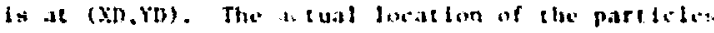

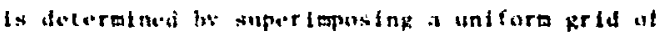

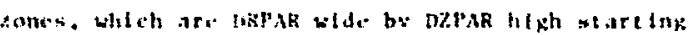

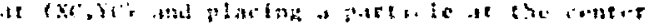

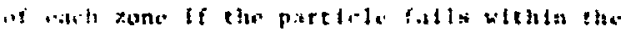

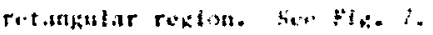

6iratent Resion

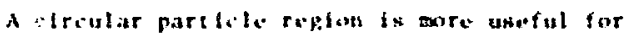

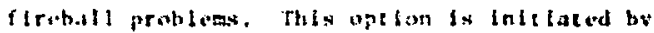

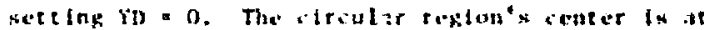
(7), YC), its soptus is XI) (XC is not uned).

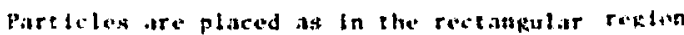

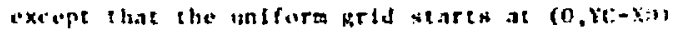
and only particlog that roll within the stoth tro tuscod.

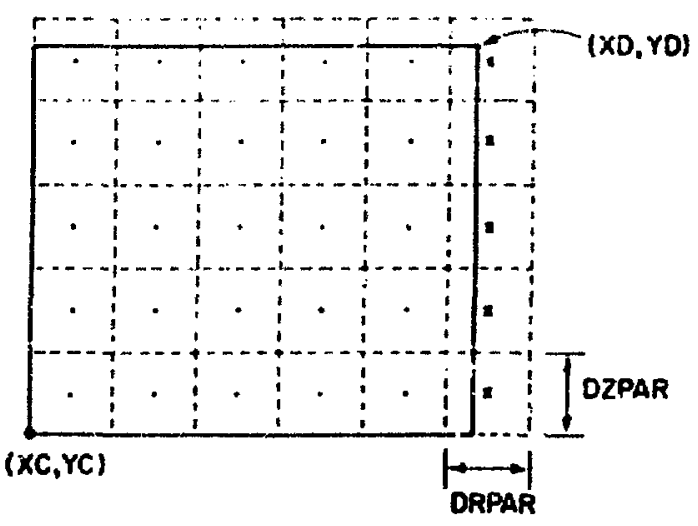

Fig. 7. Particle goneration scheme. 
b. Parstele Movesnent

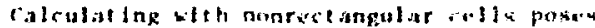

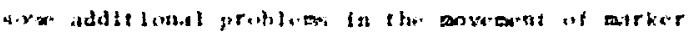

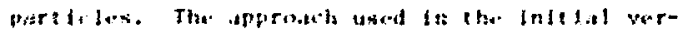

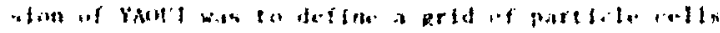

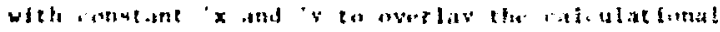

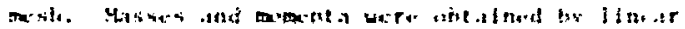

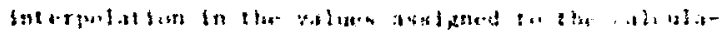

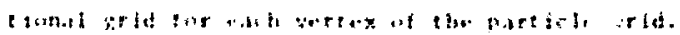

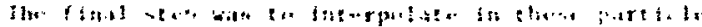

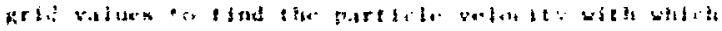

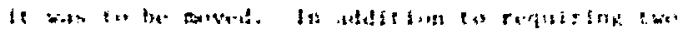

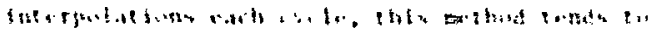

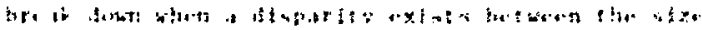

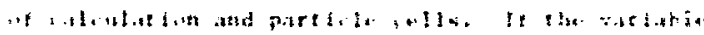

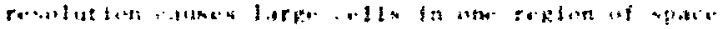

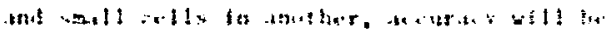

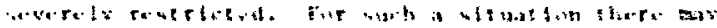

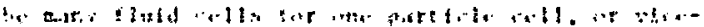

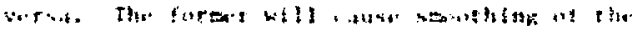

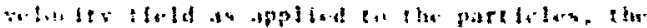

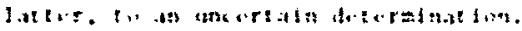

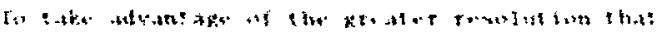

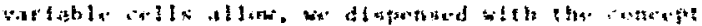

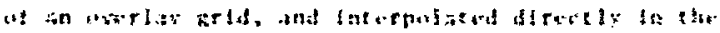

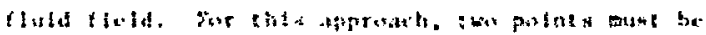

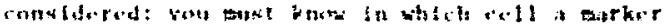

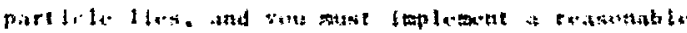

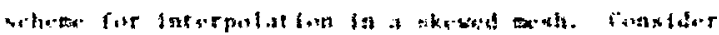

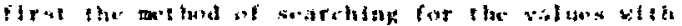

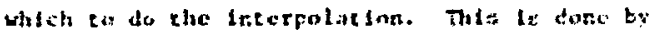
Arating rectors da wuceseston trom the parefele to cach of lise veretect of is calculationat atll. If chene proceced in order ard the angles between wuccesalve vecents are lere ehan - for wath of the four vertors, the particle lsos within the rell. This way be sean more clearly in Fig.

fig. B(a) the particle lick inside che cell. in

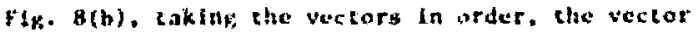
to vercex \& liew between the vectors no vertless 2 and 3, and hence the particle lfesi outgide the cell. In $\mathrm{Ft}_{\mathrm{g}} . \mathrm{g}(\mathrm{c})$ the angle betwen the vectors to verclces 4 and 3 is greater than $\pi$, and the paredcle iles outside the cell.

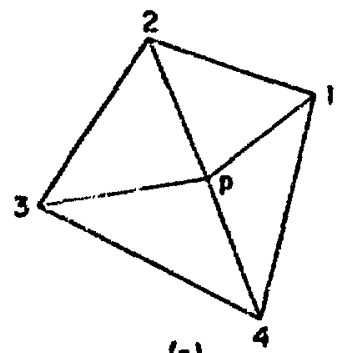

(a)

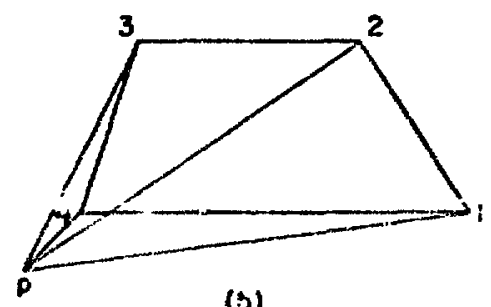

(3)

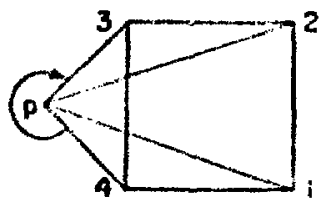

(c)

Fat. A. inereination of parelete postelons.

The numering of verelces in arbltary and waty

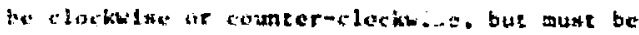
cunserutive. The ratlonale for this sectingly

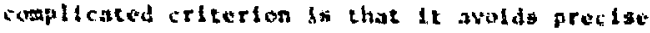
knowledge of any angles and tence requires no

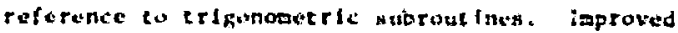
soctinds for whdeh this is also true have since been found, one of which we will mention later. However, in che curtent version of the cede, the above applosch lo used. To increase efticlency a one-dimensional array loolds the number of the celi contalning a partlele at the beginning of a caliulational. cyc:e.

If a partitie is no longer in the cell in wilch it began the eycle, an efricienc search is undrriaken to find the now lacation. For stewed cells, the particle can move ware than one cell away. and hence detamining an optimus trajectory along which to search is useful. This wlutmizes 
the number of tests that aus: be tande.

Two eriteria aro laposed in aclecelng the interpolation schere ance the appronriate cell has men ldent if ted:

1. The interpotacid ralaciey gus: he bounded

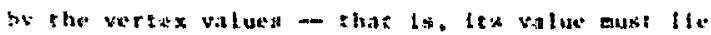

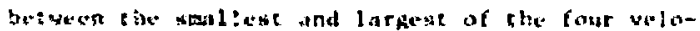
c18:10.4.

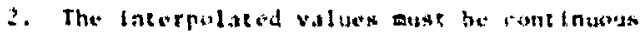
a. rosin enll bermeartas.

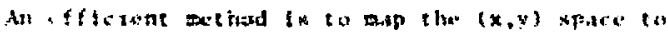

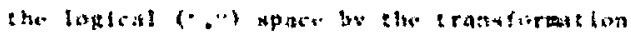

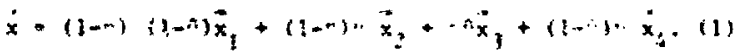

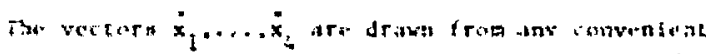

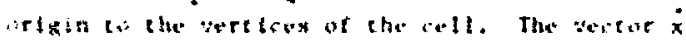

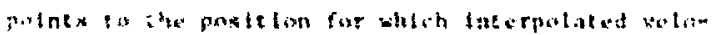

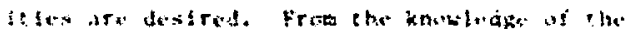

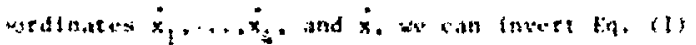

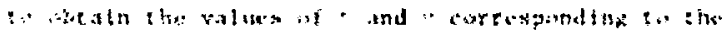

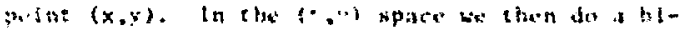

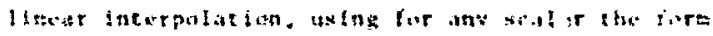

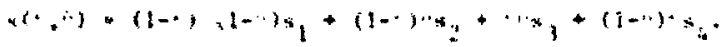

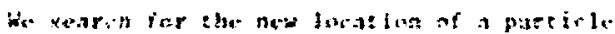
by draxting it the fron the renger ni the aelt in which the partlcle thegat the rete to its present

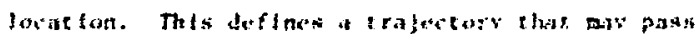
through soveral cells and along which we perform our

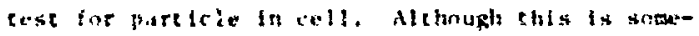

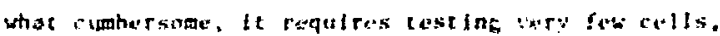
untulity juke one ar lwo. An toproved approish used by Prache clatuates the separate resting and aute

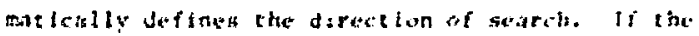
particia lies in the cell $1 \mathrm{n}$ questem, the values of

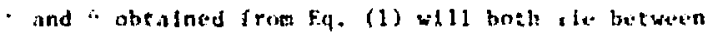
0 anc 1. If efther does noc, the cell lendialed by the values of " and "Is eximined. Fist eximple, If - 1.7. increar I by une and recalculate " athol ". This approach is nuticer and hore efficlenc. In future versions of the particle transport, we plan to insorporate such a scheme into YAqut.

Ar adultional component of particle dlsplacement 1s required when the effects of turbulence are being calculated. This is described in the next section. tin Turbulenis:

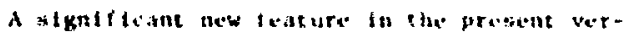

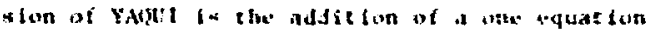

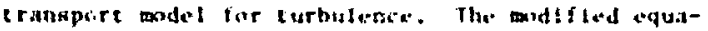

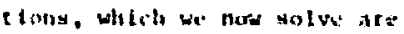

che ansy enuat ion

$$
\frac{2}{30}+\because \cdot, \because+\because \cdot \therefore \because+.
$$

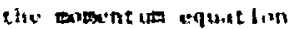

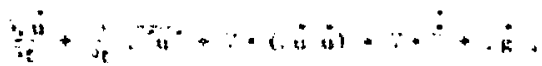

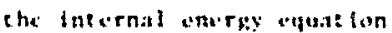

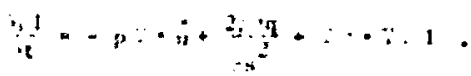

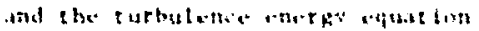

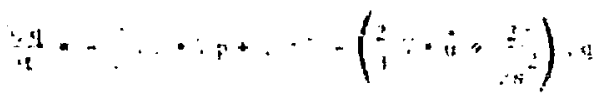

$$
\begin{aligned}
& -\frac{2}{3} \cdot \because \cdot y^{2}+\cdots \cdot \cdots
\end{aligned}
$$

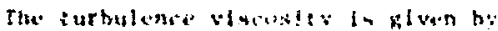

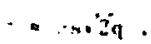

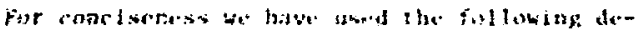
fing ixin:

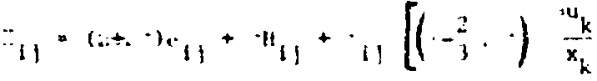

$$
\begin{aligned}
& \left.-\left(p+\frac{3}{j}, q\right)\right]
\end{aligned}
$$

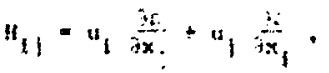

$$
\begin{aligned}
& \because=e_{j} i_{j} i_{j} \text {. and } \\
& \epsilon_{11}=\frac{1}{3 x_{j}}+\frac{1}{3 x_{1}}
\end{aligned}
$$


The purameters of the model are $t$ and the sitale, $s$, Values ire obeatned phenomenologically from fits to experiment. For : we use the constant, $E=0.02$. Fur the srale. corstint values over the mesh and the mart complatioted phenumenulogicai form

$$
\begin{array}{ll}
s=0.1 \div d(x)\left(2-\frac{v(\vec{x}, z)}{v(1+, z)}\right) & v(r, z)=0 \\
=0.24 d(z) & v(r, z) \cdot 0
\end{array}
$$

have toren ured. The function d $(z)$ is the radia?

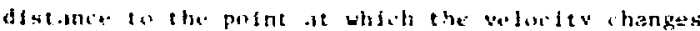
wign, and $v(\cdots, f)$ is the axtal component of the yelorey un the axis, $r=0$, In a skewed mesh r.q. (!2) requeras ichelderable bogte and interpoiation.

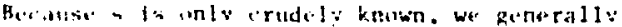
ipprexithate the aluve larm by

$$
\checkmark n \text {. Ind }\left(2-\frac{v(t, 2)}{v(0,2)}\right) \text {; }
$$

In this simplitiod r.elat ton, d is a comstant,

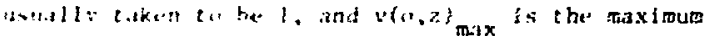

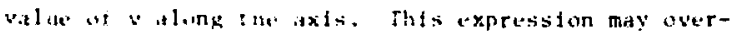
antmate the scale tor fireballs and cut duwn on the rate of decas of the turbulence e'nergy. Erring in

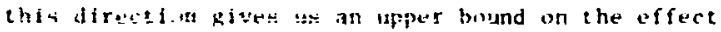

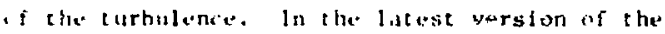
rode, we simpls incorpurate a constant. icale tincoughint the mesh, though proviston extsts in the ende far i mure fienoral treatmenz.

In difforeme ing the turbulence additions, we ras take advantage of much of the cexist ing framework of the haste VAyll program. Bccause small time-

level fnconsistencies in the turbulence equat ions are insigraficant, economy is a major criterion in cistablishing the order in which the several additions are included. For example, looking at the structure of che modifled striss tensor, we are led to replace

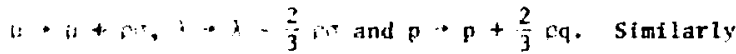
$H_{1 j}$ is calculated from $F$ and it at the old time level: this 1 lows the stress tensor tn be handled explicity in Phase I simplifylng the addition. The term $\frac{j}{\partial t} \overrightarrow{0} u_{1}$ in the momentum equation is modeler. usirig the flux approximation, as $-\frac{\partial}{\partial t} \frac{\partial \mathcal{E}}{\partial x_{i}}$ : this requires saving the two components of $\sigma \frac{\partial p}{\partial x_{1}}$ for each cell from the previous tine step. Clearly such an approach centers the time derivative about $t-\frac{\delta t}{2}$ and not at the same $t$ ime level as $n_{1 j}$. Por reasonable the varations, the Inconslstency should not be important.

Throc more diffusion terms must be differenced: sne in the wass equation, one in the internal energy equation, and one in the turbulence energy equation. Fach of thesc is added explicitly in Phase I with derivat lues from $x$ ime level $n$.

The transport equat ion for the turbulenc: enurgy $q$ is mainly handled explictily. However we ran irclude some advanced tipe information by wit lng Eq. (5) in the form

$$
\begin{gathered}
(\cdot q)^{n+1}\left[1+\frac{2}{3} \because \cdot \vec{u}+\frac{2 n}{2}\right]^{n}=(r q)^{n}-r=t\left[\frac{\nabla c \cdot \Gamma p}{j}-F !\right. \\
\left.+\frac{2}{3} \cdot(\cdot \cdot \vec{u})^{2}\right]^{n}+(\cdot \cdot-(\cdot q))^{n}
\end{gathered}
$$

In rylindrical geometry : takes the fort

$$
=?\left[\left(\frac{u}{\partial r}\right)^{2}+\left(\frac{v v}{\partial z}\right)^{2}+\frac{1}{2}\left(\frac{u}{\partial z}+\frac{i v}{\partial r}\right)^{2}+\left(\frac{u}{r}\right)^{2}\right] .
$$

All the terms on the right-hand side of Eq. (14) are eva!tited at time level $n$ as cell-centered quantitfes. For most of the terms this proceeds naturally; but for the buoyancy creation, $\frac{C}{S}: c . \mathrm{p}$, a small reach fis necissary. In the notation of Fig. 9 we could evaluate :he cerfuatives directly at the

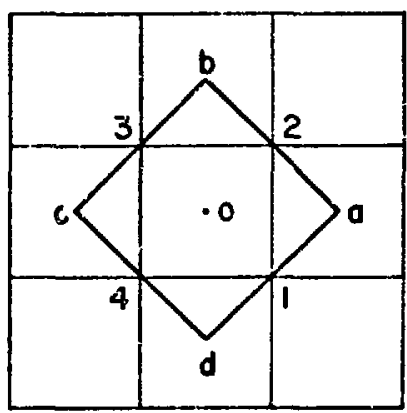

Fig. 9. Quantities involved in YAQUI decivative evaluation. 
vertices $1-4$ and then average to obtain $\left(\nabla \rho \cdot \nabla_{p}\right) 0_{0}$ This uses information at nine cells and is unnecessarily smoothing. For this reason we use cells $a, b, c$, and $d$ and obtain the derivatives at the center of cell o in tems of these. For example,

$\frac{\partial \rho}{\partial r}=-\frac{1}{2 A}\left\{\left(\rho_{a}-\rho_{c}\right)\left(z_{b}-z_{d}\right)+\left(\rho_{b}-\rho_{d}\right)\left(z_{c}-z_{a}\right)\right\}$,

where $A$ is the area of the quadrilateral abcd. We are particularly concerned about smoothing out derivatives because the sensitivity of the turbulence energy and the level of turbulence that can be supported depend on the size of gradients of various quantities. Derivatives of vertex duantities are calculated at cell centers by the equations

$\frac{\partial u}{3 r}=\frac{1}{2 A}\left\{\left(z_{2}-z_{4}\right)\left(u_{1}-u_{3}\right)+\left(z_{3}-z_{1}\right)\left(u_{2}-u_{4}\right)\right\}$

and

$\frac{\partial u}{\partial z}=\frac{1}{2 A}\left\{\left(r_{2}-r_{4}\right)\left(u_{j}-u_{1}\right)+\left(r_{1}-r_{3}\right)\left(u_{2}-u_{4}\right)\right\}$,

where $A$ is the area of the cell.

If we expand the derivatives about the ccater of the cell, we find that the error is proportional to second and higher derivatives. In a similar fashion we can obtain derivatives of cell-centered quantities at cell centers (as discussed above) by appropriate choice of configurations. The necessity to optimize the calculation of gradients implies that high-resolution caiculations are important in evaluating turbulence models.

Simllar problems artse for the Laplacian or diffusion-1ike terms. Again, several approaches are posstble and in this case optiaization is much less crucial, because the level of turbulence is only Indirectly affected. The criteria applied to select an approach for differencing such terms were: that an equation of the form

$$
\frac{\partial c}{\partial t}+\vec{u} \cdot \nabla c=\nabla \cdot \sigma \nabla c
$$

could not lead to negative $c$ anywhere in the mesh. and that the difference form of $\nabla \cdot \sigma \nabla c$ should reduce to the expected form for the case of a uniform rectangular mesh. For example, if $c$ represents the concentration of a chemical species,

$$
\frac{1}{v_{0}} \sum_{j=1}^{4} \frac{c_{j}-c_{o}}{\frac{1}{2}} \frac{\left.A_{j}+A_{o}\right)}{\left(A_{0}\right.}\left\langle r_{j u}\right\rangle\left\langle\sigma_{j o}\right\rangle=\left(\nabla_{\sigma} \nabla_{c}\right)_{o},
$$

where $c_{j}$ is the concentration in cell $l, d_{j o}$ is the length of the cell side between cells o and $j,\left\langle r_{j o}\right\rangle$ is the distance between the centers of cells 0 and $j$. $A_{j}$ is the area or cell $j, v_{o}$ is the volume of cello, ind $\left\langle\sigma_{j o}\right\rangle$ is $\frac{\sigma_{j}+\sigma_{0}}{2}$. See Fig. 10 for examples. In Cartesian cooritinates for a uniform rectangular mesh with sides $\delta x, \delta y$, and constant $\sigma$, this reduces to

$\sigma\left(\frac{c_{1}+c_{3}-2 c_{0}}{\delta x^{2}}+\frac{c_{2}+c_{4}-2 c_{0}}{\delta y^{2}}\right)$

as we would wish. The vertices of this quadrilateral are at the center of their respective cells.

In tite finite difierence approach with finite time steps it is possible for the turbulence energy to become negative in certain cells. If, for example, $\delta t \frac{\sigma}{\rho} \nabla \rho \cdot \nabla p$ is positive and greater than $\rho q$ in a given cell, more energy will be subtracted from the cell than it contains. One could reduce the time step, but this would never really solve the problem. The assumption we make is that sinco, numerica1ly, turbulence can go negative in regions in which it is decaying, if $q<0$, we set $q$ to zero. Experience has shown for the firebali calculations that less than $1 \%$ of the turbulence energy is lost by this procedure.

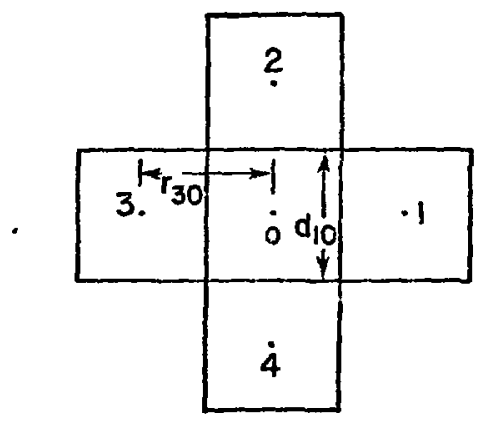

Fig. 10. Defintion of quantities used in differencing of turbulence part of the concentration equation. 
As far as convection is concerned, the quantity iq is convected and, because the difference equations for the convection conserve the convected quantity identically, the turbulence energy is conaerved in Phase III. The total energy, however, is not, In the Initial code versior ${ }^{3}$ an equation for the total energy is written, and this is the quantity that is convected. Momentum is also convected. and hence conserved; the internal energy is obtained by subtracting the kinetic energy from the total energy. This places all the uncertainty in the ircernal es-ergy, which if 1 t is a small part of the total energy, can lead to large fractional errozs in the internal energy.

With the introduction of the equation for tur. bulence energy, it has seemed convenient to deal directly with the internal energy. In the code the equation for the internal energy follows the pressure iteration, allowing us to calculate the pdv work with a time-advanced pressure. The quantities that are convected in Phase III, then, are the internal energy, the turbulence energy, and the momentum, which are individually conserved. In general, this means that the kinetic energy and, thus, the total energy, $E=\rho I+\rho u^{2}+\rho q$, will not be conserved. This lack of energy conservation does not seem to be significant and is ignored in actual calculations.

A small change has been made in the energy equation related to the smoothing of the velocity field for computational stability. If alternate mesh vertices are not coupled in some way (see Ref, 3), an instability arises. The approach we elect is to couple the alternate nodes only when a local minimum or maximum in the velocity field uccurs. We apply a restoring acceleration to vertex 4 of the form

$$
\frac{1}{a_{n c} \delta t}\left[\frac{I}{4}\left(\vec{u}_{1}+\vec{u}_{3}+\vec{u}_{6}+\vec{u}_{8}\right)-\vec{u}_{4}\right]
$$

(See Fig. 2 of Ref. 3).

In Ref. 3 this is applied to each vertex each cycle to control the instability. In our version we apply the restoring force only to those components of $\mathbf{u}$ at vertex 4 that have values larger than or smaller than kny of the neighbors $(1,3,6$, and 8$)$. That is, a local maximum or minimum in the r- component of $\vec{u}$ is smoothed by a restoring acceleration in the r-direction and similarly for the zcomponent. This is less diffusive than clte approach that applies it everywhere each cycle. The intent is that when no instability threatens, this will not smooth gradients.

This node coupler clearly reduces the kinetic energy of the system, acting like a viscuss dissi-

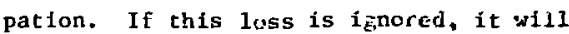

lend to a gradual diminishing of the system's energy. On the other hand, to include the eaergy in the internal energy equation as viscous heating reaily has no basis in physical reality. However, in our version, we choose the latter option and include the energy removed by the node coupler in the equation for the internal energy. In the original version of the code the other choice was made.

one can see by examining the model equations

for turbulence that no mechanism has been built in to initiate the curbulence spontaneously. That is it there is no turbulence present, i.e. $q=0$, nor:e can be created or can grow. For this reason, the turbuleirce must be seeded initially and allowed to equilibrate with the mean flow through the creation and decay terms in the equation for the turbulence energy. Several alternative seedings have been tried and found to lead to the same turbulent configarations after a fairly short time. A very reasonable approack is to seed the turbulence proportional to the vorticity of the mean flow fiald. This is done after the field has been established, that is, shortly before torus formation time This riming is not crucial. It can be seeded earlier and fino its way to a similar level and distribution in a short time, We miss any highintensity early time turbulence, likely initated bv Taylor instabilities as the device case and the very hot debris dzcelerate. We assume that the fluctuations deray in a few seconds because nothilsg appears to be present to support thew. The equilibrium turbulence we calculate really only has meaning at later times.

Because the measured properties of the fireba11, rate of rise and radfal expansion, depend on the positions of the marker particles, it was felt that their motion should be coupled directly into the turbulence. This is done by adding a random turbulent diffusion velocity to the perticle motion by 
the following techrique.

The difiusion of mass as a function of time

from a point source of urit mass at position $\vec{r}_{0}$ is described by the diffusion equation

$$
\frac{\partial \rho}{\partial t}=\lambda \nabla^{2} \rho+\delta\left(\vec{r}-\vec{r}_{o}\right)
$$

where $\rho$ is the density and $\lambda$ is a constant diffusior. coefficient. Define the quantities $\delta \vec{r}=\vec{r}-\vec{r}$, $\delta x=x-x_{0}, \delta y=y-y_{0}$, and $\delta z=z-z_{0}$. If $\rho(\delta \vec{r}, t)$ is wititen as $\rho(\delta \vec{r}, t)=X(\delta x, t) Y(\delta y, t) Z(\delta z, t)$, it can be shown that

$$
x(\delta x, t)=\frac{1}{\sqrt{4 \pi \lambda t}} e^{-(\delta x)^{2} / 4 \lambda t}
$$

with similar expressions for $Y$ and $Z$.

In calculating the additional particle motion due to turizulence, consider the particle at time $t_{0}=0$ to be a massless point at $\vec{r}_{0}$ and use Eq. (22) as a probability distribution function for determining the position of the particle at time $t=$ $t_{0}+\delta t$. The turbulence $v i s c o s i t y$ then serves as the diffusion coefficient $\lambda$. In cylindrical coordinates one should solve Eq. (21) in a cylindrical basis

$$
\rho(\hat{o} \vec{r})=R(\hat{o r}) z(\hat{o z}) .
$$

However, $R$ cannot be determined lis closed form and for small $\delta t$ and $\delta x$, with $j x>\frac{\lambda \delta t}{x_{0}}$, $R$ reduces to the form of $x$ in Fq. (22). Thus, Eq. (22) can be used with confidence in cylindrical geometry as long as it is applied in its region of validity. Furthermore, $\delta \mathrm{x}$ must be small compared with a cell dimension so that the turbulence viscosity being used as the diffusion coefficient remains constant in the region and during the time considered.

The general Gaussian (norma1) distribution is

$$
f(y)=\frac{1}{\sqrt{2 \pi} \sigma} e^{-y^{2} / 2 \sigma^{2}},
$$

where $\sigma$ is the standard deviation. Equation (22) can be put in this form by setting

$$
\begin{aligned}
& \sigma=\sqrt{2 \lambda \delta t} \text { and } \\
& y=\delta x .
\end{aligned}
$$

where we have replaced $t$ by $\delta t$.

The standard probability distribution function (randow number generator) avallable on most computers is the uniform distribution $p(x)$,

$$
\begin{aligned}
p(x) & =1, \quad 0<x<1 \\
& =0, \text { elsewhere. }
\end{aligned}
$$

Whate we need is the distribution given by Eq. (23) with $\sigma$ given by Eq. (24). To accomplish this Eq. (25) is mapped on to Eq. (23) (see Fig. 11) with the exprosion

$$
p(x) d x=2 f(y) d y,
$$

because the probability of finding $x$ in $d x$ is equal to the sum of the probabilities of finding both $y$ and $-y$ in their respective dy's. Therefore,
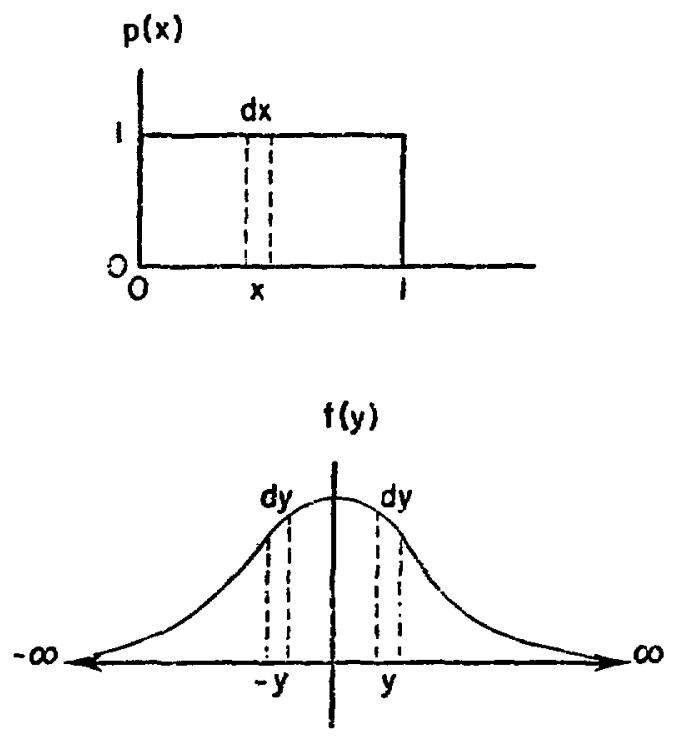

Fig. 11. (a) Uniform distribution, (b) Gaussian distribution. 
$\int_{0}^{x} f\left(x^{\prime}\right) d x^{\prime}=2 \int_{n}^{y} f\left(y^{\prime}\right) d y^{\prime}$,

$d z \int_{0}^{x} d x^{-}=-\frac{2}{\sqrt{2 \pi} \sigma} \int_{0}^{y} e^{-y^{2} / 2 \sigma^{2}} d y^{\prime}$

Whth the vartable transformation $z^{-}=\frac{y^{\prime}}{\sigma_{v}^{\prime} \overrightarrow{2}}$,

$x=\frac{2}{\sqrt{\pi}} \int_{0}^{y / \delta \sqrt{2}} e^{-z^{-2}} d z^{\prime}$

By definition, the standard error function is

$\operatorname{erf}(t) \equiv \frac{2}{r \pi} \int_{0}^{t} e^{-t^{-2}} d \tau^{-}$

therefore,

$$
x=\operatorname{erf}\left(\frac{y}{\sigma \sqrt{2}}\right)
$$

and frow Eq. (24),

$$
y=\sqrt{4 \lambda \bar{c} t} \operatorname{erf}^{-1}(x)
$$

The above is the mappling from Eq. (25) to Eq. (23)

that is desired.

In principle, then, one determines a random number using Eq. (25) and maps it onto Eq. (23) using Eq. (28). One can see that the y in Eq. (28) is the required particle displacement due to turbulent diffusion if he remembers that the diffusion coefficient $\lambda$ in Eq. (2l) is replaced by the local turbulence viscosity.

One problem remains, namely, making the procedure efficient enough computationally so that one can afford to use it. The major difficulty is the calculation of inverse error functions. To do this without undue cost the following interpolation procedure was establisied.

The error function is monotonic increasing on the interval $[0,1]$; erf $(0)=0$; and $|\operatorname{erf}(y)|$ approaches 1 asymptotically (see Fig. 12), Care must be taken in using $\operatorname{erf}^{-1}(x)$ for $x \sim 1$, for in this region $\operatorname{erf}^{-1}(x)$ is very large which could lead to an abnormally large particle displacement. To

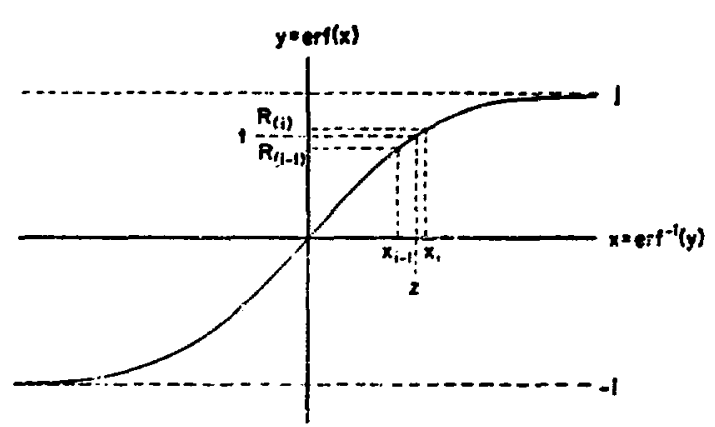

Fig. 12. Standard error function.

baandle this, one selects a number waXEF and distribut as NERFV points equally spaced on the interval [C, WMAXEF; dich point 1 located at 0 and point NERFV at WMAXEF. Thus, the equal spacing DX w111 be

$$
\mathrm{DX}=\frac{\text { WMAXEF }}{\text { NERFV-1 }}
$$

and the position of point 1 , denoted by $x_{1}, w 11$ be

$$
x_{1}=(i-1) D X .
$$

Now, let $R(i) \equiv \operatorname{erf}\left(x_{i}\right)$. Then,

$$
x_{i}=\operatorname{erf}^{-1}(R(i)
$$

(see Fig. 12). Our problem is to find $\operatorname{erf}^{-1}(t) \equiv z$ given an arbltrary $t$. To do this, we see that $t=\operatorname{erf}(z)$. Find an $i$ such that

$R(i-1) \div t \leqslant R(1)$ or $\operatorname{erf}\left(x_{i-1}\right)<t<\operatorname{erf}\left(x_{i}\right)$.

Therefore, $x_{i-1}<\operatorname{erf}^{-1}(t) \leqslant x_{i}$. One linearly interpolates to get

$\operatorname{erf}^{-1}(t) \cong x_{i-1}+\frac{(t-R(1-1))}{(R(i)-R(i-1))}\left(x_{i}-x_{i-1}\right)$.

or

$\operatorname{erf}^{-1}(t) \cong\left[(i-2)+\frac{(t-R(1-1))}{(R(1)-R(1-1))}\right] D X$

using Eq. (30). One selects another random 
number $t$ if $t>R($ NERFY $)$. Because $R(1)-0$ and R(NERFV) - WMYGF usens Eq. (26), y ts lintced to the ranpe

$$
0<4<\text { MAXXF } * \sqrt{4 \sqrt{A}}-\text { WHAXEF } * \sqrt{2}+
$$

Thus, y la liaited to batief * standard devlar.ions.

ikecause Eq. (2\%) lgh Invallid Mar Thu axas at

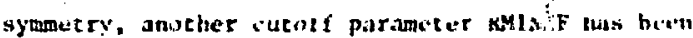
added. If the r-coordinate of the part:cle is $<$ RYINEF, the curbulent diffuslon effect is not applfed. In most cases. Rulaer an be considerably less than the Ar's of the iunes on the axis.

The current verston of the code can be run easily witn turbulence by-passed because ibx. tarbulenre mast be seeded inftially. Most of the coding related to turbulence is excladed and no efficiency is lost if chis version is uged for turbulence-free calculations.

For a discussion of the output relevant co curbulence, see the sample calculation in sec. III.

\section{F. REZONE IECHNIQUES}

The corvection phase is appended to a Lagrangian calculation in a way thac provides maximute flexibility for the continuous rezone. This is achlaved by including the convective fluxes as furctions of difference velocicies.

$$
\vec{u}_{d}=\vec{u}_{\text {flusd }}-\vec{u}_{g} .
$$

where $\vec{u}_{g}$ is the grid velocicy with which the mesh is moved in a given calculation cycle. For an tulerian calculation $\vec{u}_{g}=0$; for a Lagrangian calculation $\vec{u}_{g}=\vec{u}_{f l u i d}$, the difference veloctiy vantshes, and there is no fluxing. In general the presclption to determine $\vec{u}_{g}$ is at che discretion of the user. A general form that we have found useful and incorporated in the present version of the code is to write

$$
\left.\vec{u}_{g}=\vec{u}_{f l u i d}+\frac{f}{\delta t}(\vec{x}\rangle-\vec{x}\right)
$$

for each vertex. That is, the grid velocity is composed of two components : the fluld velocity and a term so relax the mesh such that each vertex is at the average position of its nearest nelghbors.

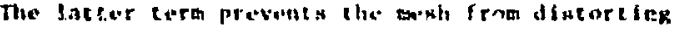
excessively. A typical value for I whe he 0.05s, whtel would relax the moth in ipproxtmately 20 calculat lonal cyciss if thers were no fluld gare fon. tony varfatlons of the relaxitton component are posstble. The lmportaut polnt la fo run as near to Lagranglan as possible to pinimize the soosthing. but st111 to malnealn sone degree of pequidrfty in the mesh.

\section{G. MIXF! ENEATIOK IF STATE}

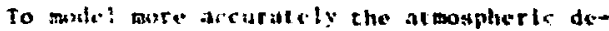
conation of a tylar balloan fllled wh thethanc. It eas necessary co incorporate twe equat tons of whate fr: one problea, one for the combust fon products and wit: for ambient afr. The metion was ta divide the

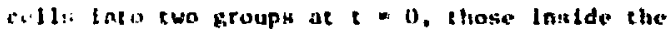
ftrespll and thoke outstale. This divixton was ding: in the tasis of the spectfi: Internal energy (e): chose colls withe $\therefore 10^{10} \mathrm{erg} / \mathrm{g}$ were consldered Inslde che fireball and all others, ourside.

Define the concentration c, an the sat to of the seass of constituene i in ofiven rell to the cotal mass of the cell. Obviously. If there are $n$ construentio, i $c_{f}=1$ in a fiven coll. For a problem liki nuts wth only two conatituents (explocied gethane and amblent a(r), $c_{\text {ach }}+c_{a l r}=1$ so tiat one only needs to keop erack of cketh Here we use $t_{\text {muth }}$ to refer to the concentration of cowbistion products axd rech to refer co the effuctive * for the cumbust ion products.

Initlally. Emeth is defined to be 1 in all freball zones and 0 elsewhere. An the problem proceeds, the concentration is convectud laco the amblent region using

$$
\frac{d c_{1}}{d t}+\ddot{u} \cdot \ddot{\partial c_{1}}=0 .
$$

Note that this is just the Lagransian form of the contisulcy equation.

To deterwine the effective $\gamma$ in a given zone, we urite

$$
Y_{\text {eff }}=c_{\text {meth }} Y_{\text {meth }}+\left(1-c_{\text {meth }}\right) Y_{\text {atr }} .
$$

The pressure is then obtalned frow 
$r=\cos t^{-112}$

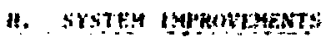

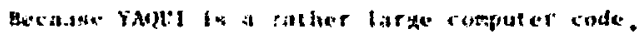

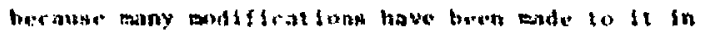

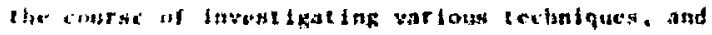

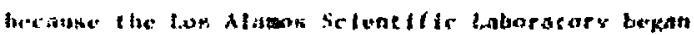

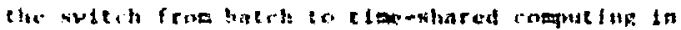

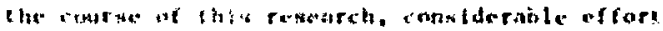

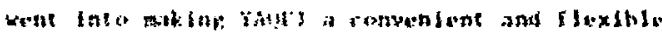

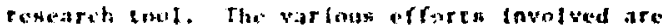

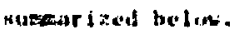

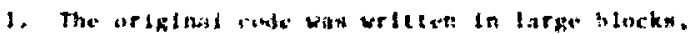

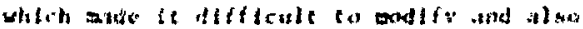
ceverely exed lie comblerk and Inadegn.

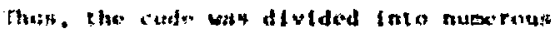

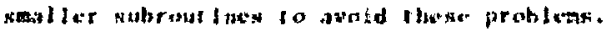

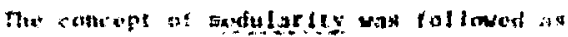
clonely an posental.

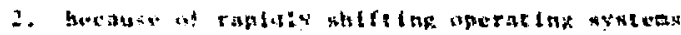

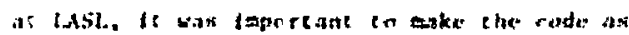
syrtem-independent wo pownthlo so that it

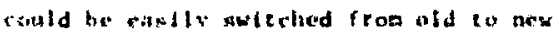

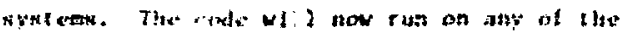

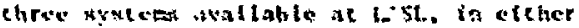
batch or tavenharbing rods. 1. coutd be

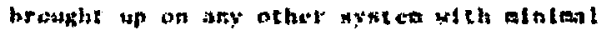

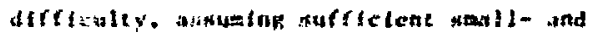

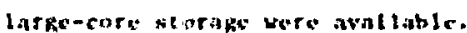

1. Fined foreat inful in prane to wrog, whereas

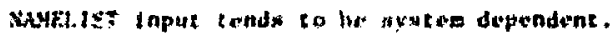

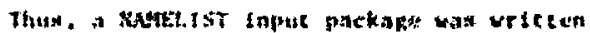

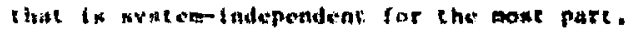
and ran he rastly mathod for ocher synteras.

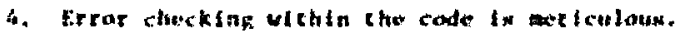
Mig cods never ankuswe anythitap on the part of the user the wantiors for errors, partlcularly in the wet up plante. as though the usur were coopletely untawllar with the code.

5. Because raqul runk often take weverai hours of cac-7600: Ine. A problete wy twave to he rur in wewolal weallot plecer. For chls reanon, a flexible reatazt procedure wax devoloped 10 lllow the vater to remeart prohlea at any polme and chanke tapul parawetern vithoul having to arcually adtery the conde leseif. b. The origtal YAqui was vory well dortunepled exeornally in tASt. report LA-S100. 3 However, a code that is under heavy developine is wuch canter tos aodify if it is carefully annotatod Internally. Wort has bean proceodise on this and in larpely completed.

\section{DESCRIPTIOS OF IXYT}

The Input to the code. except for the problem

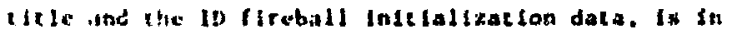

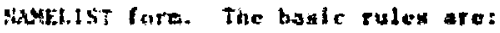

- Euch input recoed begins with 5 le tard colitan (cr) 2 tollowed fandiately by the naterelint thase.

- Inpu: values ate of the fors NAYE - MUthER.

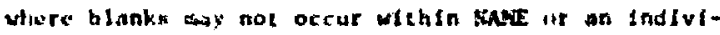
duxi number but are lanored elewhere. Staben any

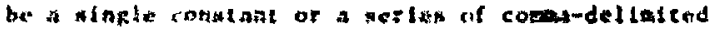

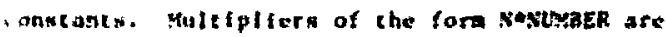
alloned but not grouplag with parenthewe te.k..

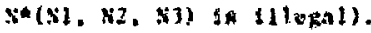

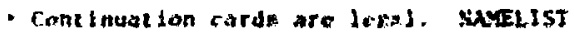
warlable names and constants ay not be splti acros: card houndarles but holtsereti delds ay if they end in ectoo of one card and begin arain in ect of the nexe card.

- in inpul record ia cerintaned by a s anywhere un the ratd exrept for ect and 2.

- Vaffables are wared wikhouk regard 50 ypu. If ane has 1 -5., I will contain a flracing potne 5. racher than an Integer 5; Itheulse $x=2$ will cause an foleger 2 to be stored in $X$ which wlll nost

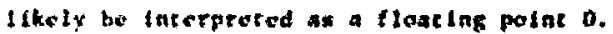

- If " "p" In punched In ecl of the firwe card of atecliat reent, the entre record will be princed an part of the sode oupute.

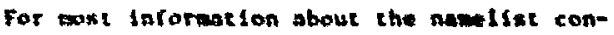
went ion, see the Inkernal documentation at the beginning of the roul ine walst in the liscing of the code in sec. V.

From here on. ach input record vill bo desm Et Ibed, the namol lat nawe glven, and the vartable nawen 1 intand and dimeuned. 


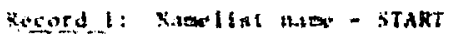

\section{X.roulikg vartabler}

\begin{tabular}{|c|c|c|c|}
\hline XAYE: & TyP $\{$ tenits) & 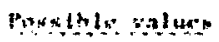 & $50+1,15 !$ \\
\hline RESTRT & I.K:ICAl. & TEVE. . FAISE. & $.1 \mathrm{~T}$ \\
\hline$F 11,4$ & I.GLICLAI. & . thtuse. Fruse. & rati. \\
\hline$A B$ & i.M:ICAs. & 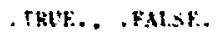 & . Fal.st \\
\hline$k+1$ & RENI. (x) & 0. dentet?- & 20.0 \\
\hline
\end{tabular}

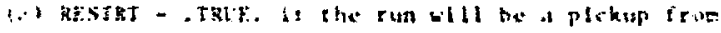

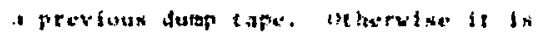
an Intst.t! selus?

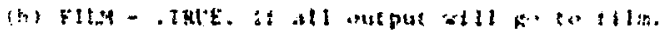

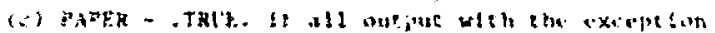
of plots stit the gaper.

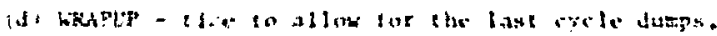

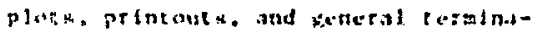
and arodede. If the the lialt Ti.14, then the saleviat fort will the scippes and terminat ton hegun as ious

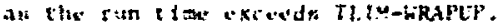

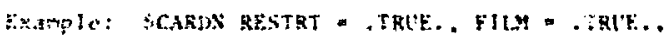

Z̃'

The nex: inpul draets an whether KESTRT Is

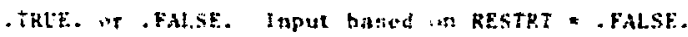

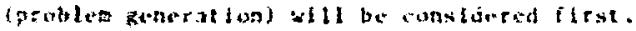
* IxtTlal problger sfret * *

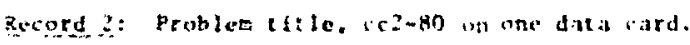

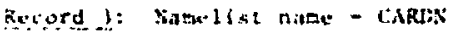

\section{latpolfat varlables}

byt Typ (units) porsfbleyalues Defalit

Ao Real (none) $0 .<10 \times 1$.

AOFAC

Real (none)

0. jorack. 5

Ais:

Real (nene)

0.5 stisk 1 .

A.tic:

sos

cit.

ok

ut

\section{DTS}

DTAC

$$
\text { Aul (none) }
$$

0.54150 .2

Rerl (none)

0.2 .

$$
\text { Heal (none) }
$$

0. 1 .

เง?.

Ros) (cm)

$0 . D R$

$$
\text { that (s) }
$$

0. DTFen

$$
\text { Heat (s) }
$$

0. SDTO

$$
\text { Heat (5) }
$$

0. othcise

EDS

FKFIXX

Rred (cm)

$$
0.207 \div
$$

Eatits

Real (none)

$0.75 S C 1$.

0.1

FRtrit

Real (anone)

1. 4 FRFZXR

(iR

$$
\text { lleal (none) }
$$

1. SFRETYBO

crovet.t.

Real (none)

1. SFREZYTOO

ก. 2

1. 0

0.05

0

1.0

Must be specIf ied

$$
10^{-3}
$$

$$
\text { Real (cm/s } \mathrm{s}^{2} \text { ) }
$$

- Crem

c.\%
0., 1., 2.

$-\infty \cos r i \infty$
Iust be spectifled

$$
10^{-5}
$$

1.0

1.0

1. 0

o. 0

2. 0

$-980.0$ why:

c.t?

IAXF

GEN

Ist

Ixtr

ID4:

$3 \%$

I)1

1195

xis

1.24

vi'

(⿻) 14

sic

ws

()1.7.

BEXKWS

Ke. 2 SI:

REXY:

kyISt:-

r

I!)

TiTsti

TLI!

TLSI

ThFl:

wAXXF

$Y B$

Zunic:

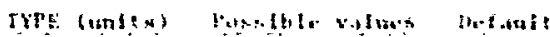

$$
\text { Heal } \left.\left(100 / x^{2}\right) \quad-6 ;\right)^{2}-
$$

11. 0

Interer (none) Mathak

$$
\text { scotage }
$$

Yust be iper tited

inengret (neme) o, 1

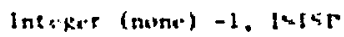
seorsine

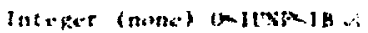

Yist he tpecIf ied

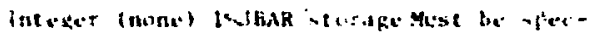
if ice

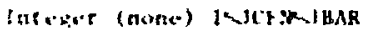

Mast be ipgetIf ix.d

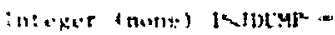

$\mathbf{7 4 9 9 9 4}$

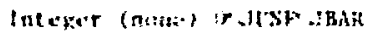

Must be spme litied

Inkerat (note) -1.0. 0

$-1$

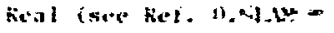
3)

$1) .6$

kn: $: 11$

0. Nit?

0.0

994494

interes (nesne) ibsictst-m

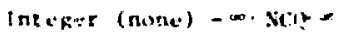

keal (nomè)

o. W. 2.

$-1$

$$
\text { Heal (none) }
$$

.02

Rend ( $\mathrm{km} / \mathrm{cta}^{3}$ )

0. REZANH $=$

4. 02

$$
\text { Real }\left(\mathrm{cos}^{2} / \mathrm{s}^{2}\right)
$$

11. inEZS1F: 0

0.0111

$$
\text { Real ( }(n)
$$

YB REzYit -

$2 \times 10^{10}$

0.0

so. 0

Real (cm)

0. SRMINYF -

ก. 0

Real (s)

0. $x=$

0.0

Rea] (s)

0. $\operatorname{tar}-\infty$

1. 0

Real (s)

0. STSTRTIO

0.0

Rent (cm $\left.{ }^{2} \cdot s\right)$

0. Trupl-

0.0

Reil l $(\mathrm{cm})$

o. Tl'sicfireball radius

I.E. 30

Ketil (s)

0. :ThFlas

2.0

Real (none)

0. HWAXEF

0.0

Real (cra)

$0.5 \%$ \% $\div \infty$

6. 0

- Amount of dotror cell in momentum fluxing (0. Is centered differencing; 1 . is full donor cell).

AOFAC - Siability condition u.t $1: x<$ AOFAC. 
$\therefore$ areat: 1: 1:

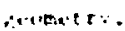

ith - Intetiol viluo we the sidth of the cones in

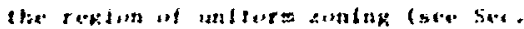
I. A).

DI

(nTi1.

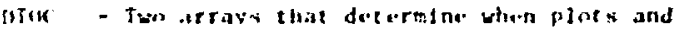

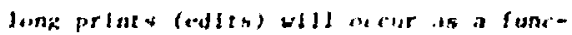

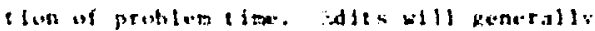
necur evert litu(t) secands in the interval

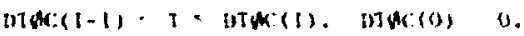

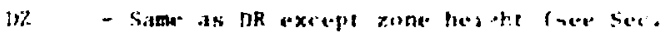
I. A.

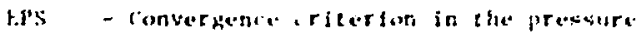
itceration (stek ket. ?).

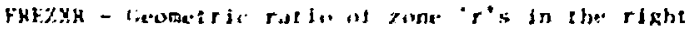

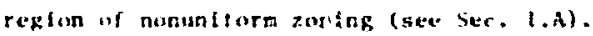

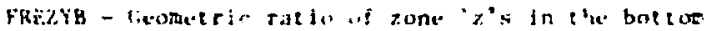

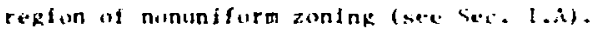

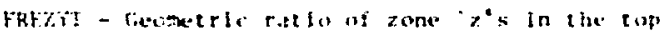
repjon of nomaniform zaming (stat bex. J i i.

(7)

- Hodv force derelerate idr in the radial dirston.

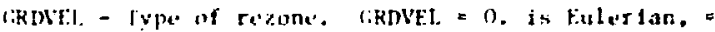
1. Is labtrangbin, and $=2$. causes the rozone subrotutine to be called.

i:s - Bady forse arederation in the axial ditecton (usiallv gravitu).

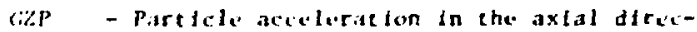
Ifom (nol appliad unlests part if jes have mass.)

IBAR - Nir $T$ of real zanes in the rindial diterton (sce Sin. 1..i).

IFIP

- Input of the racord 3 saction is lerminated bv inputelng a record with $t \mathrm{FOH}=1$.

IST - Sumber of parclelos whose poslt fiss are to be ploted as a function of time. If IST 0 . no particles are followed.

IU:F - Number of zones in the radial direction in the reption of unlforir zonthe (sies se... I. A).

JBAR - Number of real zones in the axial dirccelon (see sec, 1.A).

JCEN - Number of radi zones from bot om of the problem to enter of region of unt form zaning (sect bee. I.A).
Jbizl - Frequency of duaps besed on cycles. Dueps wild uccur wher the cycle nuber is an even tule tple of jorgap.

rexf - Yumbe of rones in the axtal direction in region of unliarm zonlng: wust be an even number tecause Jotif/2 zones all occur above and below the polnt deflned by JCEx (stes ser. I.A).

KXI - VIscosity flas (sec Ref. J).

liny - Viscasity parameter (net Ref. 3 ).

4! - Viscosley parazefer (are kef. 3.)

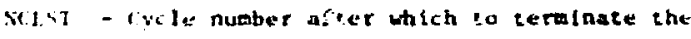
risn.

Sici - (otile nupber after wich to seed the turbuitence: if $\mathrm{YCO}{ }^{-1} 0$. the turbulence is disabled: if $\mathrm{ACQ}$ - 0 , sceding will occug based on prot lew tinc instead of cycle number. i.e. When toty (see tQ).

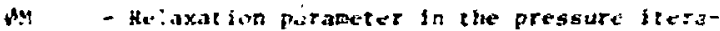
t ton.

"t.FtE. - Fienomelogical eurbulence viscosity para* meter relating to specific turbulence enerfi: (set Ref. S).

RlzRdS - Initial denstry of the ambient atmosplie at $y=$ REZio: the denstey of the atoosphere above and below REZYo is deceralned Fv the condftion that the entire atwosphere inftialiy be in hydrostatic equilibrium.

kFzslt - spectfor internal energy of the entire amblent nemosphere.

HFXIn - ciencer of y-coordinate of the region of unlform zoning (set sec. $1 . A$ ).

RMINEF - Partities with ratiNef aro not subject to turbulent difinsion.

T - Time at wich the problem begins.

$\because$ - Tfme at which to seed the turbulence if $\mathrm{NC}, \mathrm{Q}=\mathrm{D}($ see $\mathrm{X}, \mathrm{Q})$.

TSTRTD - Time at wich to start turbulent particle diffusion if the turbulence is on.

TUQl - Proportionalizy constant for seeding lurbulence energy. Should be chosen such that curbulence energy is a few percent of kinetic energy in any cell.

THSI - Turbulence scale (constant over mesh). (Code could be easily changed to allow scale variation throughout mesh).

TWFIN - TImc at whlch to terminate the run.

WhAXF - If the turbulence and particle turbulent 
diffusion are on. A particle can be moved no nore than maxeFtSQRT (4.*\$IGH*DT) because of curbulent diffuaton in anv one cycle (see sec. E).

- Botcon of the problem wesh if the zoning is encstely untform. If the zoning is nonunifora, ya will be calculaté Intur nally and need not be specif fed.

$\operatorname{zan} 16$

- Nimber of fireball radil away from the

f I reball that the Ight problew boundary Is kept.

\begin{tabular}{|c|c|c|}
\hline \multirow[t]{18}{*}{ Exaraple: } & SCARON & $\mathrm{aR}=200 . \mathrm{s}$ \\
\hline & SCARDX & $n x=200, \mathrm{~s}$ \\
\hline & SCARDE & $I B A R=30 \$$ \\
\hline & SCARDS & IJNF - $5 \$$ \\
\hline & SCARDN & JBAR - $45 \$$ \\
\hline & SCARDM & $J C E N=15 \mathrm{~s}$ \\
\hline & SCARDS & JtwF $-10 \mathrm{~s}$ \\
\hline & SCAPDN & REZTO $=4300 . \$$ \\
\hline & SCAHEN & REZRAA $=1 \cdot E-1 \mathrm{~s}$ \\
\hline & SCALDN & REZZSIE $=1.95 E 9 \$$ \\
\hline & SCAHDN & $T=.0083 \mathrm{~s}$ \\
\hline & ScAuns & TWFIS $=30 . \mathrm{s}$ \\
\hline & SCARDN & DTd $=.1 .1,5.5$ \\
\hline & SCARDK & DTdC $=1 \ldots 10 . .30 . s$ \\
\hline & SCARDX & PREZYB $=1.089359 \$$ \\
\hline & SCARDN & FREZYT a 1.0893595 \\
\hline & SCARR: & FREZXR $=1.0893595$ \\
\hline & SCARDK & $I E O F \cdot 15$ \\
\hline
\end{tabular}

Agatn asguming RESTRT - FALSE., the next record wil be to define marker particles.

Record 4: Namelibt name - PARTN

Namol lint variables

\begin{tabular}{|c|c|c|c|c|}
\hline NA표 & TYPE & (untes) & Poselble value & Default \\
\hline DRPAR & Real & $(c a)$ & 0. GDRPARS & $\begin{array}{l}\text { Must be spec- } \\
\text { ffled }\end{array}$ \\
\hline DZPAR & Real & $(\mathrm{cts})$ & 0. TZPAR< & 0. \\
\hline XC & Real & (c) & $0.5 x<<0$ & 0. \\
\hline XD & Rea 1 & $(\mathrm{~cm})$ & $0.8 \times 0<\infty$ & $\begin{array}{l}\text { Must be spec- } \\
\text { If ted }\end{array}$ \\
\hline YC & Rea 1 & (ca) & $0.8 x<<0$ & 0. \\
\hline YD & Rea 1 & $(\mathrm{~cm})$ & $0.5 \times 0$ & 0. \\
\hline
\end{tabular}

(a) DAPAR - Spacing between particles In clie radial direction. Particle definttion cards are read unt $I 1$ one $1 \mathrm{~s}$ input with DRPAR = 0.

(b) DZPAR - Spacing between particles in the axtal direction. (c) Xc: - (Sec Sue. 1,c)

(d) $\mathrm{xn}-\left(\mathrm{s}+\mathrm{c}^{+} \mathrm{sin} \cdot 1 . \mathrm{i}^{\circ}\right)$

(e) $10:-(\sec s+2.1 .6)$

(f) $\mathrm{iD}=($ See Se.. 1.11

Examp le:

SHARTS DRPAR = IOG.. DZPAR = $100 \ldots$ YC $=4200$. (it) $=1000 \ldots r b=0.5 \mathrm{r}=\mathrm{H}, \mathrm{s}$

SPAKTS DRPAK - $0 . \$$

The inal input will be ibse firebali Initialfzat fon data. Hno namelist record is nected: Kecord 5: Nimelist name - FIRE:

\begin{tabular}{|c|c|c|c|}
\hline \multicolumn{4}{|c|}{ Nanul ist yatlables } \\
\hline NAYE & TYPE (unIts) & Posstblo values & Defaul! \\
\hline PBFIL.F. & Loglcal & .TRUE.. FALSE. & .FAl.SE. \\
\hline SRAI & Interger & I ANRTD $\infty$ & 5 \\
\hline NTH & Integer & 1 ONTH<O & 180 \\
\hline
\end{tabular}

(a) FBFILE. - If .TRUE. the fireball initializacion Input will be found on logical unit 3. otherwise, the tnput will follow the SFIRF: nimelist card.

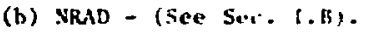

(c) XTH - SSere Siv. I. IS).

Example: SFIRE FBFII.F = TRUE. 5

for the torw of the fireball Inttiols eat Ion data. see that section Sat. 1.B.

ThIs completes the Input for an initial setup. Restort dumps are writcen on each edit eycle as detormined by DTO and DTOC or as spectffed by JWUNP and go out to logical unit 8 .

-* PHOBLFH RFSTALT * *

To restart, a restart dump ipe must be present on loglcal snit 7. 1nput record I must have RESTRT = .TRUE. Next follows a namel ls: record telling from which dump to reatart.

SRCYCIE INTCYC $=\mathrm{N} S$

where $N$ is elther' the cyclis on the dup tape frow which one wishes to resturt or -1 . In the lacter case, restart occurs from the last dup on logleal unit 7. last, records of the type degcribed under Input record 3 any appear if obe desires to overtide any of the paraweter values in effect at the tiae the problen is being restarted. This section Is teminated by SCARDN IEOF $=1$ s. Example:

SSTART RESTAKX = .TRUE., PAPER = .FALSE., FILY $=$.TRUE. . WRAPUP $=60.5$

SRCYCLE INTCYC $=-1 \$$

SCARDK THFIN $=30 . \$$ 
SCARDN

SCARDN

$$
I E O F=1 \$
$$

\section{RESUITS OF A SAMPLE CALCULATION}

A care?ul comparison of a YAQUI calculation with experiment was macie and has been reported in Ref. 6, Fig. 1(c). In that slmulation the unixed equation-of-state, turbulence, and curbulent particle diffusion uptlons we all used. To help the user to understand the oitput options and to provide a comparison calculat on, we include detalled results of a sample calculation, patterned after the simulation in Ref. 6.

In Sec. A the input parameters are listed along with the detalled one-dimensional fireball input data. Also glven are the Initial marker particle configurations, the initial grid for the complete mesh and for a smaller region surrounding the fireball, and the initial velocitles.

In sec. B contour plocs of the vorticity and the specific turbulence energy $z_{;} t=.5 \mathrm{~s}$ (imediately following the seeding of the turbulence) are given. Note that the general shapes of the two contour plots are sivilar because the turbulence energy is seeded proportional to the vorticity.

In Sec. C the positions of the marker particles and contour plots of the specific internal energy and the specific turbulence energy are given at $t=3 \mathrm{~s}$ at which time all memory of the seeding is gone. Note that the reglons of greatest specific internal energy closely colncide with the reglons of greatest specific turbulence energy. Also note the toruldal forw of these contour plots, rememberIng tiat the left side of the mesh is an axis of cylindrical sywetry.

In sec. D complete graphical output at $t=10$ a is given. This is a moderately late time because torus formation occurs at $-t=1.25 \mathrm{~s}$.

\section{A. Initial Conditions}

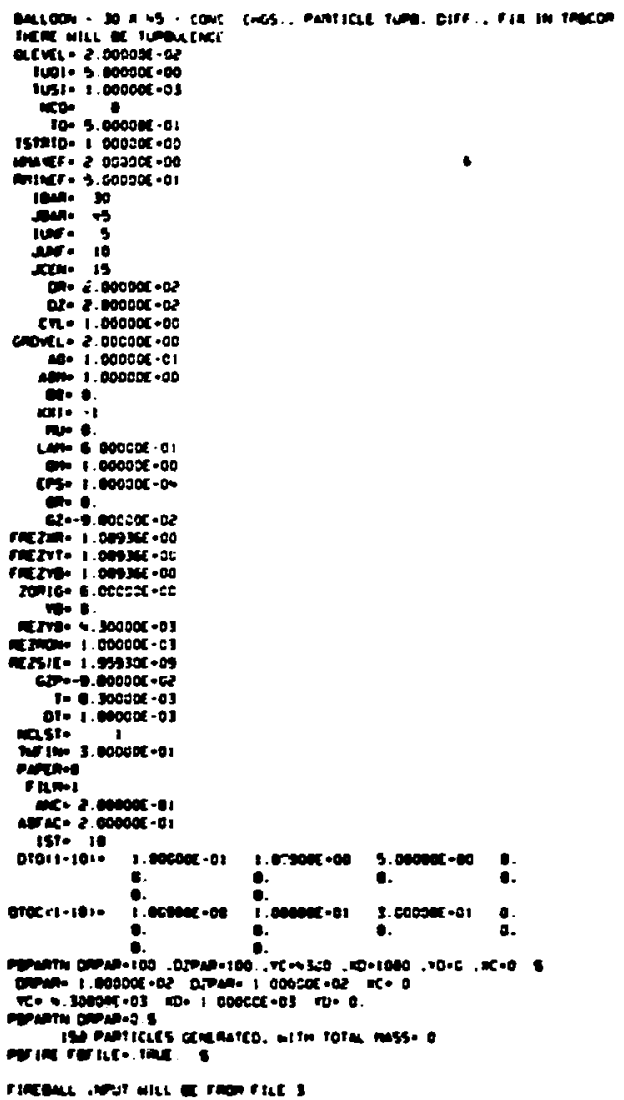


3. manutur ol 7. worte il.03

1. 1917sisc.00 1.eren xat - S c. 1esex+t-04 2 ssist:7- 0 c.enstersio - on 5. $1040100+0$ 1. 7900 1706 oco - ajpiecar - ov - assoreoc +av - neosicte-jo - chasese 40

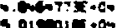

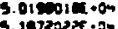
3. 1erpext -90 3. Mersit -0 s. sow0odenten S. $0421116-0=$ 3. g. - 3mess

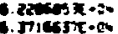
s. st $7315=0$ - csiestar -on

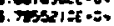

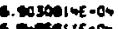
- tevicitics - $7215072-0$ - roscescon - Doverite-on s. Thosere - D 5. siposese -ov 3. 31 나다. s. 251500 -10Boilac on

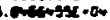
s.encipicon - enisivir+as - Estan-0

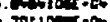
- Tosisnc-e - cilosic-o. - $61055 \mathrm{scc}-00$ - sterter $-\infty$ - sstion $x=0$ - $+40 \cos \tau+c$ - tryest -0 - - Mi Fi - scover +eo . 3453se +os - $27-29 \pi+0$ - azmitco - .2475ex -0*

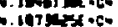
- temeix $x=$ - 1 tersecto. - 1 ass'e $x+0$ -

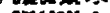
.04-10re-9. - esimsx ost

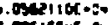
3 . Instow 00 S.FIM?IE:00

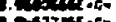

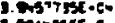
3. Alocsic.0.

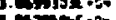

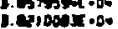

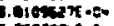
1. Tyanteos 3. mesing 05

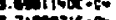
3. Jiesprix -o - cestagrate

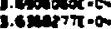
cienserto 0 . Hajactor 1. c. sanok on b. Aillizen .

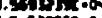
. - Masmor 1.mons ox spriers.o

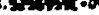
. Triviture no 1.5riven c.stipicion

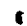

no

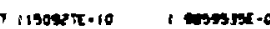

esca7k-10

- +167 Ke-30

$-1773750+10$
$-5670 x+10$

$6-36: 0 x=10$

$6-9 x 09 x+10$

5. +2869: 010

- $-451-736+10$

- $-57230-1+10$

- $-56051+10$

5 -509ter-10

- - istare

6. - is ib 10

- $5935215=10$

- ISTSte-10

3. - $10130 x+10$

- ocsoier-10

- Sosisicr+10

c. $\operatorname{sen} 7 \sin x=0$

3 sishet 0

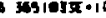

$5 \operatorname{sen} x+10$

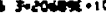

- Essinar 10

J194 Eute +10

c. Dor

6 207721 5.10

$6.270550+10$

c zroter 150

4. 27mase 10

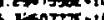

- ksorrt + 10

- Decsice - 10

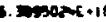

- wsisoc.10

6. Not dace - 1

- ofmesceit

- vissest 10

- 17 incelo

c. - 2115350

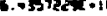

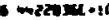

- traste.

- meseser -10

$6.05 \pi 5516-10$

- $0607+10$

- 63574 . 10

- -7 noot 10

- -7i T21E-10

- THSE-i

- arese to

- resmacio

- -9mistr.0

- Treicor +10

-721-ke:0

- soleryti:-io

sogscy.10

sitesir.10

sivese 19

- sistest

seas $x+10$

- micara

- $\sin 3+6-10$

S3asiont-10

suoseret +20

surforet 40

- sonesex *1"

- gsoresti - 12

- gsolesel - 19

- Graxectio

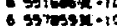

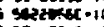

- s7i-5ed - to

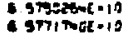

- srast let.i

- soprater 10

4. srrescer - 10

- soratereicio

- gervesie - se

6. resmex 1

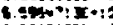

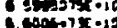

- constix - 19

- consuex +10

- contuse 16

- sobnert a

- charex.10

- Sivitercele

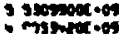

- inerencos

- andist 0

$\checkmark$ teder zosiser - 0 as7070 x.00 2 26530iti-on 2 romese -00 disteist - 0 2. 29rezcut-os 3001916-0n - 1275i-sc-ar 2 ascosos -on - Evenick-an 22 risolet -6 cectesc-on

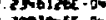
. 20030045

ickerecto

2 $1550171 \mathrm{x}-16$

? 12010: $95-00$

ost leser - on

2 gestoss - an

1 - Mol roc. os

sonotet is

cosier -0

1 ciencise-on

Titelies -0

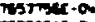

Truacic -

coseces - 0

- sobre-0.

$2.002194-2$

2.003iser-o

2.1116-5 -

2.111025=-0.

2 145s: Fac-o

- 1eantret-on

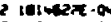

2 insesere

$2.2 \mathrm{~m}$ - $131 \mathrm{II} \cdot 0$

a arenestat

2 enster-o

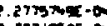

ordsox -0

sigsower -a

Mistic-cos

J4373 $10 x-04$

stesect - 0

mesiata

c. norier - 0

. $: 701 \mathrm{ME} \cdot \mathrm{O}$

$-2150=1 \cdot 9$

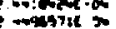

c woreset-o

2. veresces - b

- incertion

sitsise.to

solinise-0n

soteic on

2 suct:ac-00

a now $x-0$

- ssertert-c-

Sniod $x-00$

sermoer-o

G12:306-av

2 $10377 \mathrm{x}-5$

2 spostat - o

7 enceses 0

cosster -0

- contact.

z Bowist.on

2. Torvara

? 7250004 - 00

2. Tombict-on

2 Nasescon

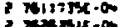

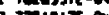

2. 77w1017-0

c.mil or on

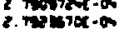

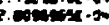

3. $150-\infty$

2 a creat - os

- exwere - os

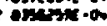

- eqmiacos

1 II $190 \pi-\theta$

- 216trte-0s

; braner-o1

son $13 x+0$

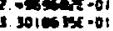

iresplif -

Trovereol

5. 75 shile 01

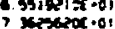

$172769 x$.

- 5ospoic -0

- cosesise-ol

1057tace o

incist +2

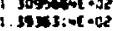

- Ter you a

secel s5t - 02 


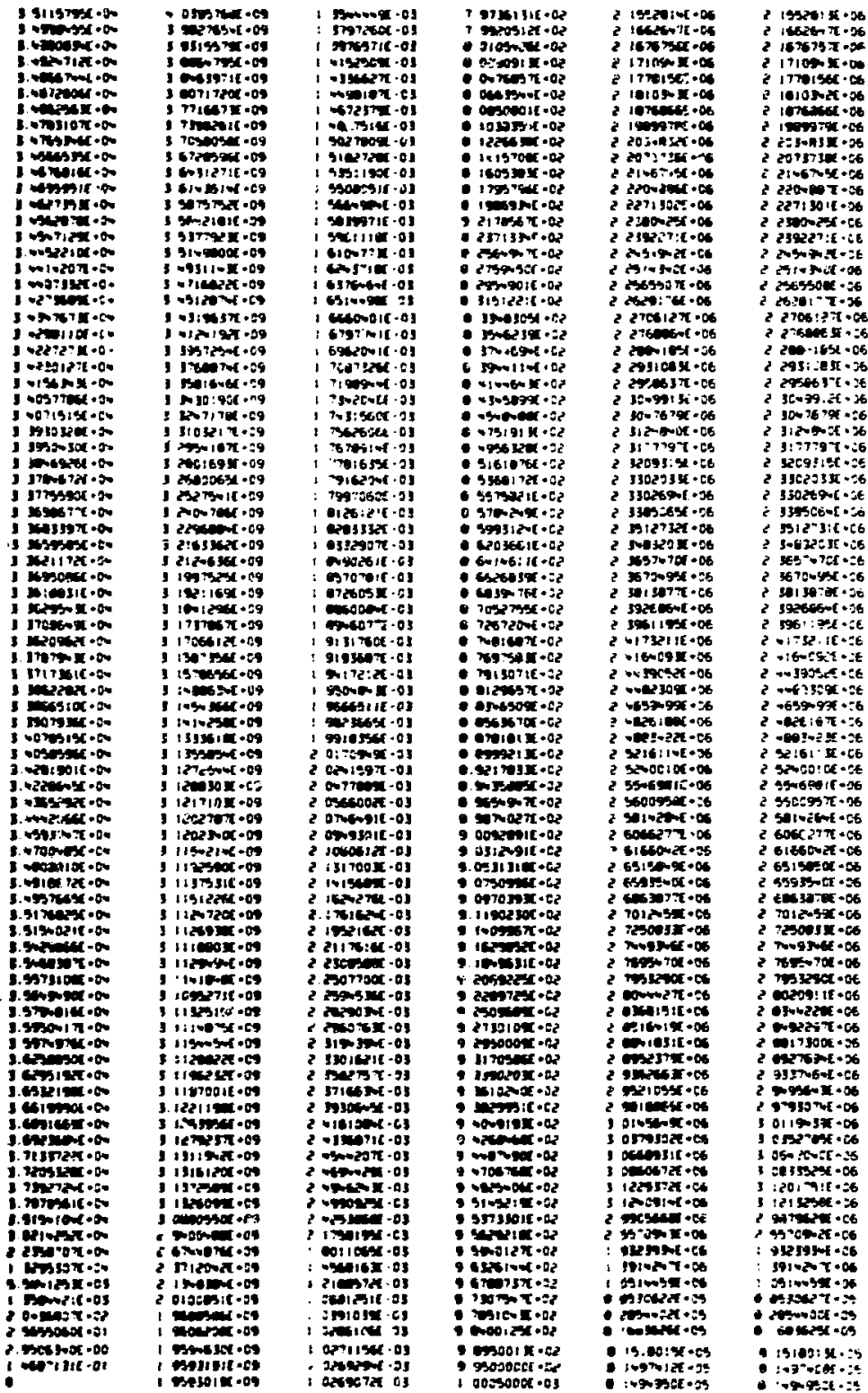




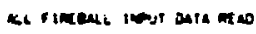
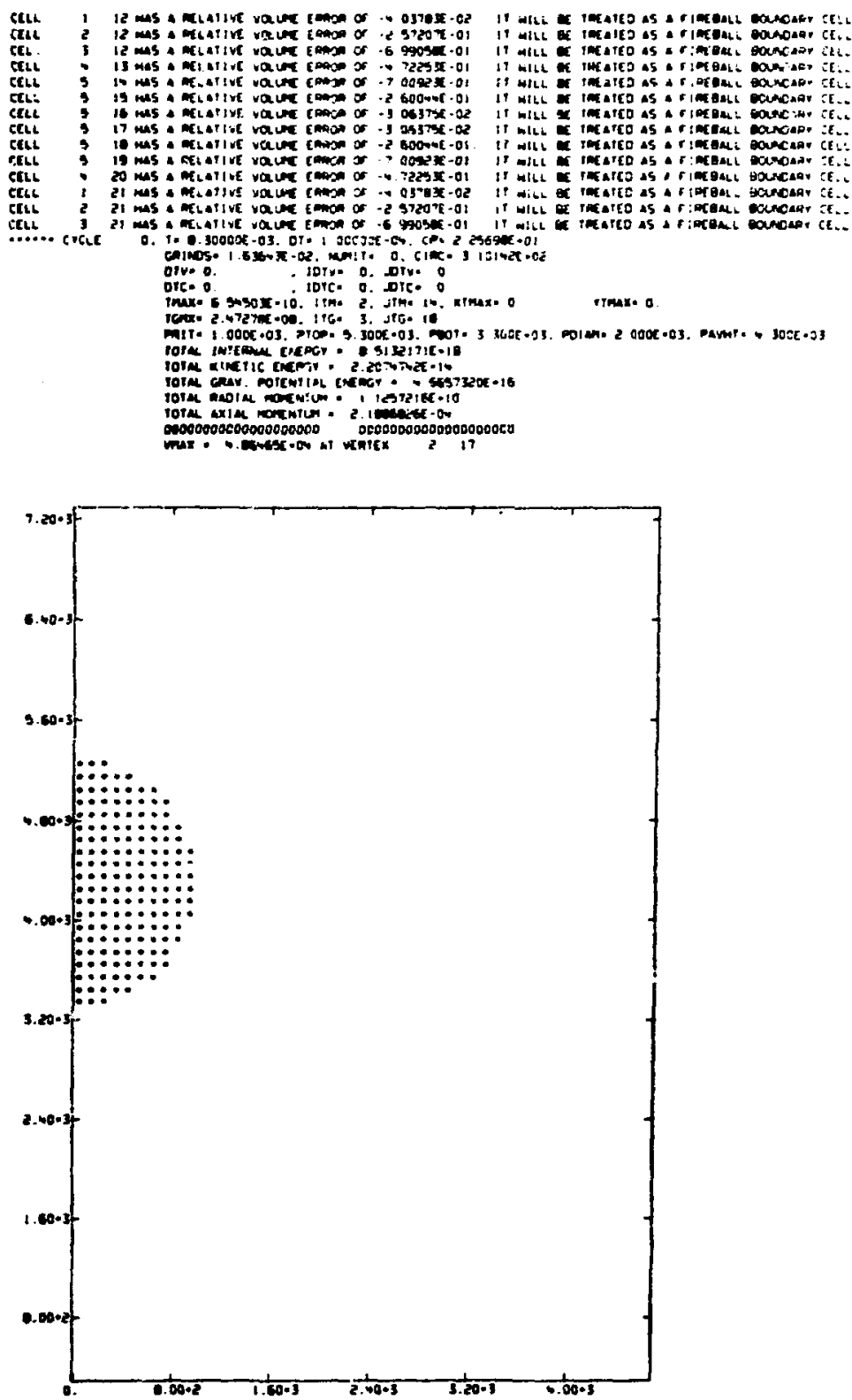

-micles 


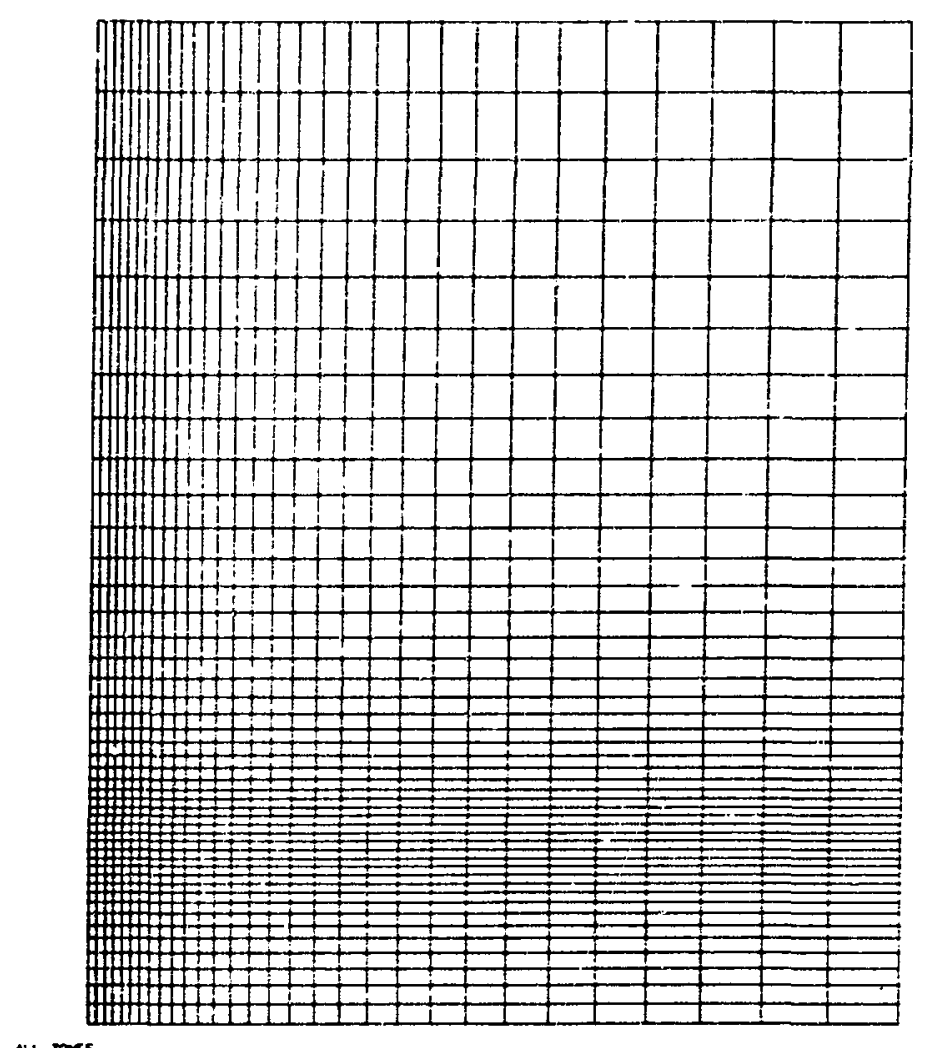

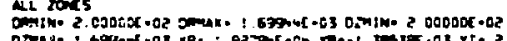

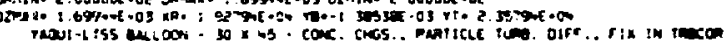

I. D. J0000C-03 Grste. J 


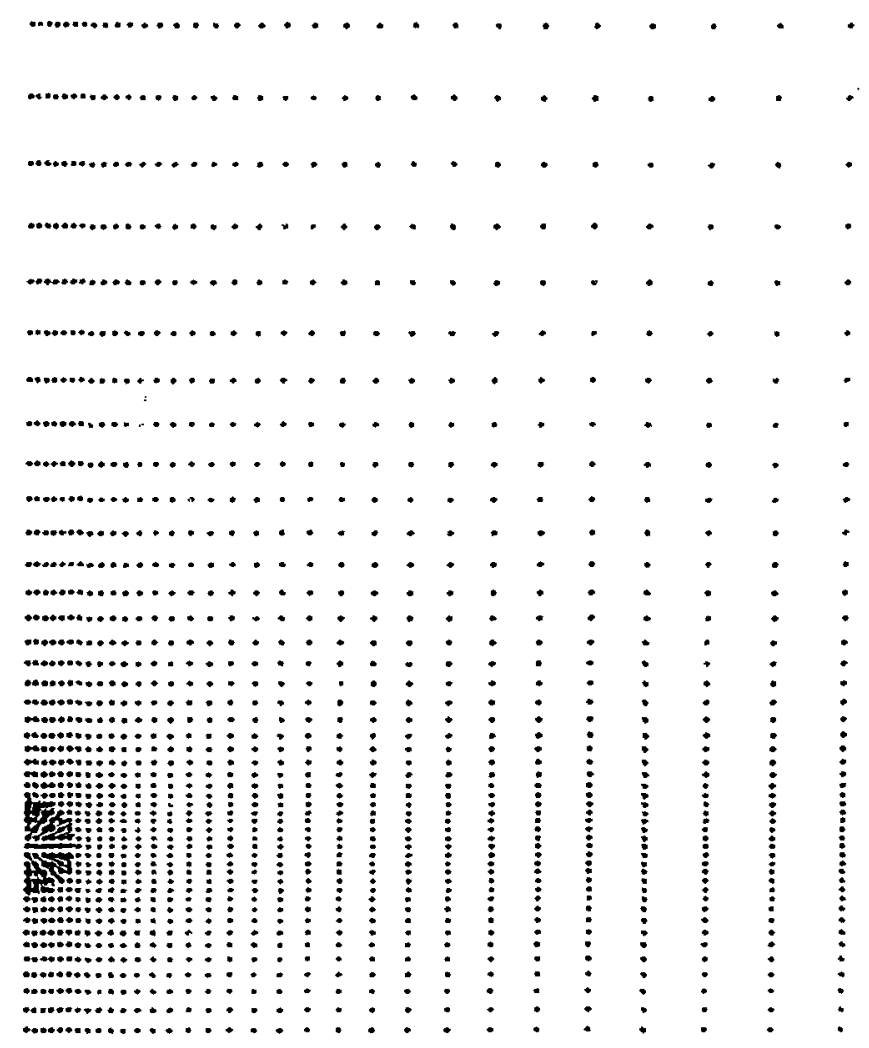

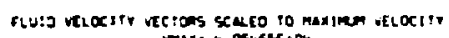

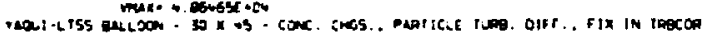




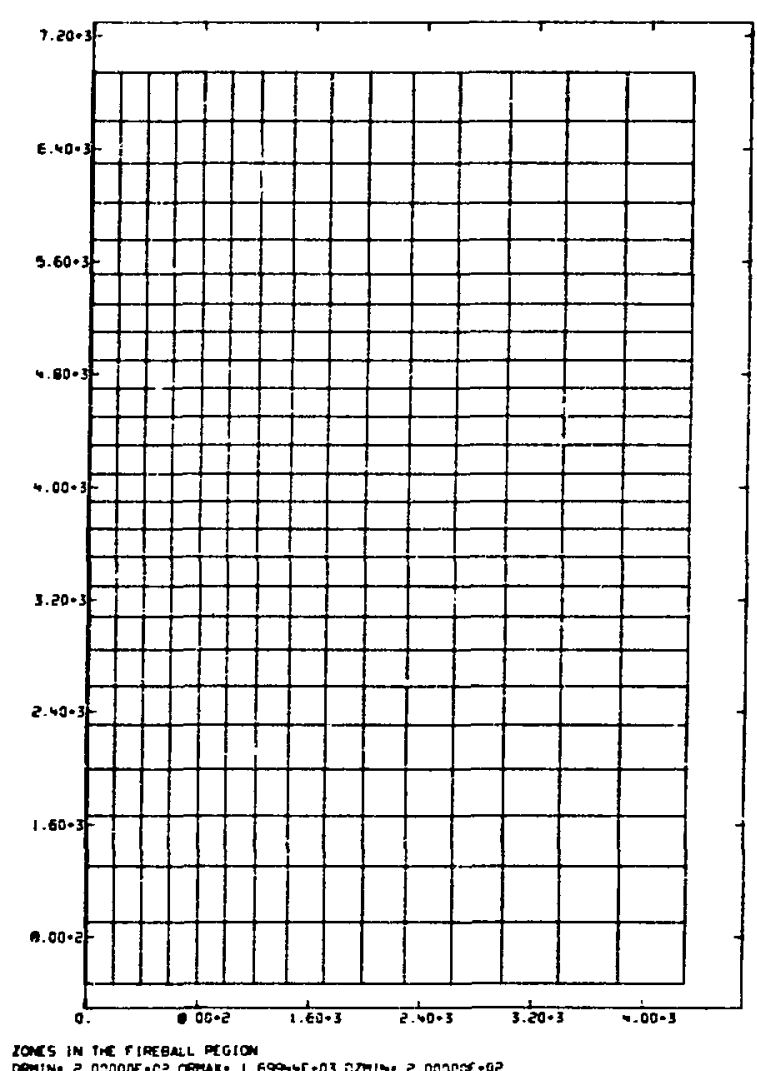

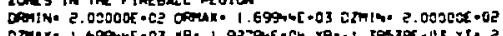

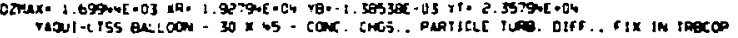

T. D. Juoeer-os crele. 2 


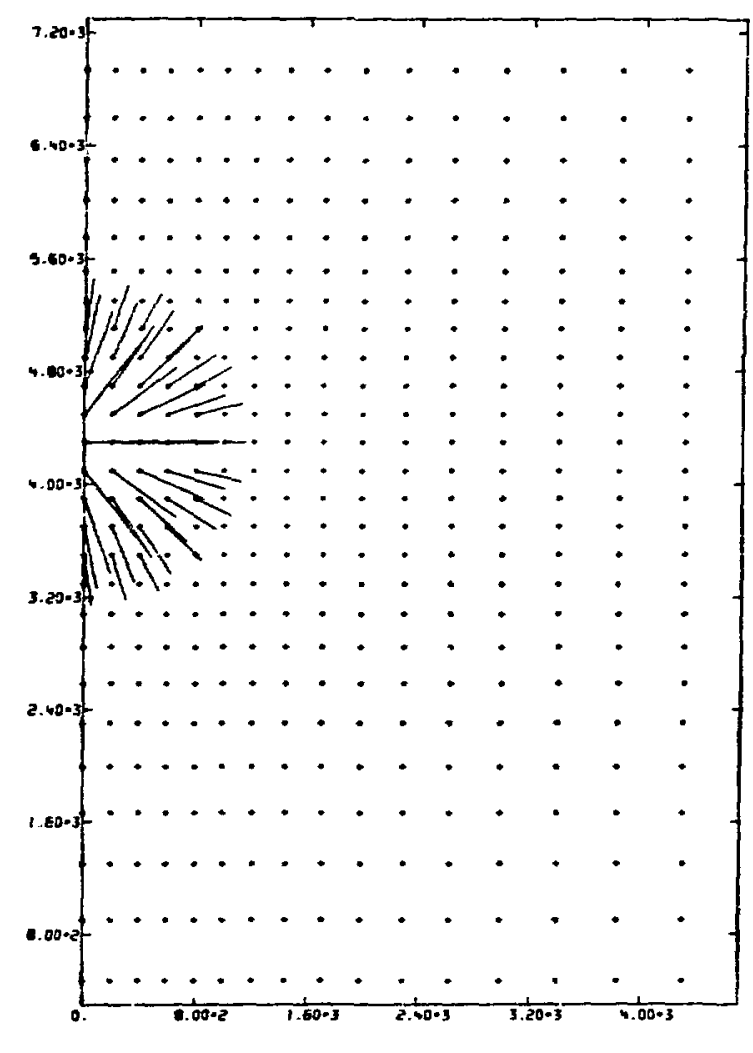

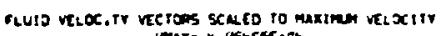

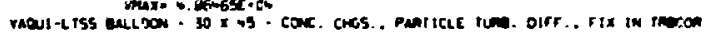

T. O. 30000E-DI CVELE. O 
B. Turbulence Seeding Conditions

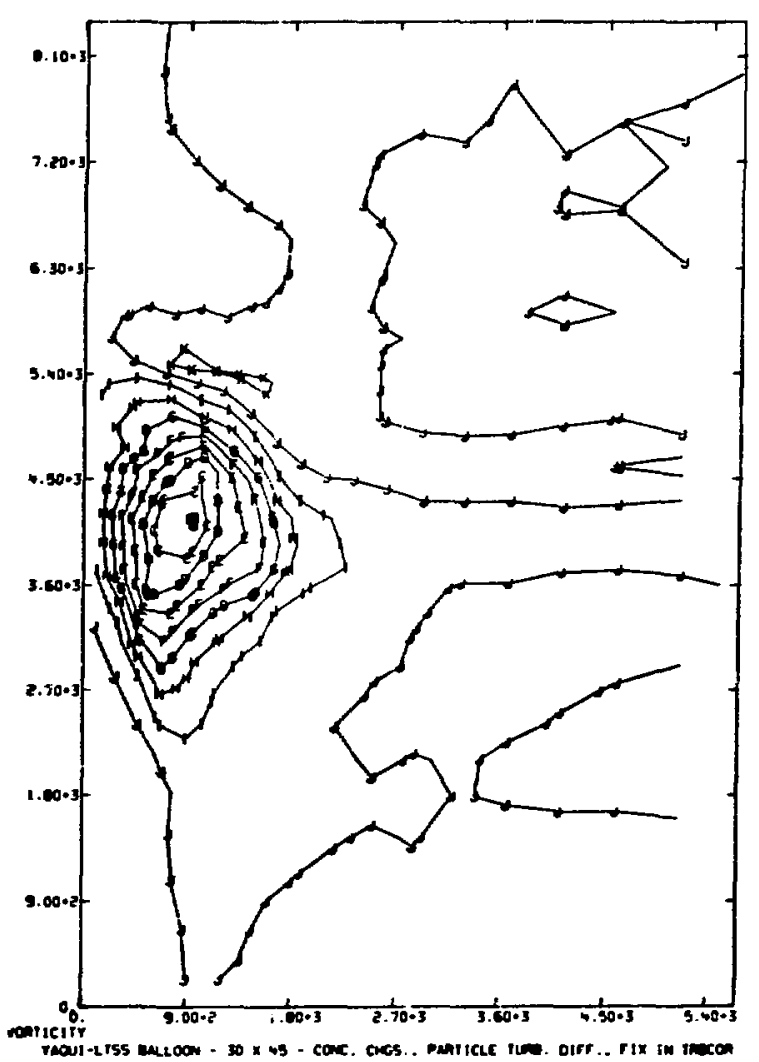

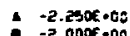

- $-2.0006-00$

c $-1.730 \mathrm{de}=00$

-1.5000 .09
$c-1.7005-00$

c $-1.250 \mathrm{C}+00$

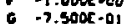

i. $-5.000-0$.

$1-2.5000-01$

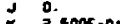

2
$+\quad 5.0005-01$

ow $\begin{array}{r}-2.026 x+02 \\ 3.103 x+01\end{array}$ 


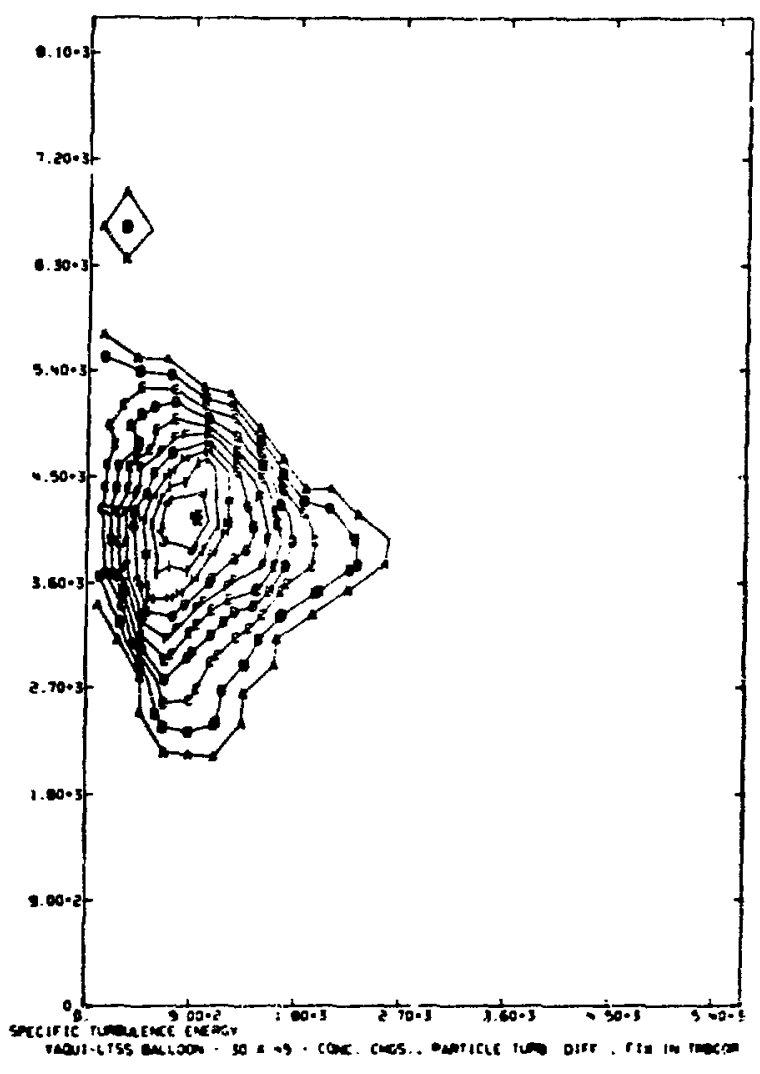

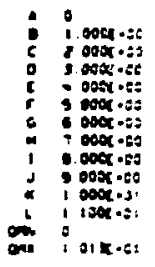

26 


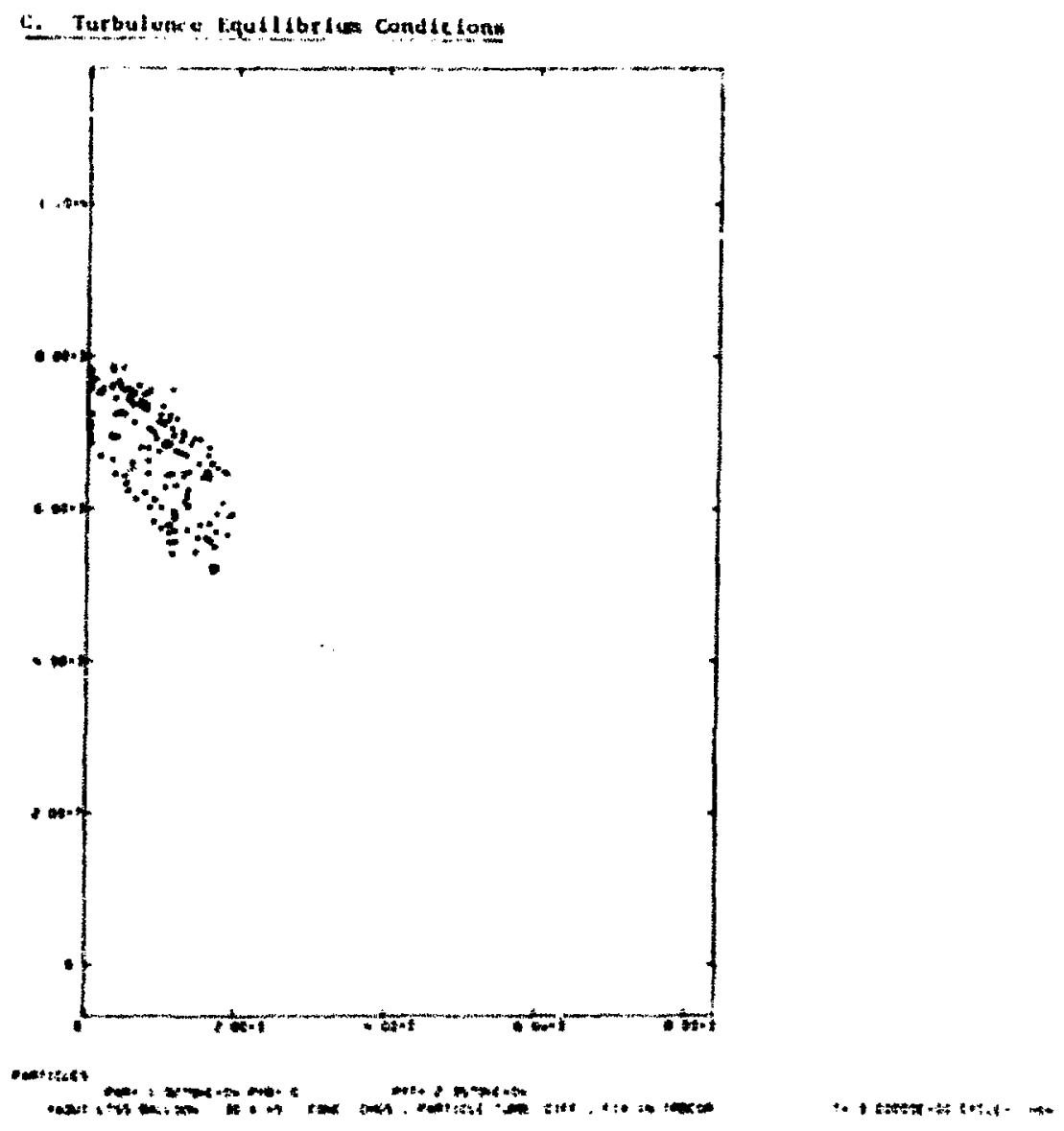

27 

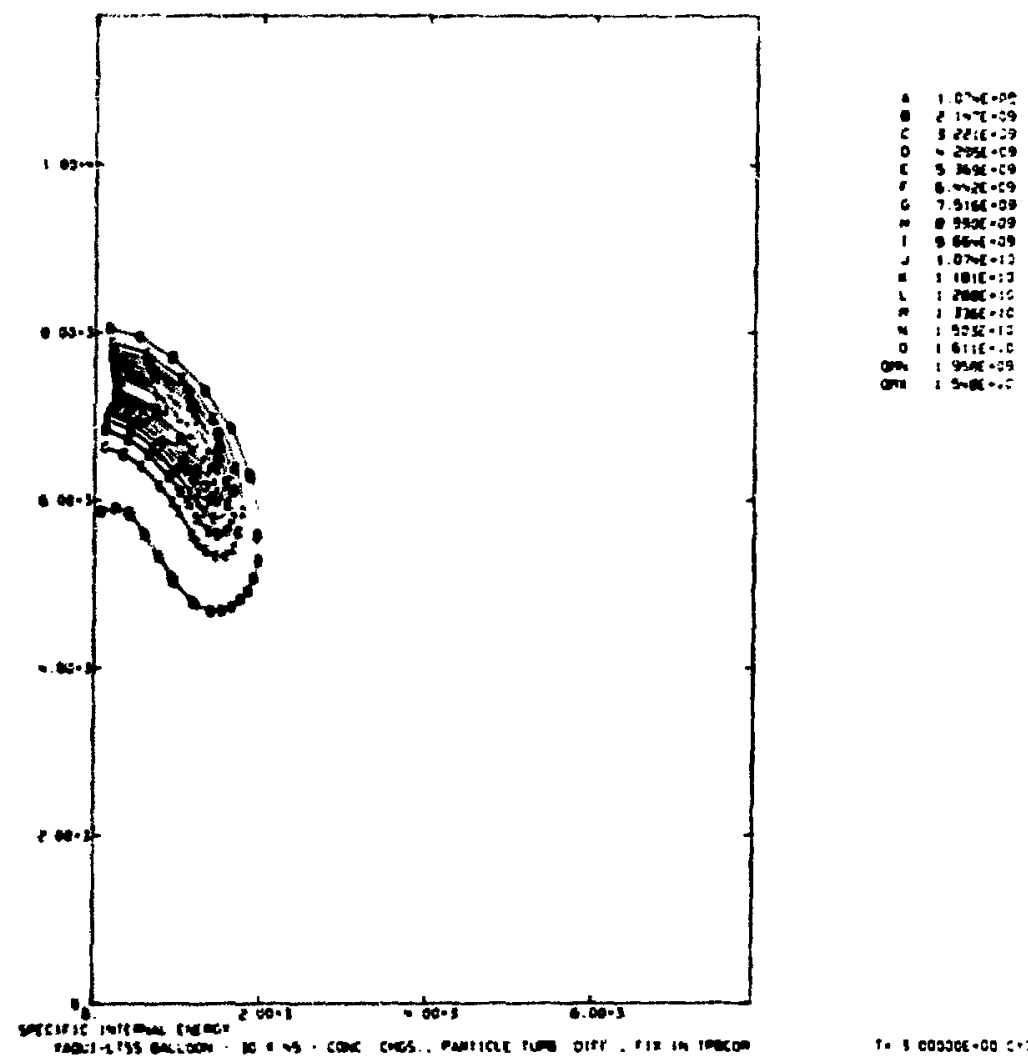

1. 1 cosjes +co : ... . +6 

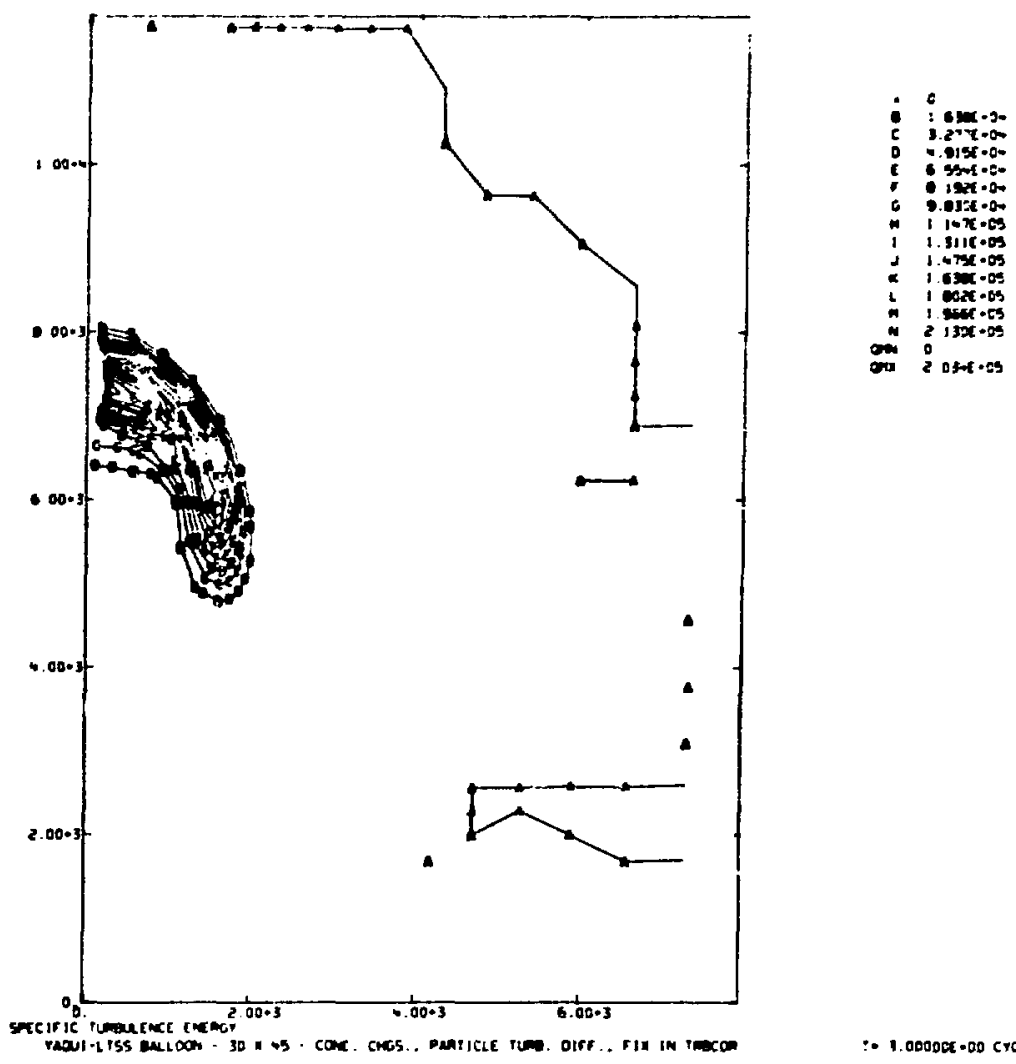

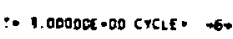


D. Moderately Late-Time Cond it lons (E1ght Torus-

Formacion Times)

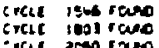

icie 2050 ino

crcit rates rino

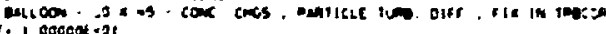

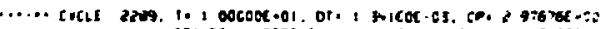

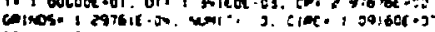

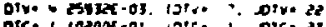

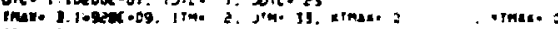

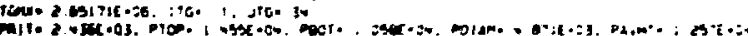

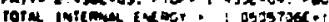

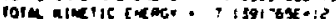

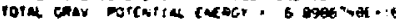

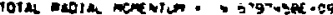

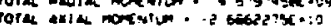

17104271087656720223 :

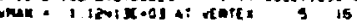

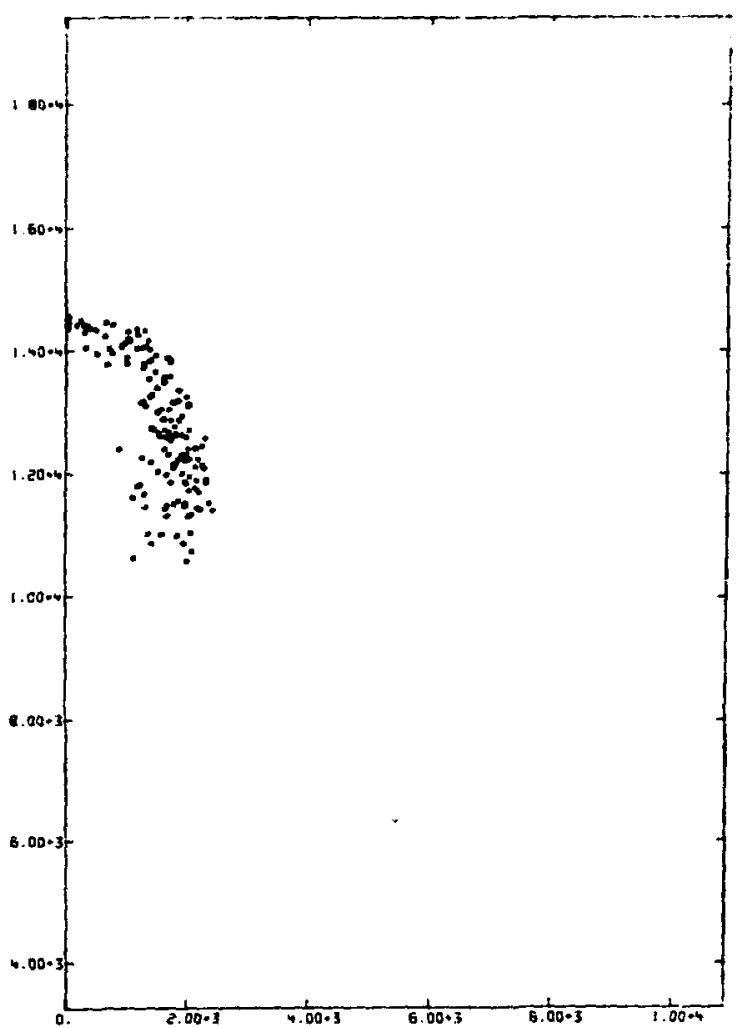

- Danticles

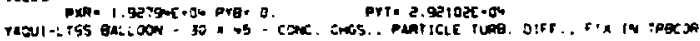

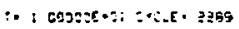




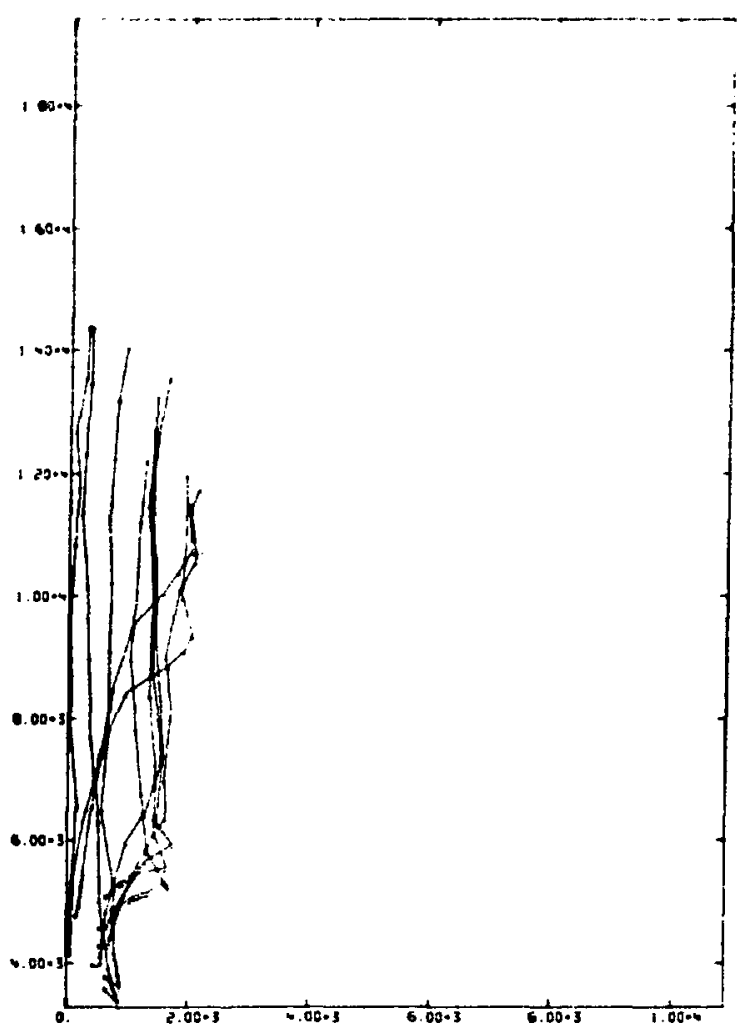

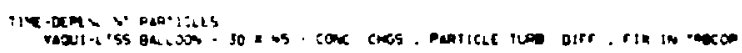




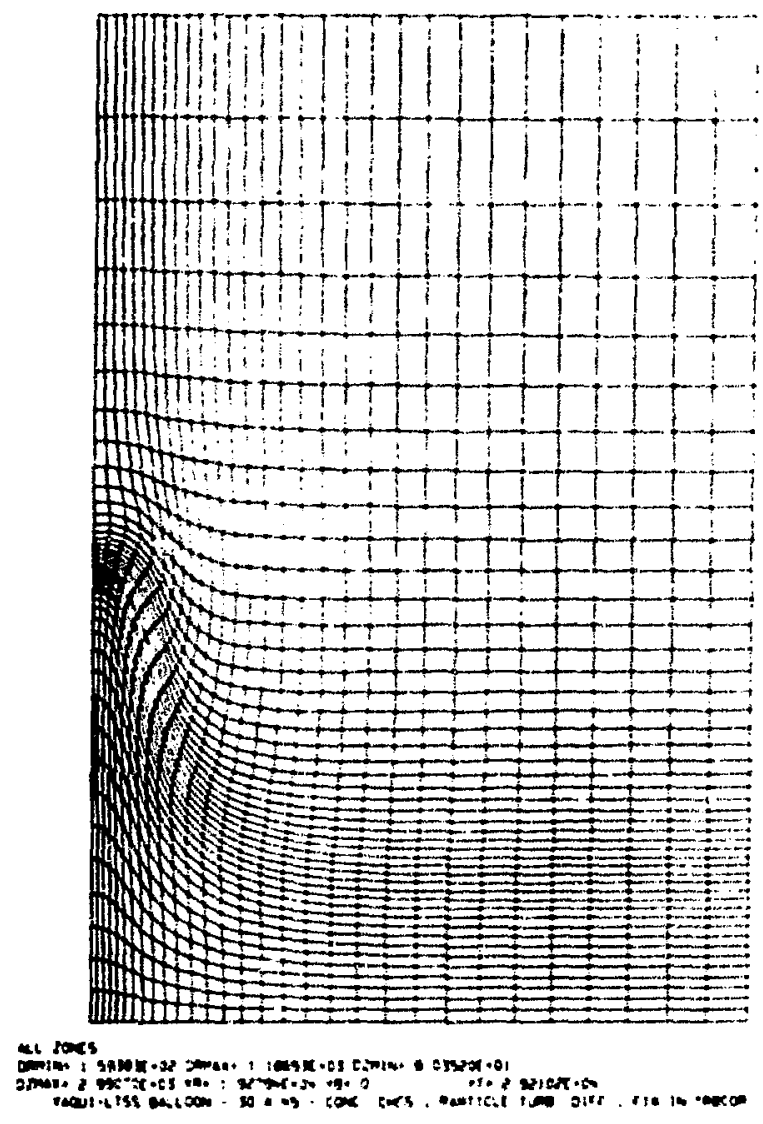

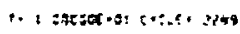




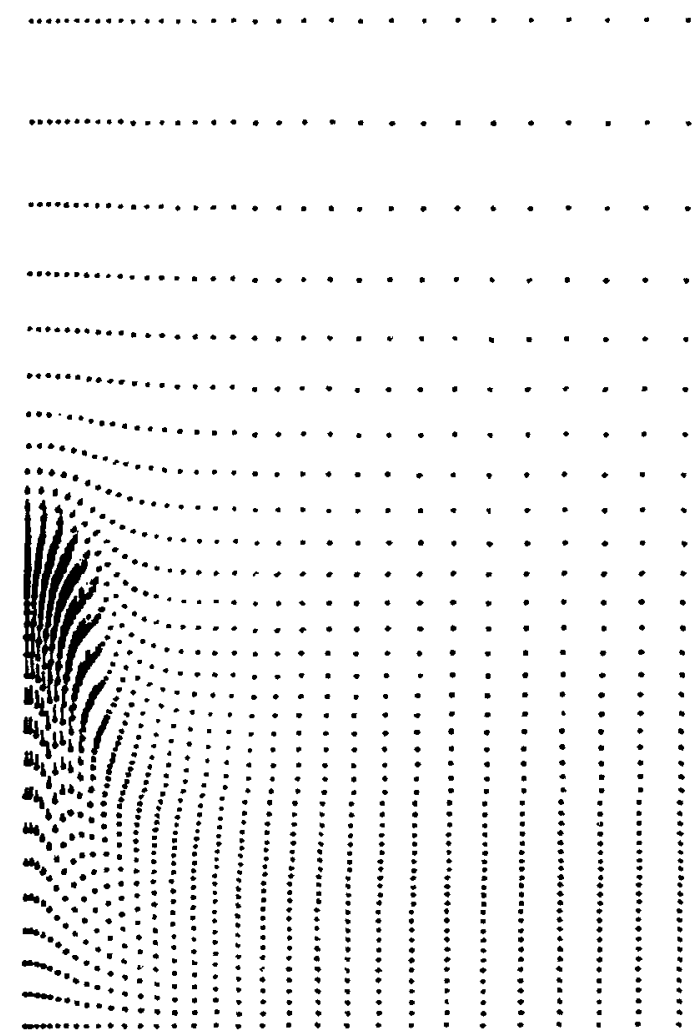

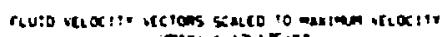

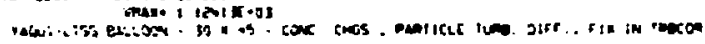




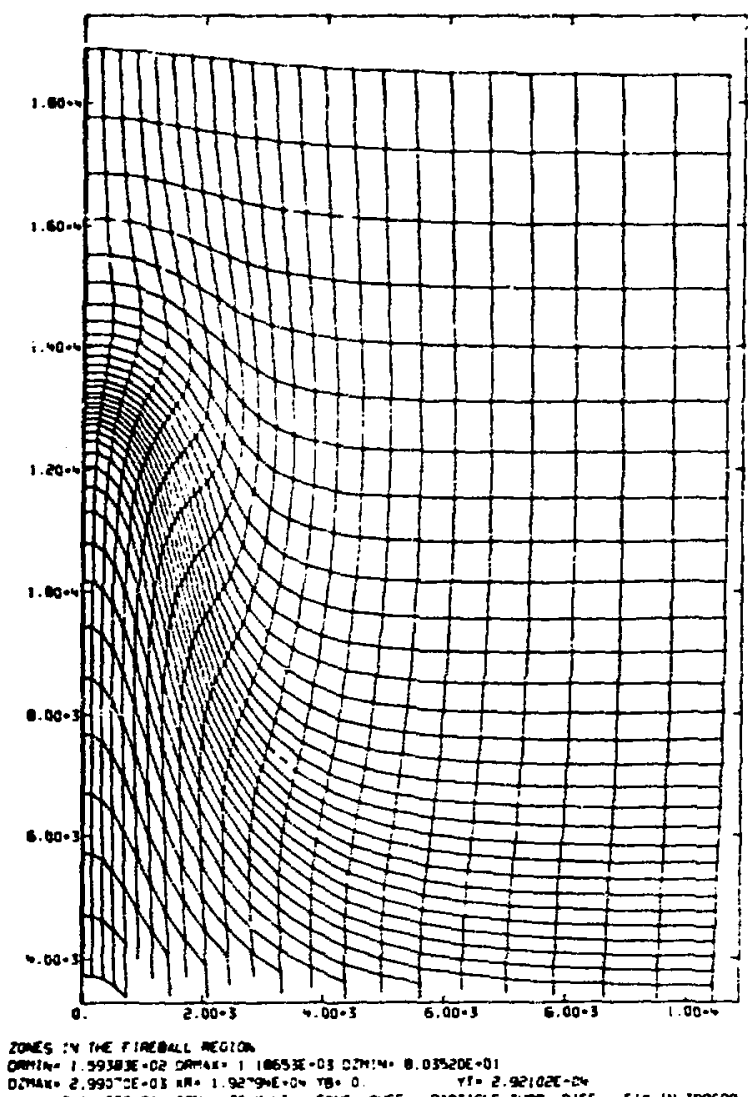

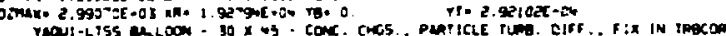

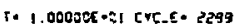




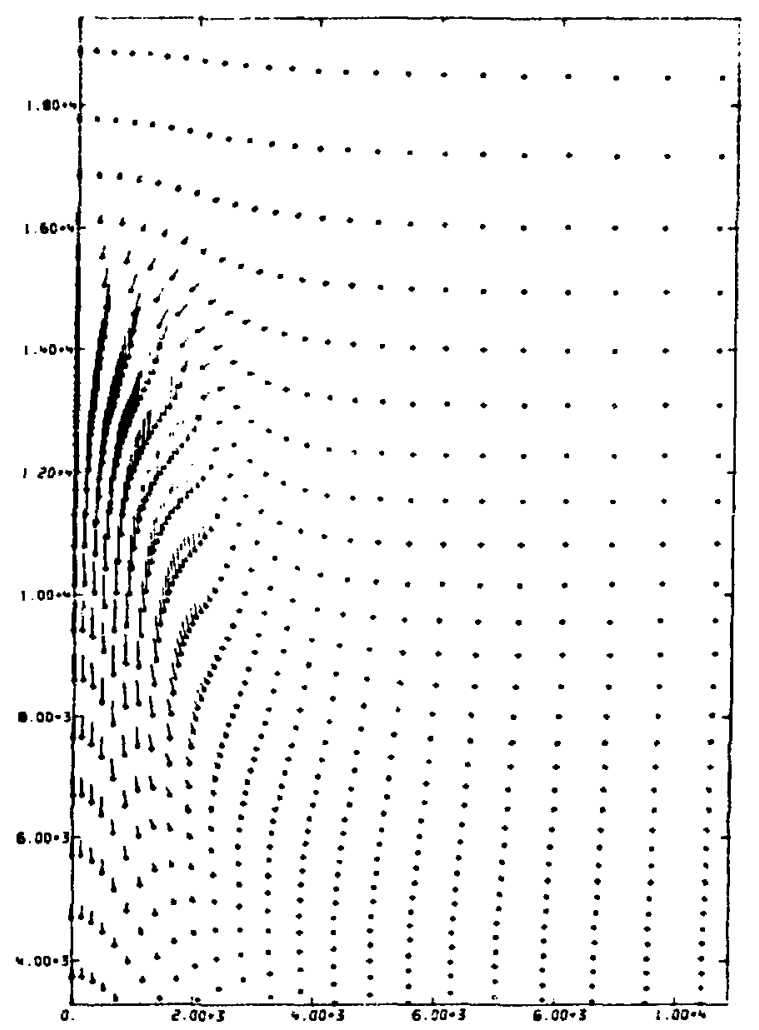

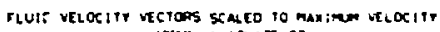

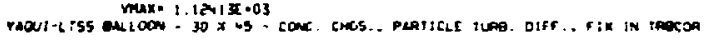

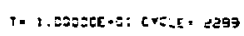




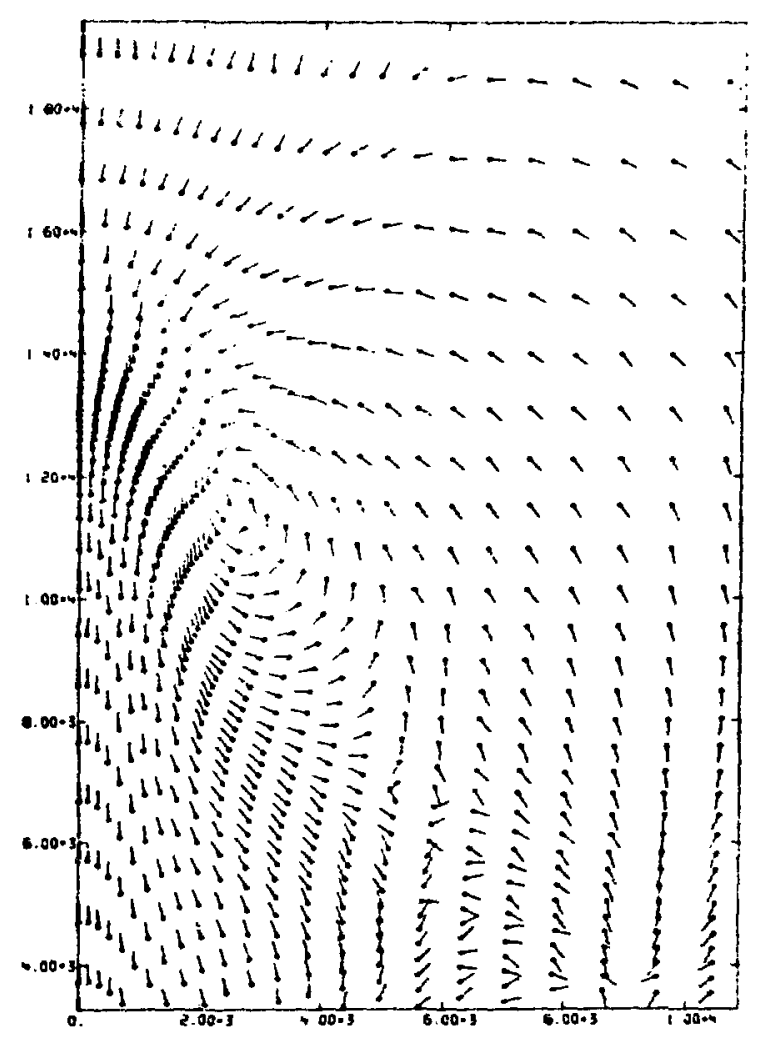

unscuto r. Ute vetacite netroes

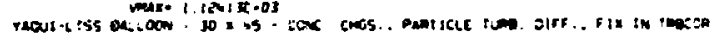

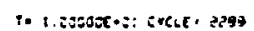



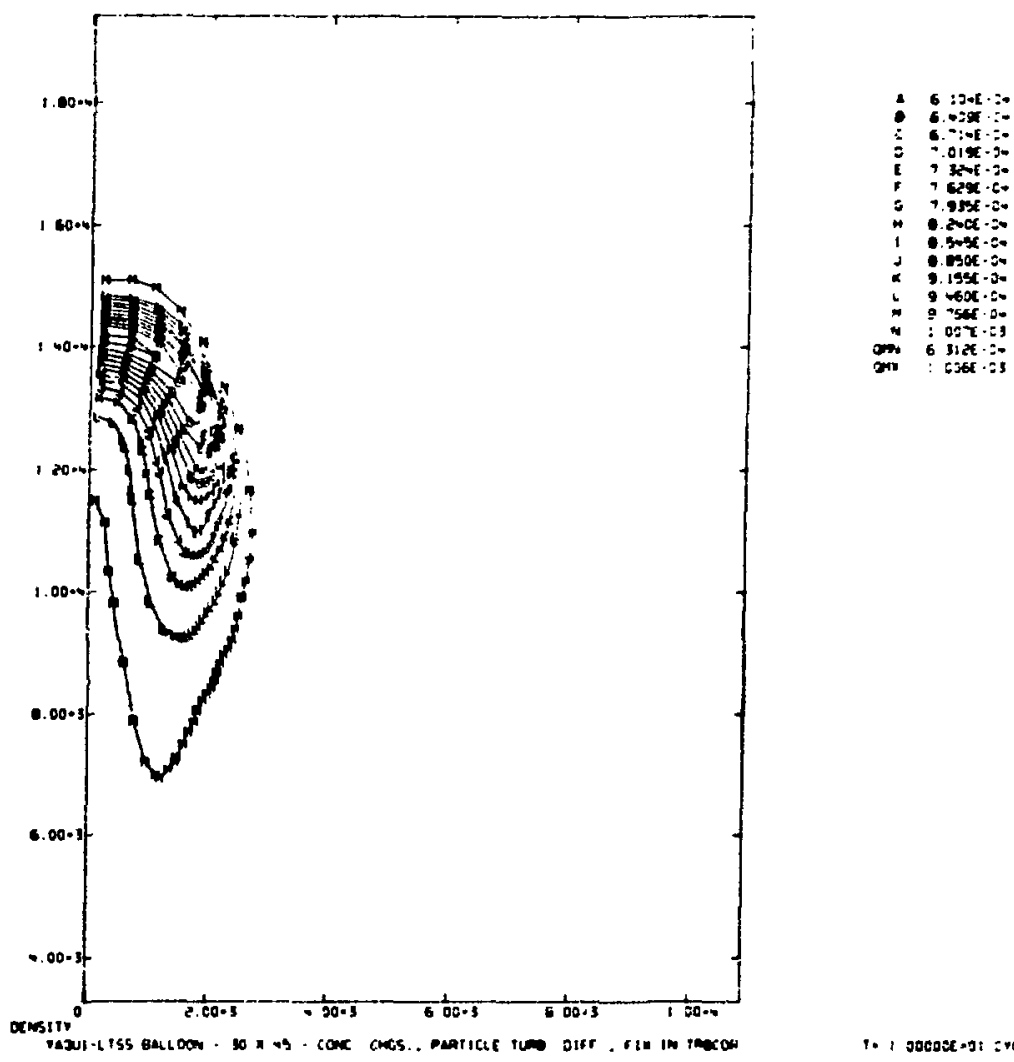

1. 1 gacosegt iret +2803 

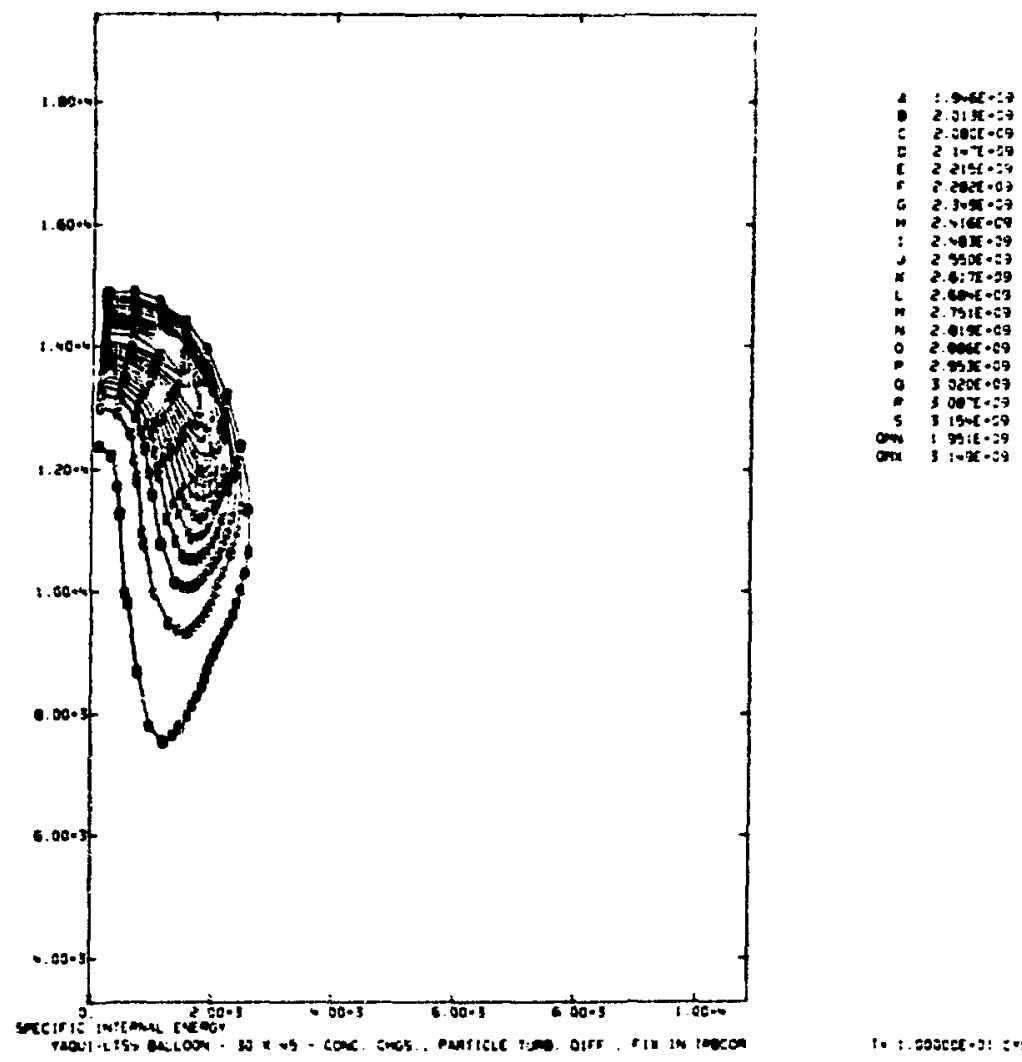

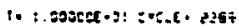



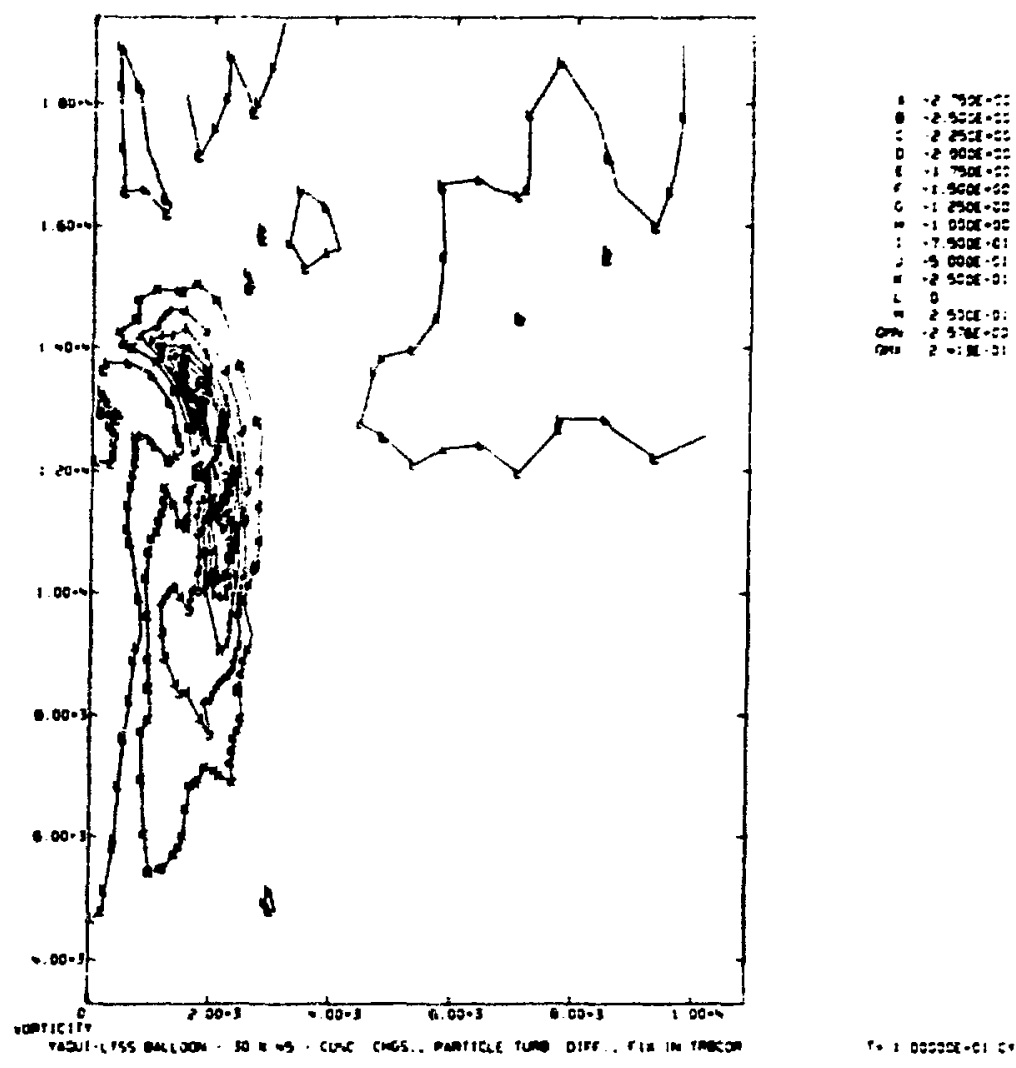

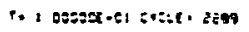



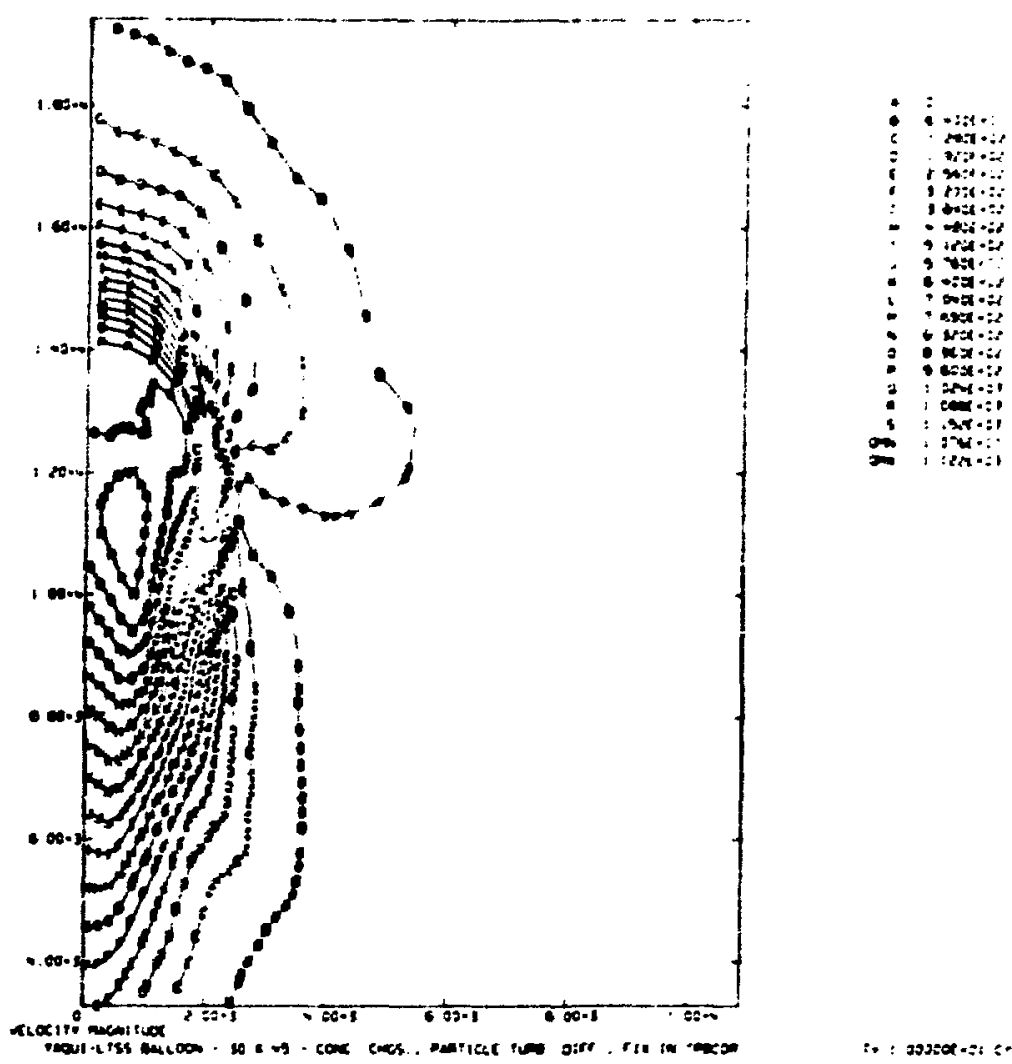

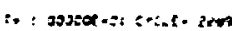



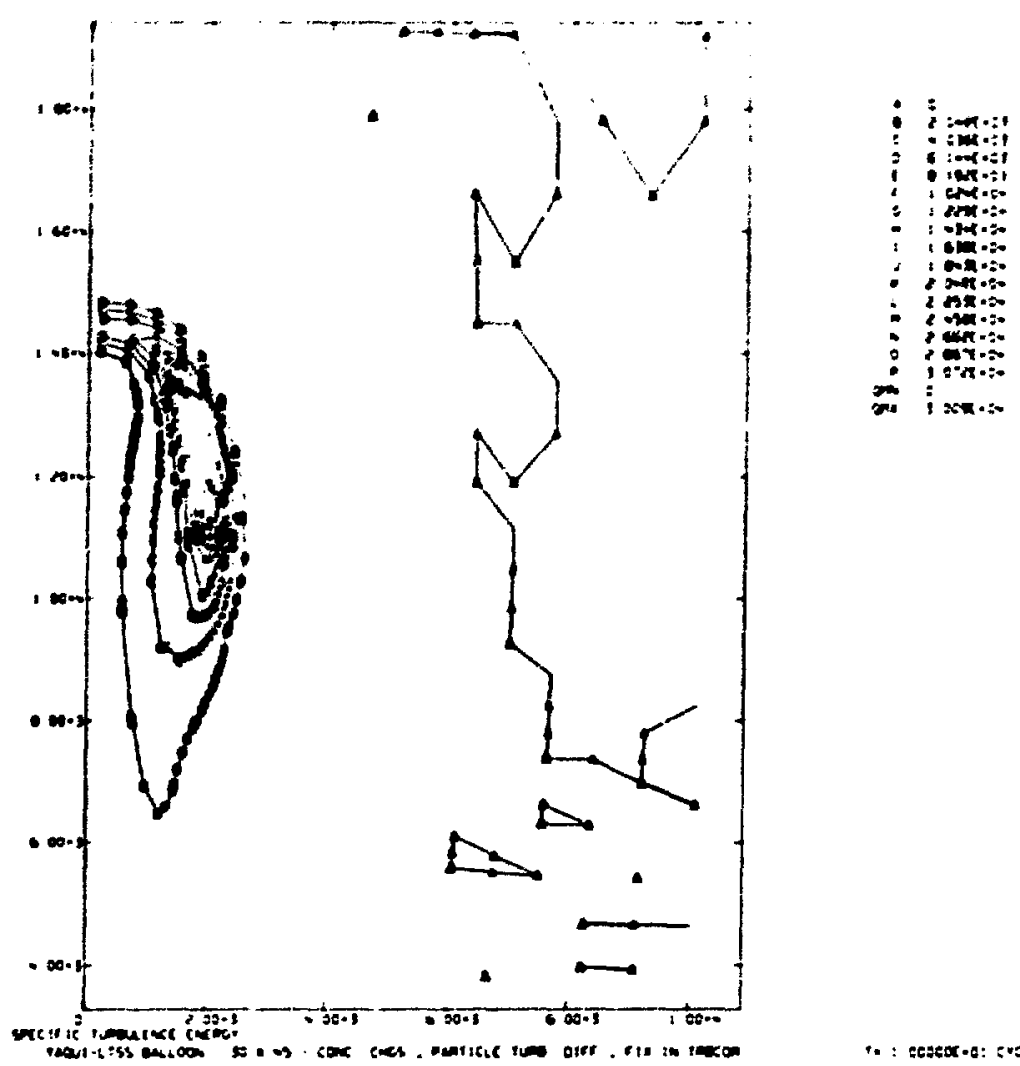

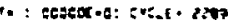



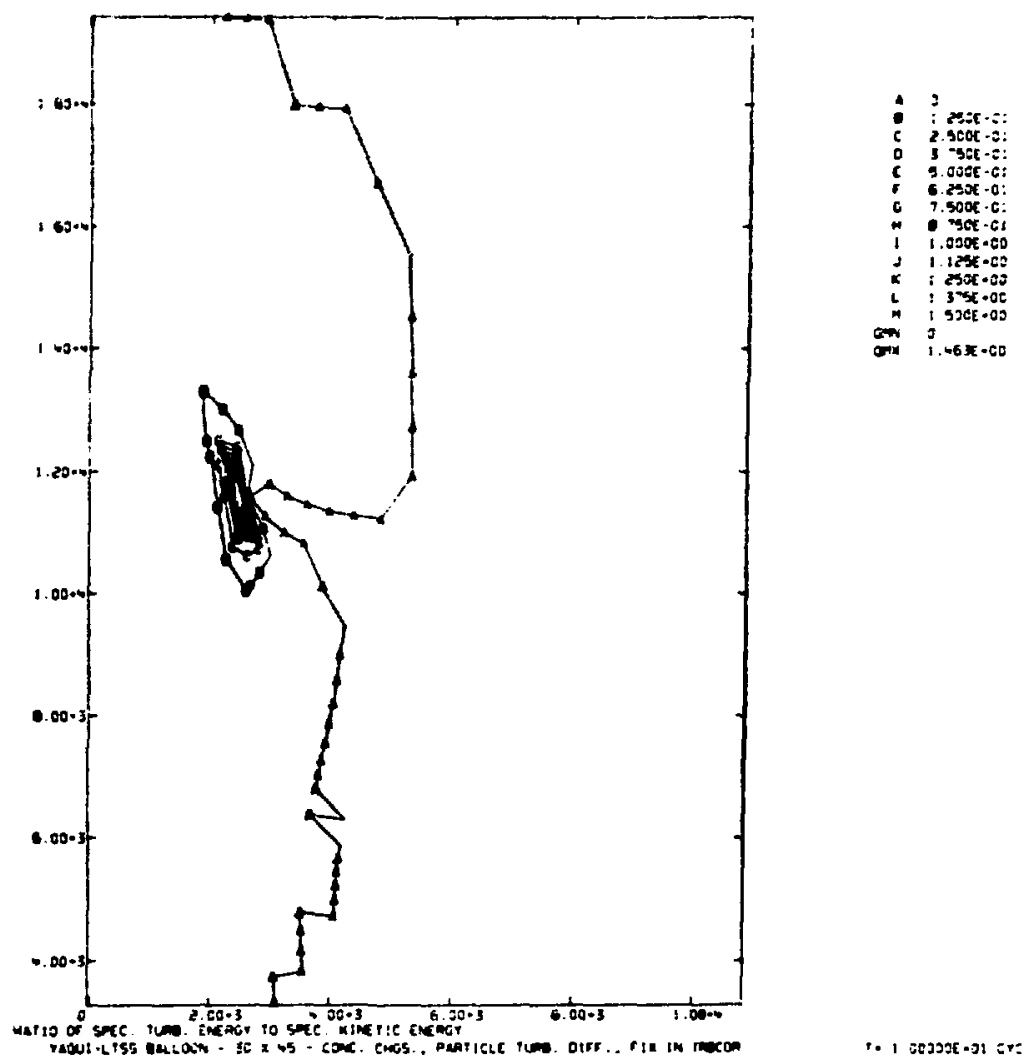

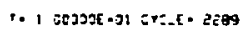



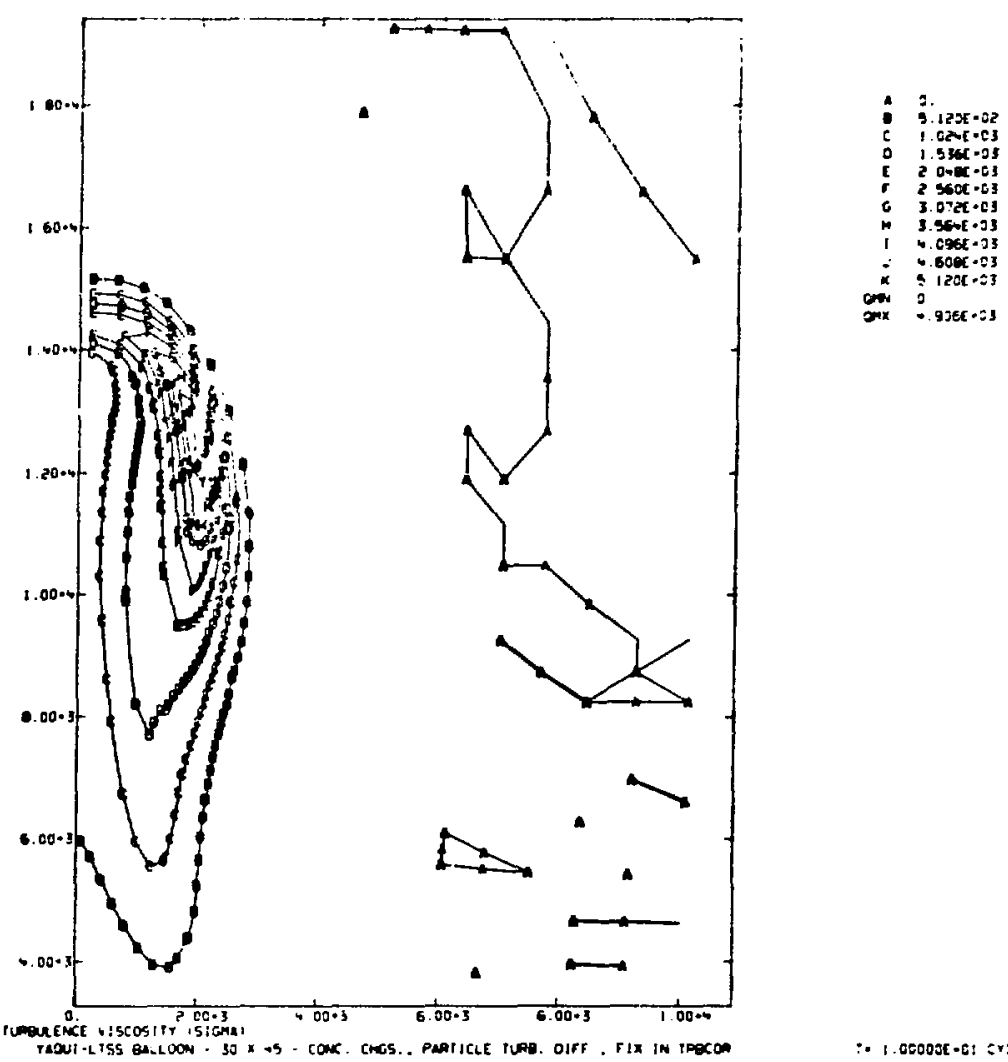

$\therefore=1.060026-21,0,8: 6,553 \theta$ 

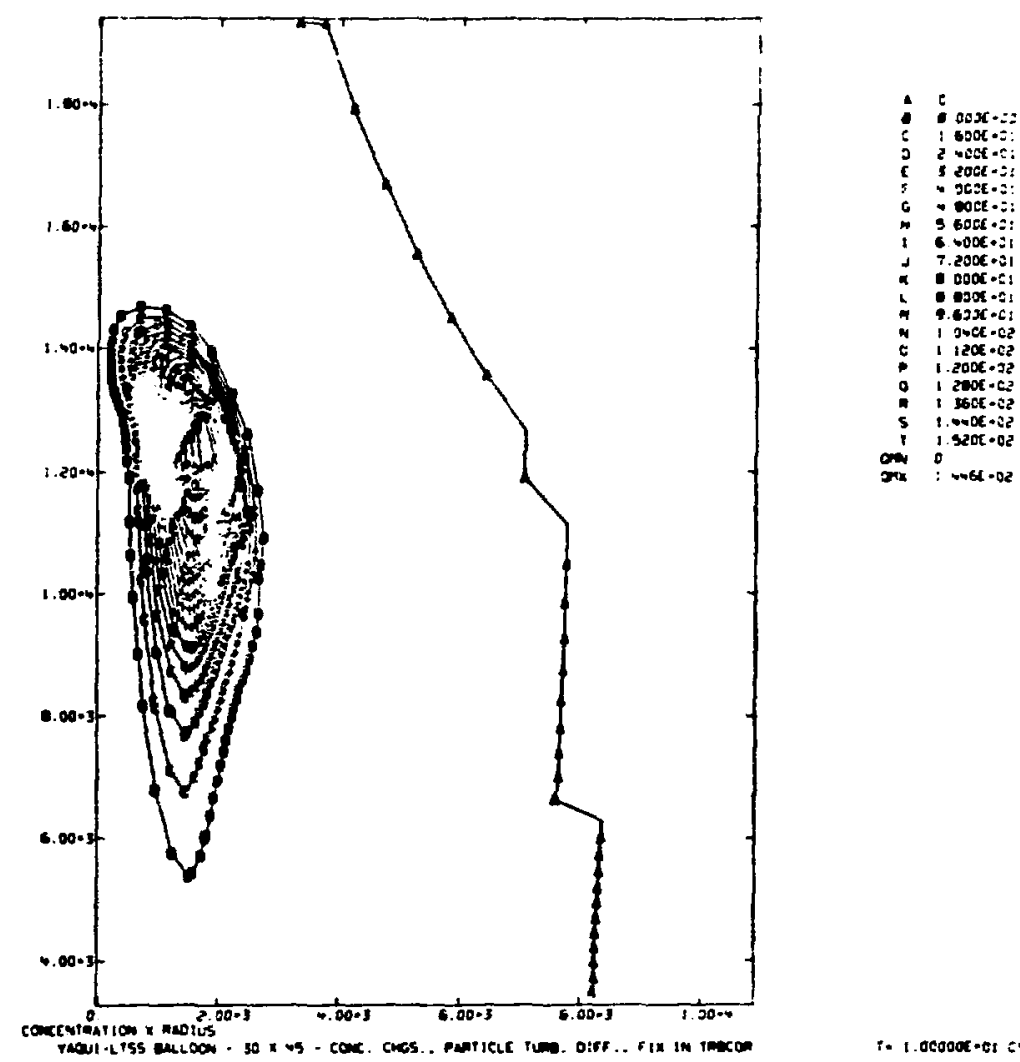

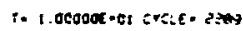




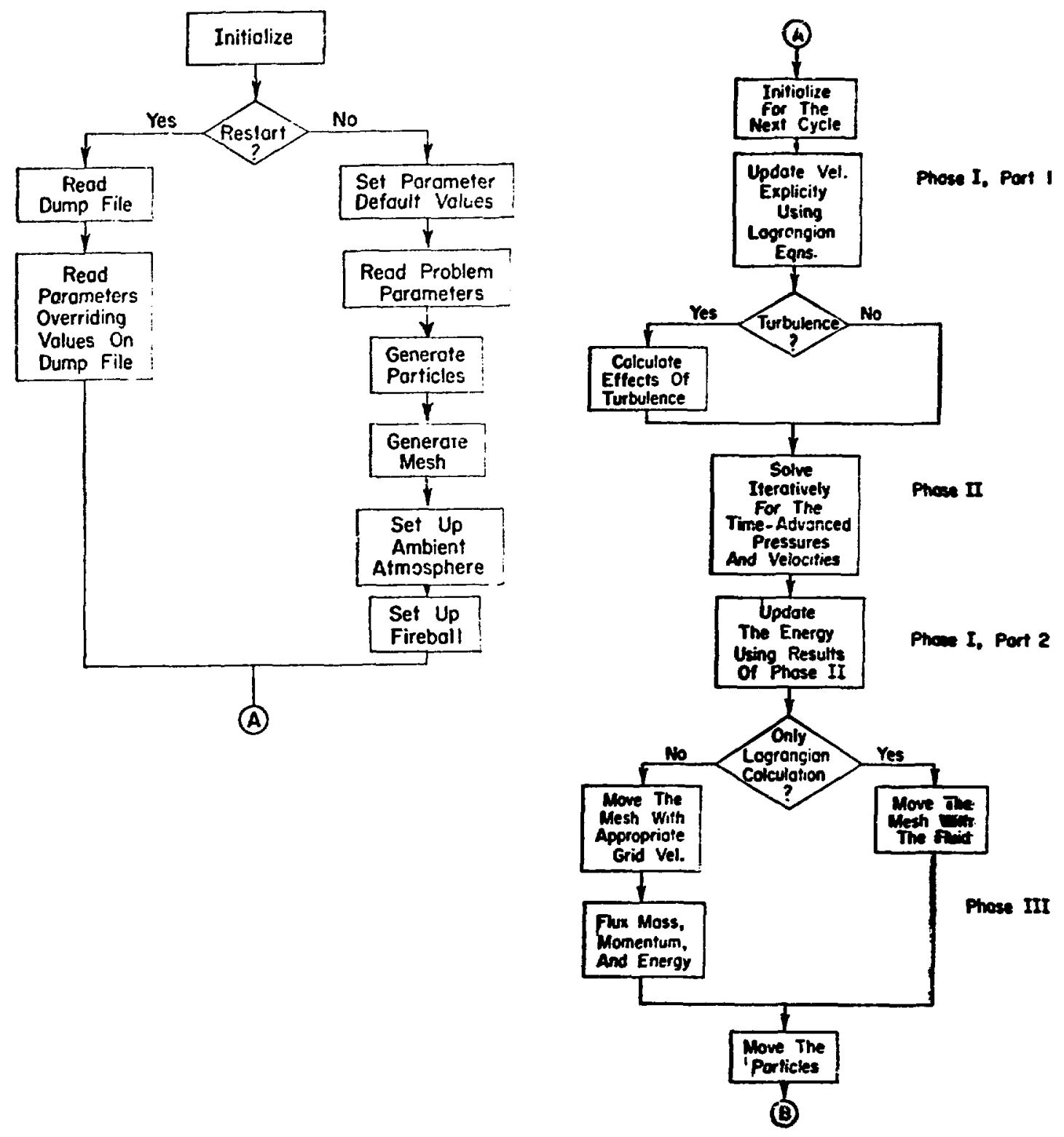




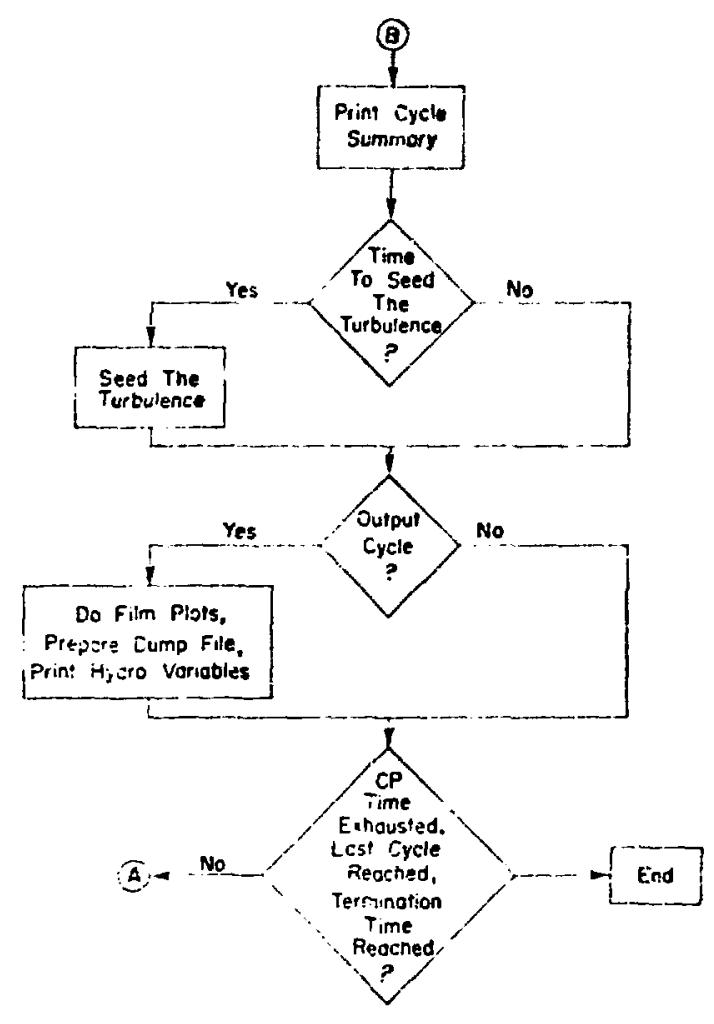


A. LTSS-Dependent Code

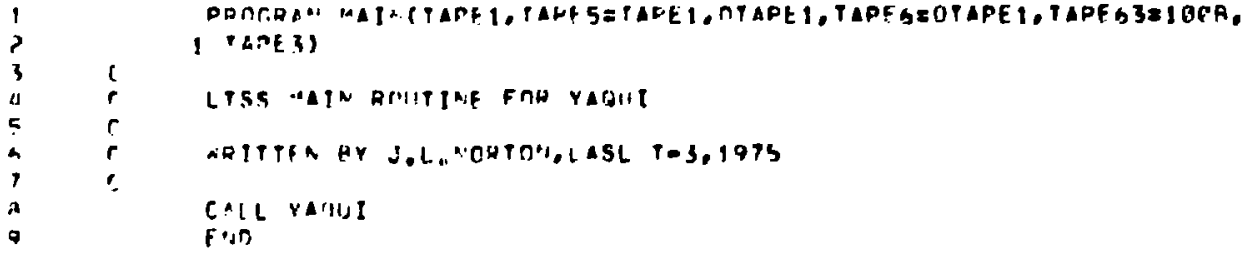

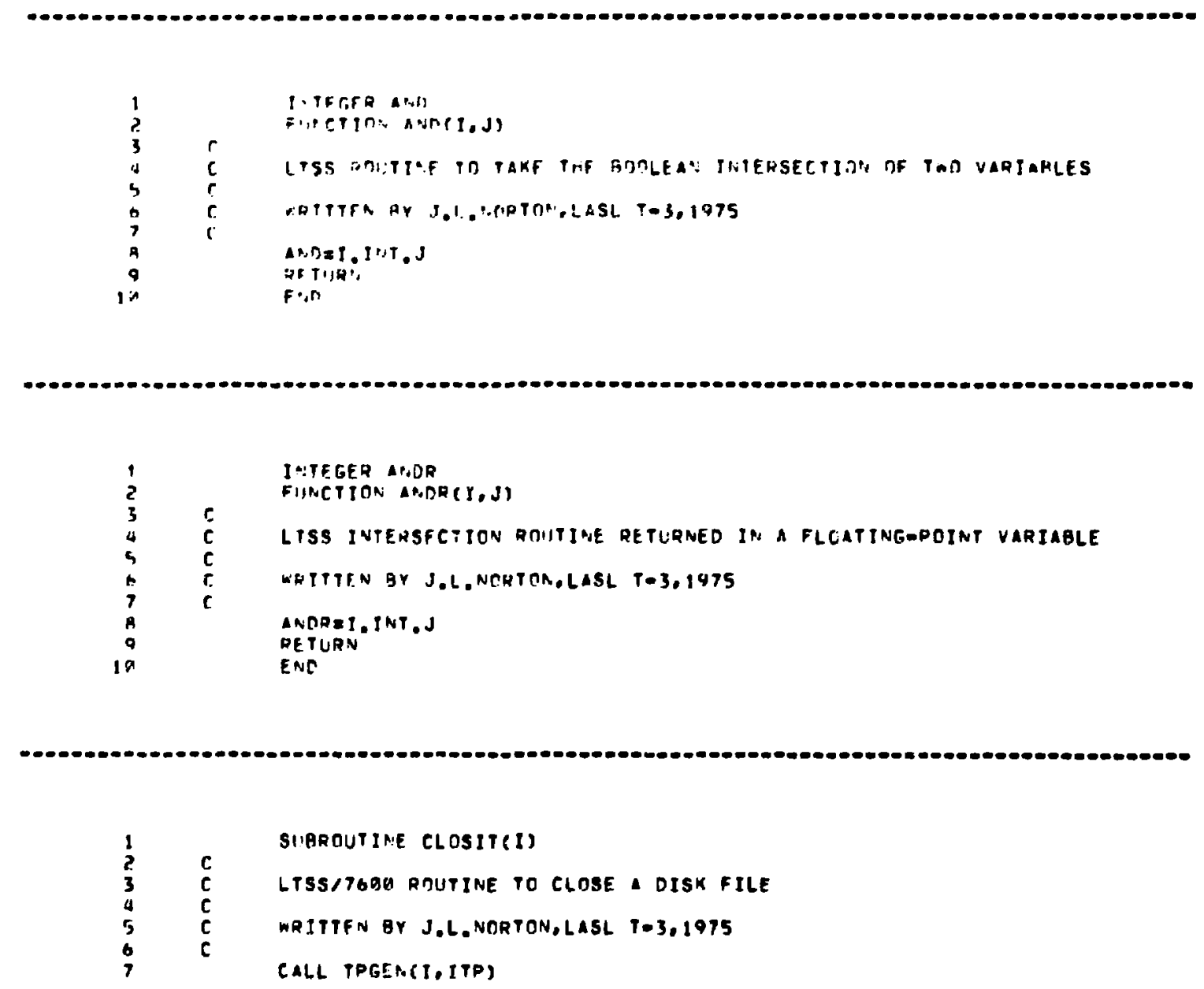


CALL ASSISA, (I,D,ITP,-2)

RE THON

F?
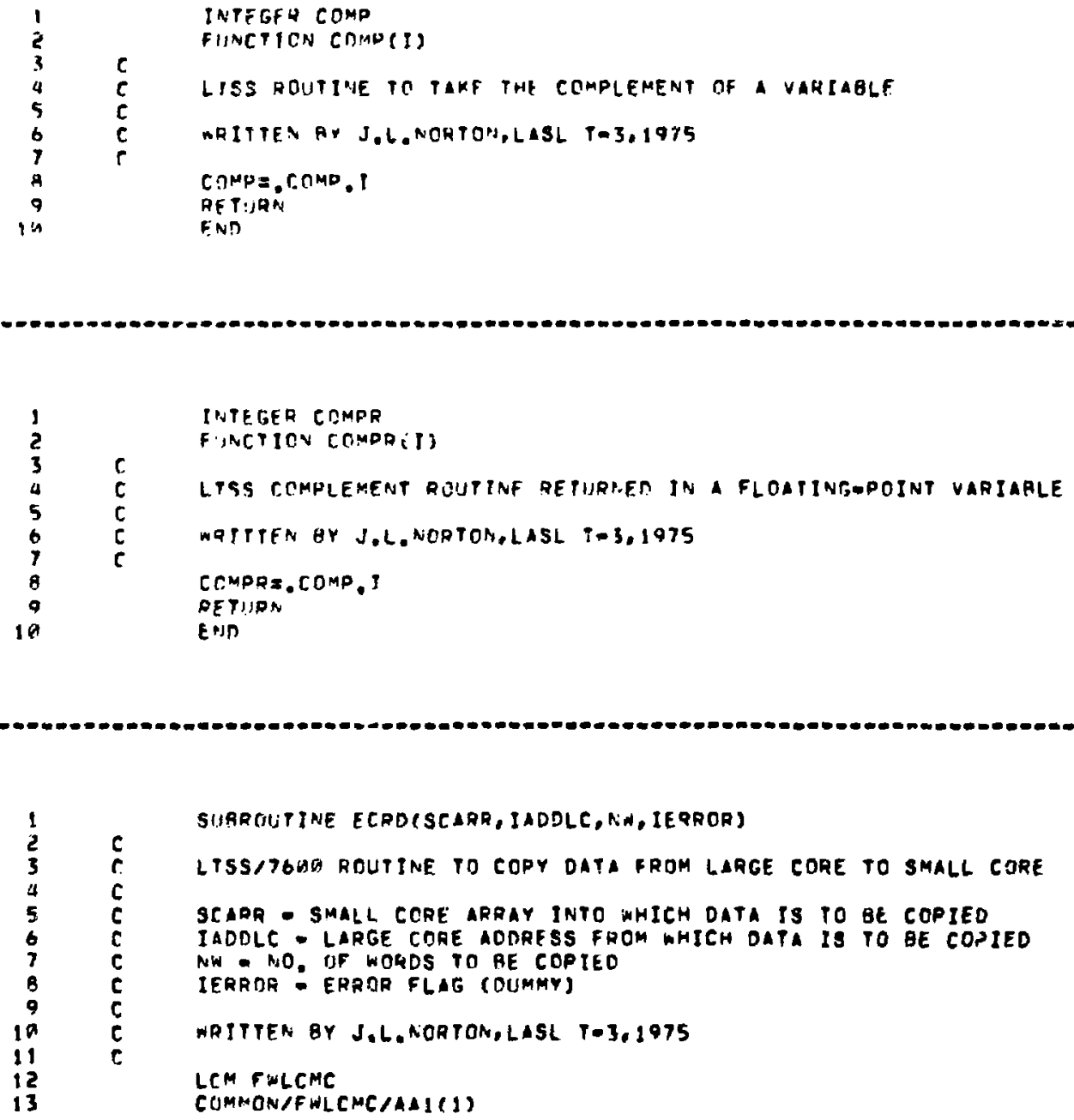


\begin{tabular}{|c|c|}
\hline $\begin{array}{l}14 \\
15 \\
16 \\
17\end{array}$ & 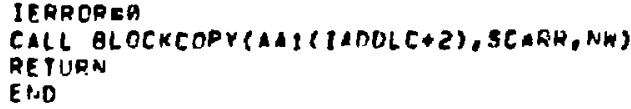 \\
\hline
\end{tabular}
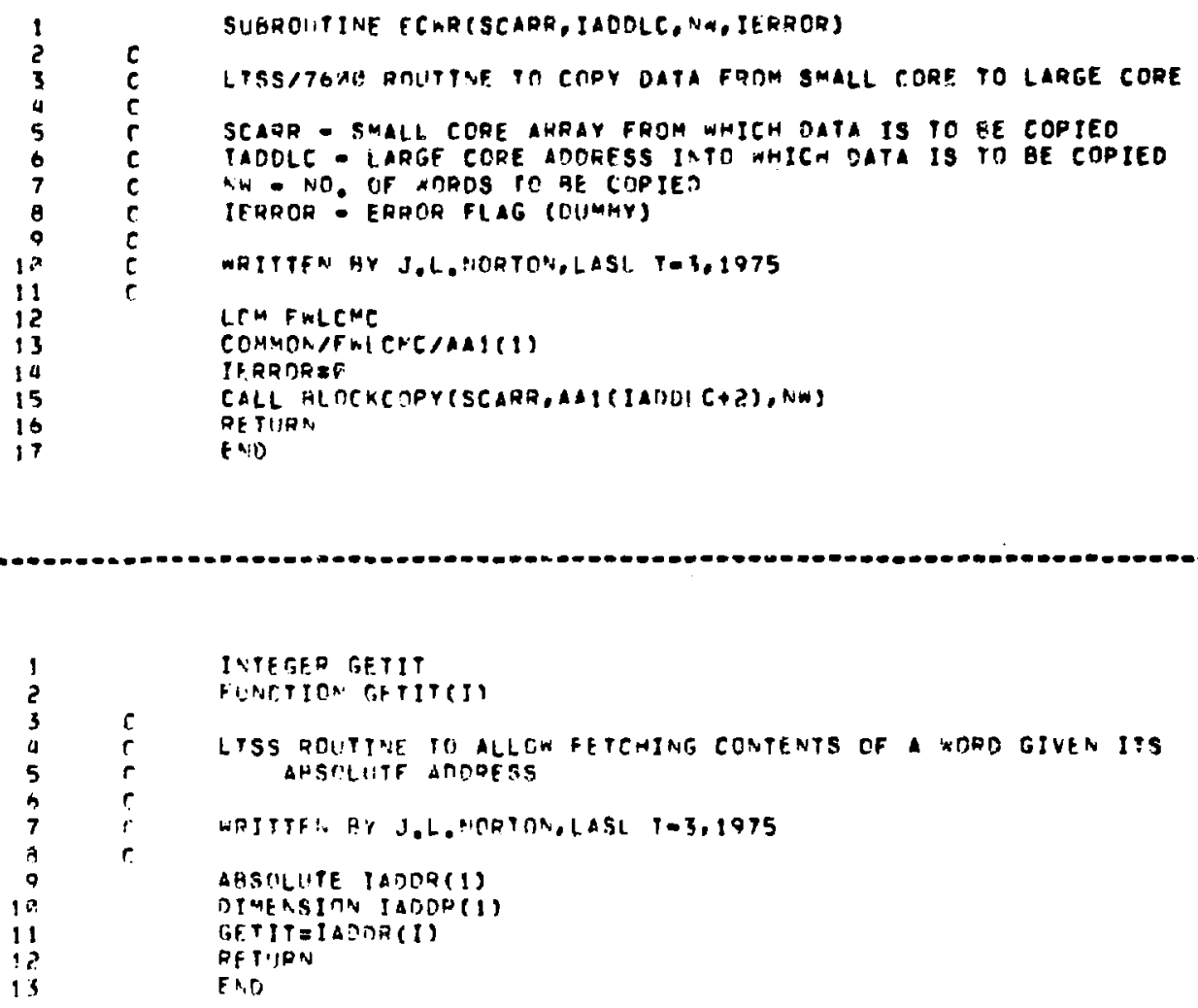

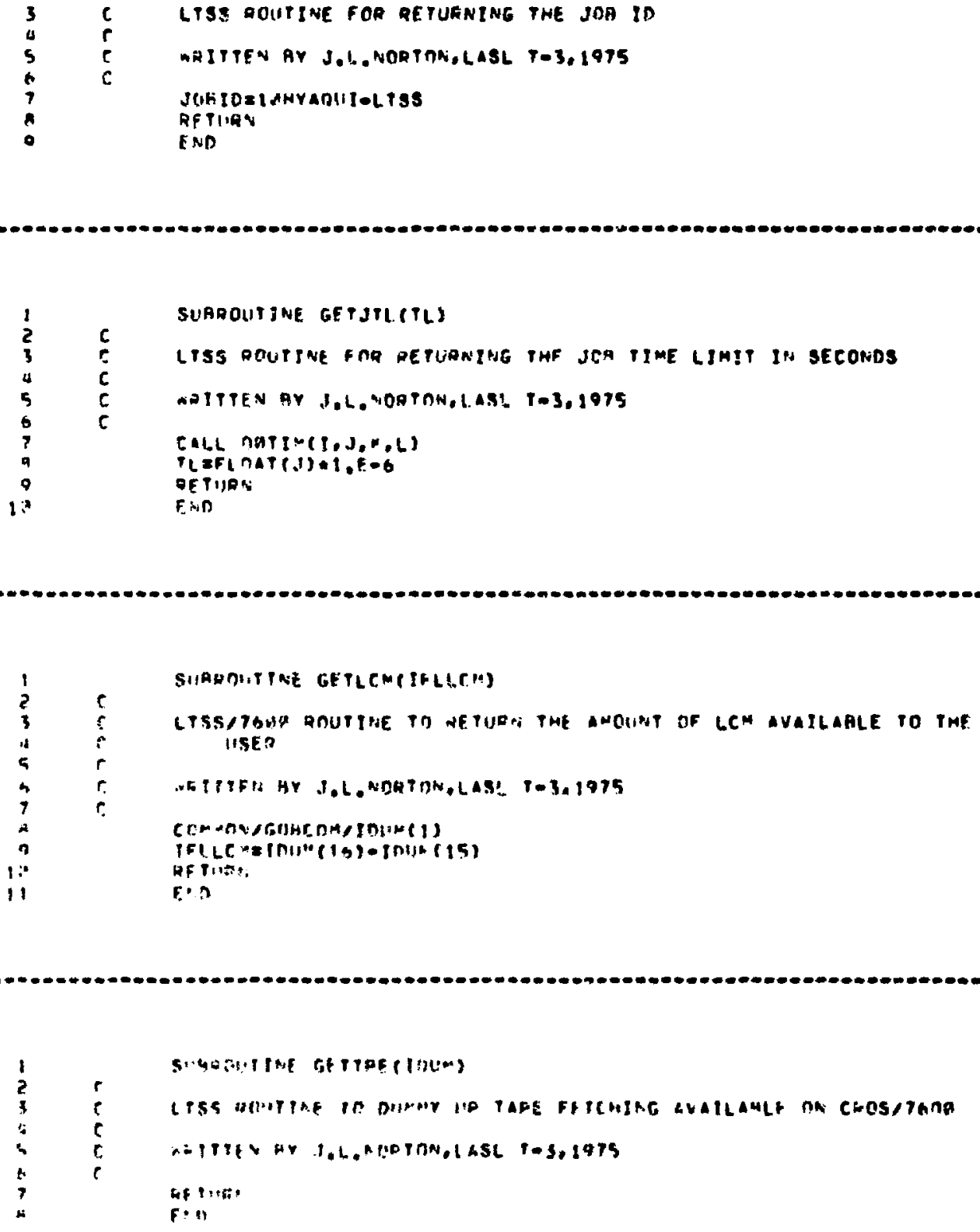


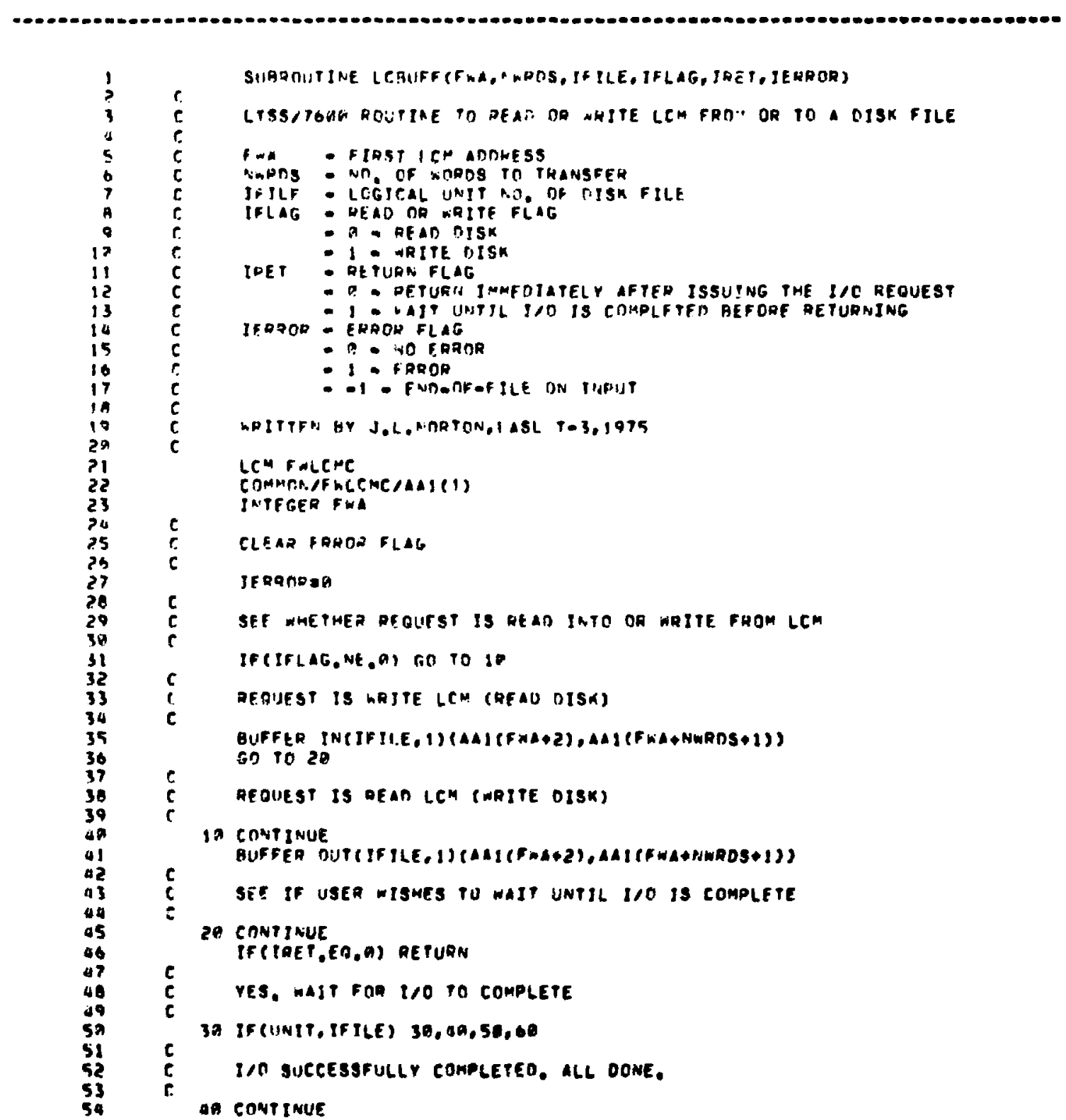




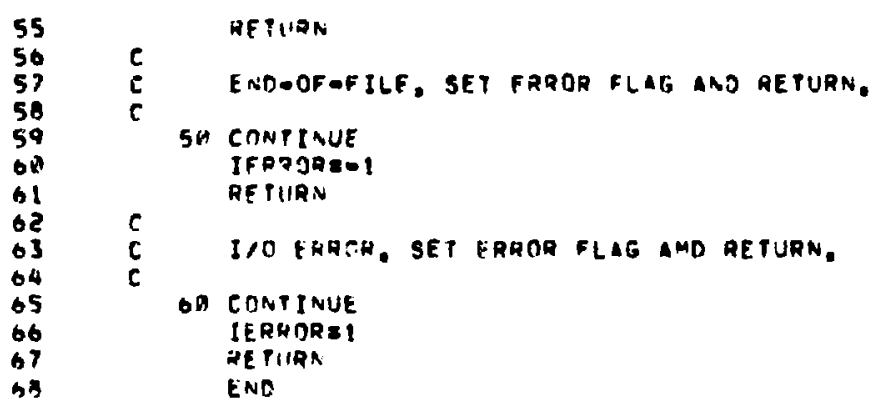

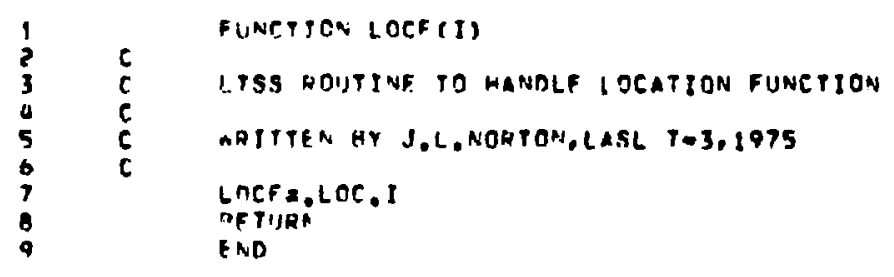

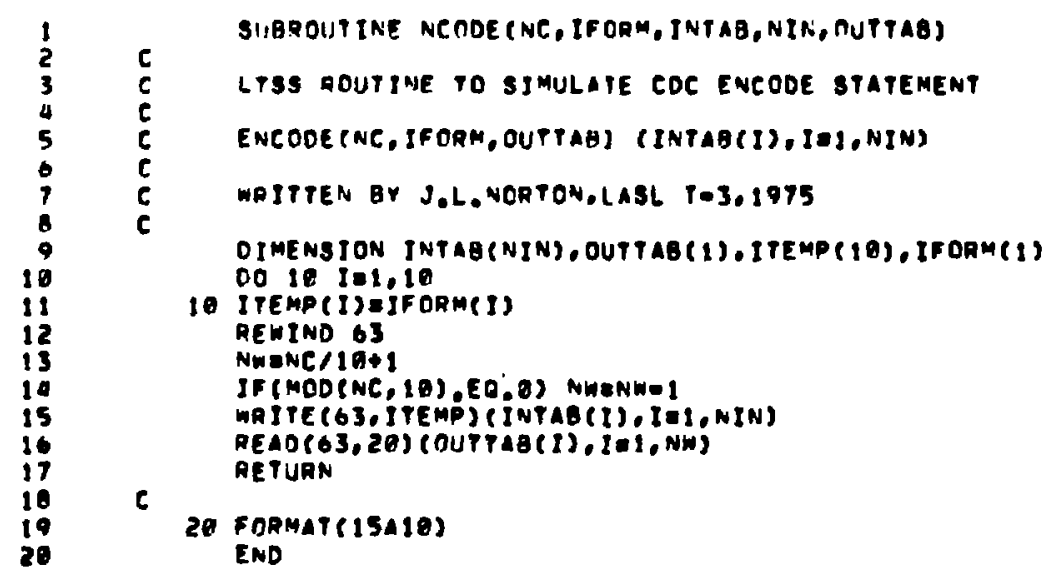




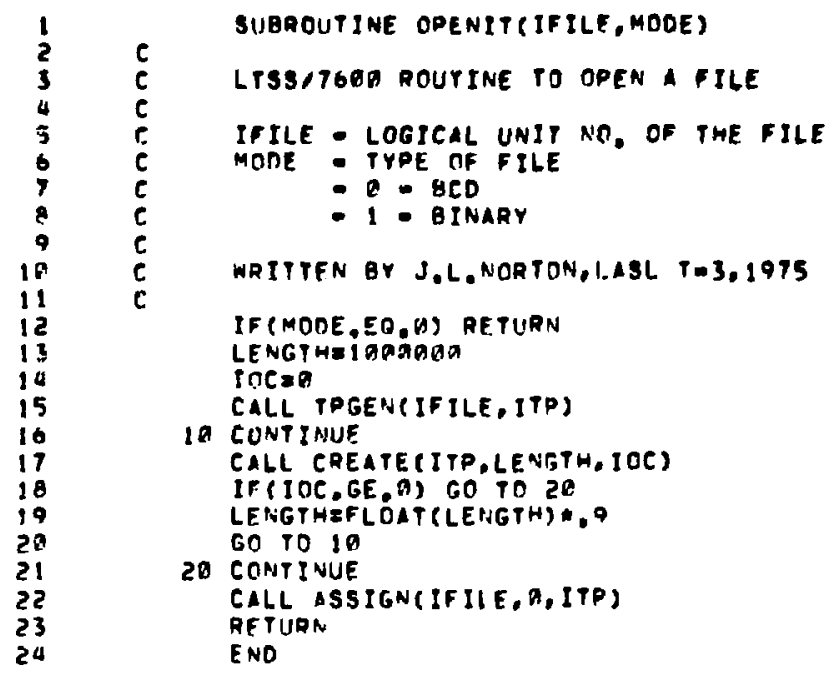
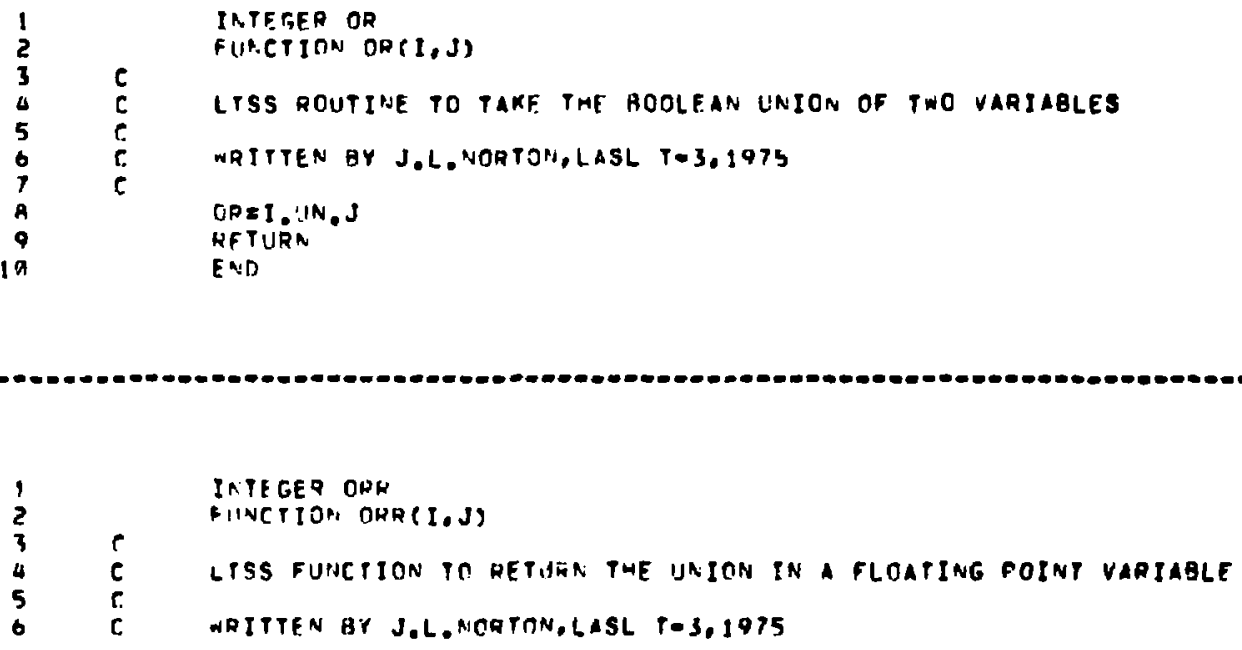


\begin{tabular}{|c|c|c|}
\hline $\begin{array}{r}7 \\
8 \\
9\end{array}$ & $c$ & $\begin{array}{l}\text { ORAEI IUN.J } \\
\text { RETURN } \\
\text { END }\end{array}$ \\
\hline
\end{tabular}
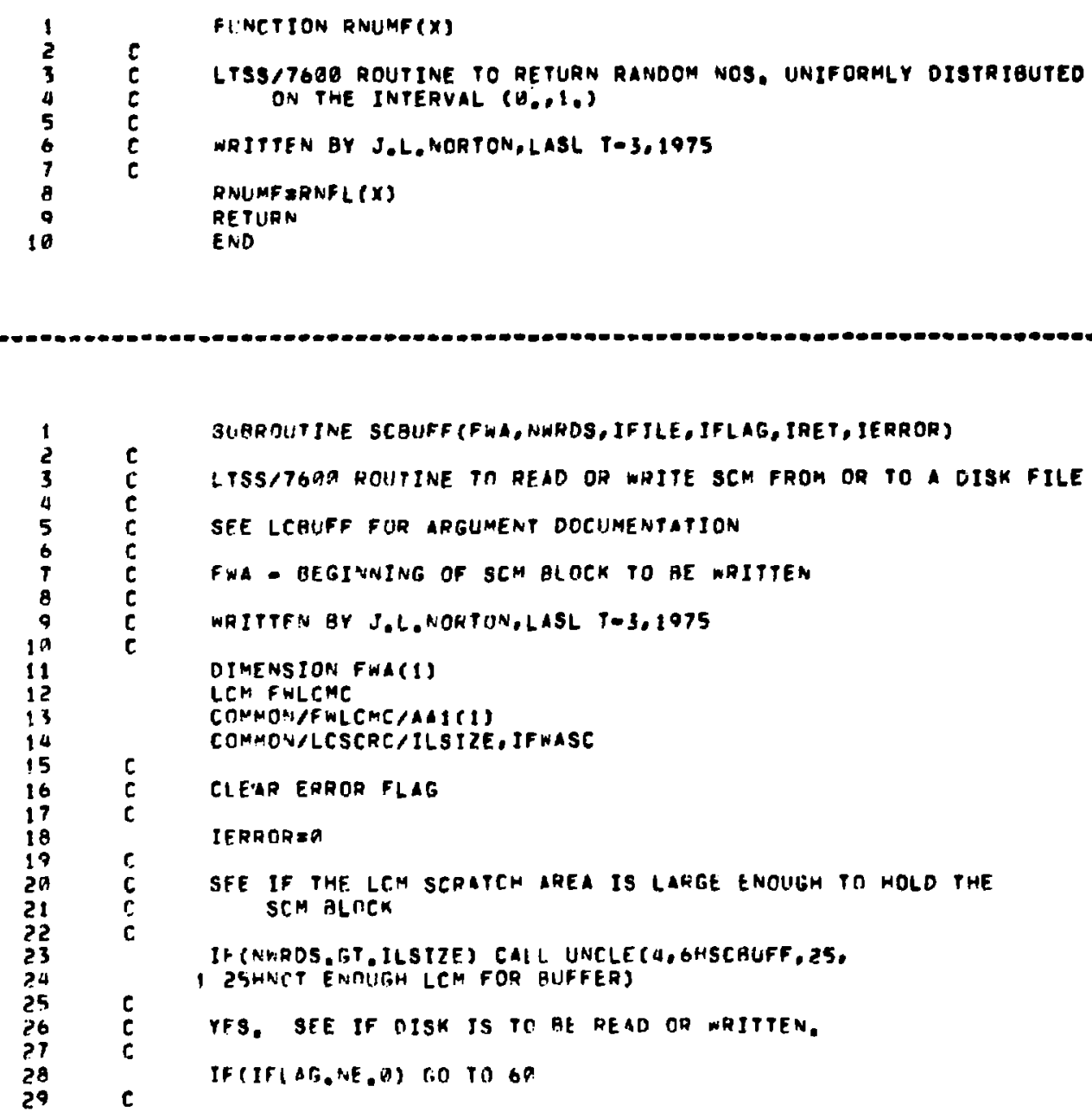


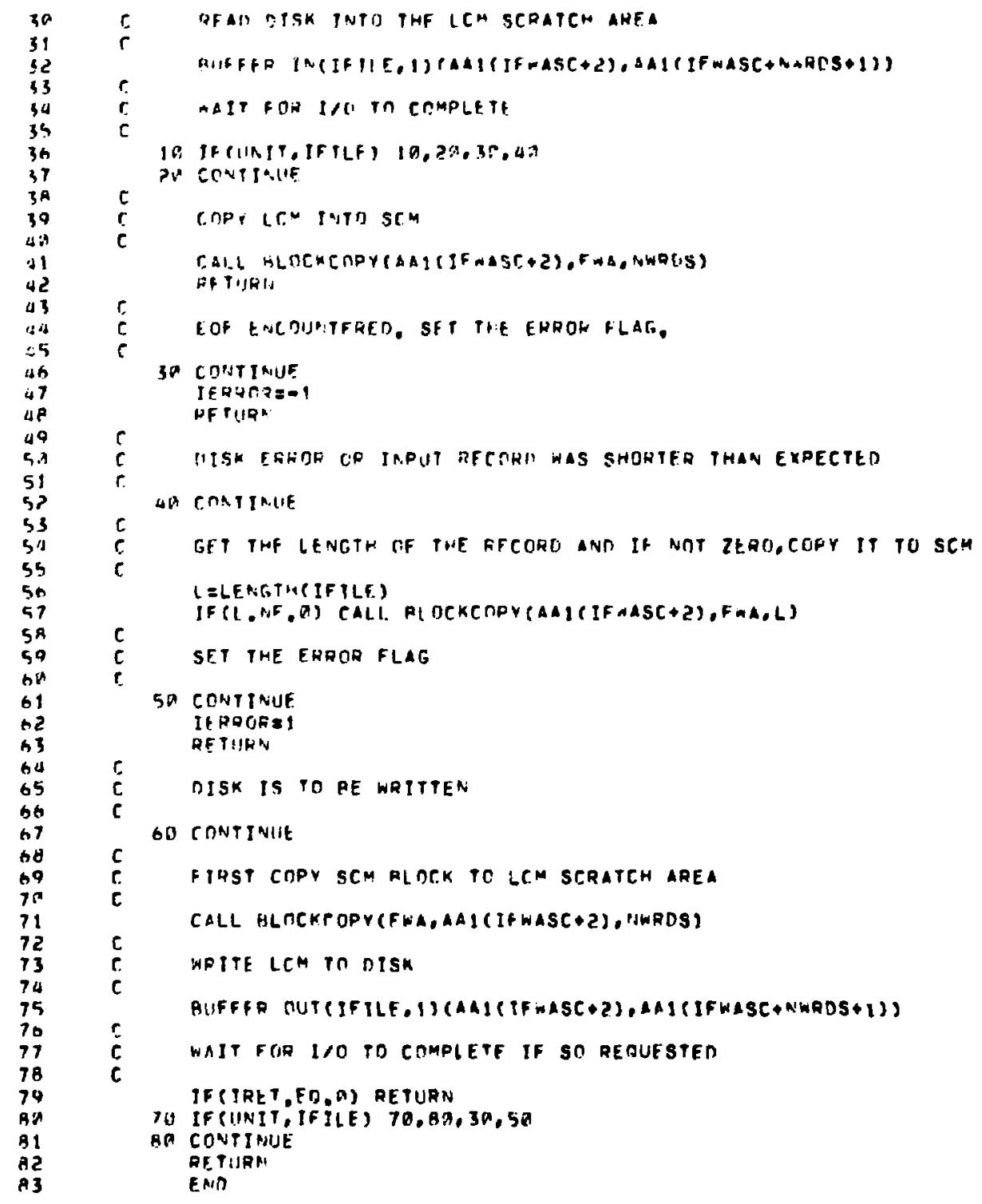


SHEROHPINE $S \cap G(X)$

LISS/ TGHA FOUPINF TO FINO SINES ANO COSINES

OF AOGI:NENTS TN DEGREES

WOITTEN AY J.L. WORTON, I.SSL T-3,1975

DATA REGRAD/.H17453292519943/

$Y=X \Vdash D E G R A D$

$\operatorname{S\cap G}=\operatorname{SiN}(Y)$

RFTURN

EATRY CRG $(x)$

$Y=X * B F G R A D$

$\operatorname{SDG}=\operatorname{Cos}(Y)$

RF rlika

ENก

INIEGER SHIFT

FI. NETION SHIFTEIX,N)

c

I. TSS POITINE TO PERFORM BIT SHIFTING

TX IS THE DUANTITY TO BE SHIFTED

i: IS THE NO, DF RITS TO SHIFT. N POSITIVE MEANS LEFT ENDAAROIJND SHIFT INO N NEGATIVE MEANS RIGHT ENDEOFF SHIFT.

WQITTER BY J,L.NCRTON,LASI. T-3,1975

IF (N) GE, (A) 60 TO 1 G

HPE $A$ N

SHIFTIIX,SHR,NP

RETIIRN

IG CONTINUE

SHIFT:IX, SHL.

AFTUAN

END

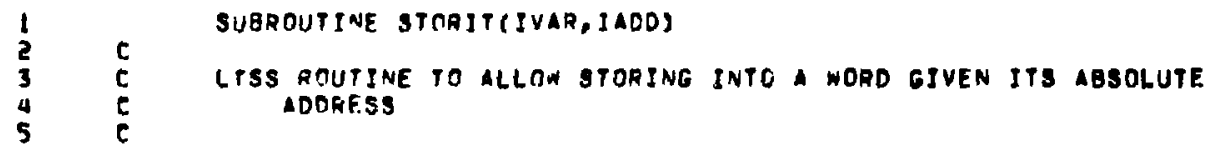




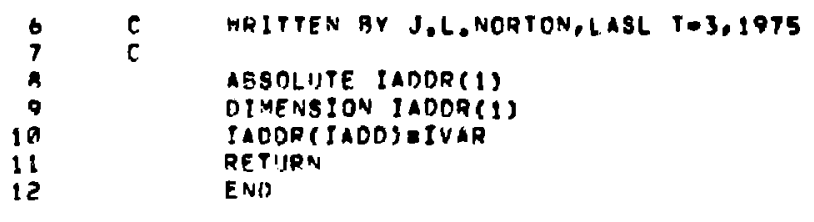

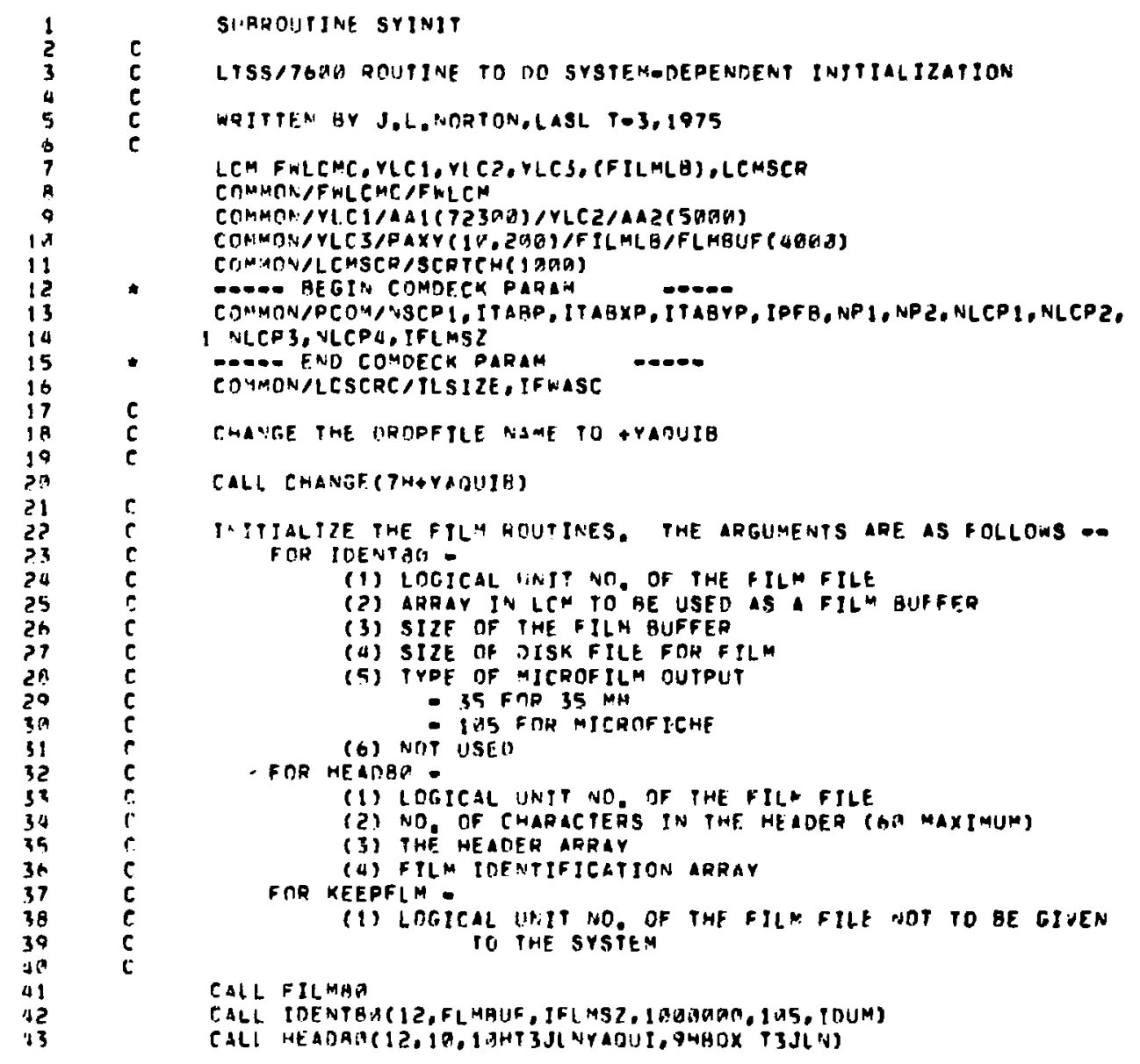




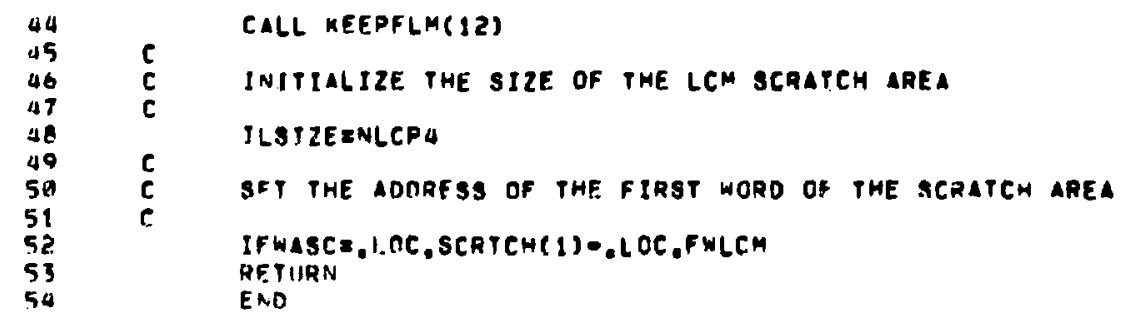

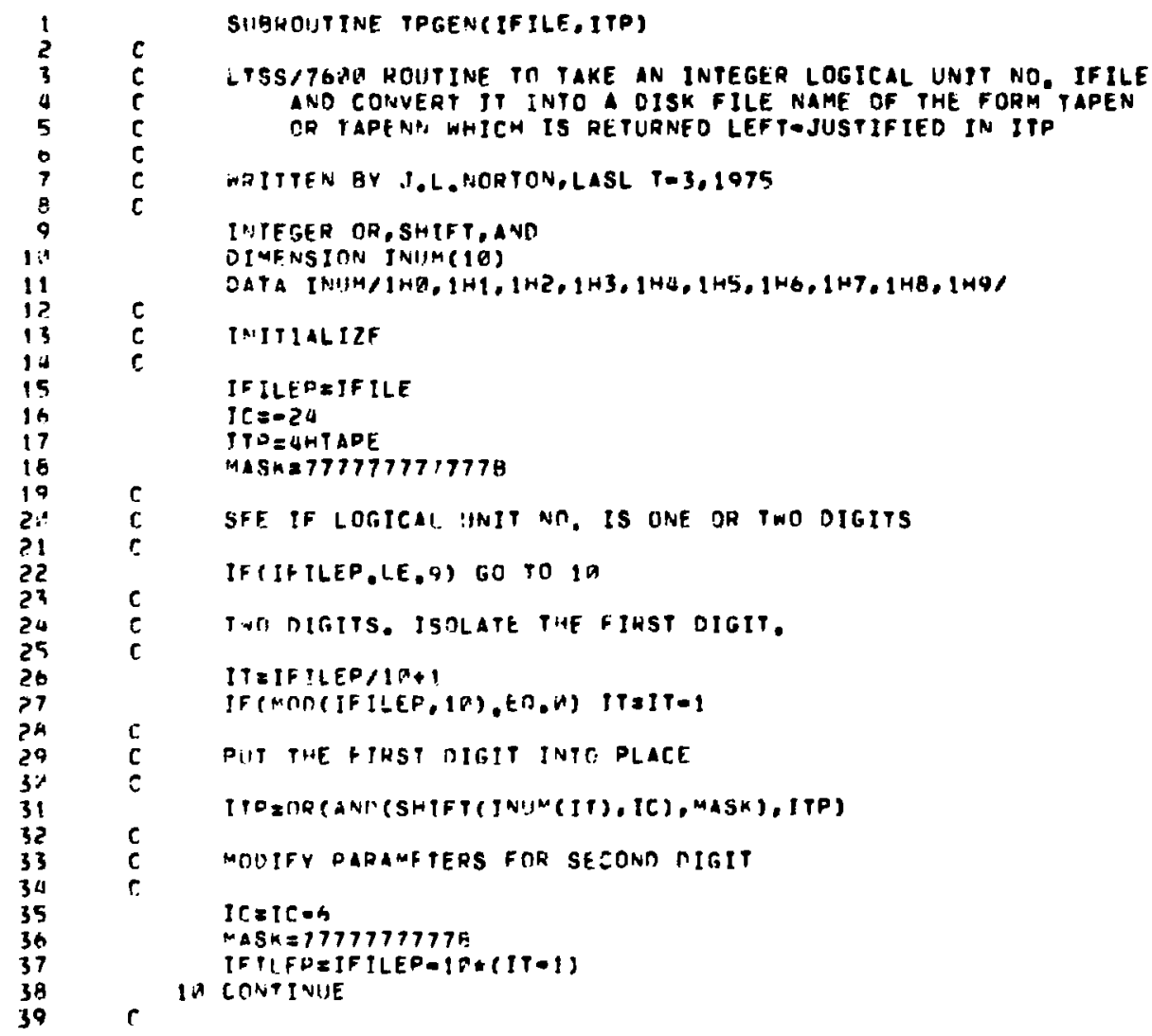




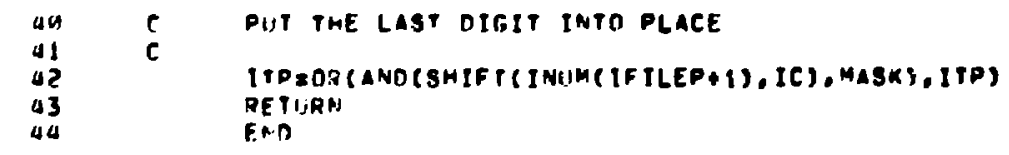

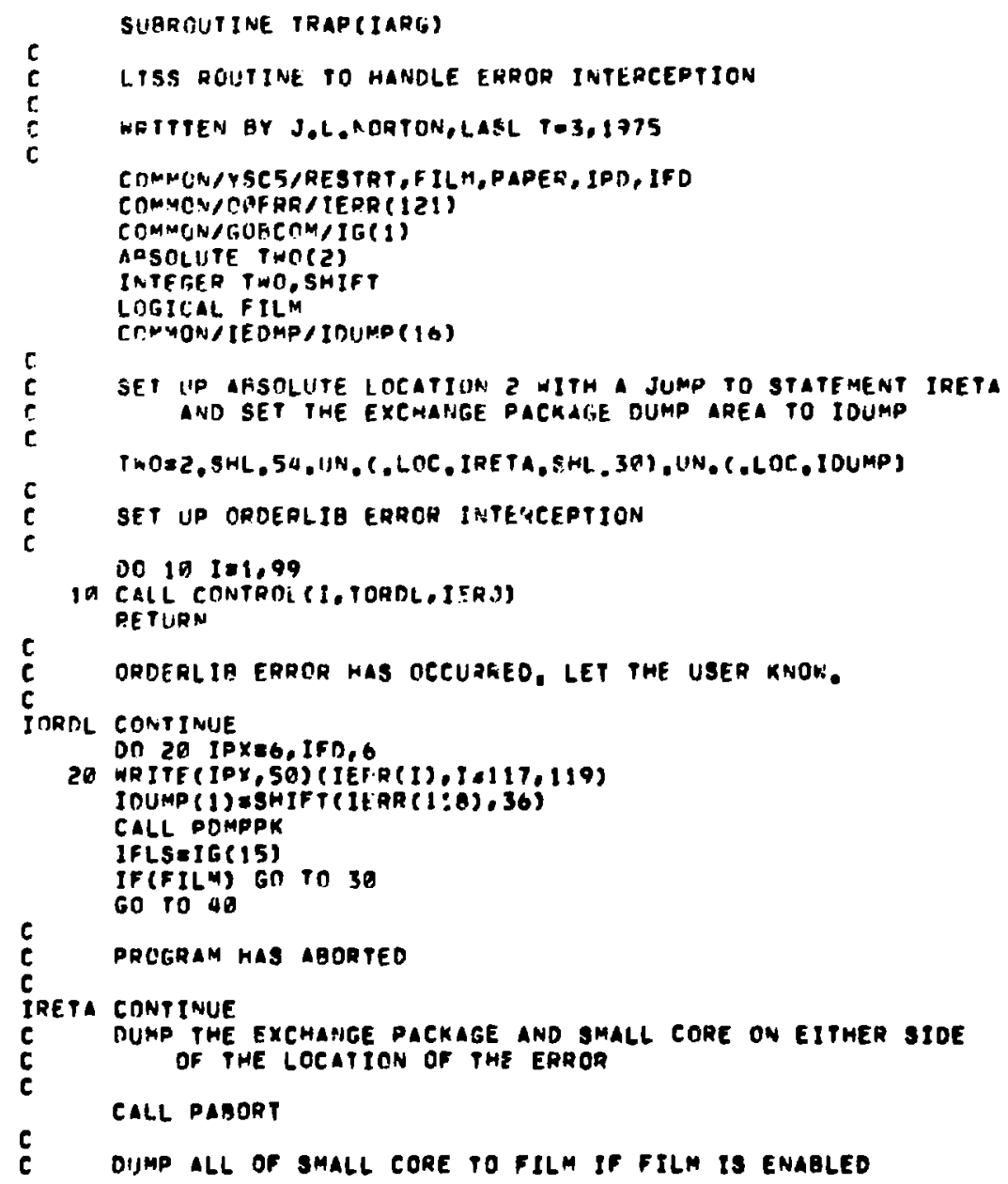



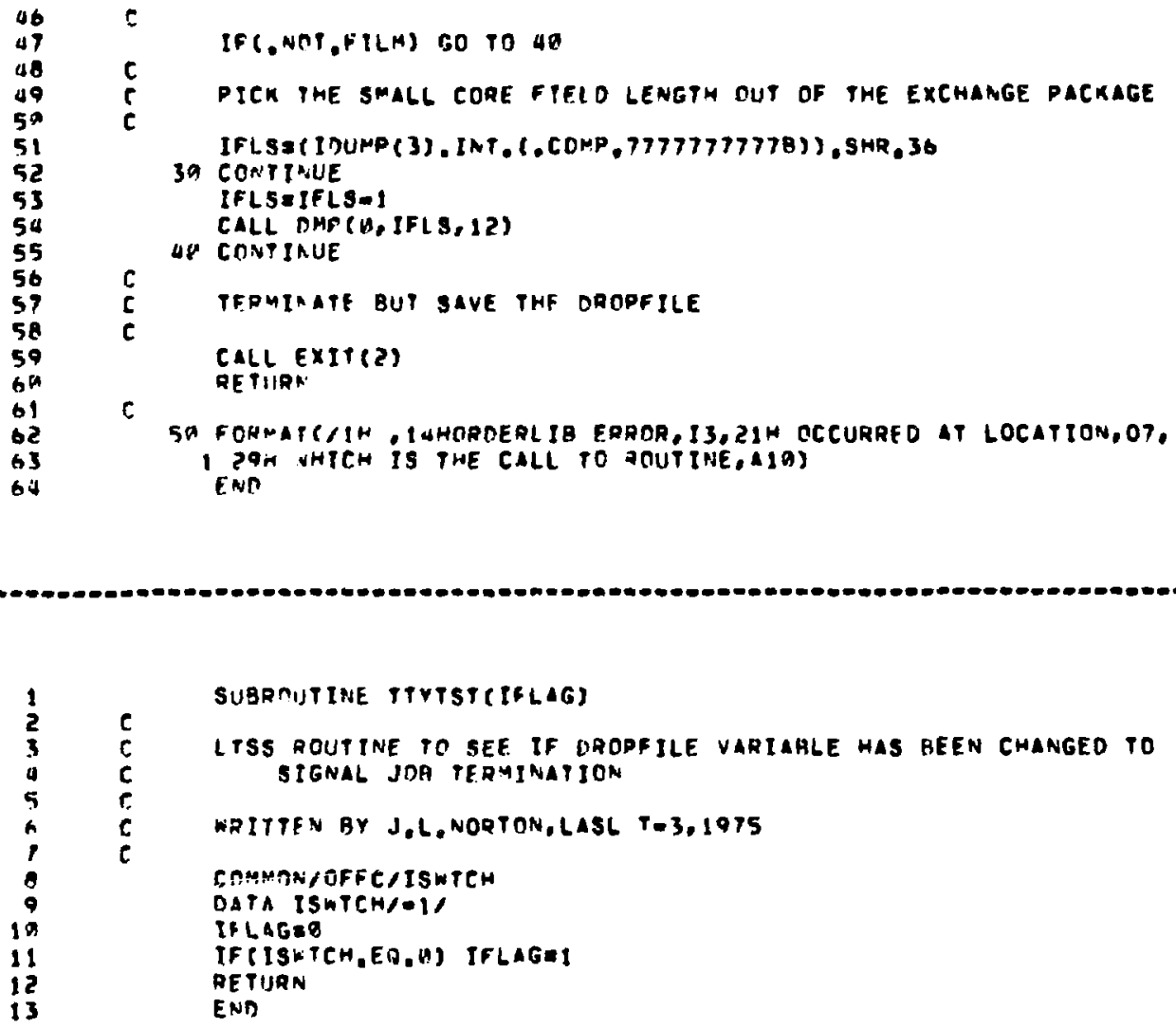
B. CROS-Dependent Code
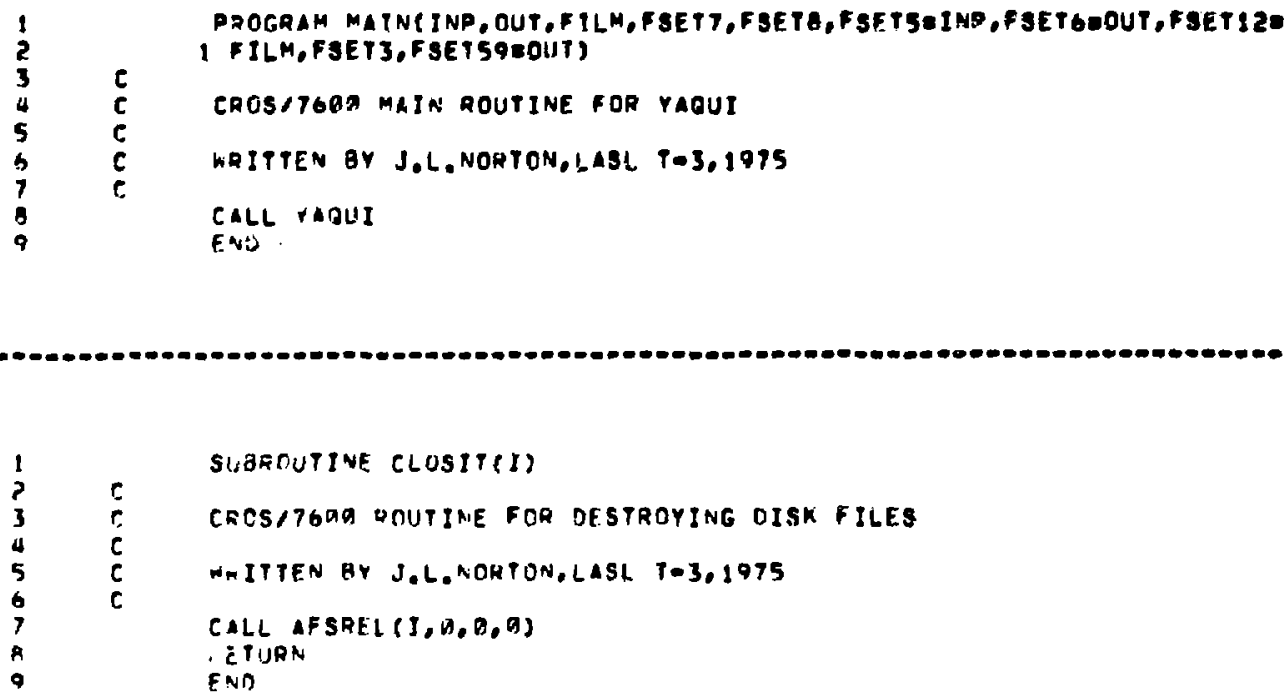

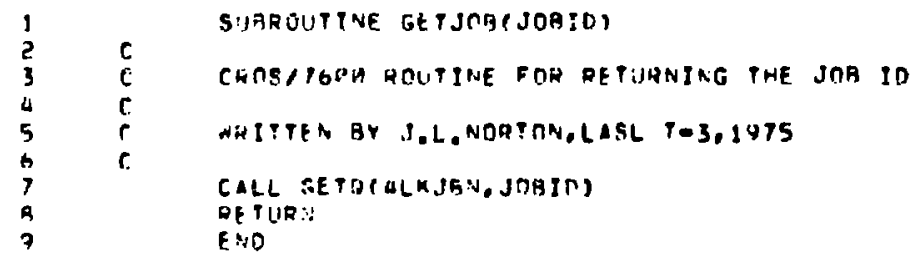

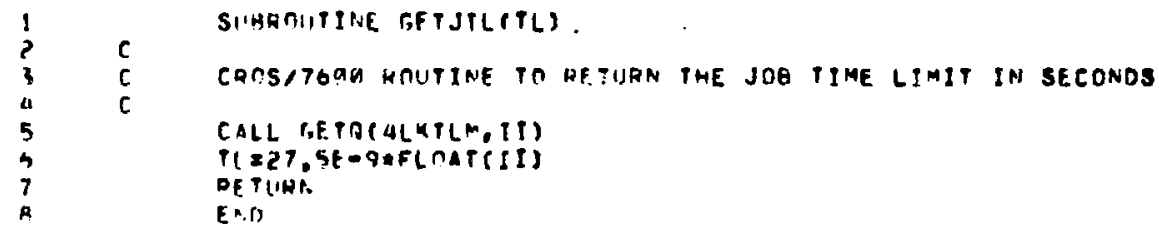



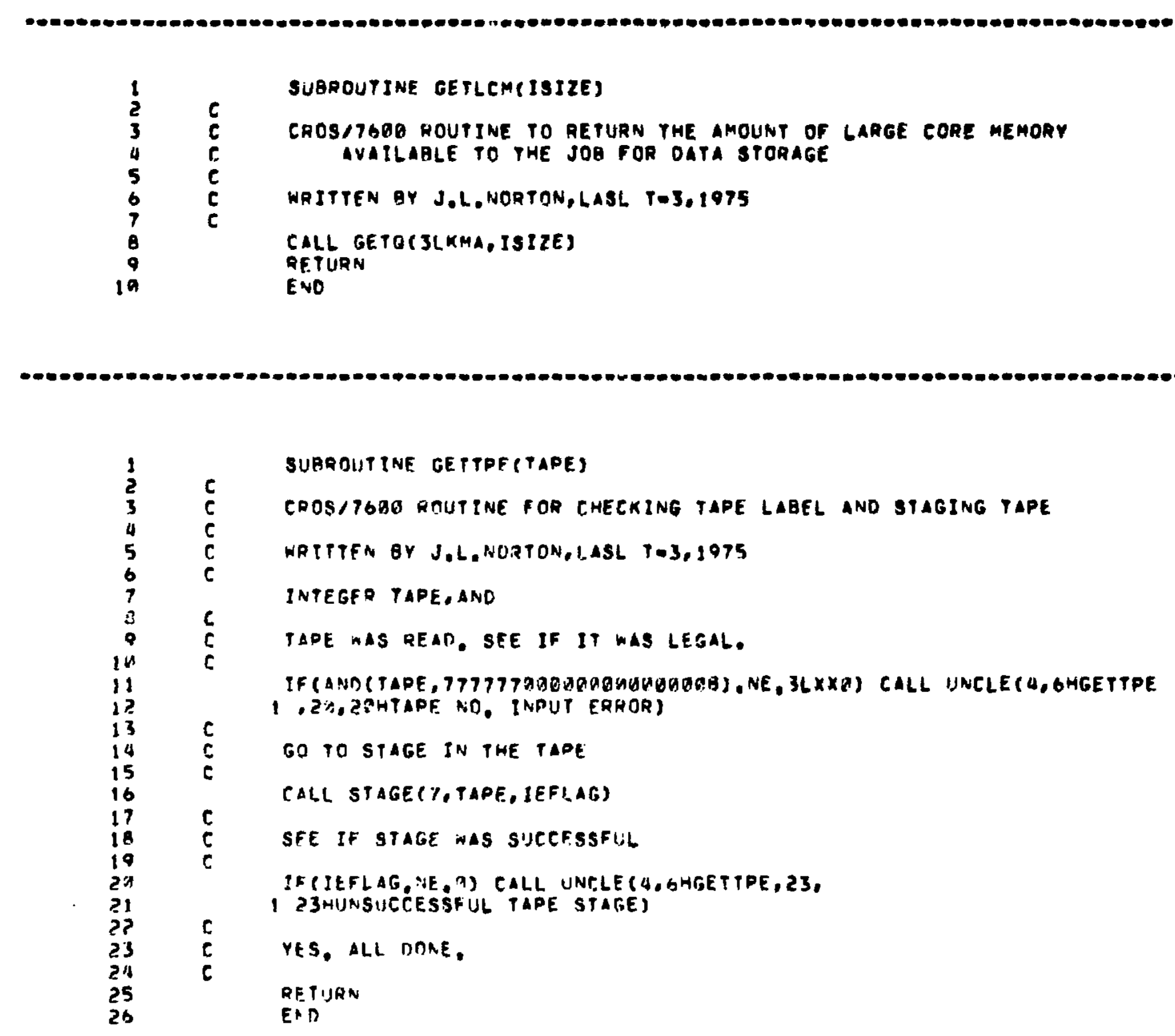

$\begin{array}{lll}1 & \text { SUBAOUTINE DPENIT(TFILE, MOQE) } \\ 2 & 6 & \\ 3 & \text { C } & \end{array}$



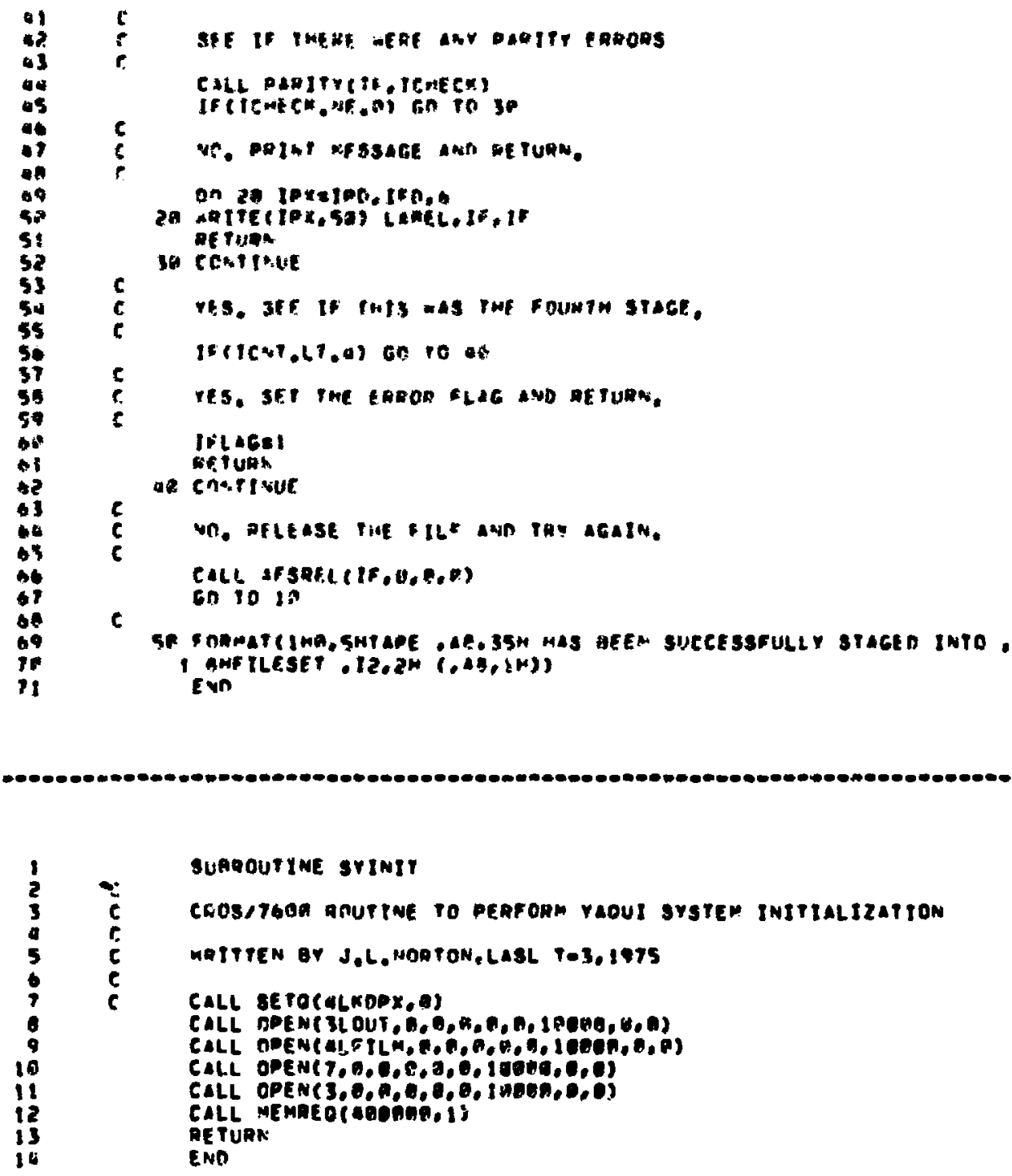


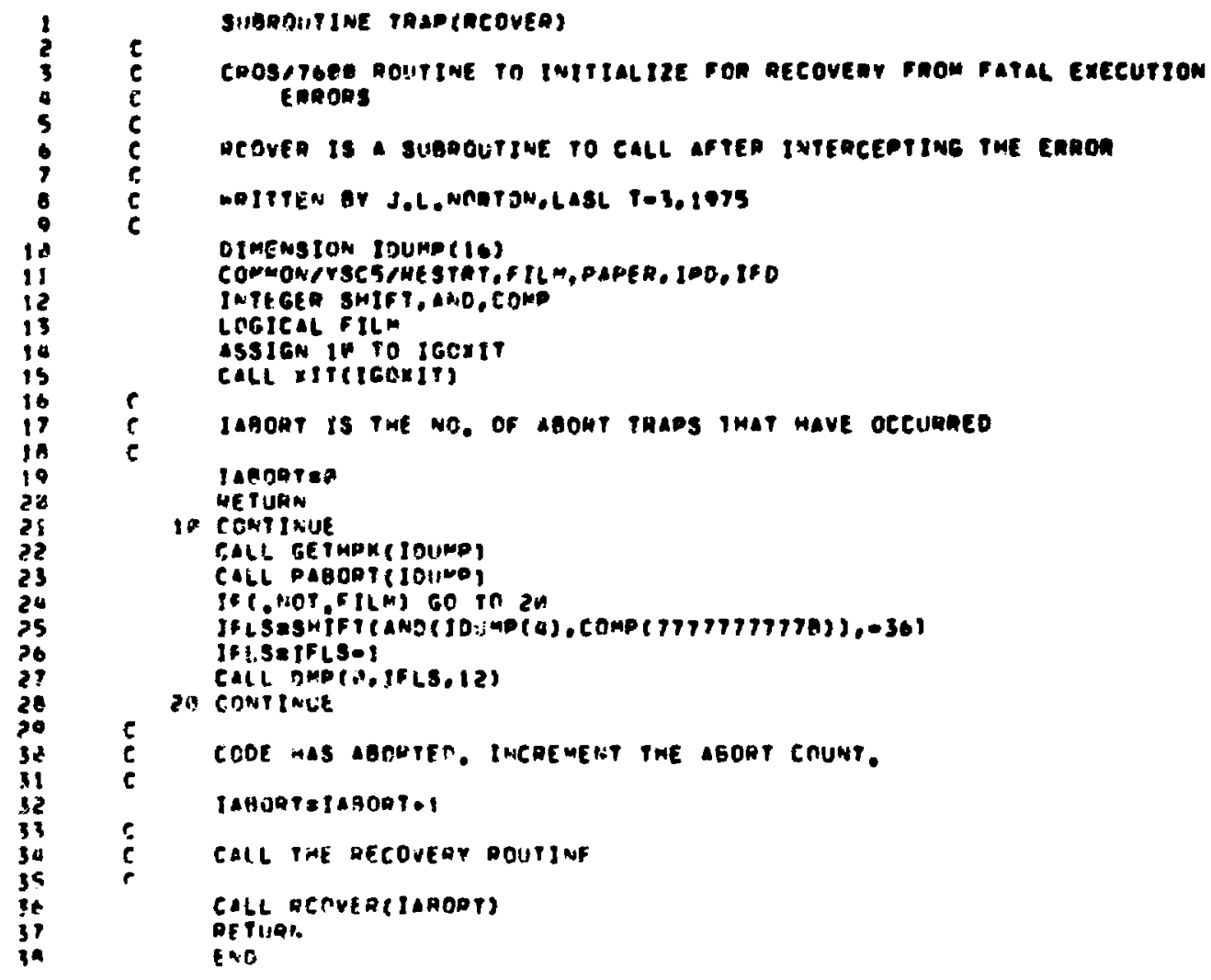




\section{c. Knowos-Denendent code}

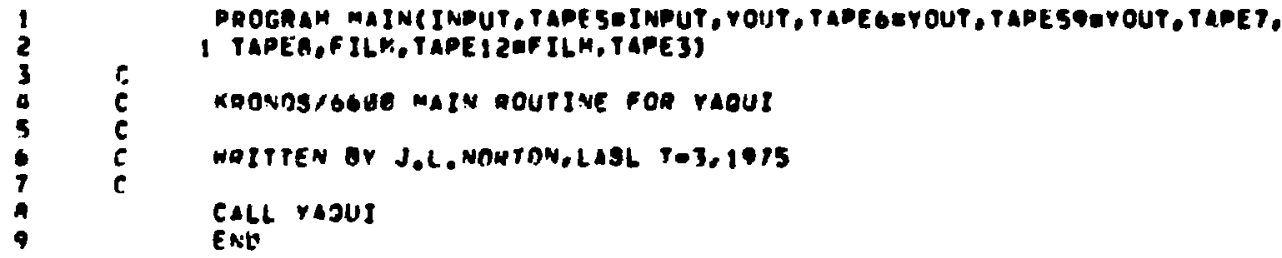

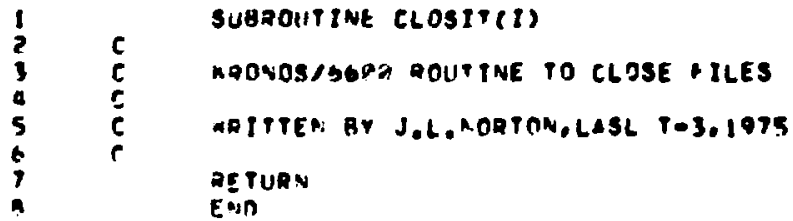
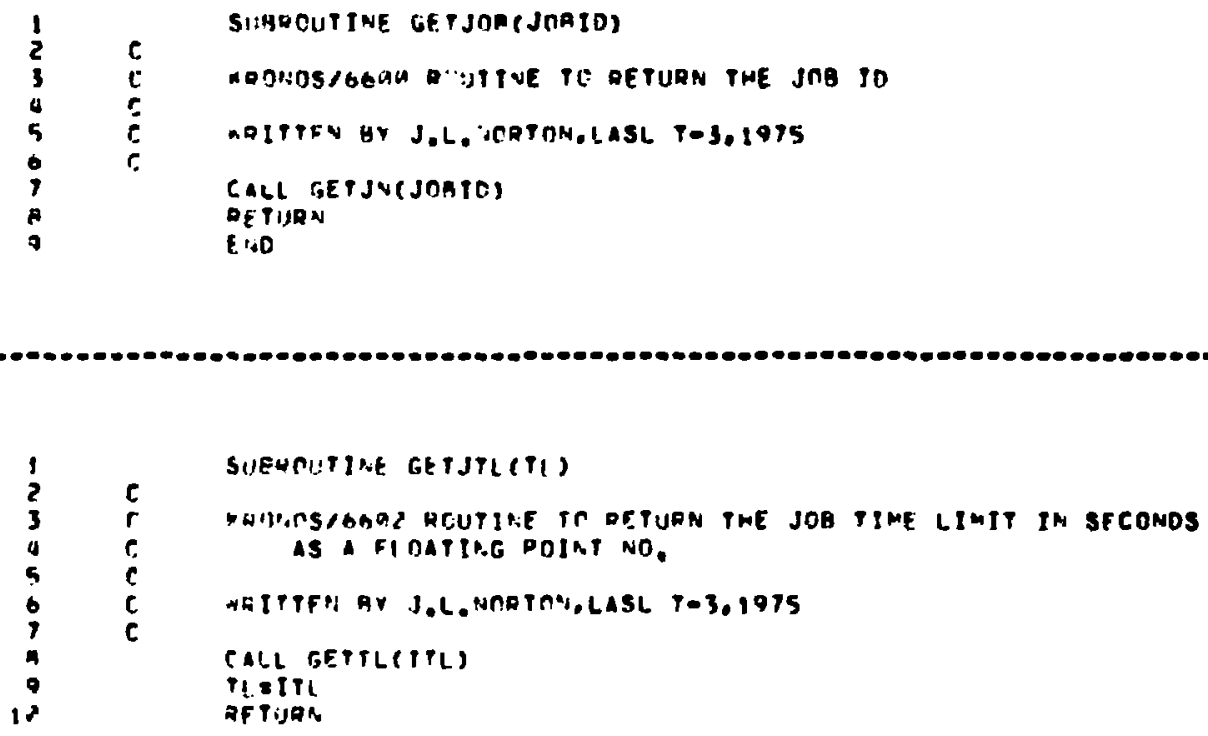


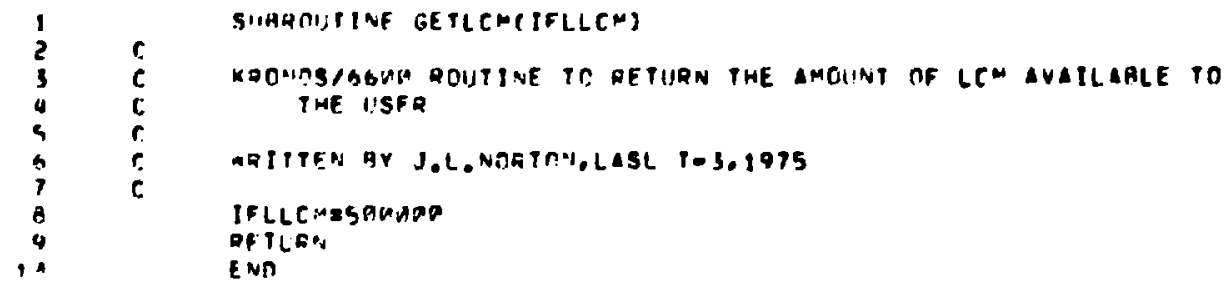

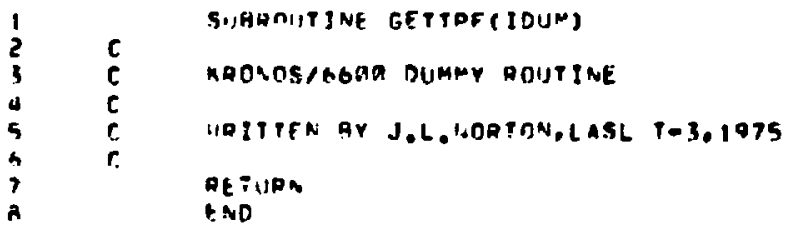

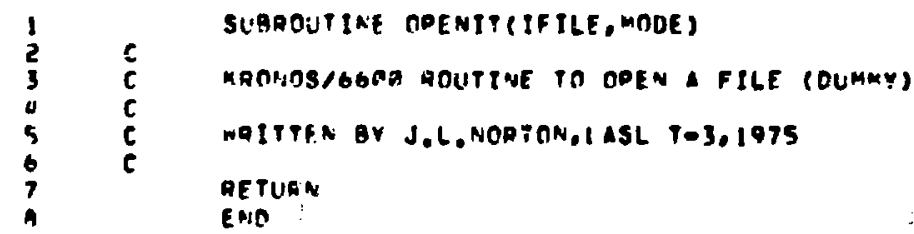

-

1 SUBROUTINE SYINIT



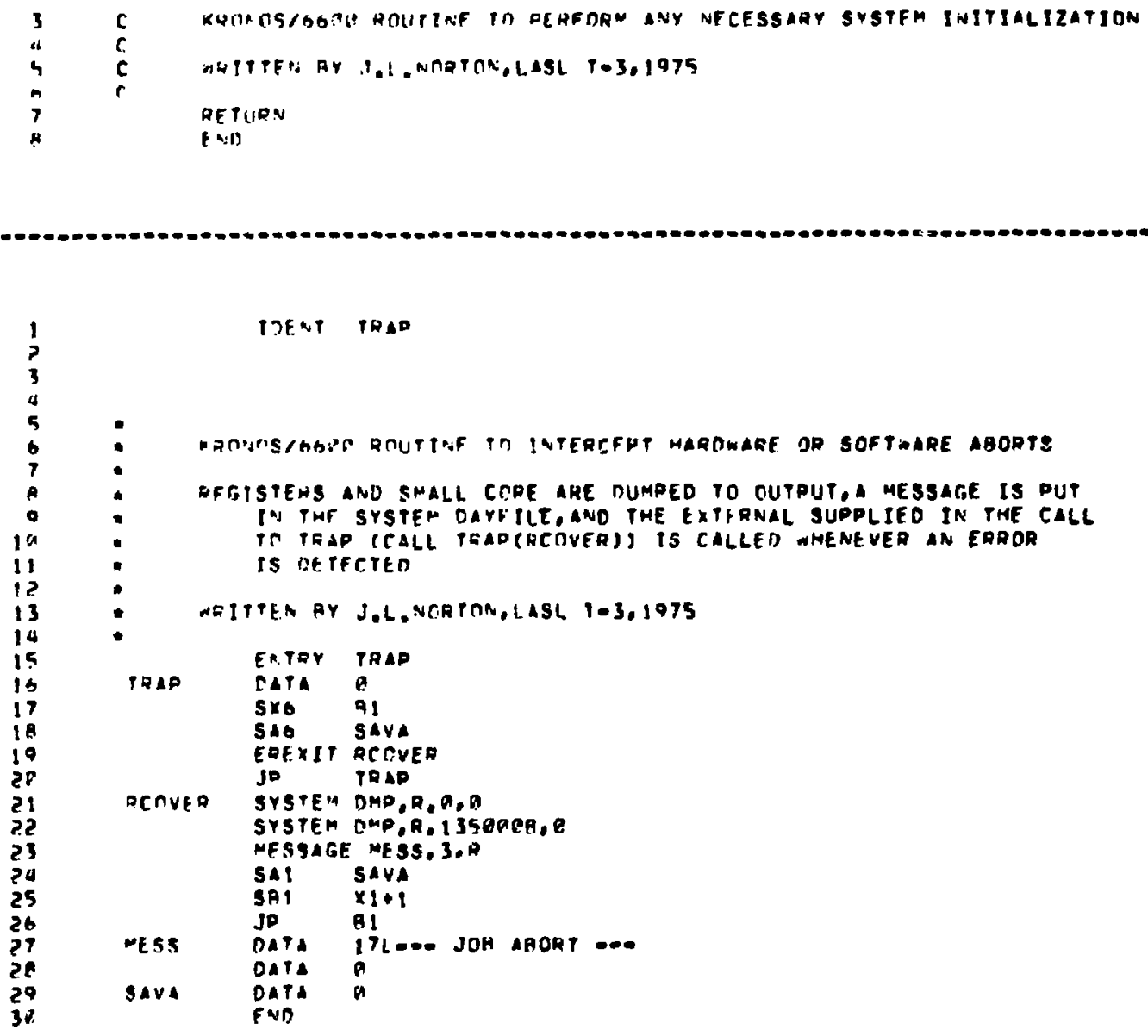


\section{KRONOS/CROS-Dependent Code}
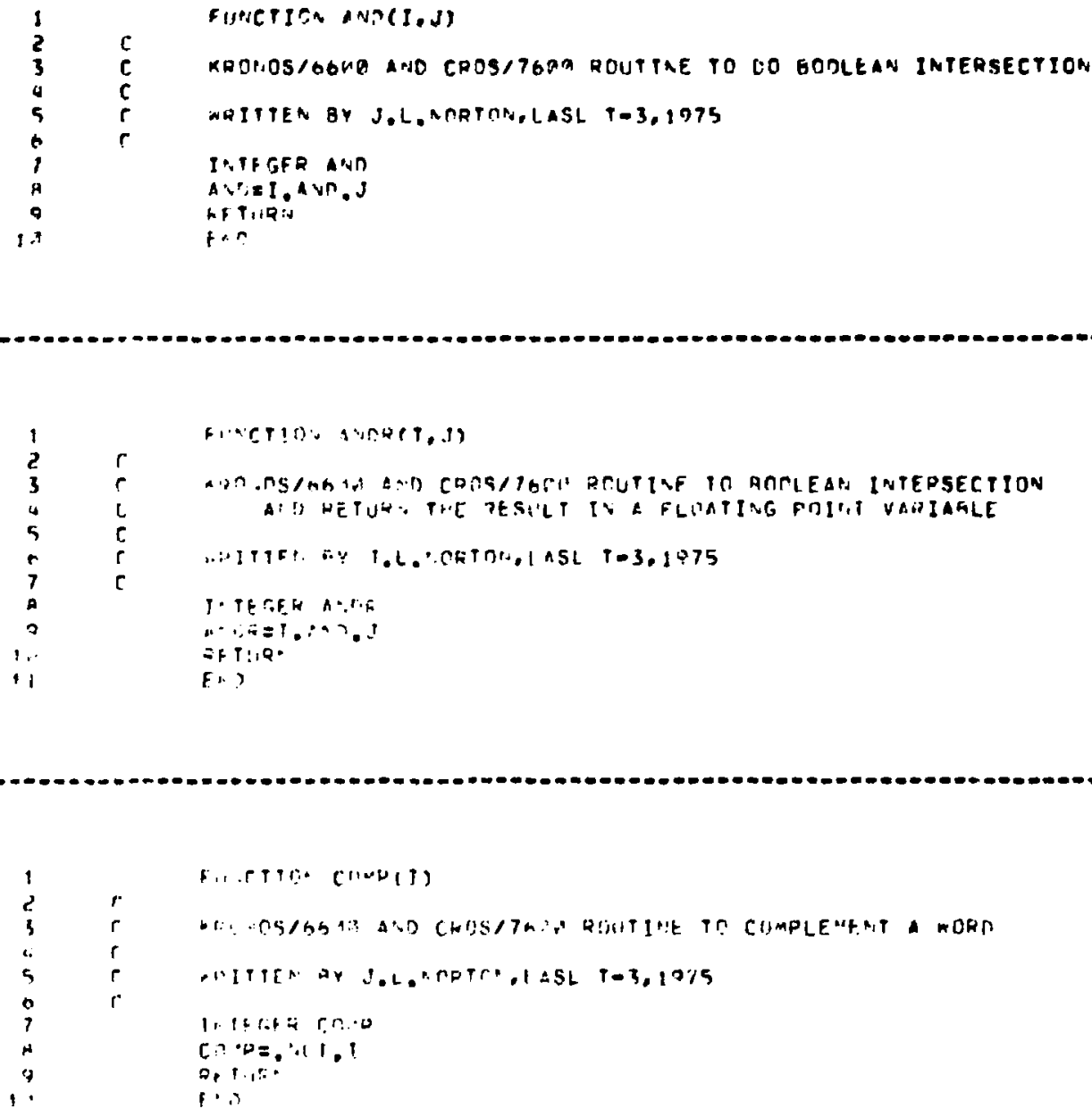

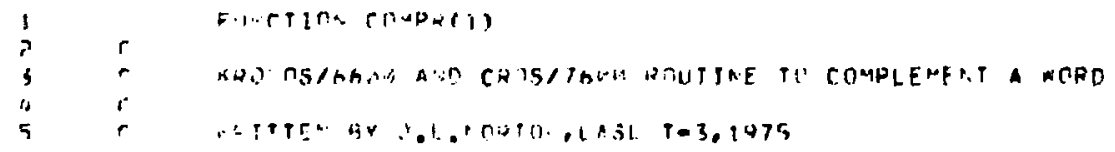




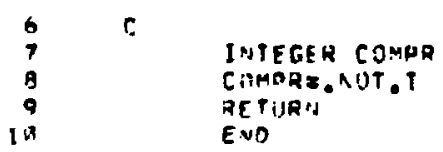
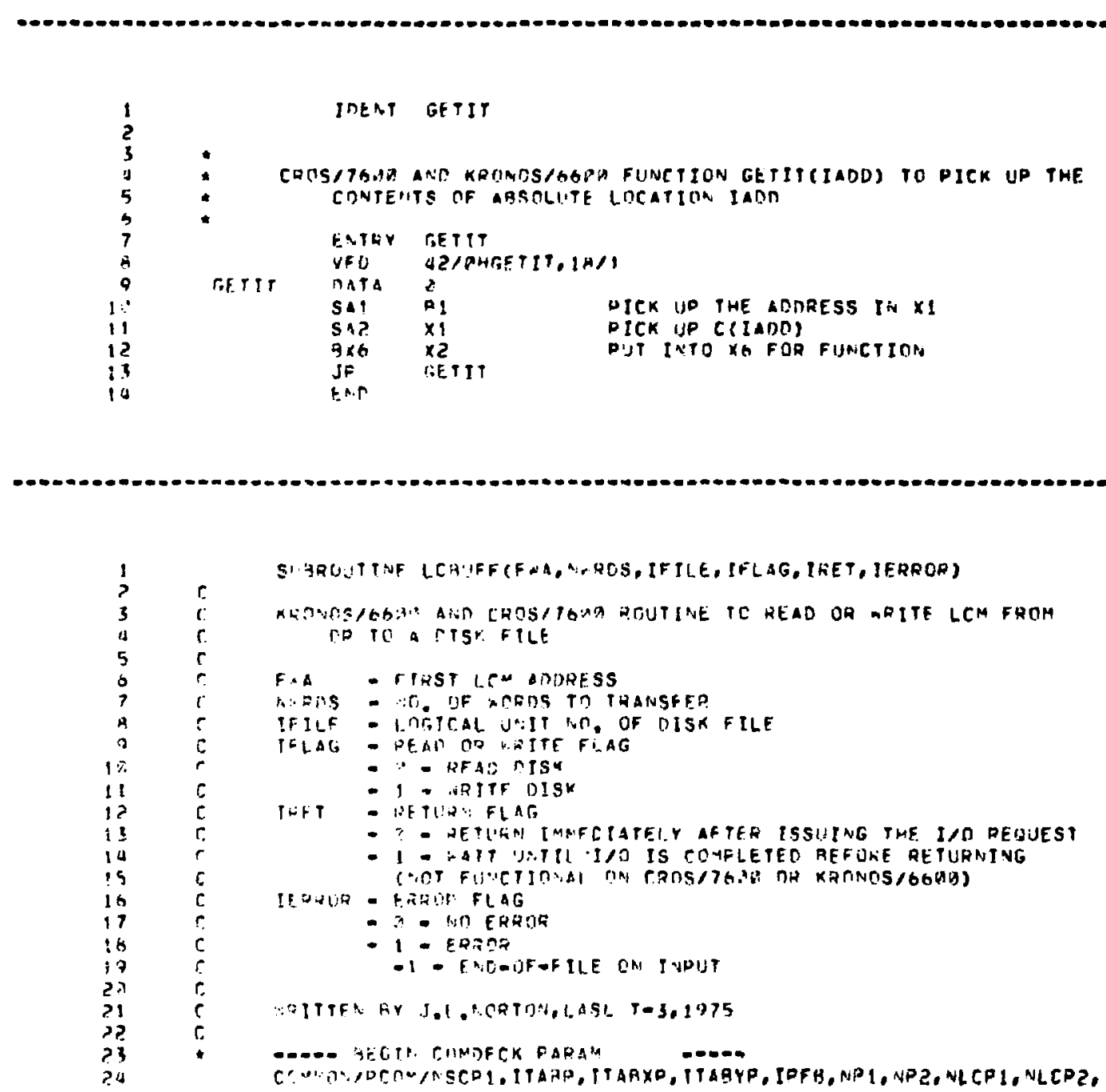


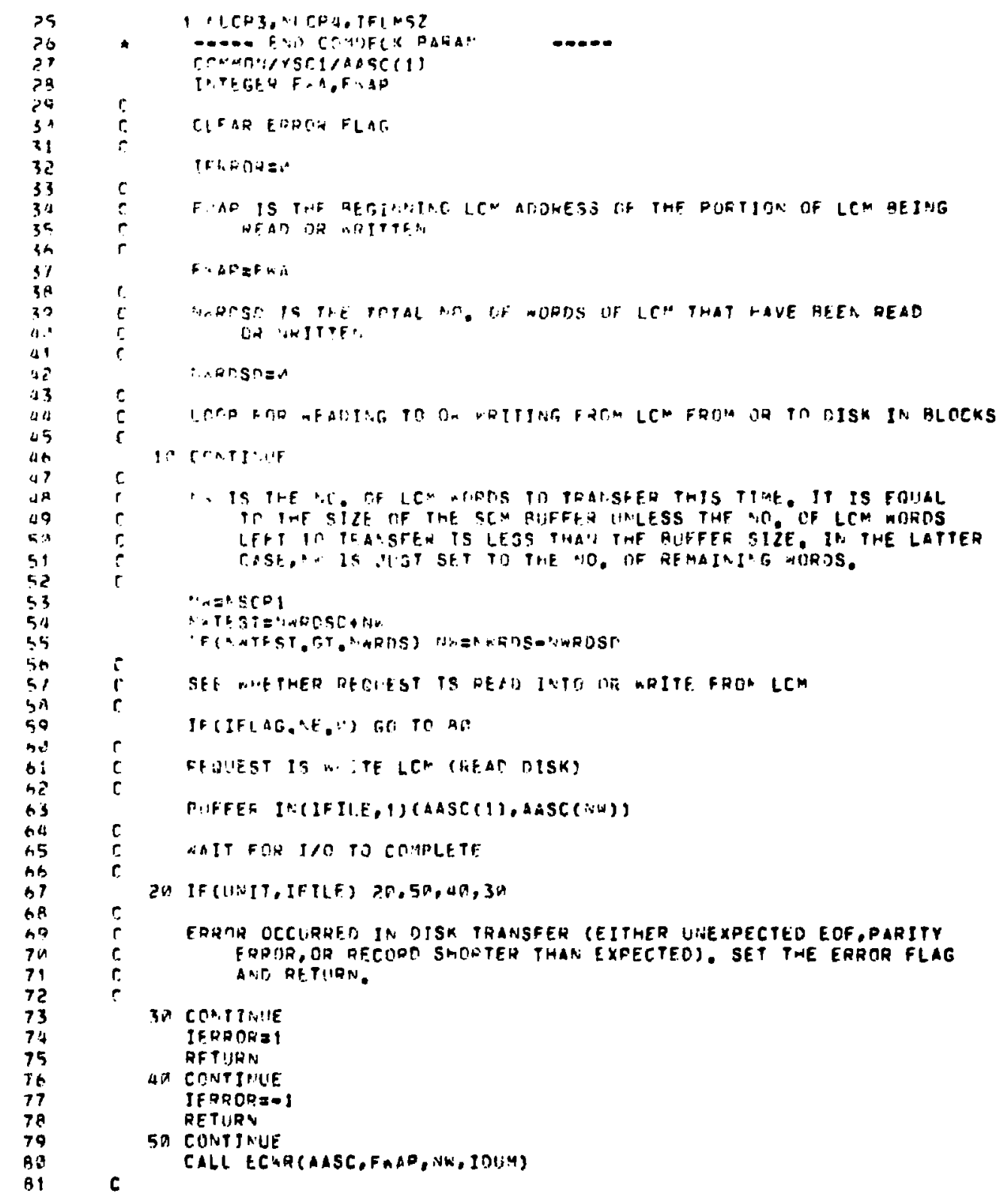



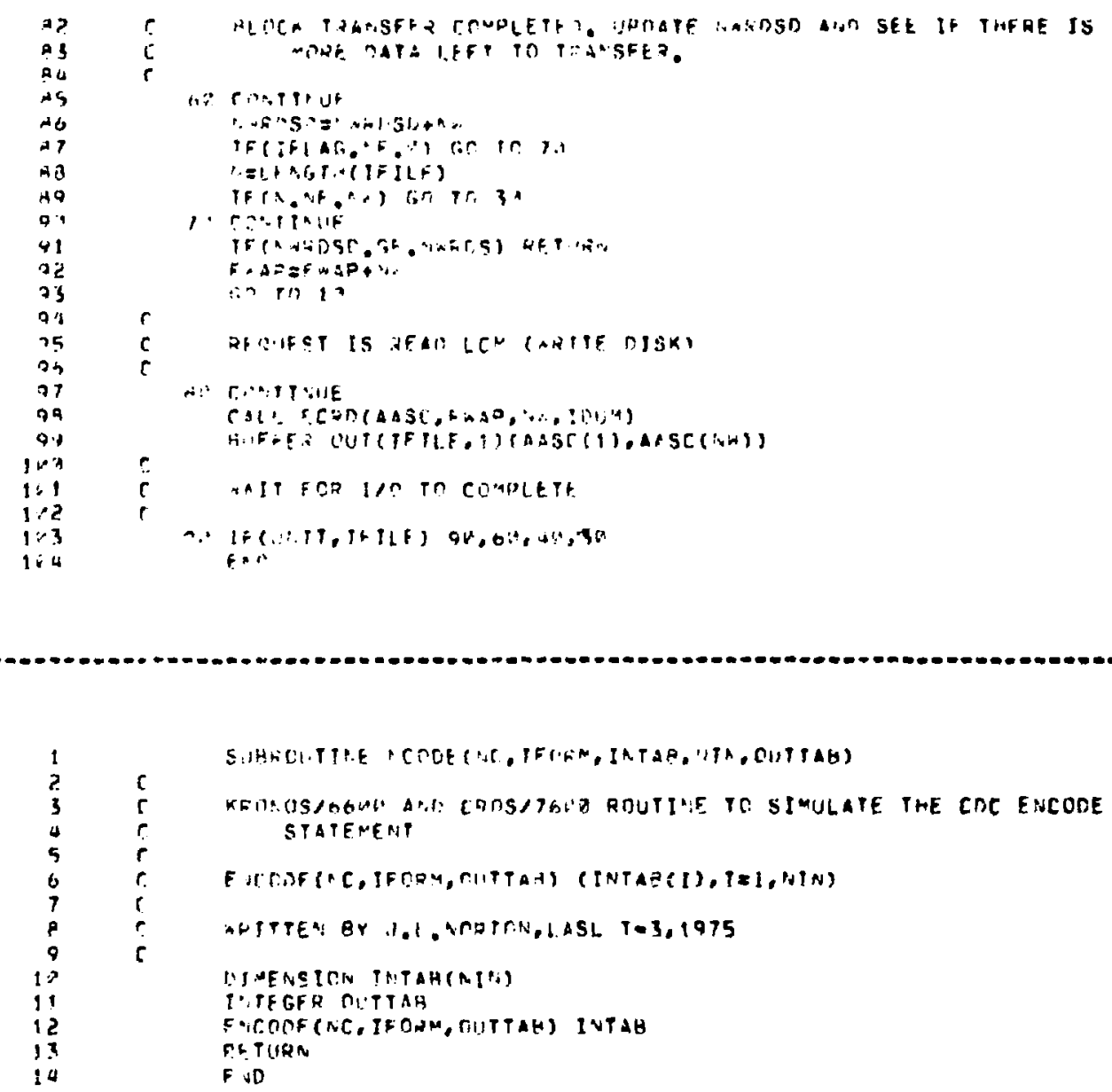

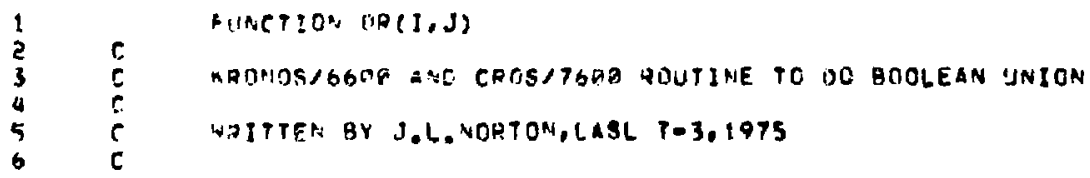


1 IT TFGER NO

CQE J.0Q.J

DE TH:

I?

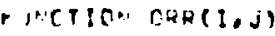

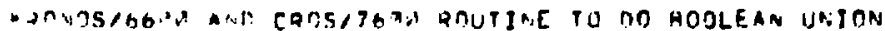

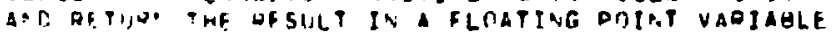

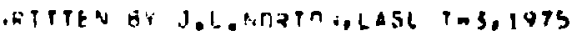

I.TFGH TOLO

$c \rightarrow R=1, O F$.

trivan

Fin

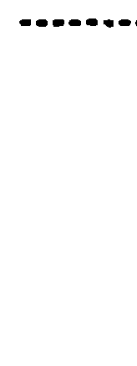

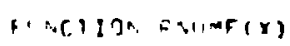

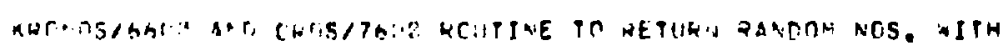

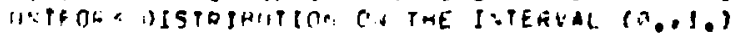

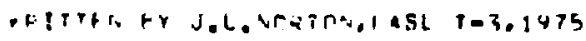

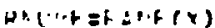

DP Ti:?a

C*i;

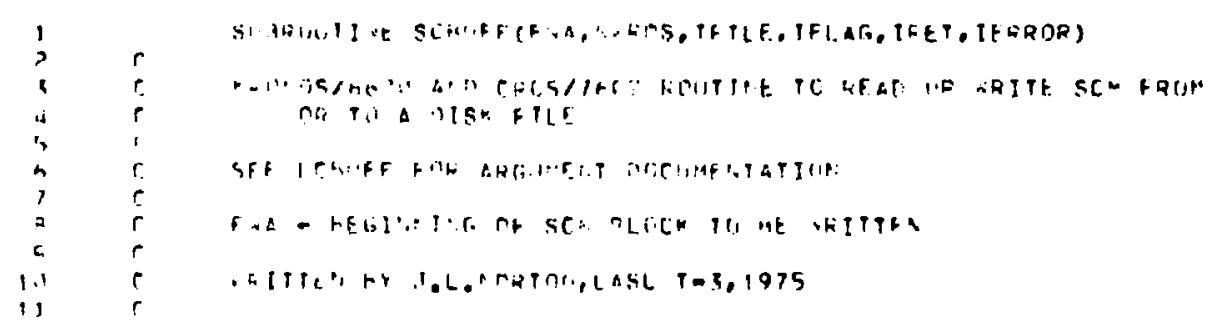



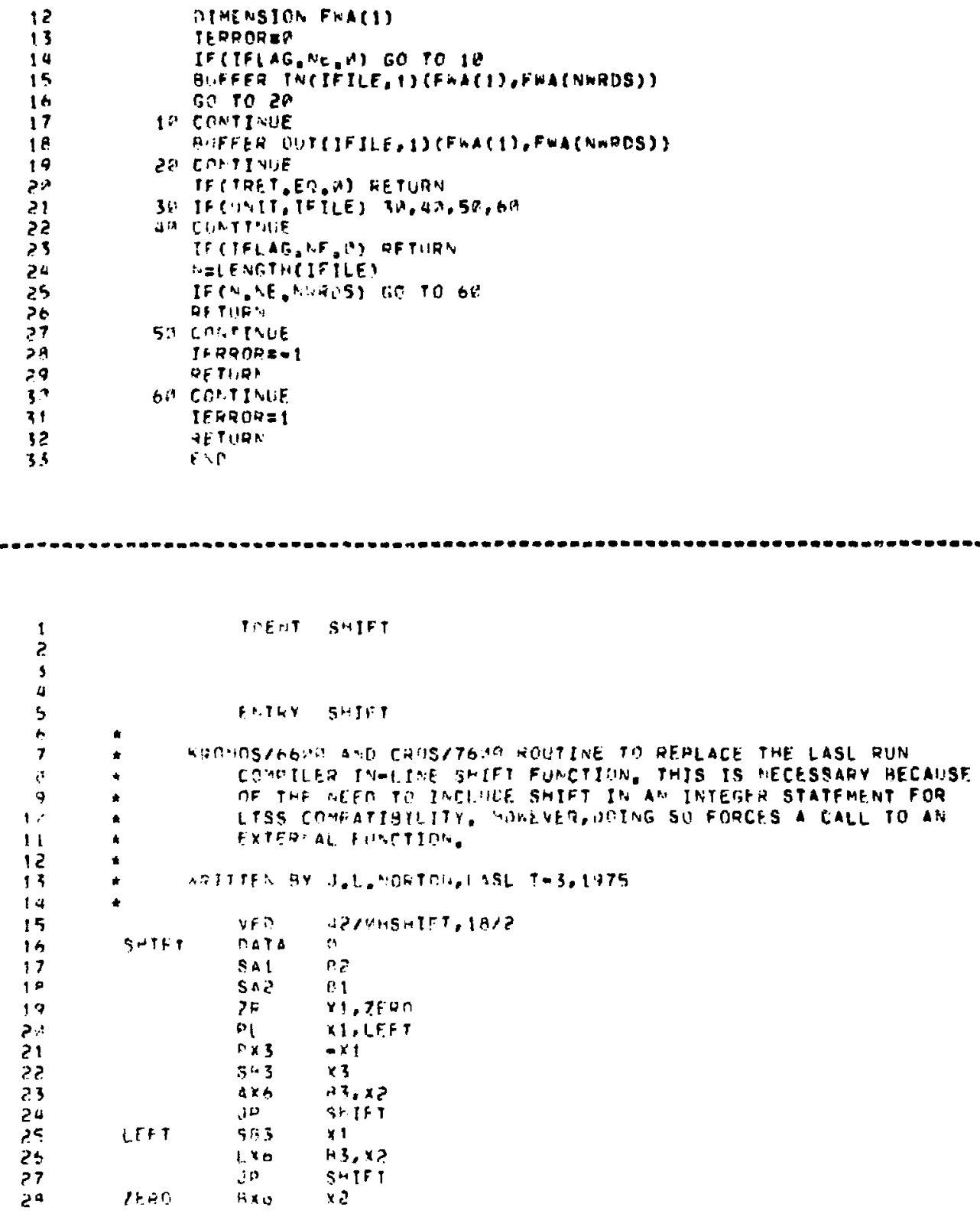

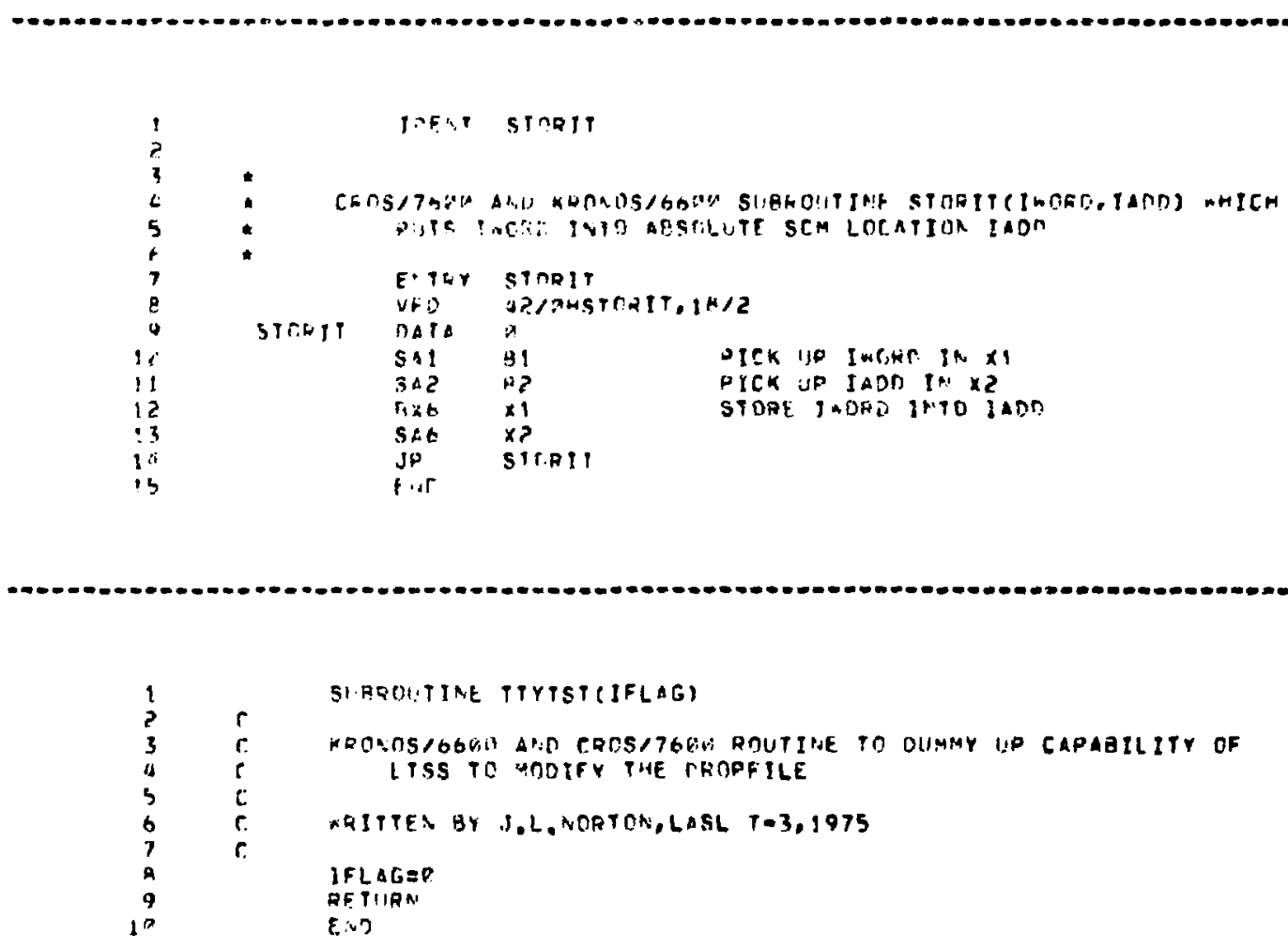


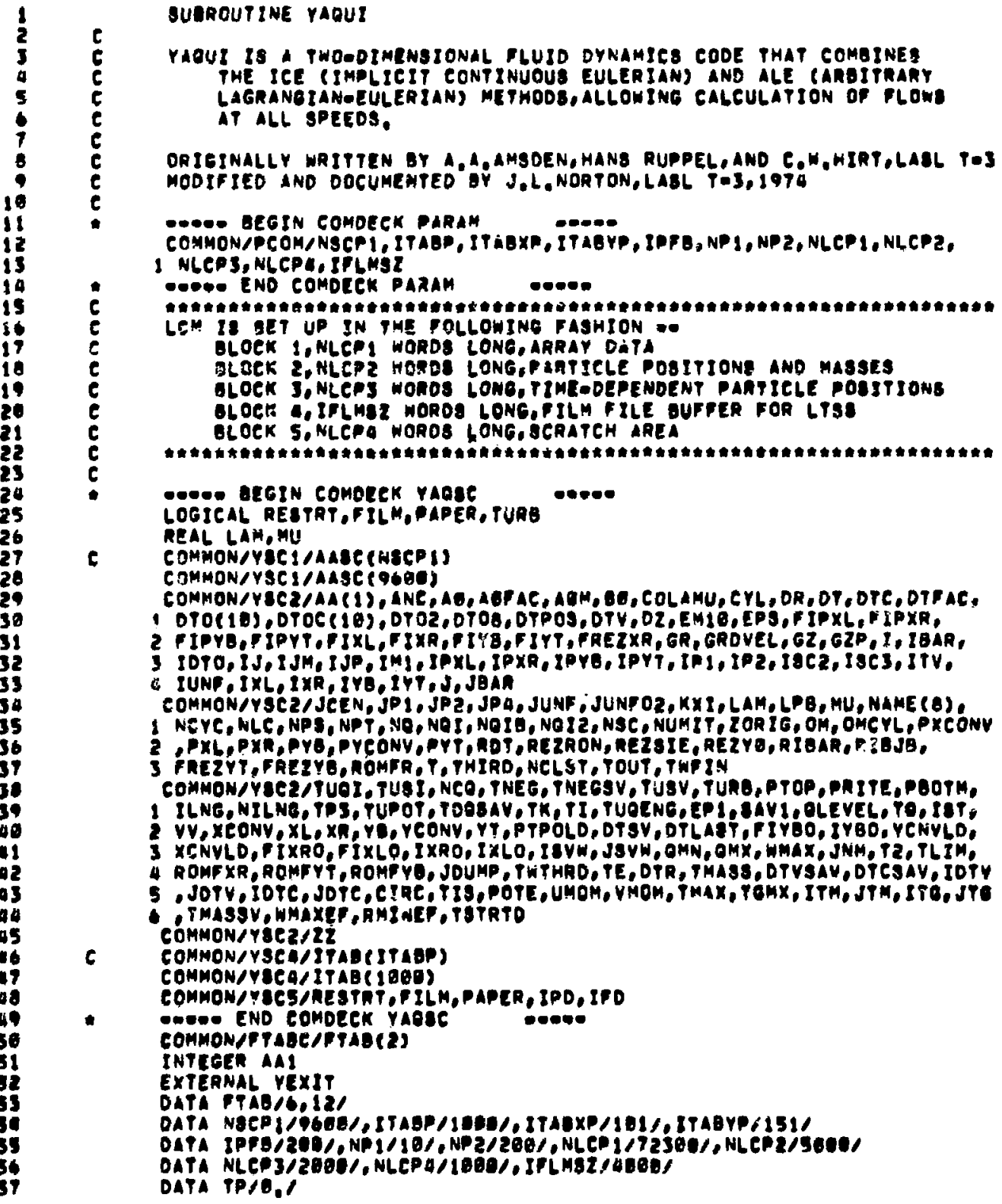




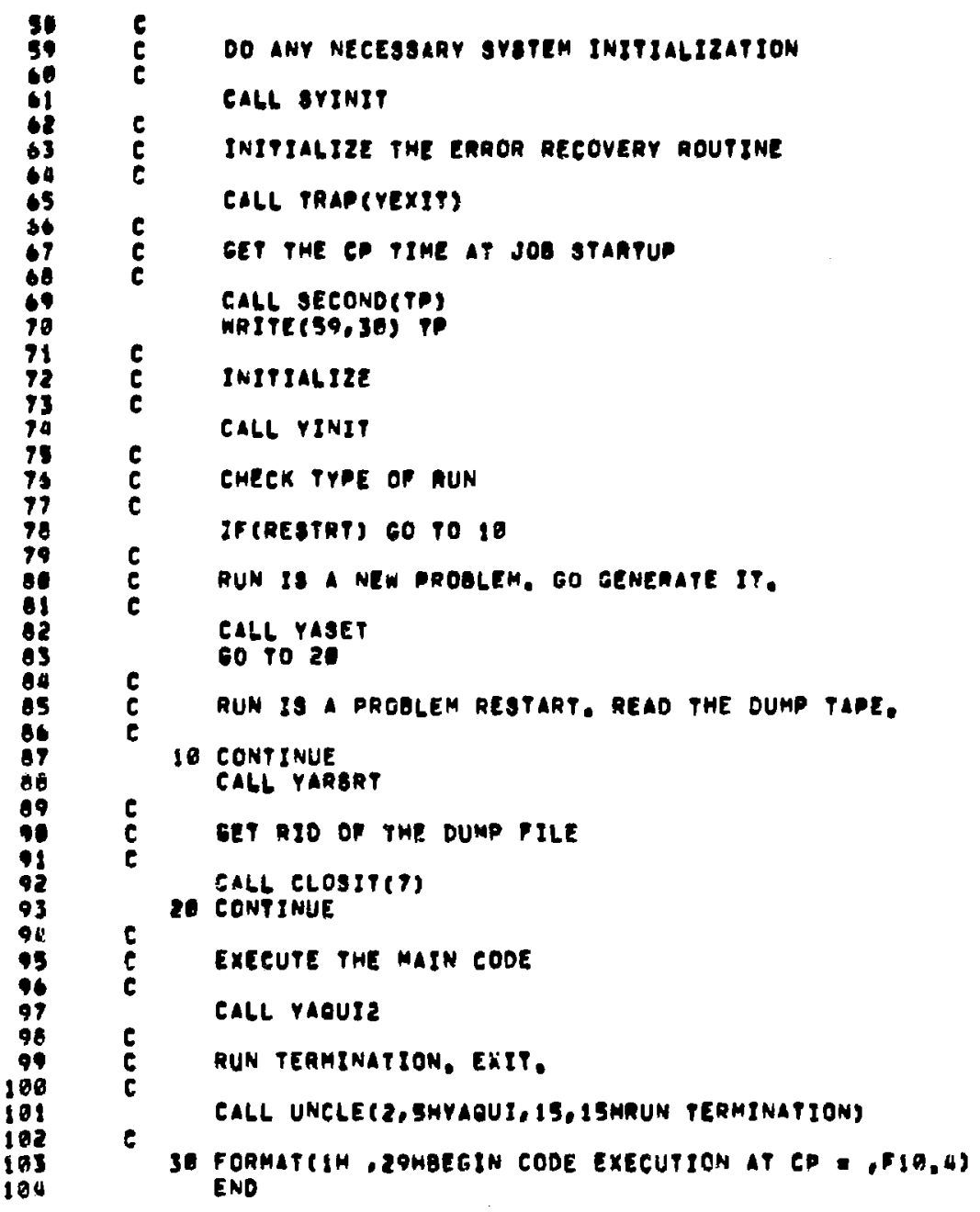

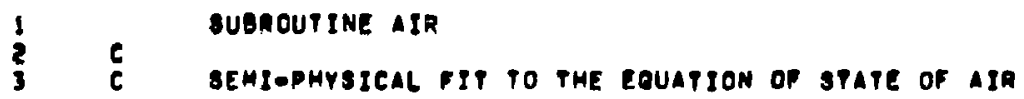




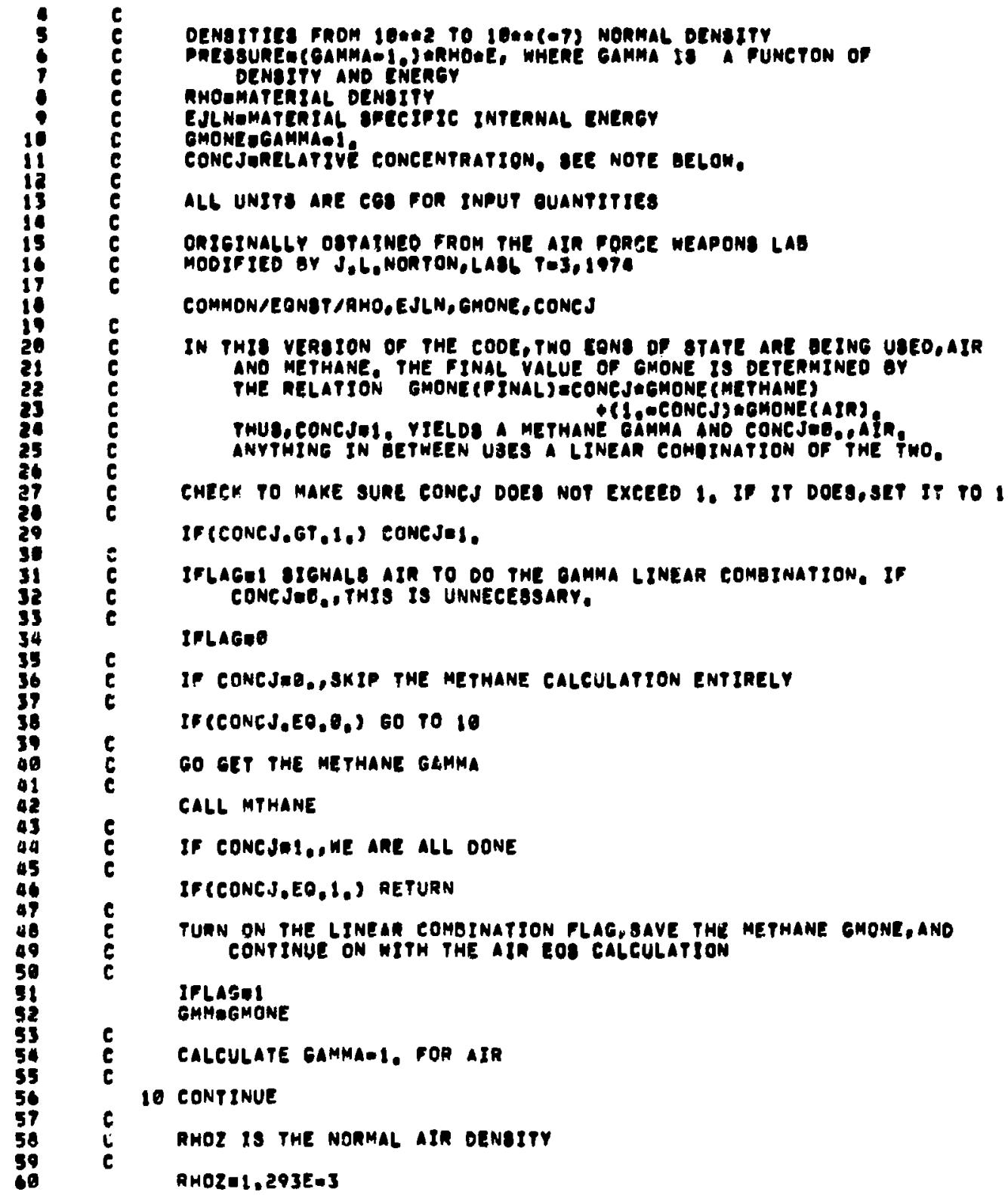




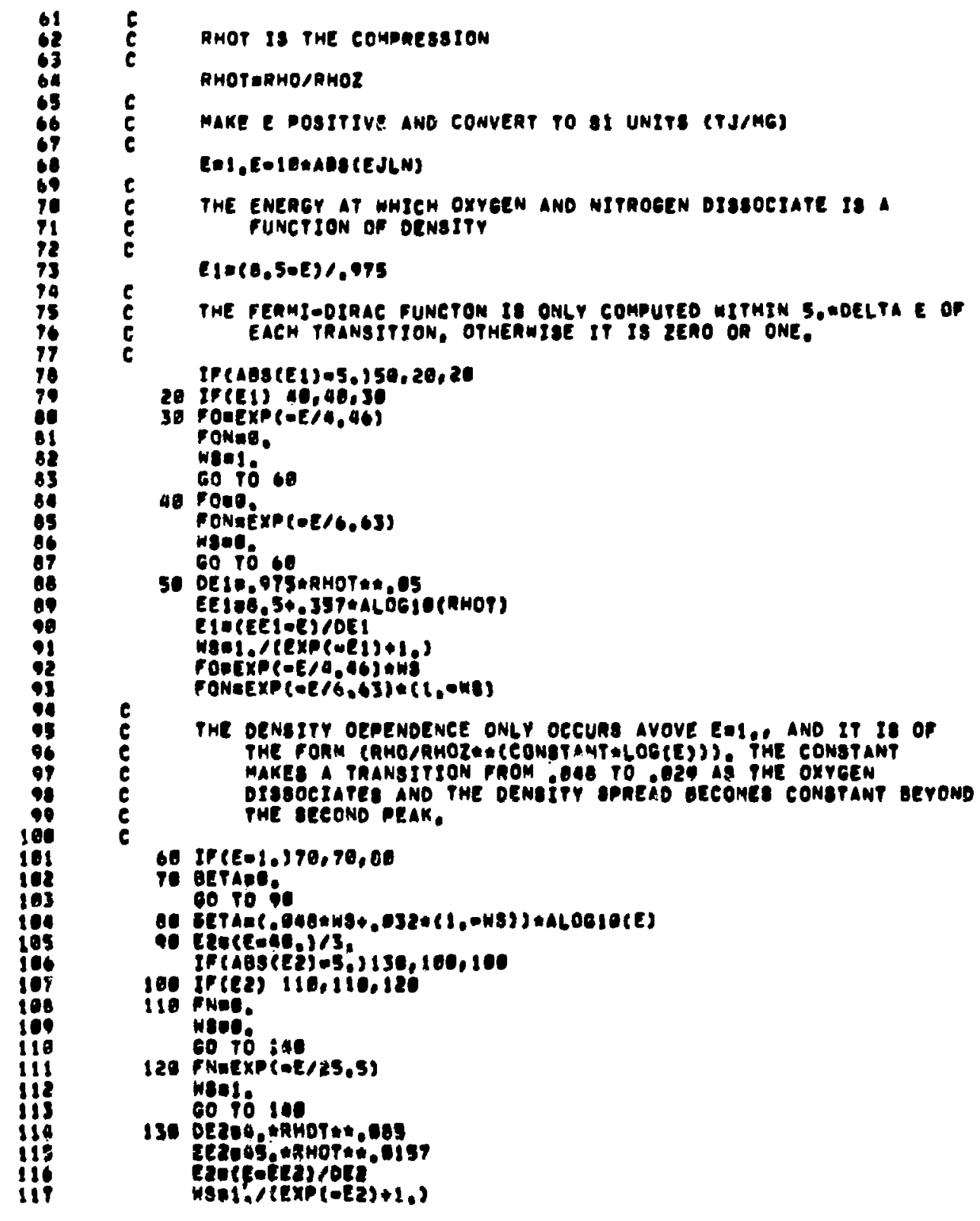




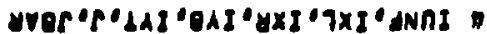

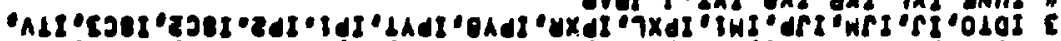

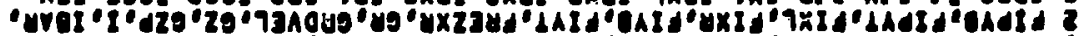

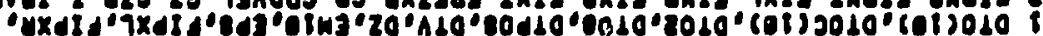

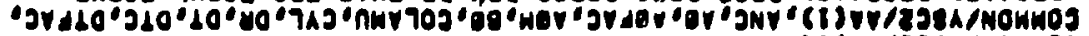

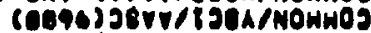

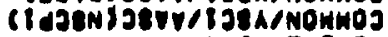
กแ

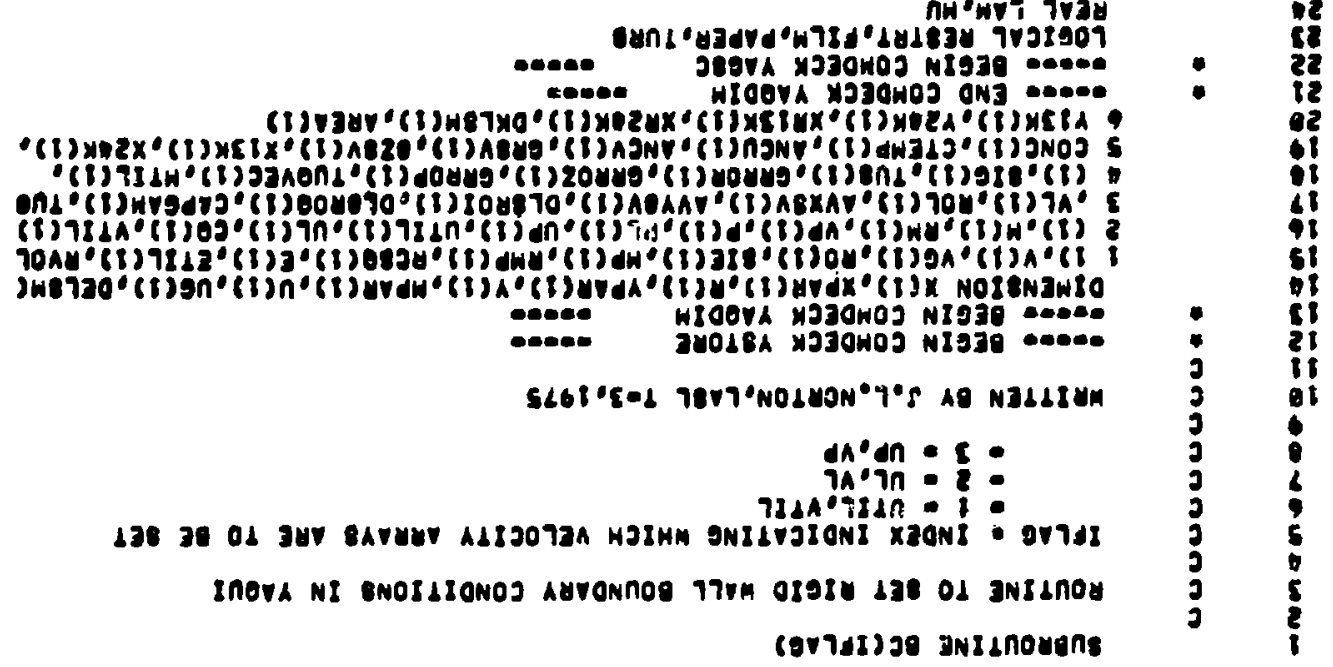

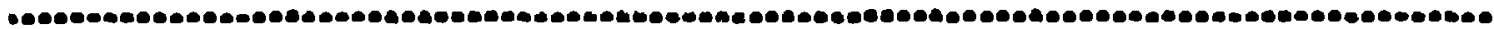

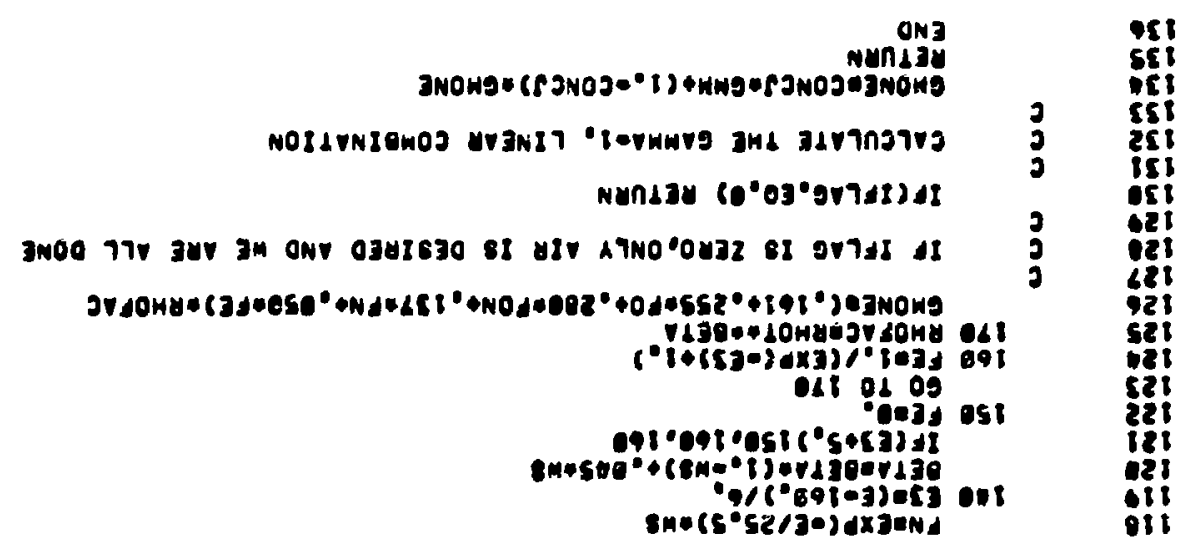


COMmON

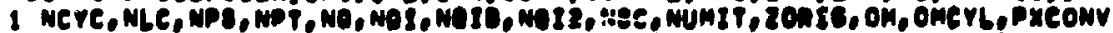

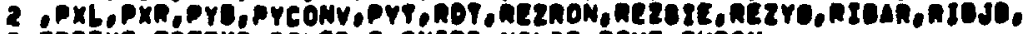

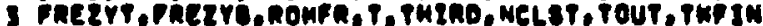

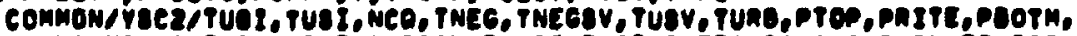

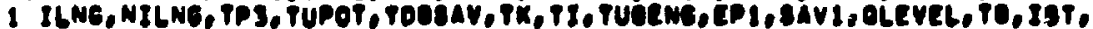

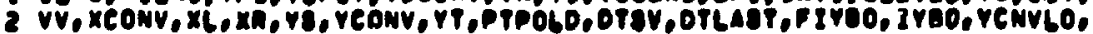

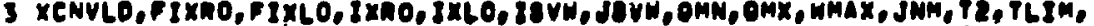

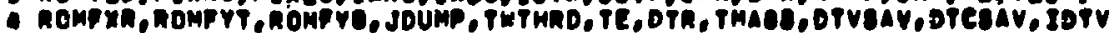

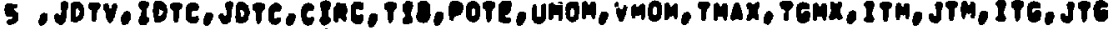
- tmadev, whatep onminet totato

Common'rocer2z

e commonersectraectiapg

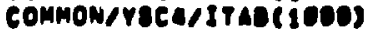
Common/ YGes

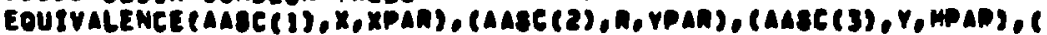

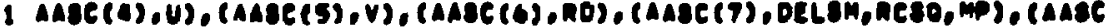

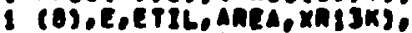

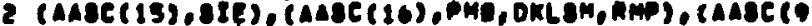

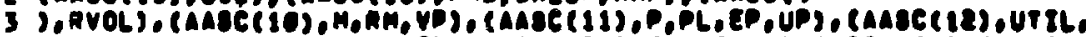

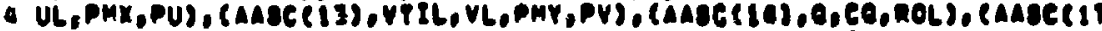

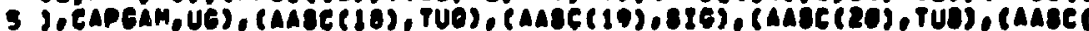

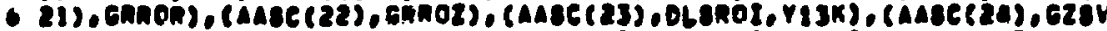

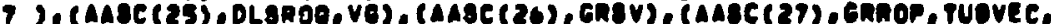

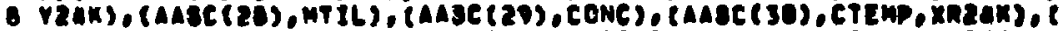

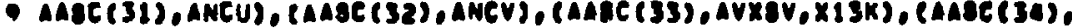

1 AYYaV, XzOKS

REAL M, MP, MPAR, MrsL

- - E. ENO COMDECK YAOEO

-000.

- 000 ENO COMDECK VETORE

-

SET UP THE LOOP OVER CELLO

CALL JTANT

e

e

SEP THE GOTTOM GOUNCARY VELOCITIES

I JaveIJ

DO ie 201,281

60 TO (16,20,30), 1FLAG

10 continue

VTILIIJ)E.

60 to 10

2. CONTINUE

$V(t)=0$.

60 To 40

31 CONTINUE

$v(L)=0$.

ne IJEIJ\&NO

I JeI J8V

c

e

SET PHE LEFT AND RIG:YT GOUNDARIES

Do 90 jeg.jp I

60 TO $(56.60 .70)$, TFlaE

50 CONTINUE 

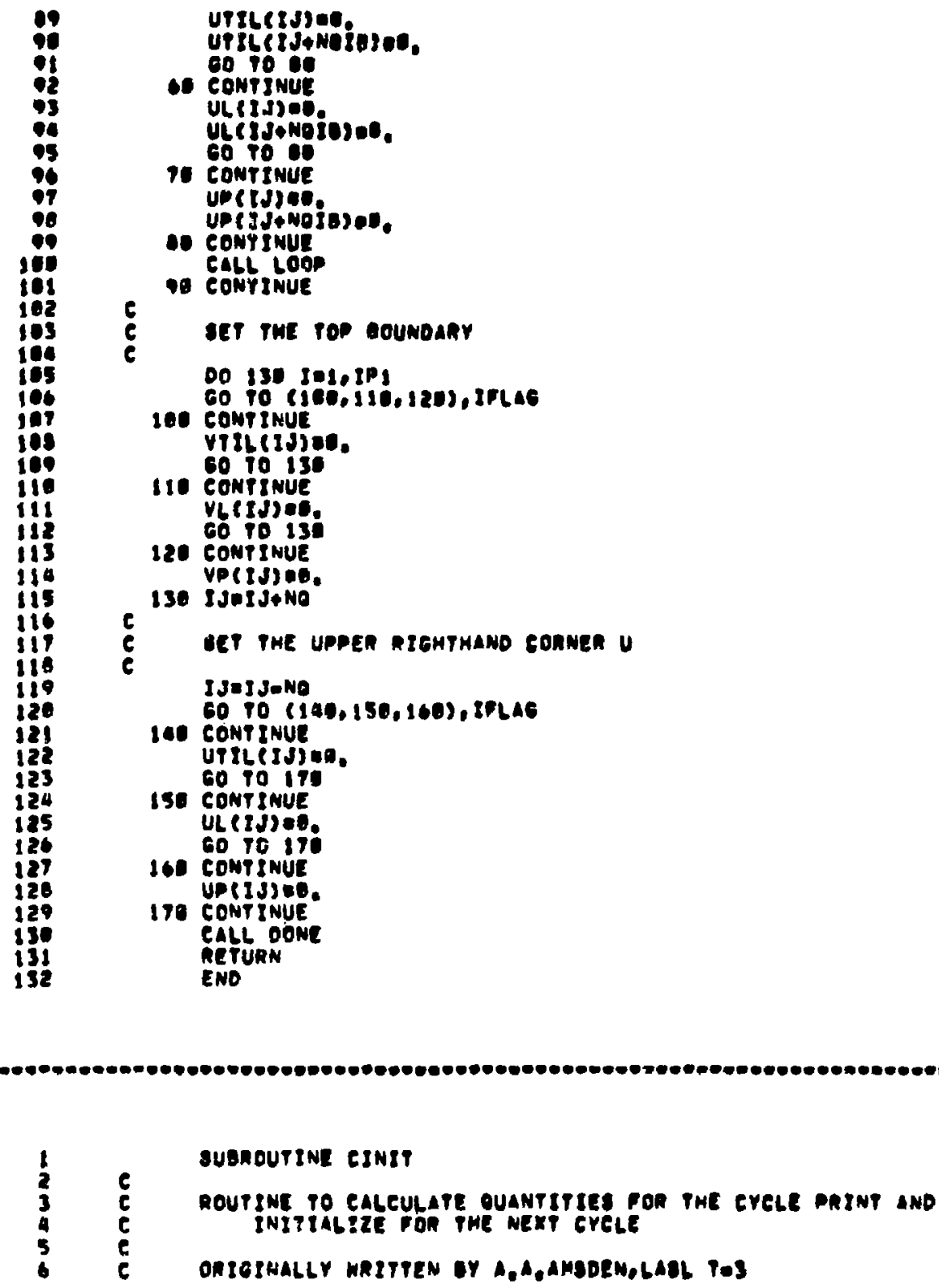


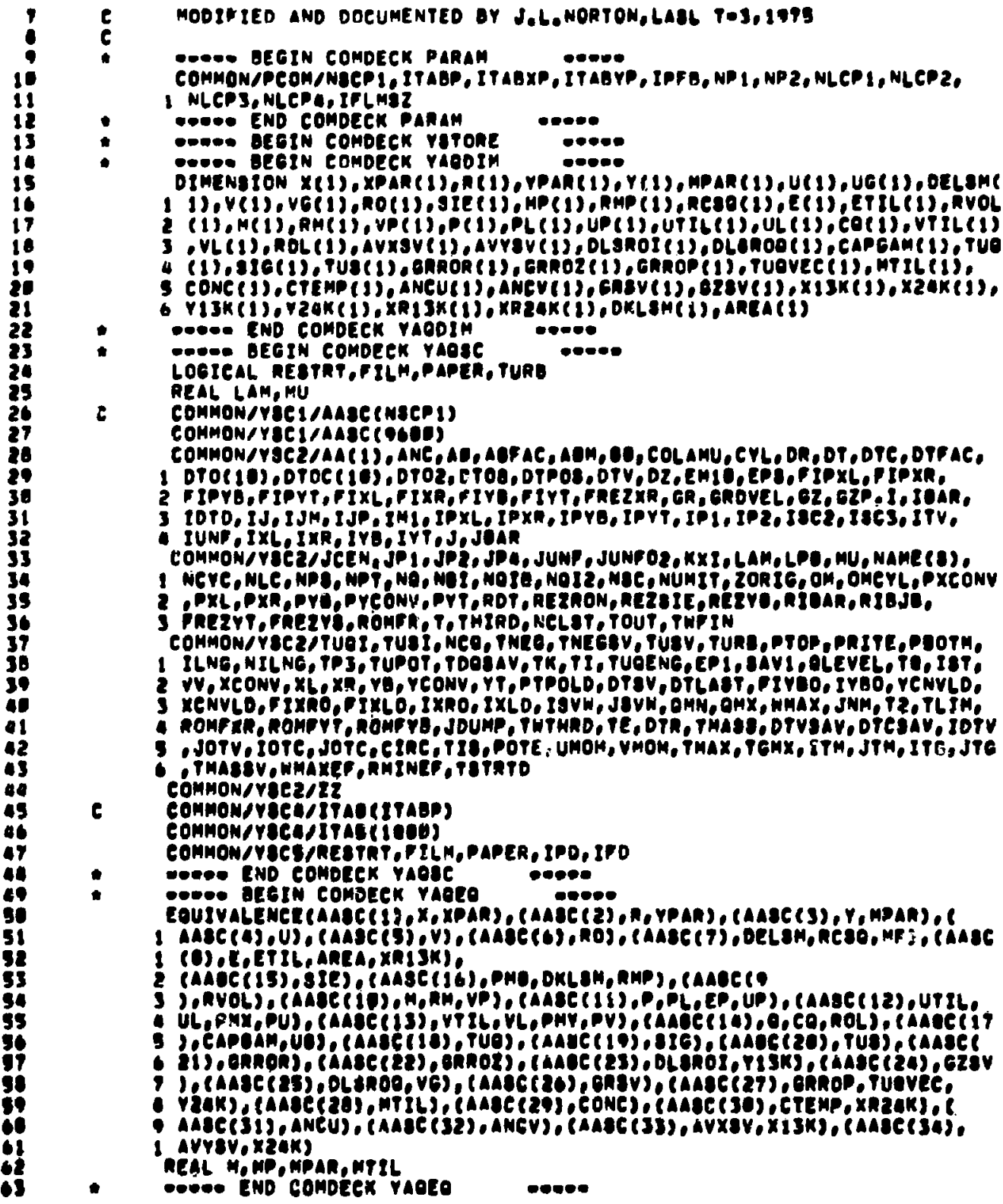




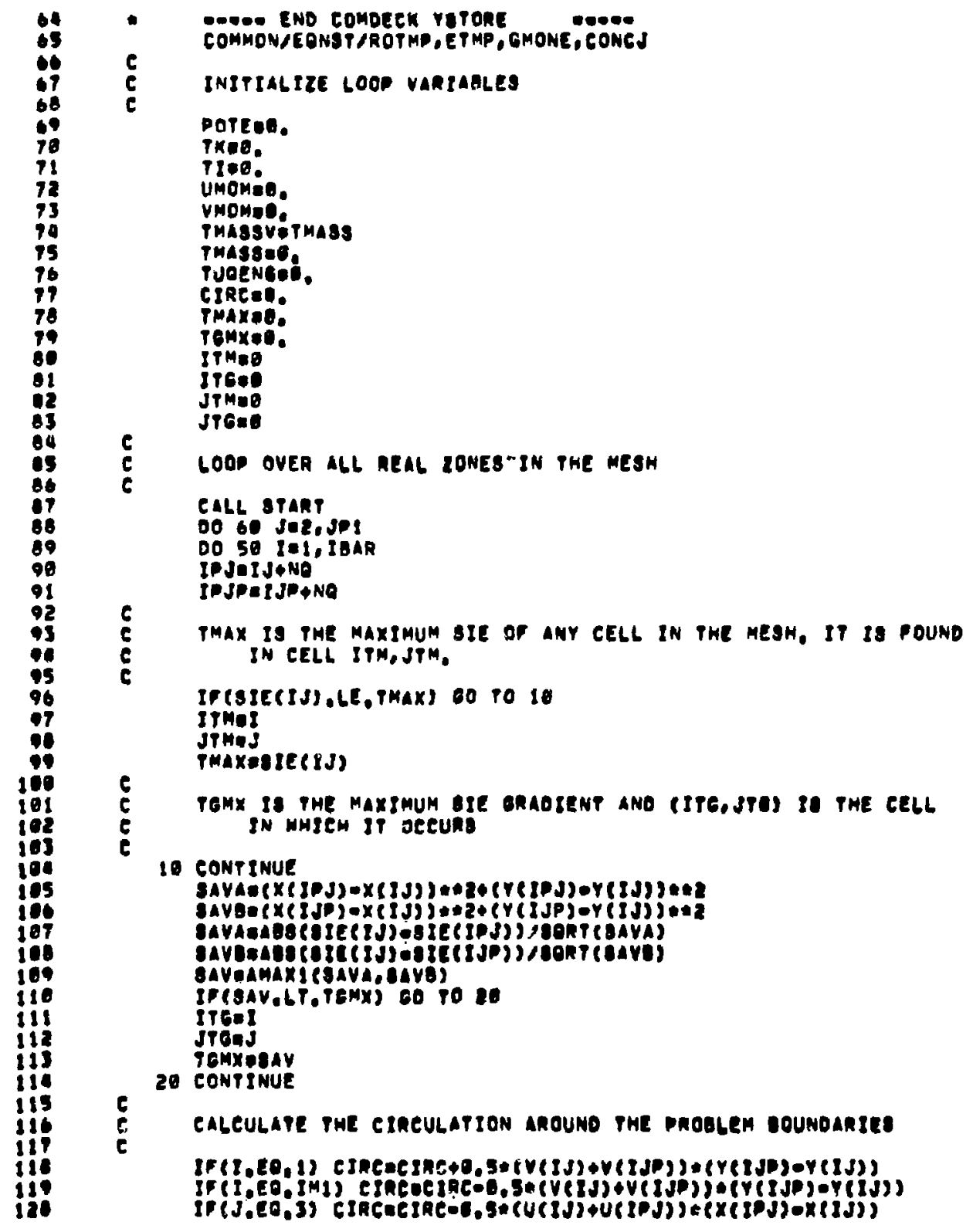




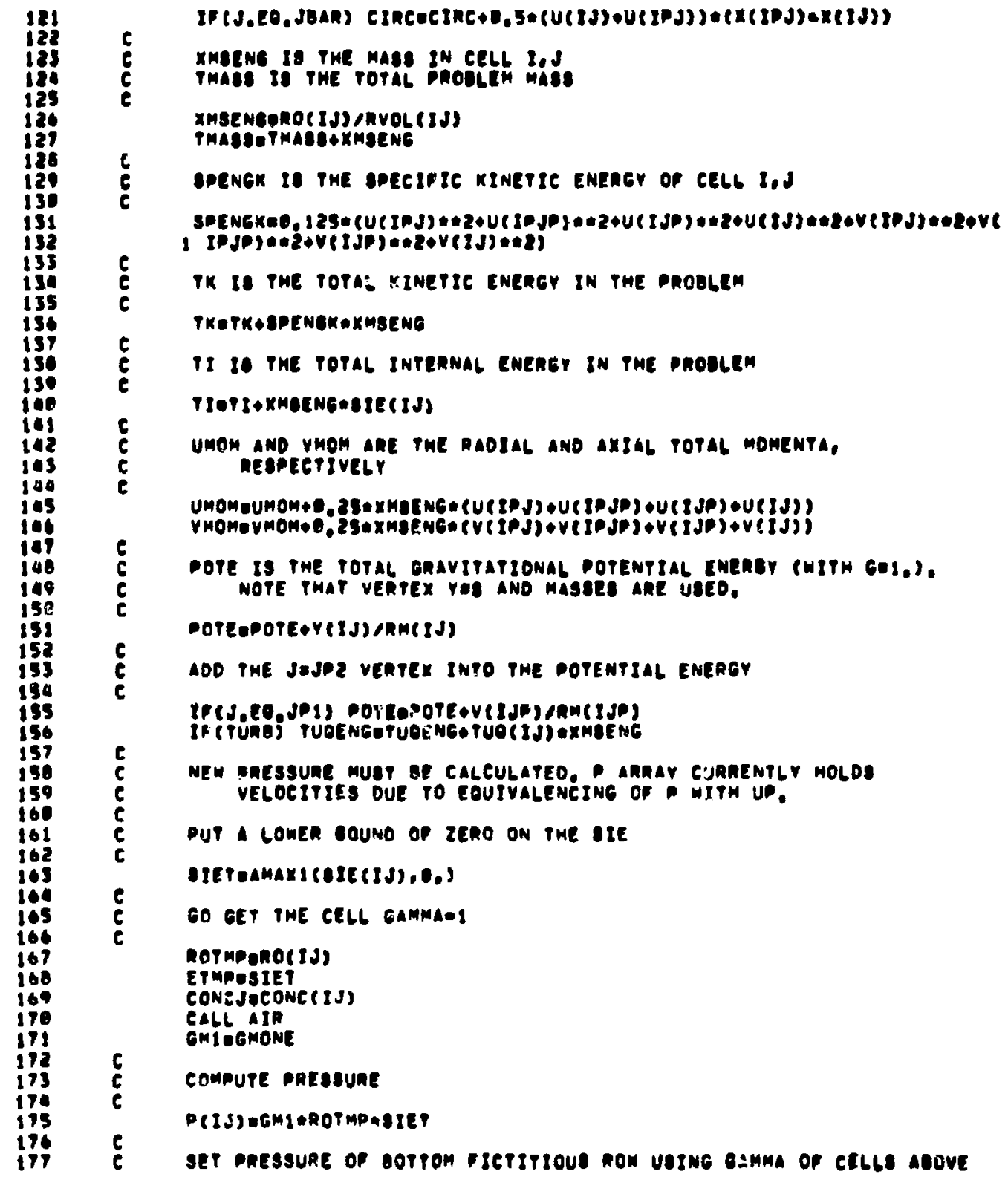




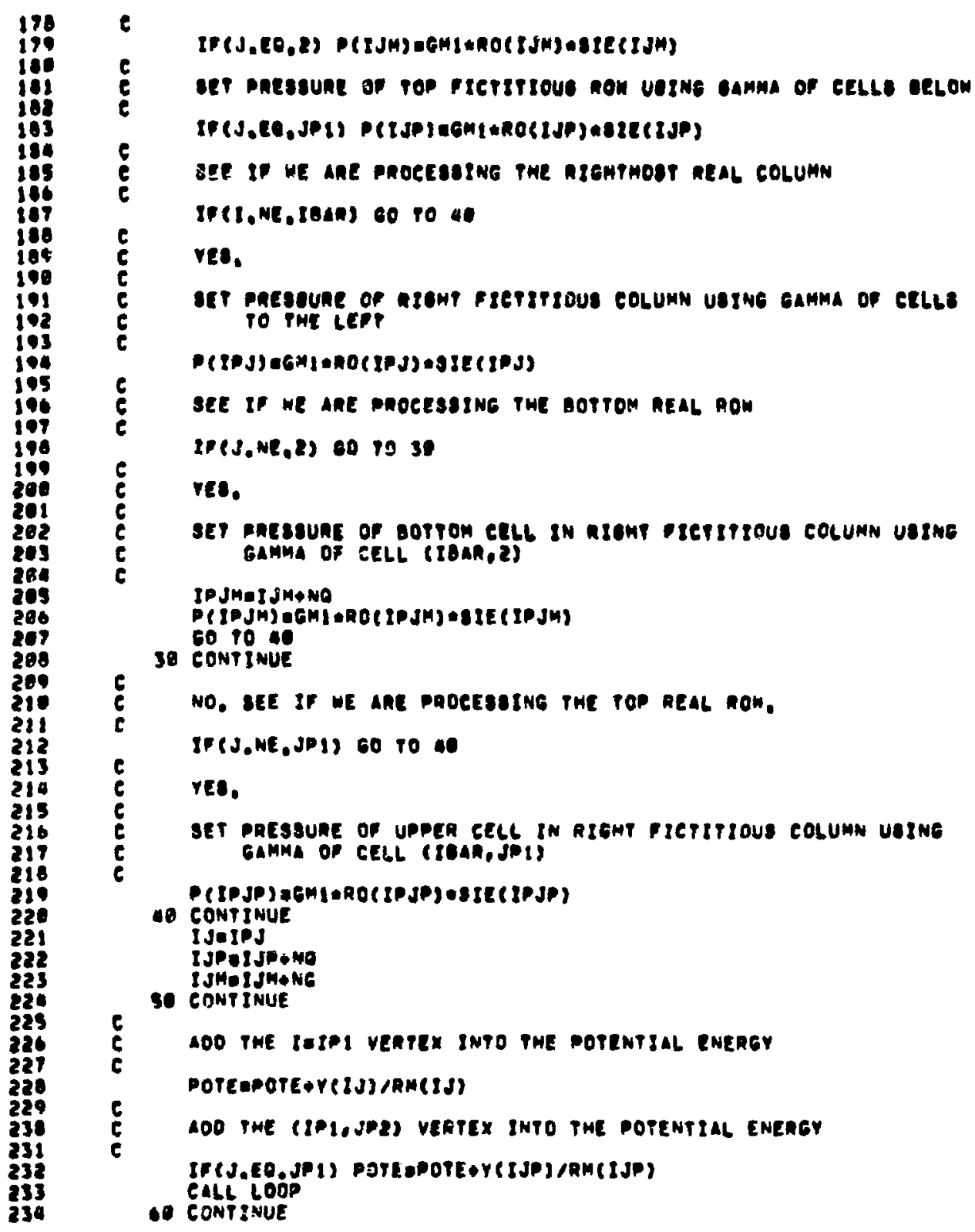


SUAROUTINE CONTON(ILOG, ITITLE, NWT)

MOUTINE FOA DOING CONTOUR PLOTS IN YAOUI

ILO IO 0 IF LINEAR CONTOUA INCAEMENTS ARE TO DE UOEO ILOG IS FOR LOGARITHMIC CONTOUA INEAEMENTS ITITLE IS THE HOLLERIPM PITLE TO DE USED ON THE PLOT NWT IS THE NO, OF COMPUTER WORDS IN THE TITLE

ThE QUANTITY ro de Plotico is FOUNO IN CO

OQIGINALLY WRITTEN OY A. A.AMVDEN,LASL TOS MOSIFIED AND DOEUMENPED BY J,L, NORTON,LASL P-3,19TS

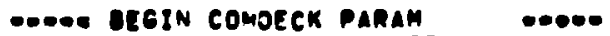
COMMON/PCOH/NECP I. ITABP, ITABXP, ITABYP, IPFE, NPI, NP 2, NLCP I, NLCPZ. 1 NLCP3. NLEPH. IFLMEZ

- END COMDEEK PARAM

- - - GEGIN COMDEEK YSTORE

- DOD DEGIN COMDECK YAOOJH

$-000 \cdot$

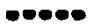

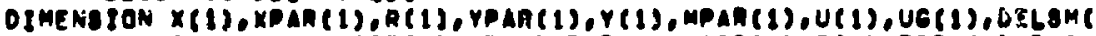

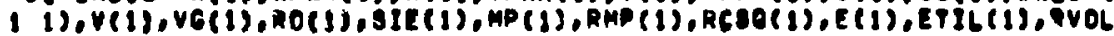

2 (1),M(1),RM(1),VP(1),P(1),PL(1),UP(1),UPI6(1),UL(1),Ce(1),VTIL(1)

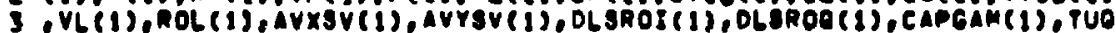

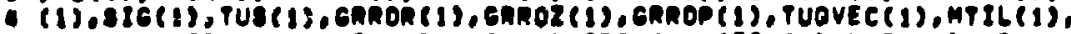

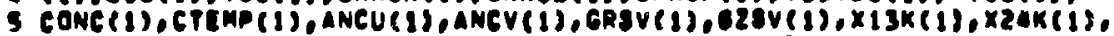

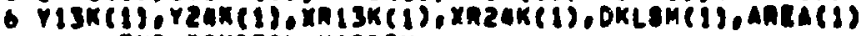

-

-

LOSICAL RESTRT, FILM,PAPER, TUAD

ReAL LAM, HU

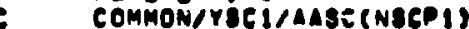

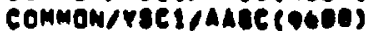

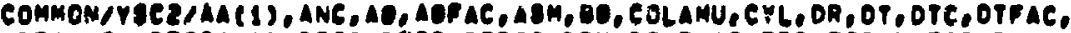

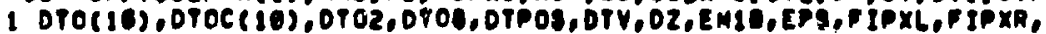

2 FIPYA,FIPYT,FIXL,FIXR,FIYG,FIYT,FREZXR,GR,GROVEL, G2, GZP, I, IEAA,

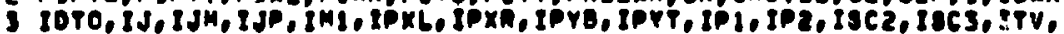

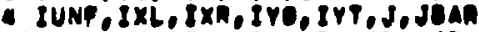

Common M

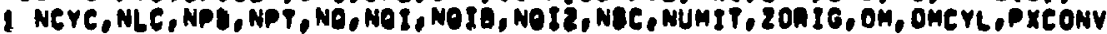

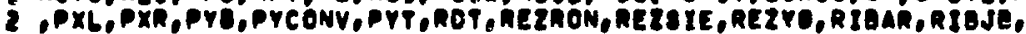

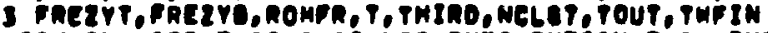

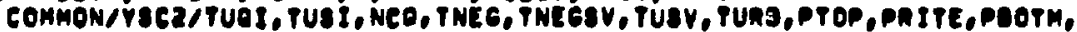

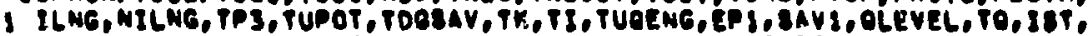

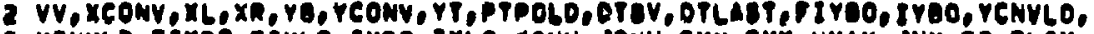

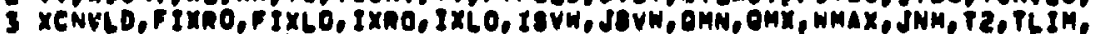

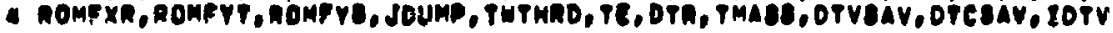




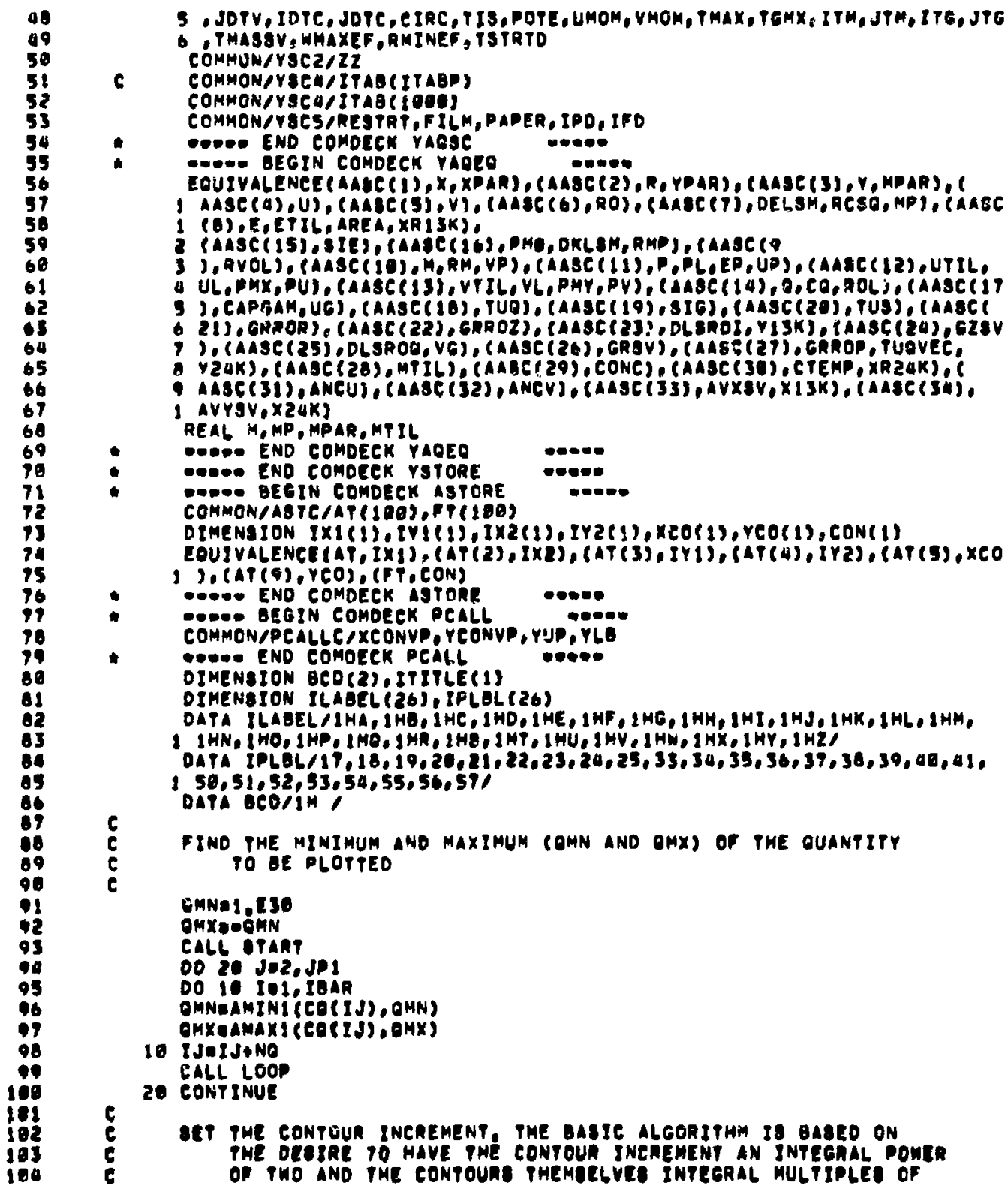




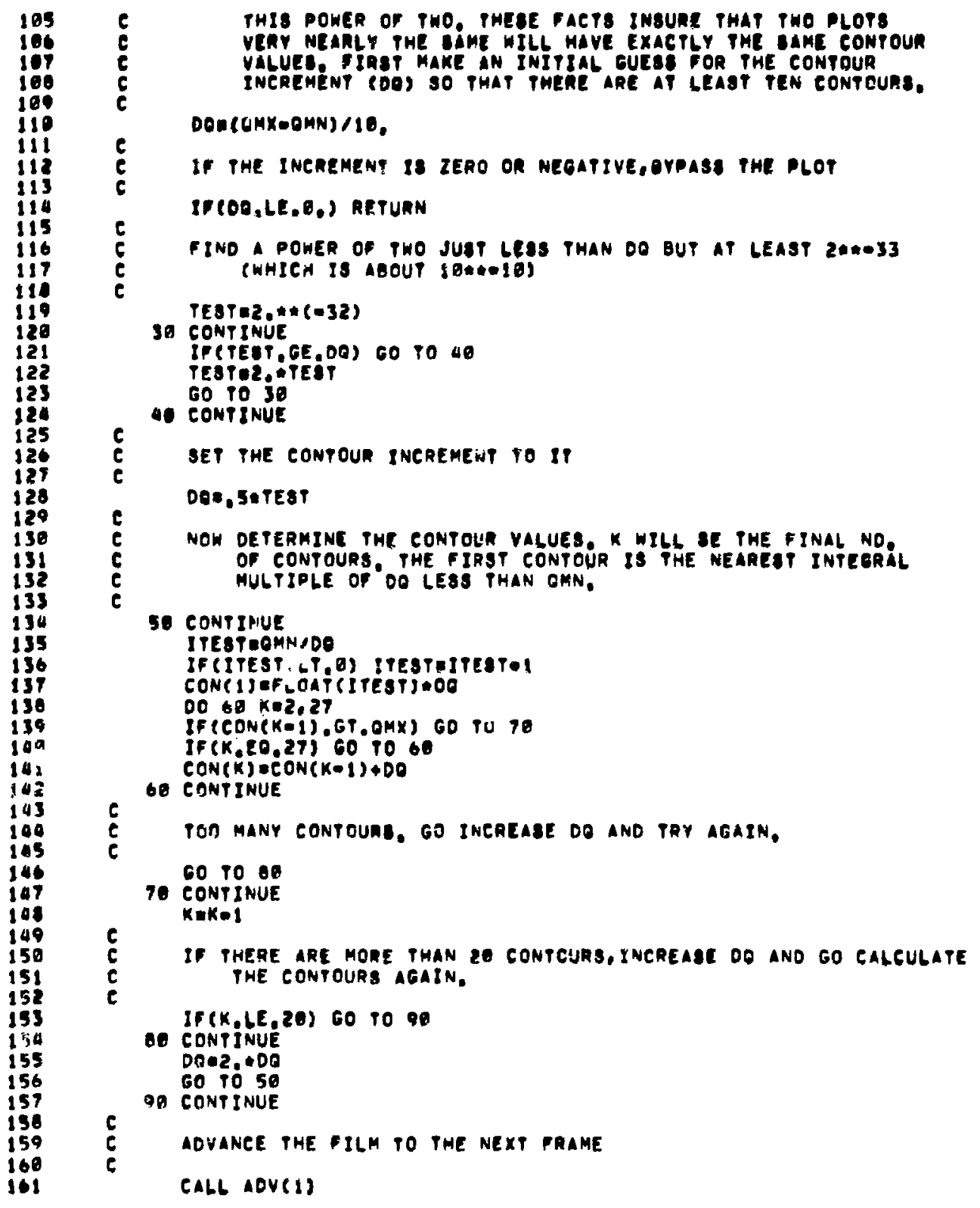




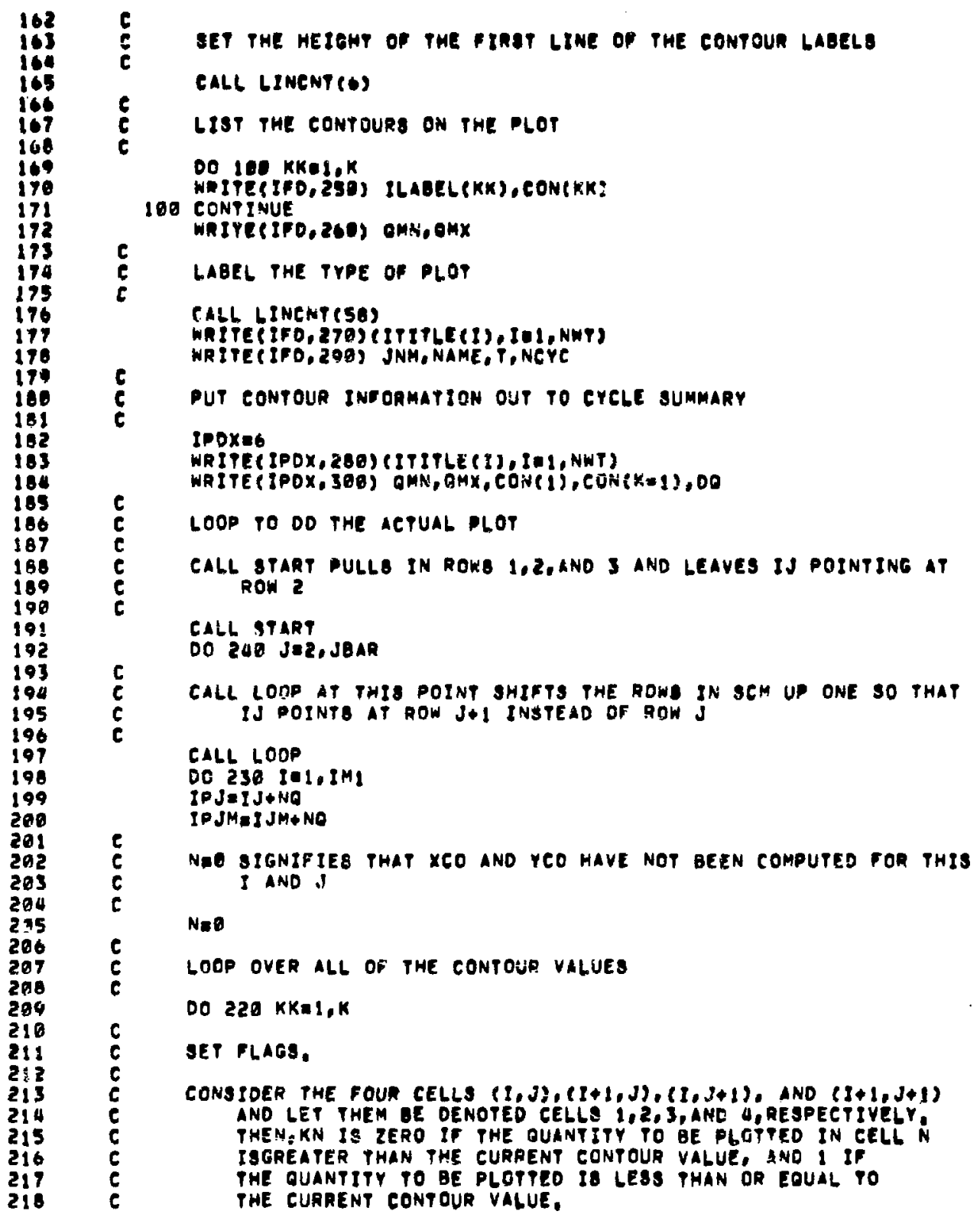




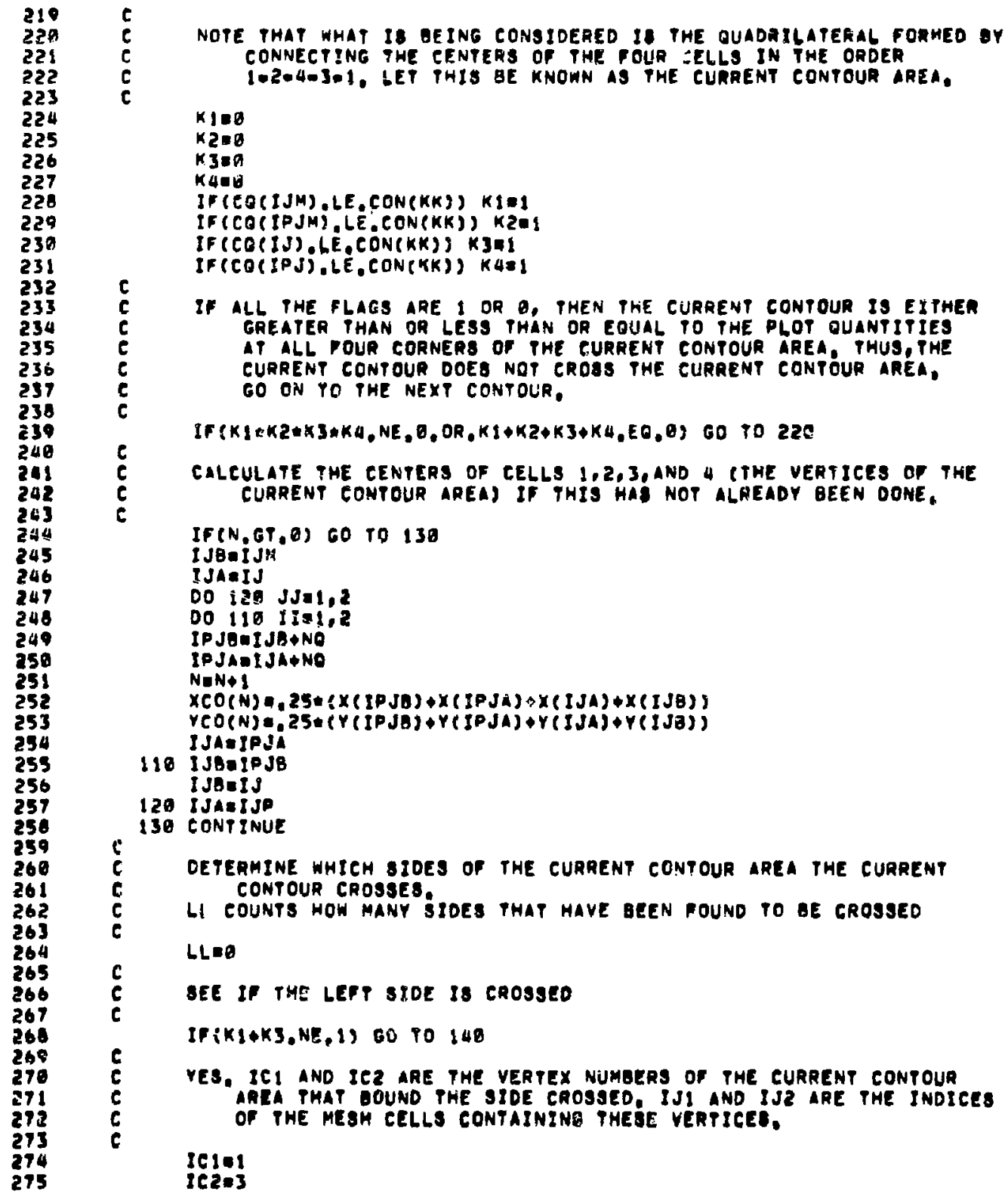




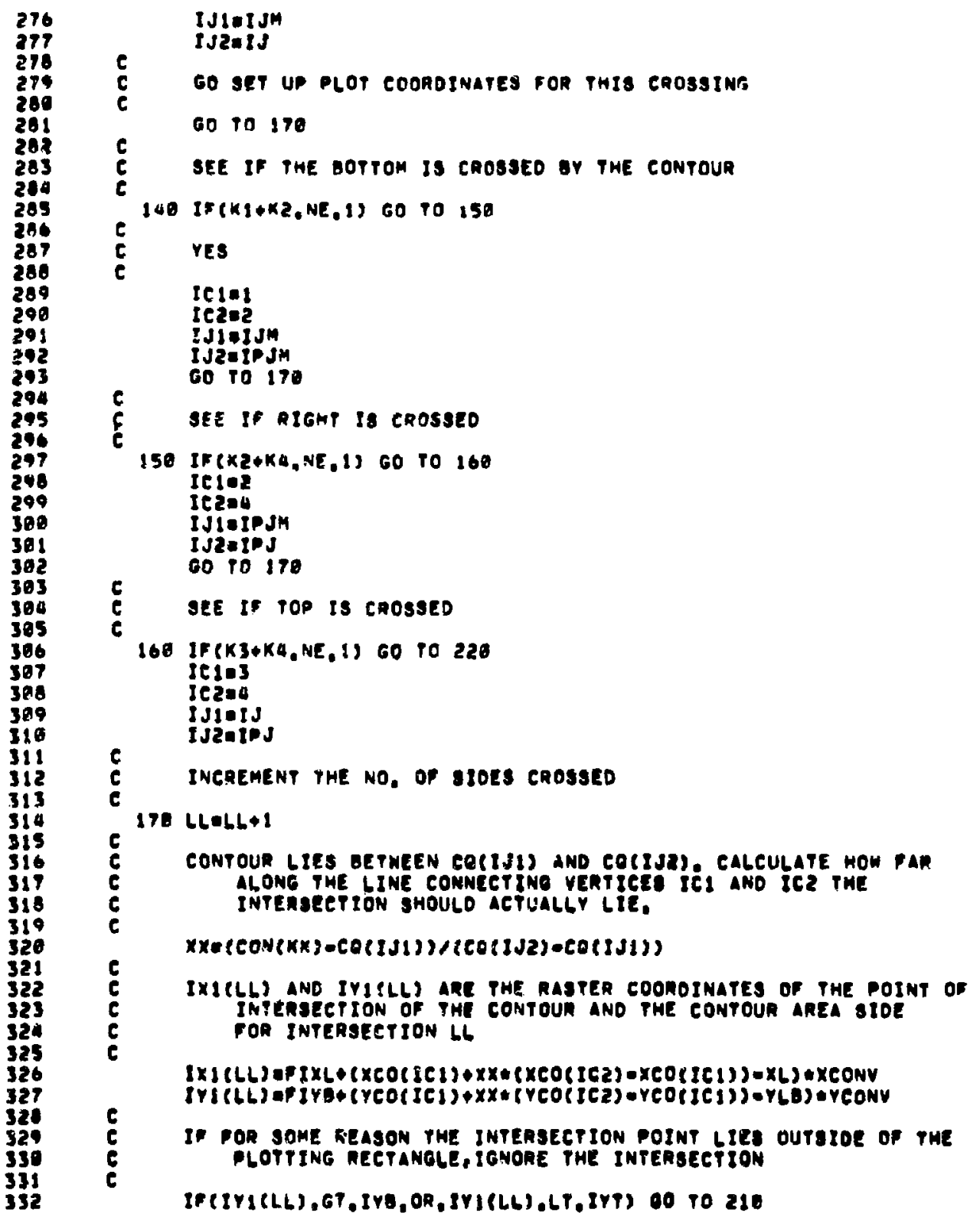




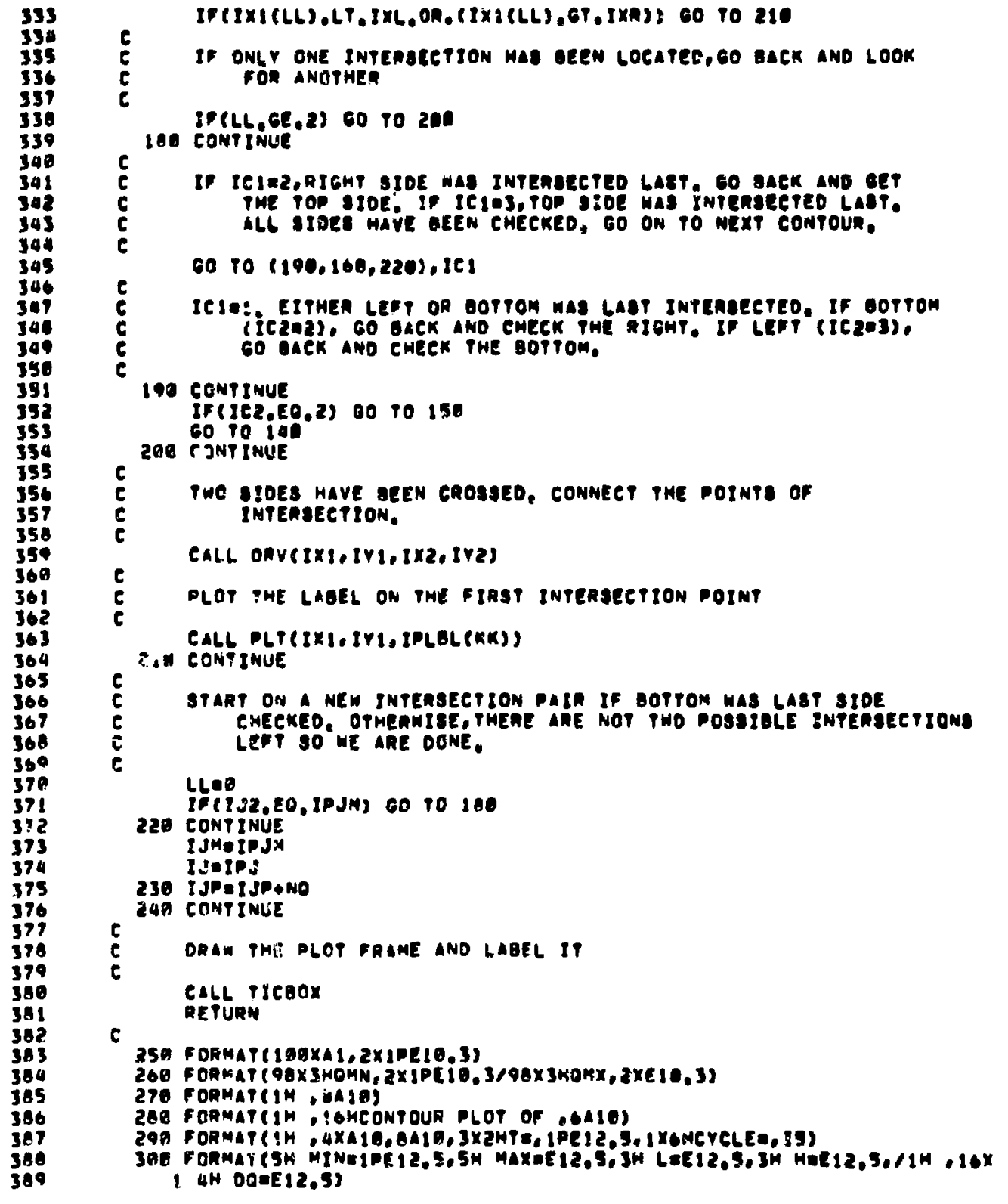




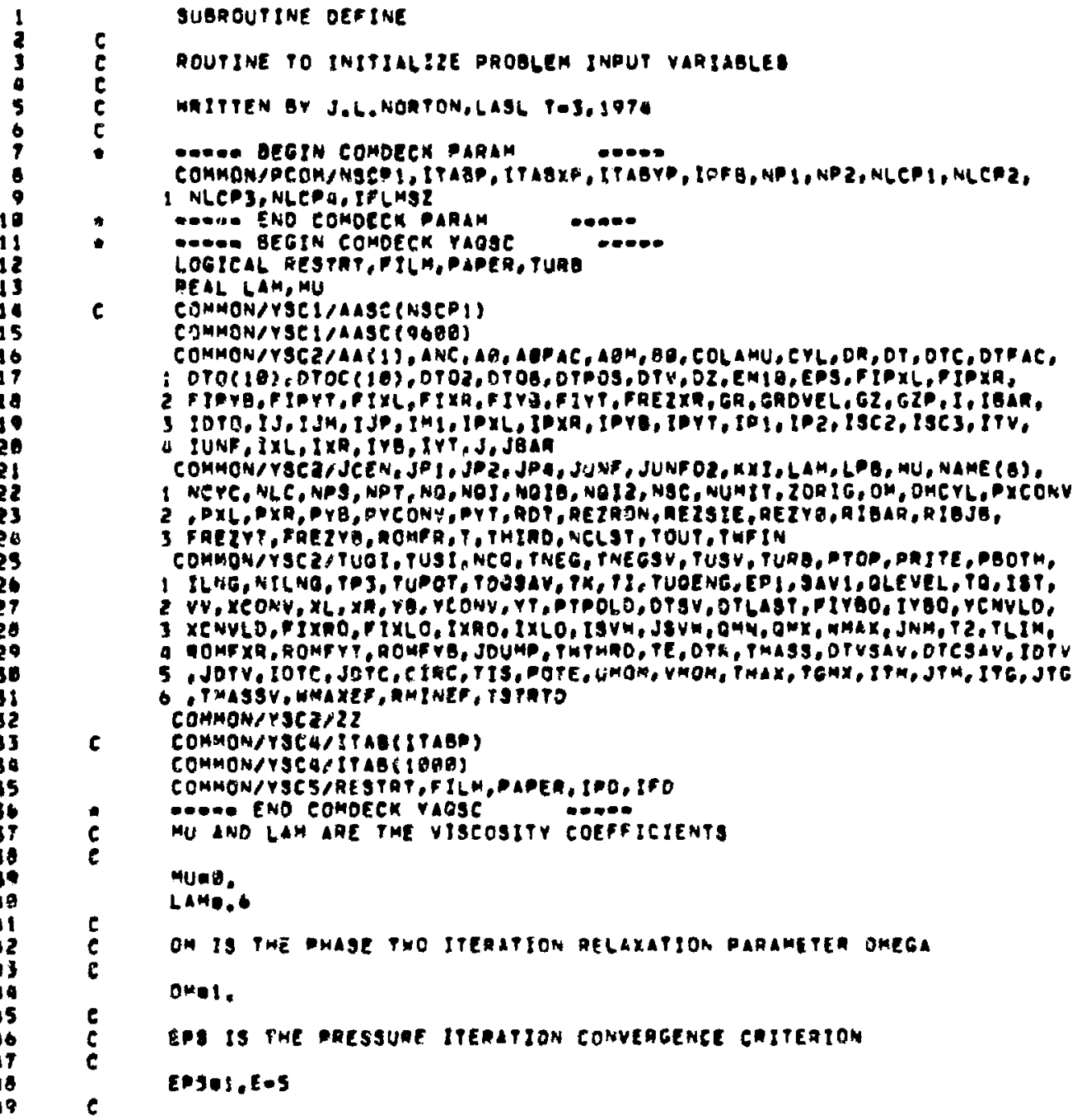




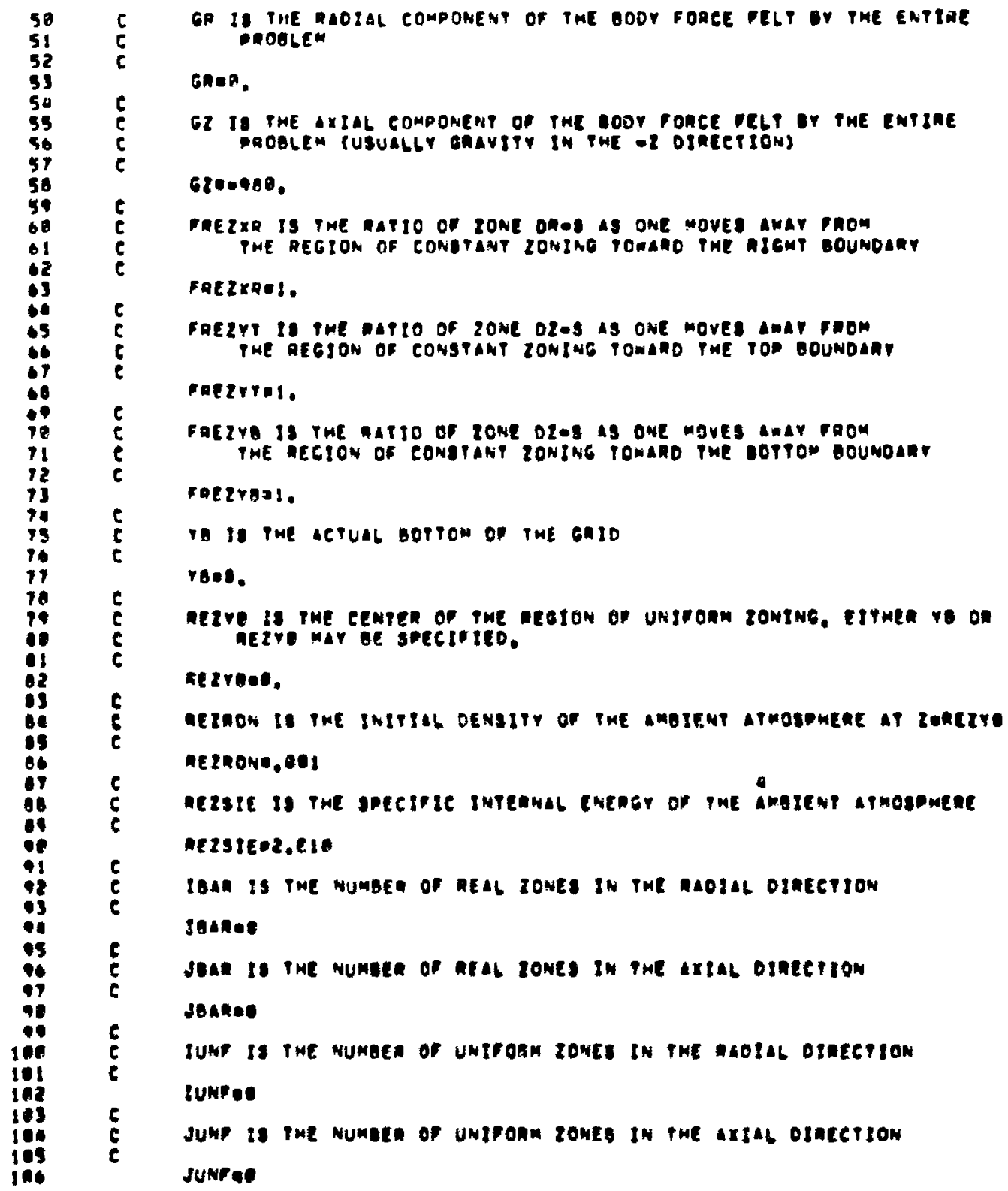




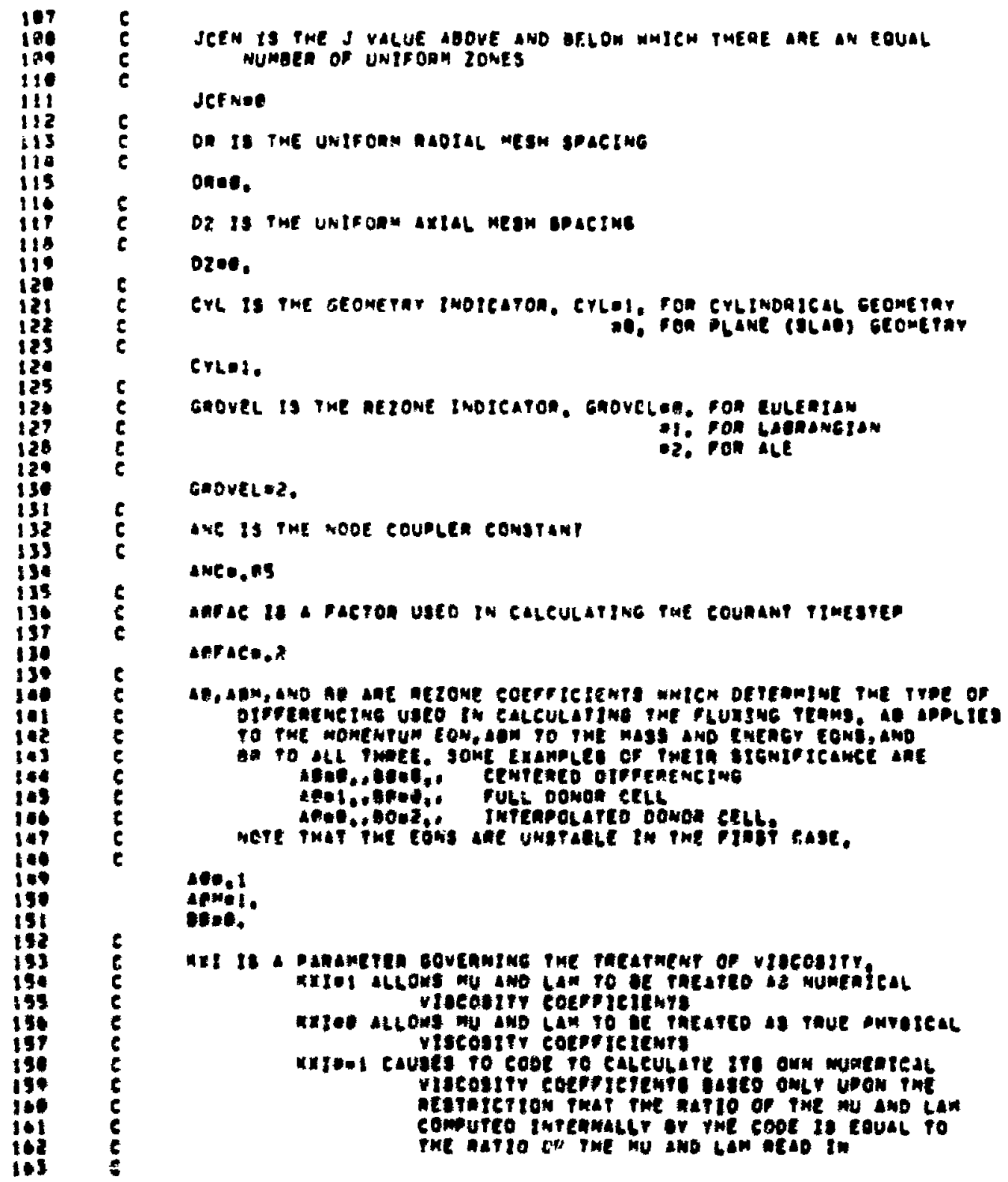




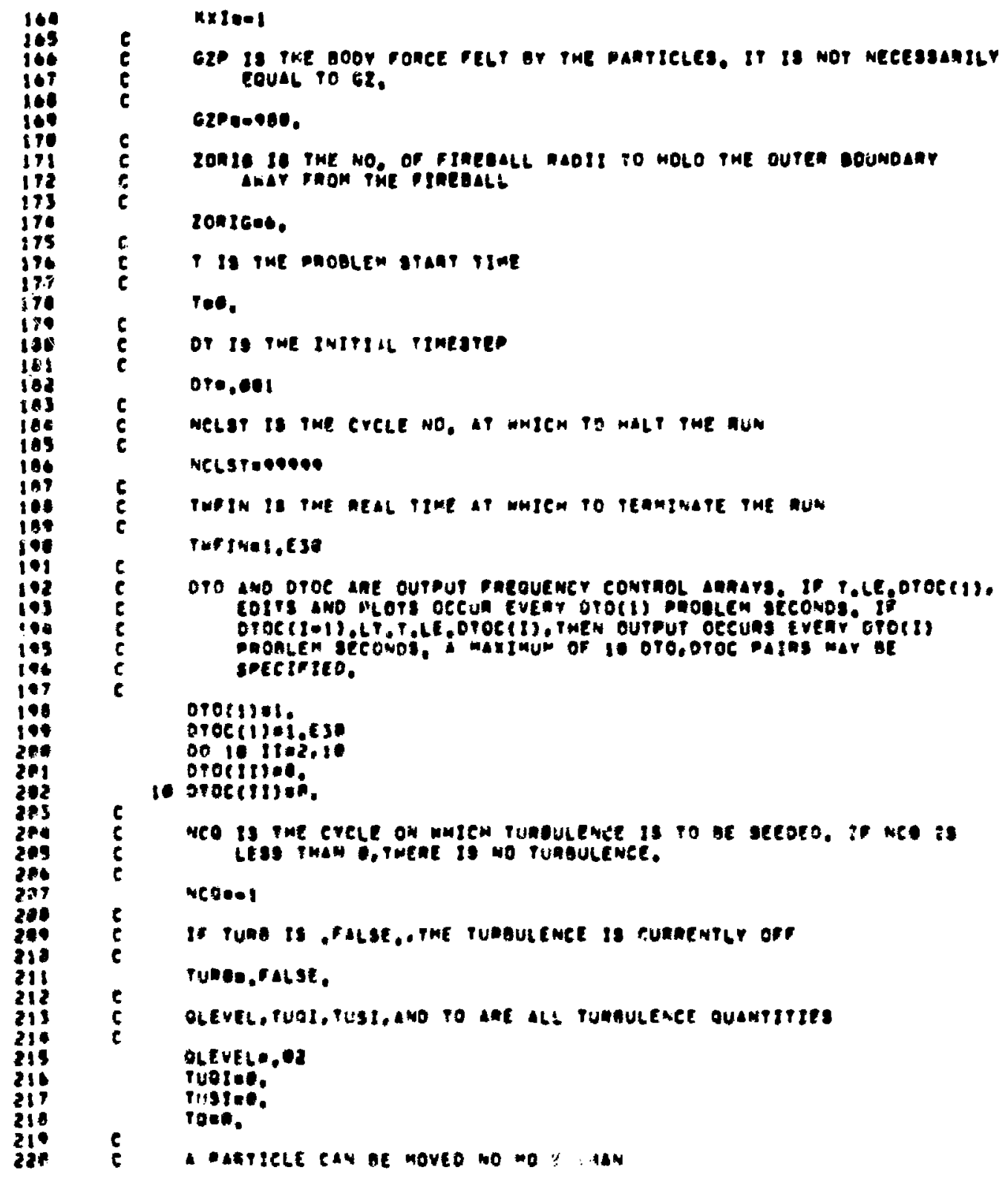



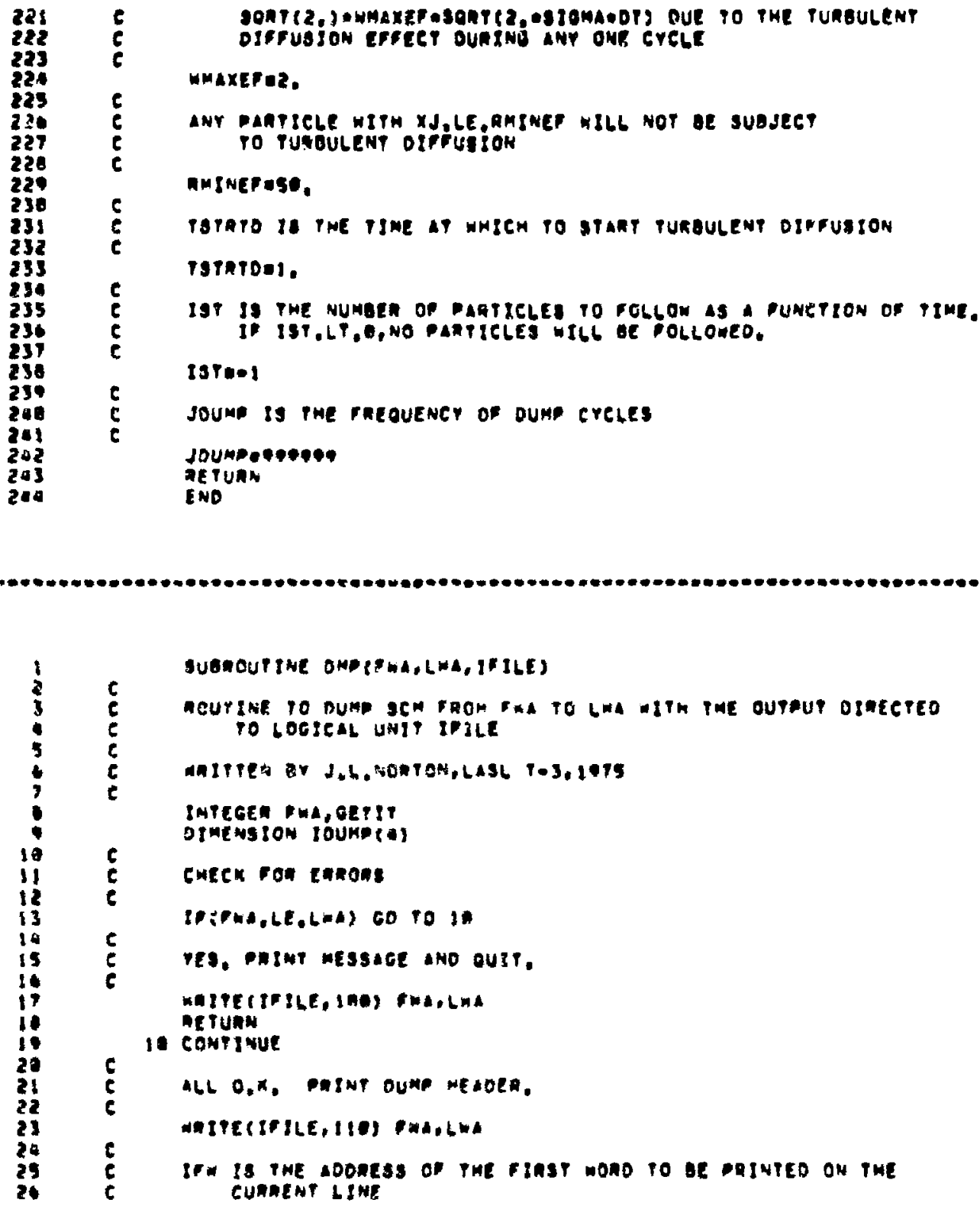


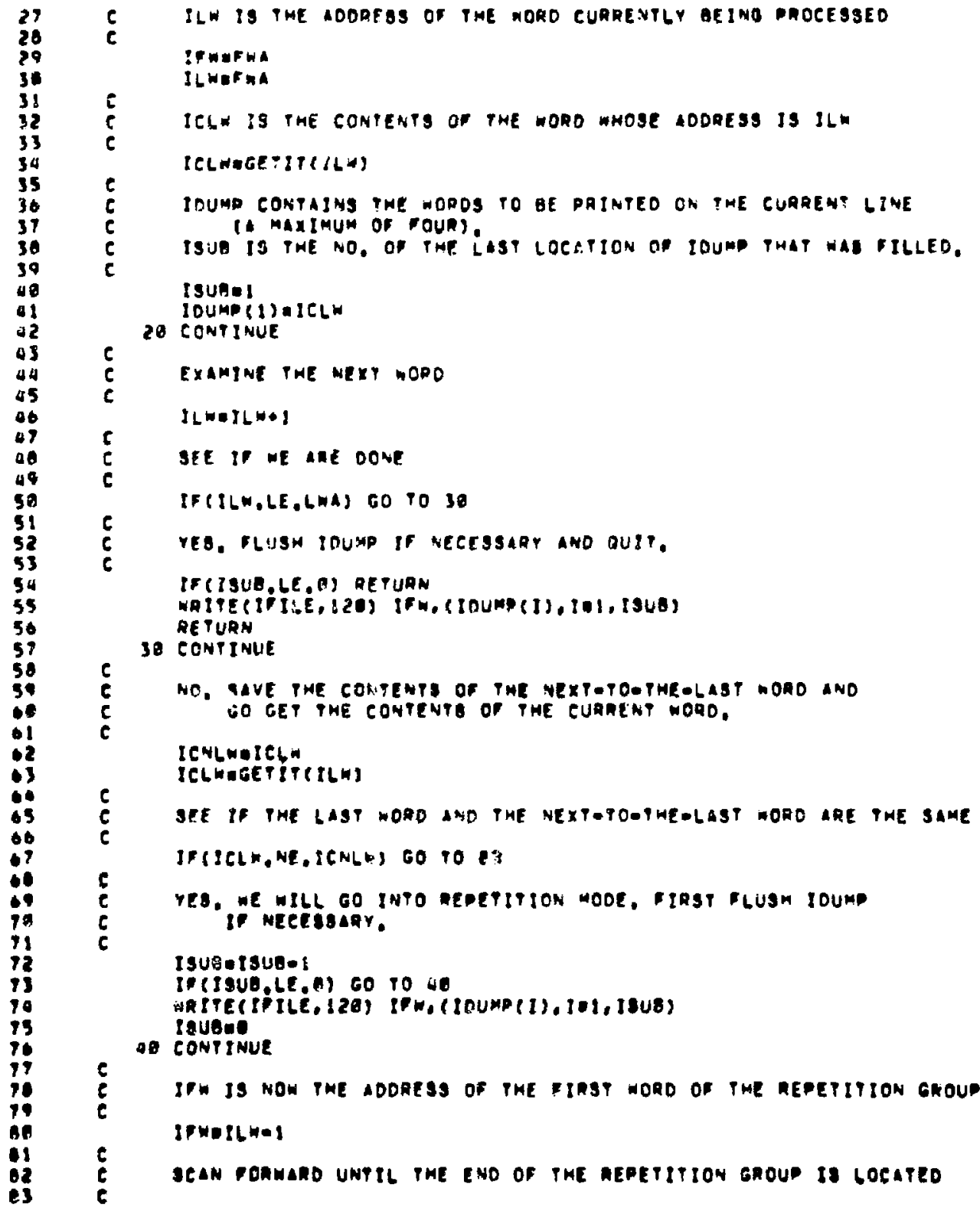




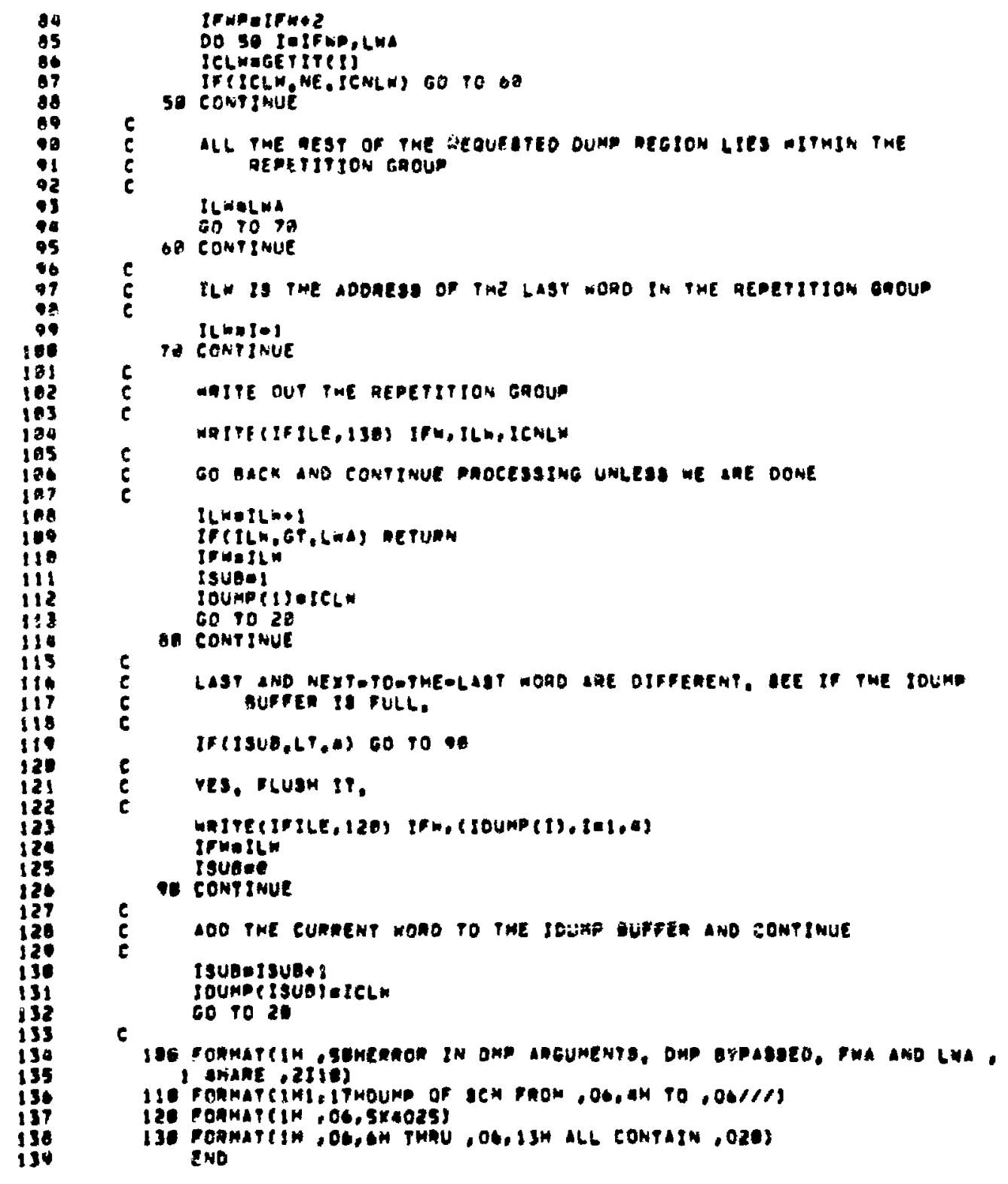




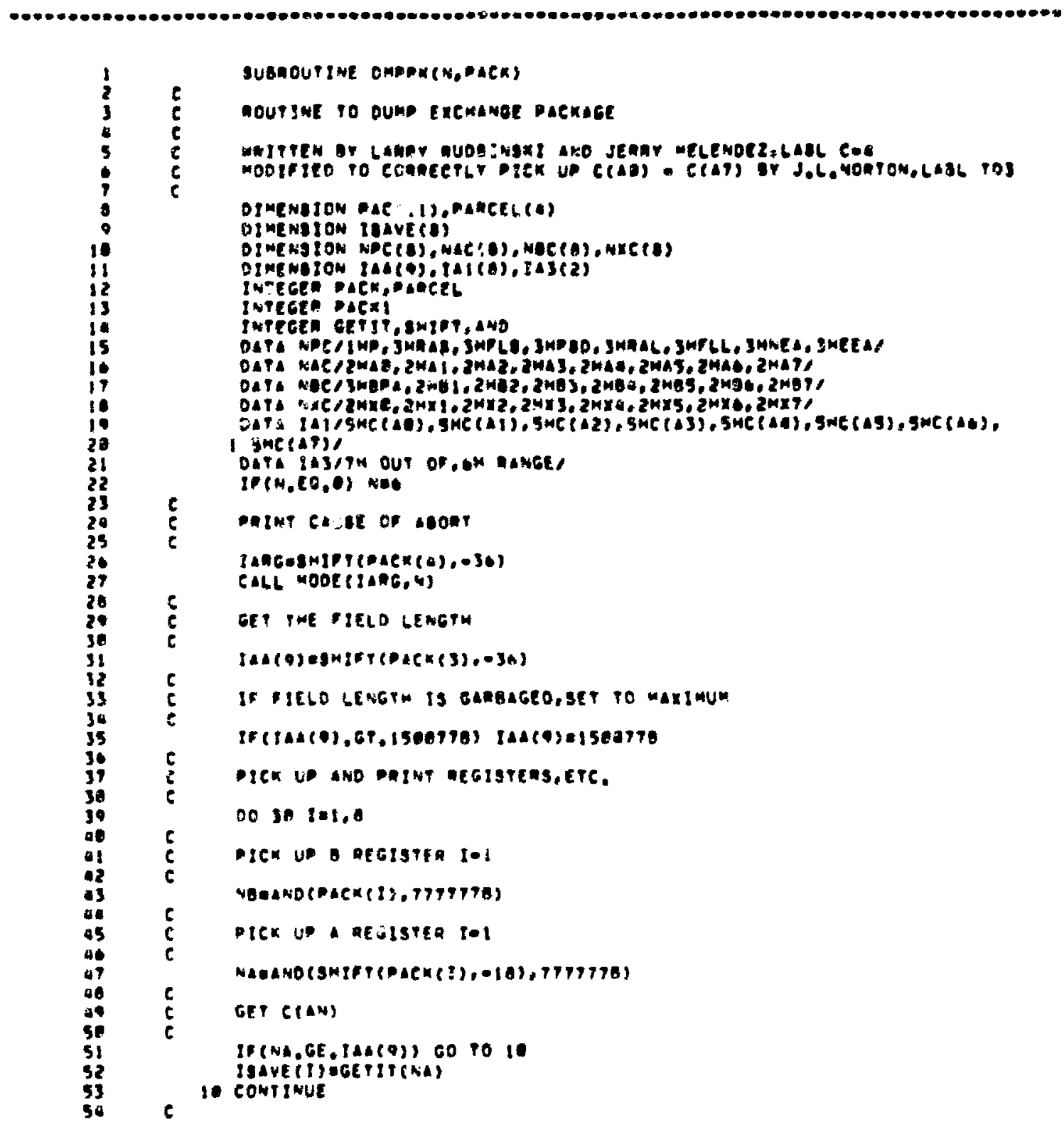

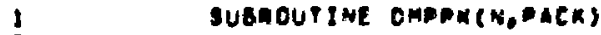

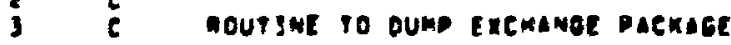

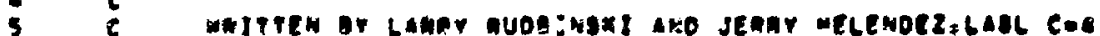

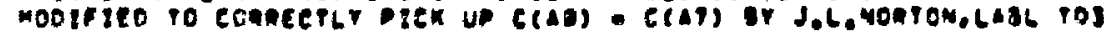

Dimeneton cae . 1), nanceto(s)

DI WE HEION IBAVE(O)

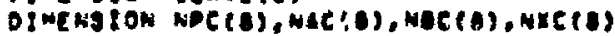

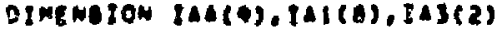

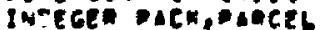

INTeger Dexi

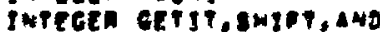

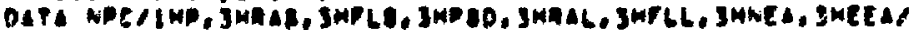

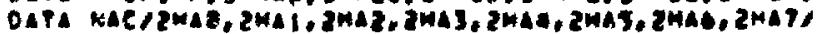

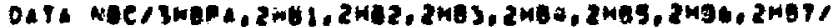

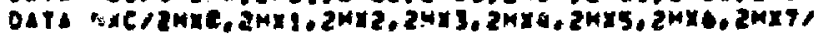

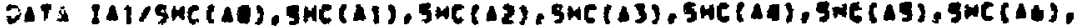

I Sure(as)e

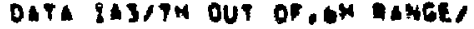

if(H.c0.0) nes

E

oelug cajer or seont

jangesmiptenen(a),-3el

CALL MOOC $(2 A M 6,4)$

E

GET IWE TIELD LENGTH

$\operatorname{ras}(4) \sin (0)(\theta+c)(3) \cdot-34)$

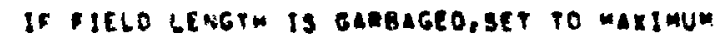

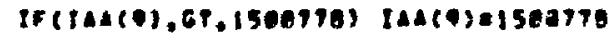

PICK UD GNO PEINT DEGISTEMSETC.

Do in 101,0

C Picm UP D DEgistea Iol

6

YBEAND(FACX(2).777977B)

c

c

c

pick ue a a jsteg tol

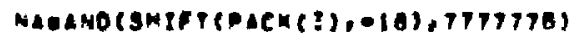

Get $(I A)$

IO(N.GE,TAS(Q)) GO PO IO

ISAVE TISOGETIT(KA)

c

1e continue 


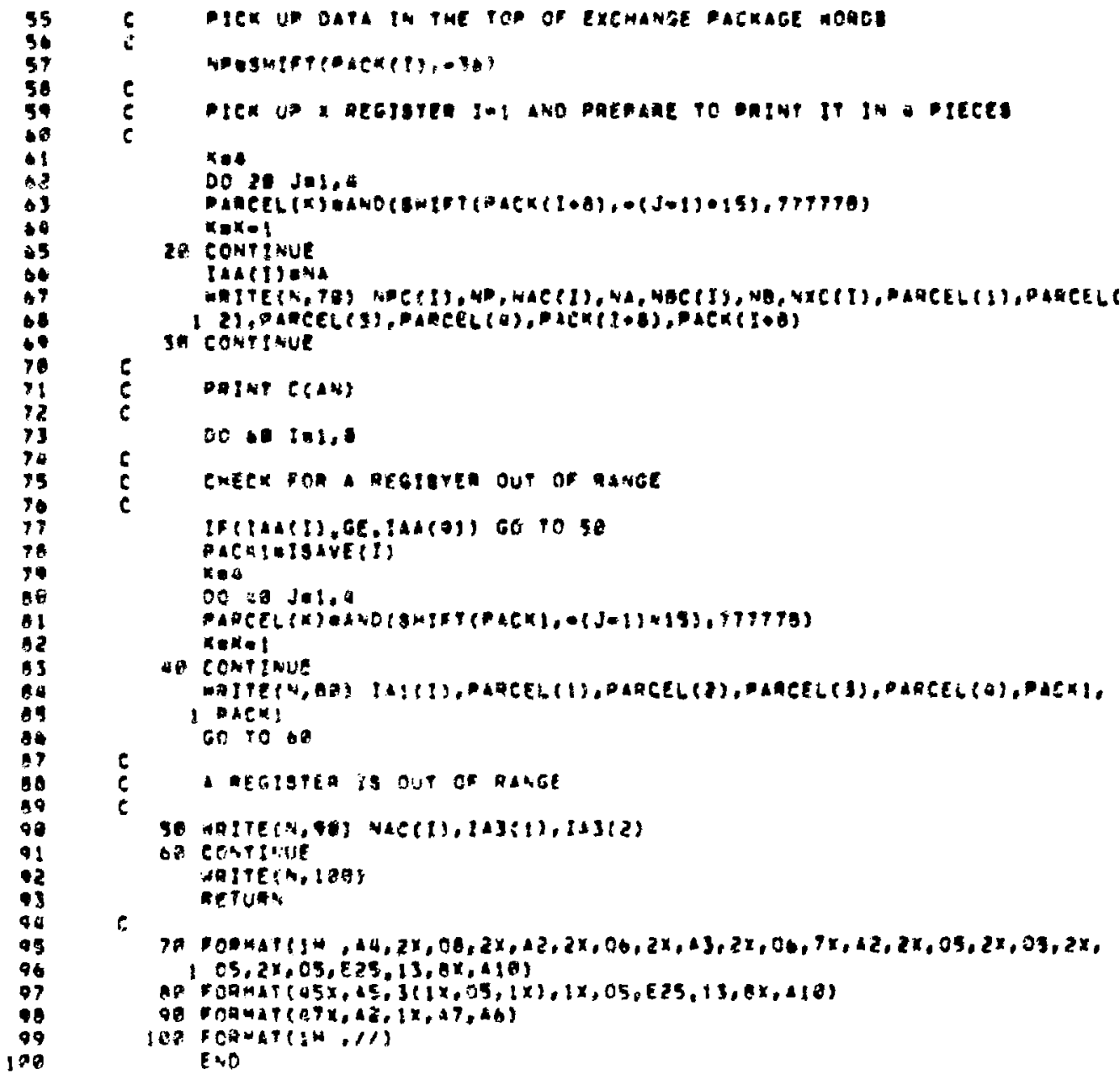




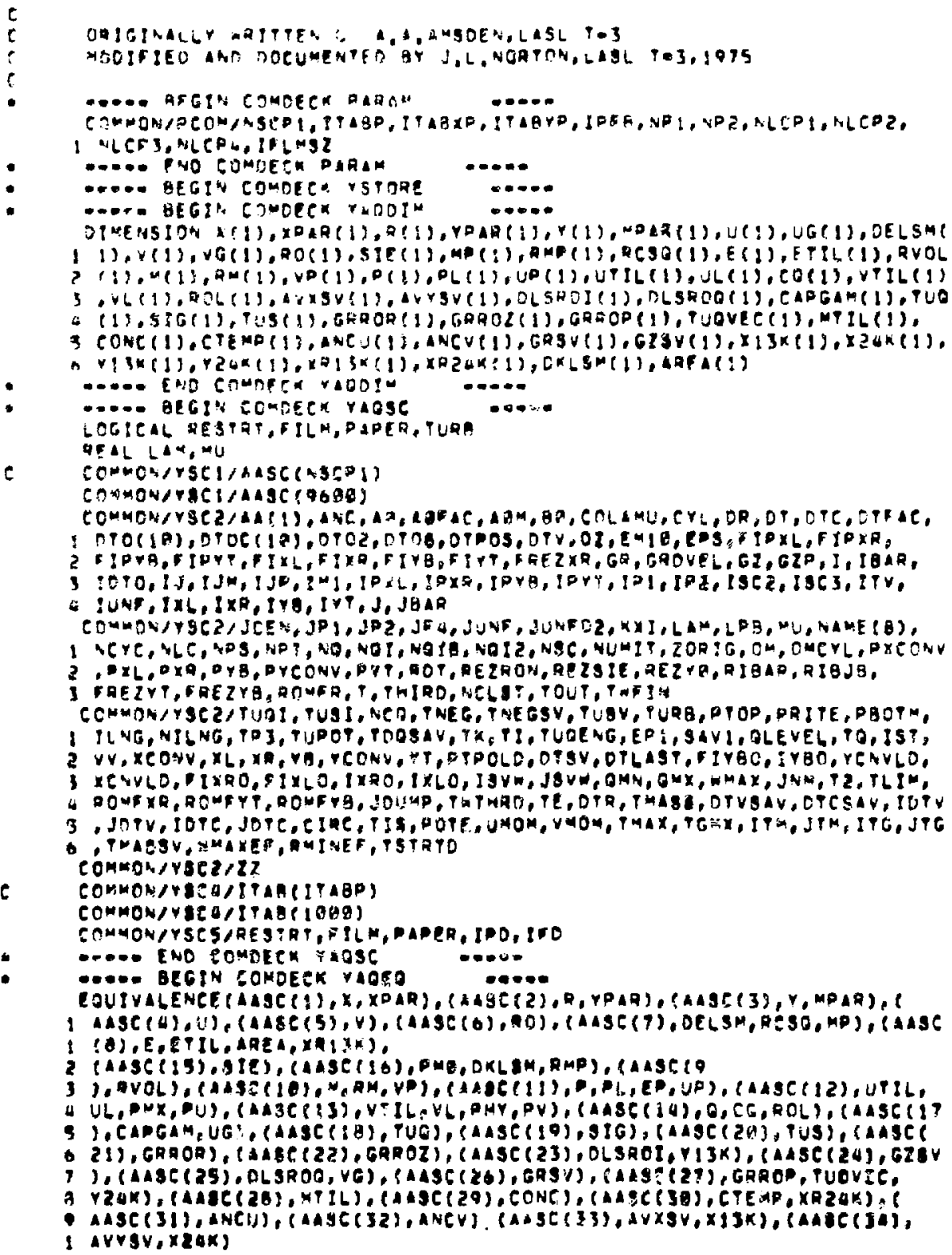




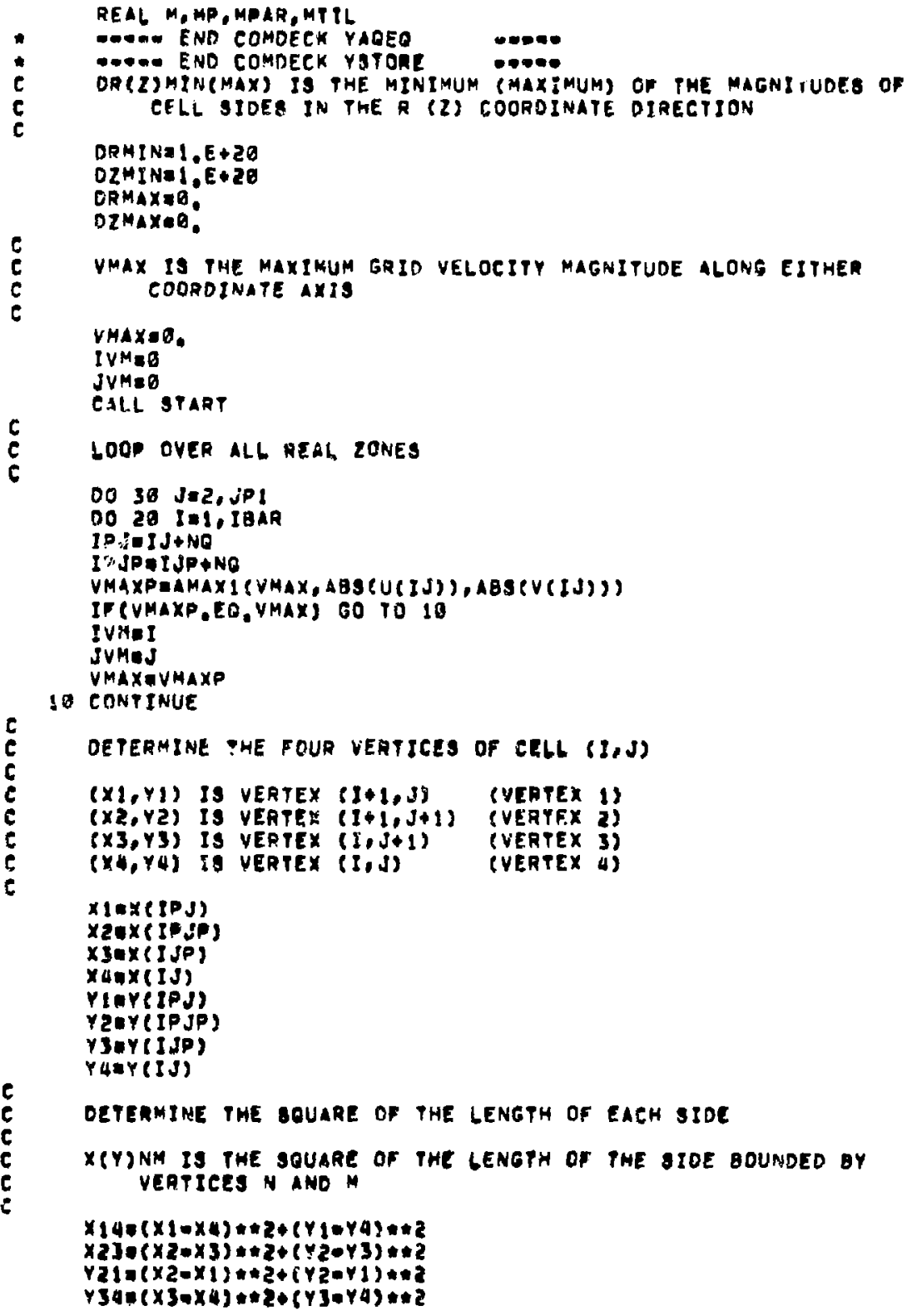


30 CONTINUE

DAMINaSERT (ORHIN)

DRMAXIERT Y (ORMAX)

DZMINESORT (DZHIN)

DZMAXESGRY (DZMAX)

RETURN

END

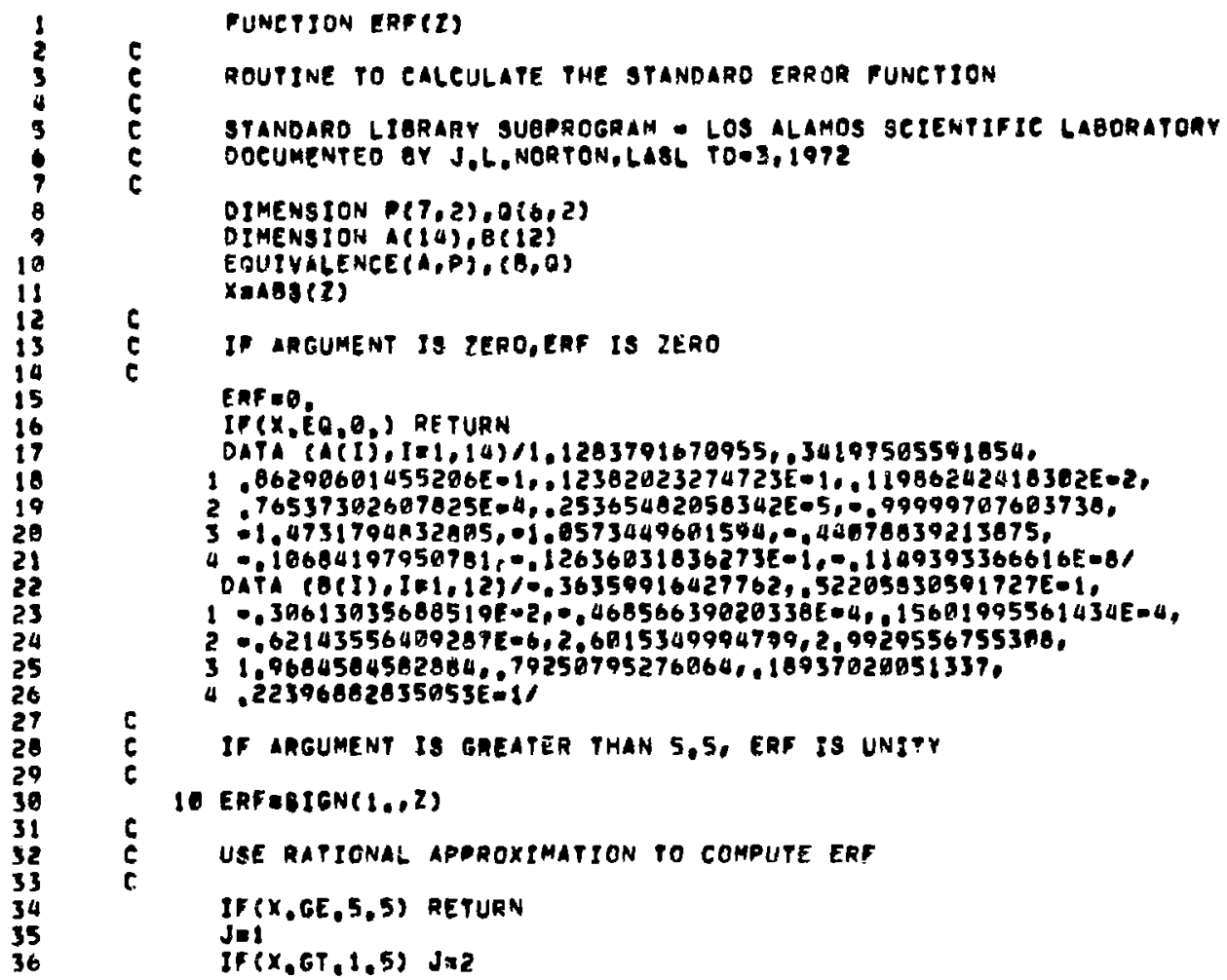




37
30
39
48
41
42
43
44
45
46
47
48
49

$5 \mathrm{je}=1$

$\operatorname{Dax} x \rightarrow(2-9)$

$\forall \rightarrow D \rightarrow x$

c

PWO SEPARATE RATIONAL APPROKIMATIONS ARE USED. BOTH HAVE GEEN DERIVED USIMG a PROGRAM BASED OH MAEHLYOS SECOND DIRECT METHOD DESCRIBED IN JOURNAL OF THE ACM, VOL, $10, N O .3$

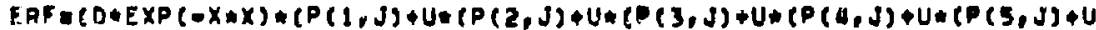

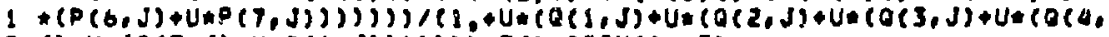

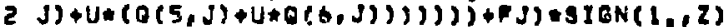
RETURN

END

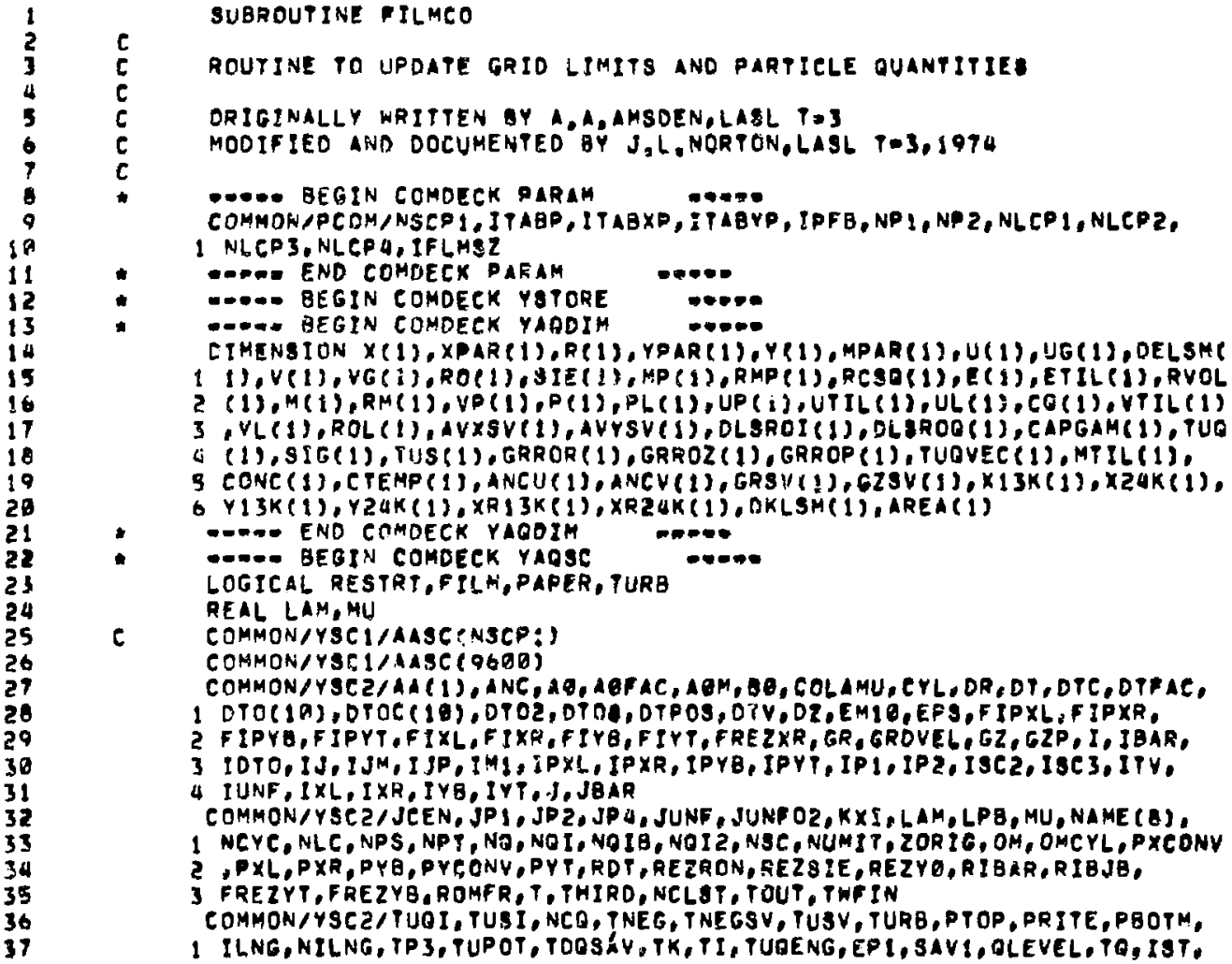


2 VV, XCONV, XL,XR, YD, YCONV, YT, PSPOLD, DTSV, DTLAST, FIYBO, IYBO, YCHVLO, 3 XCNVLD, IXAO, IXLO, IXAO, IXLO, ISVM, ISYM, AMM, OMX, NMAX, JNM, TZ, ILIM, 4 ROMF XR, ROMFY R, ROMFYB, JCUMP, PITHARD, TE, DTR, TMASS, DTVSAV, OTCSAY, IDTY 5 . JOTV. IOTC, JOTC, CIAC, II , POTE, UMOM, VMOM, PMAX, TGMX, ITM, JTH, ITG.JPG b TMASSV, WMAXEF, AMINEF, TSTATO COHMON/YSC $2 / 2 Z$

COMMON/YSC A/ITAB ITABP,

COMMON/YSCA/ITAB(IOOP)

COMMQN/YSC5/AE BTAR, FILM,PAPER, IPD, IFD

- OO- END COMDECK YAGSC

0.00

-MAOE BEGIN COMDECK YABEO

0000

EQUIVALEMCE (AASC (1), X, XPAR), (AASC (2),R, YPAR), (AASC (3), Y, MPAR), I

1 AASE $(A), U),(A A S C(5), V),(A A S C(6), R O),(A A S C(7), O E L O M, R C S O, M P),(A A S C$

1 (B),E,E:IL,AREA, XRI3K).

2 (AASE (15), gIE), (AABC (16), PME, OKLEM,RMP), (AASC

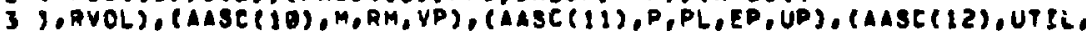

$₫ U L, P M X, P U),(A A S C(13), V P I L, V L, P M Y, P V),(A A E E P 14), 0, C O, R O L),(A A S C G 17$

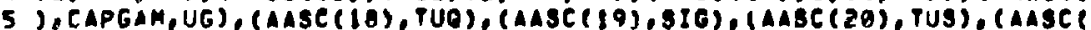

6. 21 ), GRAOR), (AASC (22), GRROZ), (AASC (23), OLSROI, YI3K), (AABC (24), G2SV

$T$ ), (AASC (2S), DLSROQ, VG), (AASC (26), GRSV), (AASC (2T), GRROP, TUAVEC,

B $Y 24 K),(A A S C(28), M P I L),(A A S C(29)$, CONC), (AAgC (3B), CTEMP, XR2AK),

9 ASC (31), $\triangle N C U),(A \triangle B C(32), A N C V),(\triangle A S C(33), A V X S V, X 13 K),(A \triangle S C(34)$,

1 AVYSV,X2\&K)

REAL M, MP, MPAR, MTIL

- - OO END COMDECK YAQ

- OD- END COMDECK YBTORE

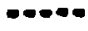

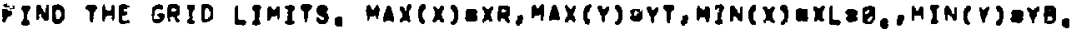

$X L 0.0$

$Y B=1, E+20$

XREYTERY

CALL START

DO 20 JE⿰, JPE

DO 18 Iอ1,IPI

XREAMAXI $(X R, X(1))$

YBNAMINI $(Y G, Y(I J))$

reTEMAXISti, Y(IJ)

10 IJUIJ+NO

call loOP

20 CONTINUE

VV IS USEO IN SCALINE Veloeity VECTOR PLOTS. VV $=$ Qtmax(x)/IBGA

VVฯด, OAXR・RIBAR

FIYB IS THE LOCATION OF HINCY) IN RASTER COUNTA

FIVB=916.0

XD IS THE RATIO OF GAIO WIOTH TO HEIGHT

XDEXR/(YTEYB)

ONE WISHES TO MAKE THE PLOTS FILL THE FILM FRAME AS NEARLY AS POSSIBLE AT MOST THE PLOT CAN BE IBZ2 RASTER POTNTS HLOE ANO 900 RASTER POINTS TALL (LEAVING RODM FOR LABELS AT PHE BOTPOH 


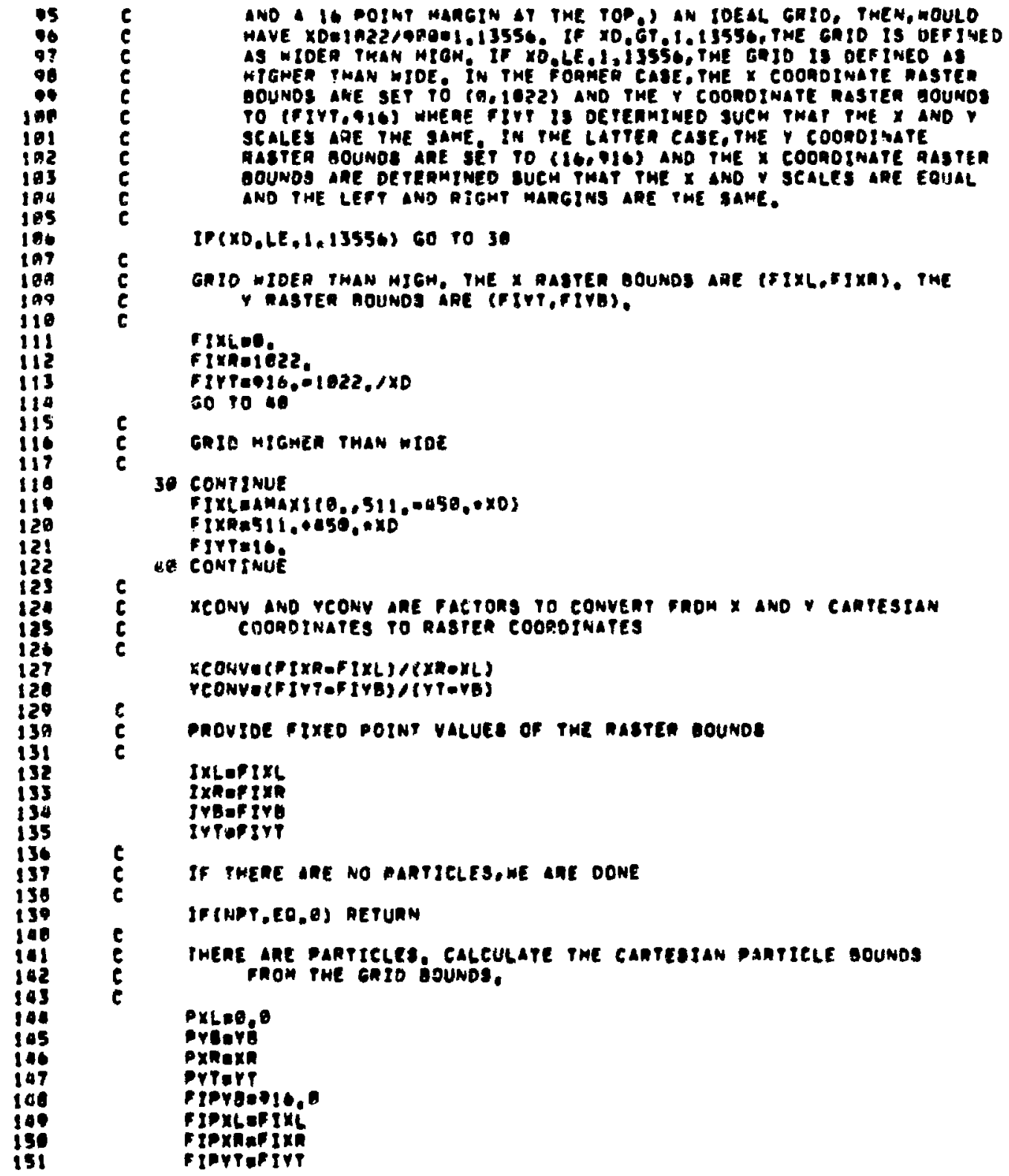




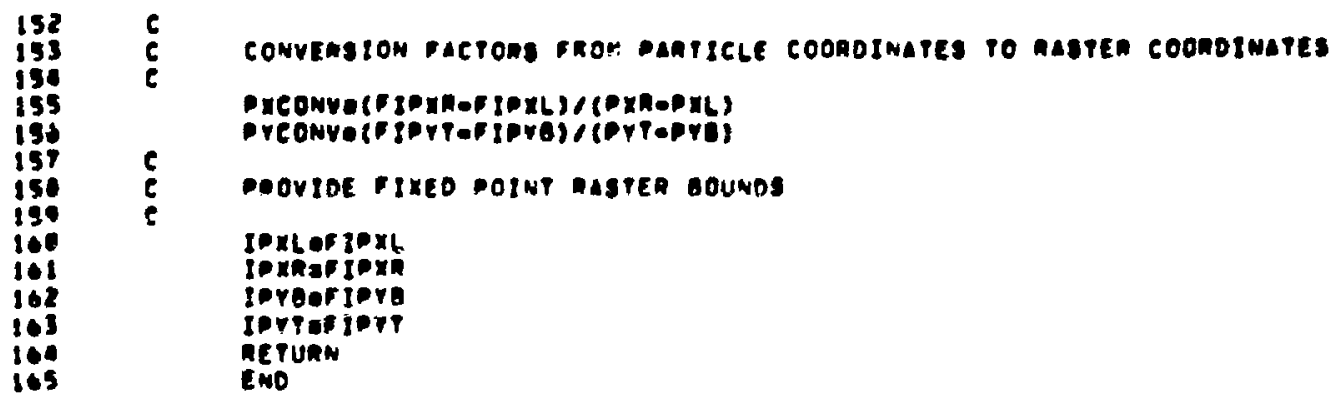




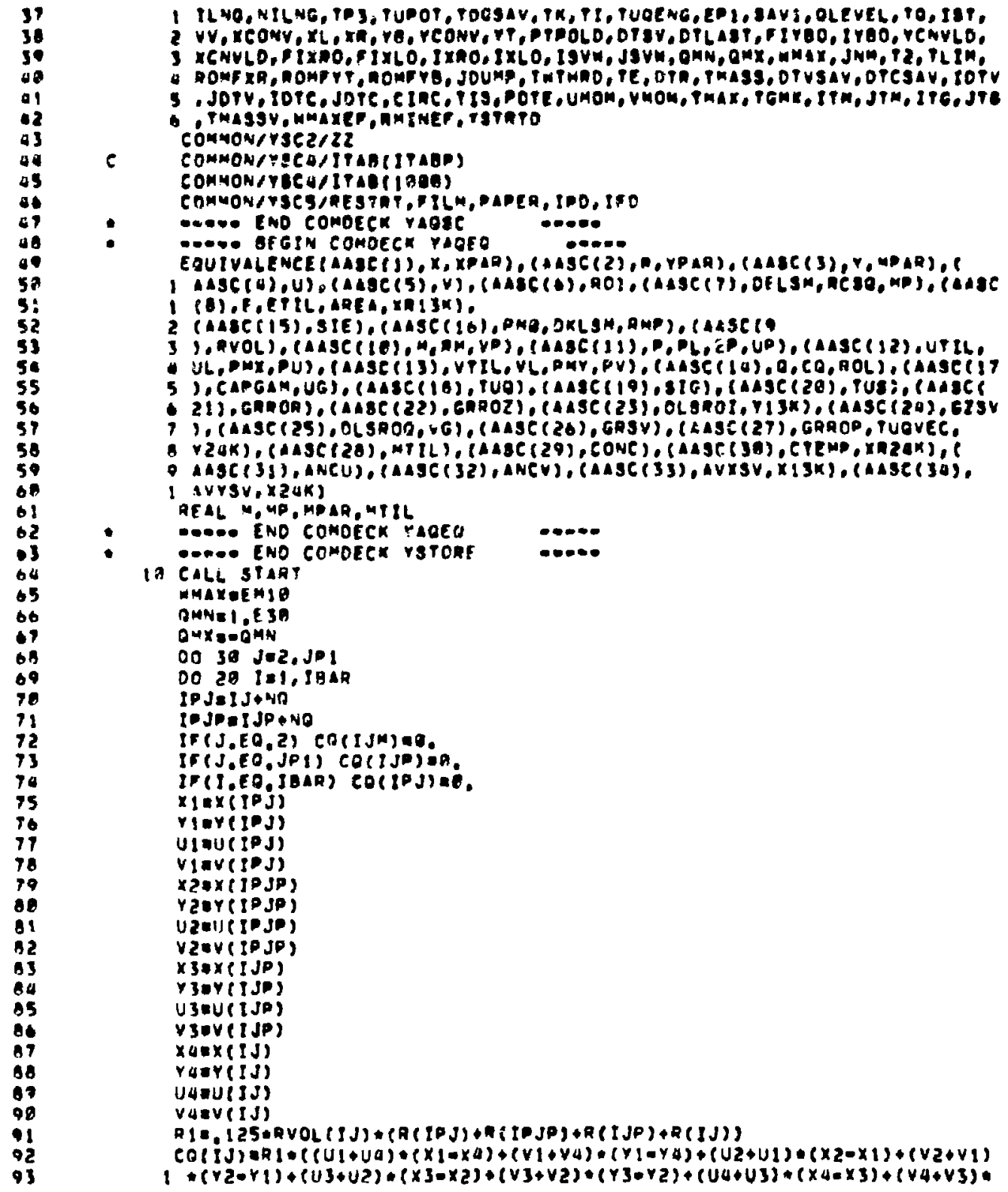




\begin{tabular}{|c|c|c|}
\hline $\begin{array}{l}90 \\
95 \\
10 \\
97 \\
98 \\
99 \\
108 \\
101 \\
102 \\
103 \\
104 \\
105 \\
104 \\
109 \\
100\end{array}$ & $\begin{array}{l}20 \\
39\end{array}$ & 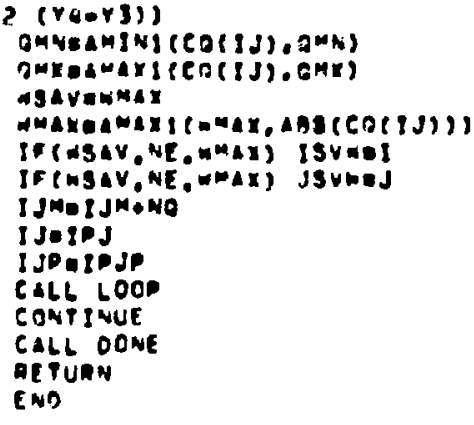 \\
\hline
\end{tabular}

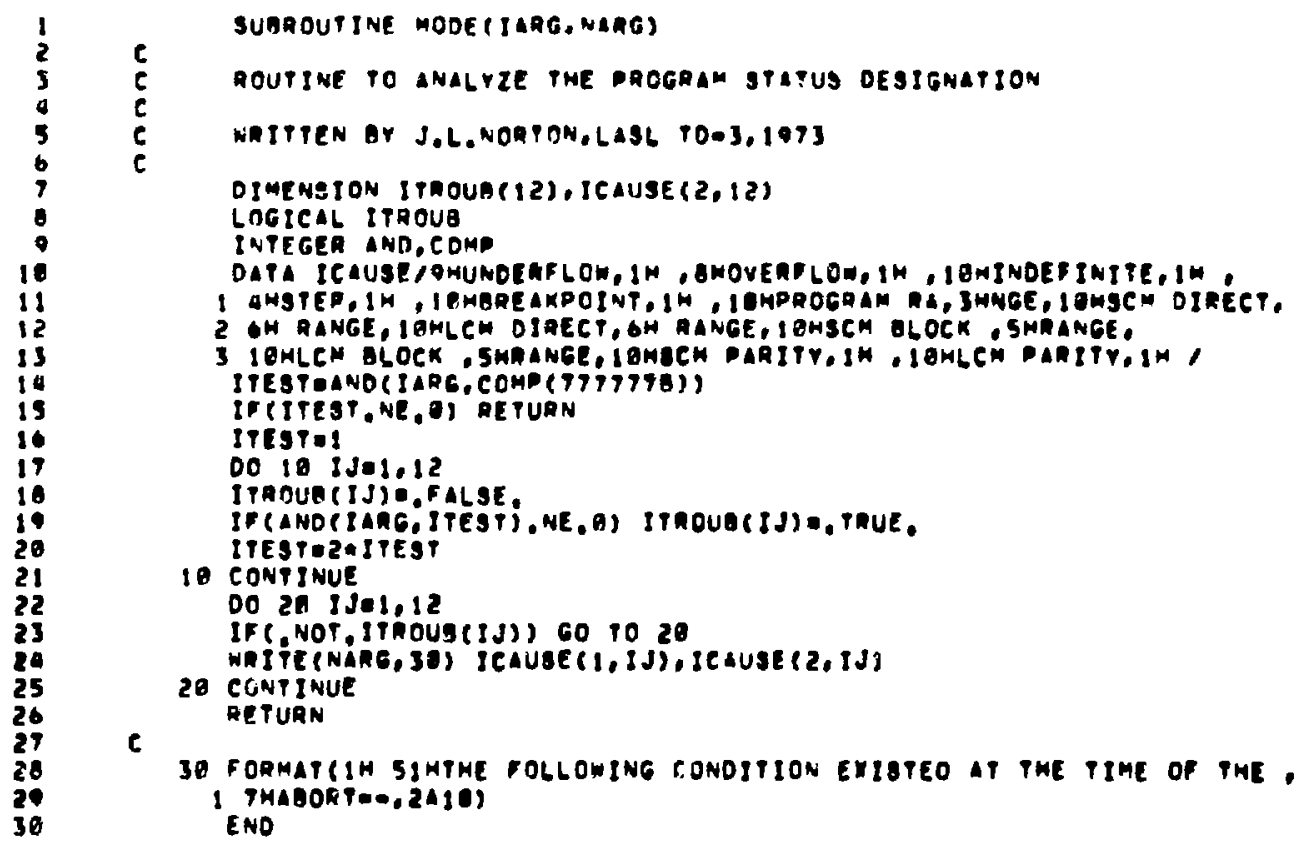




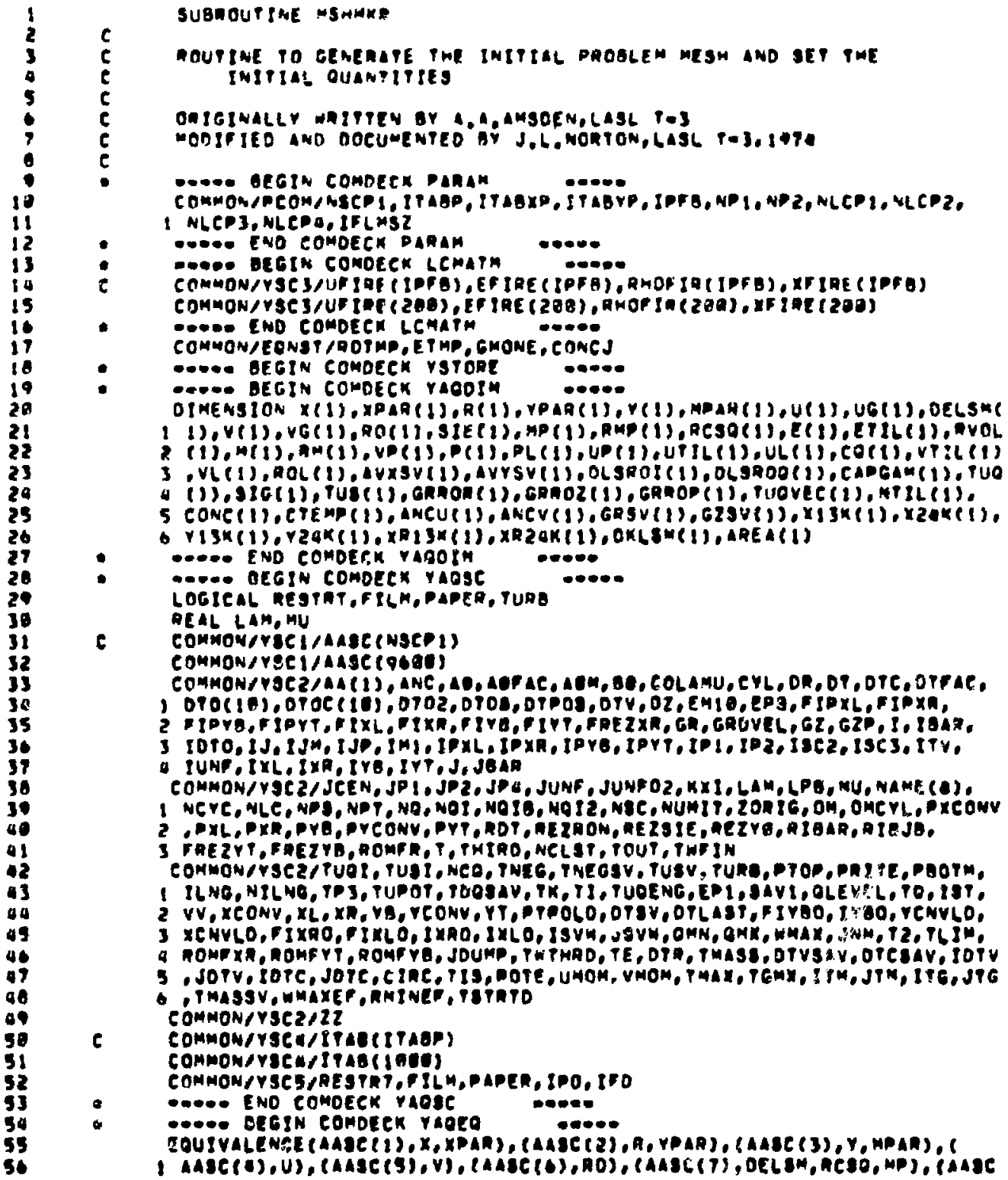




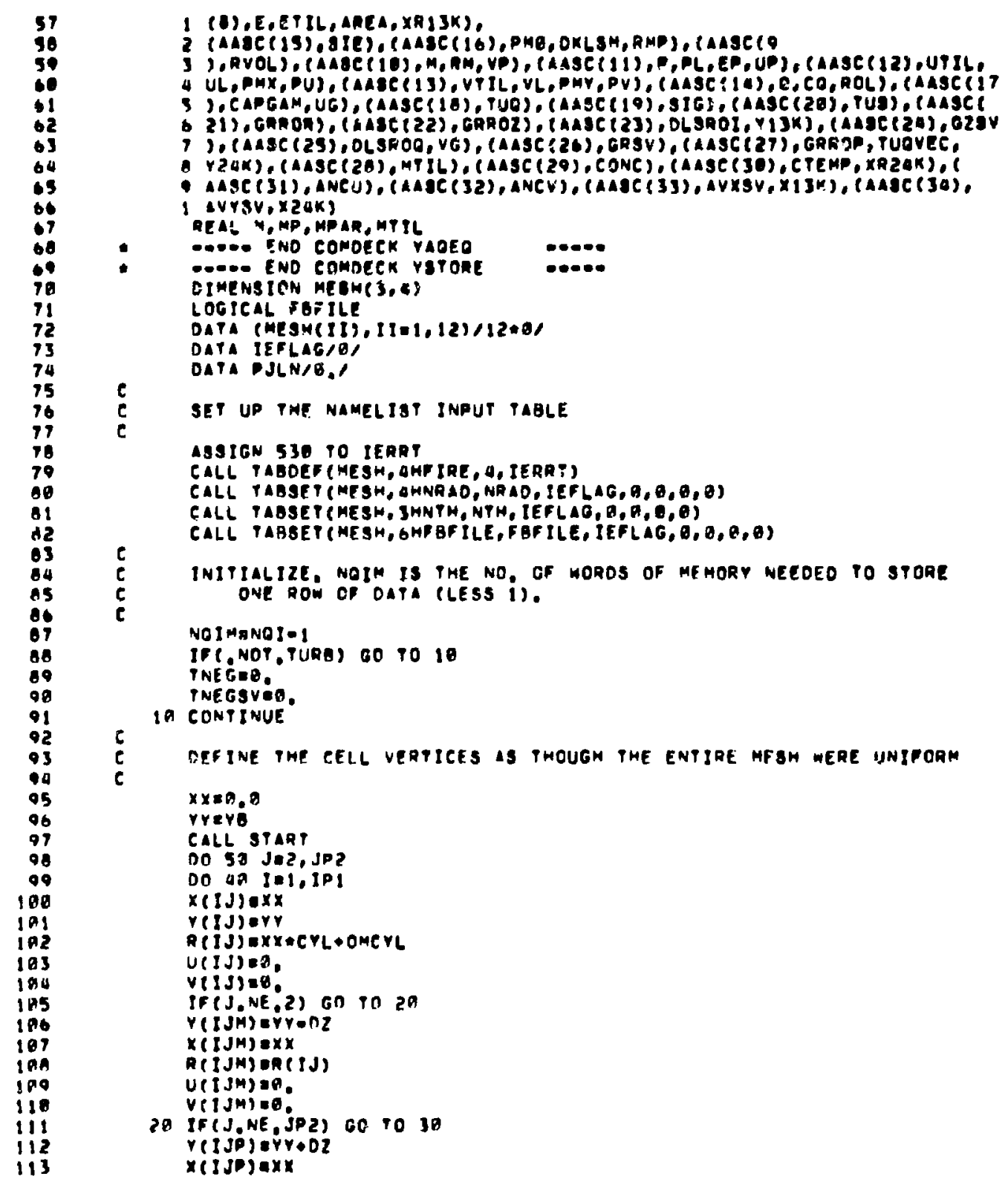




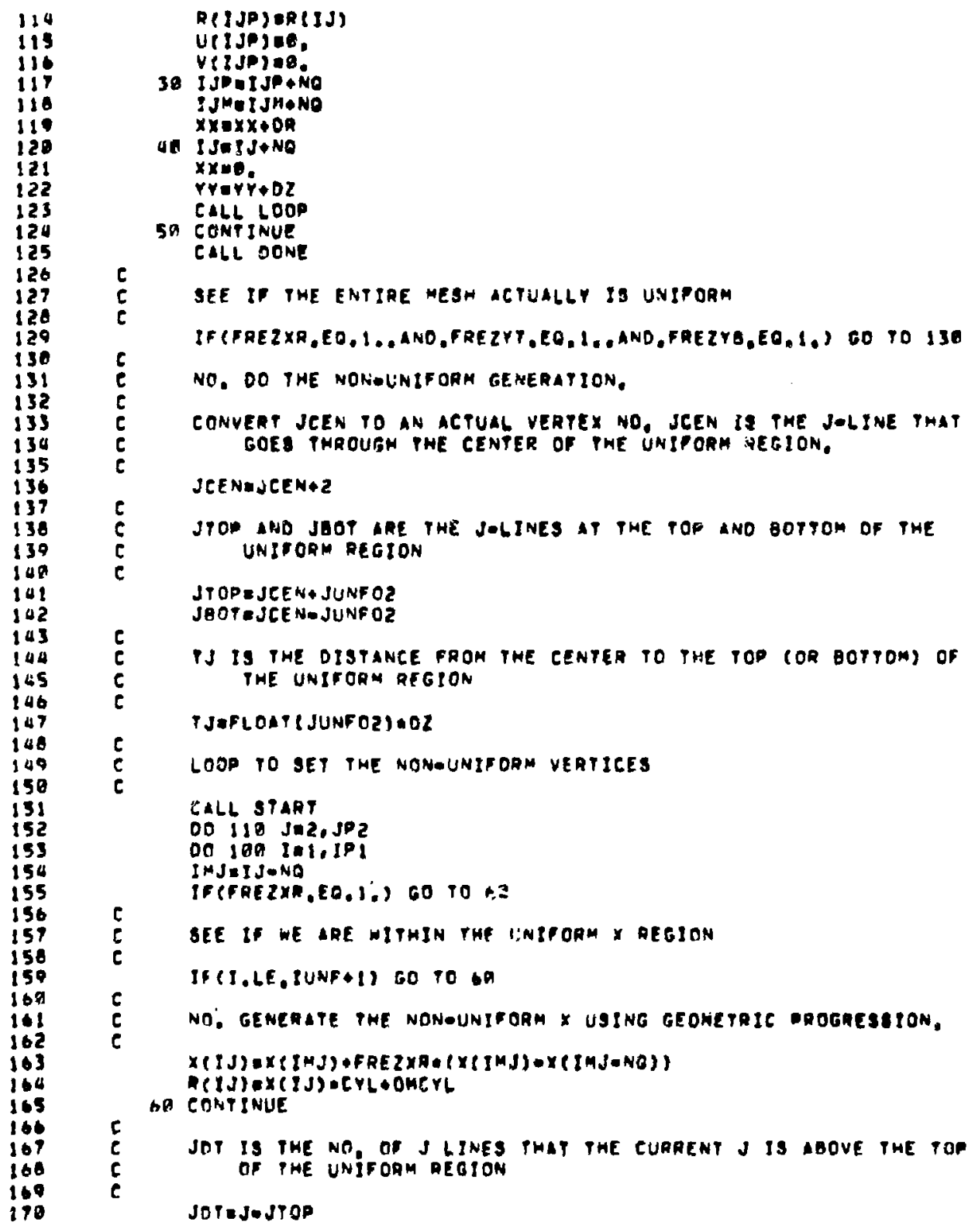




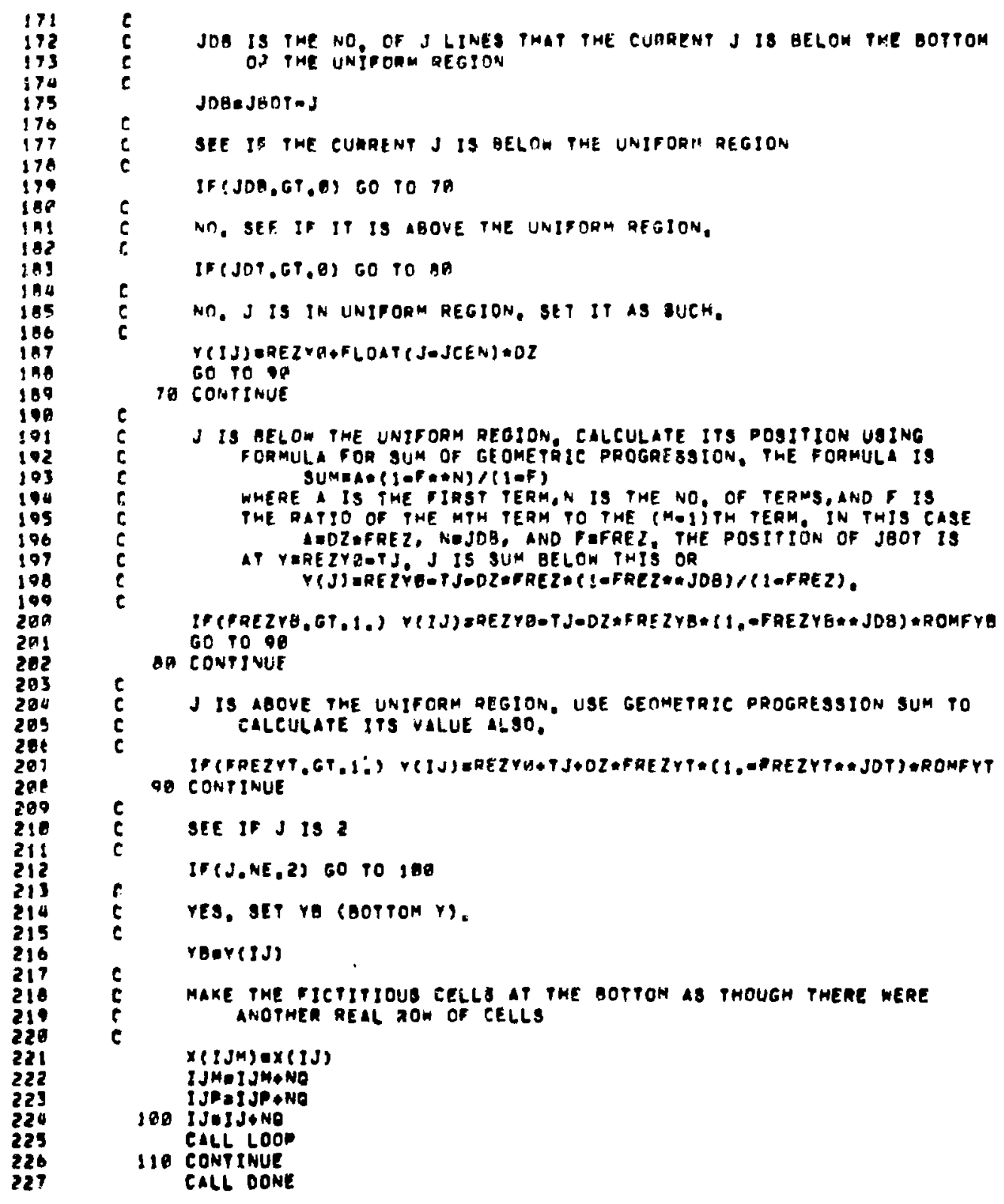




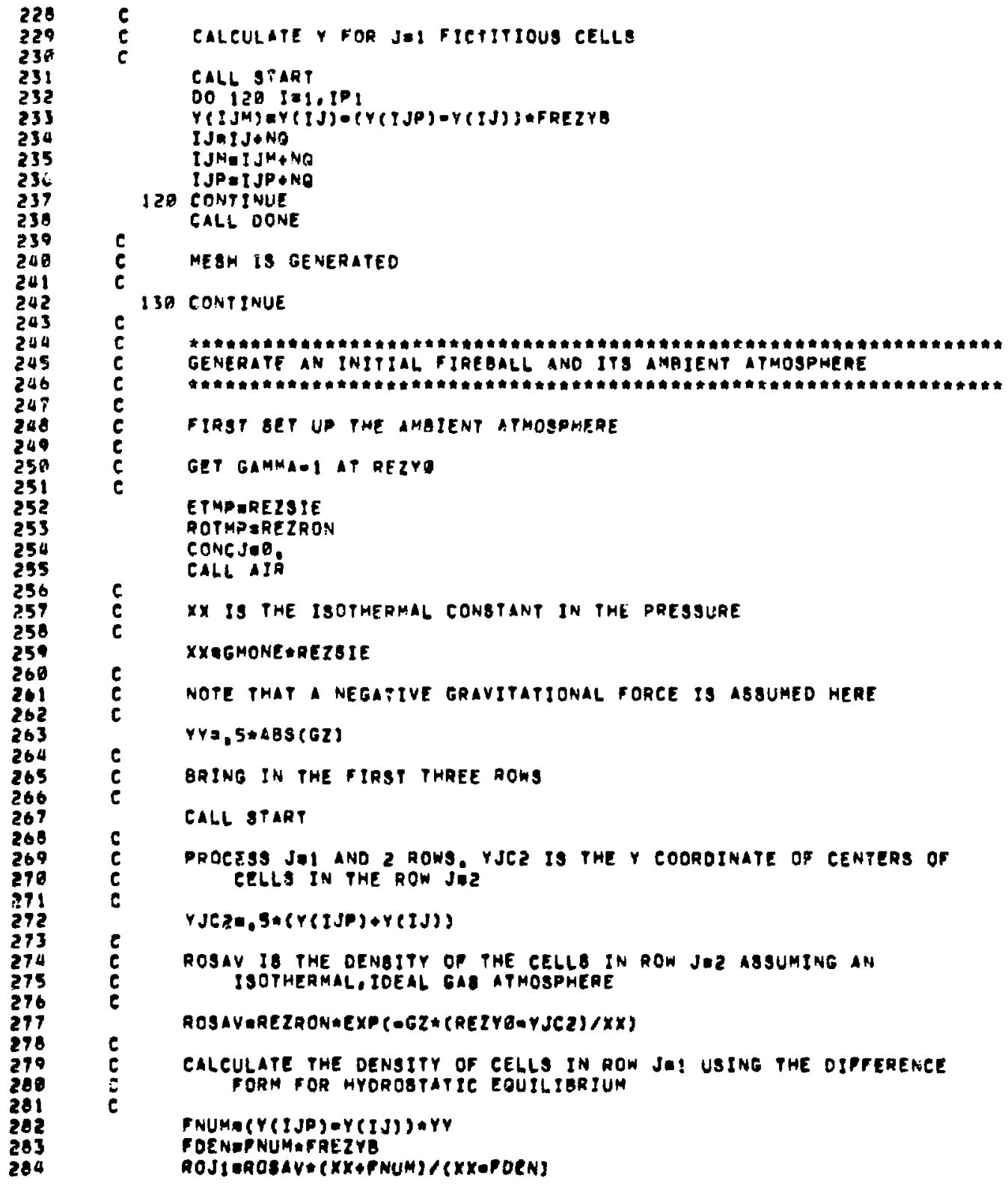




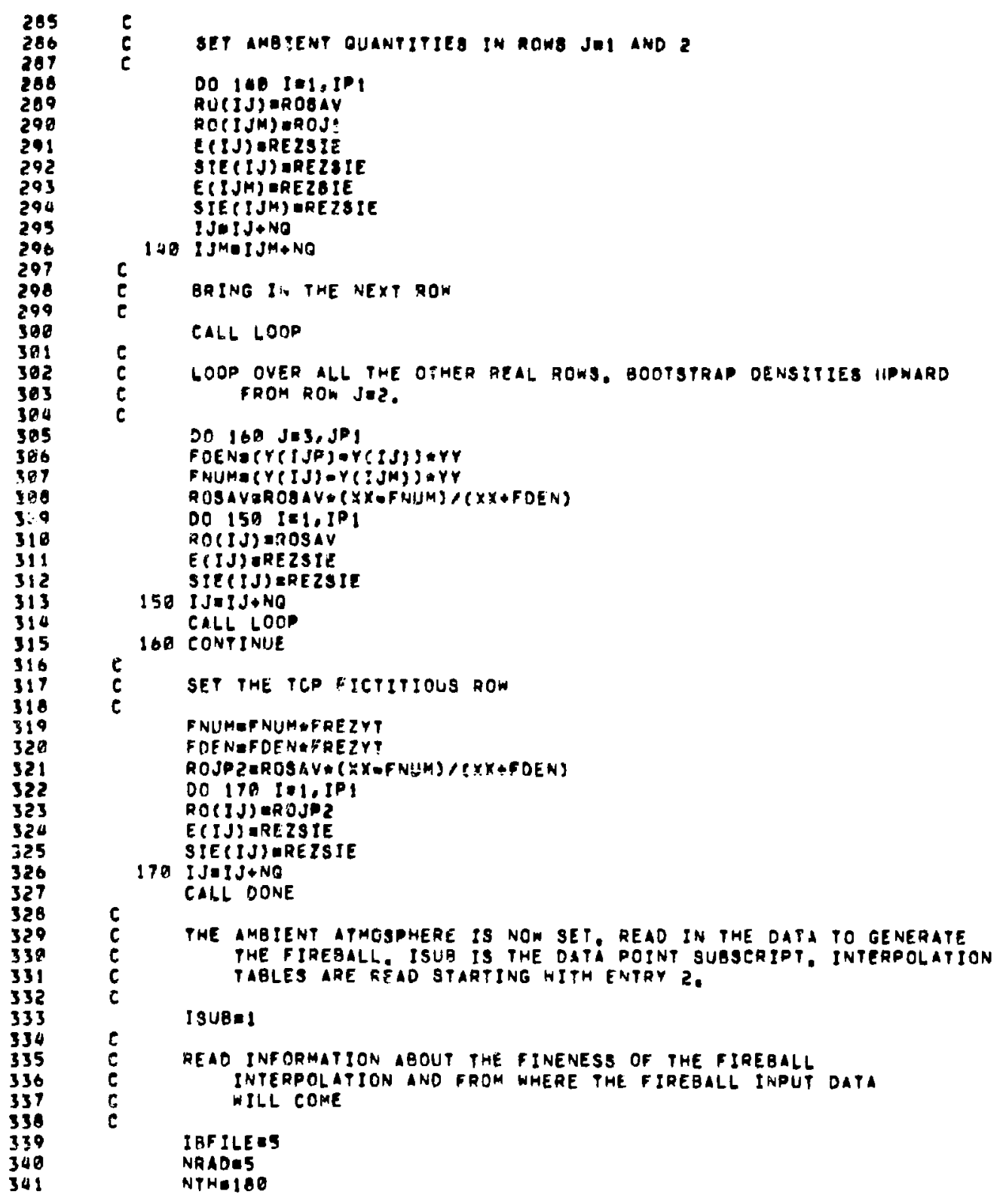




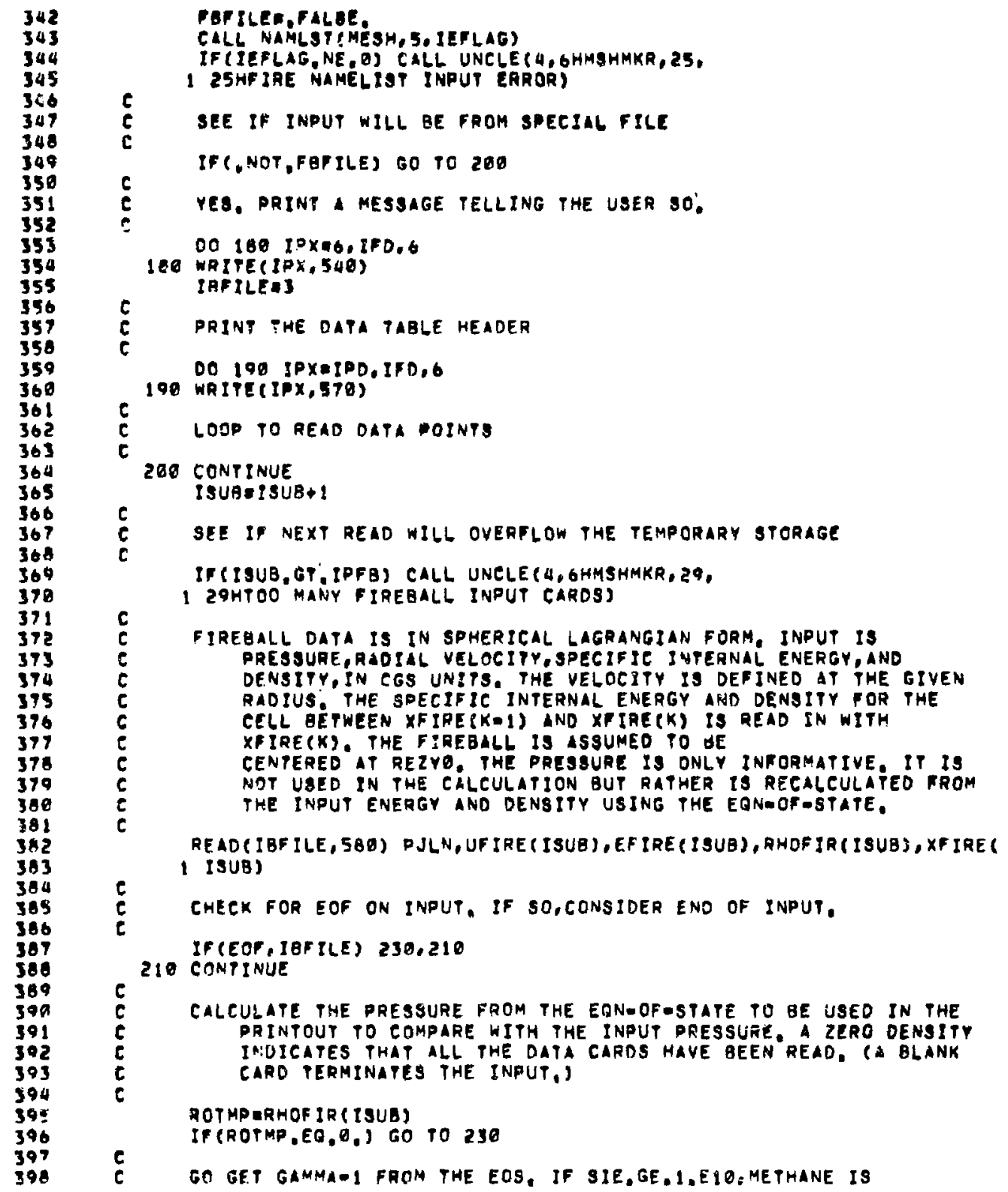




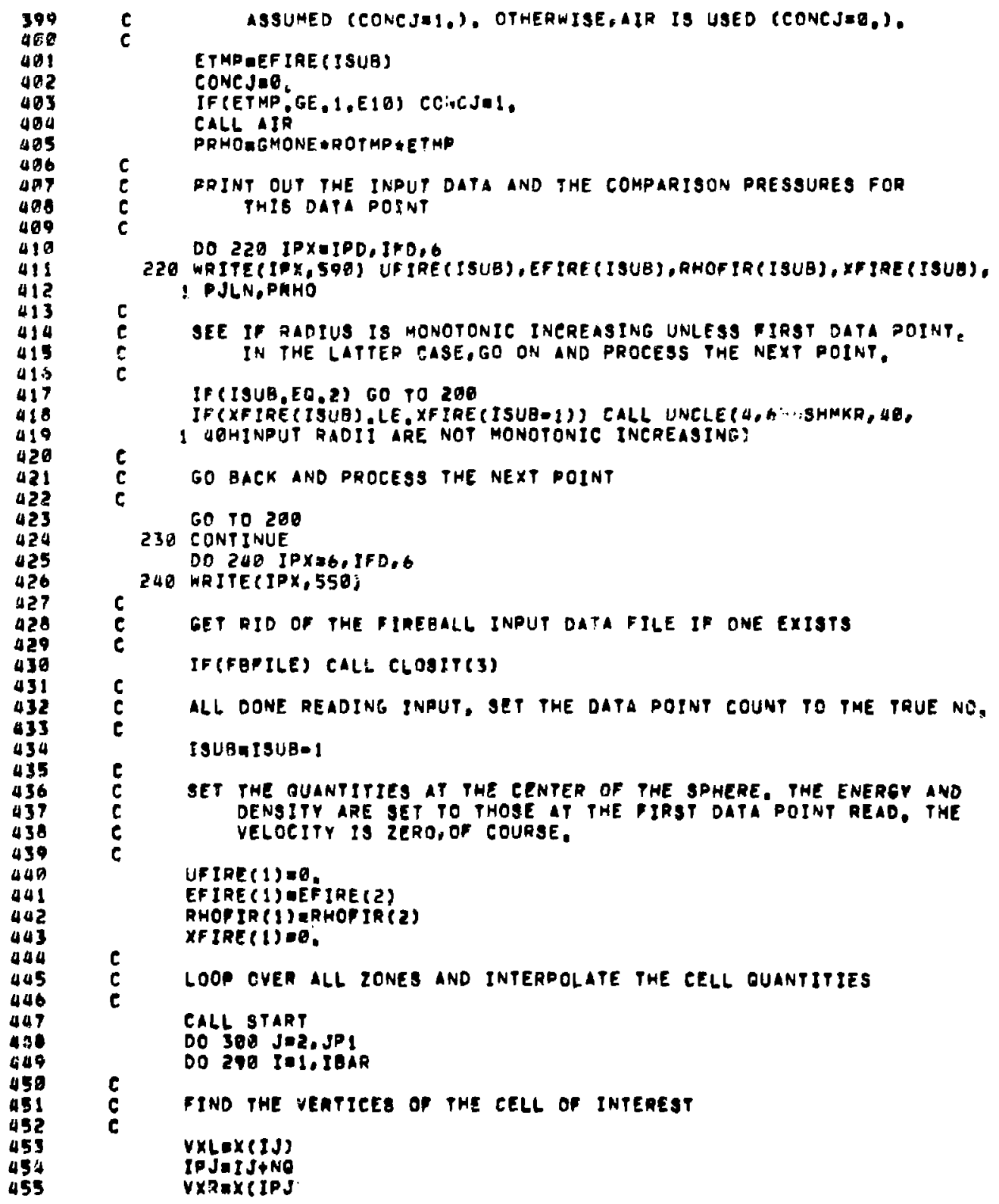




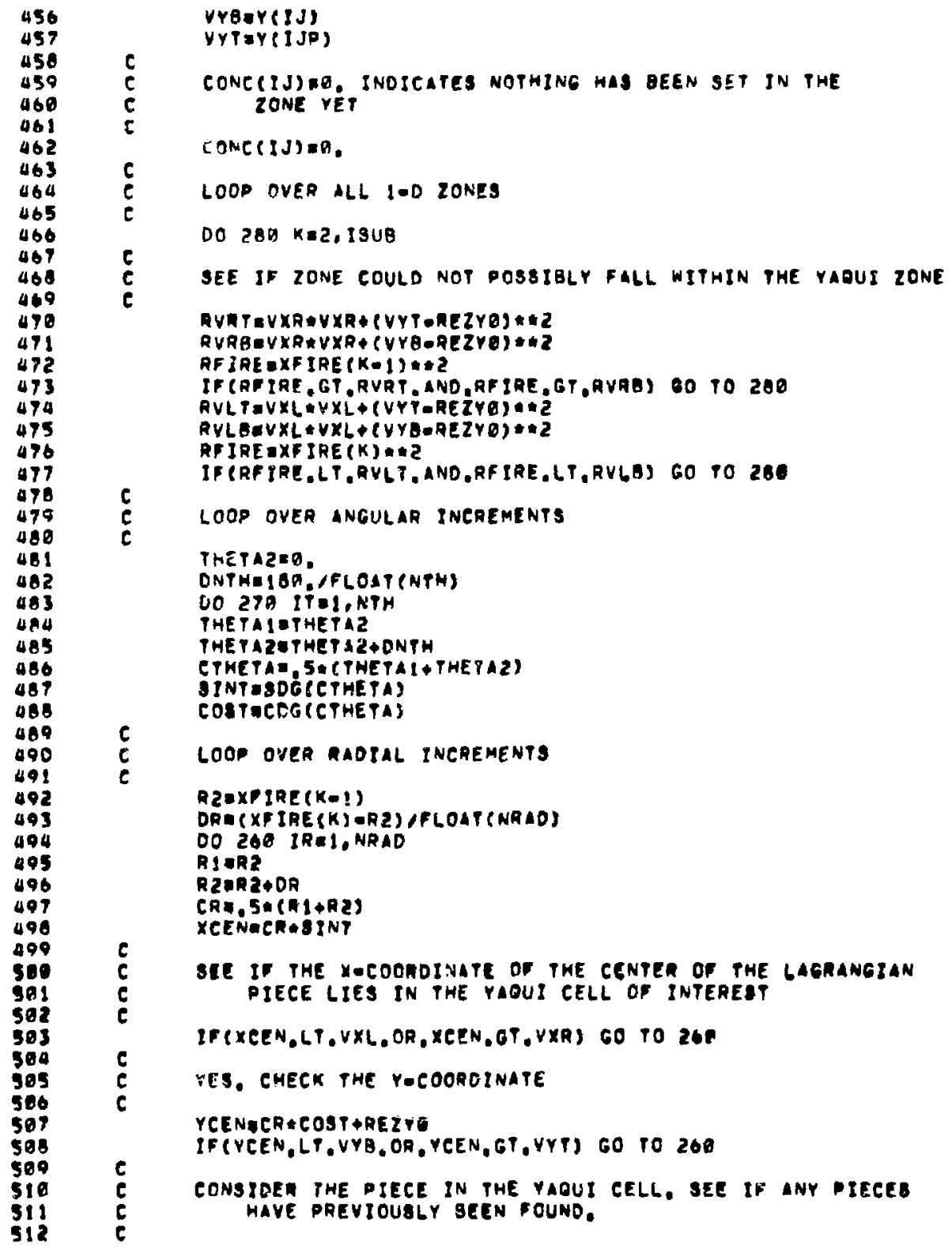




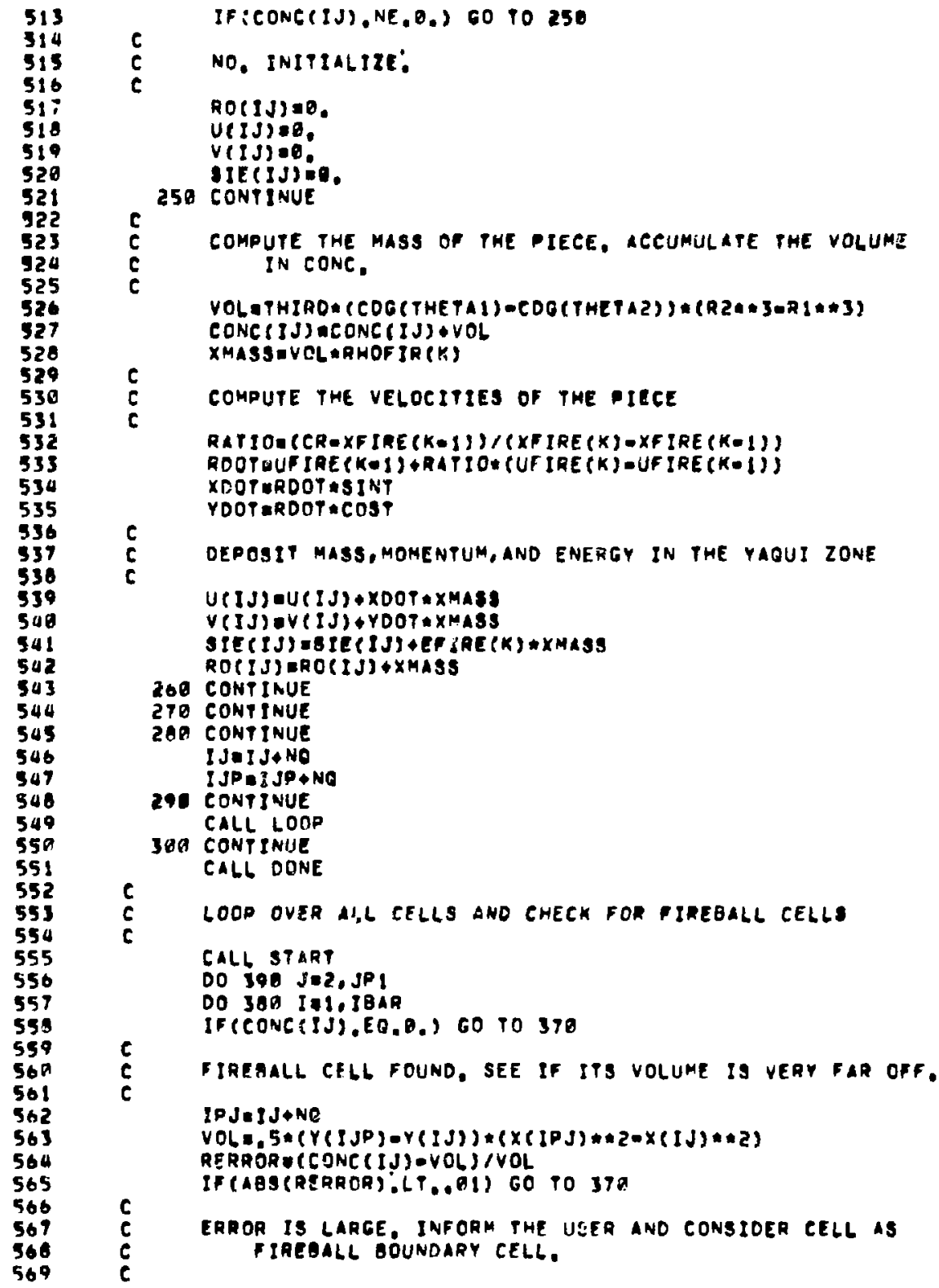




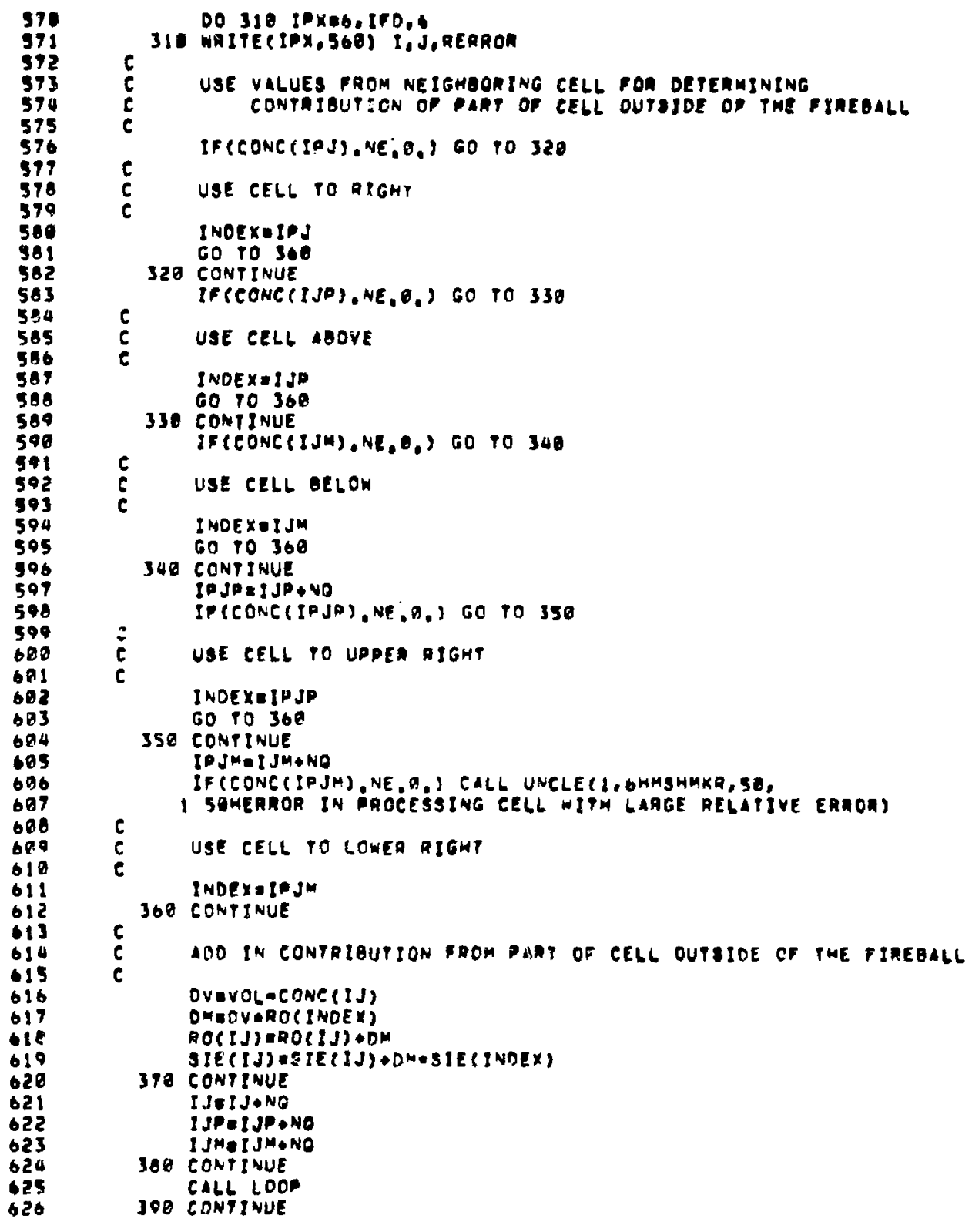




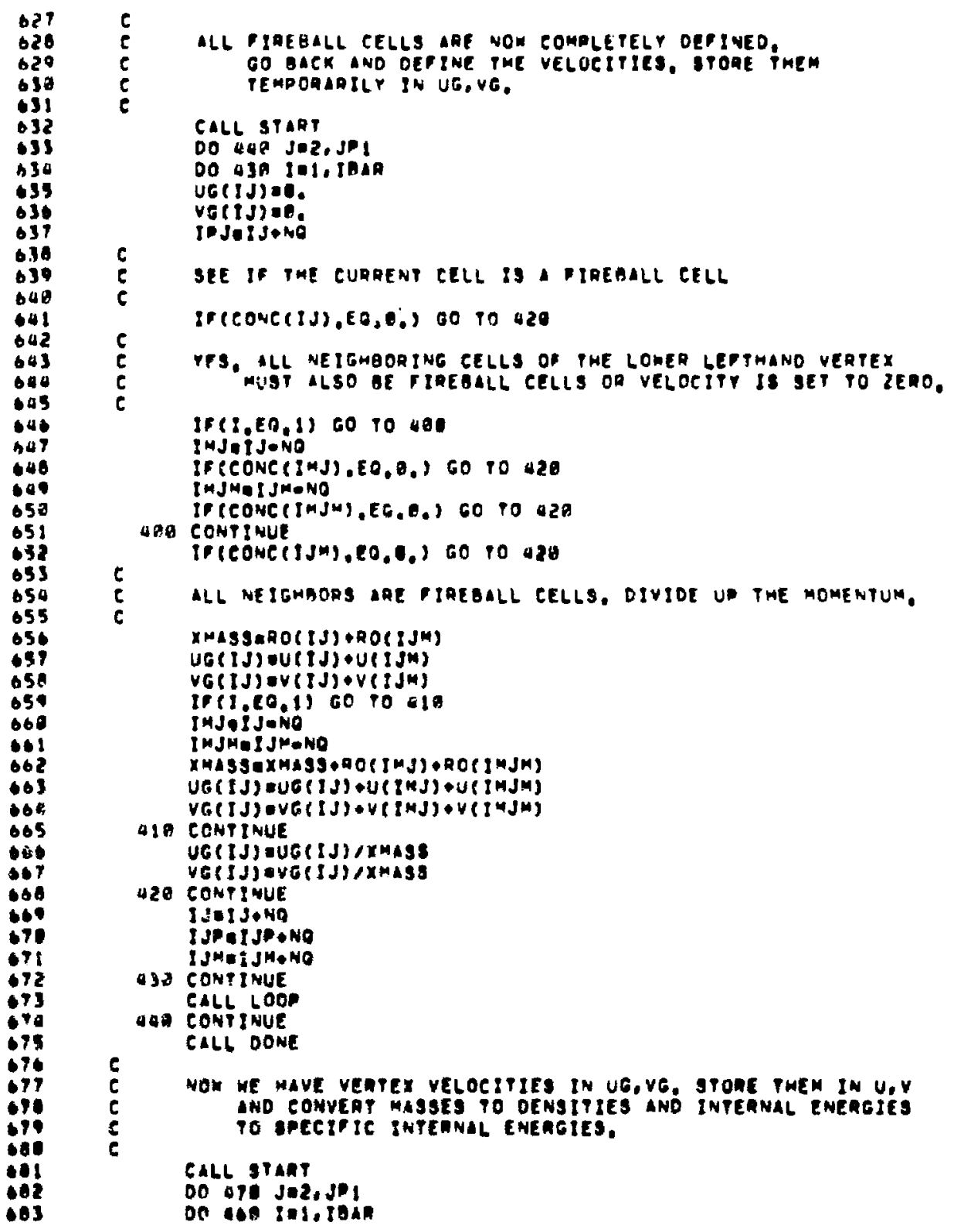




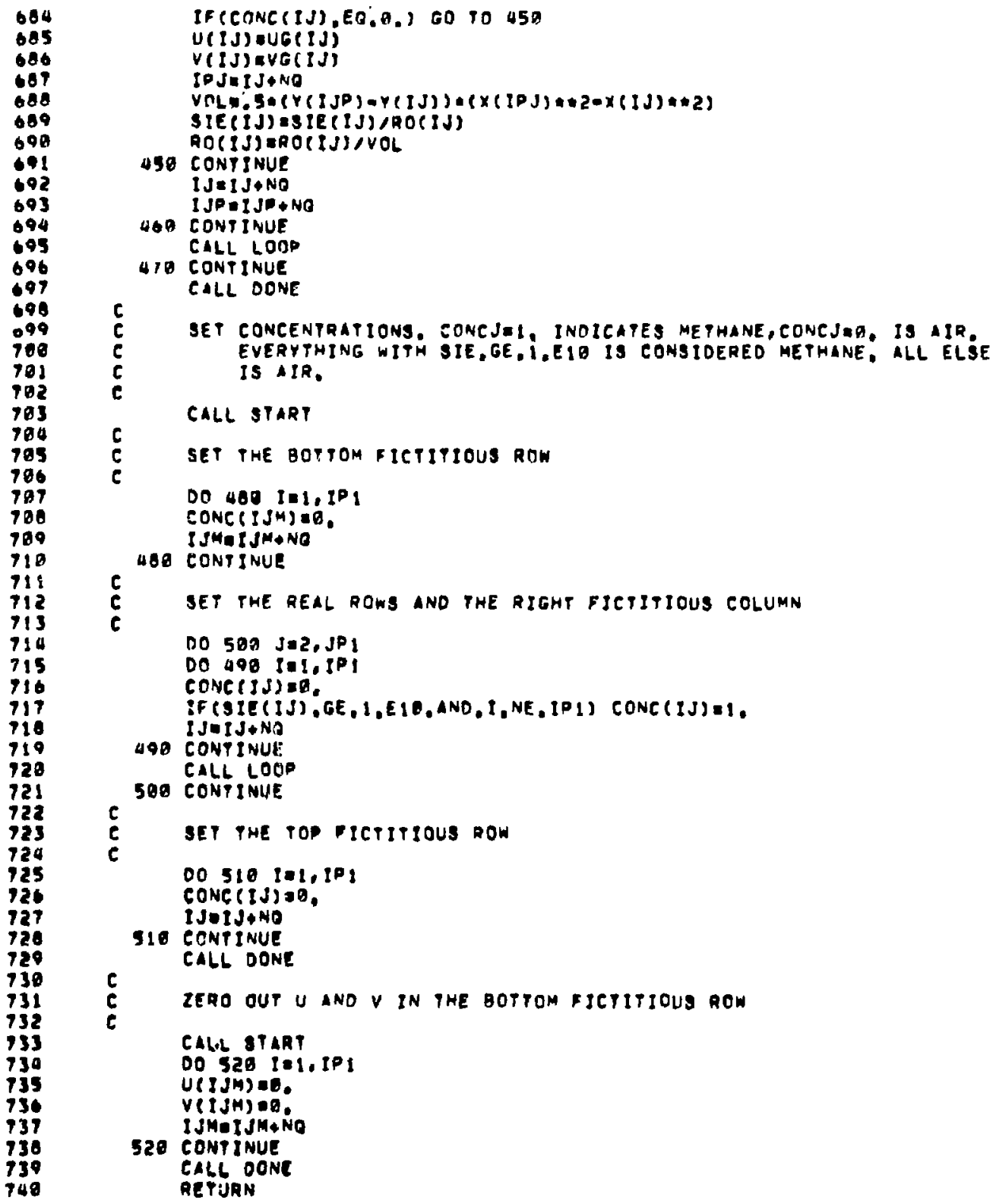




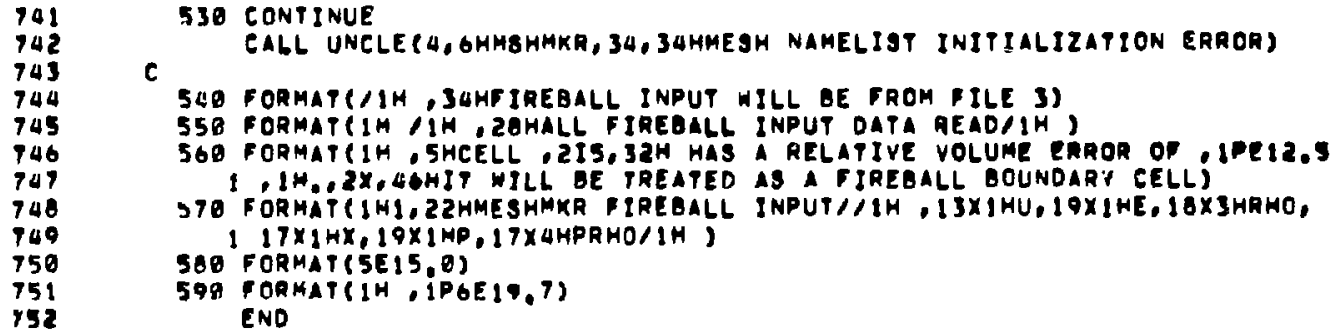

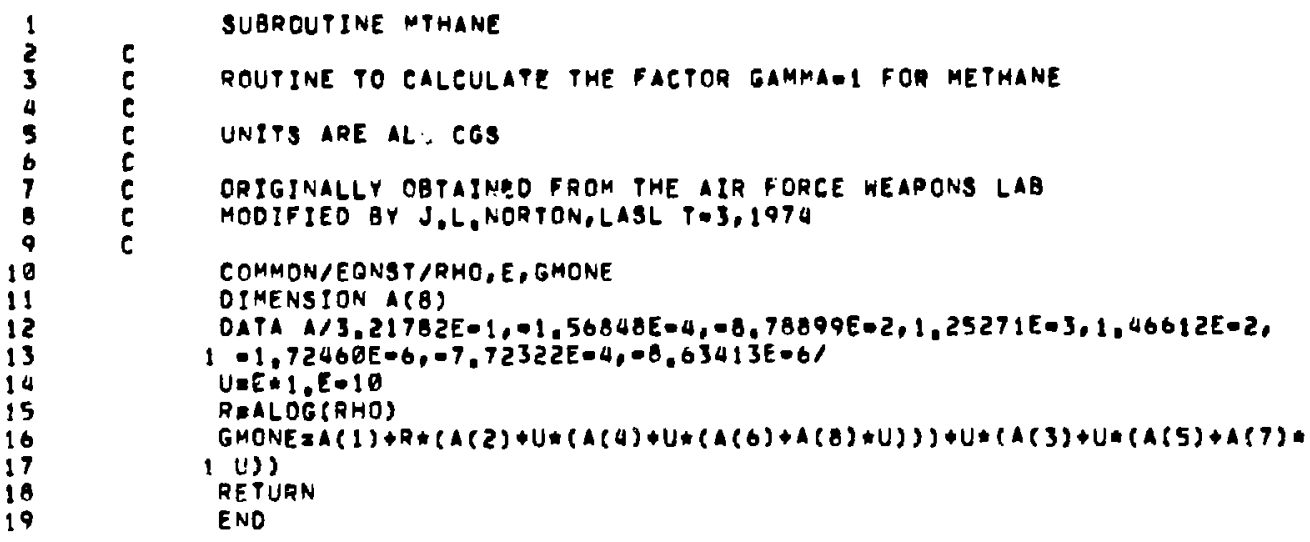

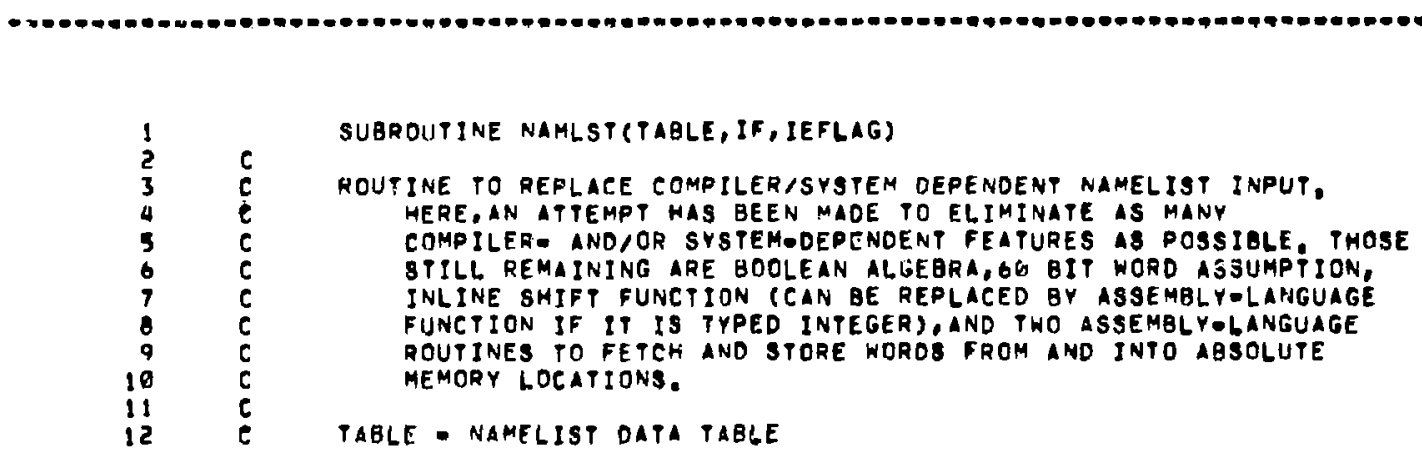




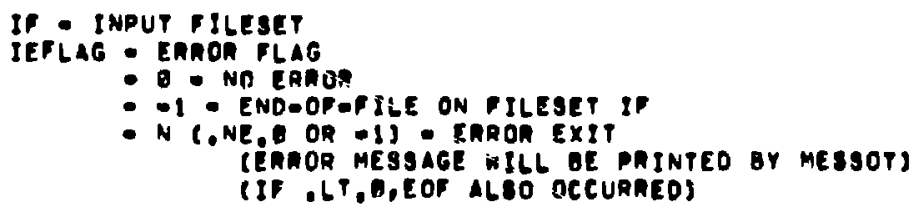

LIHITATIONg - CUARENTLY, ONLY SMALL CORE VARIABLES MAY BE READ. ARRAYS OF UP YO FOUR SUBACRIPTS CAN DE INPUT ALTHOUGM MANY COMPILERS CAN HANDLE A MAXIMUM OF ONLY THREE SUBSCRIPTB.

INPUT RULE - DATA MAY BE INPUT IN ANY OF THREe GenEALL FORMS $\operatorname{VaDl}$ $A D D 1,02, \ldots, 0 N$

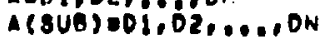

WHERE $\checkmark$ IS A NONESUASCRIPTEO VARIABLE. A IS AN ARAGY. SUB REPAESENTS FROM I TO 4 SUBSCRIPTS (INTEGER CONSPANT) AND DN REPRESENTS A OATA ELEMENT.

THE OATA ELEMENTE MAY DE OF A NUMBER OF TYOES -

INPEGEA BASE 10 (EXAMPLE, 13569 )

DEAL $D I X E 0(13.25)$

- FloATIng (3,265E29)

COMPLEX $-(-13,59,3,14 E-7)$

OOUBLE J.141592653589793238460J

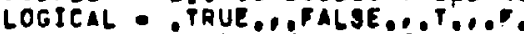

MOLLERIYH - LEFTOJUSPIFIED, BLANKAFILL (SHTHING)

- LEFT-justiFiED, zERO-HILl (3LOUT)

- RIGHTOJUSTIFIED, ZEROEFILL (4AWORD)

MULTIPLIERS ARE ALLOWEO, BUT ONLY FOR ONE ELEMENT AT A TIME. FOR EXAMPLE,5*23,6*15,3,21*27, 3E7,5*4HTEST ARE ALL LEGAL OA $(13,21.7)$ WOULO WORK, BUT ONLY BECAUSE THE QUANTITY INSIDE THE PARENTHESES IS INTERPRETED AS A SINGLE COMPLEX CONSTANT. $22 \bullet(1,2,3,4,5,6)$ WOULO BE FLAGGED AS IN ERROR. SE IJHABCOEFGHIJKLM IS ALSO ILLEGAL AS THE CONSTANT IS MOAE THAN ONE WORO LONG.

INTEGERS WITH MORE THAN IL DIGITS AND REAL CONSTANTS OF MORE THAN 14 DIEITS NOT INDICATEO AS DOUDLE PRECISION ARE ILLEGAL. FOA EXAMPLE,PI=3.1415926515897932 IS WRDNG BUT PI=3.1415926535897932D Is O.K.

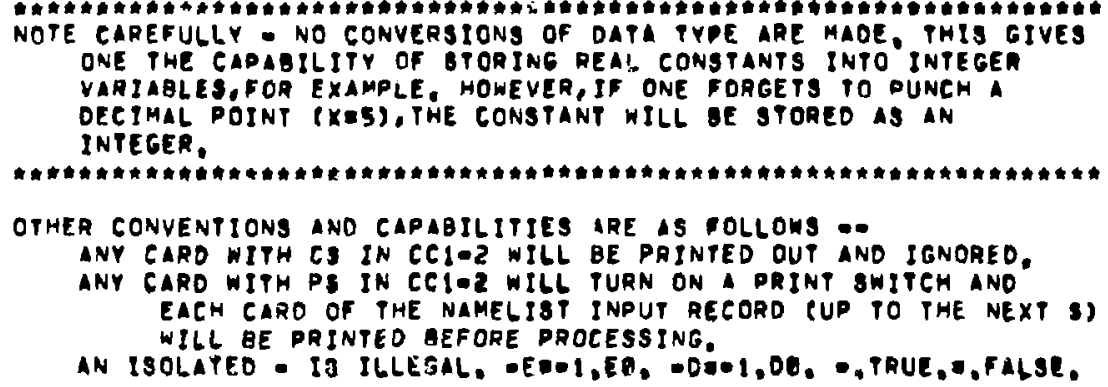


AND - FALSE, PRUE, OBEOAB, MINUS SIGN IN FRONT OF AH OCTAL CONSTANT CAUSES THE CONSPANT TO BE COMPLEMENTED. a INUS SIGN IN FRONT OF A MOLLERITH CONSPANT IS IGNOAED. AN R NOLLERIPH CONGTANP CANNOP BE MOGE TMAN IO CHARACTERS LONG.

THE TERMINATION MUST NOT OCCUR IN CCI DO 2 , IF IT OCCUAS IN CCI.IT AILL DE IGNORED. AN ERAOR WILL BE RETURNEO IF If IS IN CC2.

a namelist Pecoro may be of any length blanMs ane signifieant ANO MAY OCCUA ONLY AROUNO NONONUMERIC CMARACPERS OTMER THAN EXPONENTS, FOR EXAMPLE,LEGAL BLANKS ARE $X$ E..

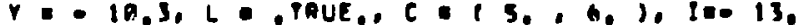

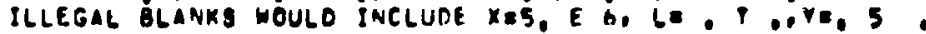
PME NAMELIET AECORO IS TAEATEO AS ONE LONG STRING OF

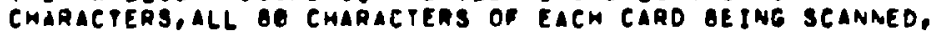
EXCEPY PHAT CCZ OF EACH CARD MAY NOT DE a 3 LALESS IT IS PAGT OF A MOLLEAITH FIELO.

RECAUSE OF THE UNLIMITEO LENGTH OF A NAMELIST AECORD, HOLLERTH CONBTANT MAY UE OF UNLIMIPED LENGTH.

BECAUSE PYPE IS NOP CMECKED, STORING A DOUBLE CONSTANT INTO A SINGLE-PRECISION VARIABLE WILL CLOBBER PHE FOLLONING LOCATION, $C X=5.0$ WILL STORE a ZEMO INTO THE LOCATION FOLLOHINE $x$ ASSUMgNG IS NOP DOUELE OR COMPLEX). SIMILAR WARNING CAN OE GIVEN FOR $x=(1, \ldots 2,1$.

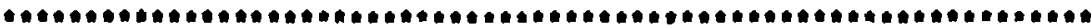
EXAMPLE OF ISACE

SUPPOSE ONE NISHED TO REPLACE THE STATEMENTS

DIMENSION A(2A), B(5,3), X(5,19, 15)

NAMELIST,CARON $I, J, K, A, B, X$

READ (5, CARON)

WITH SYSTEMOINDEPENDENY INPUT FUATHERMORE, SUPPOSE ONE WISHEO TO HAVE PS AND CS CAROS COME OUT ON DOTM PAPER ANO FILM AND ERAOR MESSAGES COME OUT ON FILE SQ, THEN ONE WOULO NEEO TME FOLLOWING -

OIMENSION $1(20), B(5,3), \times(5,19,15), 1$ TAB(2), TABLE(3, 1$)$

SET UP FILE TABLE POR MESSAGES

DAYA ITAB/BLOUT, GLFILM/, JPAB/59/

CALL NAMPRT (2, ITAB)

CALL ERRPRT $(1, J$ JAB)

DEF?NE THE NAMELISY TABLE IF THERE ARE TO BE N UNTOUE INPUT VARIABLE NAMES, THEN BO(NOI) TABLE LOCATIONS AHE NEEOED. TMUS, FOR SIX VARIAGLE, 307 LOCATIONB MUET BE SEP ASIOE. THE THIRO ARGUMENT IS THE SECOND SUASCRIPT OP TABLE, IF ANY ERRORS OCCUR IN SUBSEQUENT CALLS PO TABSET. TRANGFEA WLL OCCUR TO THE SPAPEMENT NO ASSIGNED PO IERRT. PHIS ELIMINATES ERROR CHECKING AFTER EACH CALL TO TABSET, IEFLAG CAN PMEN DE EXAMINED TO OEPERMINE WHAT TYPE OF EGROA oCCURACO. 


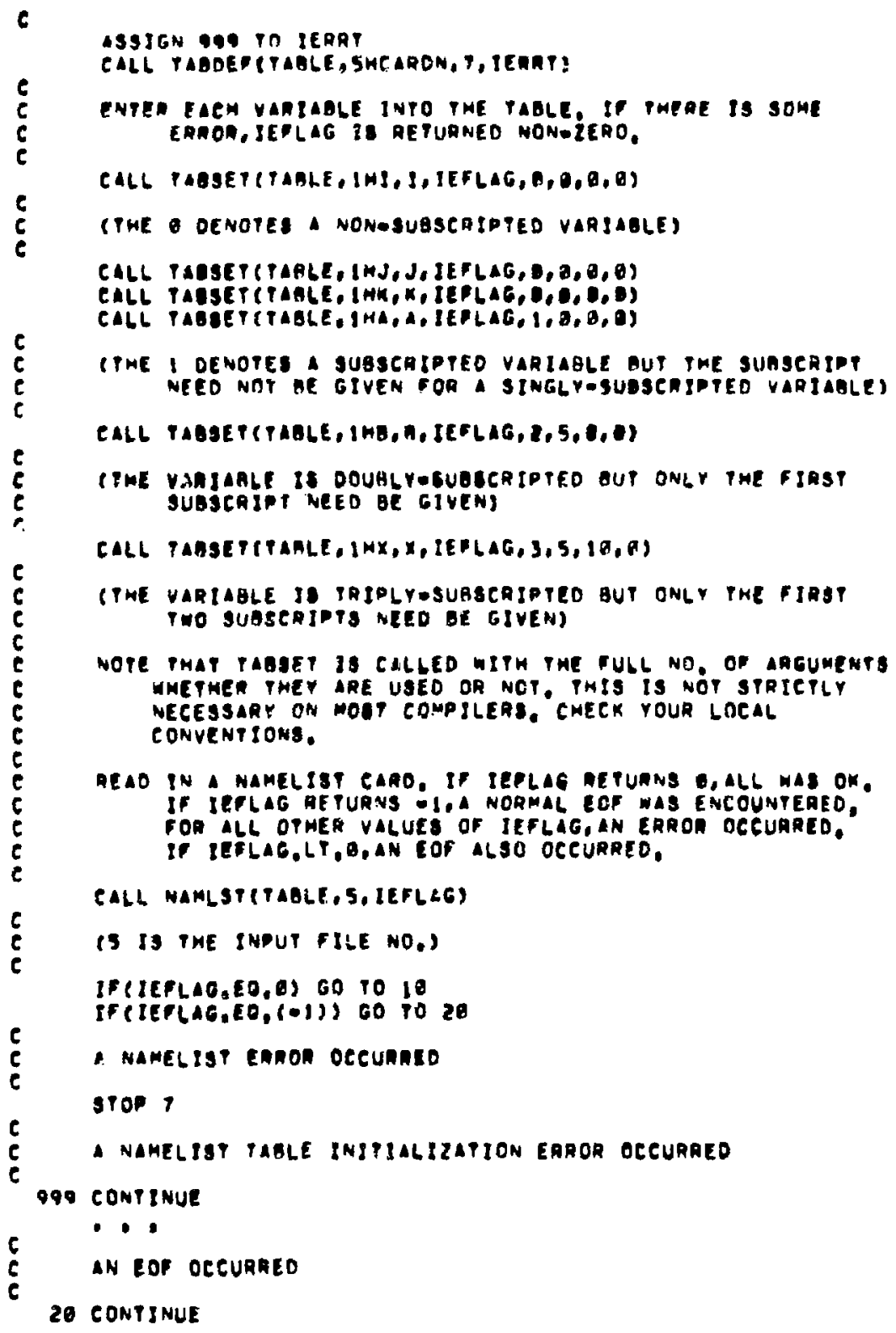




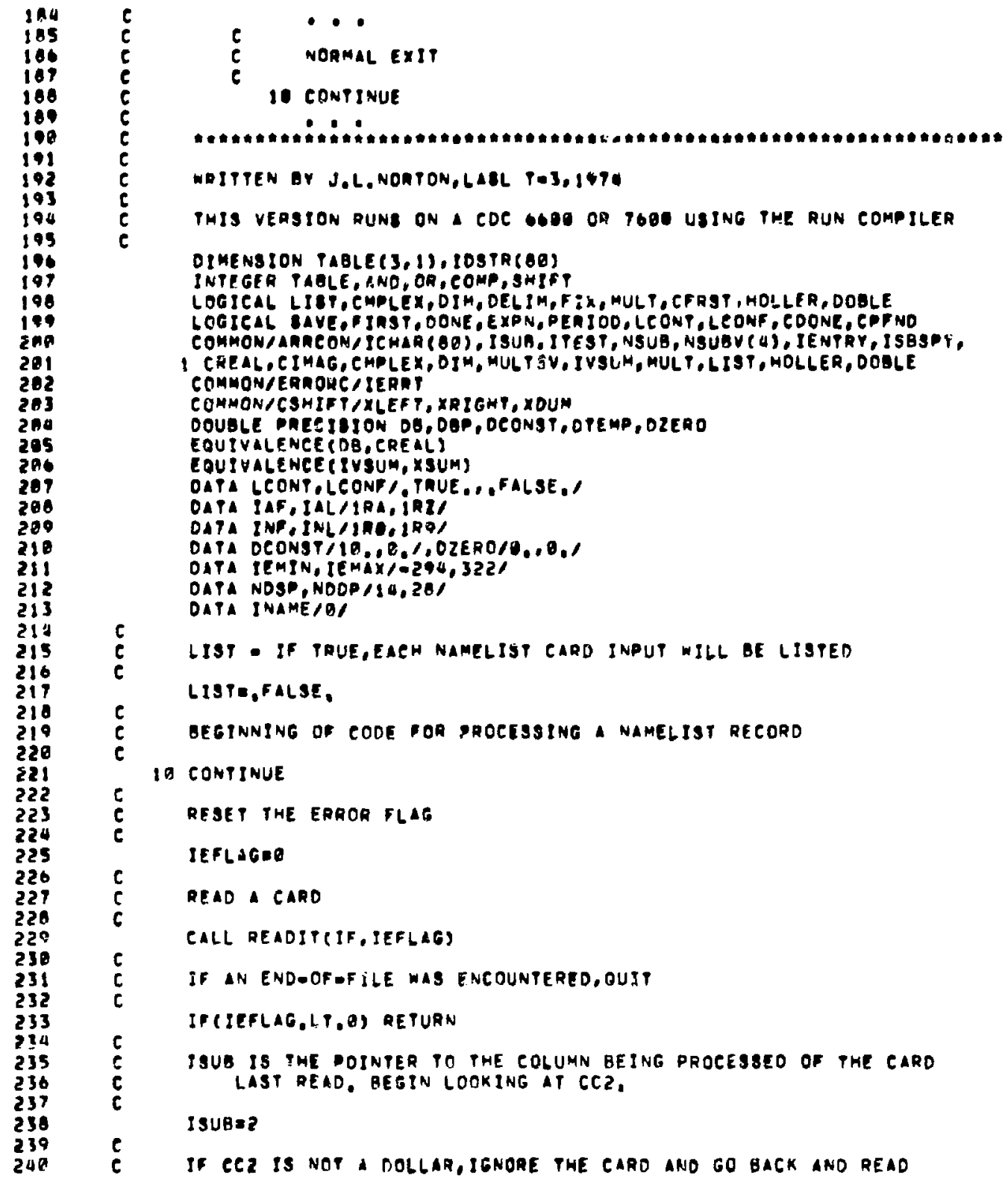




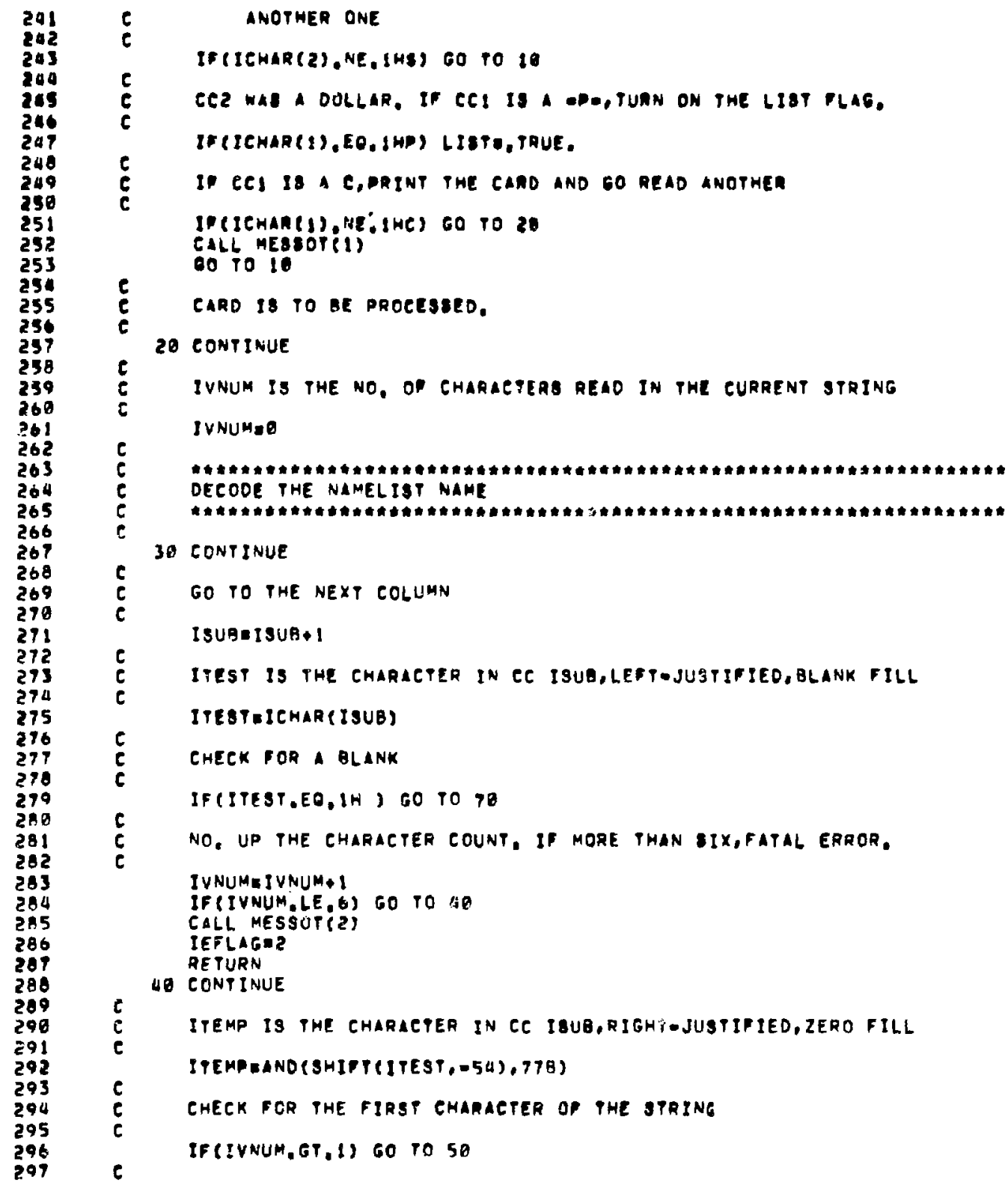




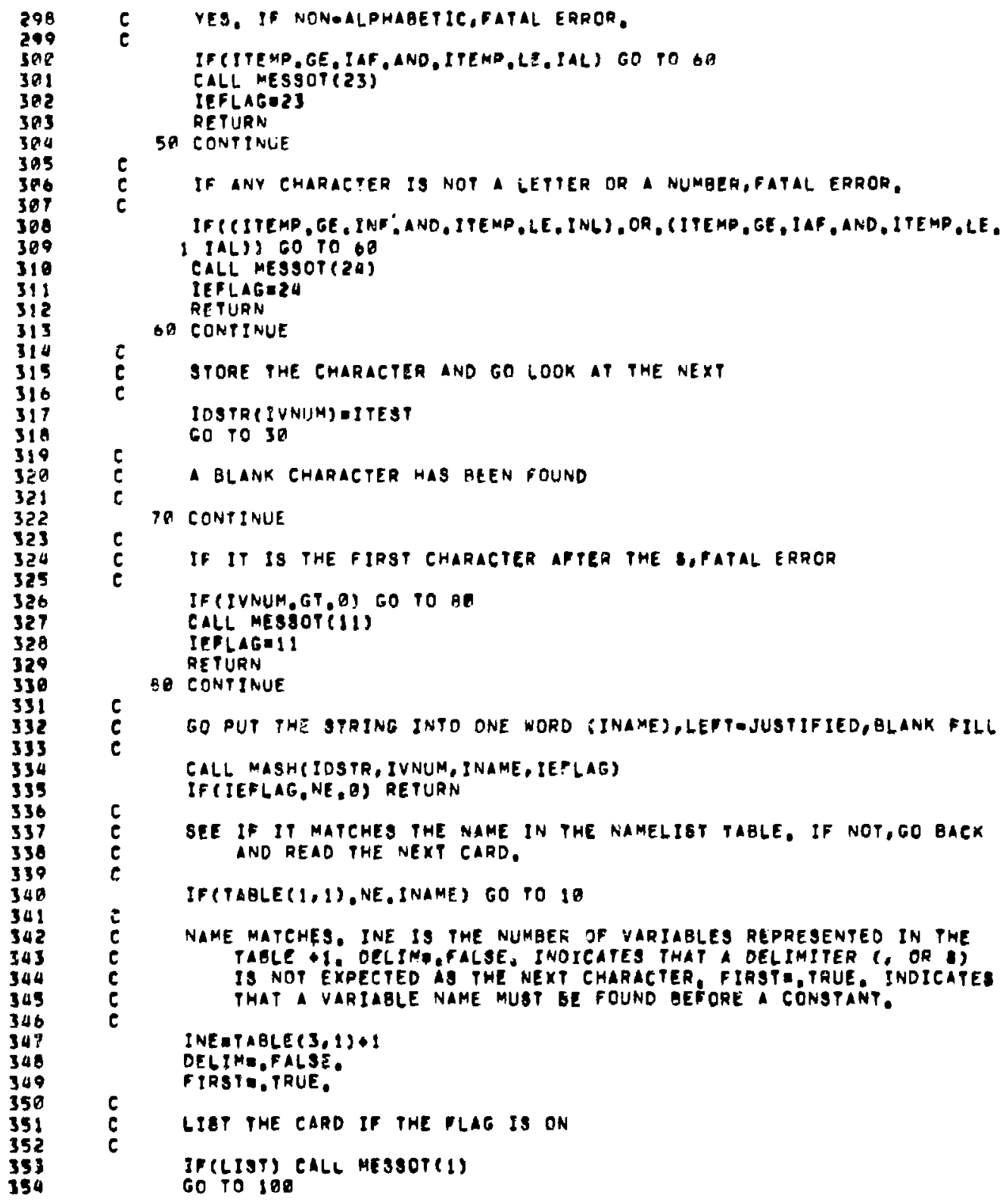




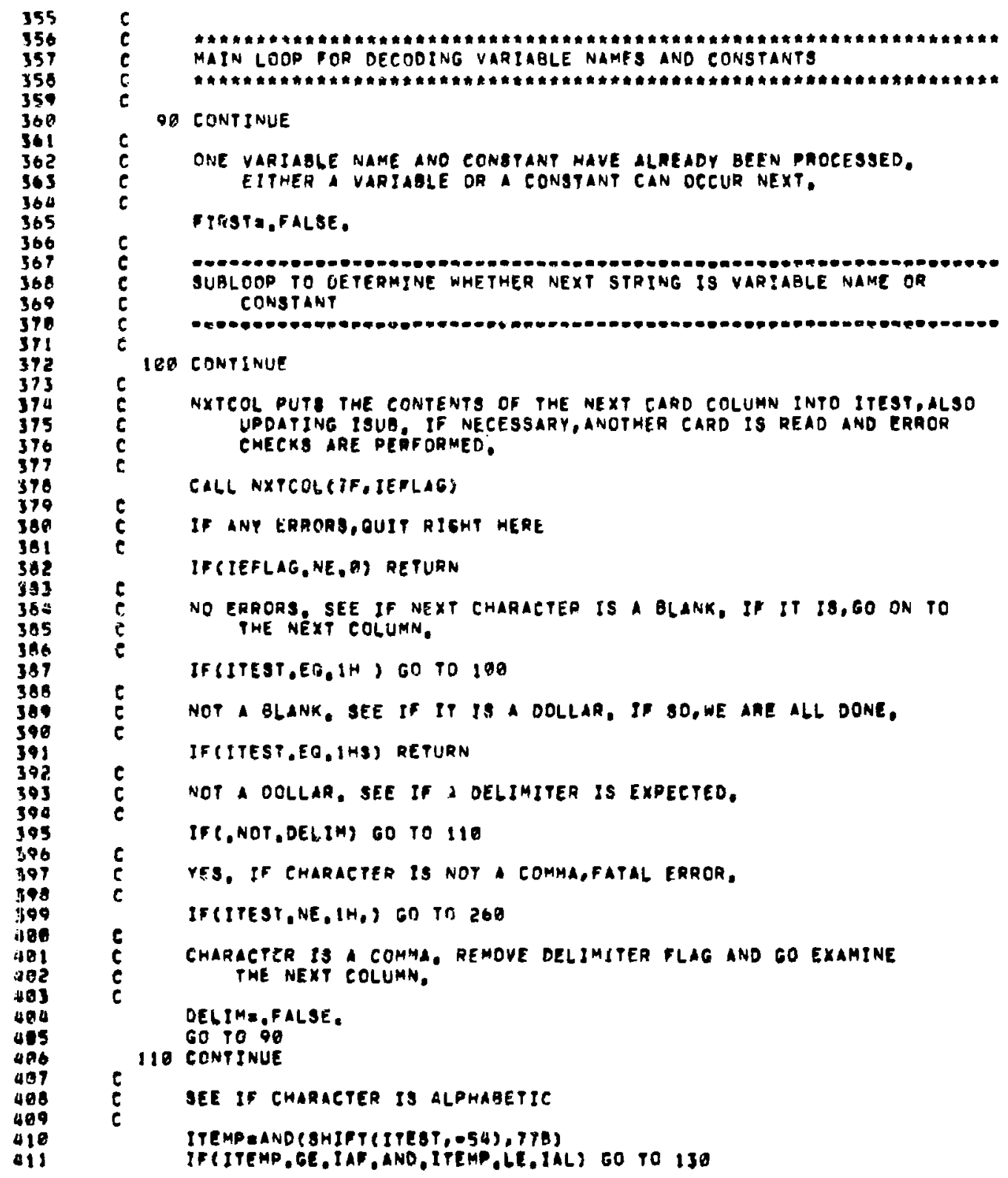




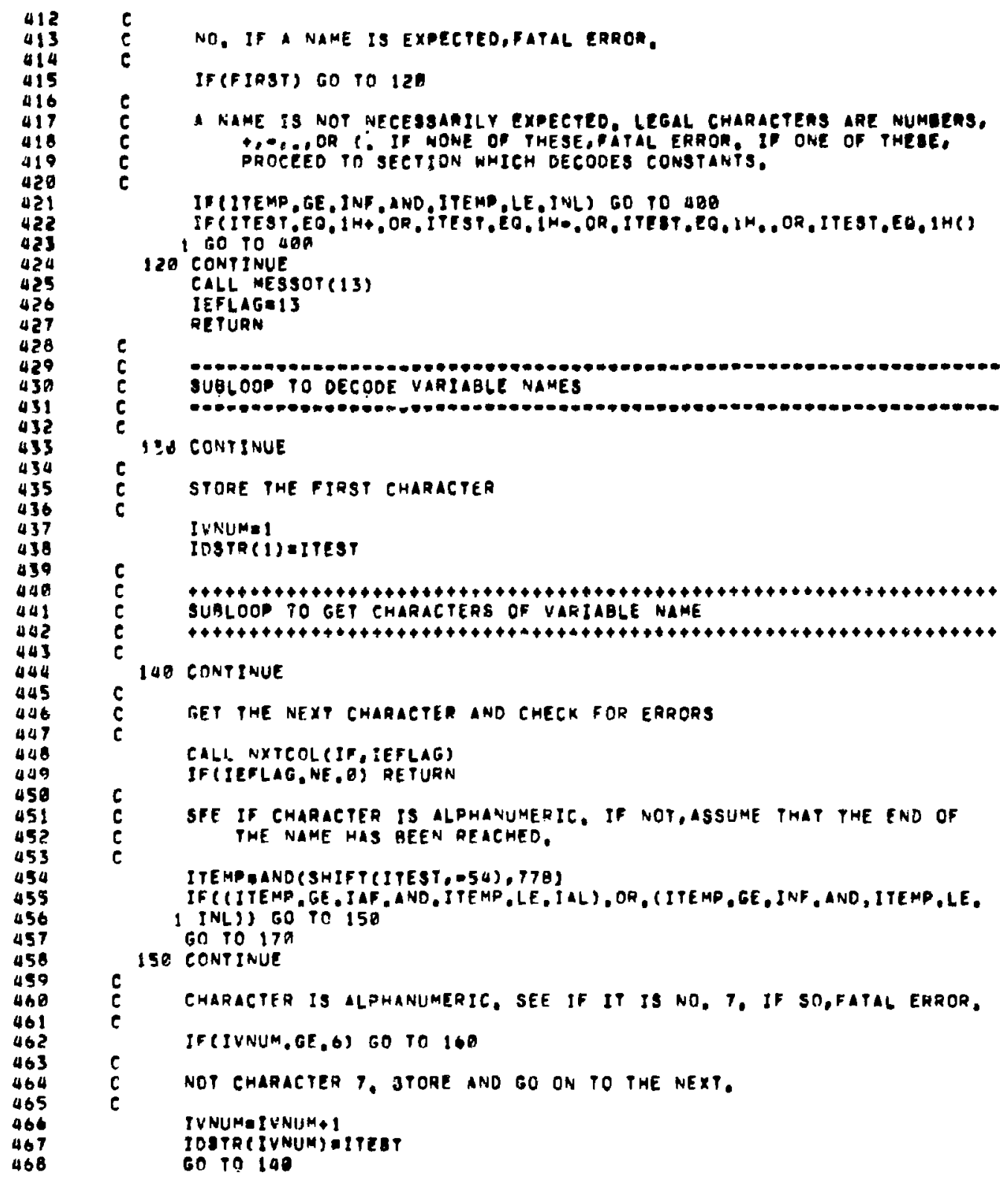




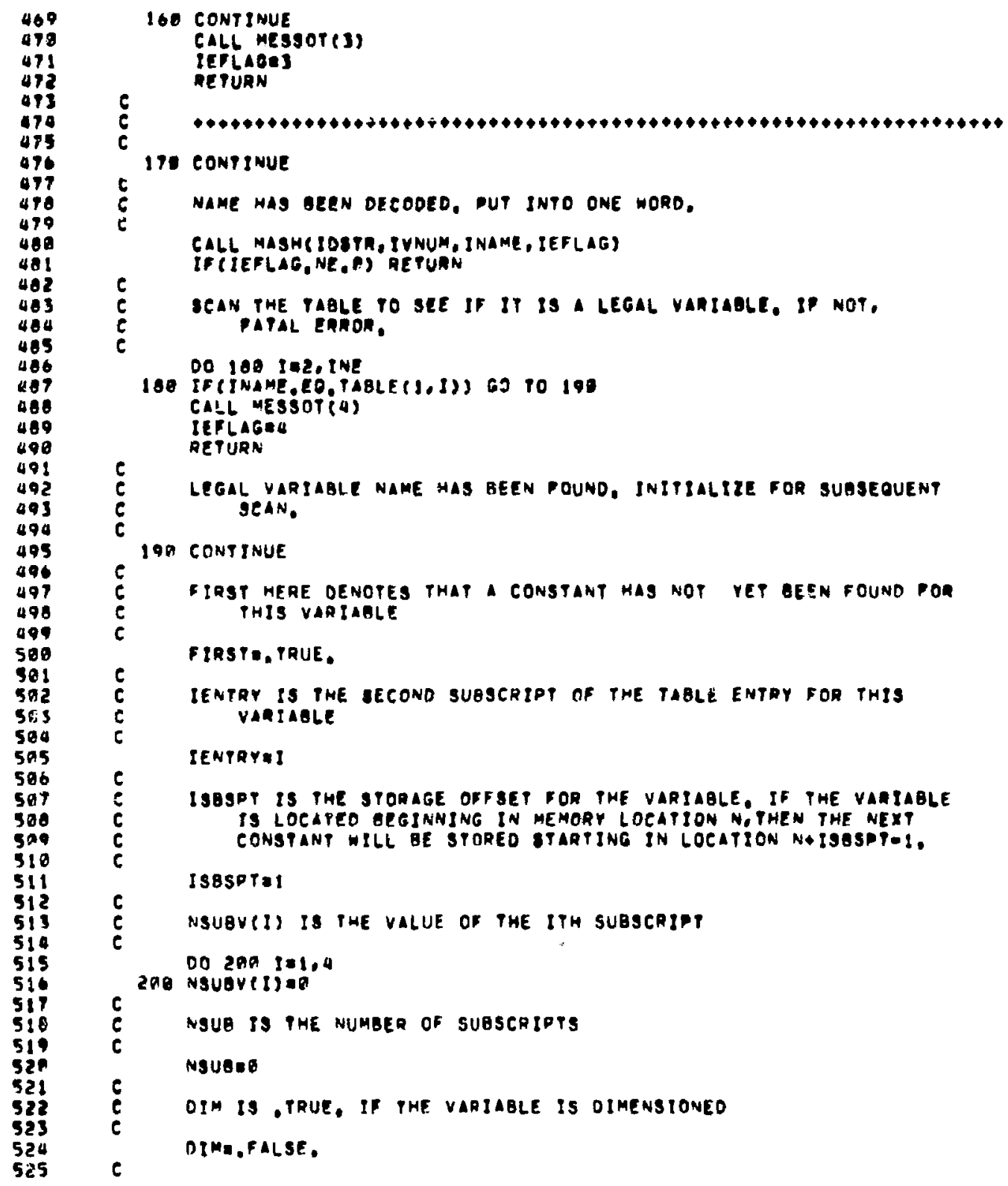




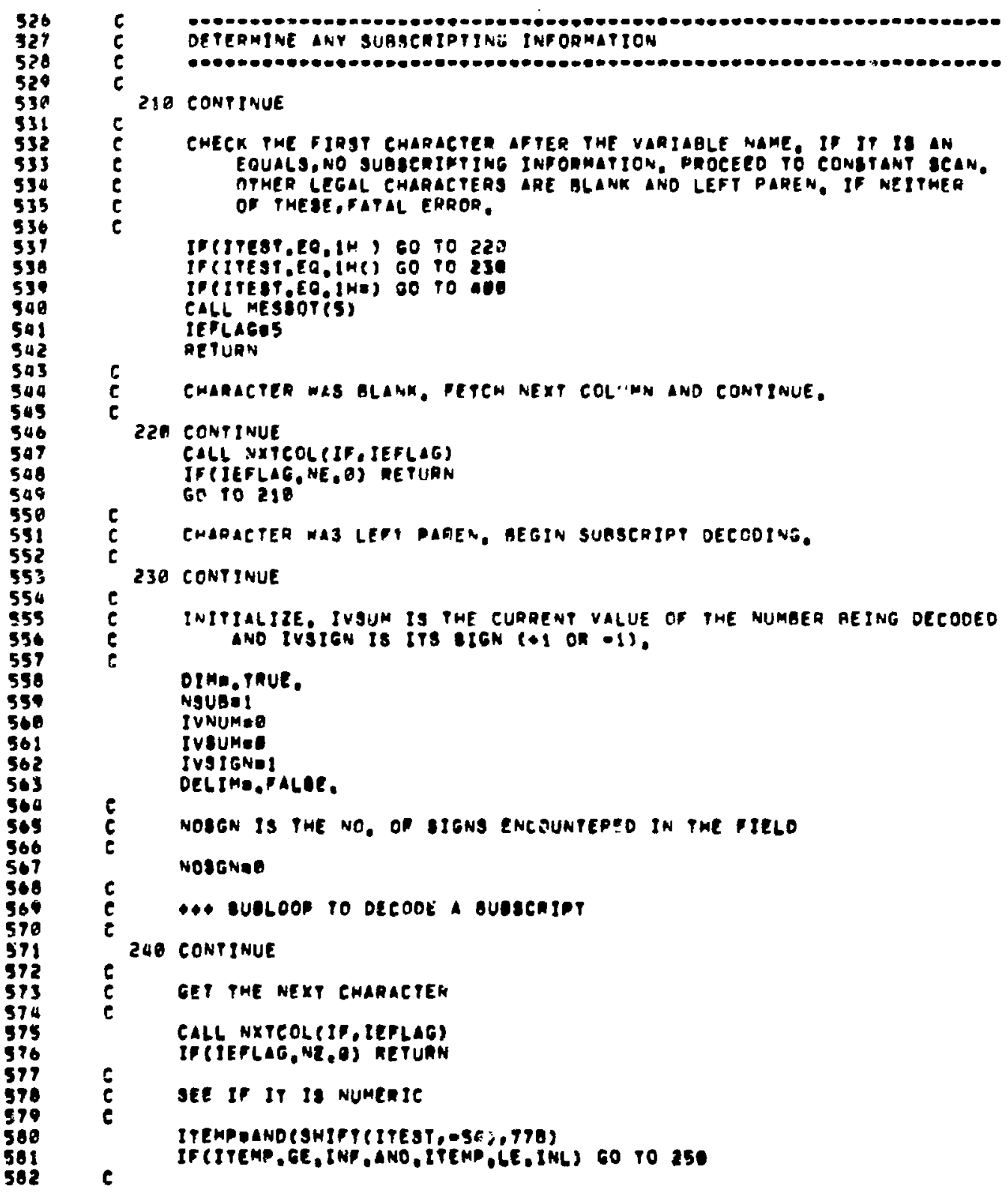




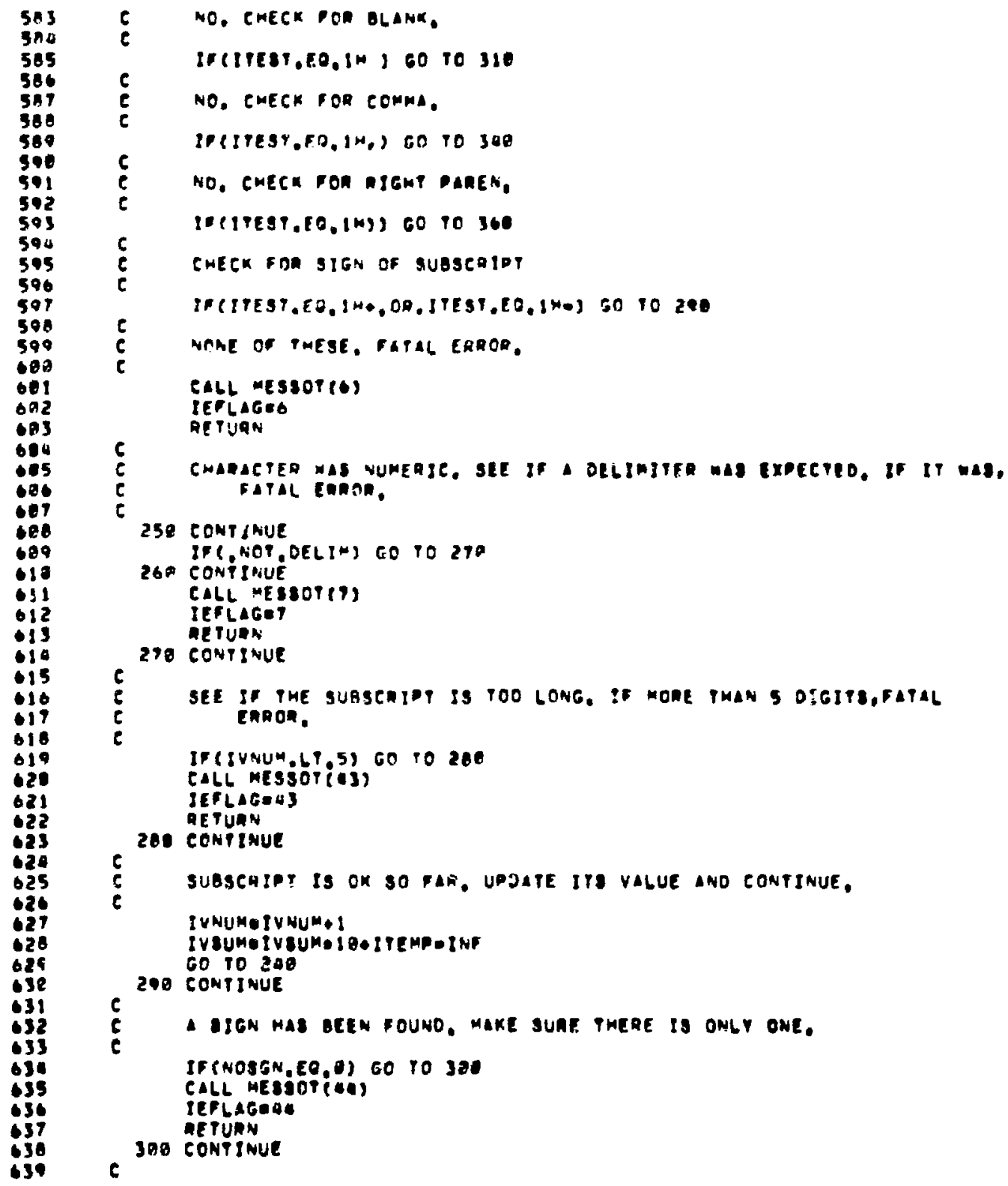




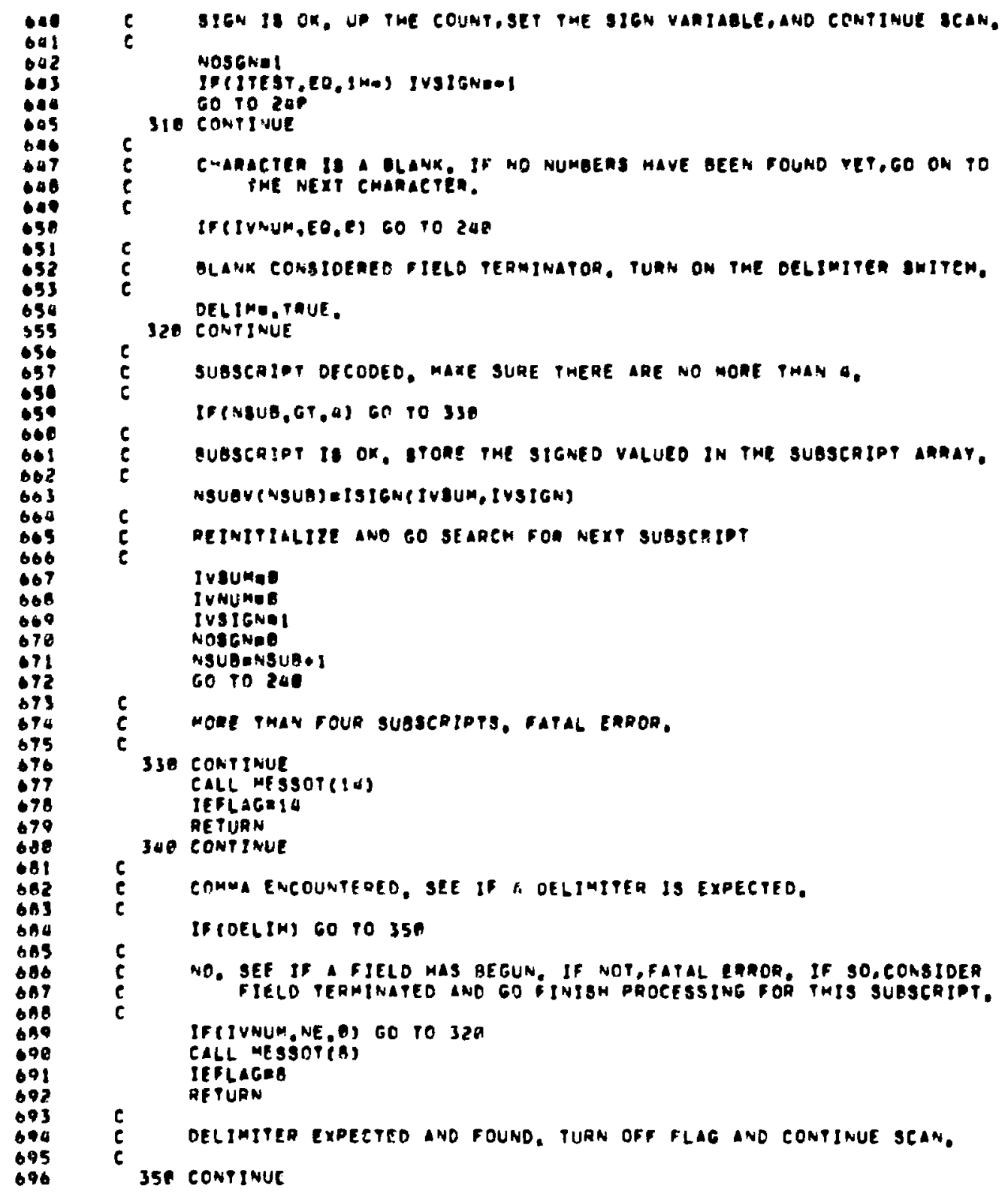




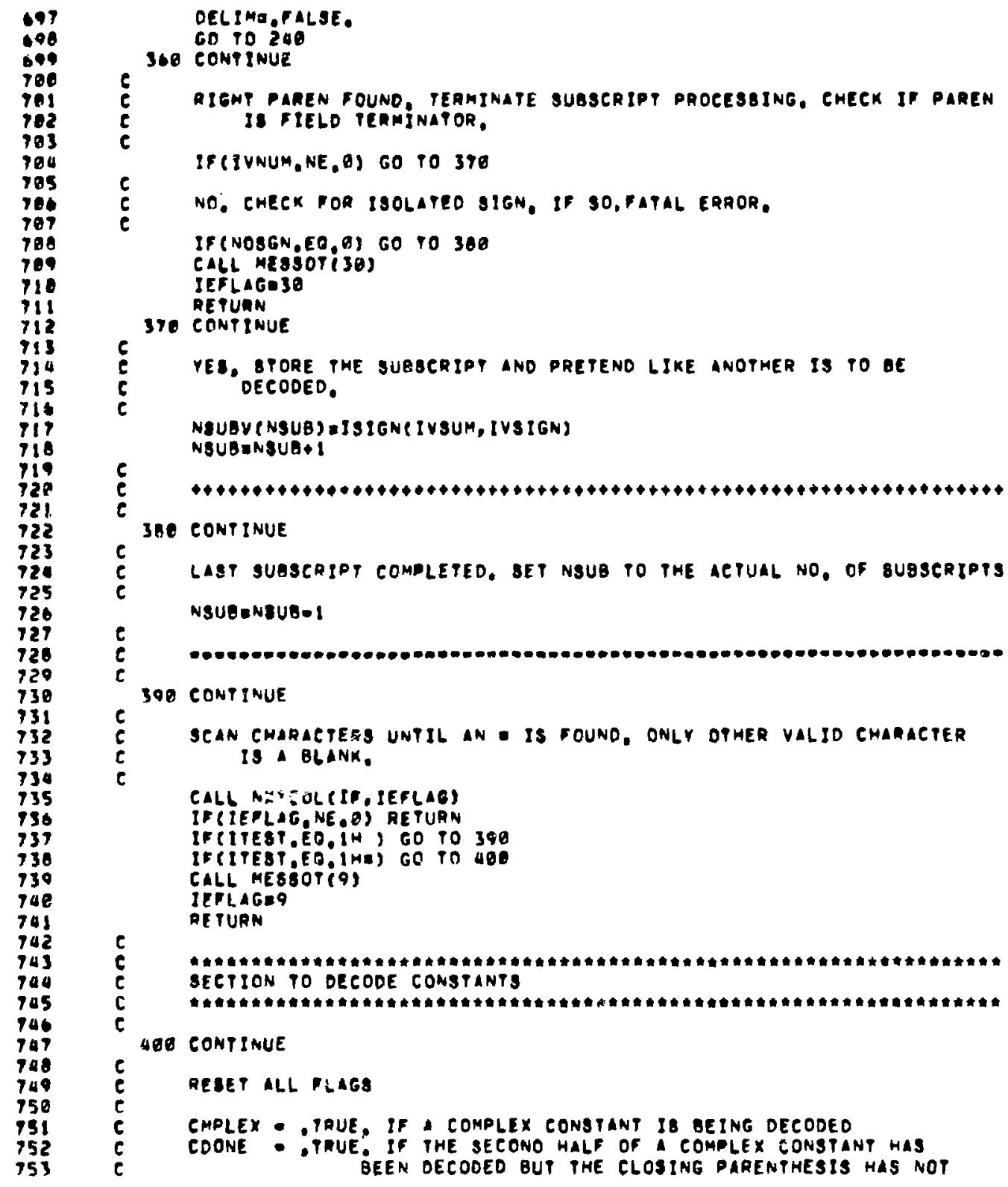




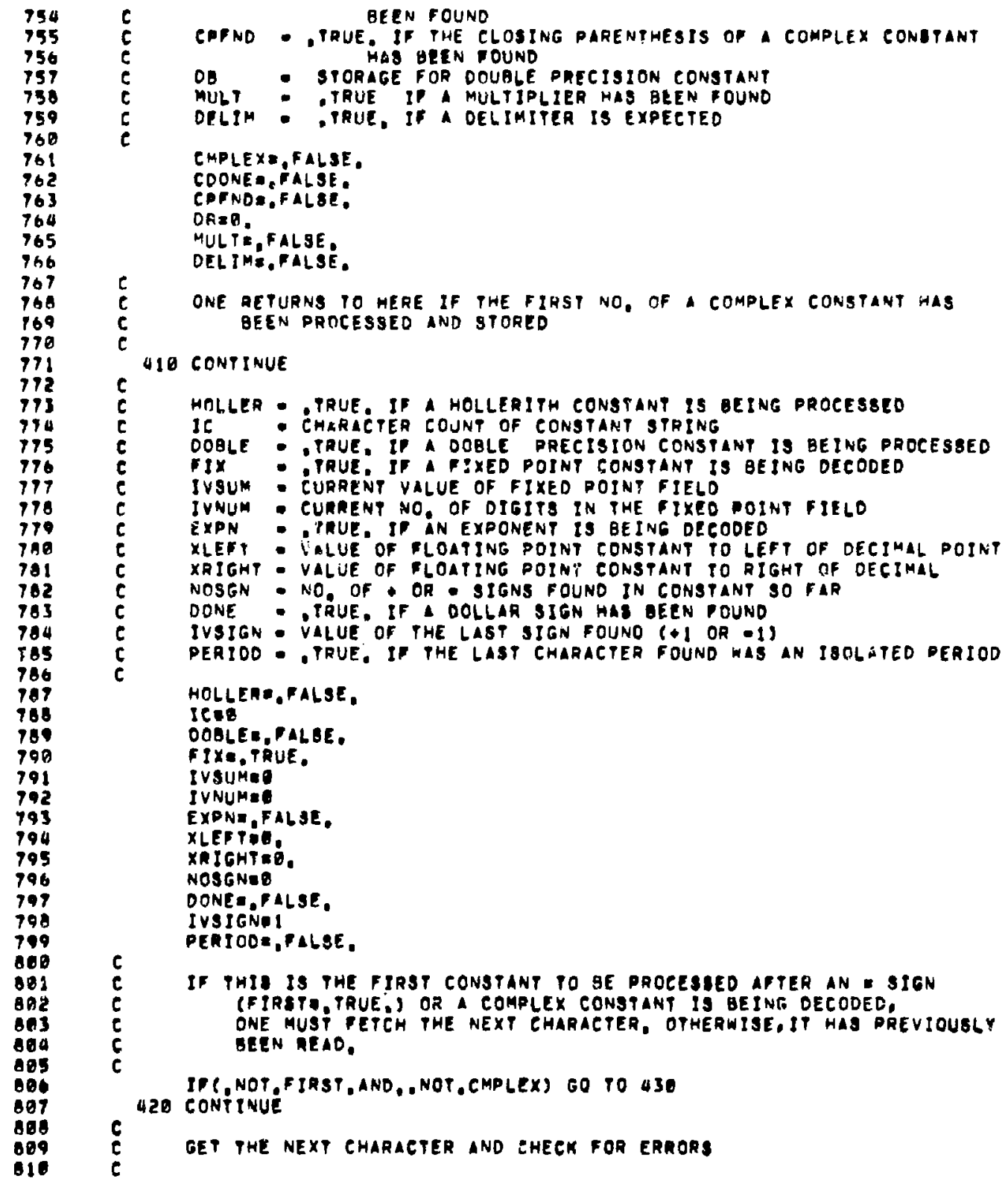




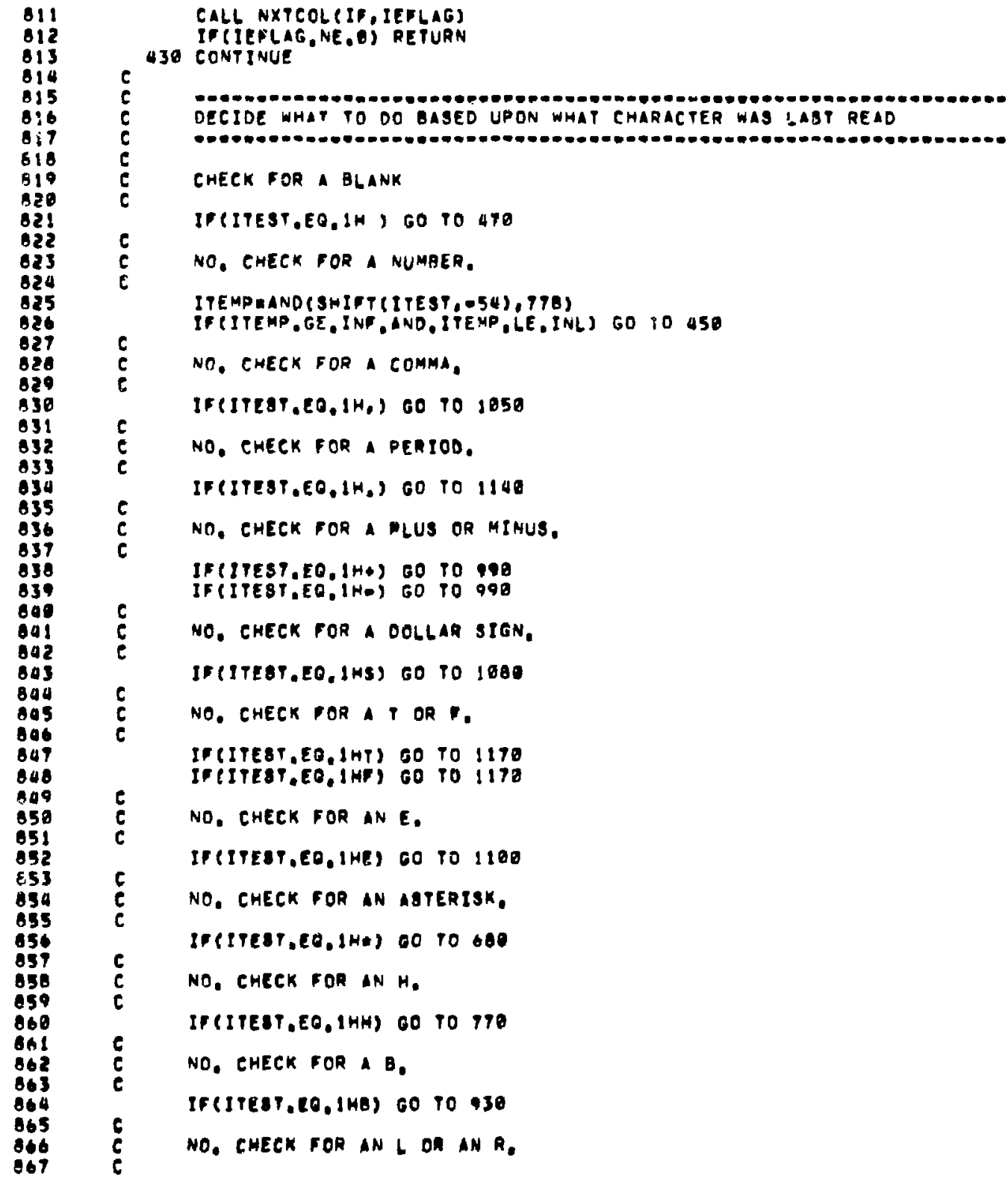




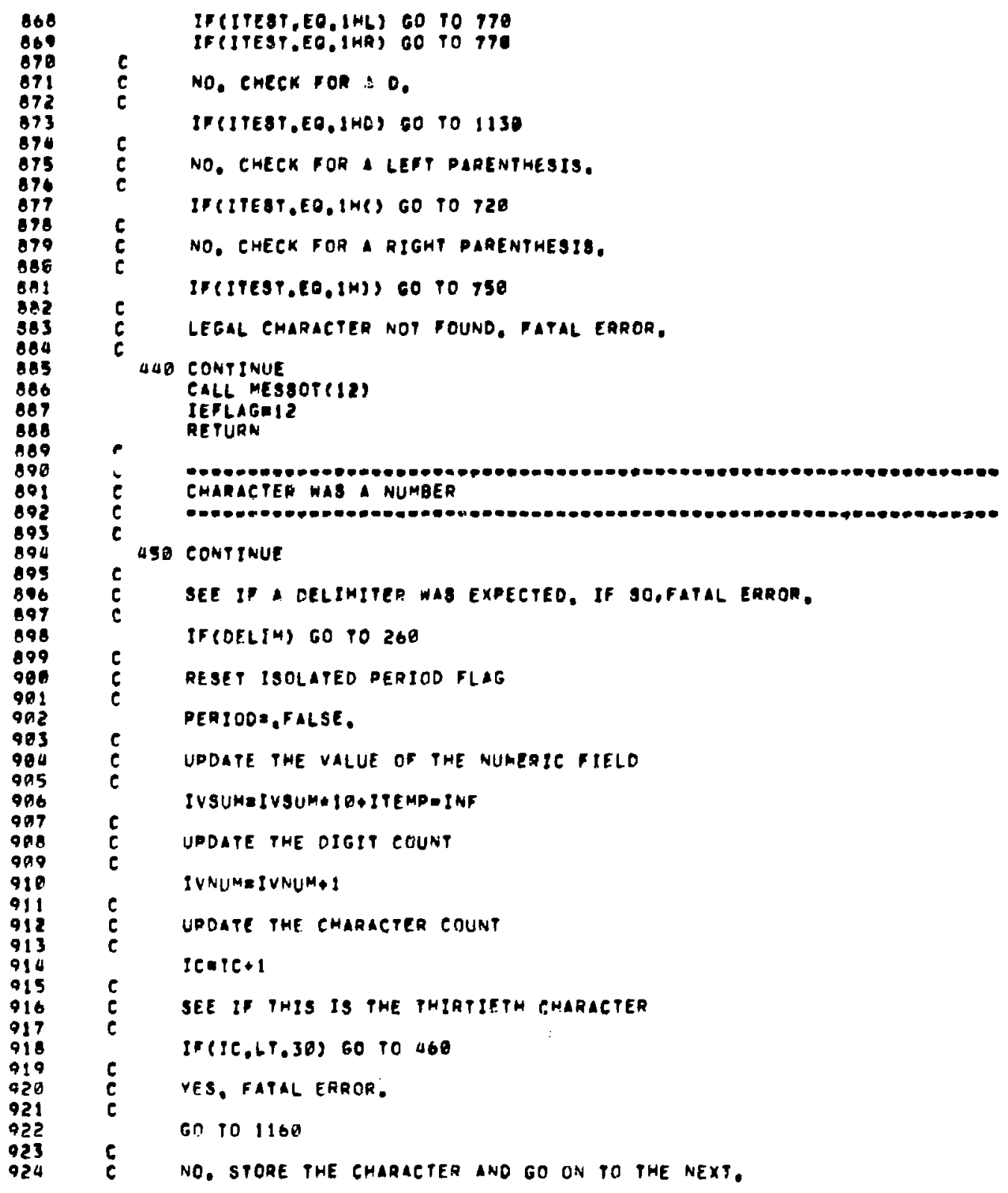




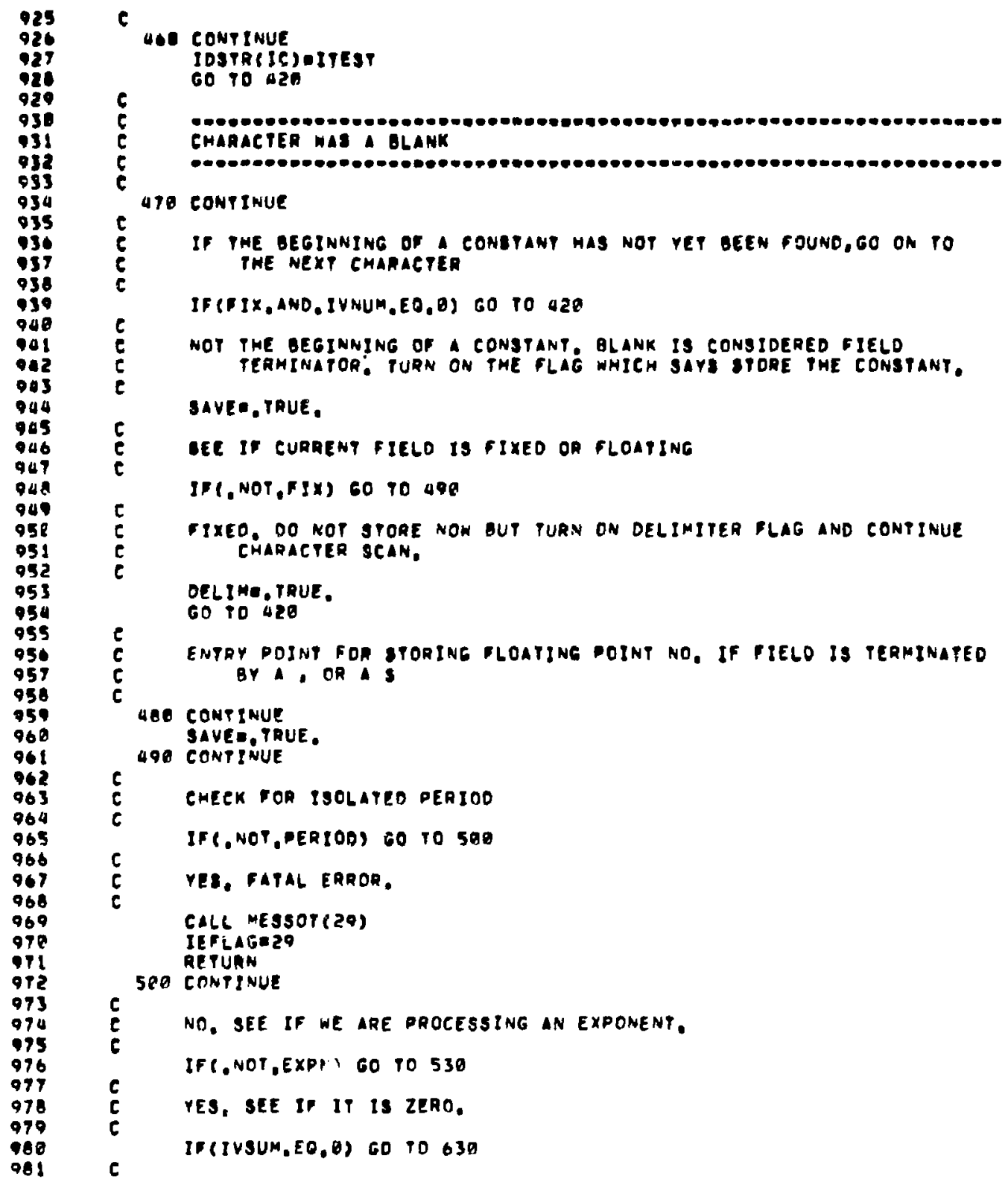




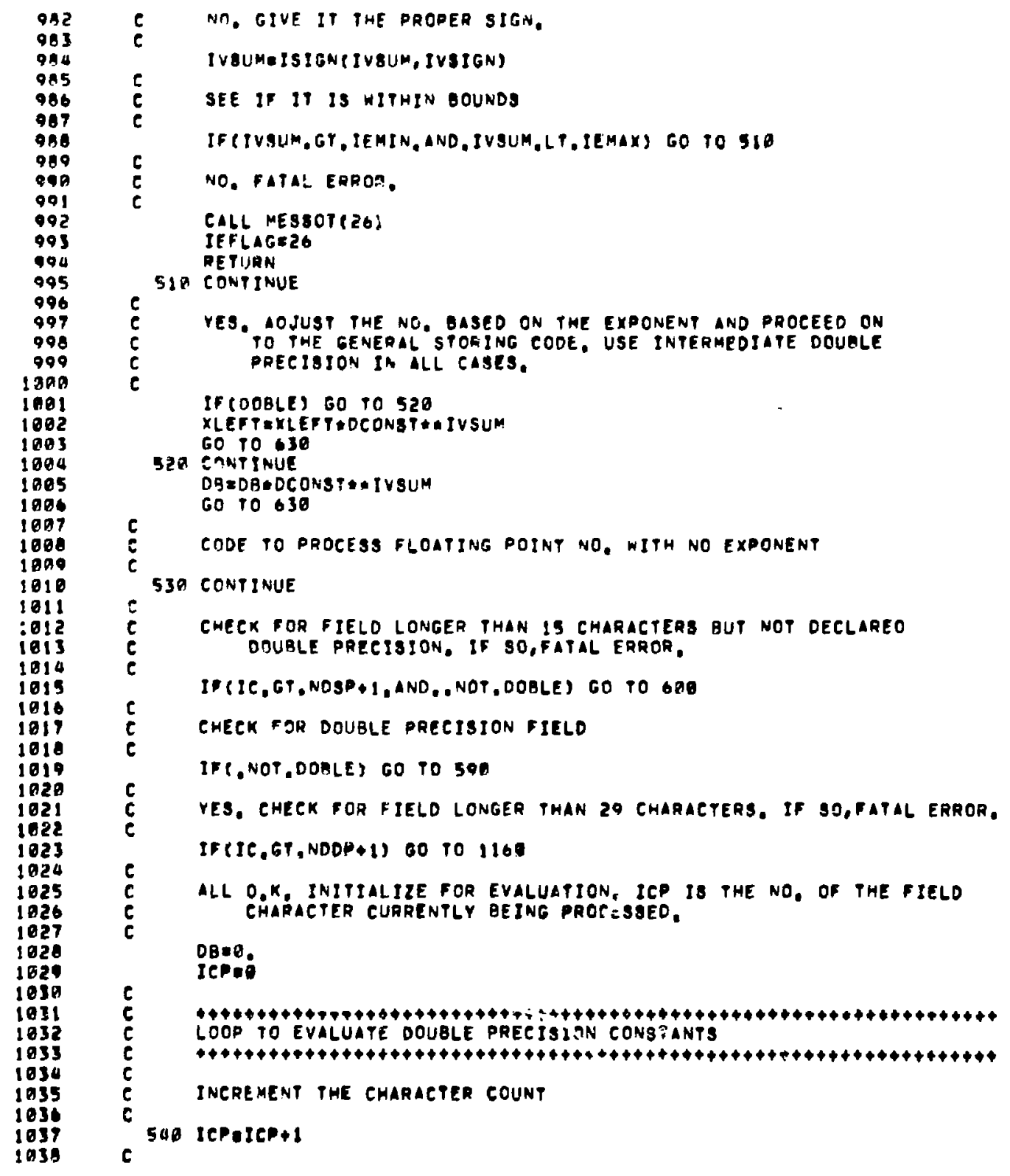




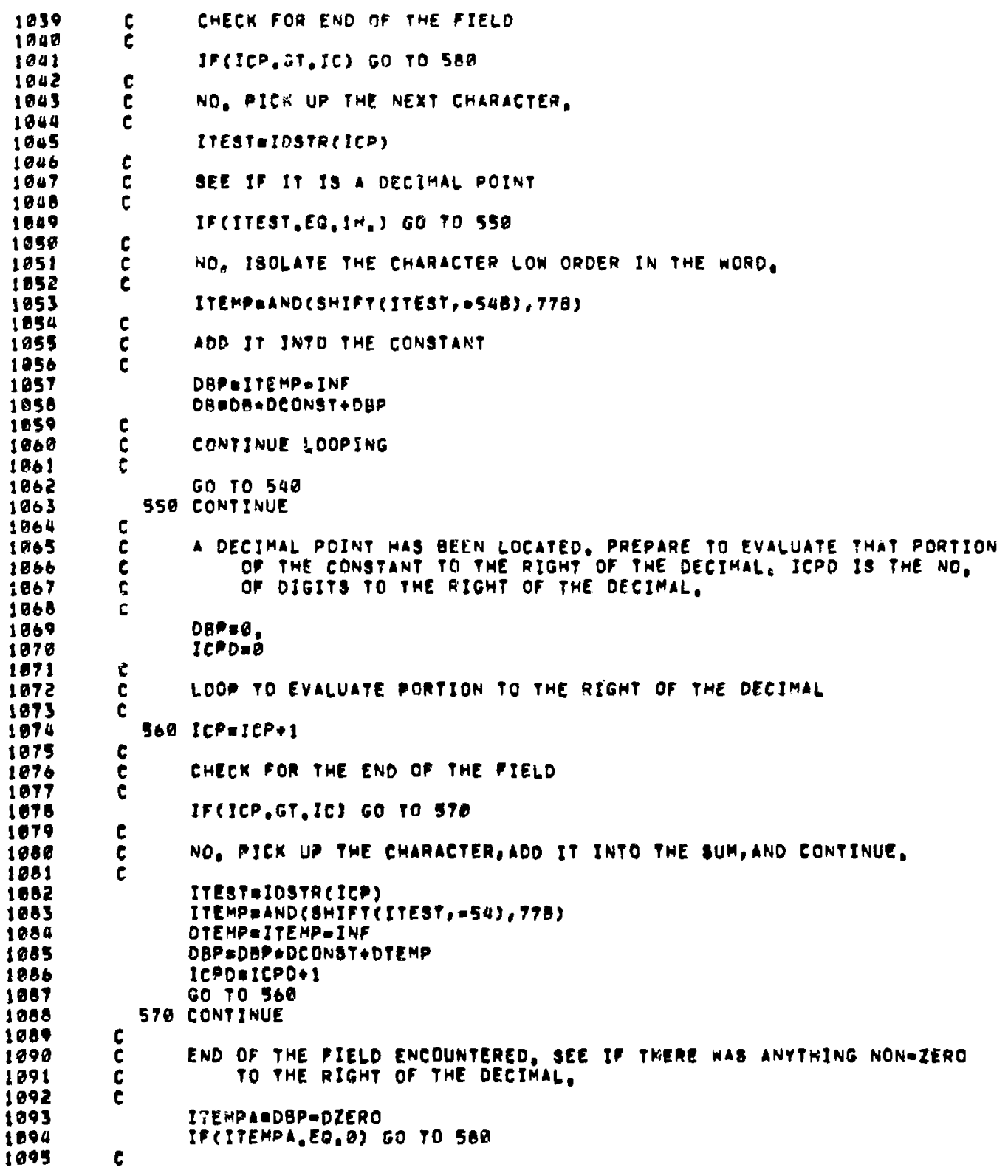




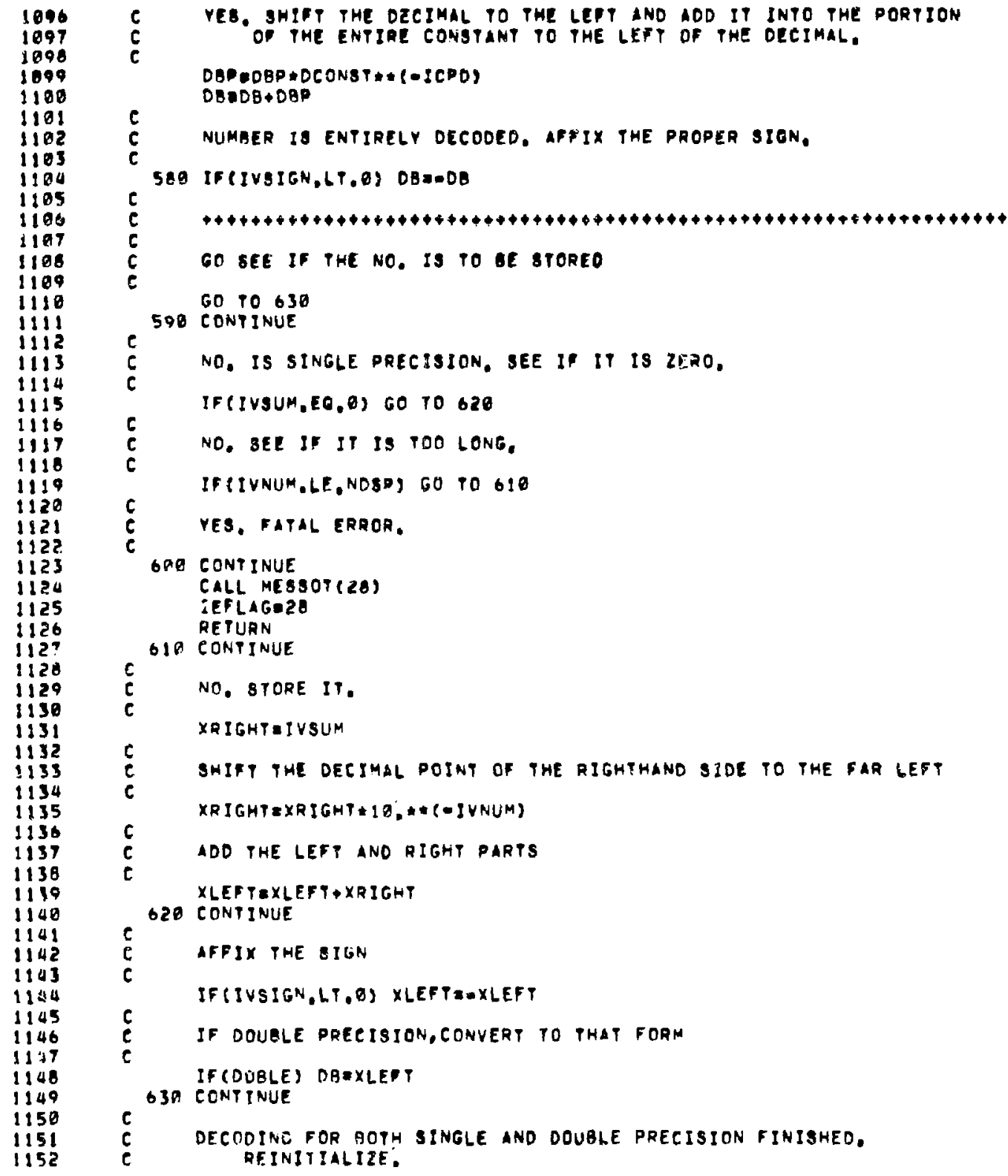




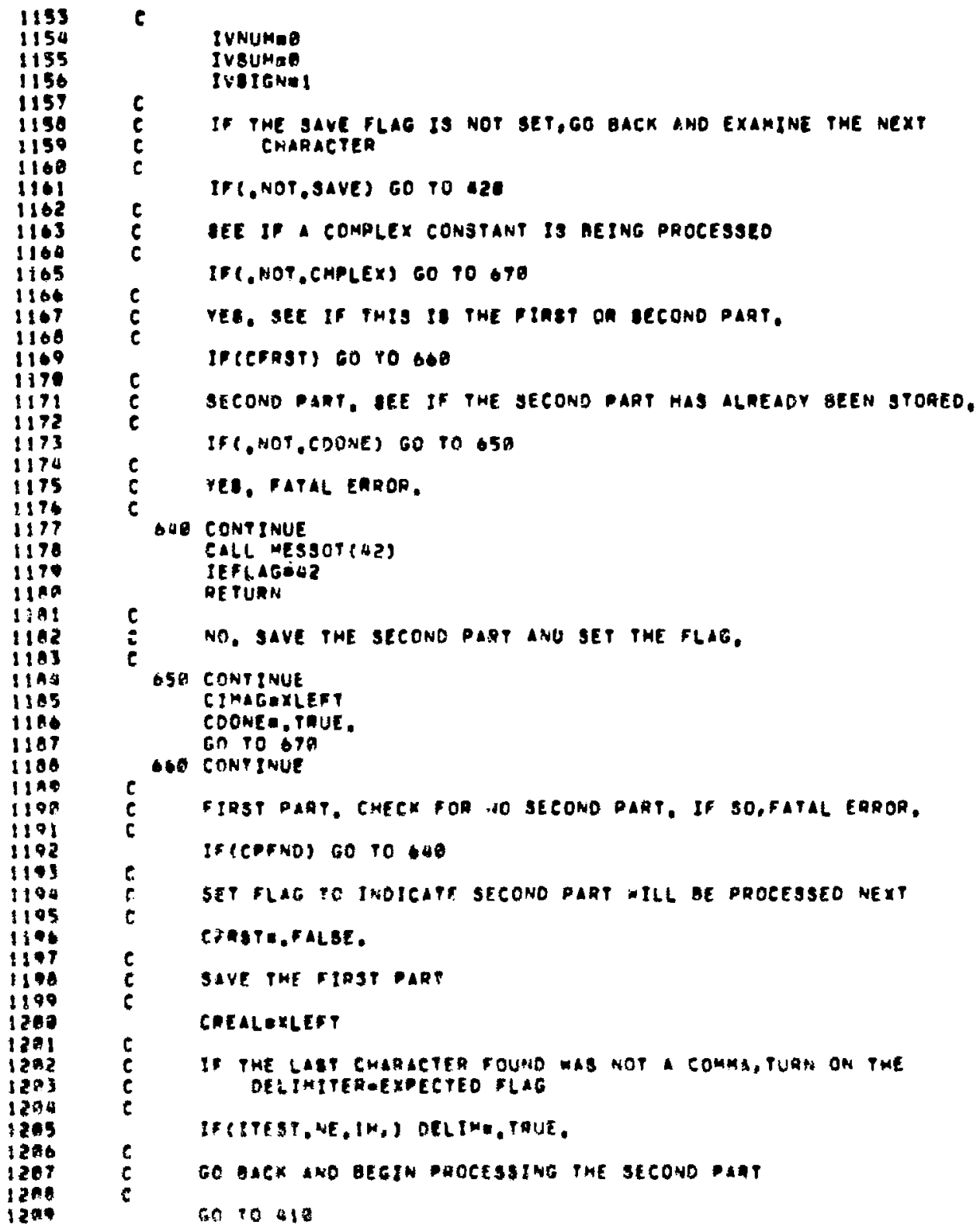




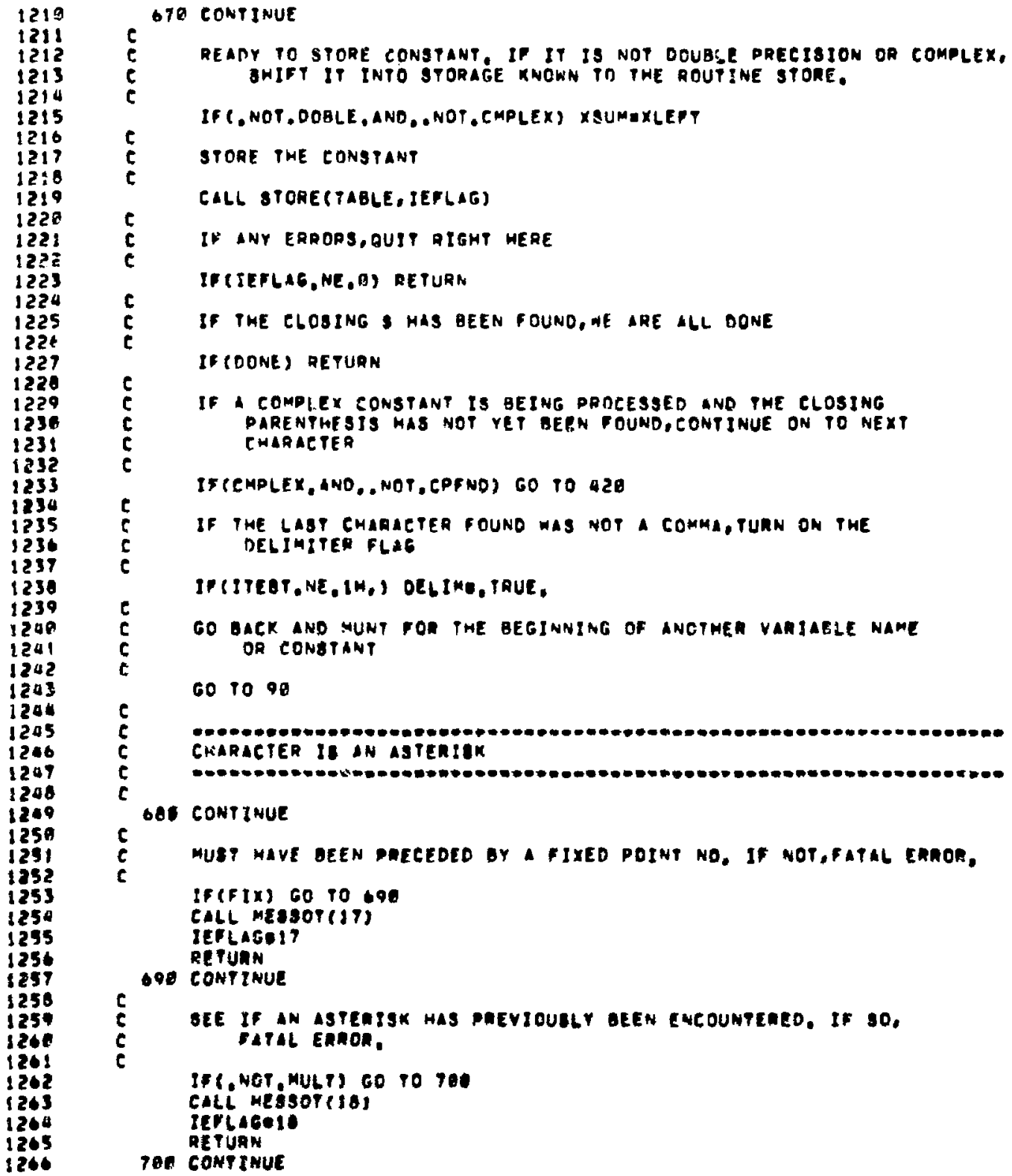




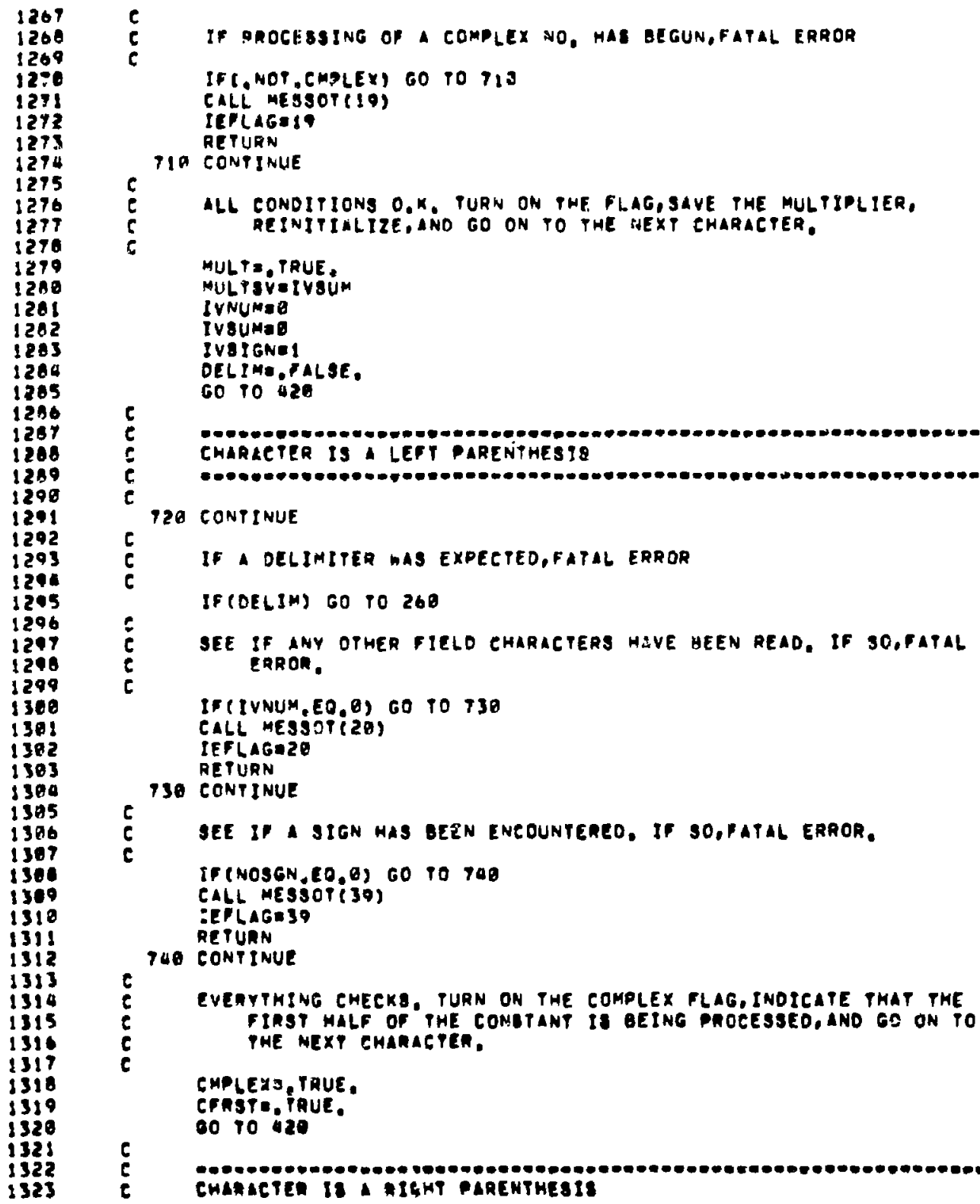




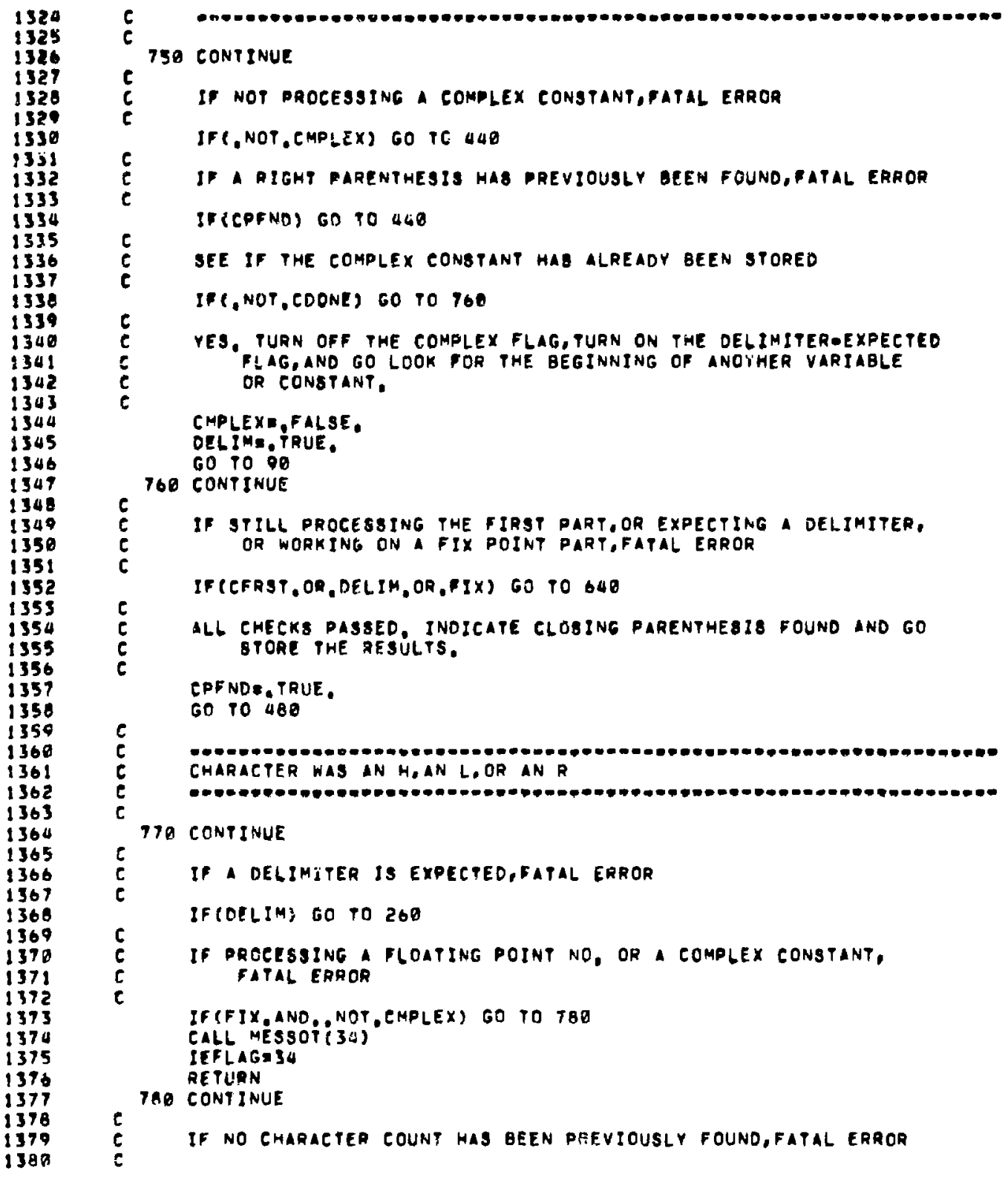




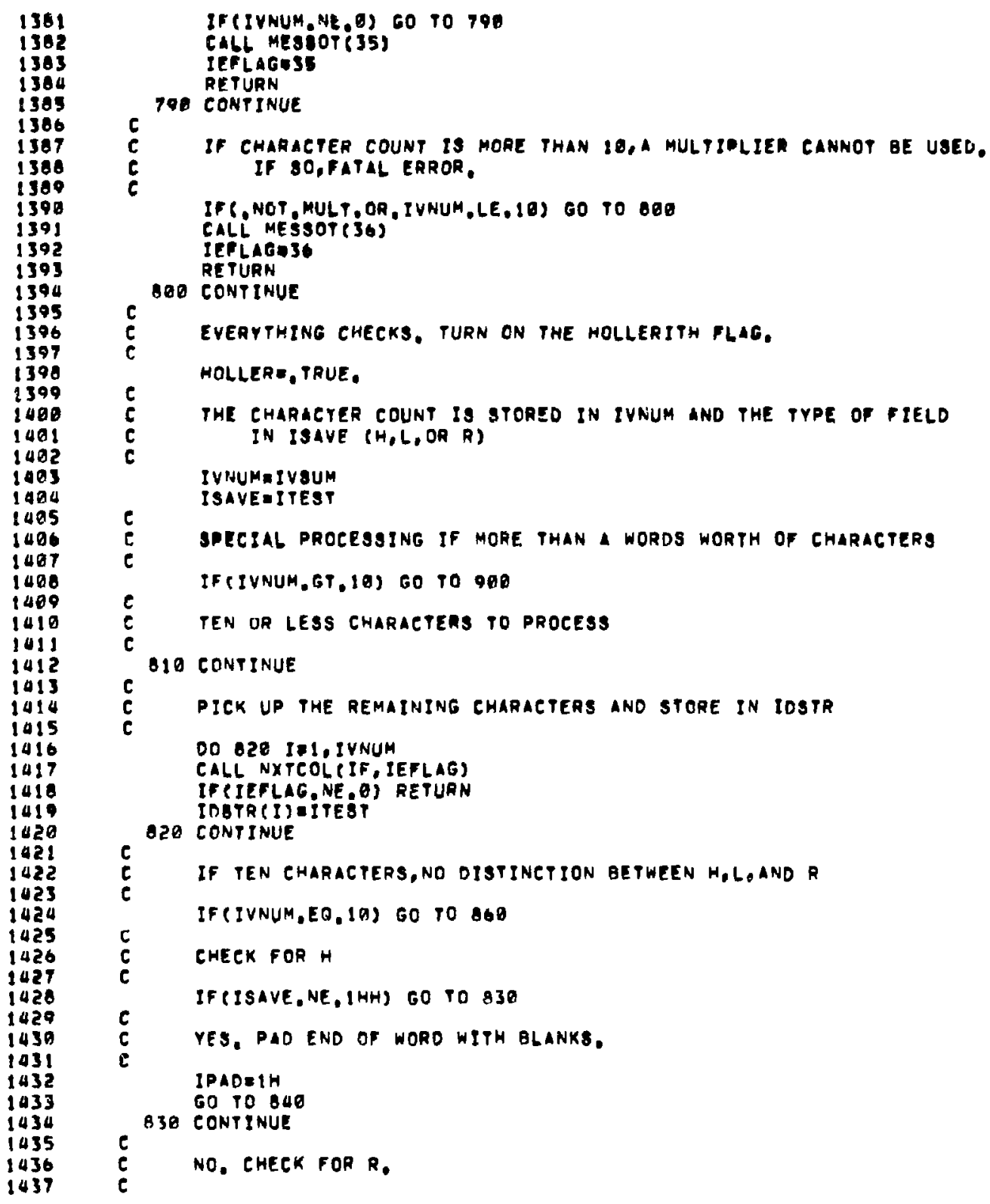




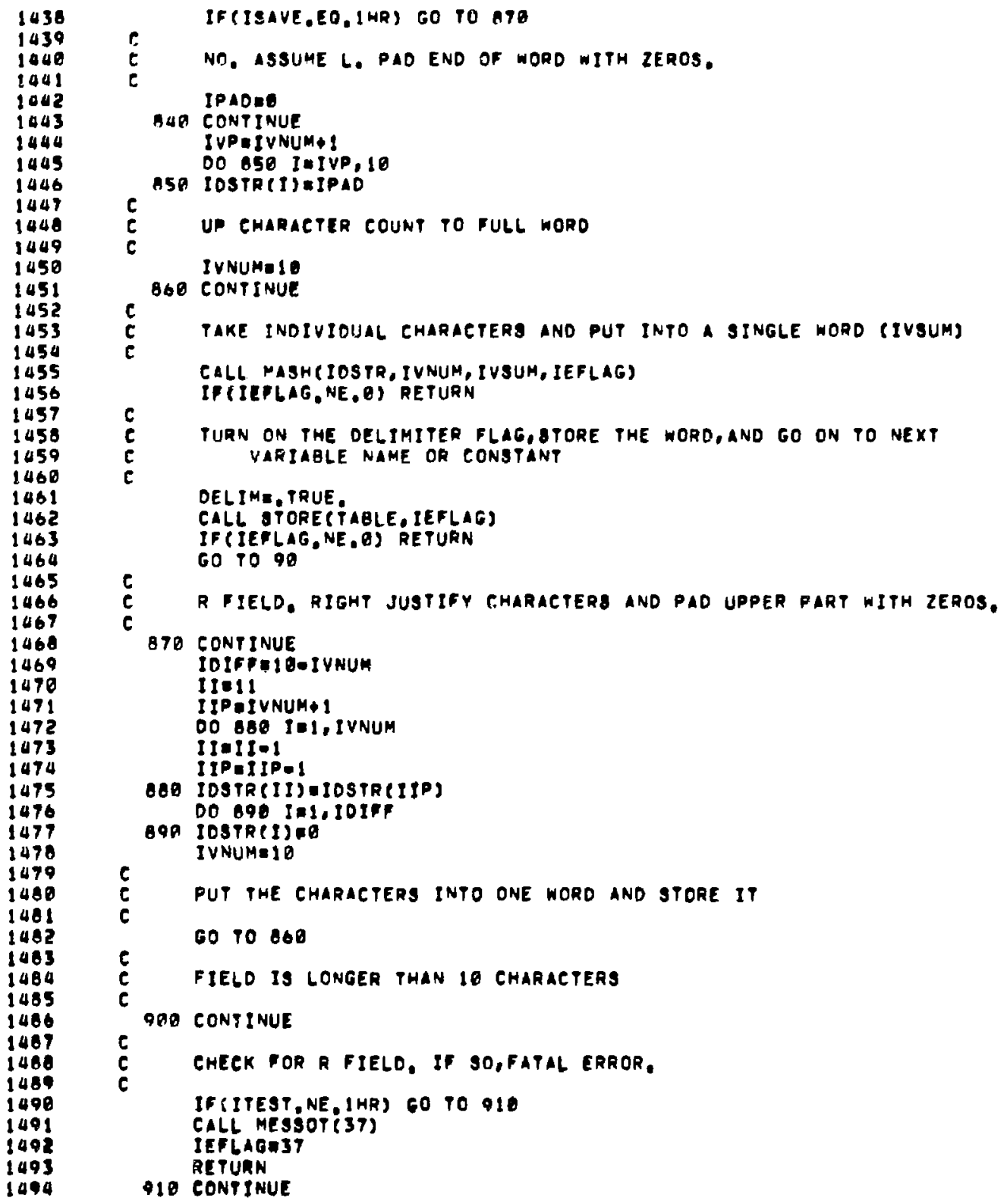




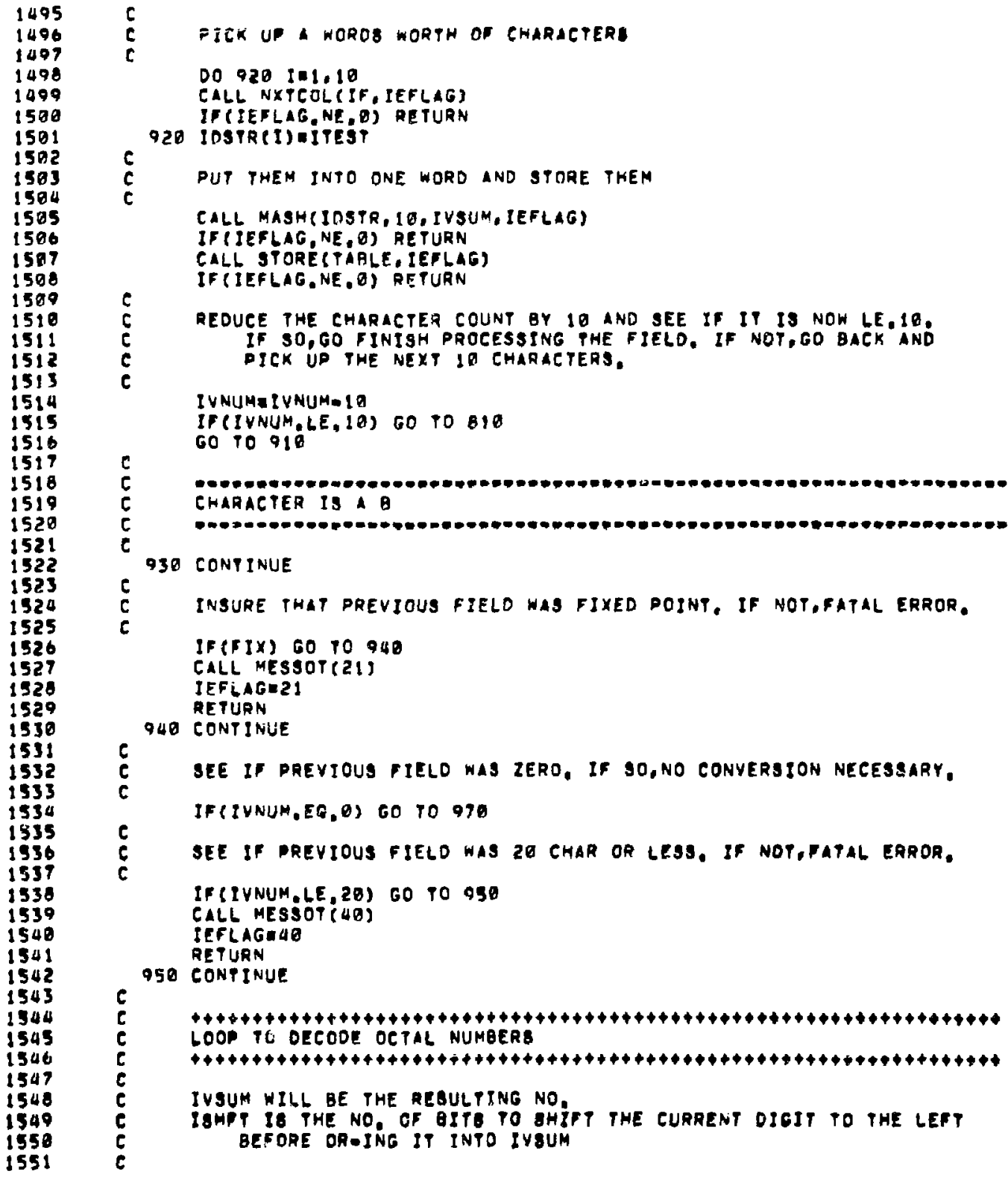




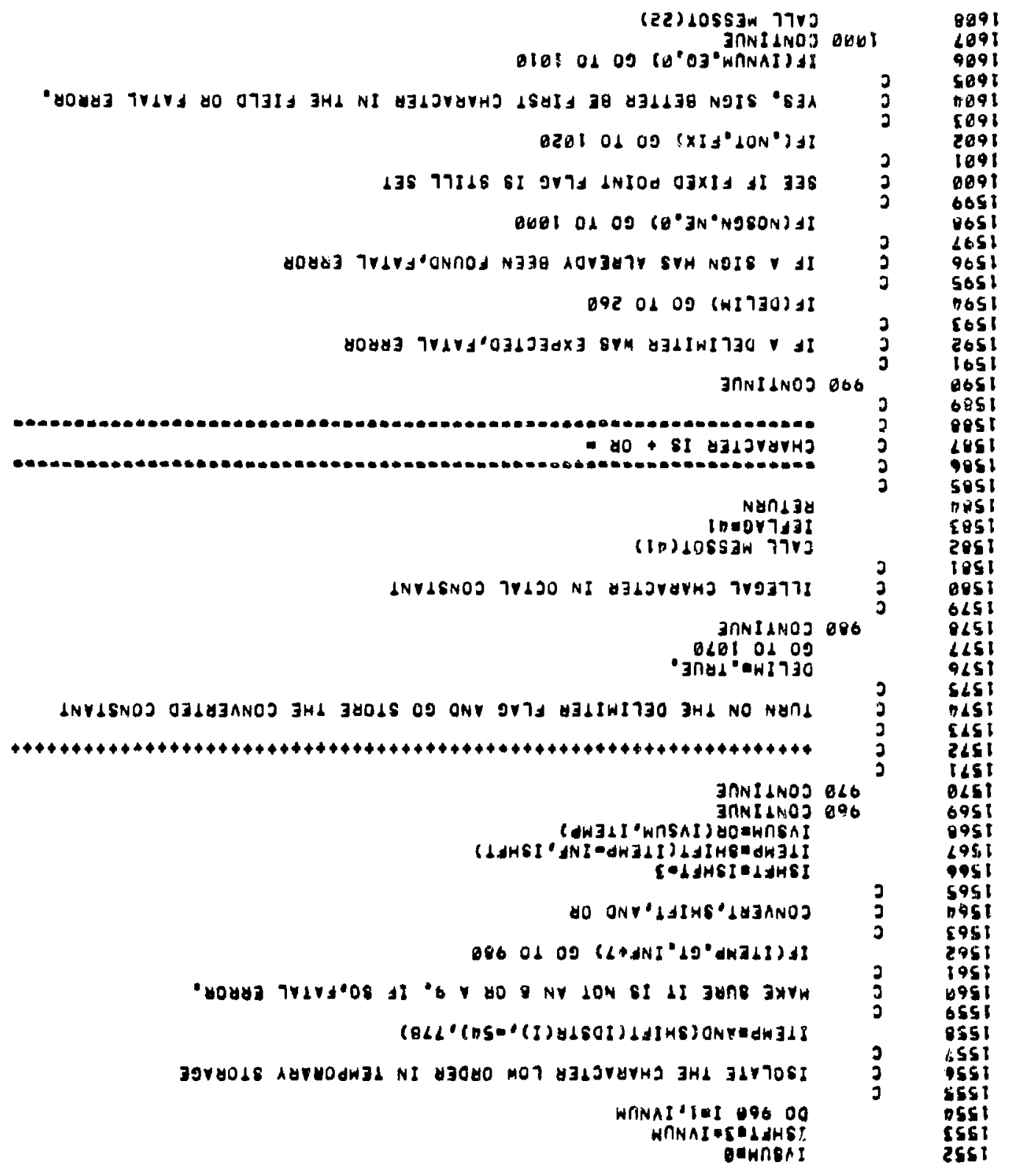




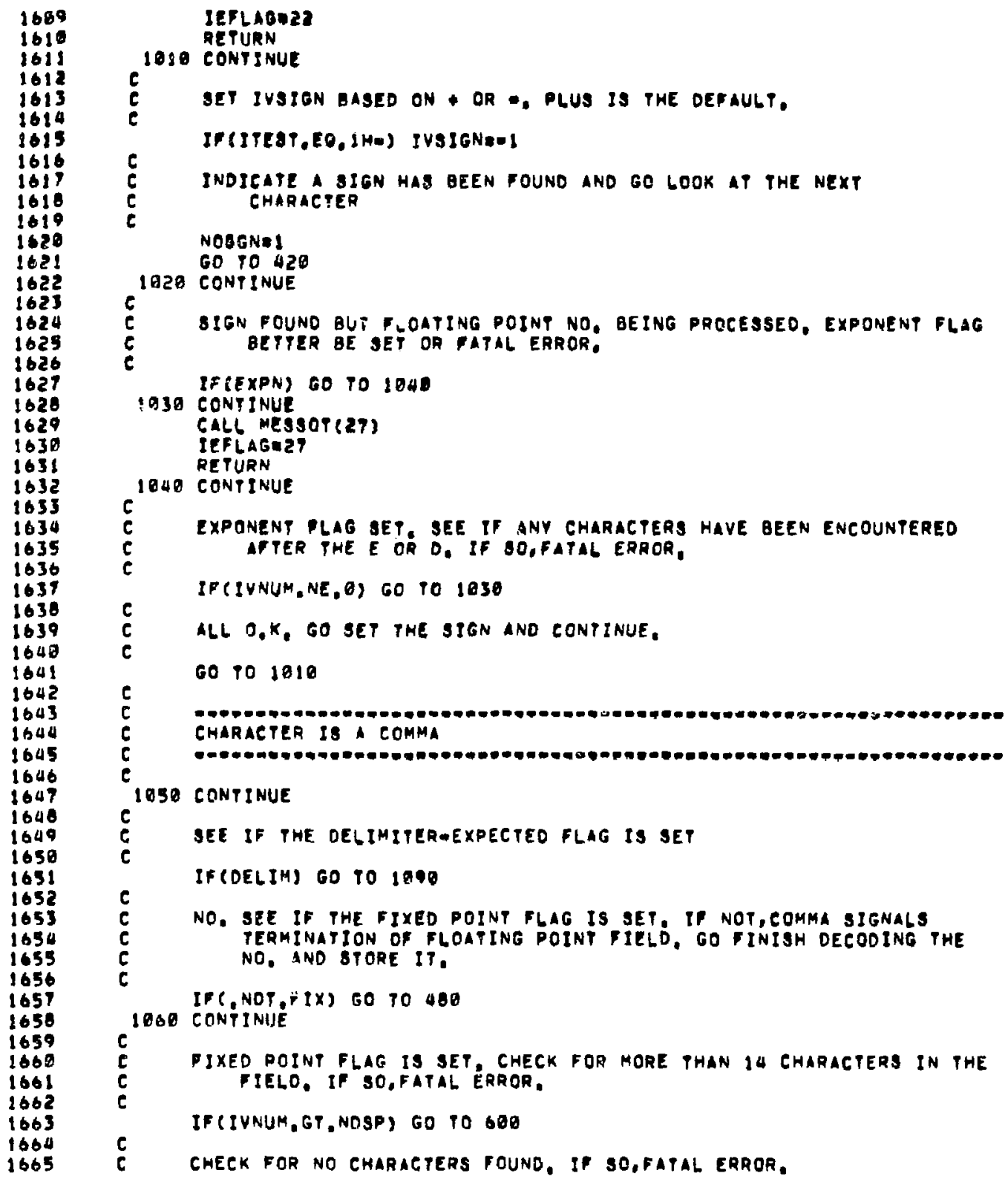




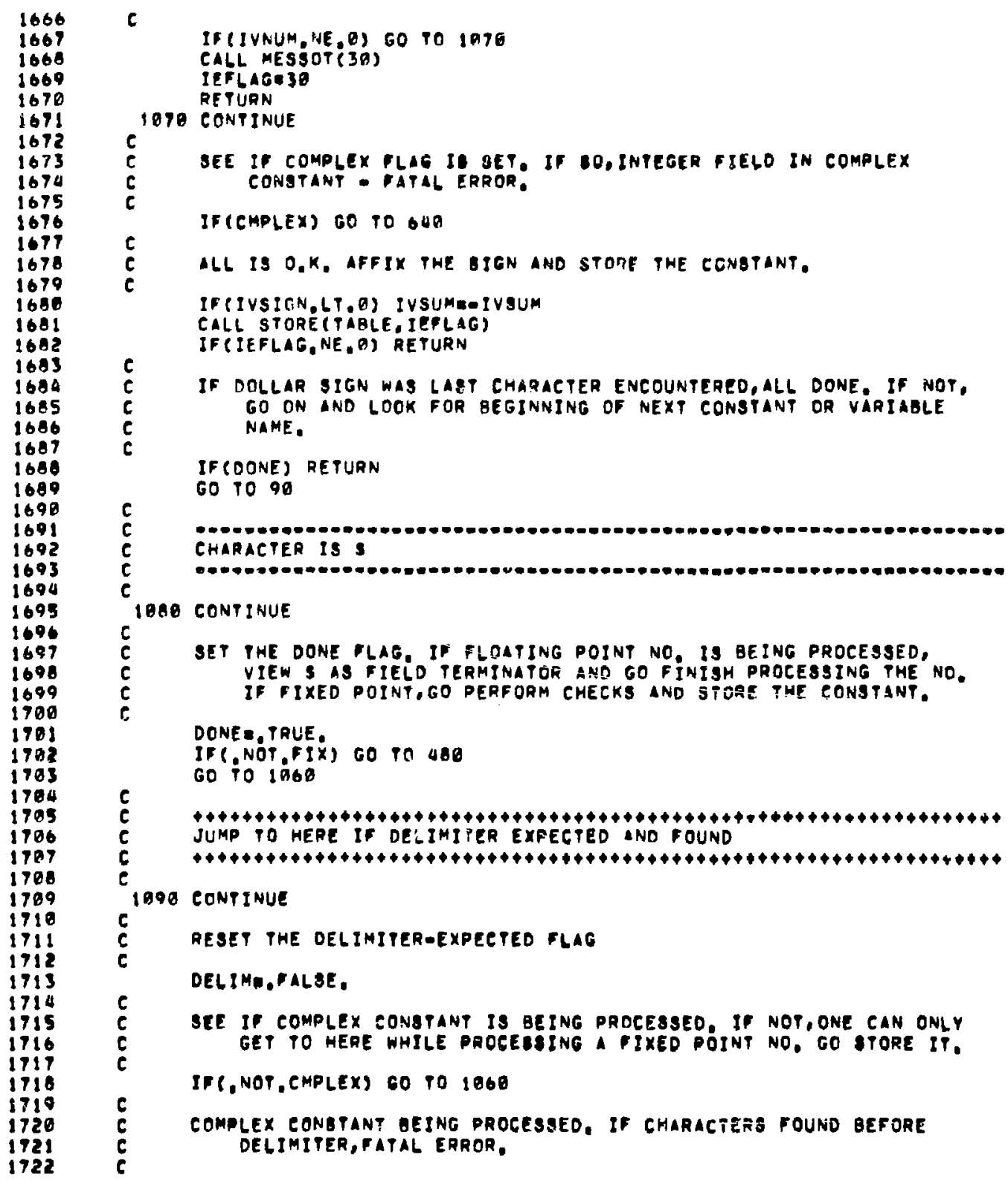




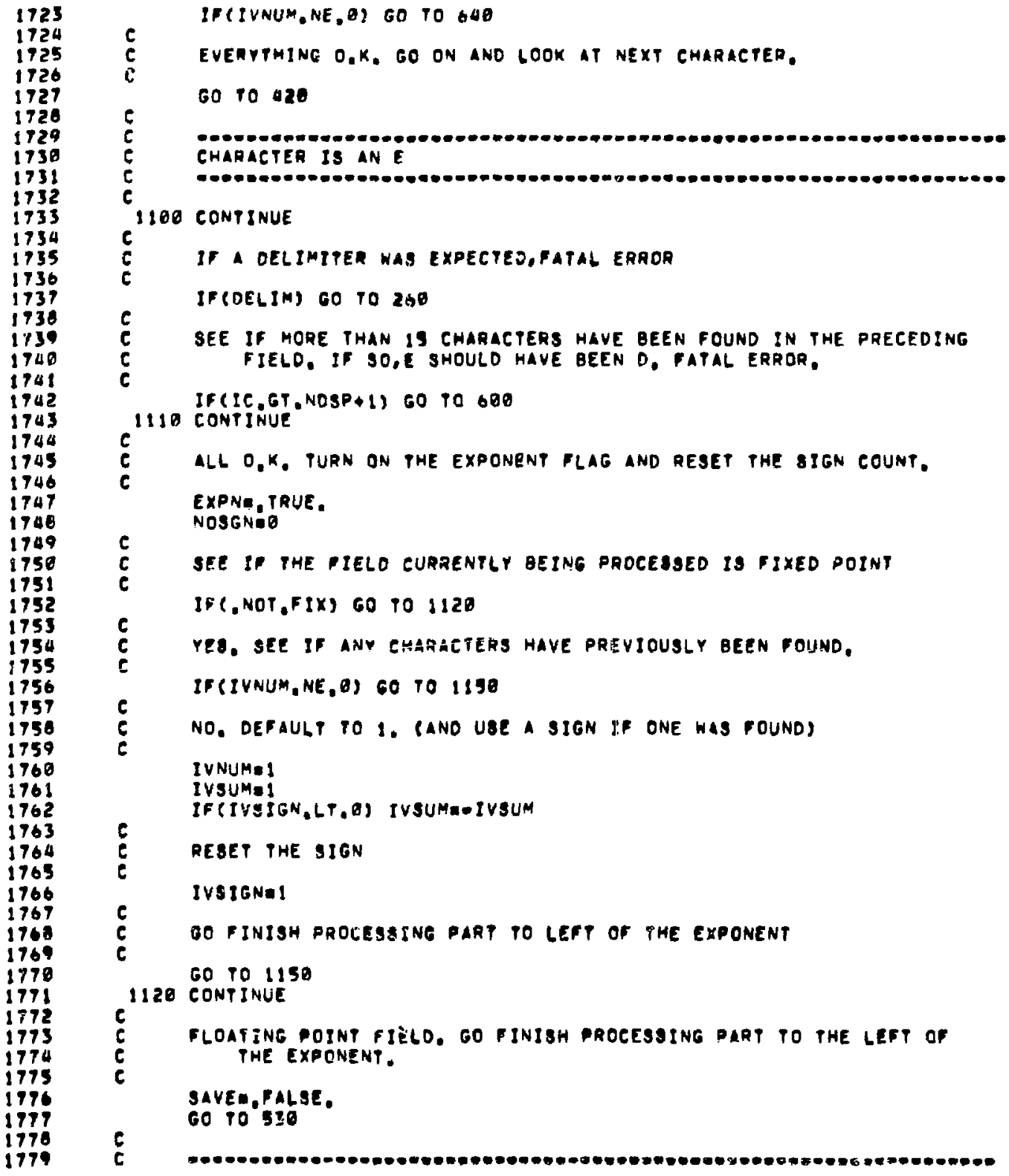




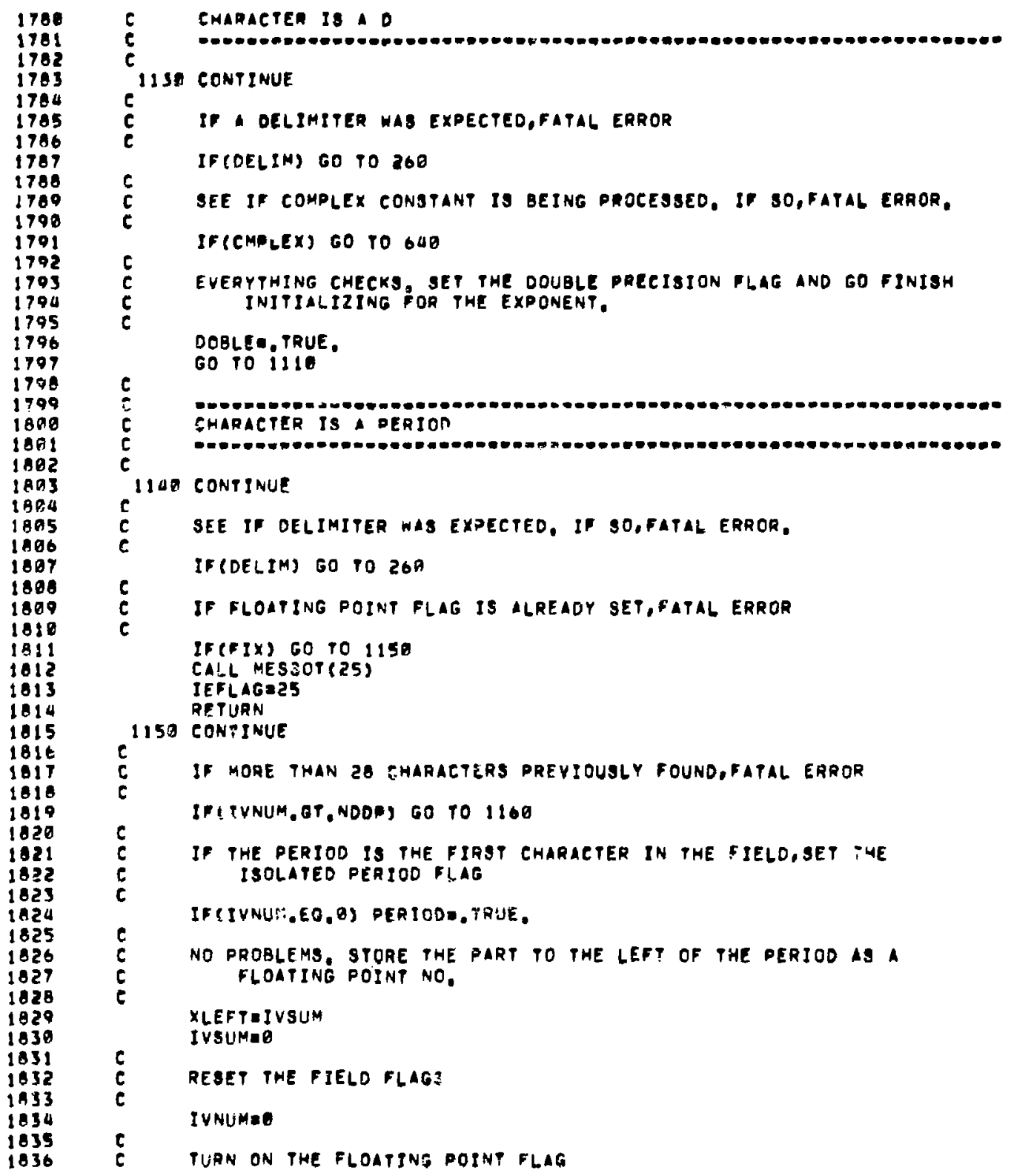




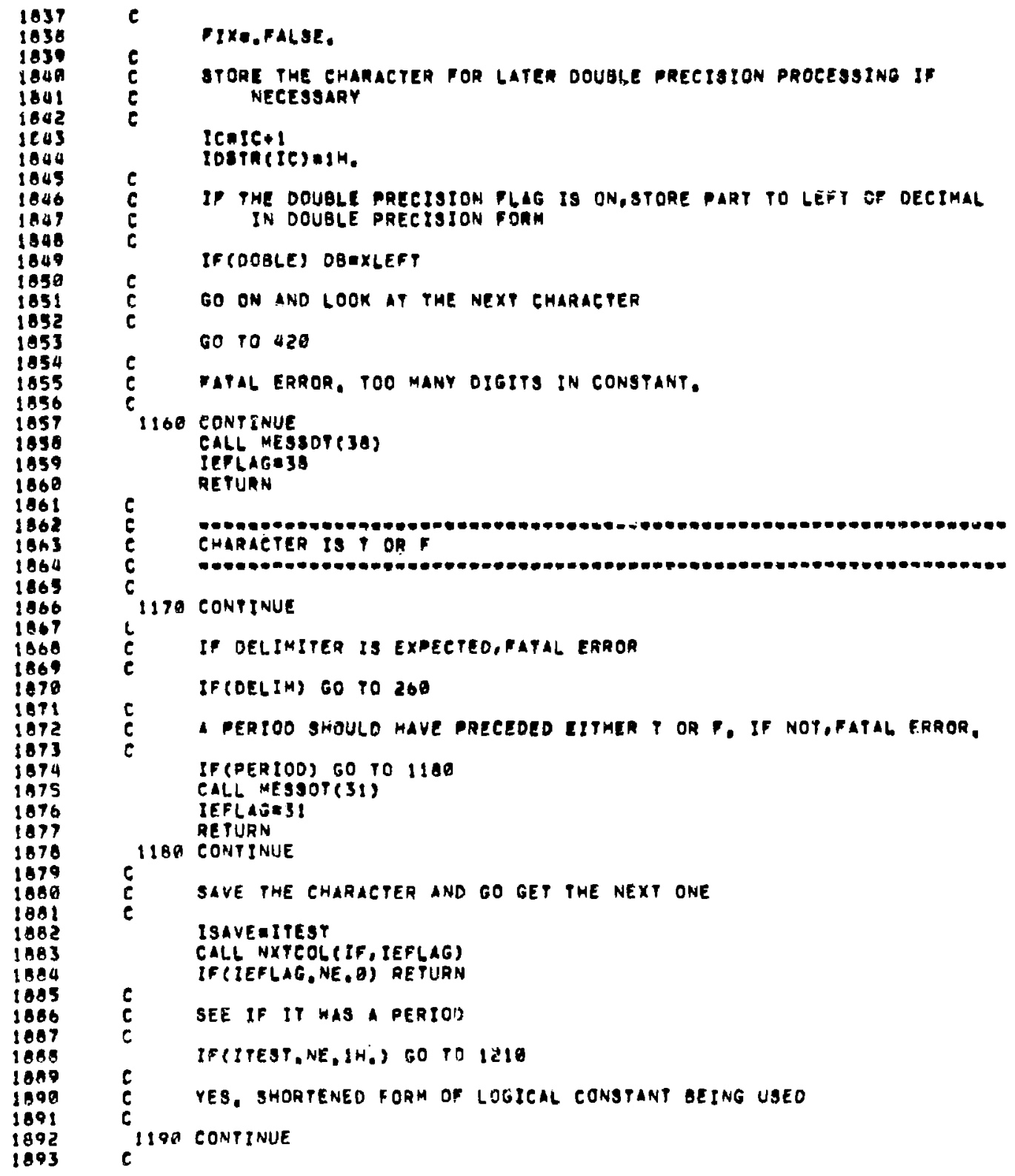




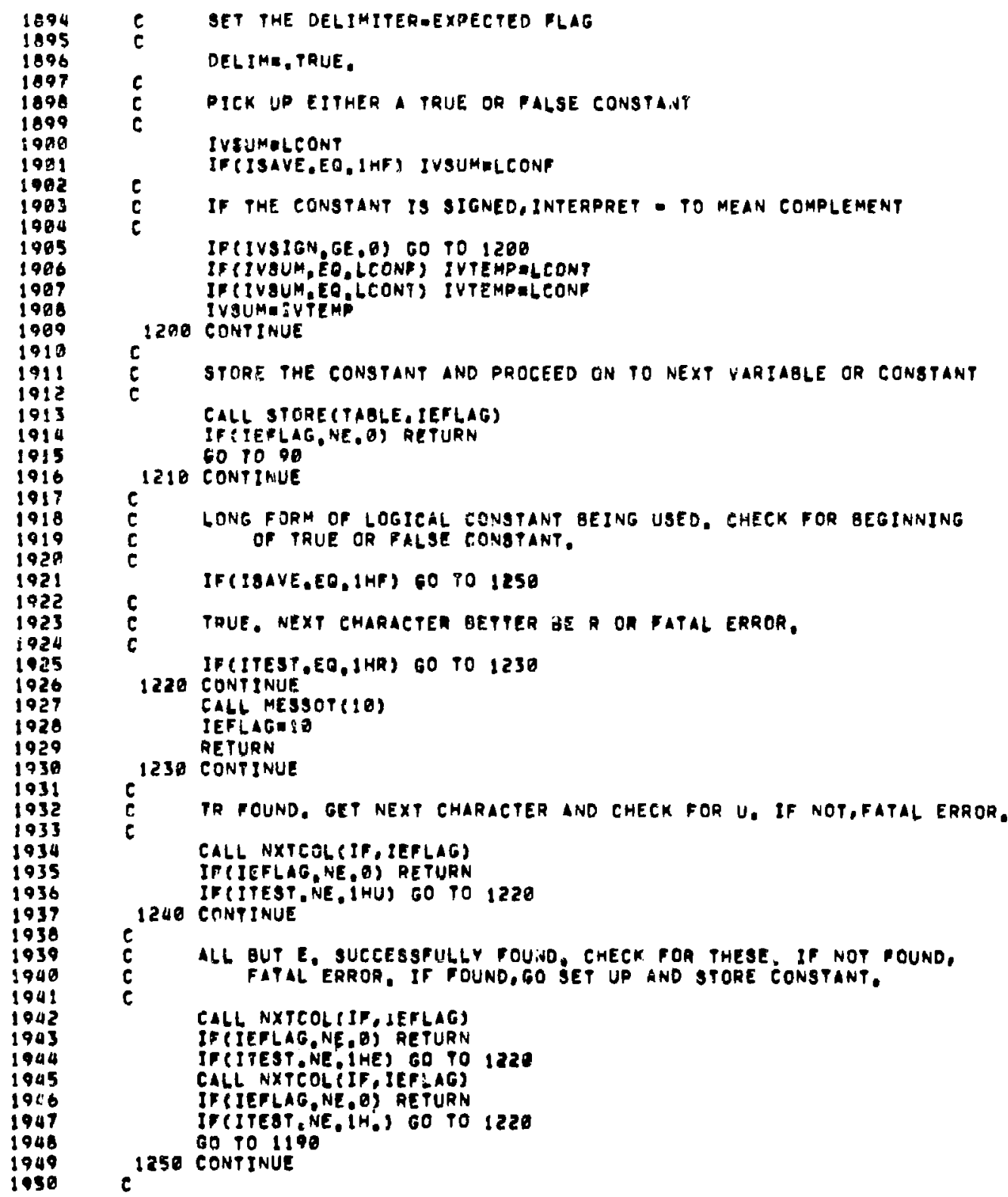




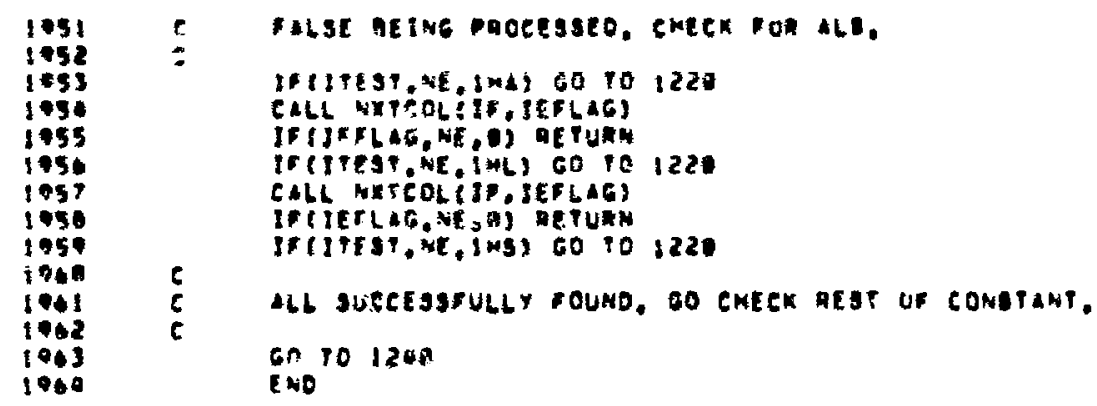

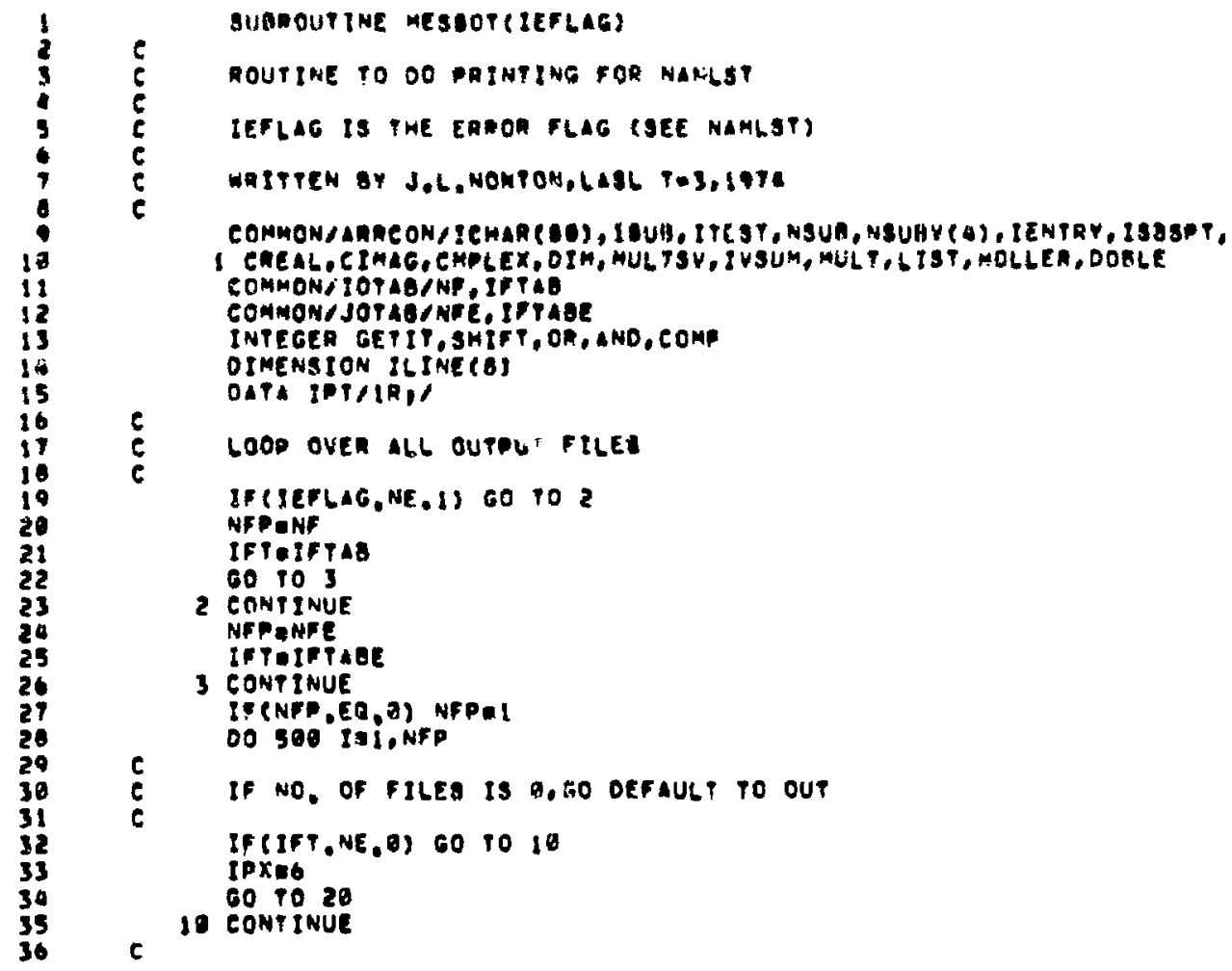




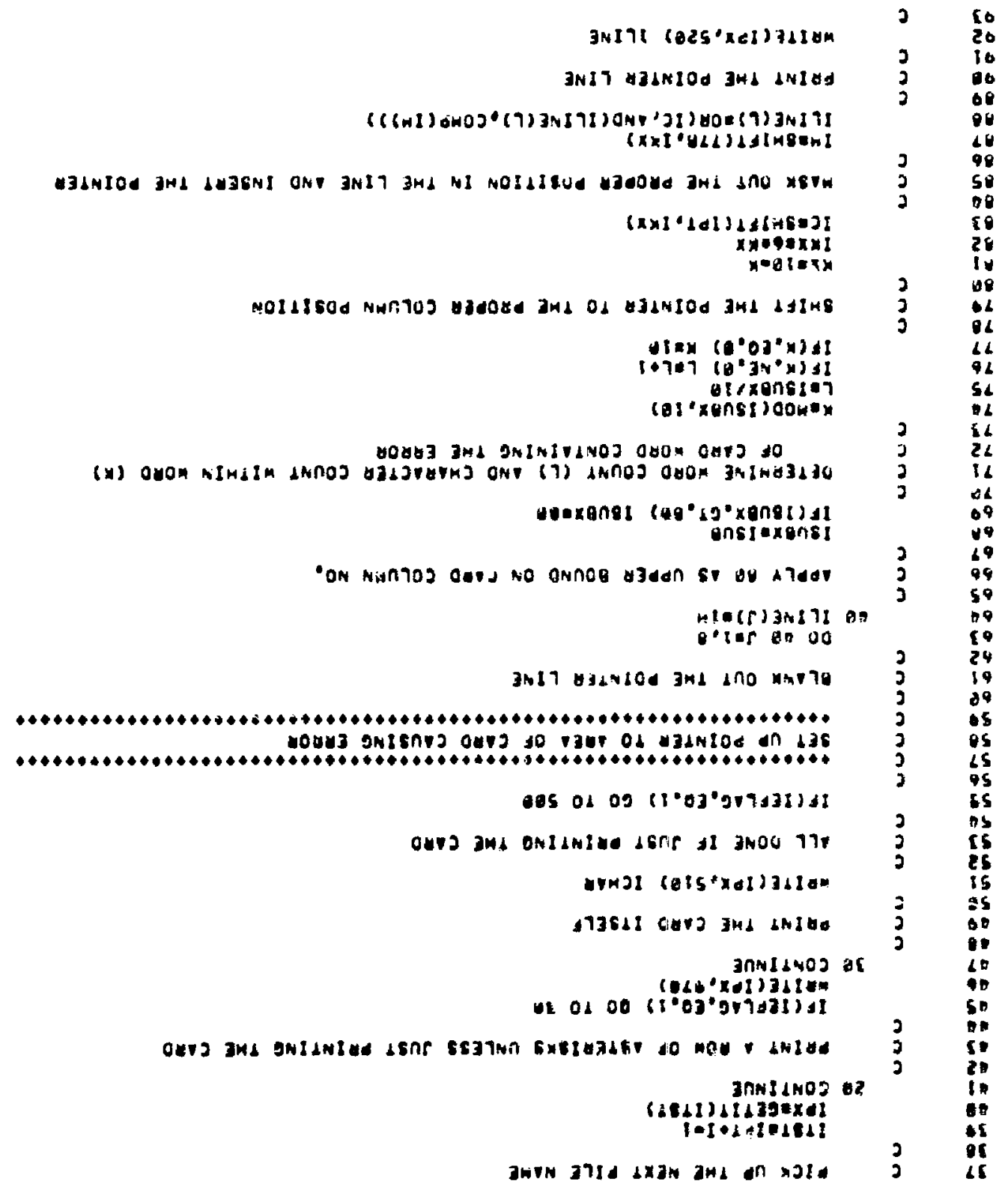




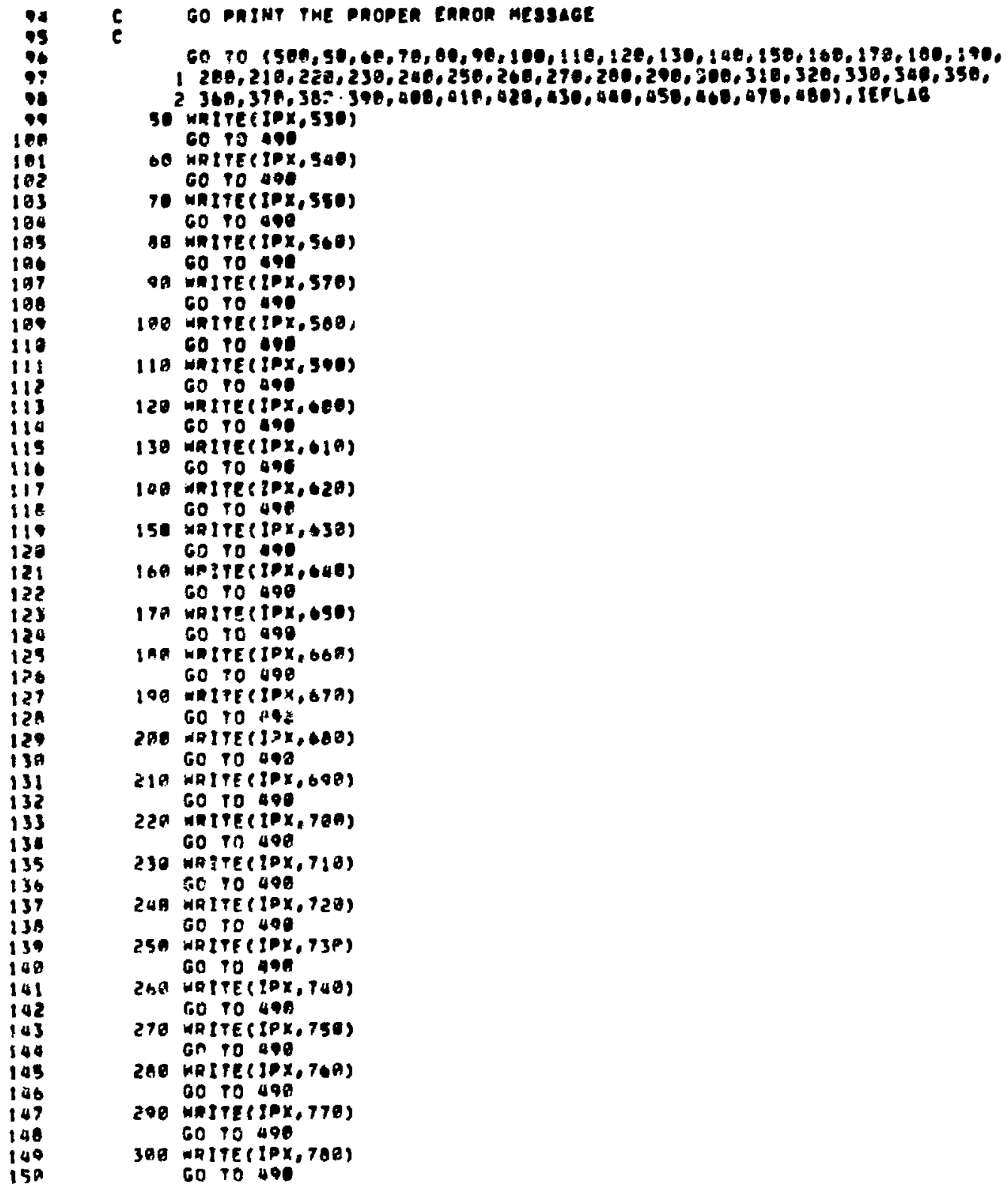




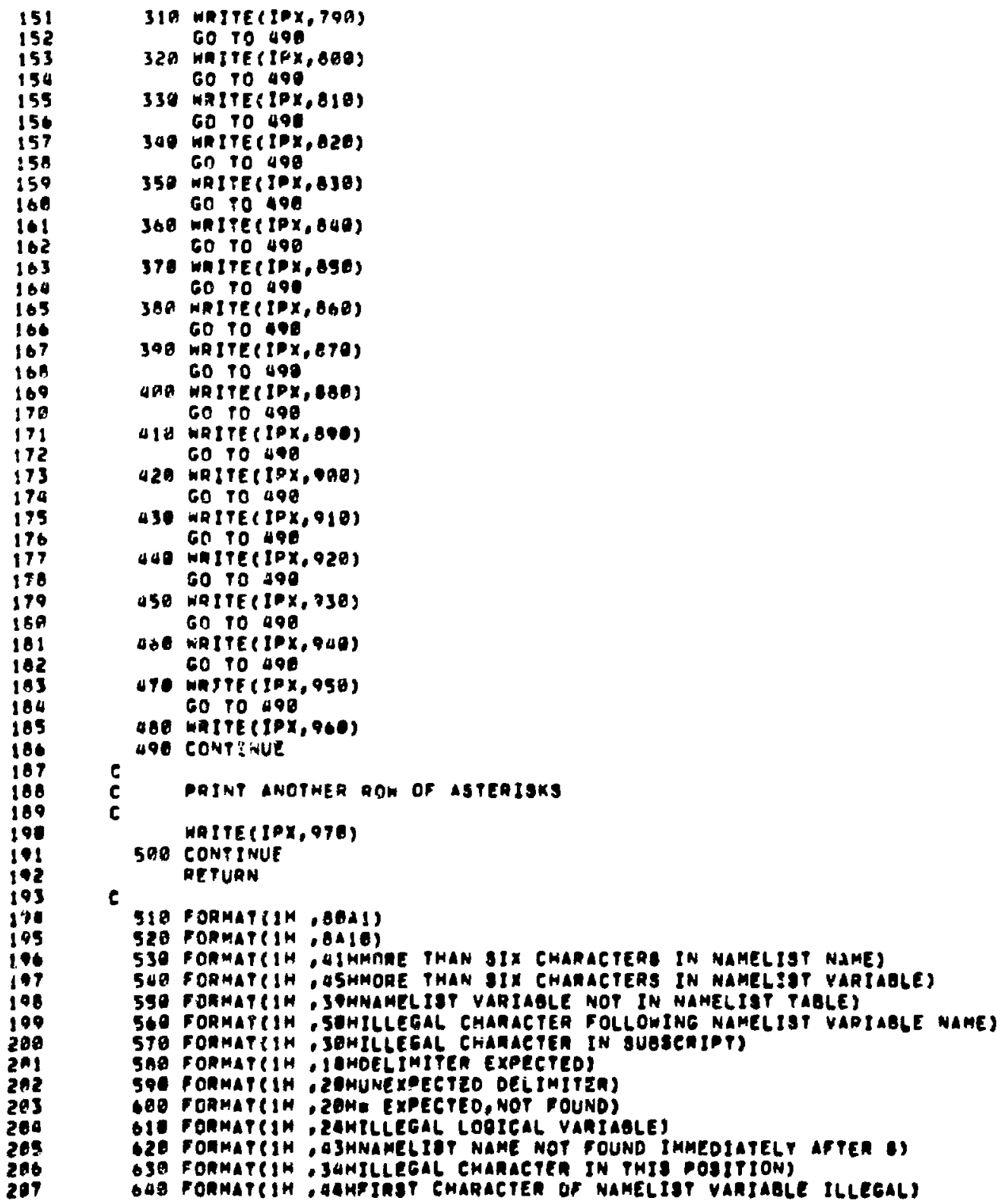
60 To 490

32月 WATTE $\{1 \% \times, 600\}$ 60 10 $490^{\circ}$

330 WAITE(IPX.818) 60 ro 098

300 HAITE(I0x, 020) Go 10 $49 \theta^{\circ}$

350 WRITE (IPX, 638) Go 10490

360 mRIPE(IPX,840) 60 To $490^{\circ}$

3To whITE (IDX, 8SE) 6070490

389 WRITE(IDX,860) go ro 40.

390 WAITE(I0X,870) 60 10 490

4AP WRITE(IPX, S80) 60 ro 498

य18 WAITE (10x, B00) 60 TO 408

42 WhITE (I $\left.9 x_{0}, 900\right)$ 60 TO 498

A30 WAITE(IPX, 910) GO 10 प9०

440 WHITE(IPX.920) 60 10 290

USO WRITE (10X.736) $6010 \quad 490$

DO WRITE(IPX, QUA) 60 10 490

uro waste (I0X, 958) 6070090

वBO WAITE (IPX, Q૯O)

c

МQO CONP? AUR

C PAINT ANOTHER RQM OF ASTEAISKS

$\mathbf{C}$

596 CONTINUE

ReTUAN

c

310 FoRmatidM , OBa!)

520 Fonmatelm. oale)

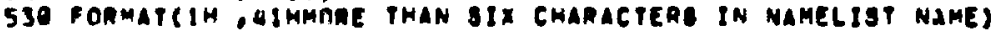

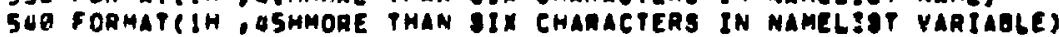

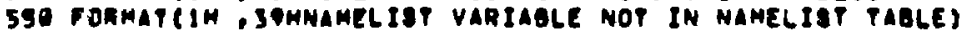

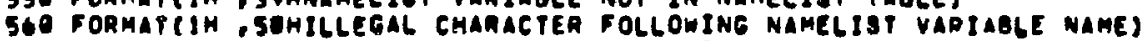

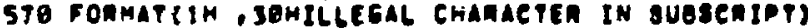

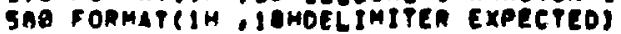

s9e Fonmatein izanuexoctizo delimitén)

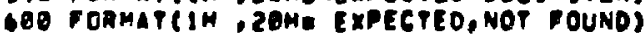

b10 Fonmarein . zantllegal logical vaniagles

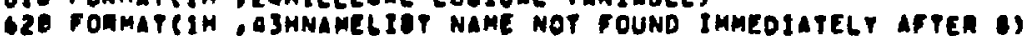

639 FonMat(IN . 34MILLEGAL CMARACTER IN PMIS OOSITION)

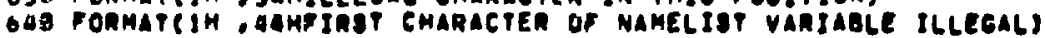



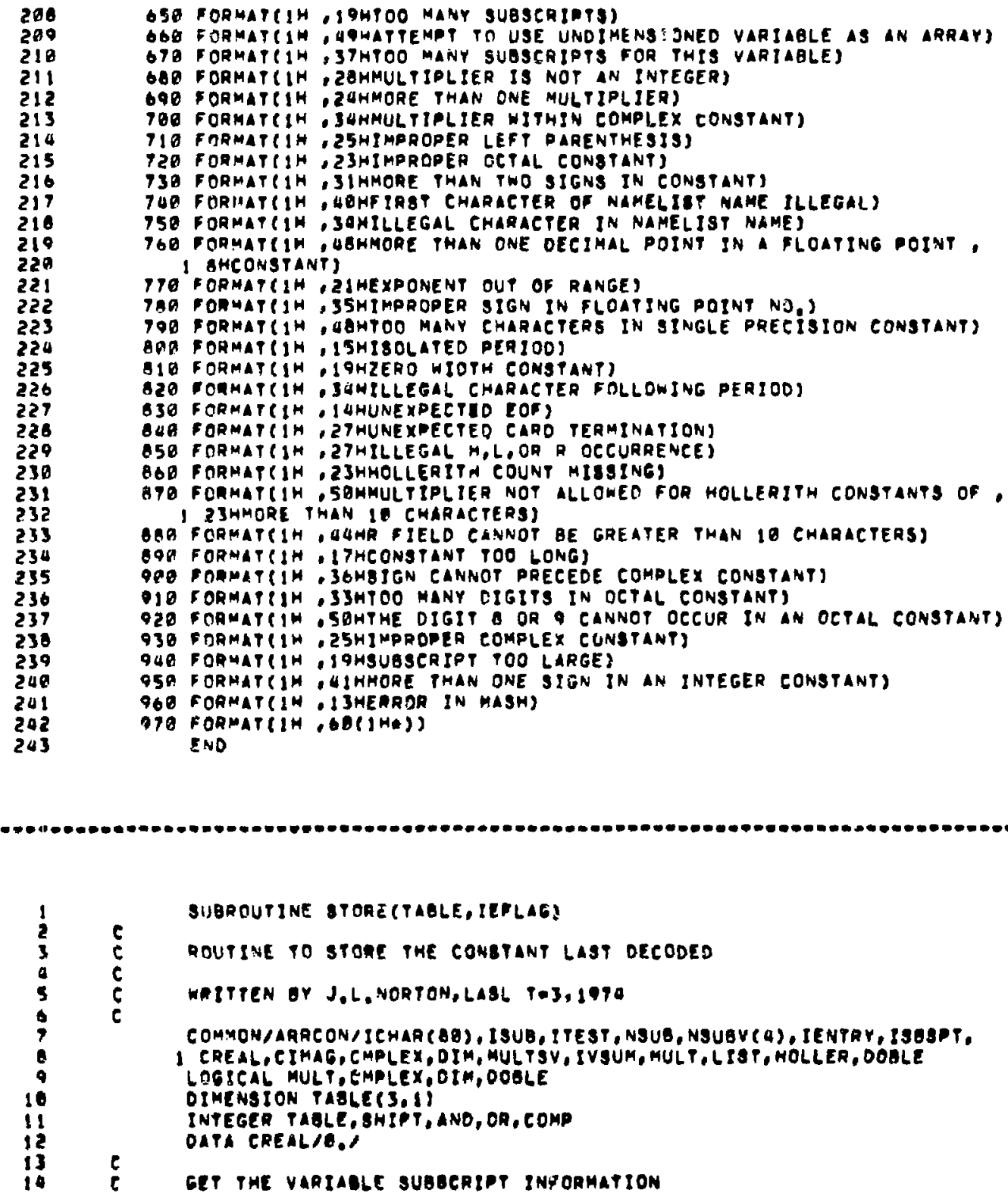


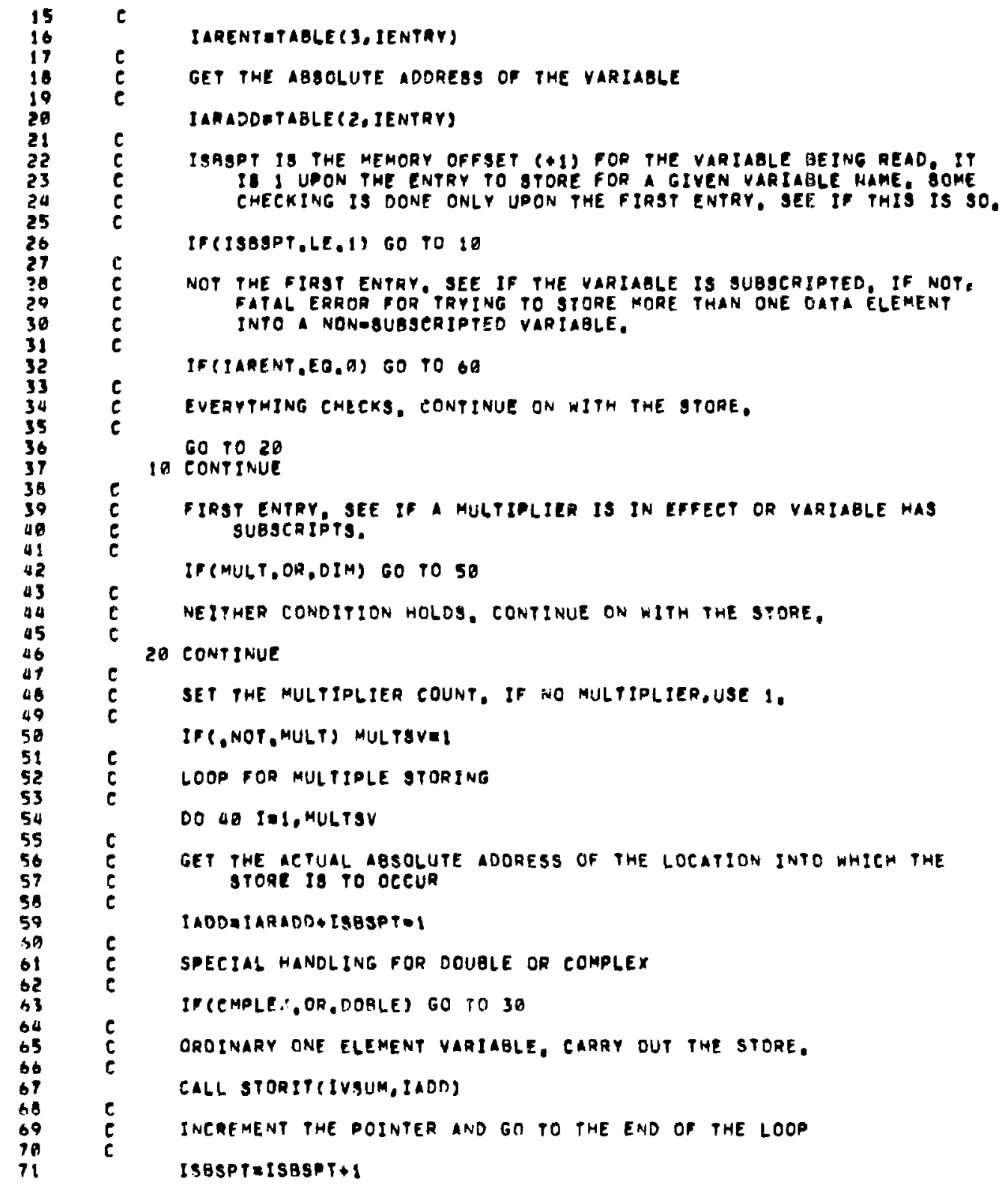




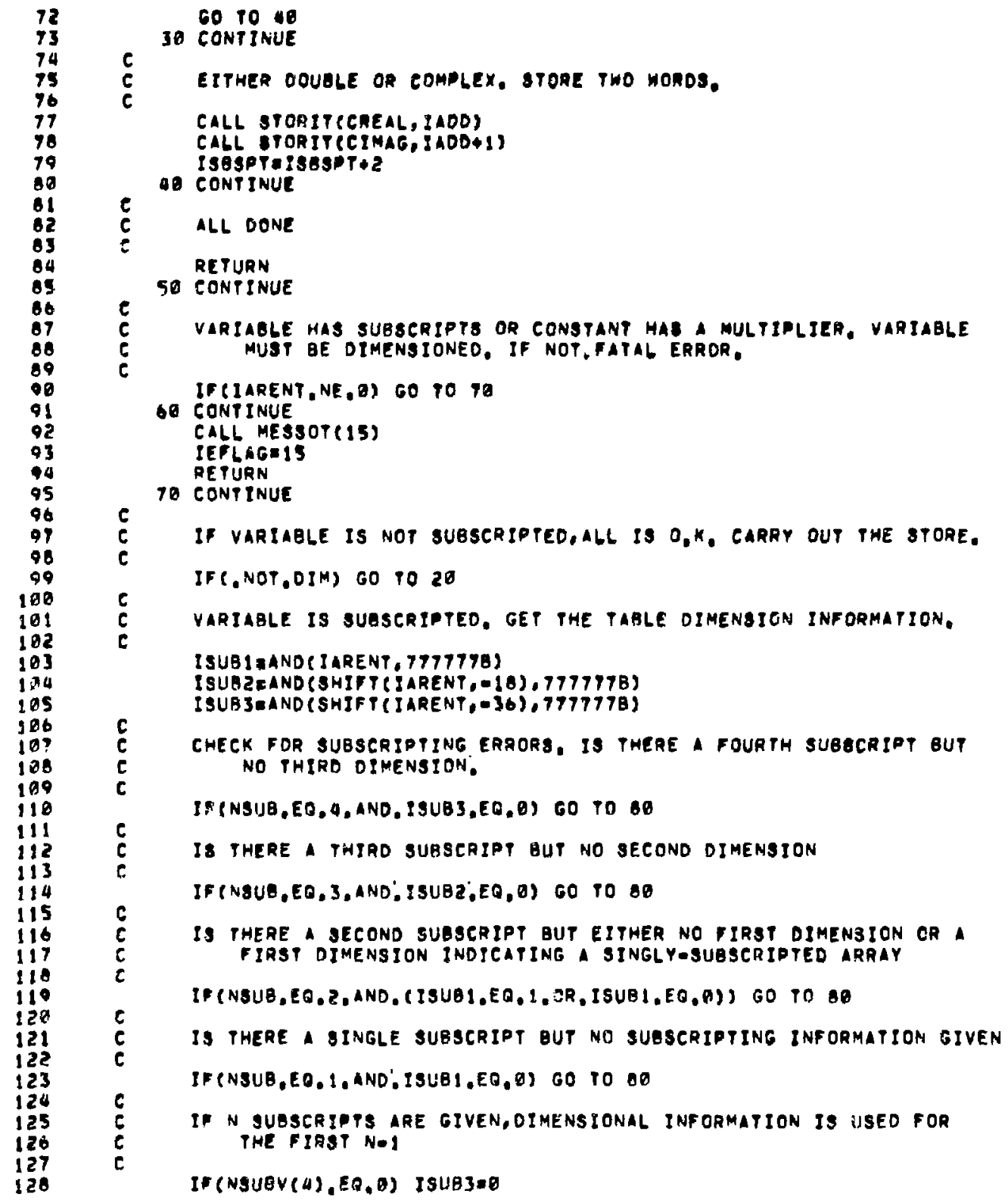



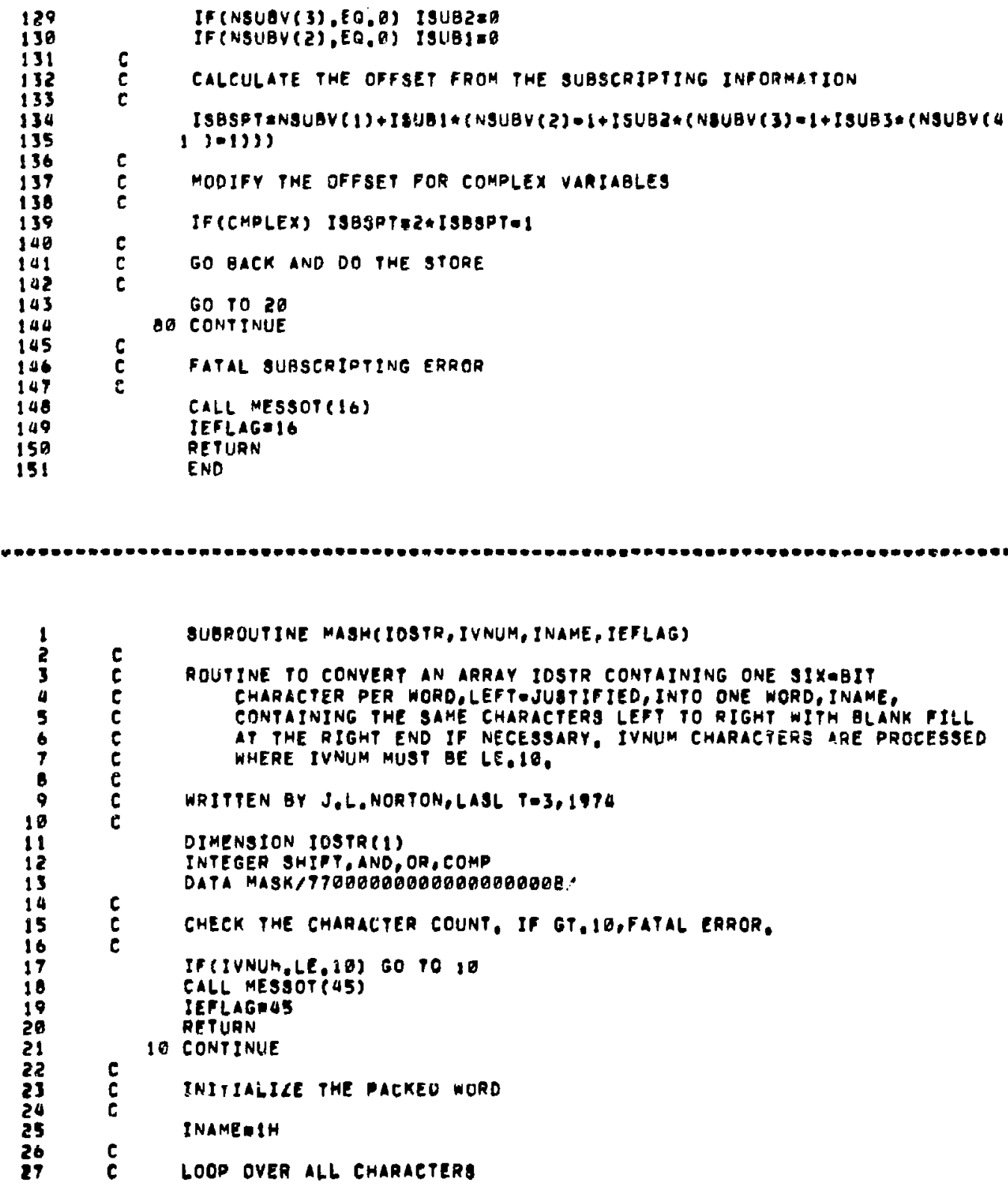

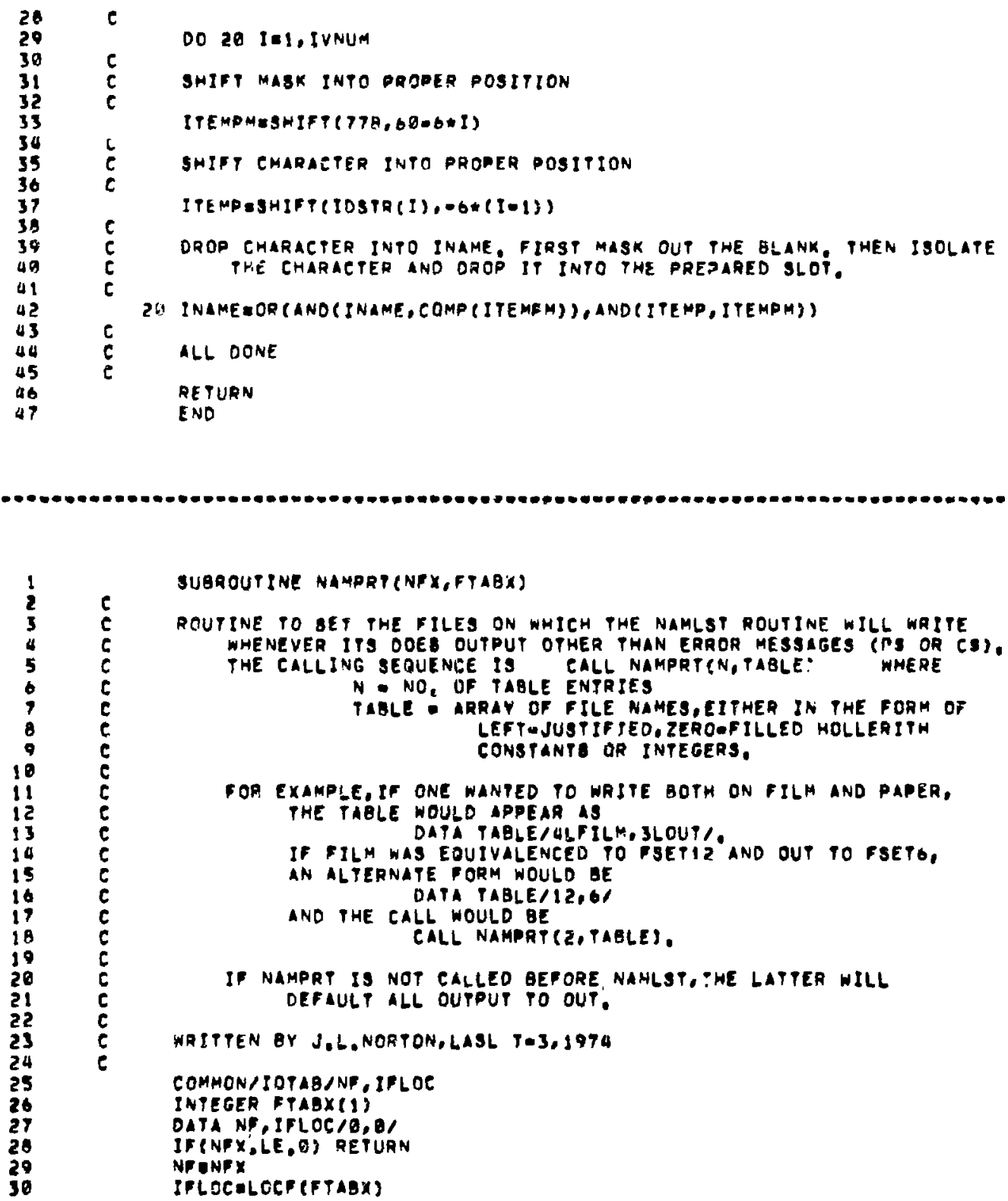
$\begin{array}{ll}31 & \text { RETURN } \\ 32 & \text { END }\end{array}$

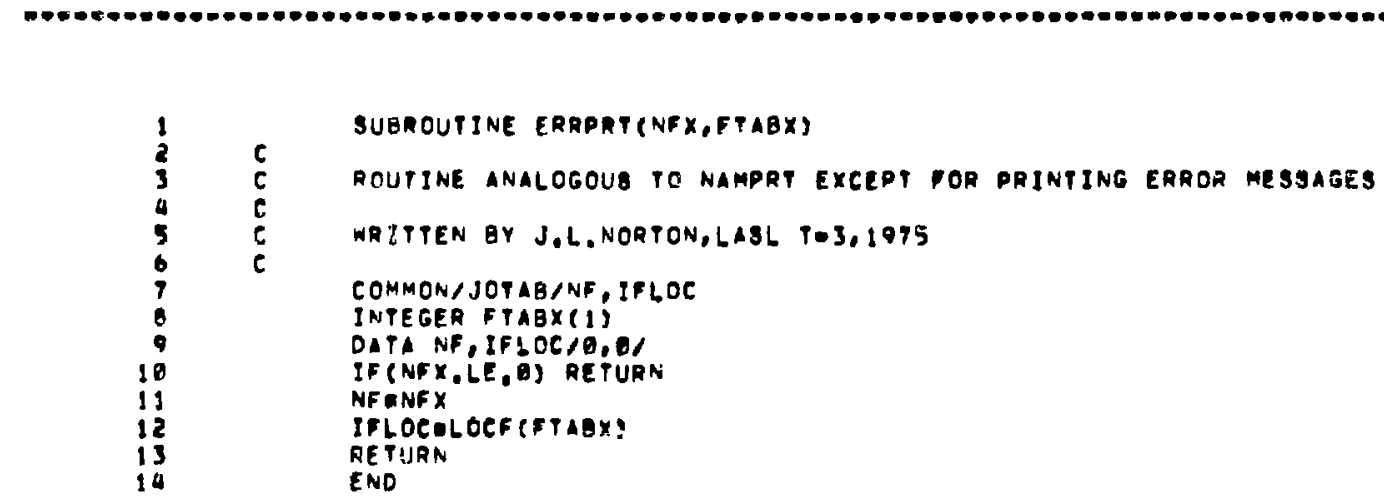

SUBROUTINE TABDEF (TABLE, NAME, ITSIZE, IEART)

ROUTINE TO INITIALIZE A NAMELIST PABLE

TABLE - ARRAY WHICH WILL BE USED TO STORE NAMELIST DATA NAMES AND RELATEO INFORMATION, IP MUSP BE I:EN+1) ELEMENTS LONG WHERE N IS THE NUMGER OF OISTINCT NAMELIST VARIABLES TO BE READ UNOER THIS NAME.

NAME - NAMELISI NAME,LEFT-JUSTIFIED,BLANKOFILLED HOLLERITH. IF ONE WERE GOING TO REAS CAROS OF THE FORM PSEODEIN.. NAME $\pi$ GHCODE IN.

ITSIZE - SECOND SUBSCRIPT OF THE TABLE ARRAY (MAXIMUM NO. OF TABLE ENTRIES+I)

IERRT - VARIABLE SET BY ASSIGNED GO TO AS RETURN POINT IF TABLE INITIALIZATION FNCOUNTERS AN ERROR CONOITION

WRITTEN BY J.L.NORTON,LASL T-3,197L

INTEGER TABLE

DIMENSION TABLE(3,1)

COMMON /ERRORC IIERRTP

TARLE $(1,1)=N A M E$

TABLE (2,1) $=1$ TSIZE

TABLE $(3,1)=0$

IEARTPEIEART

RETURN

END
} 
TABLE - AN ARRAY WHIEH HAS GEEN INITIAGIZEO OY A CALL PO TABDEF 


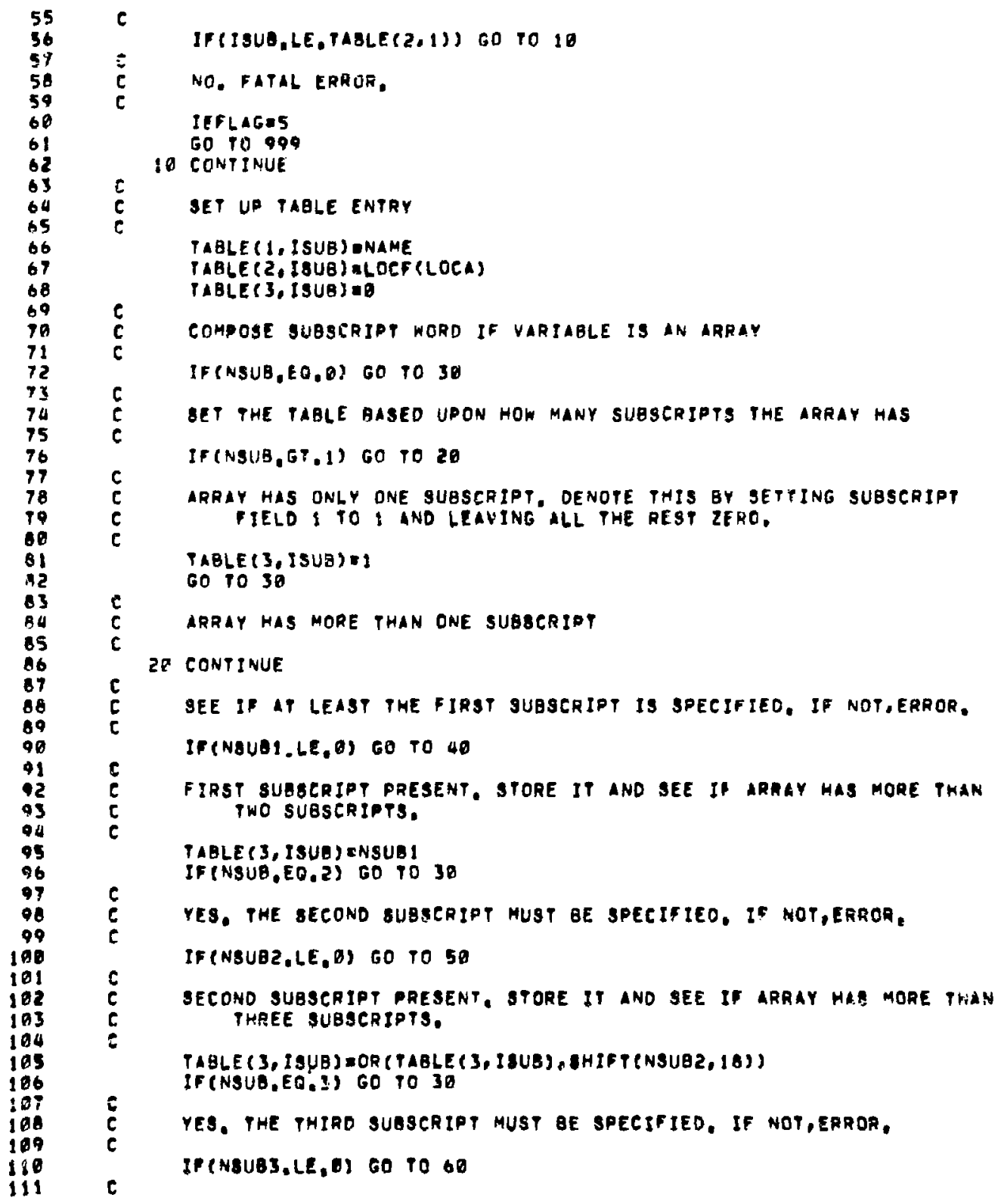



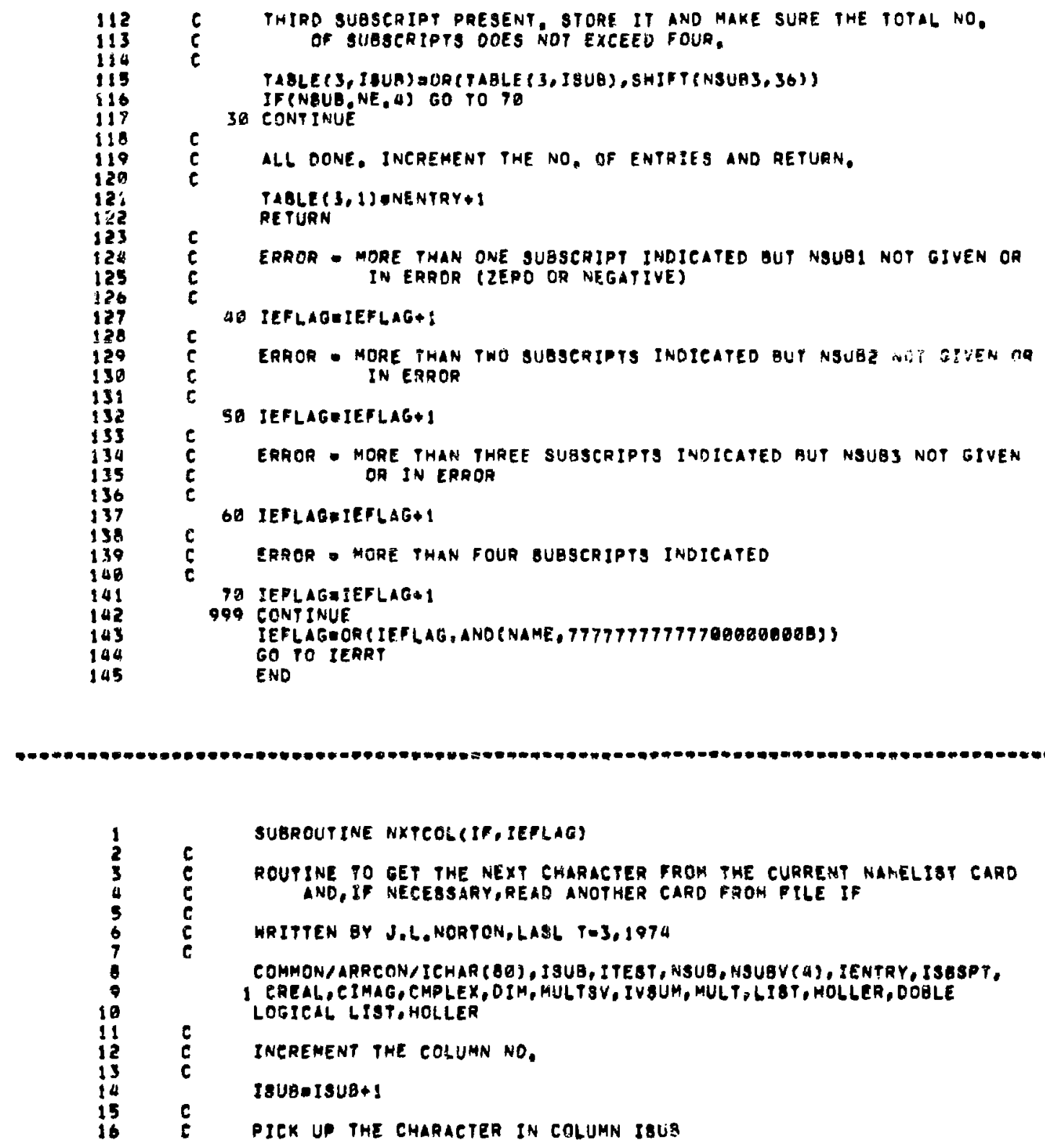


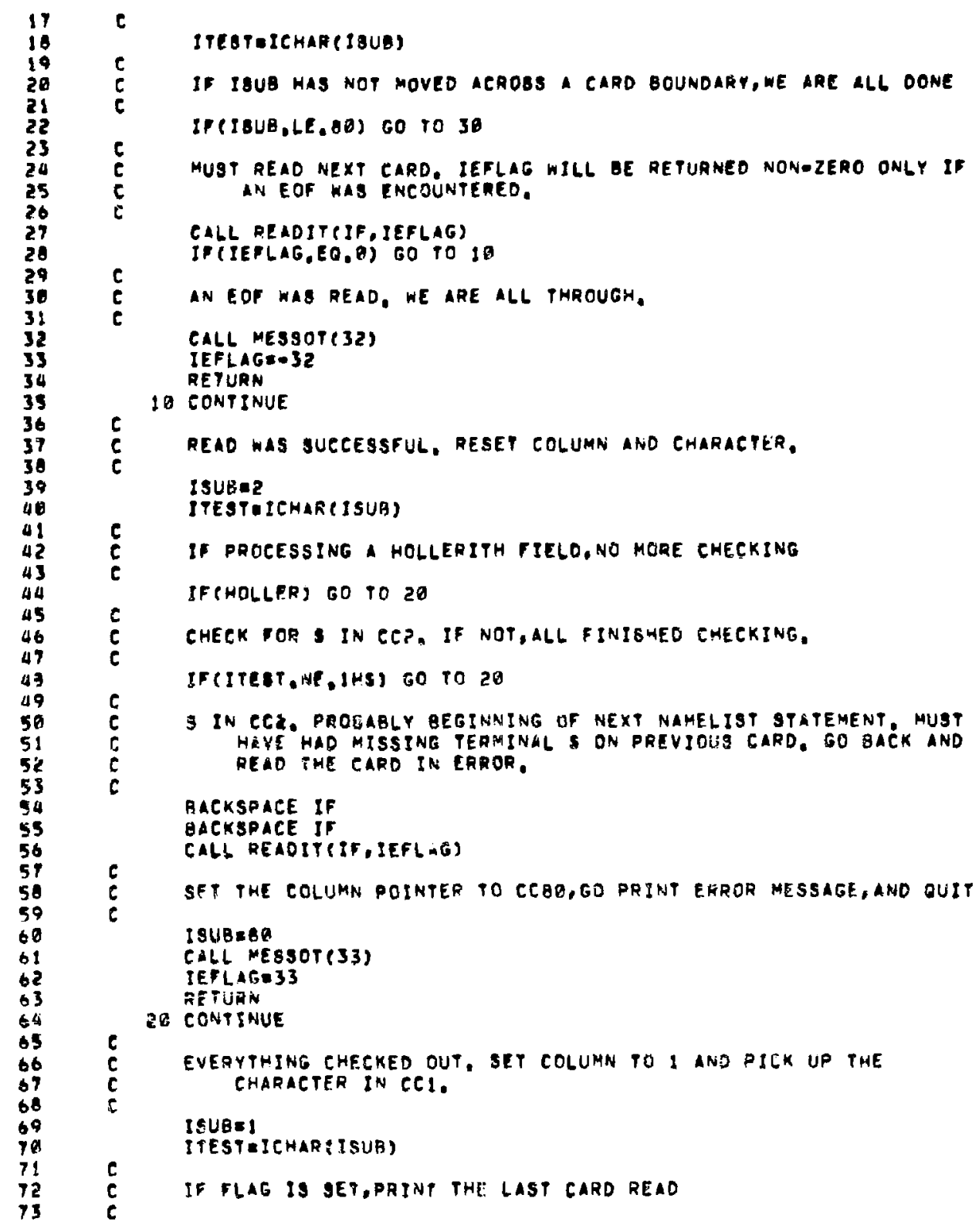




$\begin{array}{ll}74 & \text { IF(LIST) CALL MESSAYKII } \\ 75 & 30 \text { CONTINUE } \\ 76 & \text { RETUNN } \\ 77 & \text { END }\end{array}$
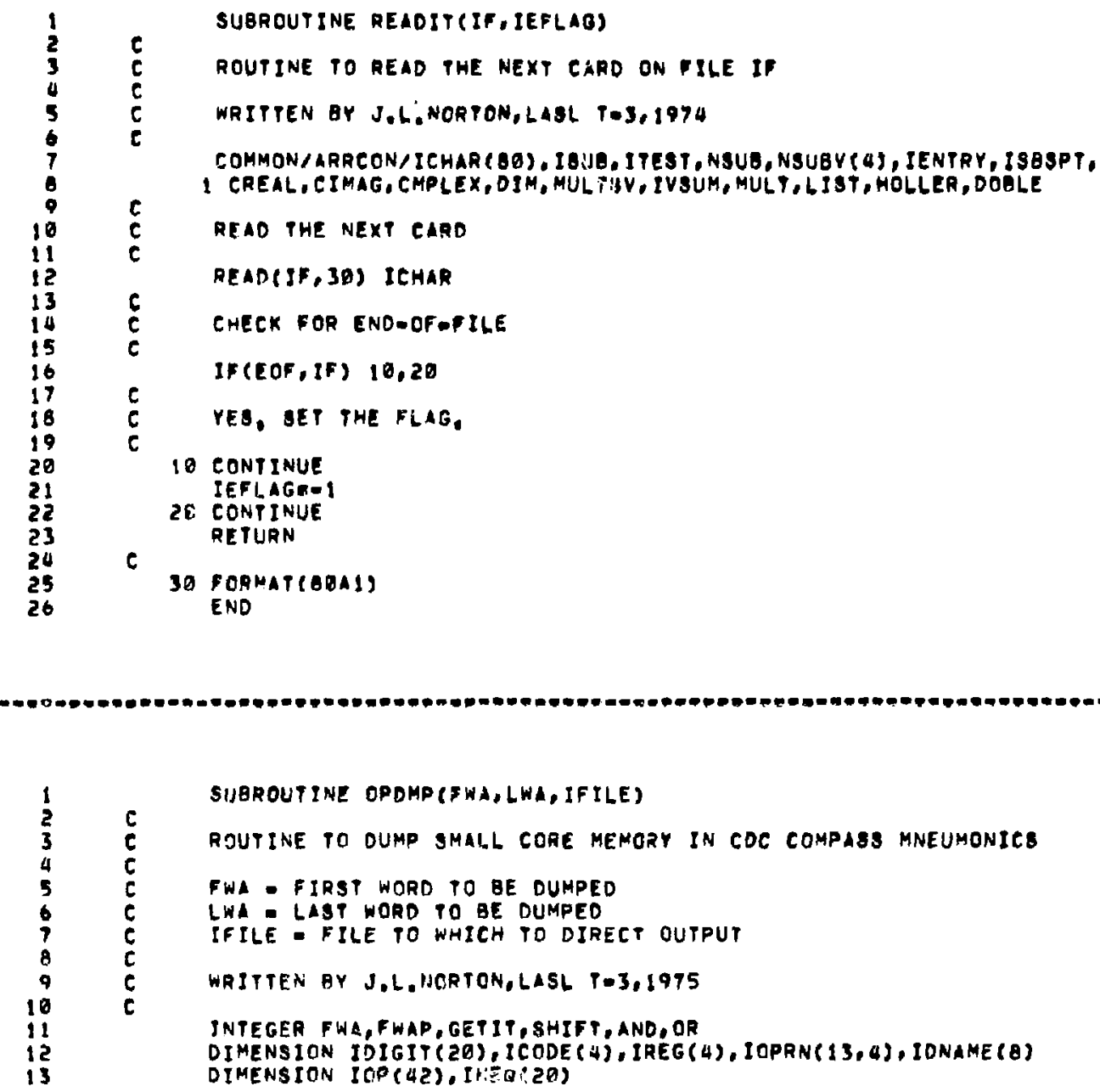


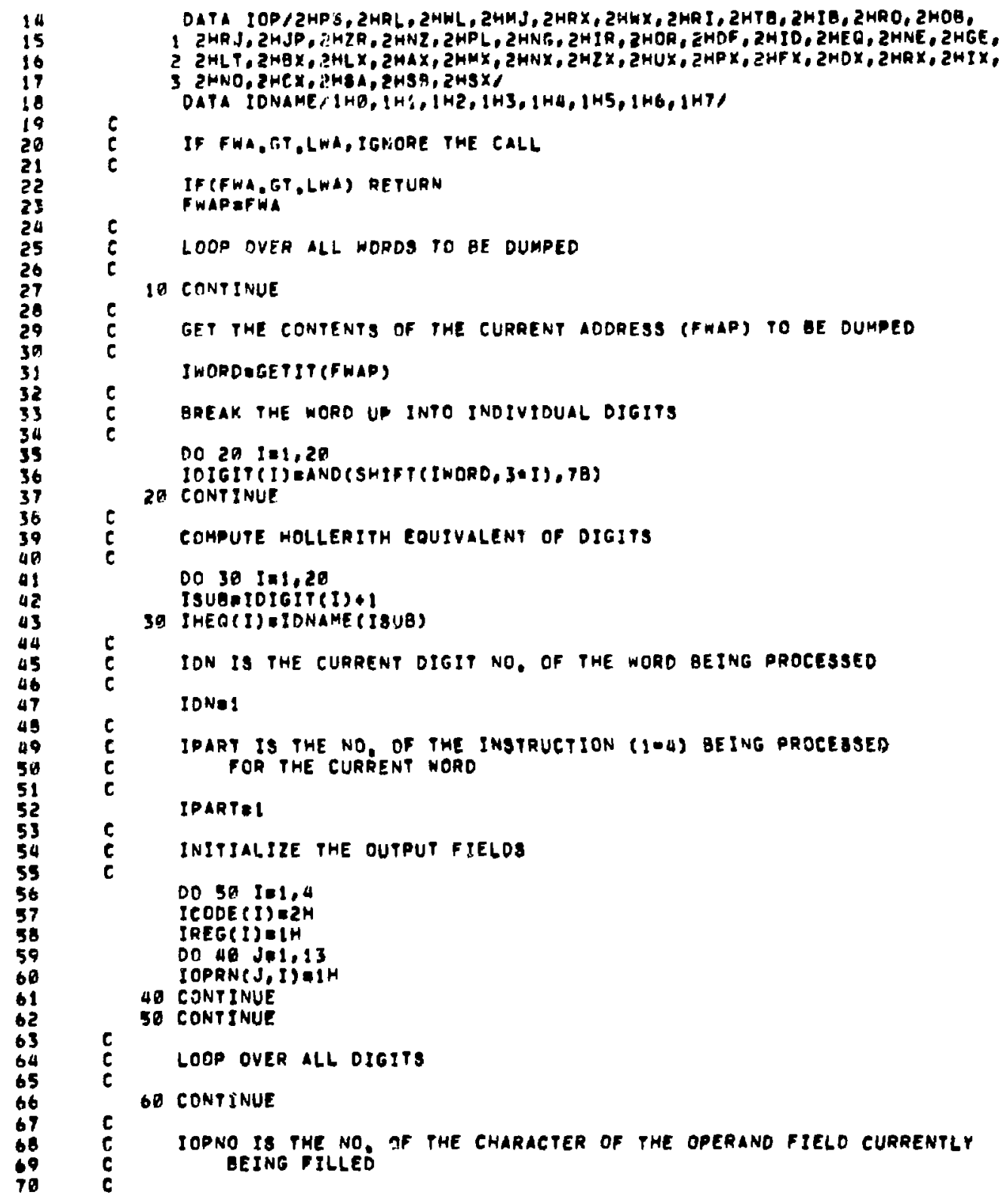




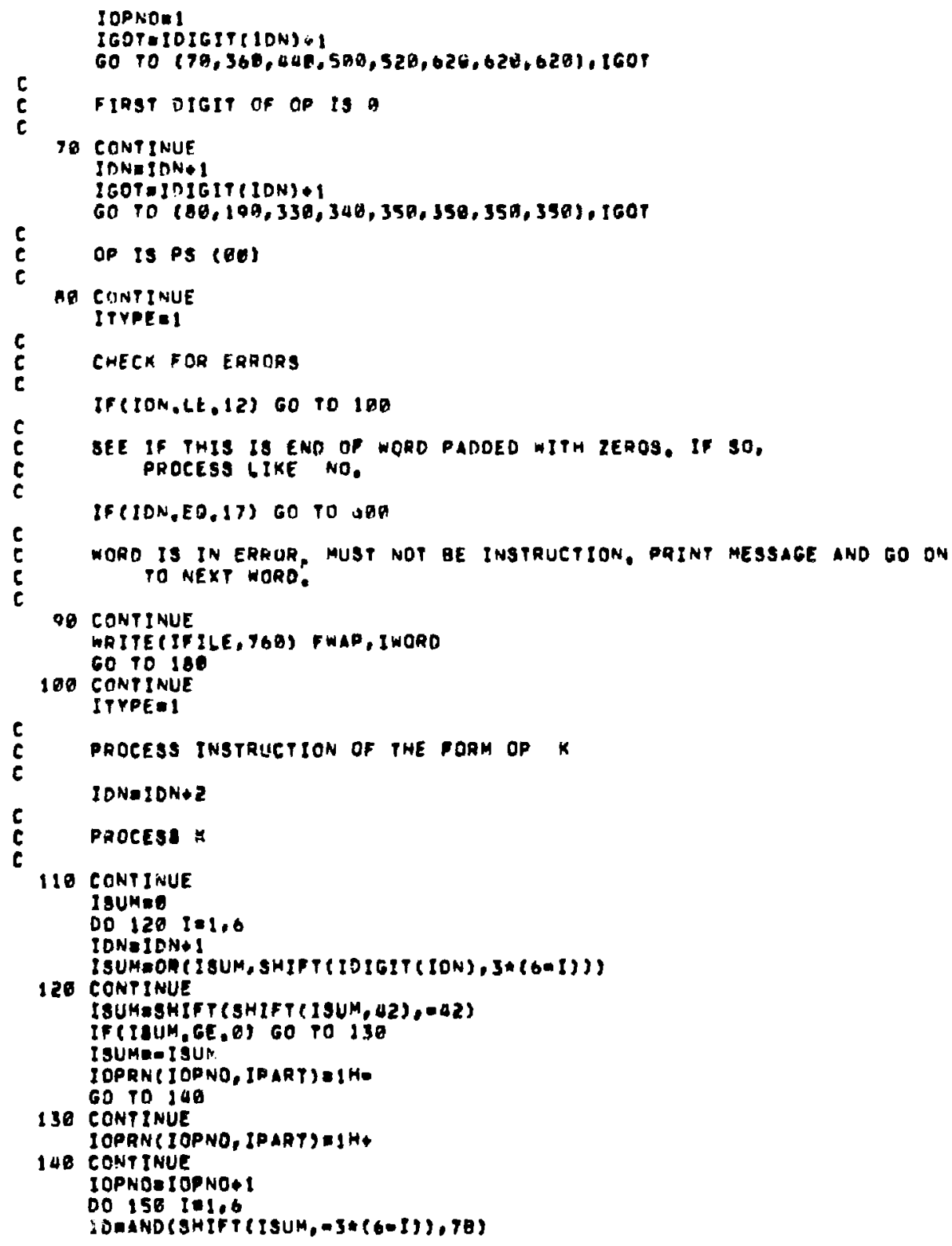




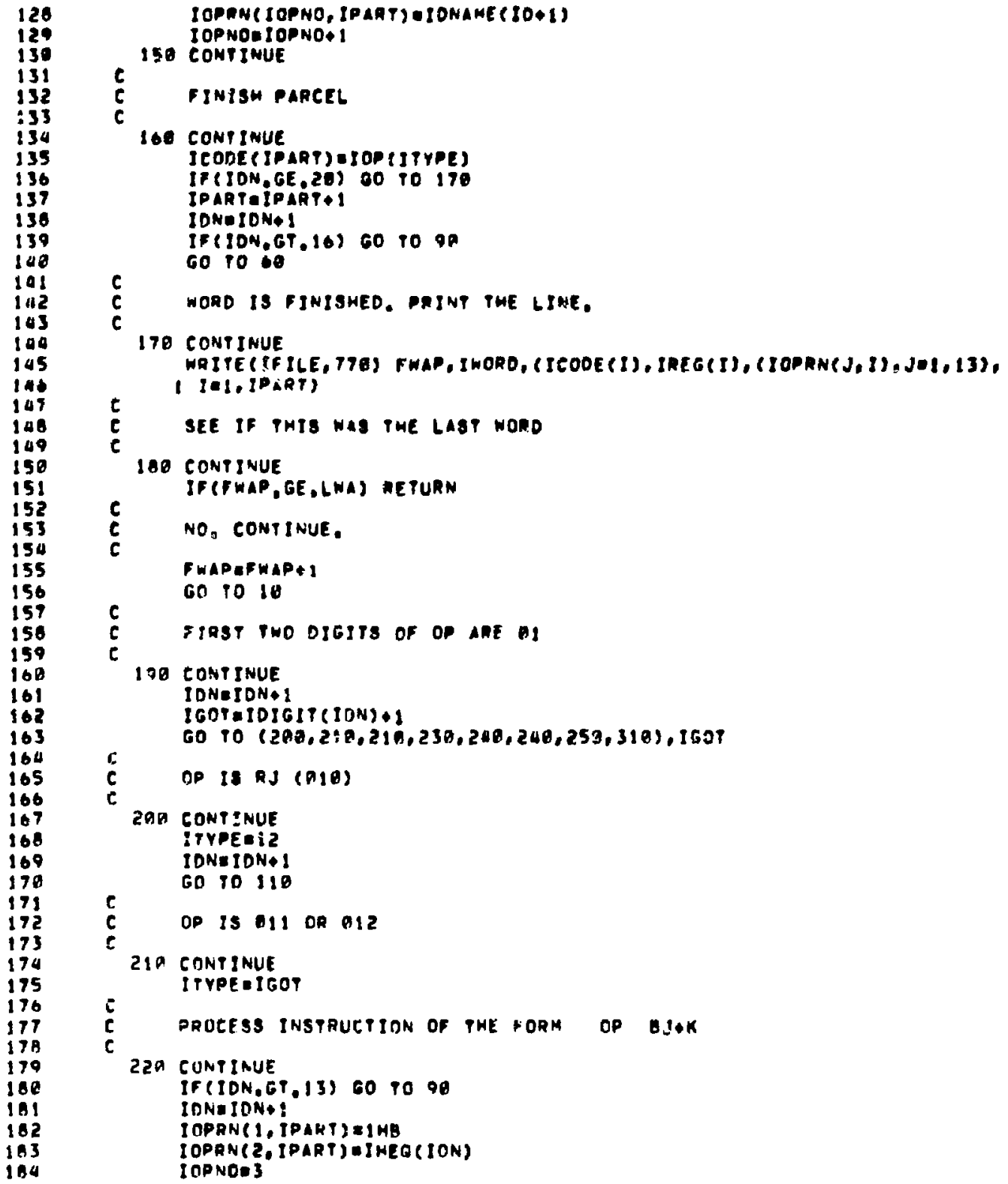




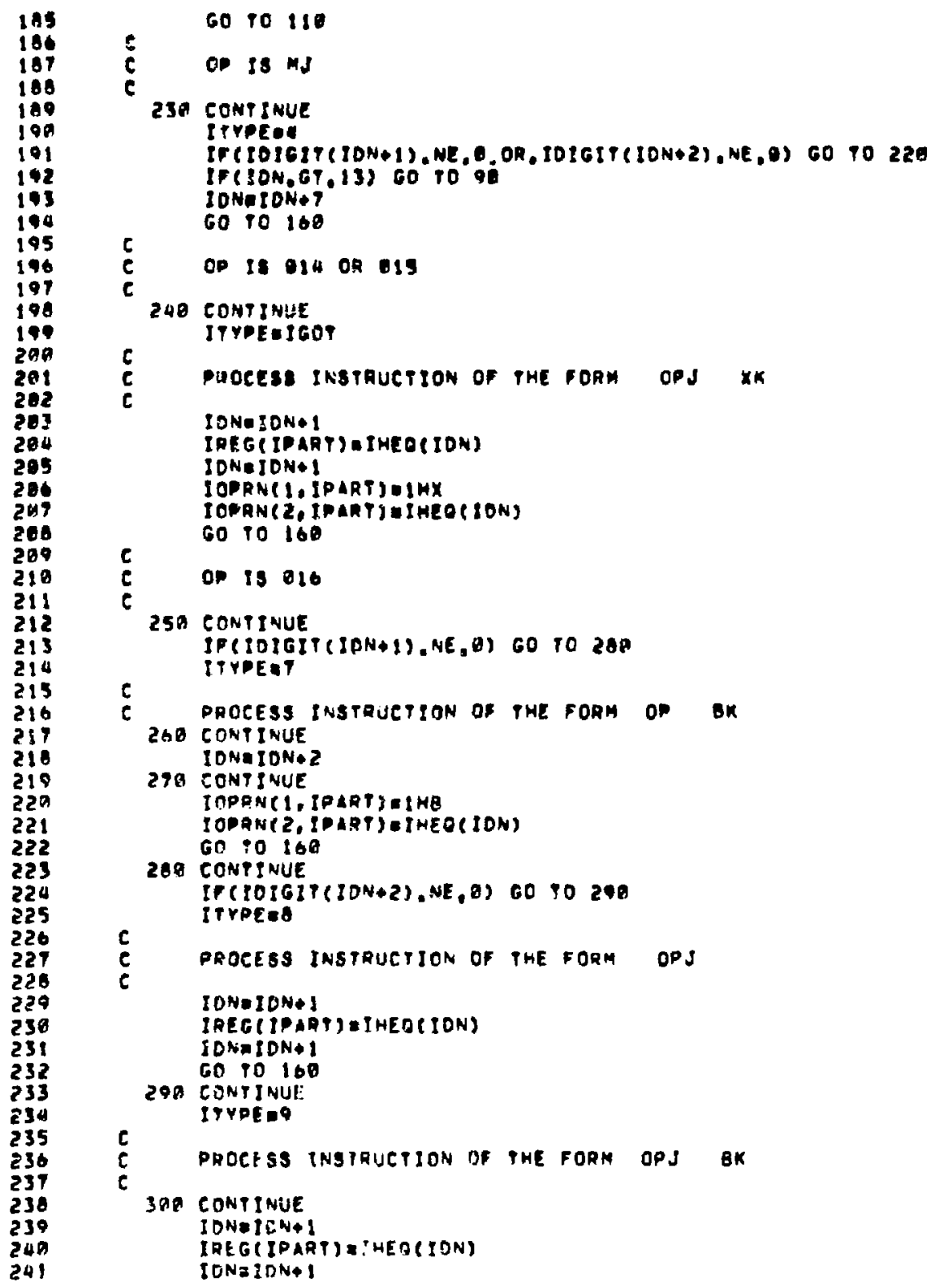




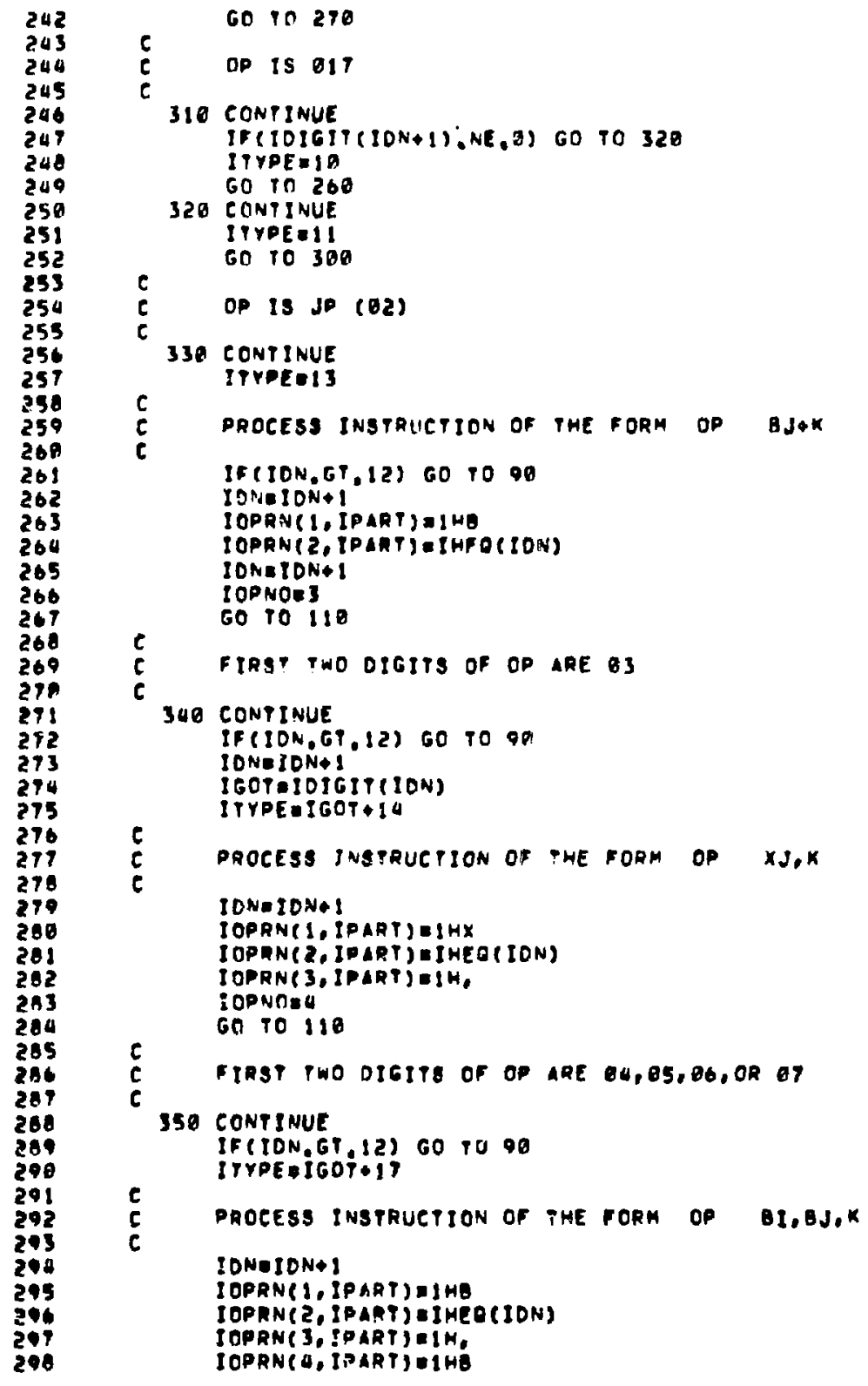


(2 $40 . h, 2.5 \cdot 1=1021)$

$x \times 16 x$

$x x=6 x$

$x x+r x$

$x x=6 x$

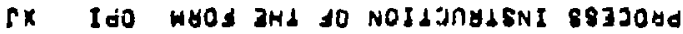

xx/ no odv

BOE OL OP

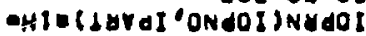
JกNI LROJ OIB

XXa no oOV

osr of og

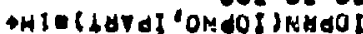
JกNI INOJ Dด"

$x x+$ no gor

0910102

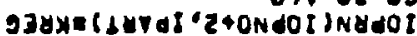

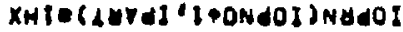

anNISNOS 808

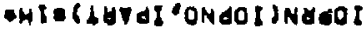

BNAISNOJ OOE

$x x=$ no oor

$7028.62 n \cdot 014.00 \pi \cdot 005)$ op 02

tolagtajogt

E=ONAOI

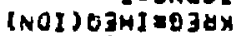

$0910102(1.03 .7005) \pi 1$

B +NOIMNGI

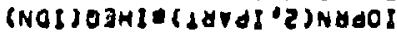

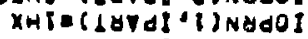
i +NOI MNOI

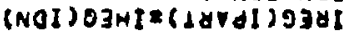

inOT.MOI

JกNI LNOJ

0,5

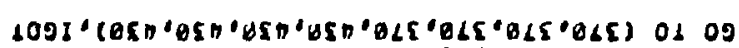

$1+(N O T)+1910 T=2091$

i+nOTONOI

$92 \div 3 d A d 1$

IINILNOJ O9E

ifxesl do is do so 11910 lsalf

0110109

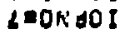

ihtechutat cishadol

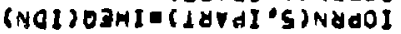

I 4NOTENOI 


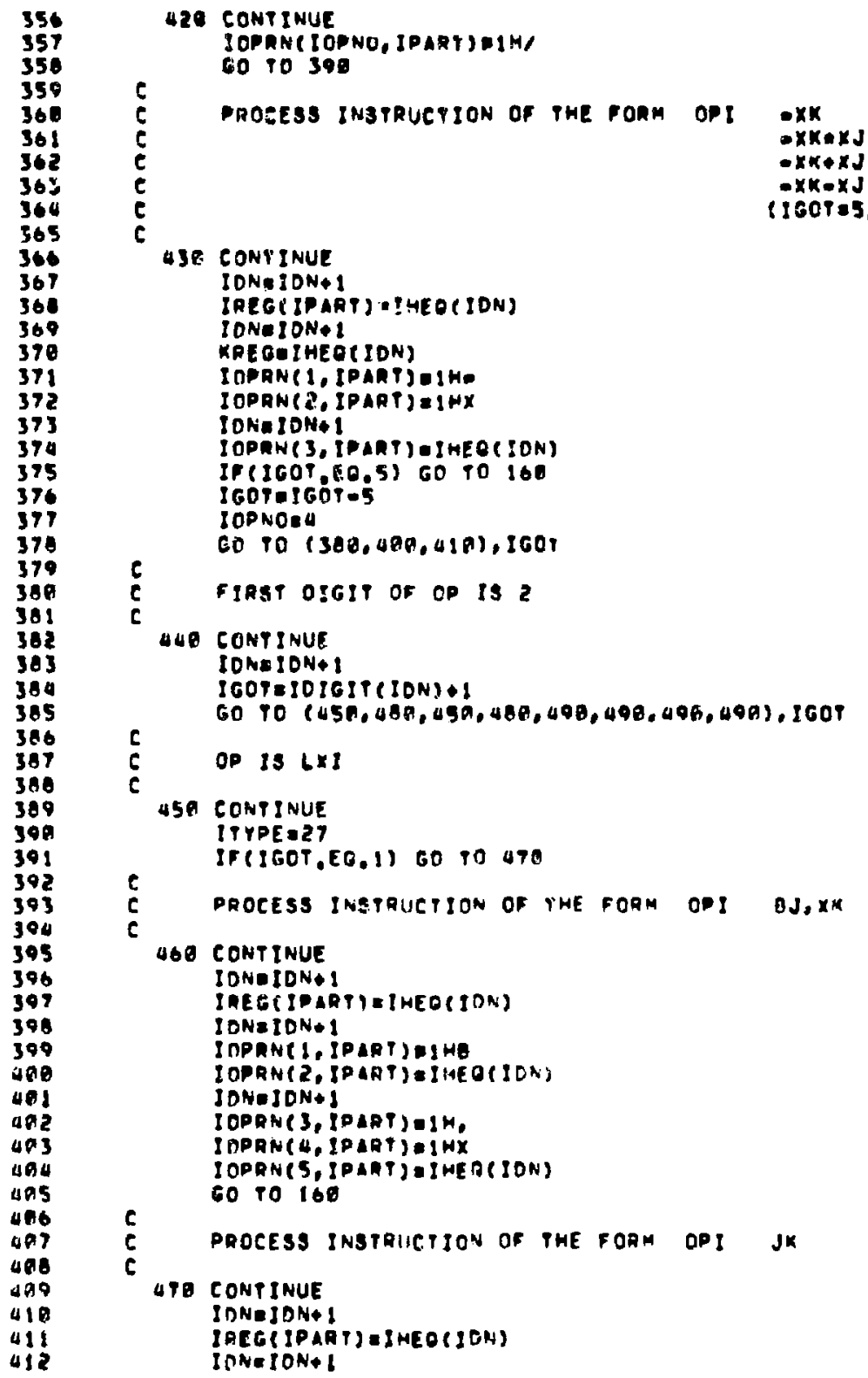




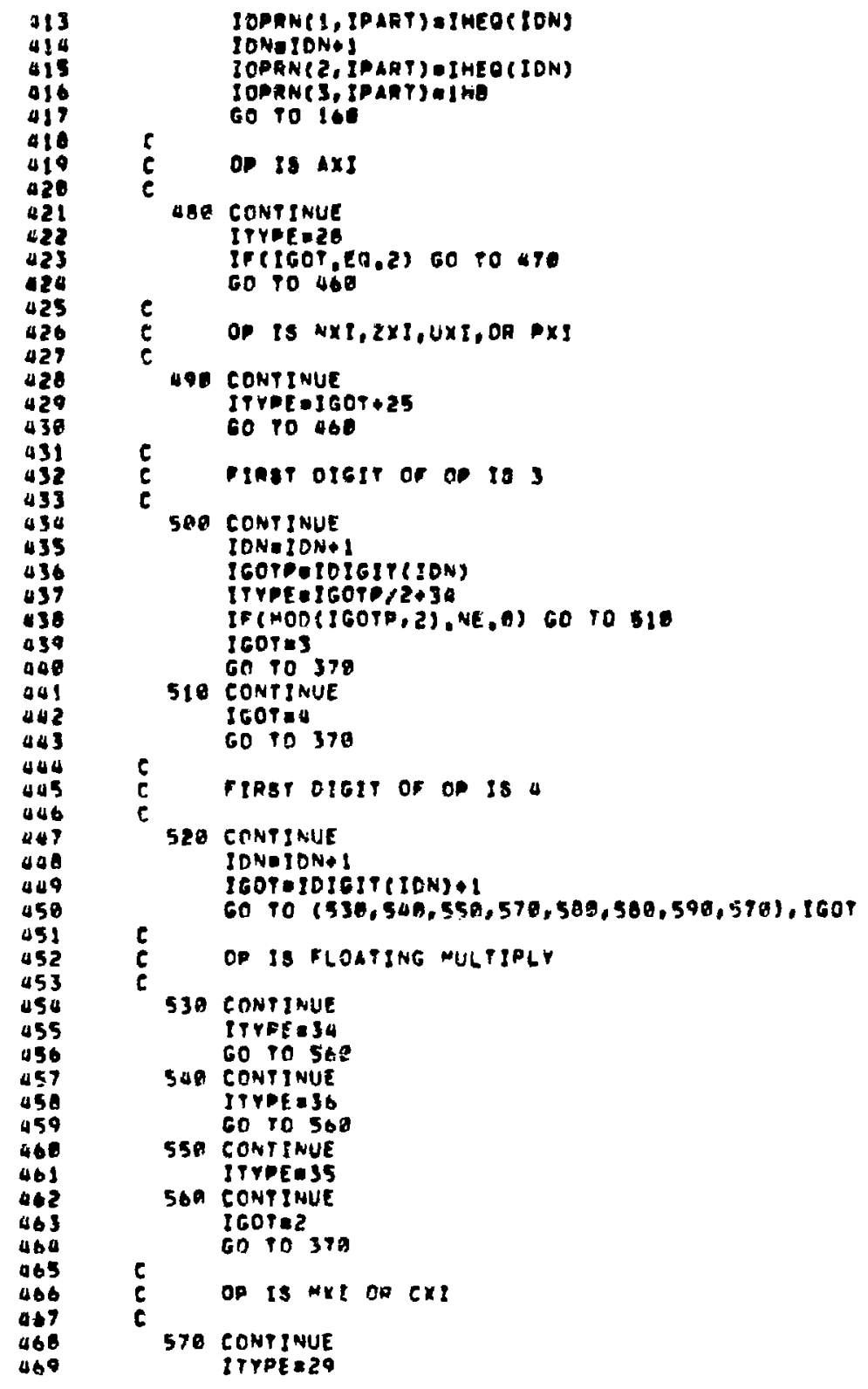




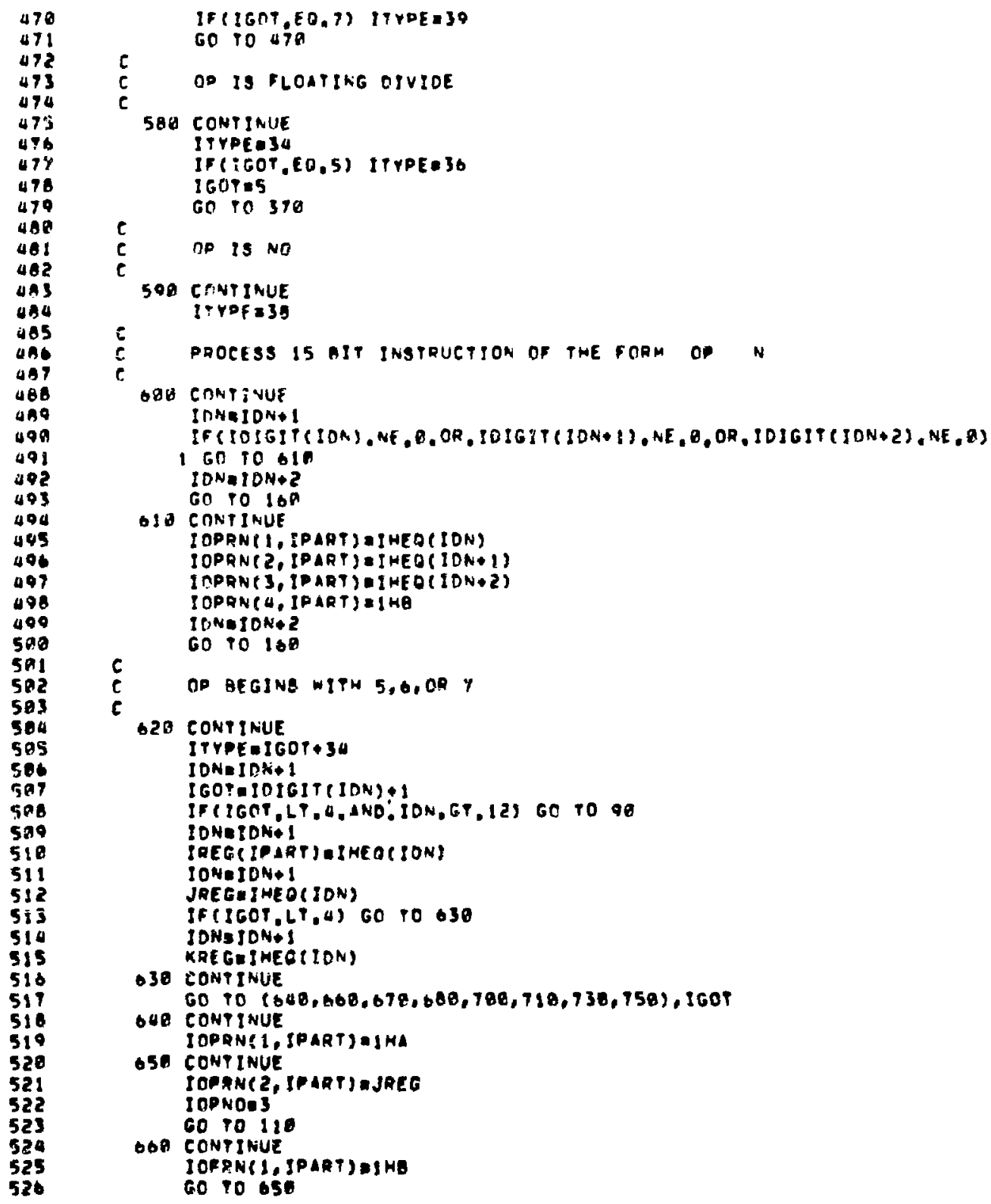




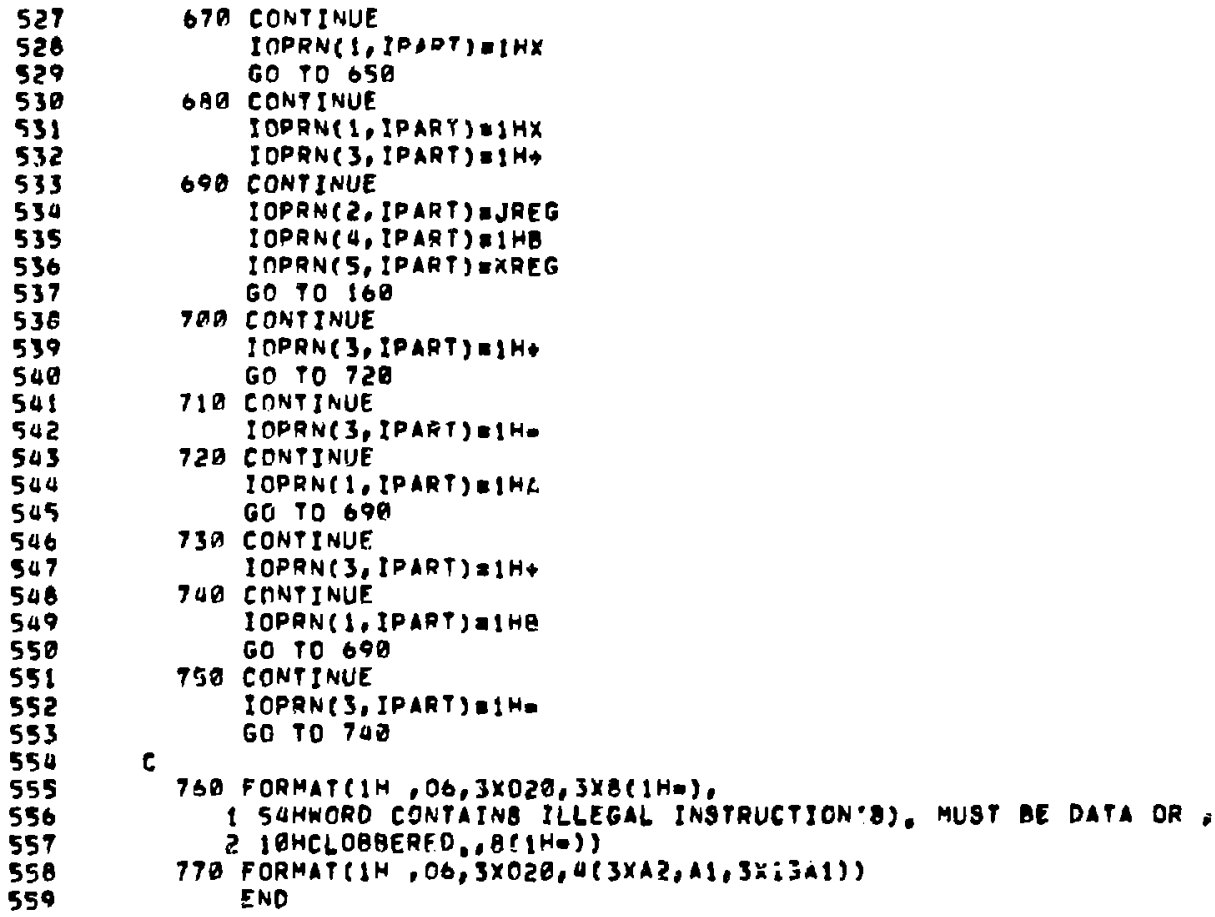

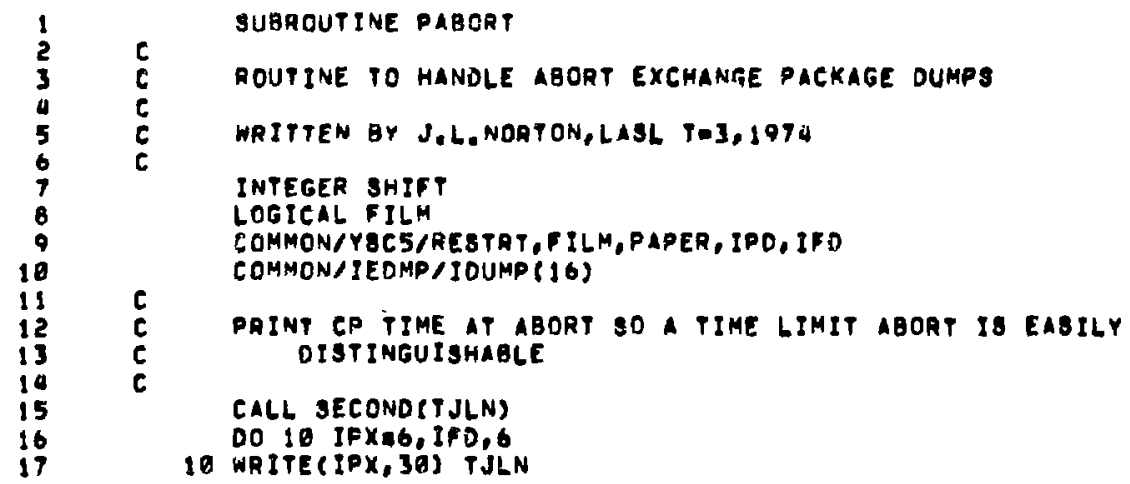




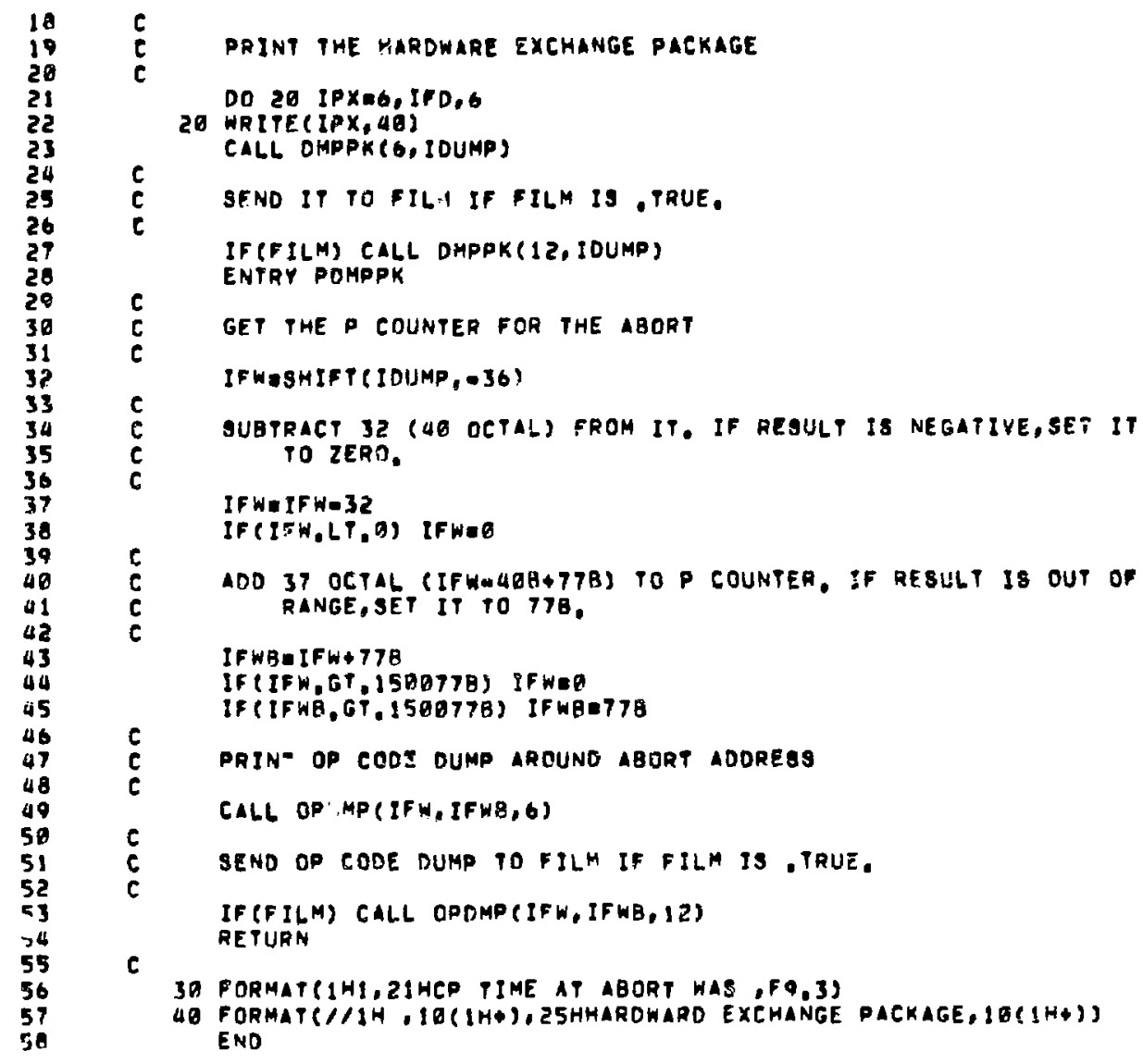

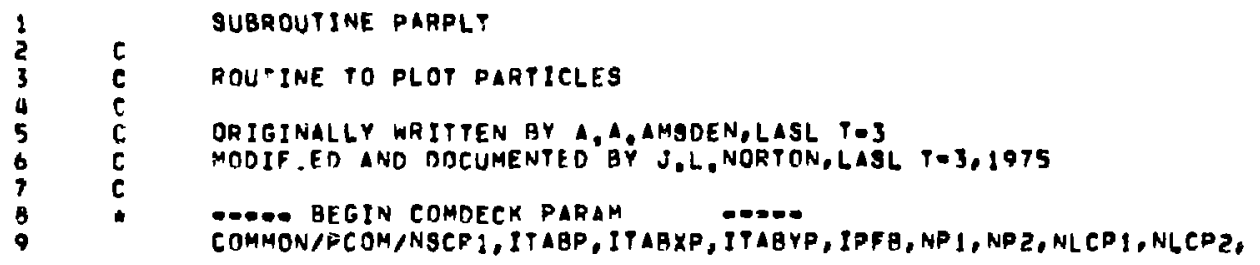




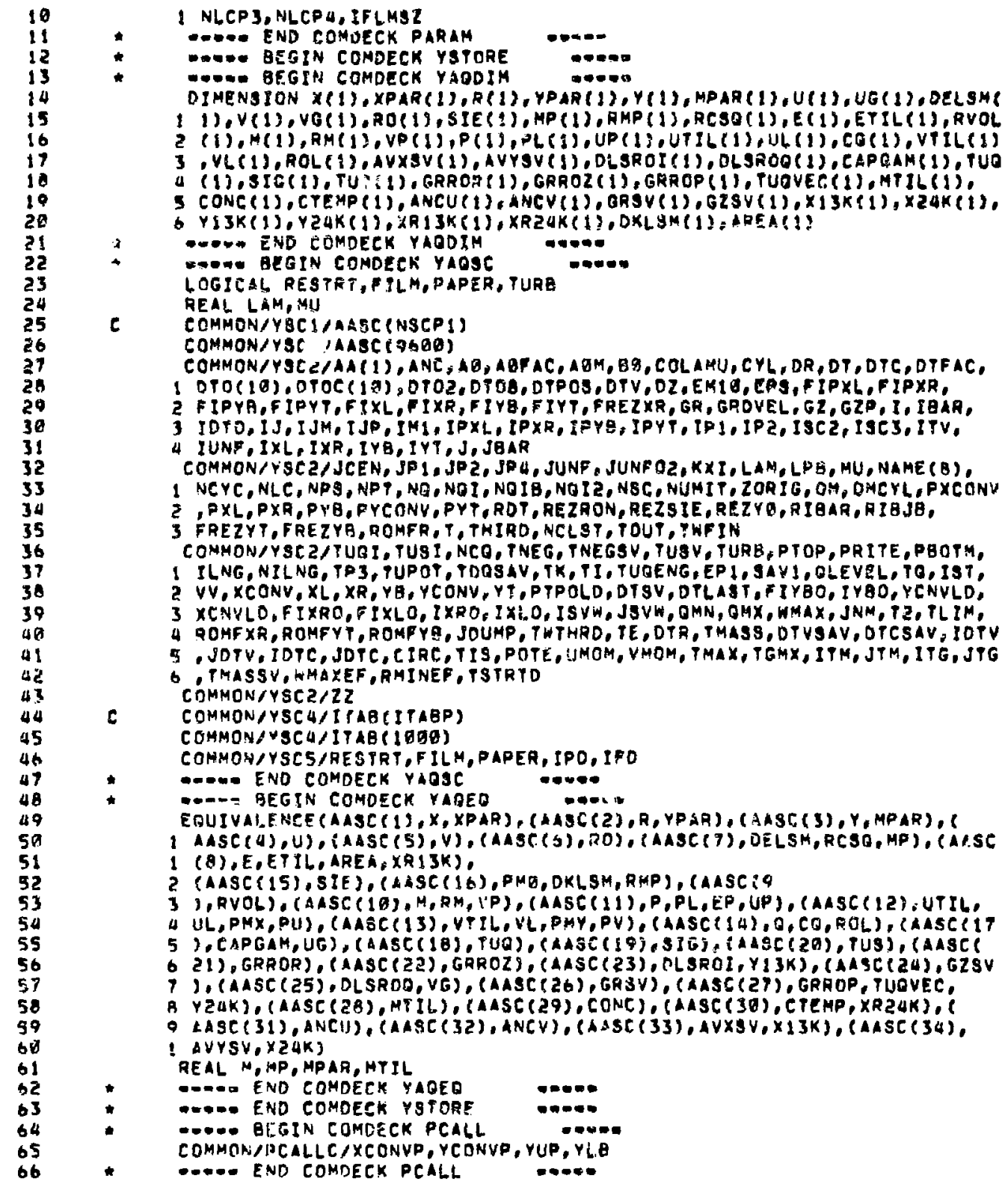




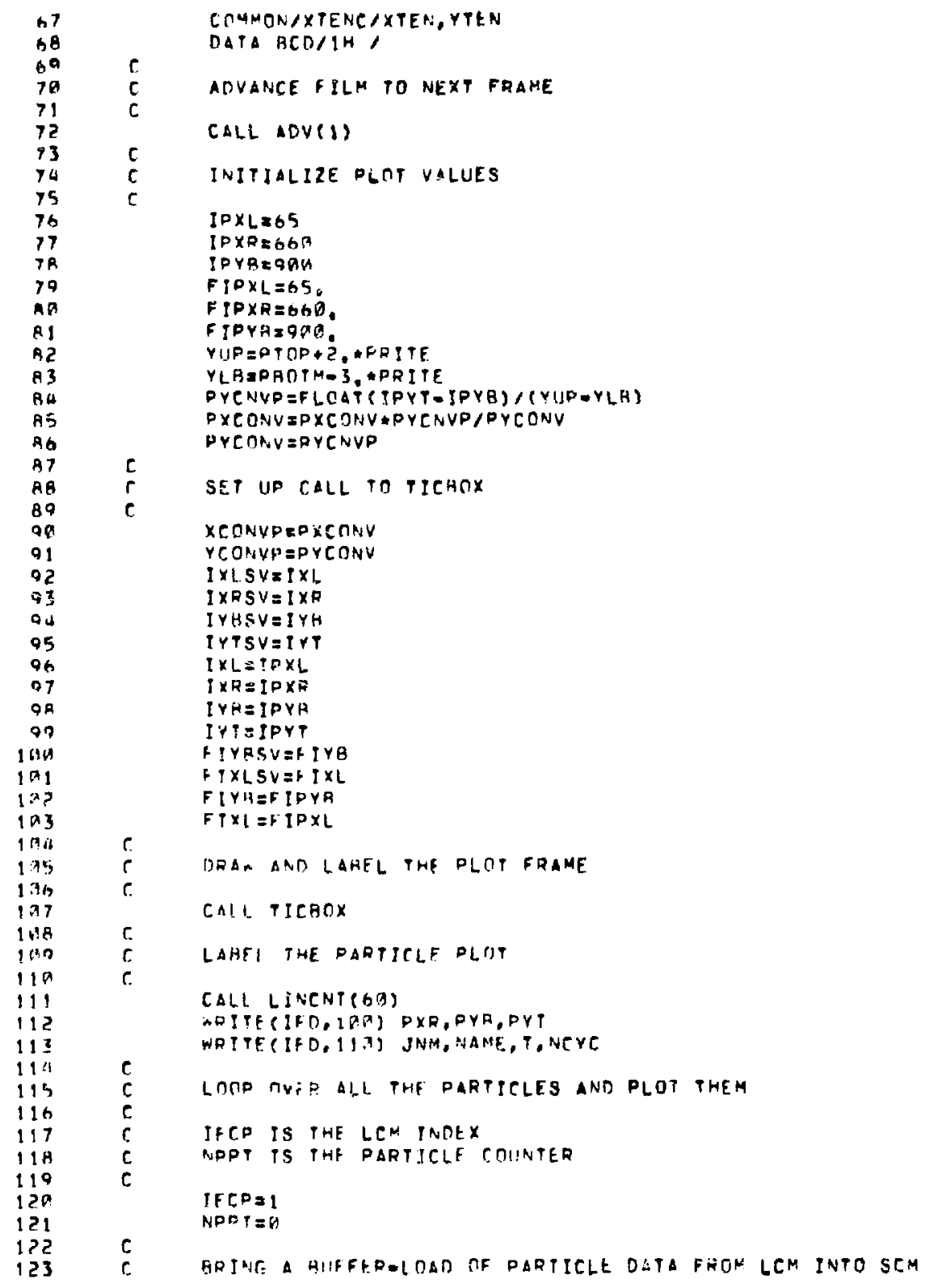




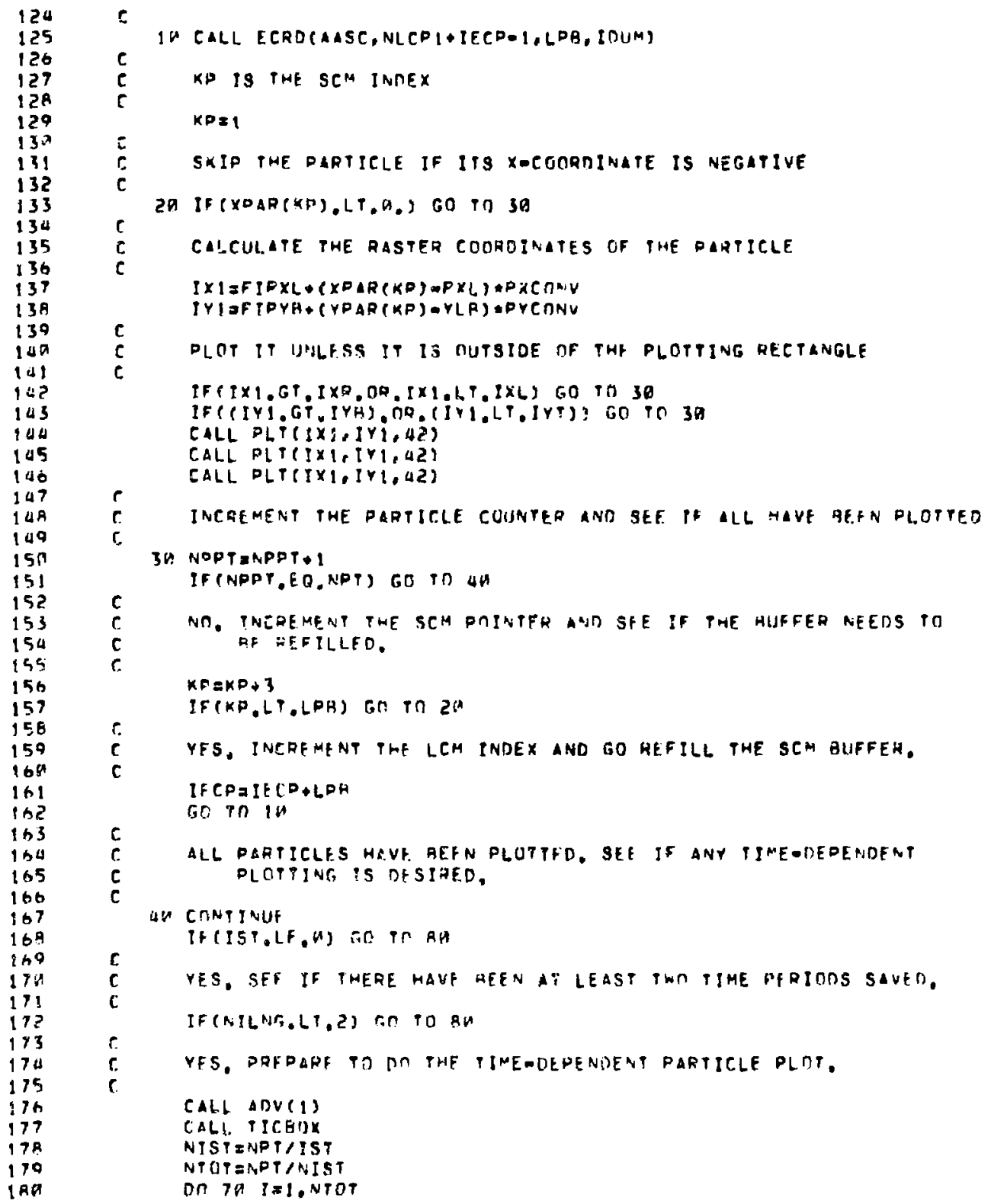




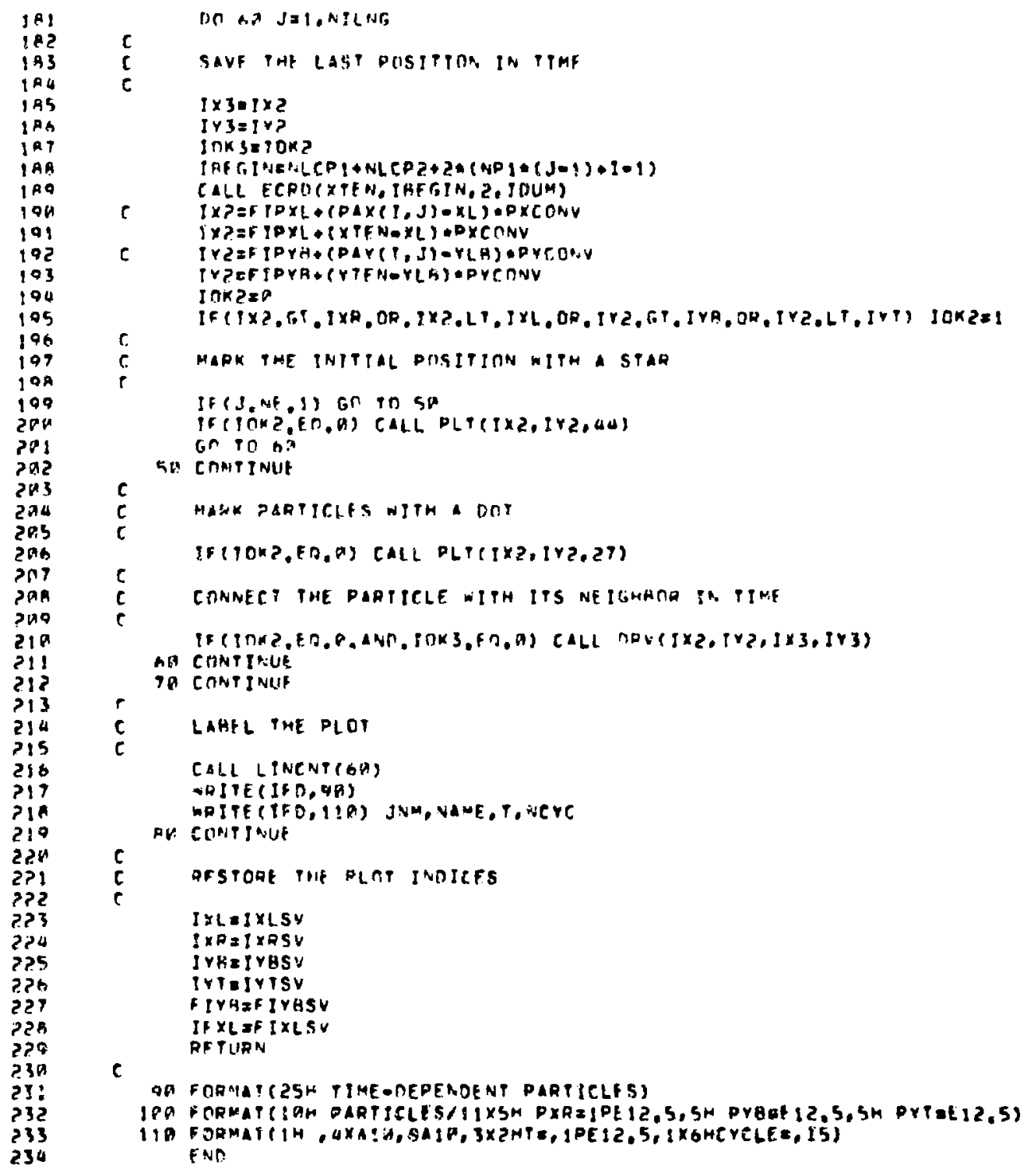




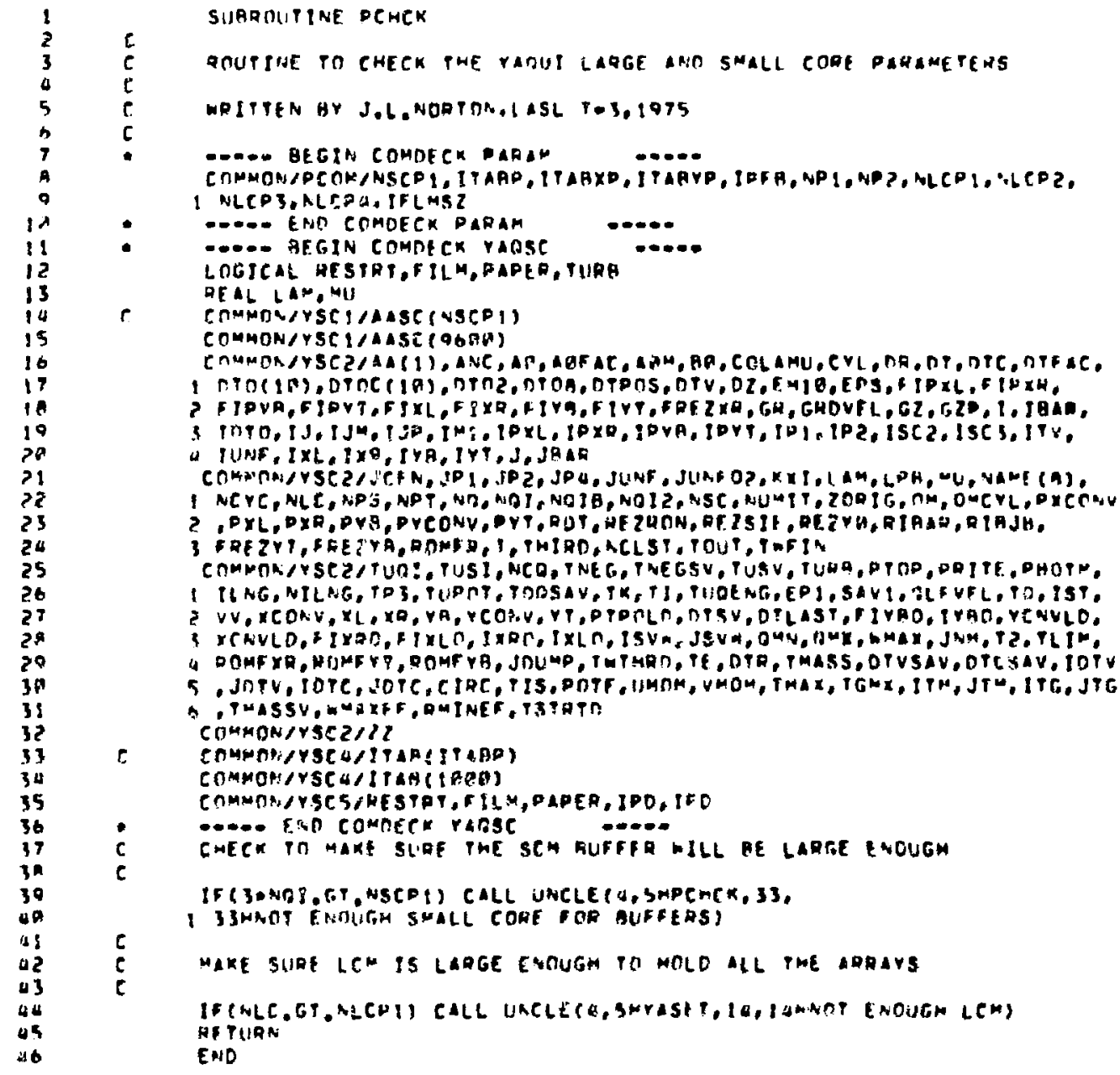




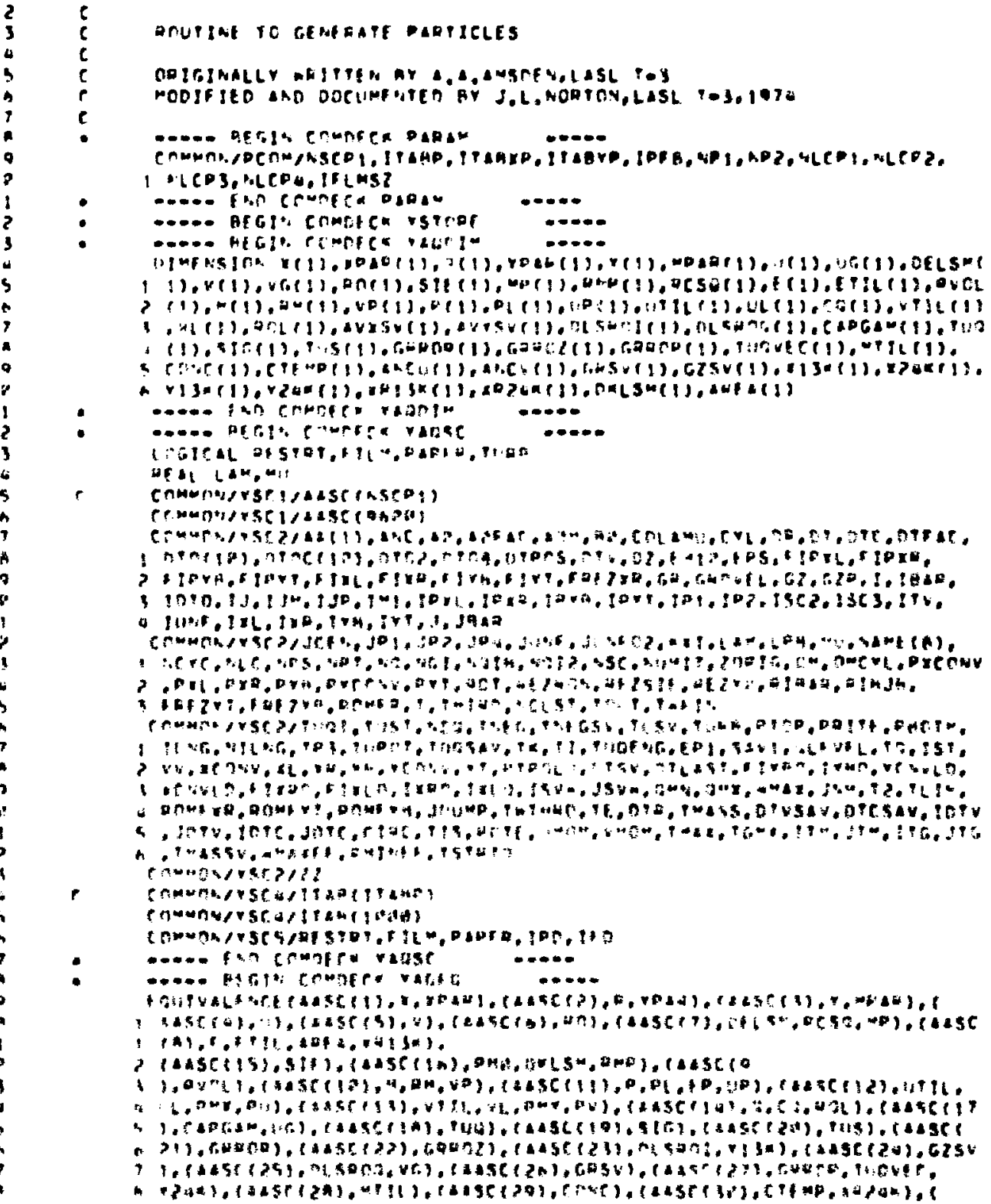




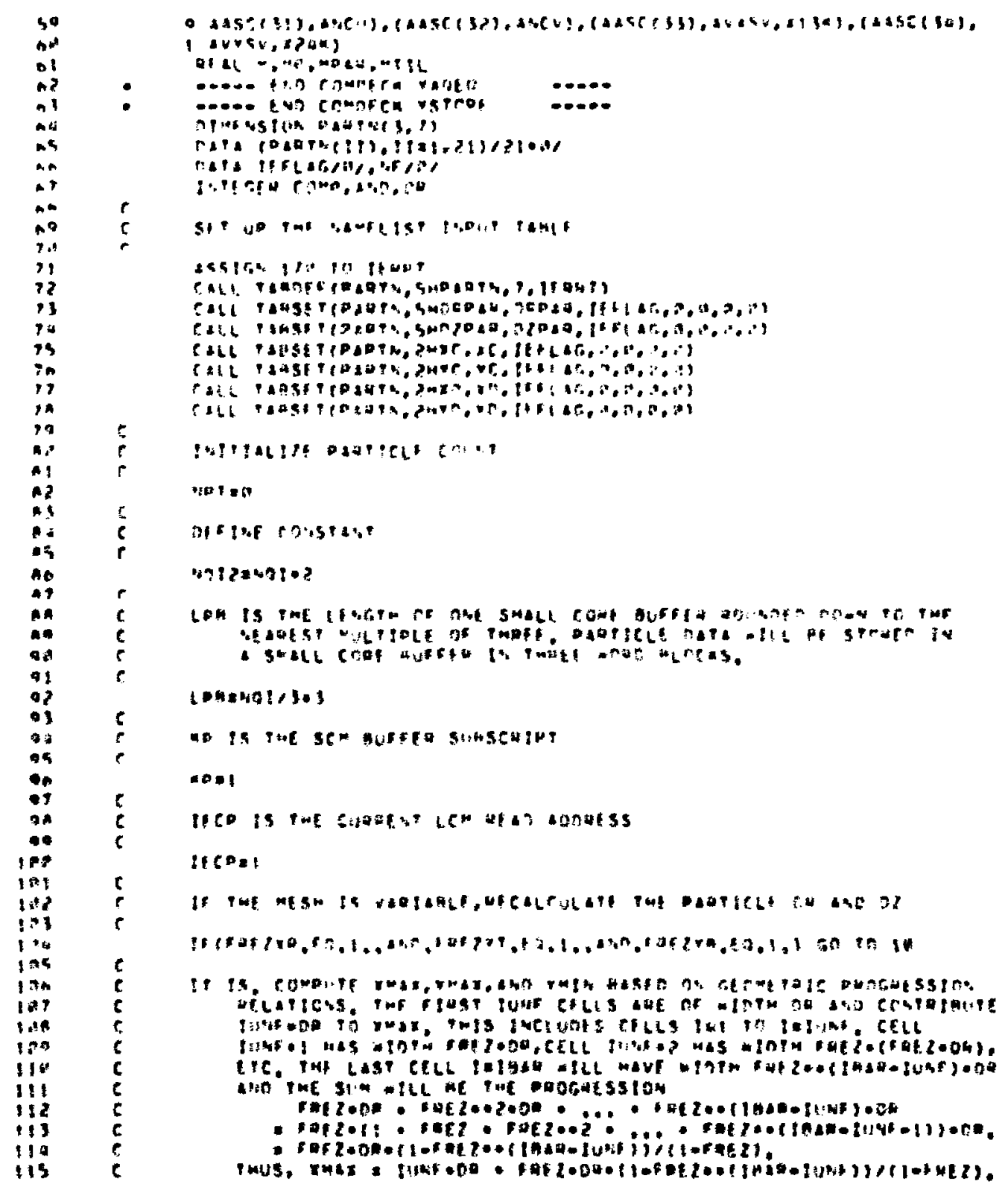




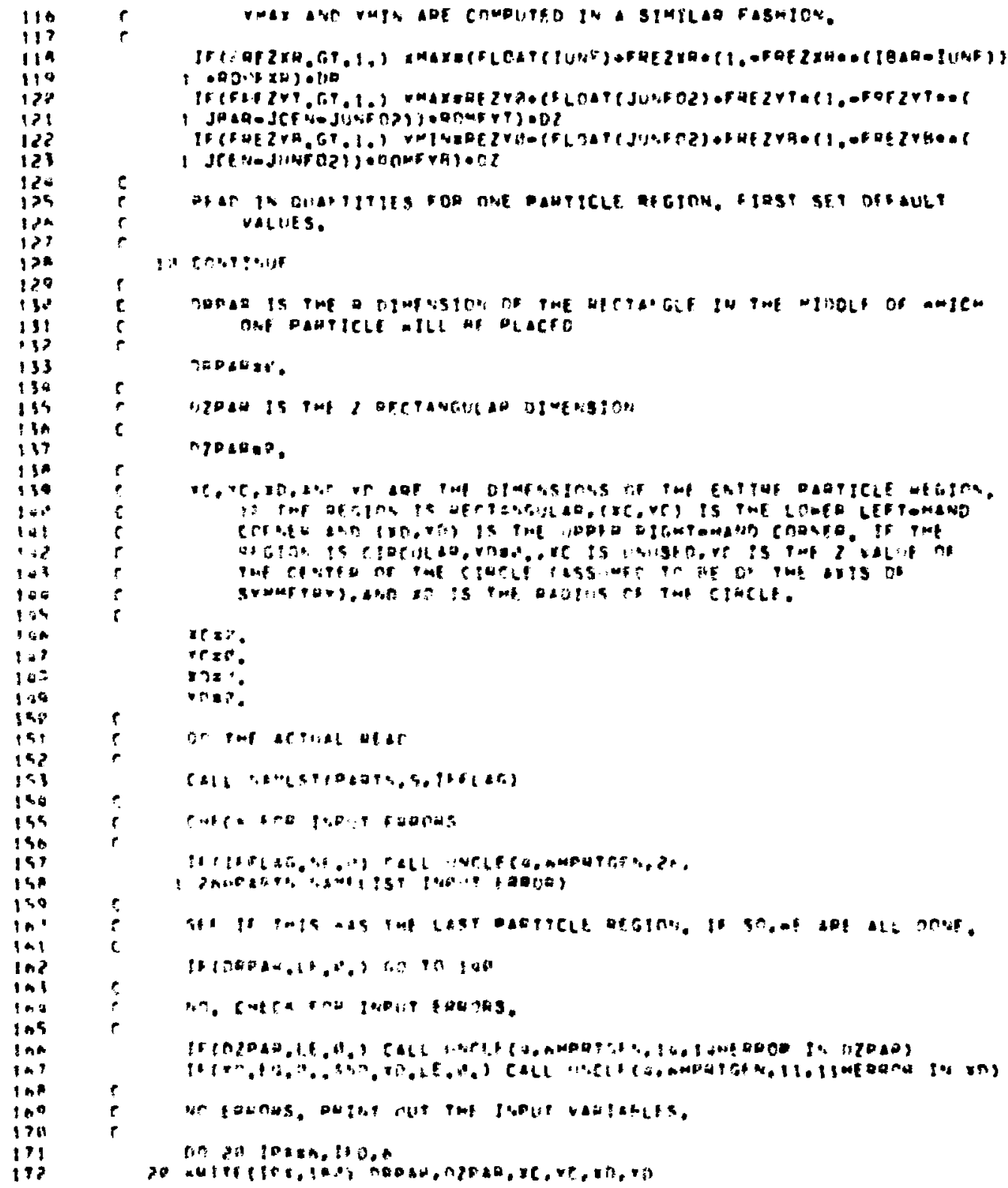




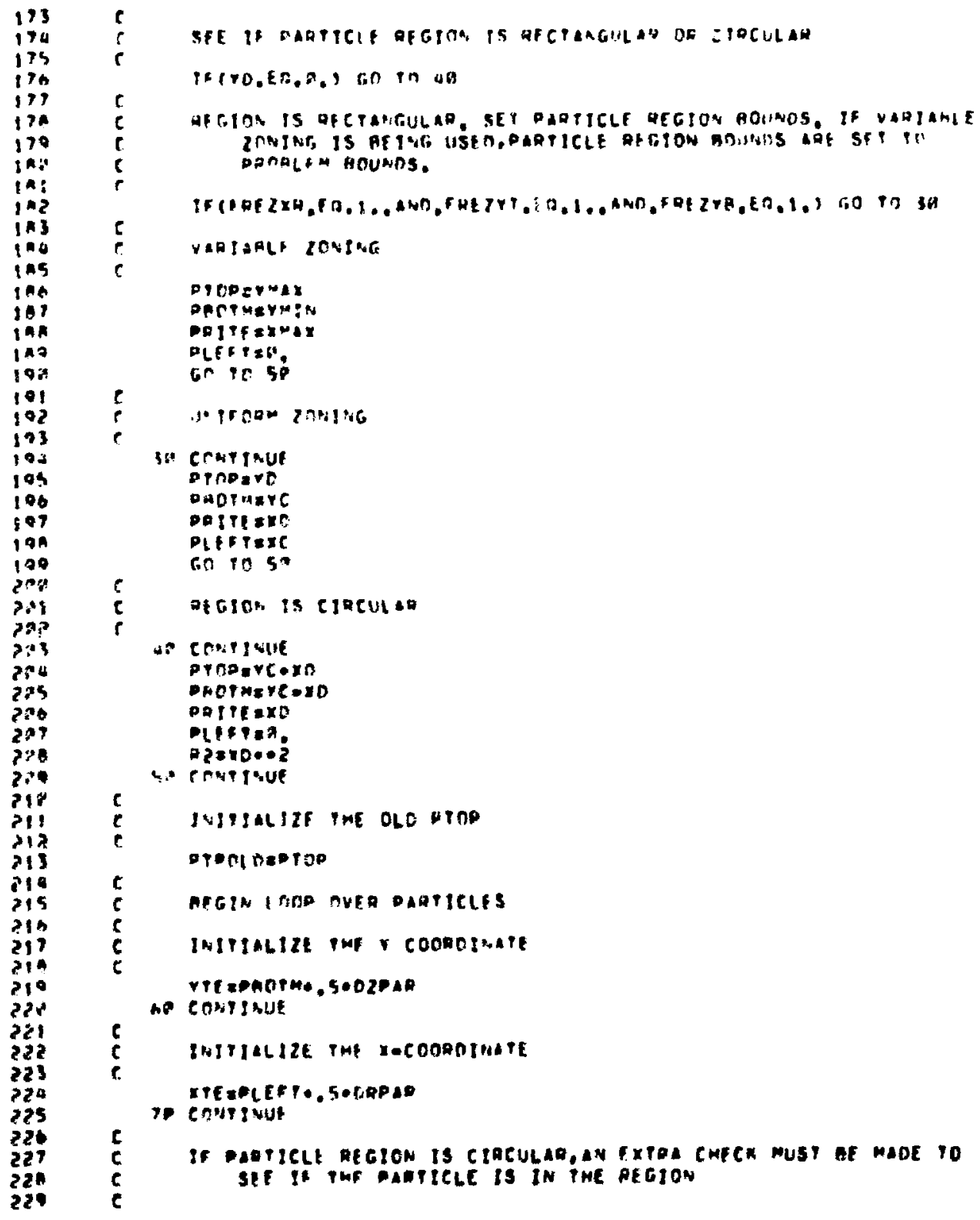




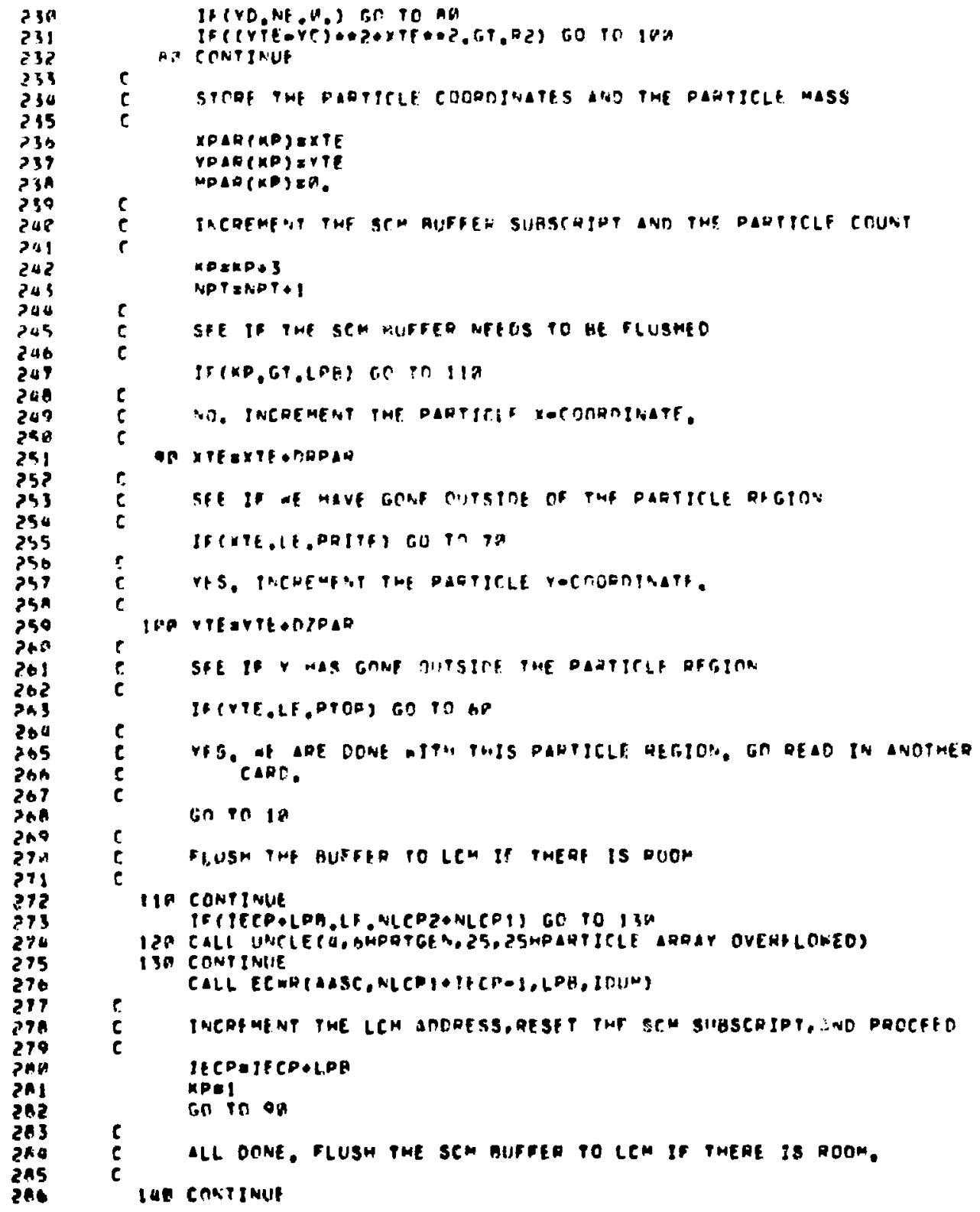



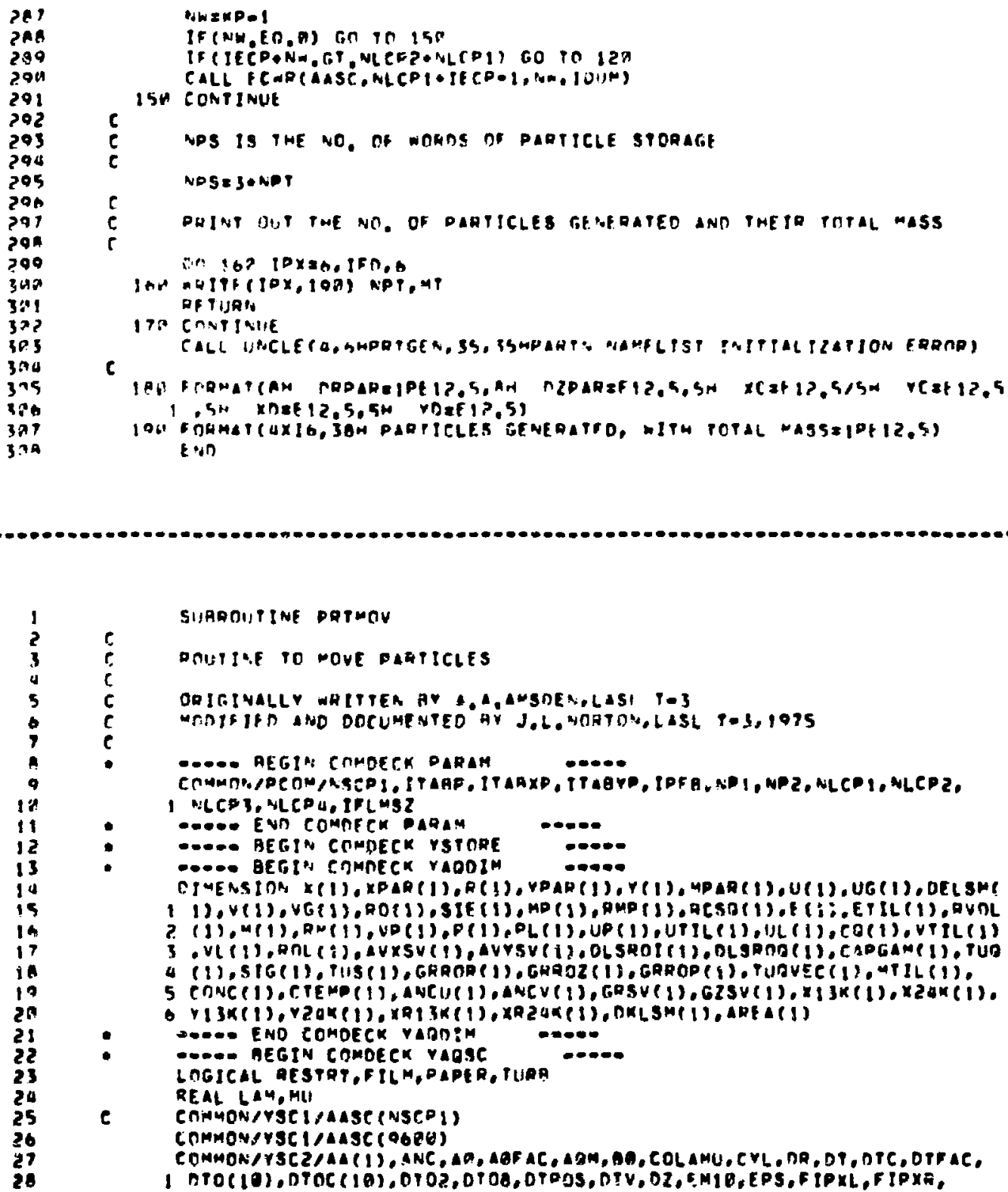


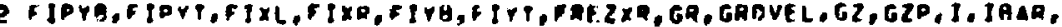

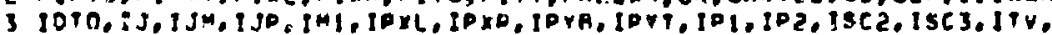

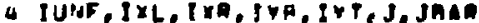

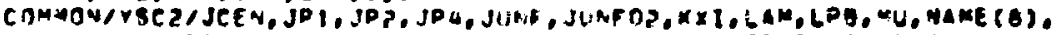

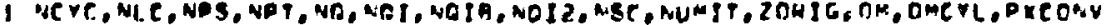

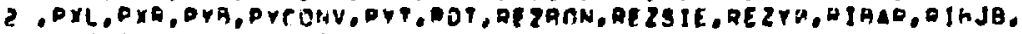

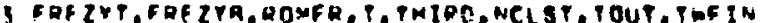

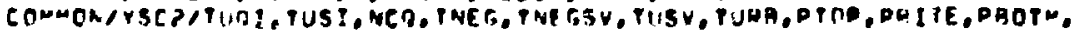

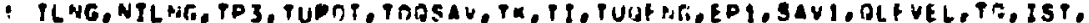

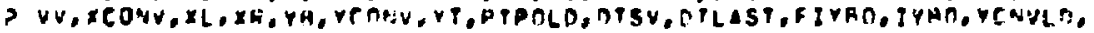

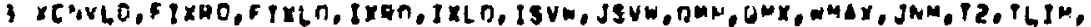

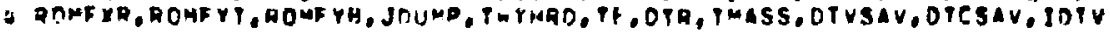

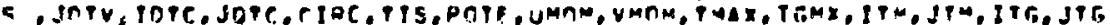

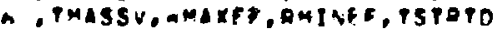
CAmMan/rsez/22

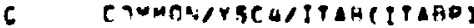

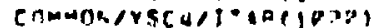

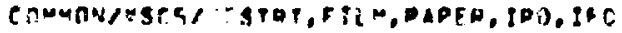

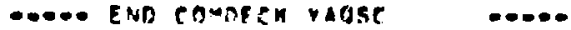

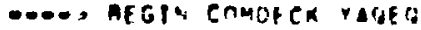

$-\oplus-0$.

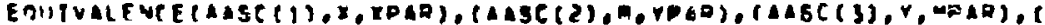

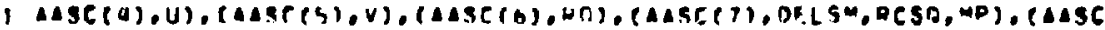

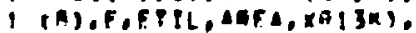

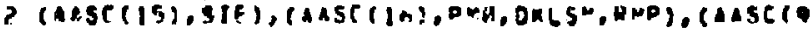

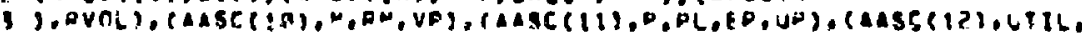

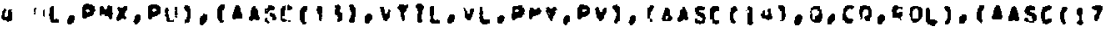

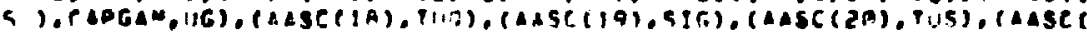

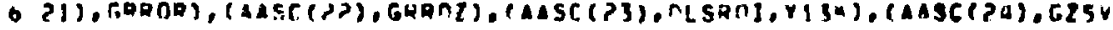

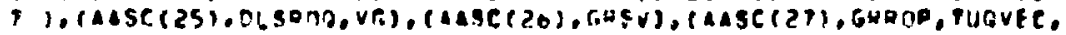

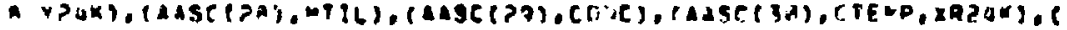

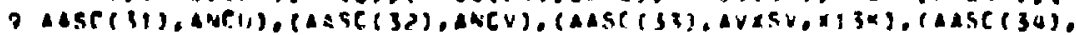

1 AVYSV, XZ\&K)

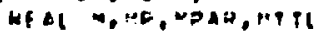

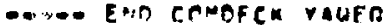

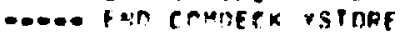

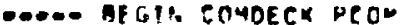

$-\infty \cdot 0$

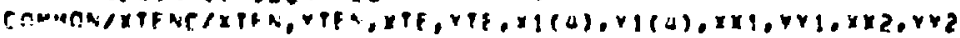

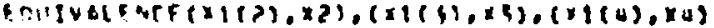

COUTVALENEETV(?),

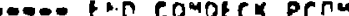

$\rightarrow-\infty \cdot$

Data roum, To,

DPCL TEDTIOP

थS

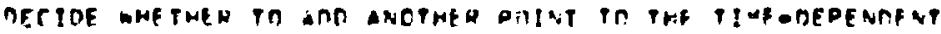
paAtetP nita

IEL $A G F=0$

itcere.

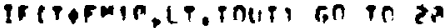

16. Continge

res

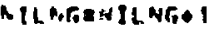

ITLAGOSI

26" CORTINUE 


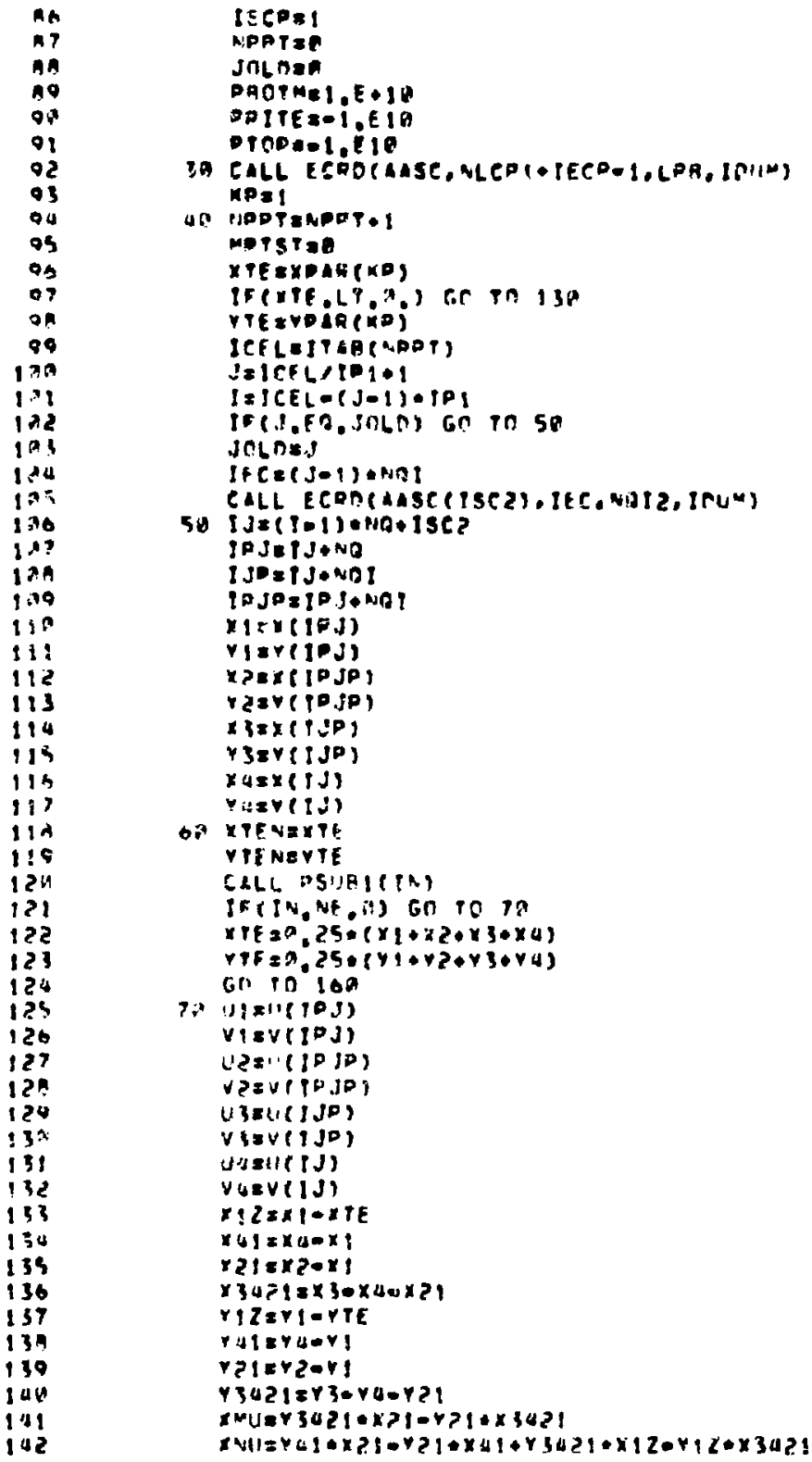




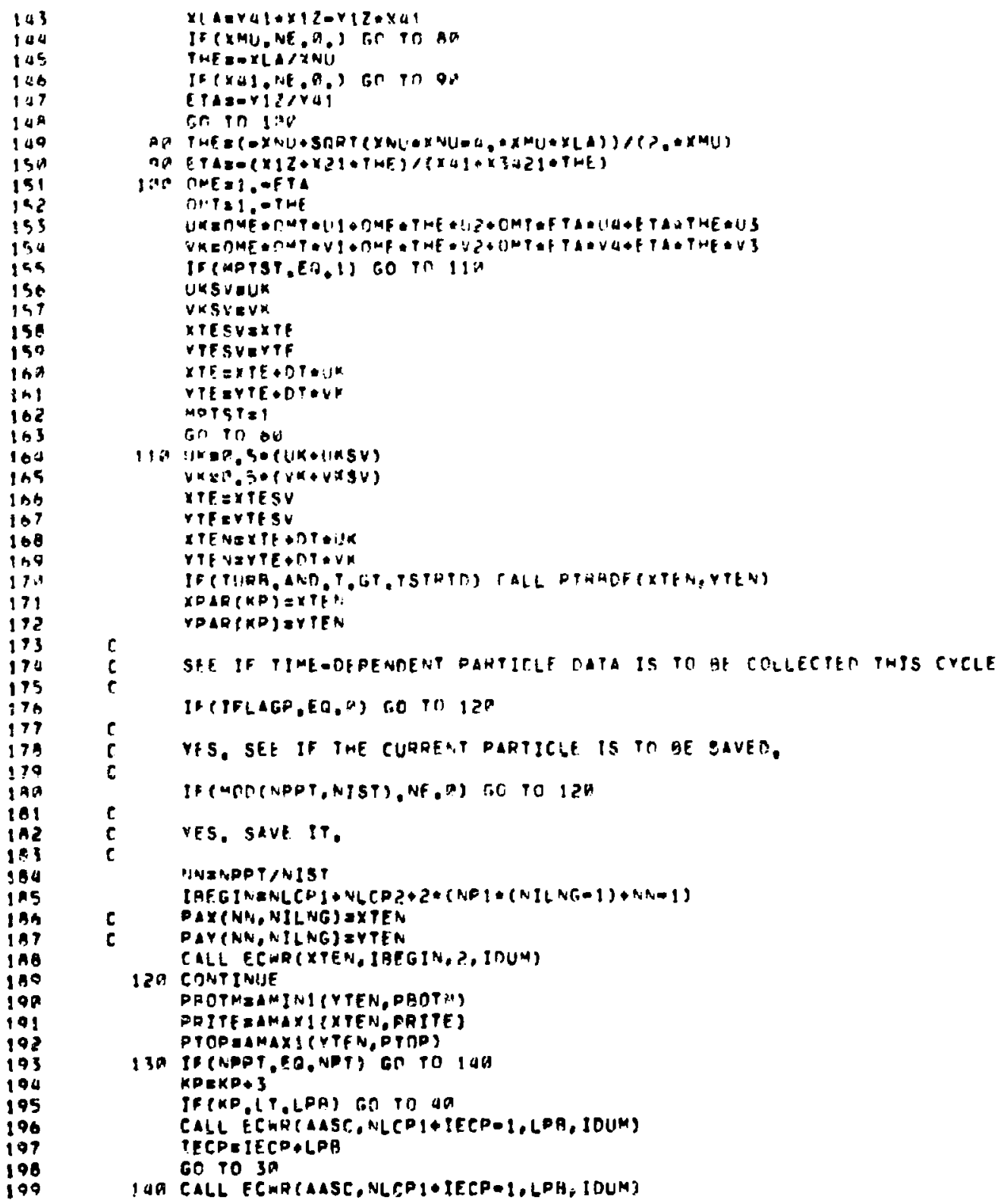




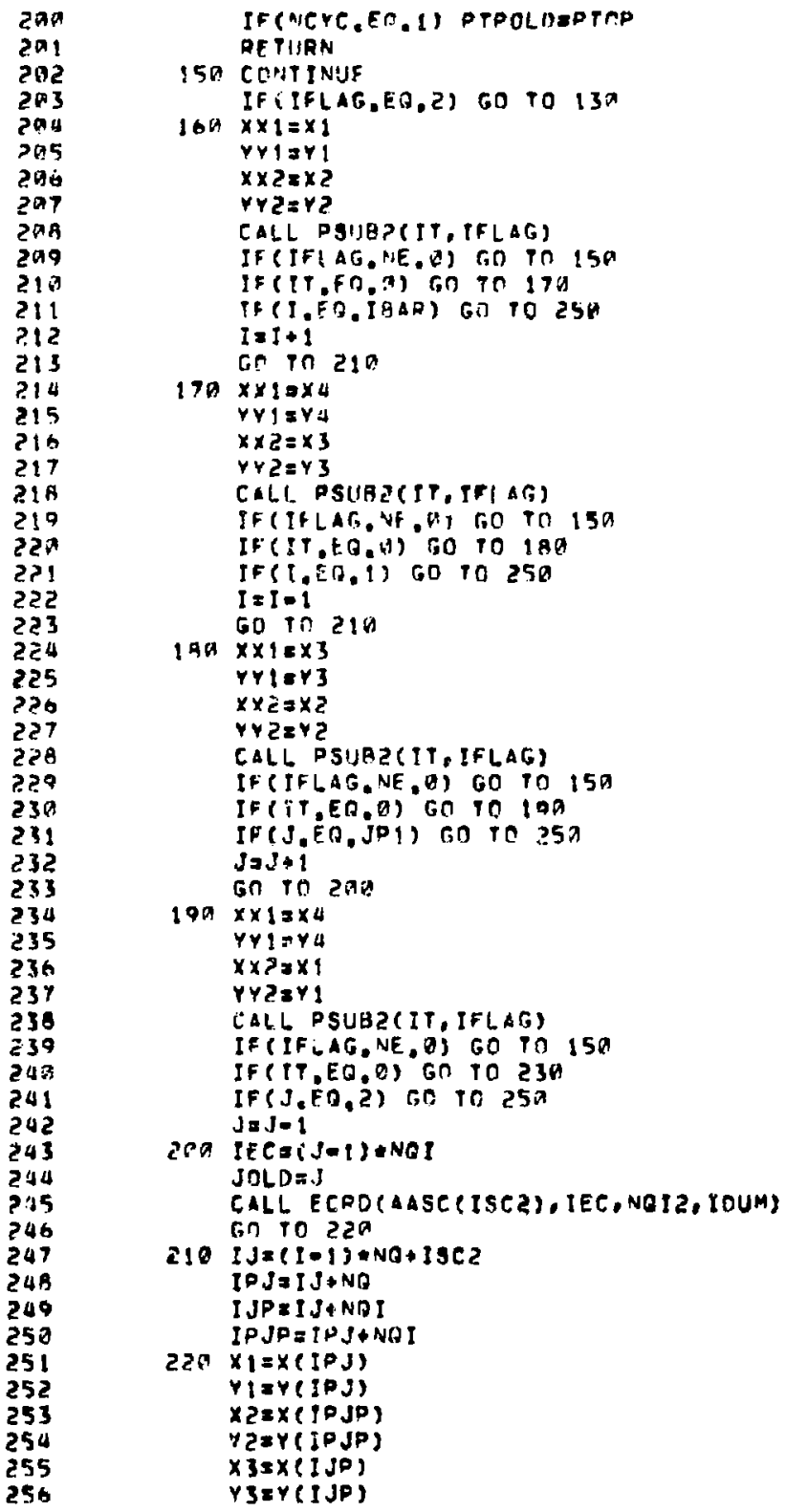




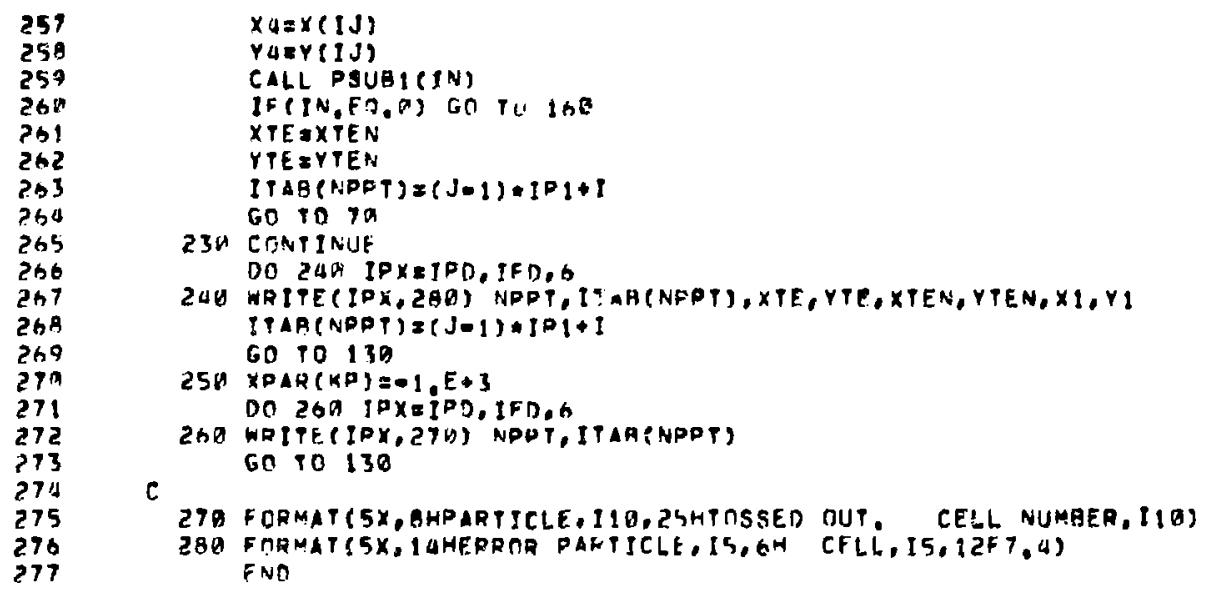

DJMENSION X(1), XPAR(1),R(1), YPAR(1),Y(1), MFAR(1),U(1),UG(1),DELSMC 1 1),V(1),VG(1),QO(1), SIE(1),MP(1),RMP(1),RCSO(1),E(1),EYIL(1), RYOL ? (1),M(1),RM(1),VP(1),P(1),PL(1),UP(1),UTIL(1),ULL(1),CP(1),VTIL(1) I,VI (1),ROL(1),AVXSV(1), AVYSV(1),DLSROI (1), OLSROD(1),CAPGAM(1), TUO

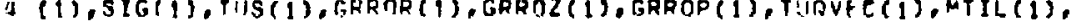

a CONC(1),CTFMP(1), ANCU(1), ANCV(1), GRSV(1), GLSV(:), X:3K(1), X24K(1), G Y13K(1), Y 2UK(1), YR13K(1),XR2AK(1), DKLSM(1), AREA(1)

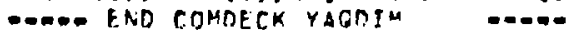




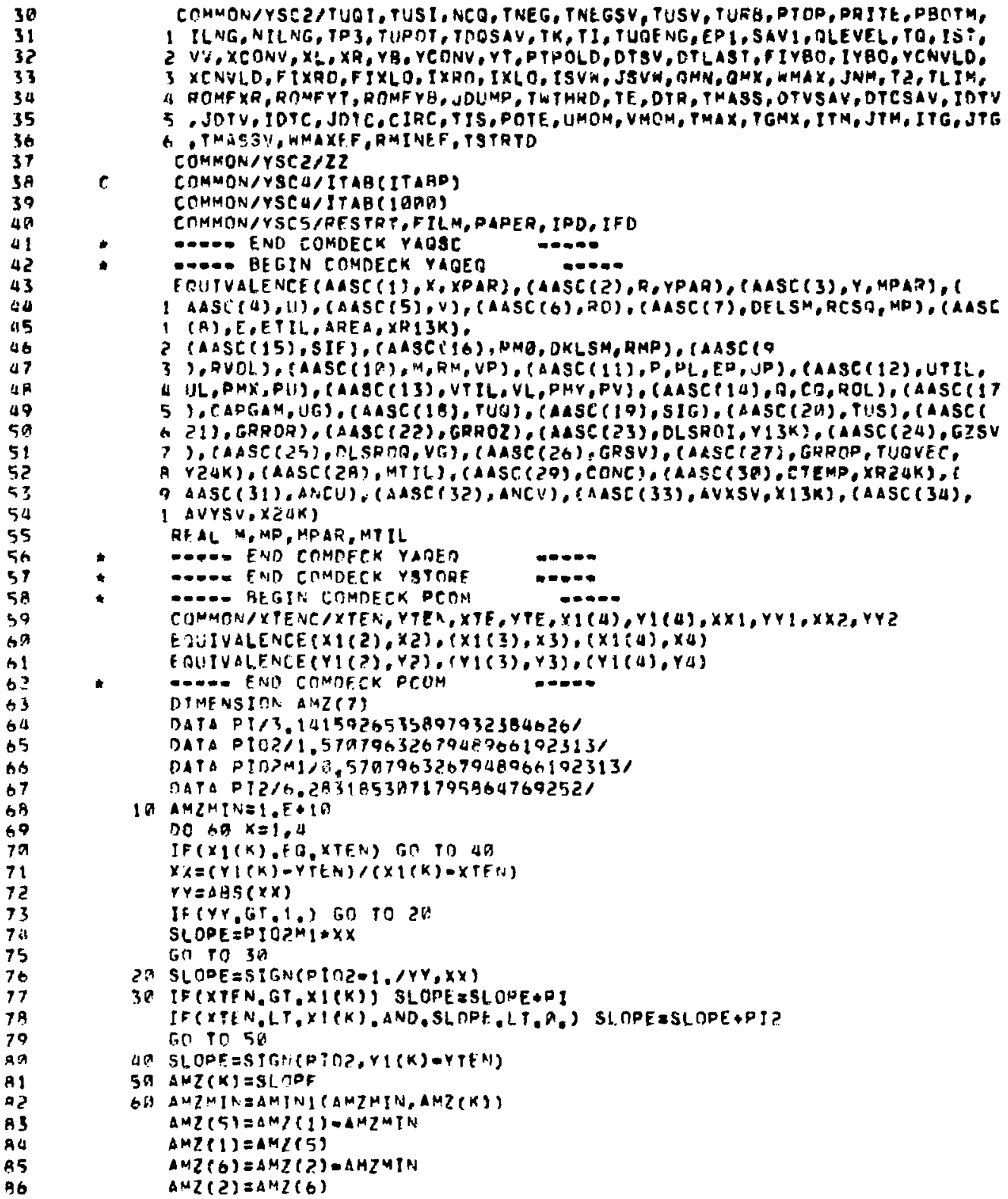



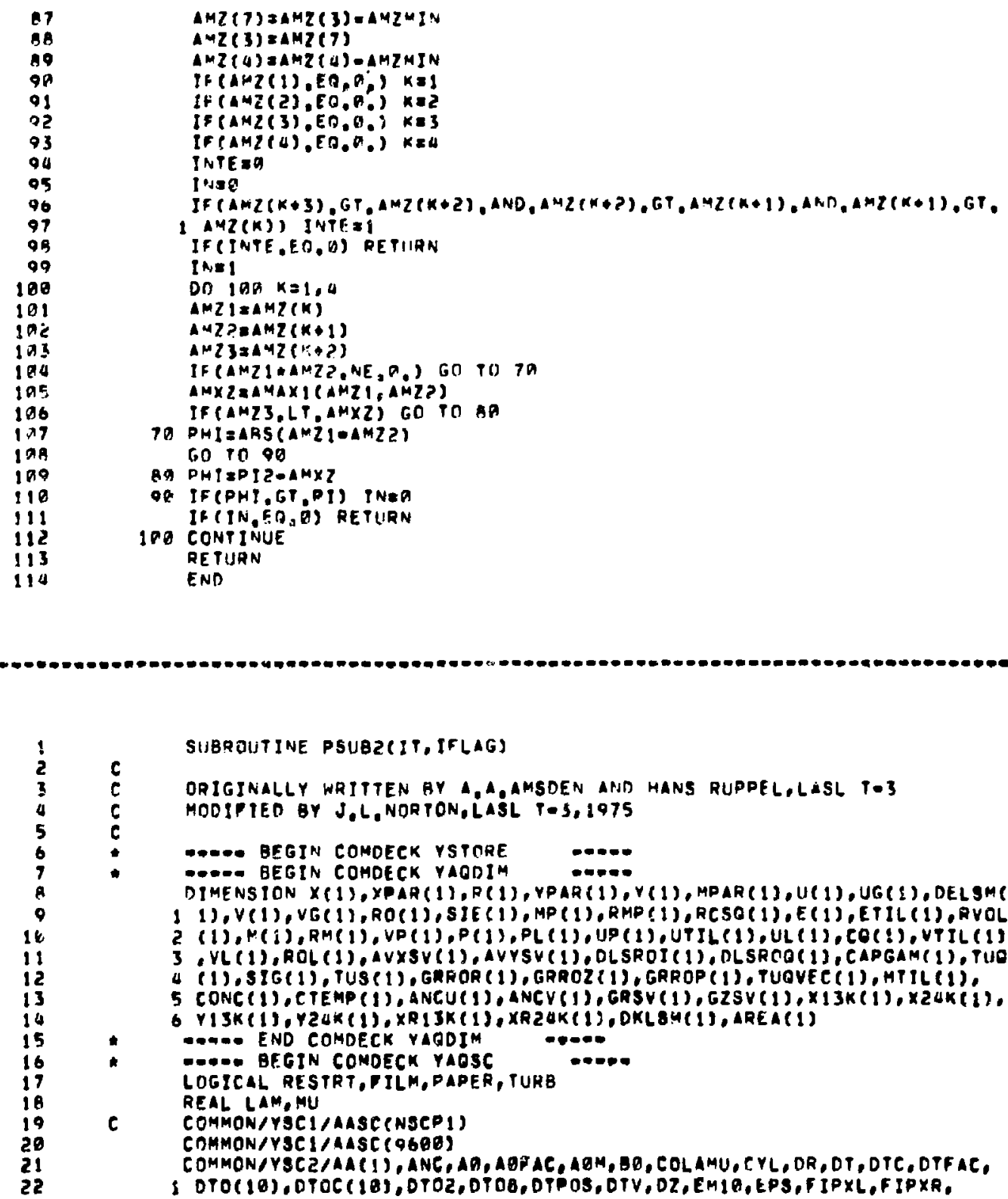


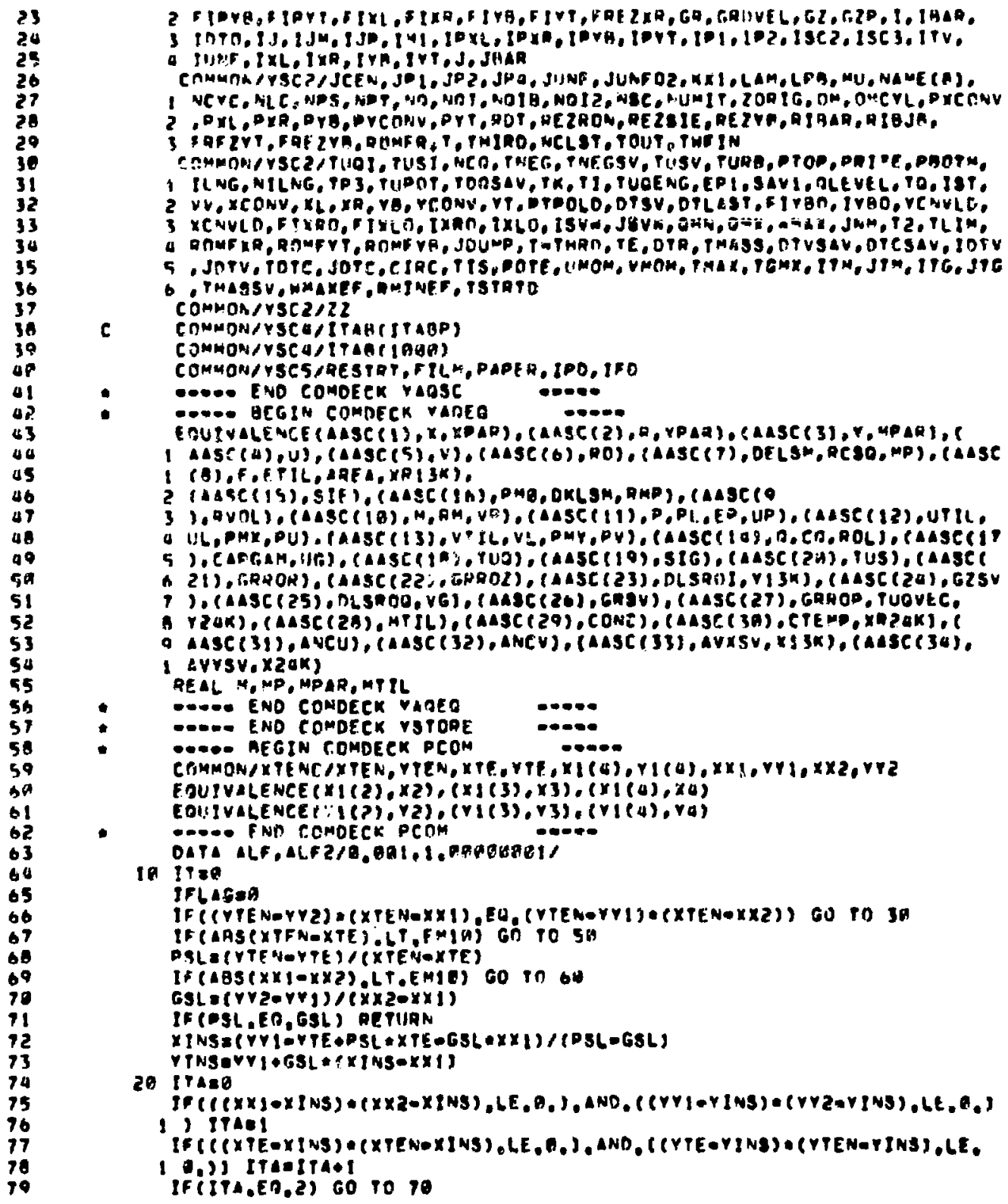




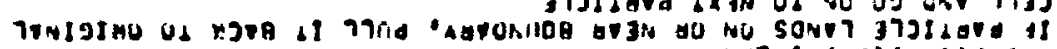
uplit (avickolitita do quel oasexal do jo $204 \div 715$

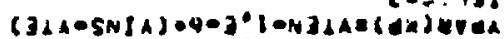

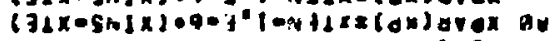
vatiag

iosi

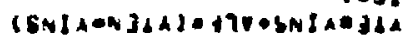

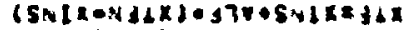

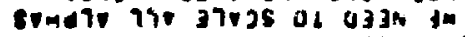
20 of 1

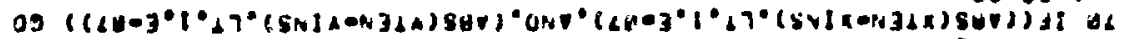
02 U⿺ 20

$(3 L X-12 N)+78 d+3 L A E S N I A$ ixisesis 04 22 os 0

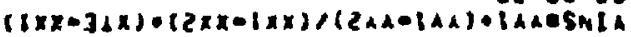
jaxesridx as ven 134

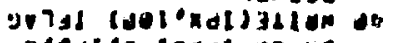
g.ost Odtexdi in of iองกาม

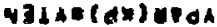
N3dxe(ax) ordx

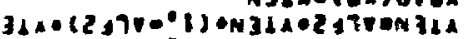

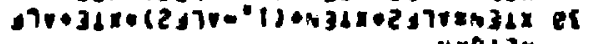




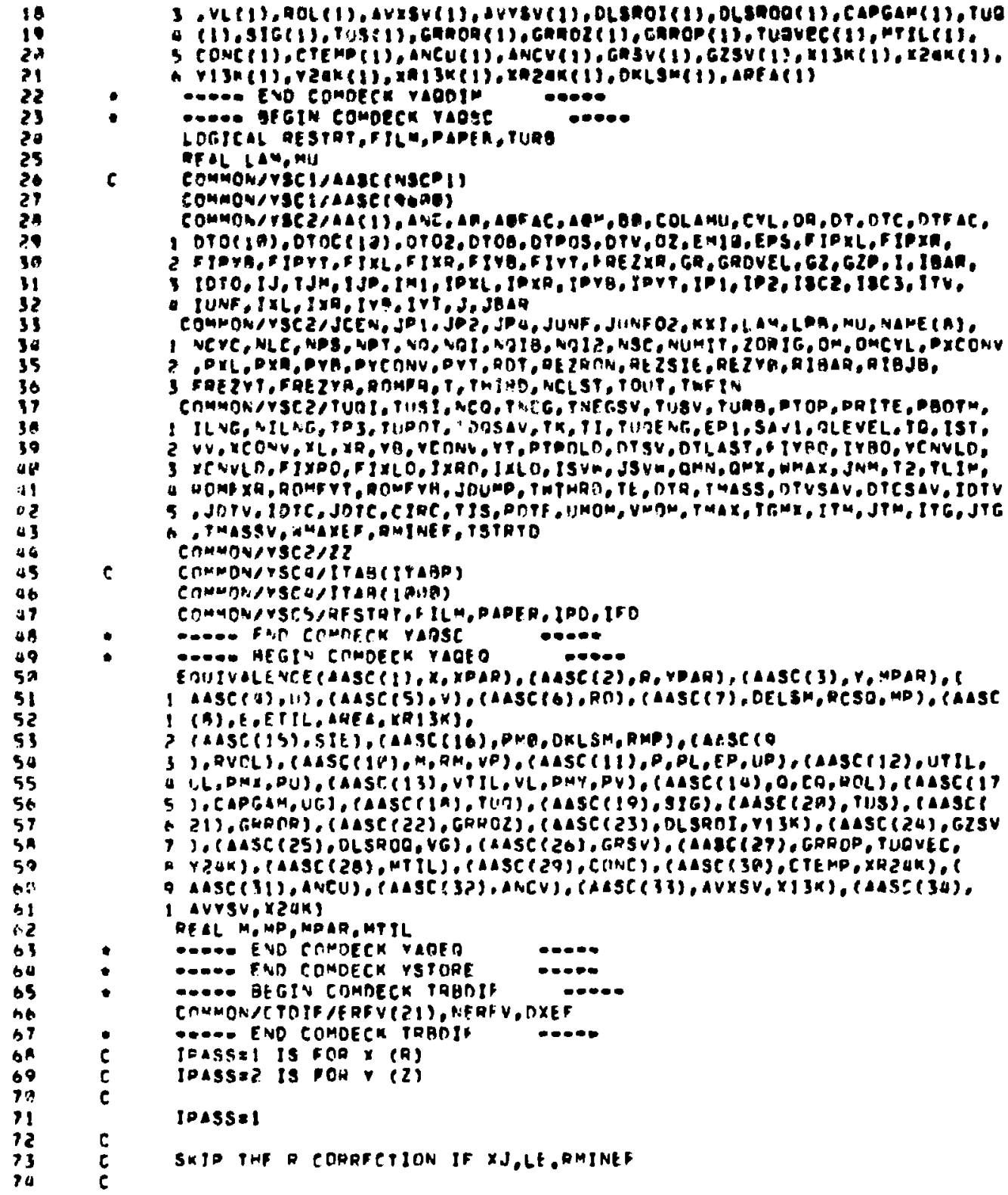




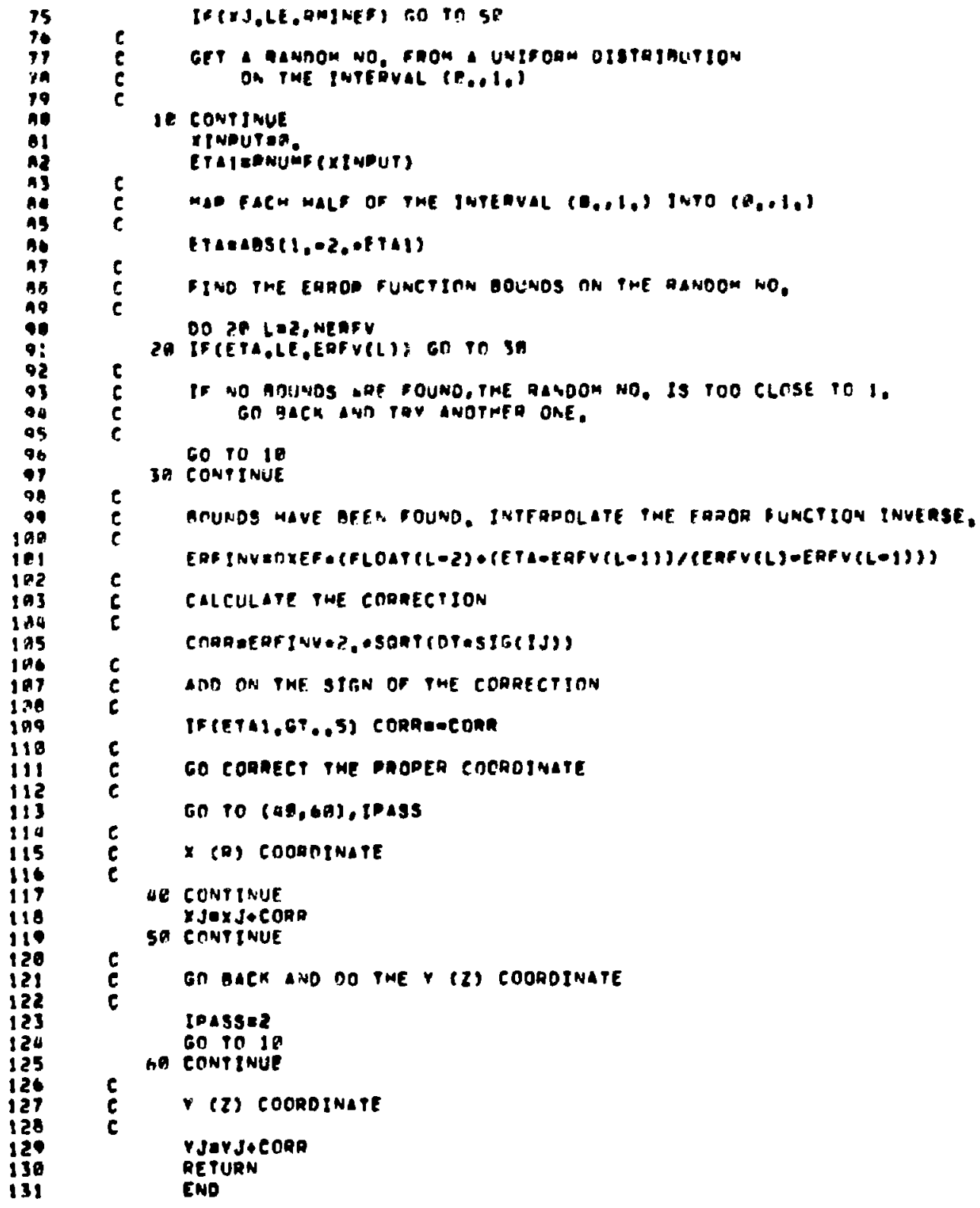




\section{SUBNOUTINE REZONE}

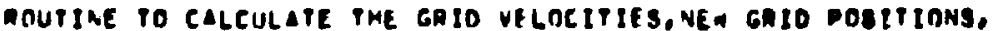

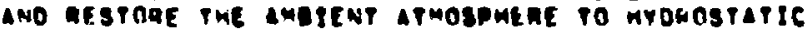
EกULLIBRIUM

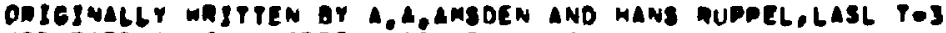

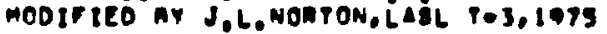

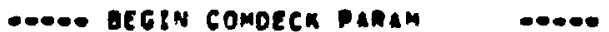


$3), A \cup O L),(A A S C(1 B), M, R M, V P),\left(A A B C(11), P, P L_{0} E D_{0} U D\right),(A A B C(12), U T I L$,

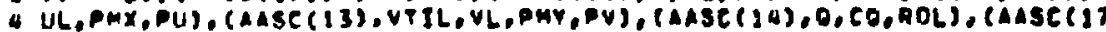

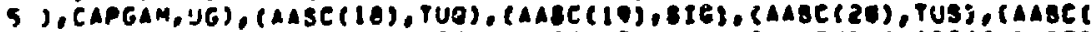

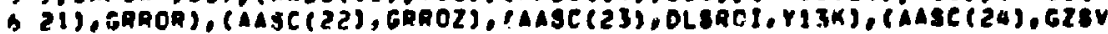

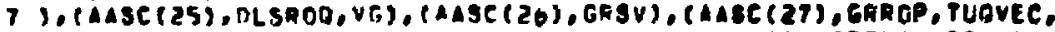

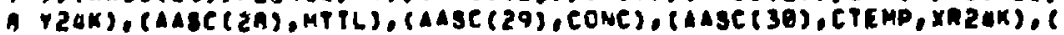

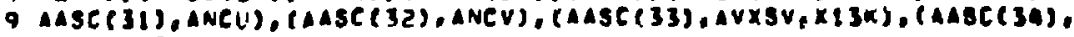

I AYrSY, $\times 24 K)$

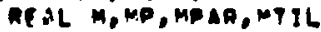

- $\rightarrow+$ END COMOECK VAOEO

DOEA END COMDECK VATORE -OE-O

COMMOY IENST/ROTMP, ETMP, GMONE, CONCJ

CSTE 0.0 .

ZRSELE STUMRS ASUME $=0,0$

DMNEI, PE + 20

CALL START

Dn $20 \mathrm{~g}=2, \mathrm{JPI}$

Do 19 I:1, iQAa

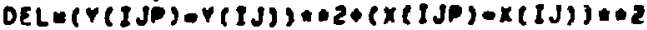

DWNEAMTNI (DNN, DFL)

ADELEL,OREL

OFLE IE (IJ)-R. 156

SUMESSUME ODELE

$Z E \backsim Z E+Y(I J) \cdot D E L E$

SUMRS ESUMAS + AREL

ZRSEZAS $Y(I J) \cup R D E L$

$17=5 \mathrm{~J}+\mathrm{NL}$

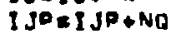

10 CONT INUE

call loop

20 CONPINUE

ZE a ZE/SUME

ZRSEZRS/SUMRS

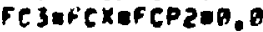

CALL BTART

DO aO $\mathrm{JE2}, \mathrm{JP}$

Co 30 IEl. IAAR

IF (J.LE, G) FC 3EAmaxitCes,ABS(VL (IJ) J)

IF (J.CE.JPI-11) FCPzOAMAXI (FCPz,AHS(VL(IJ))

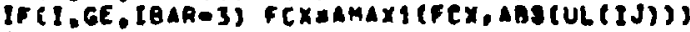

IJEIJ०NO

30 Conithue

CALL LOOP

40 CONYINUE

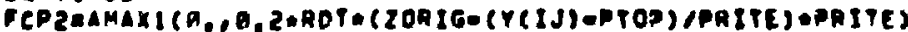

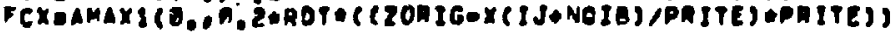

CALL START

DO 150 jez.jPz

DO 140101,101

IPJeIJ\&NO

IMJEIJ日NO

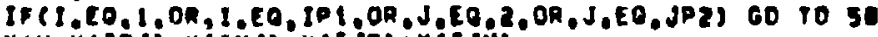

xavex(I0j)

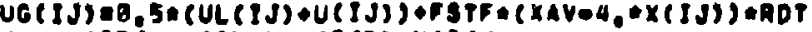

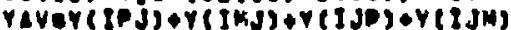

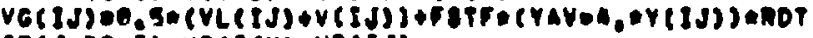

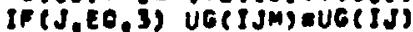




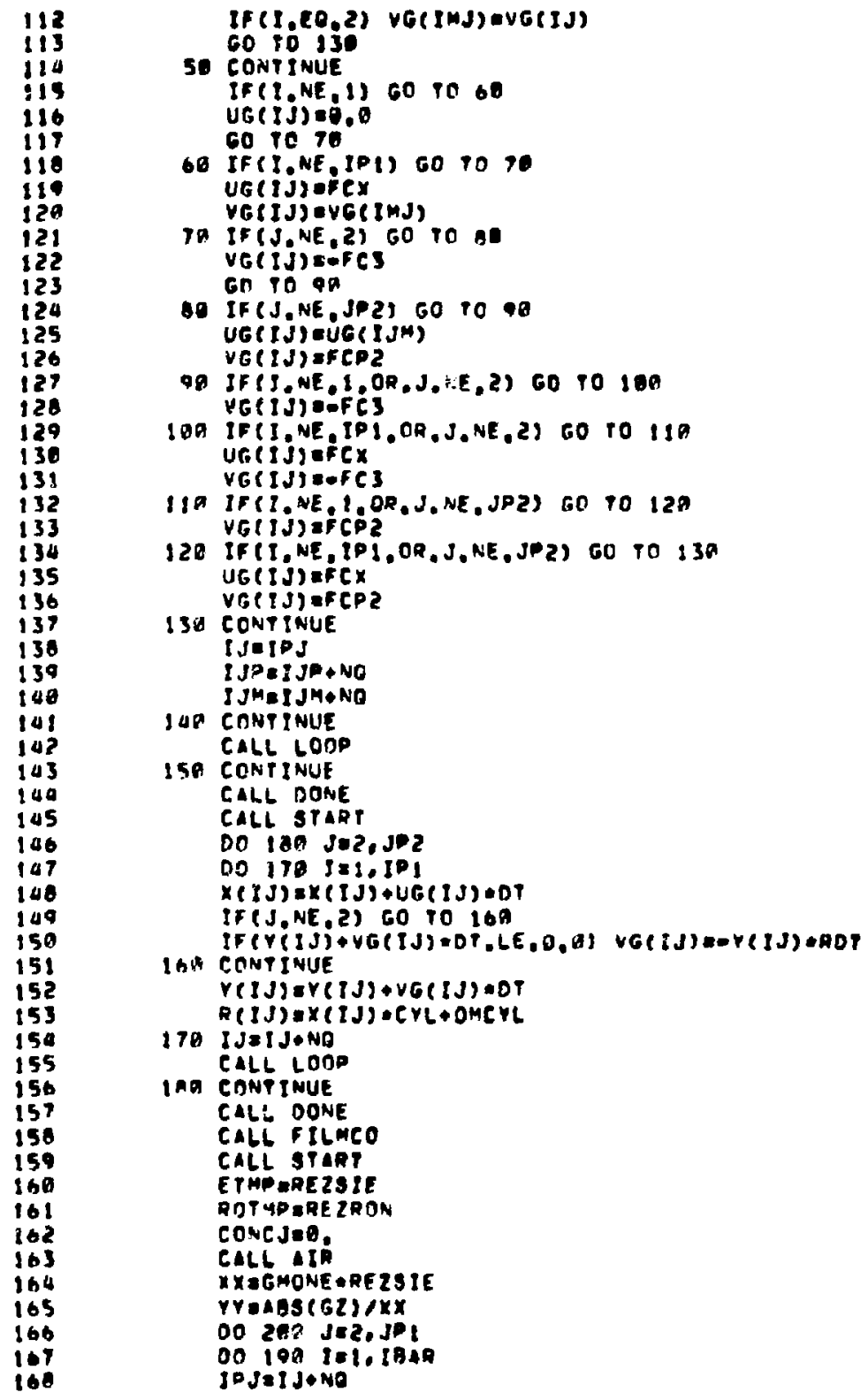




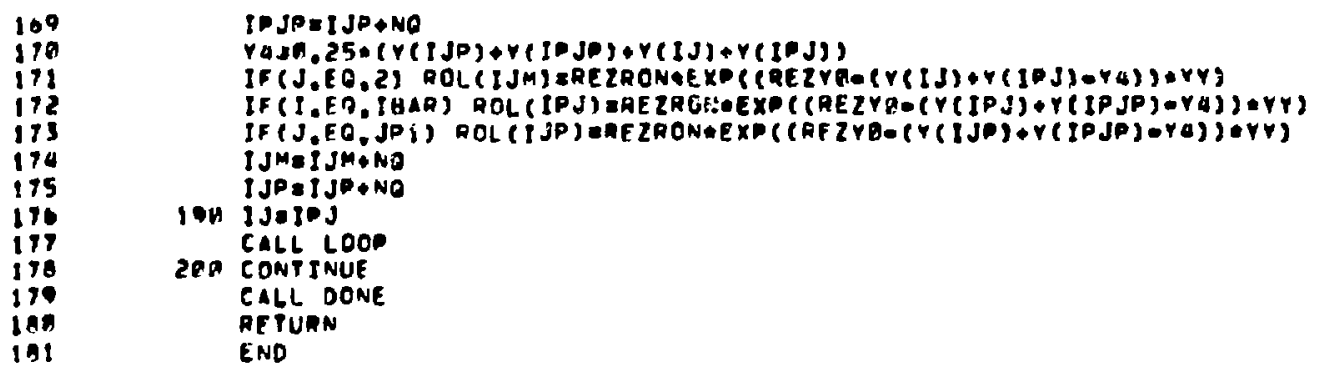



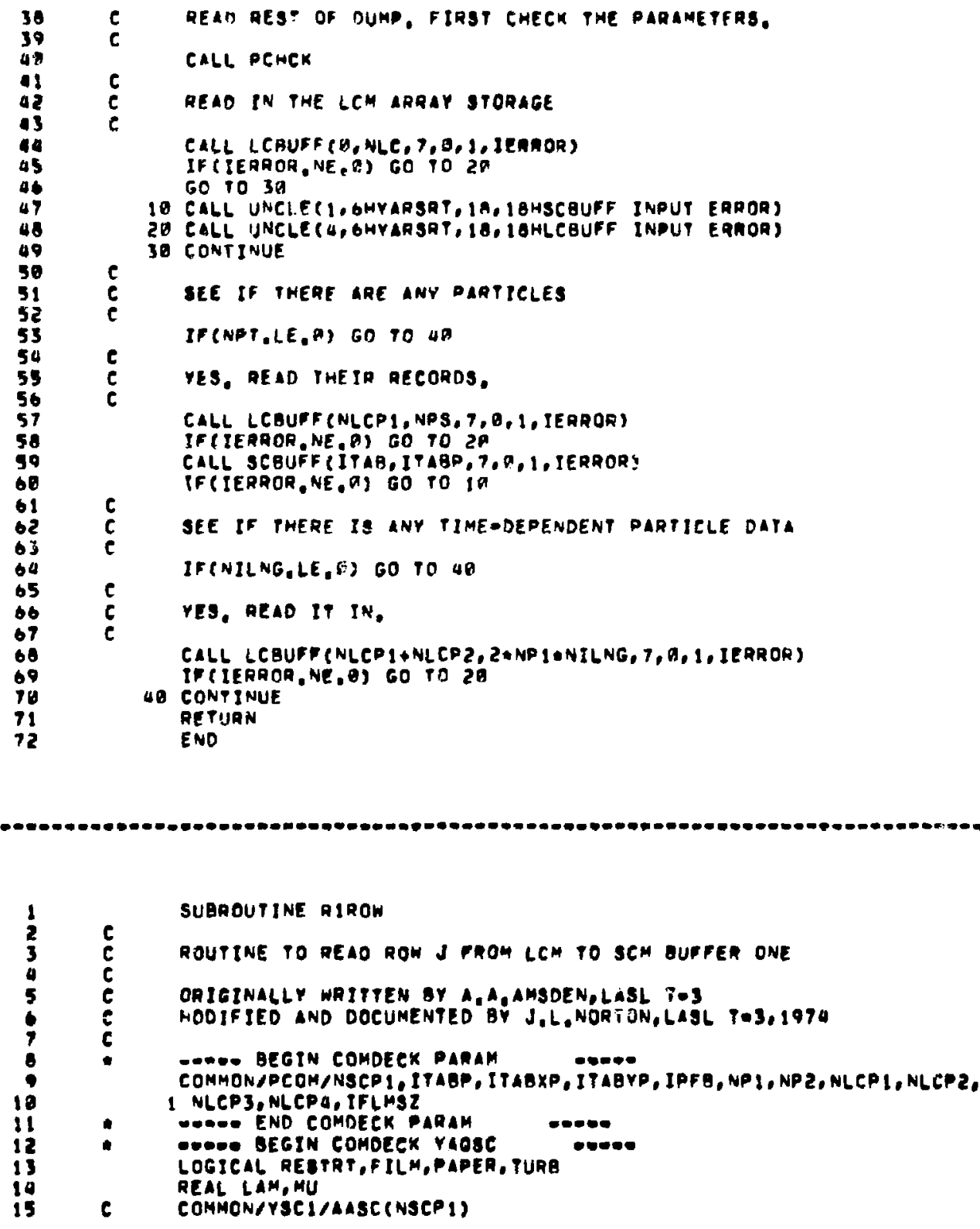


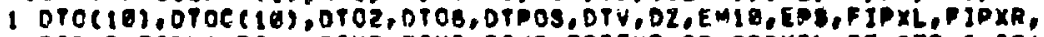

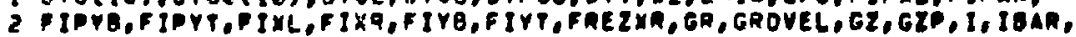

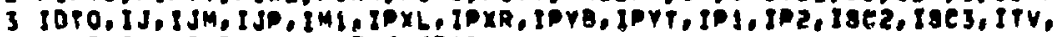

a TUNF, IXL,IXA, IVG, IVT,J, JOAG

COMMON/YSCZ/JCEN, JP 1 , JPZ, JP 4, JUNF, JUNF O2,KXI.LAM,LPB, MU, NAME (B),

1 NEYE, NLC, NPS, NPT, NA, NOI, KDIB, NEI 2 , NSE, NUMIP, ZORIG, OM, OHCYL, PXCONY

2. PXL,PXR, PYA, OVEONY, PYT, RST, REZRON, REZS IE, REZYO,RIBAR,RIEJE,

3 FREZYT,FAEZYG, ROAFR, T, PHIRE. NCLST, TOUT, PHFIN

COMMON/YSCZ/TUAI, TUSI, NCQ, PNEG, TNE GSV, TUSV, TUAD, P TOP, PRITE,PBDTM.

1 ILNG, NLNG, TP 3 , TUPOT, TDOSAV, TK, TI, TUEENG, EPI, SAVI, RLEVEL, TQ, IST.

$2 V V, X C O N V, X L, X Q, Y B, Y C O N V, Y T, P T D O L D, O T S V, D Y L A S T, P I Y B O, I Y B O, Y C N V L D$.

I XNVLO, IXRO, IXLO, IXRO, IXLO, ISVW, JSVH, OMN, OMX, WMAX, JNM, T2, TLIM.

4 ROMFXR, COMFY , ROMFYB, JOUMP, FWTHRD, PE, DTR, THASS, DTVSAV, DTCSAV, TDTY

5 . JOTV, IDTC, JDPC, EIAC, T Y , POPE, UMOM, VMOM, TMAX, TGMX, ITM, JTM. ITG.JTG

- TMASSV, WMAXEF, RMINEF, TSTATO

common

C COMMON/YSC $4 /$ ITAB (ITAHO)

COMMON/YSCA/ ITAB ( I gee)

COMMON/YSCS/RESTRT, FILM,PAPER, IPD, IFD

- Co- end camoeck YaOSC

๑๑๐

DATA NE/DI

IEC $(\mathrm{J} \cap I) \cdot \mathrm{NOI}$

CALL ECRO(AASC,IEC, NOI, IDUM)

RETIJAN

ENO

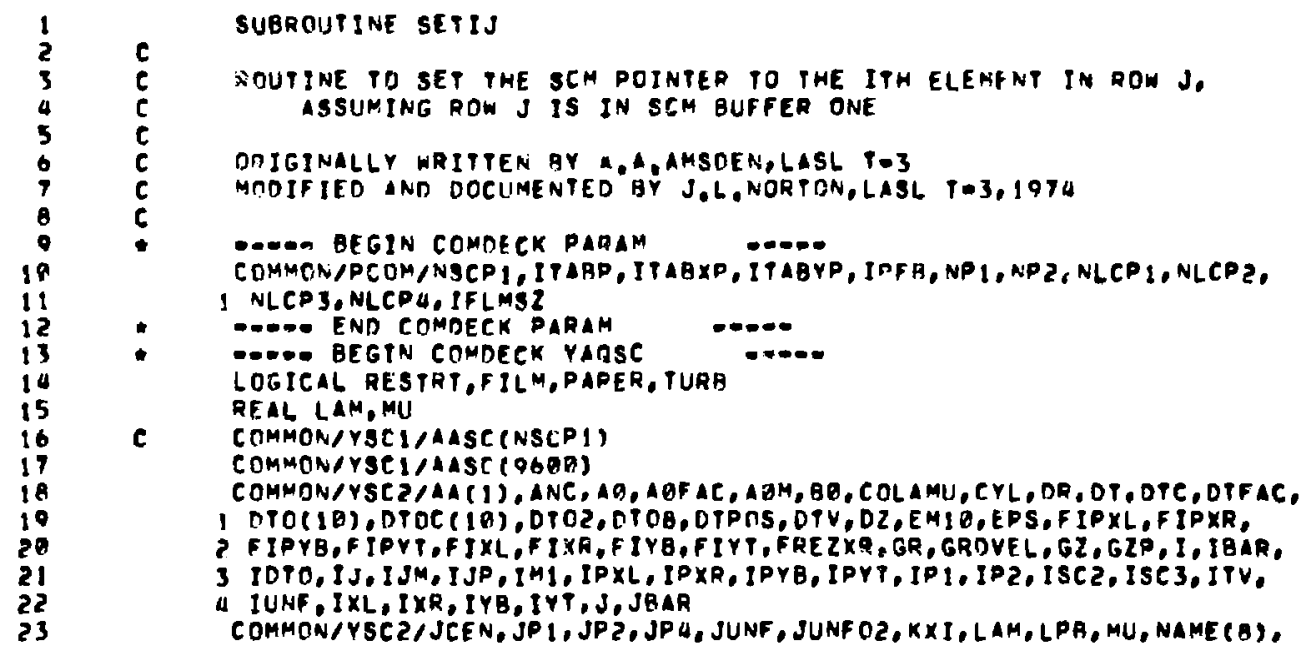


1 NCYC, NLE, NPS, NPT, NO, NOI, NOIB, NOI2, NSE, NUMIT, ZORIG, OM,OMEYL,PXCONY 2 PXL,PXR, PYB, PYCONY, PY,RDT, REZRON,REZSIE, REZYG,RIBAR,RIBJB, 3 FREZYT,FREZYB,ROMFR, T, THIRD,NELST, TOUT, TWFEN COMMQN/YSC2/TUGI, TUSI, NEO, TNEO, TNEGSV, TUSV, TURB,PTOP,PRITE,PBOTM,

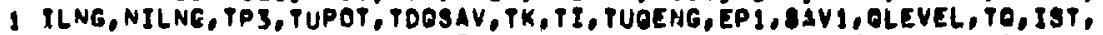
2 VV, XEOHY, XL, XA, YA, YEONV, YT, PTOLD, DTSV,DYLAST,FIYEO, IVBO, YCNVLD, 3 KCNVLD,FXRO,FIXLO, IXRO, IXLO, ISVN, JSVW,OMN, OMX,WMAX, JNM, TZ, TLIM, 4 ROMFXR, ROMPYT, ROMFYB, JOUMP, THTHRD, TE, DTR, THASS, DTVSAV, DTCEAY, IDYV

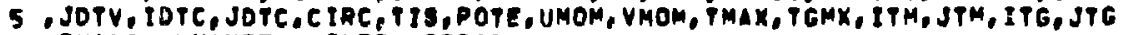
- TMASEV,WMAXEF RAINEF, TSTRTD

c COMMON/YSCZ/2Z COMMON/YSCC/ITAB (ITABP) COMMON/YSCA/ITAB (1000) COMMONIYSCS/RESTRT, FILM, PAPEA, IPD, IFD - - END COMDEEK YAOSC $1 J=(1-1) * N B+1$ AETURN

ROUTINE TO TRANSFER DATA BETWEEN LARGE CORE AND SMALL CORE IN ORDEA TO NINTMIZE SMALL COAE REQUIREMENTS

ORIGINALLY WRITTEN BY A,A,AMSOEN,LASL T-3

MODIFIED AND DOCUMENTEO BY J.L,NORPON,LASL T-3,197A

\section{DOA BEGIN COMDECK PARAM OPO}

COMMON/PCOM/NSCP I, ITABP, ITABXP, ITABYP, IPFB, NPI, NPZ, NLCPI, NLCPZ,

1 NLCP 3, NLCPA, IFLMSZ

- -. ENO COMDECK PARAM

-OA- DEGIN COMDECK YADSC H.

LOGICAL RESTRT, FILM,PAPER, TURB

REAL LAM, MU

C COMMON/YSCI/AASC (NSCO1)

COMMON/YSCI/AASC (96BQ)

COMMON/YSC2/AAC 1), ANC, ACH, $A O F A C, A B M, B Q, C O L A M U, C Y L, D R, D T, D T C, D T F A C$,

1 DTOC (10), OYOC (IO),DTOZ, DTOB, DTPOS, DPV, DZ,EMIO,EPS, FIPXL,F IPXR,

2 FIPYH,FIPYT,FIXL,FIXR,FIYB,FIYT,FREZXR,GR,GRDVEL,GZ,GZP, I, IBAR,

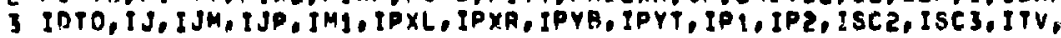

- IUNF, IXL, IXR, IYB, IYT,J,JBAR

COMMONAYSCZ, JCEN, JP 1, JPZ, JPA, JUNF, JUNF OZ, KXI, LAM, LPE, MU, NANE (B),

1 NCYC, NLC, NPS, NPT, NA, NOI, NGIB, NOI 2, NSC, NUMIT, ZORIG, OM, OMCYL, PXEONV

2 .PXL,PXR, PYB, PYCONV, PYY, RDT, REZRON, REZSIE, REZYO,RIBAR, AIBJB,

3 FREZYT, FREZYB, ROMFR, T, THIRD, NCLST, TOUT, TWF IN

COMMON/YSCZ/TUPI, THSI, NEQ, TNEG, TNEGSV, TUSV, TURA, PTOP, PRITE,PBOTM,

1 ILNG, NILNG, TP 3, TUPOT, TDASAV, TK, TI, TURENG,EPI, SAVI, QLEVEL, TO, IST.

2 VV, XCONV, XL, XR, YR, YCONV, YT, PYPOLO,DTSV, DYLAST, FIYRO, IYBO, YCNVLO,

3 XCNVLD,F IXRO, F IXLO, IXR I, IXLO, ISVH, JSVH, QMN, QMX, WMAX, JNM, TZ, TLIH,

A ROMFXR, ROMFYT, ROMFYE, JSUMP, TWTHRO, TE, DTR, TMASS, DTVSAV, DTESAV, IOTV

5 . JDTV, IOTC, JOTC, CIRC, TIS, POTE, UMOM, VMOM, TMAX, TGMX, ITM, JTM, ITG.JTG 


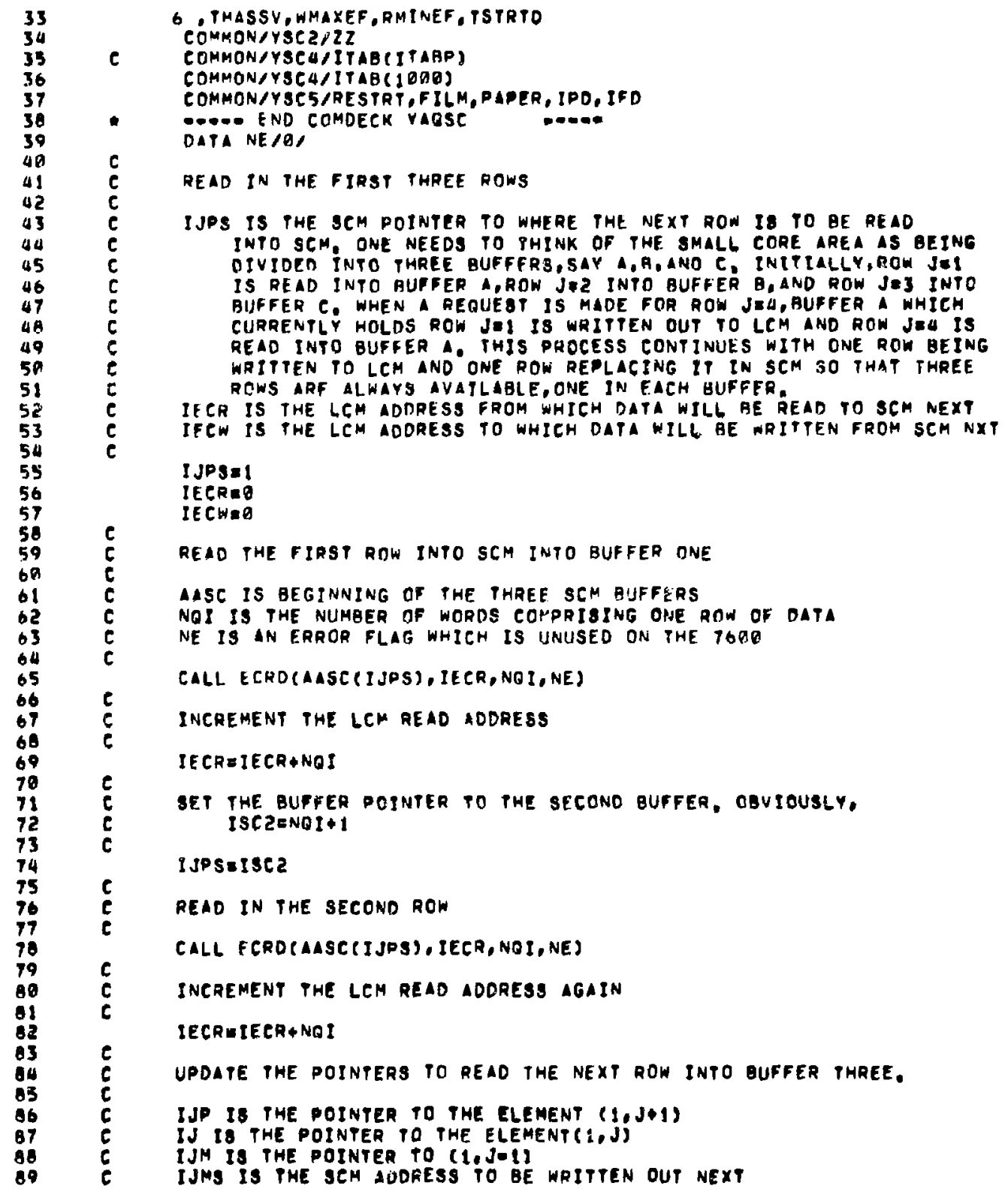




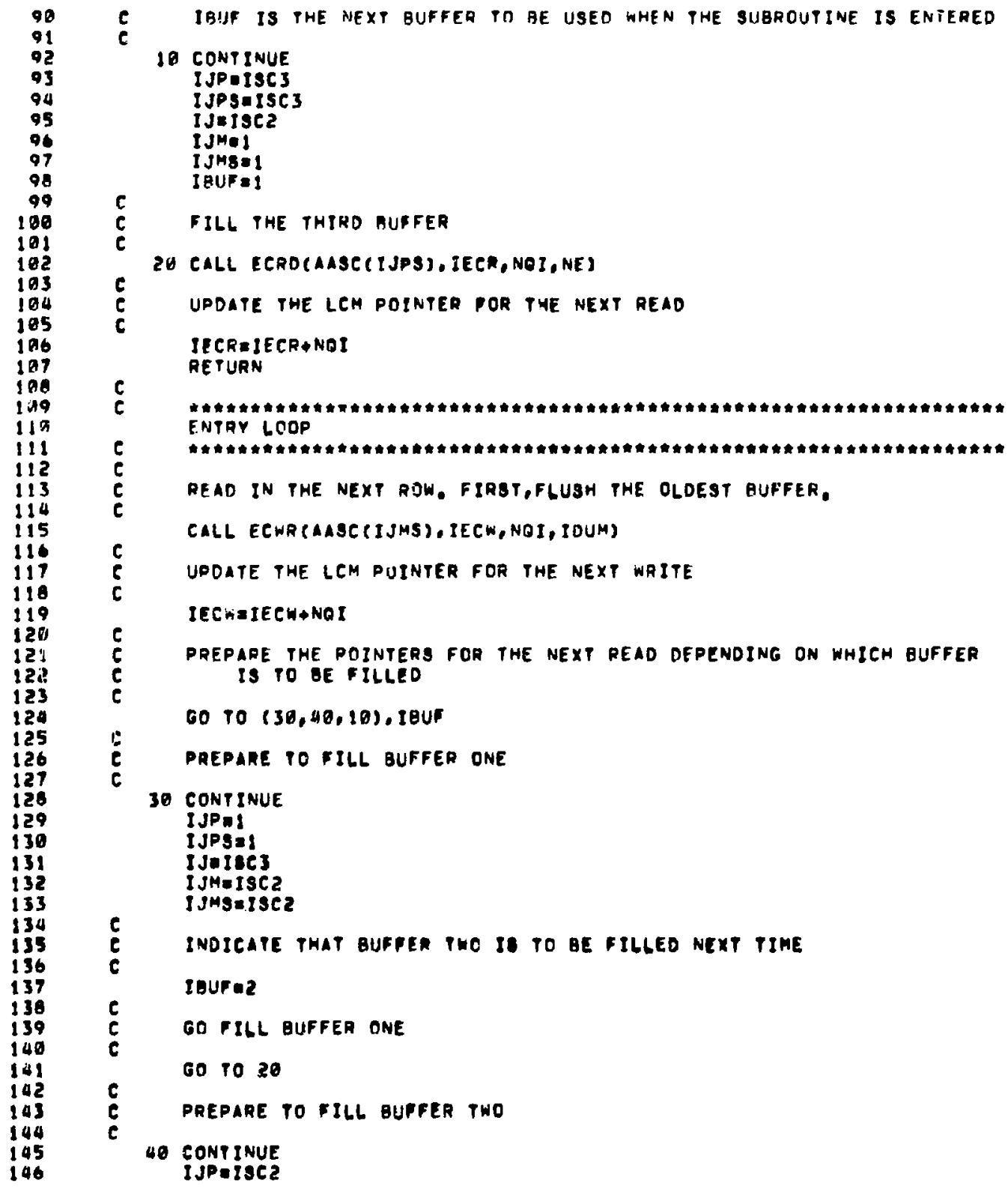



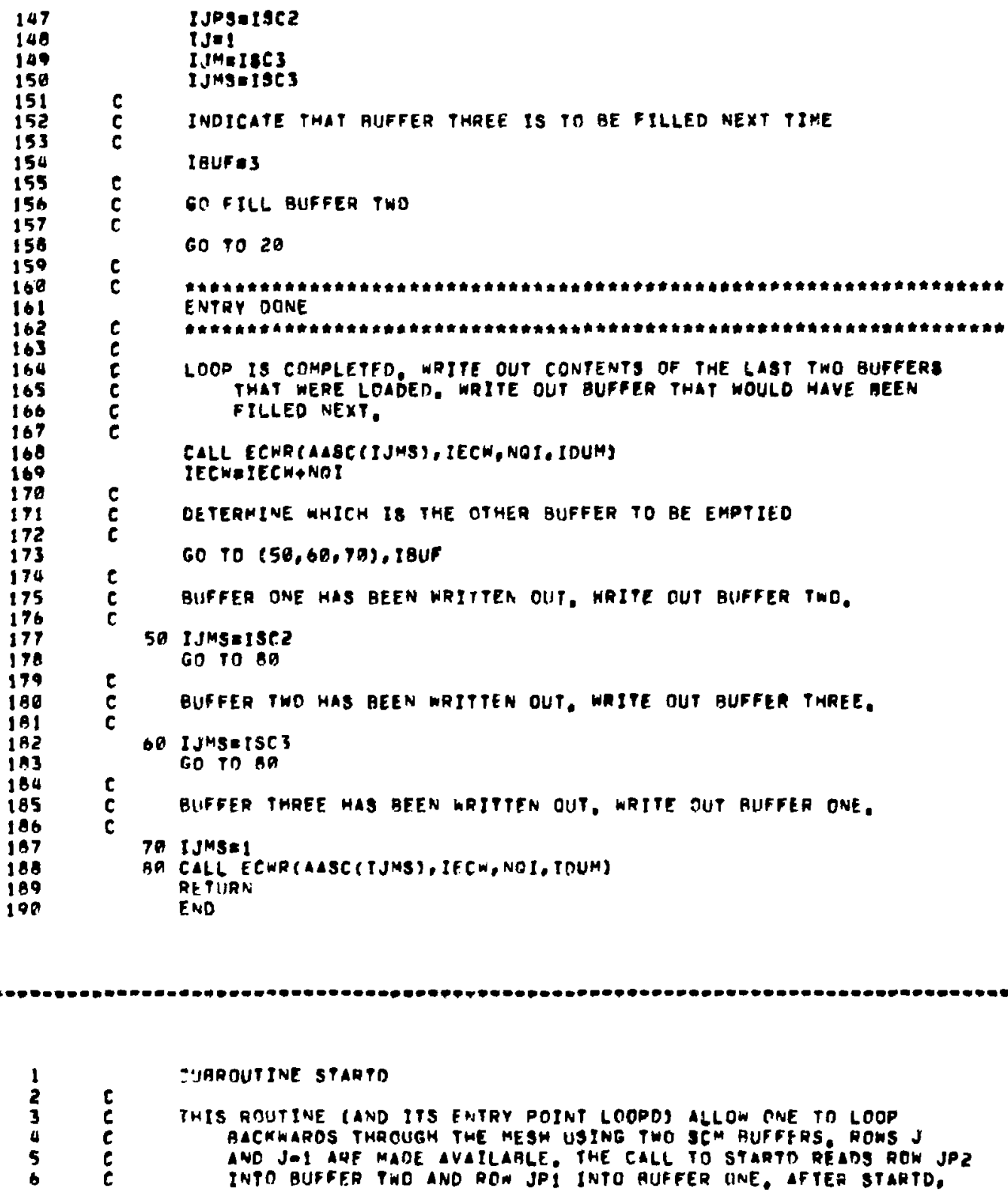


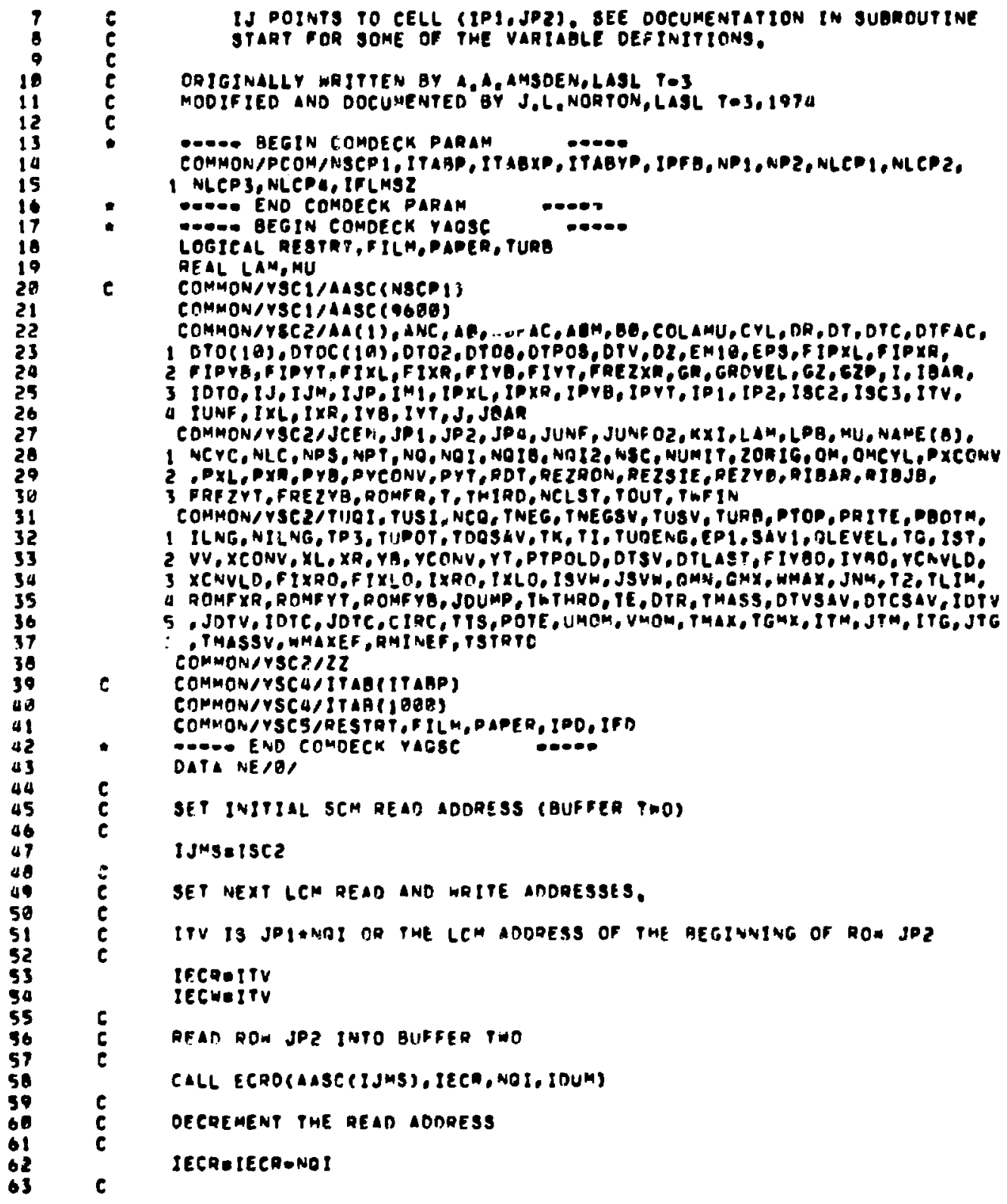




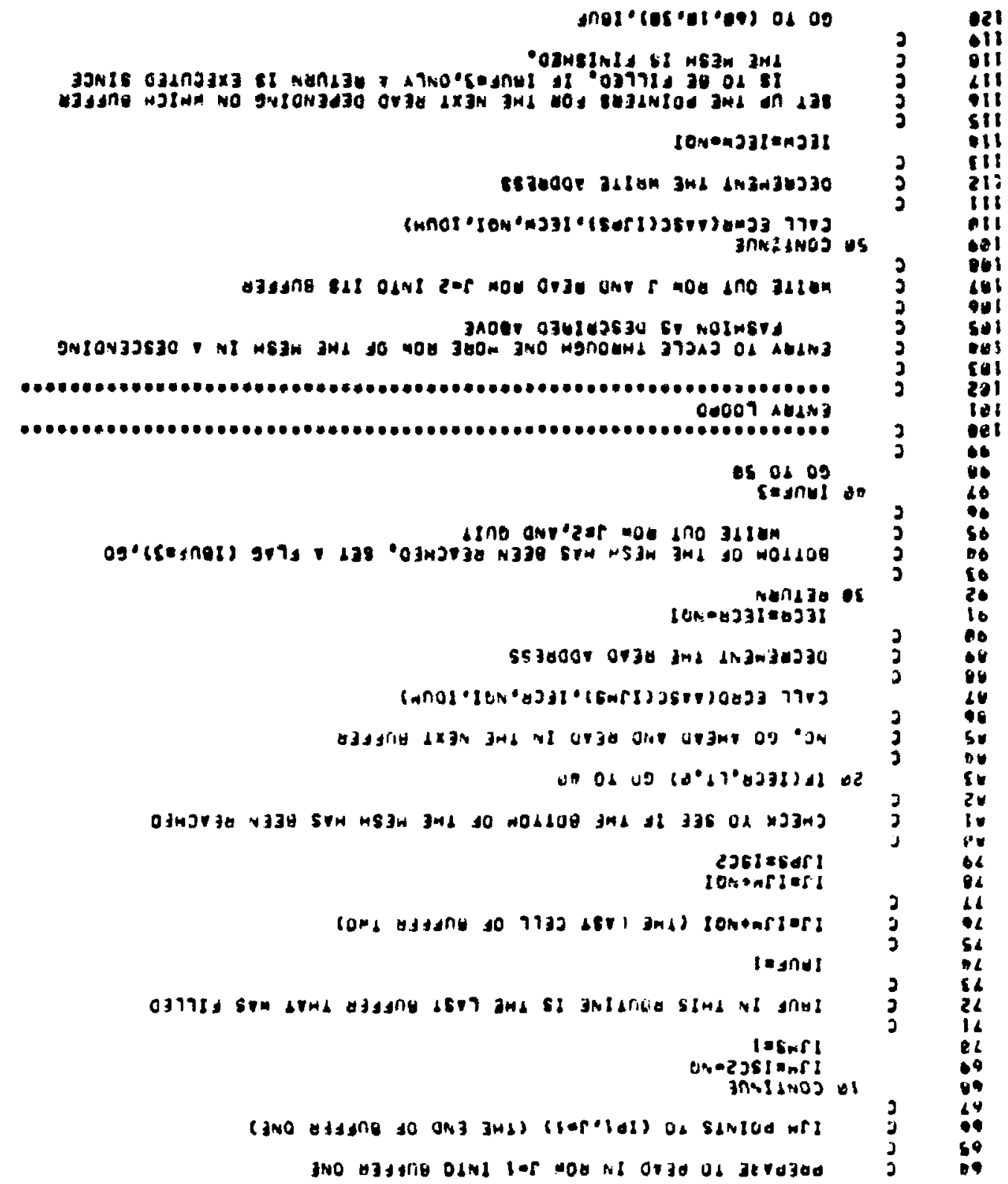




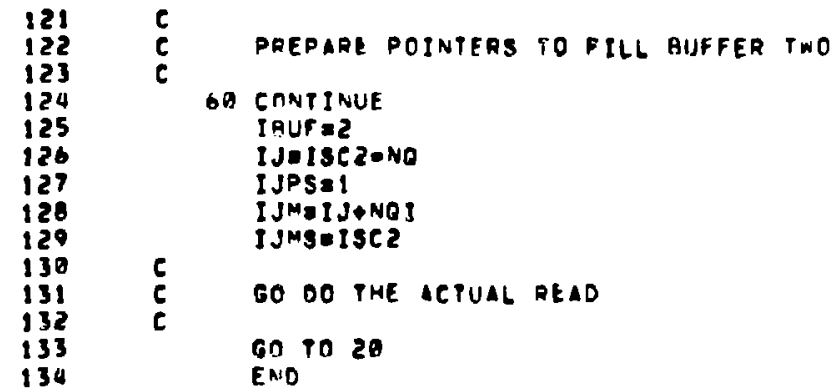

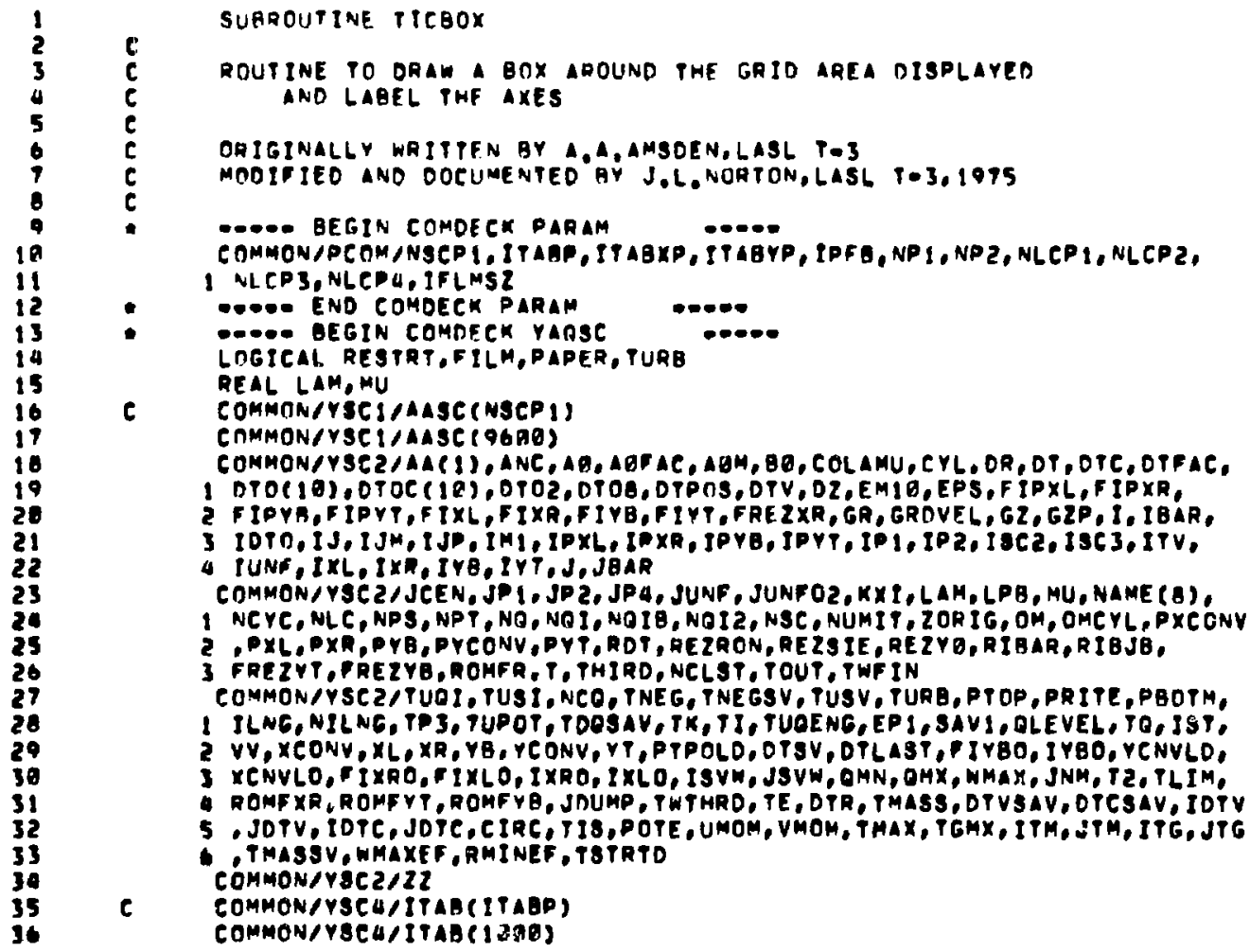




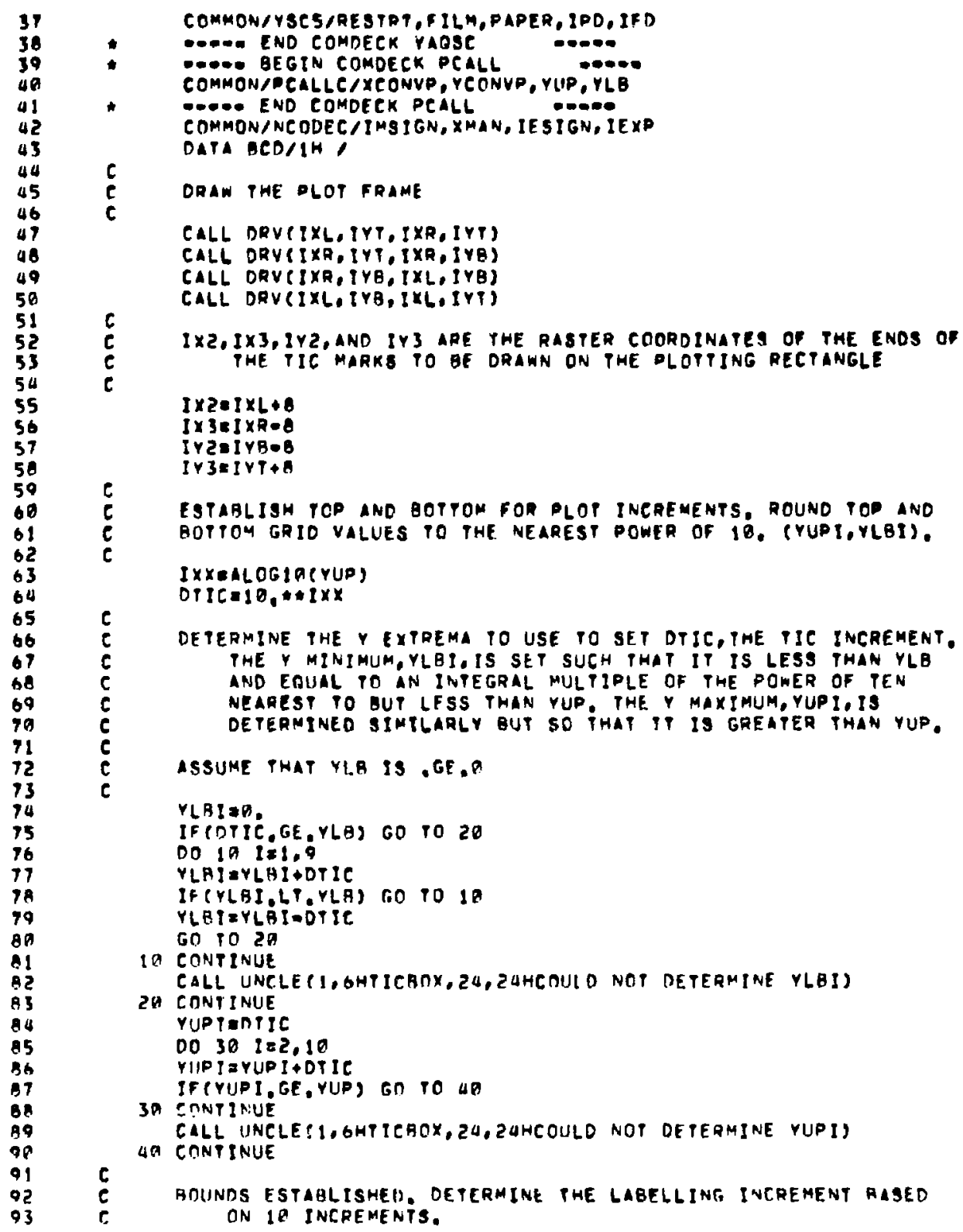




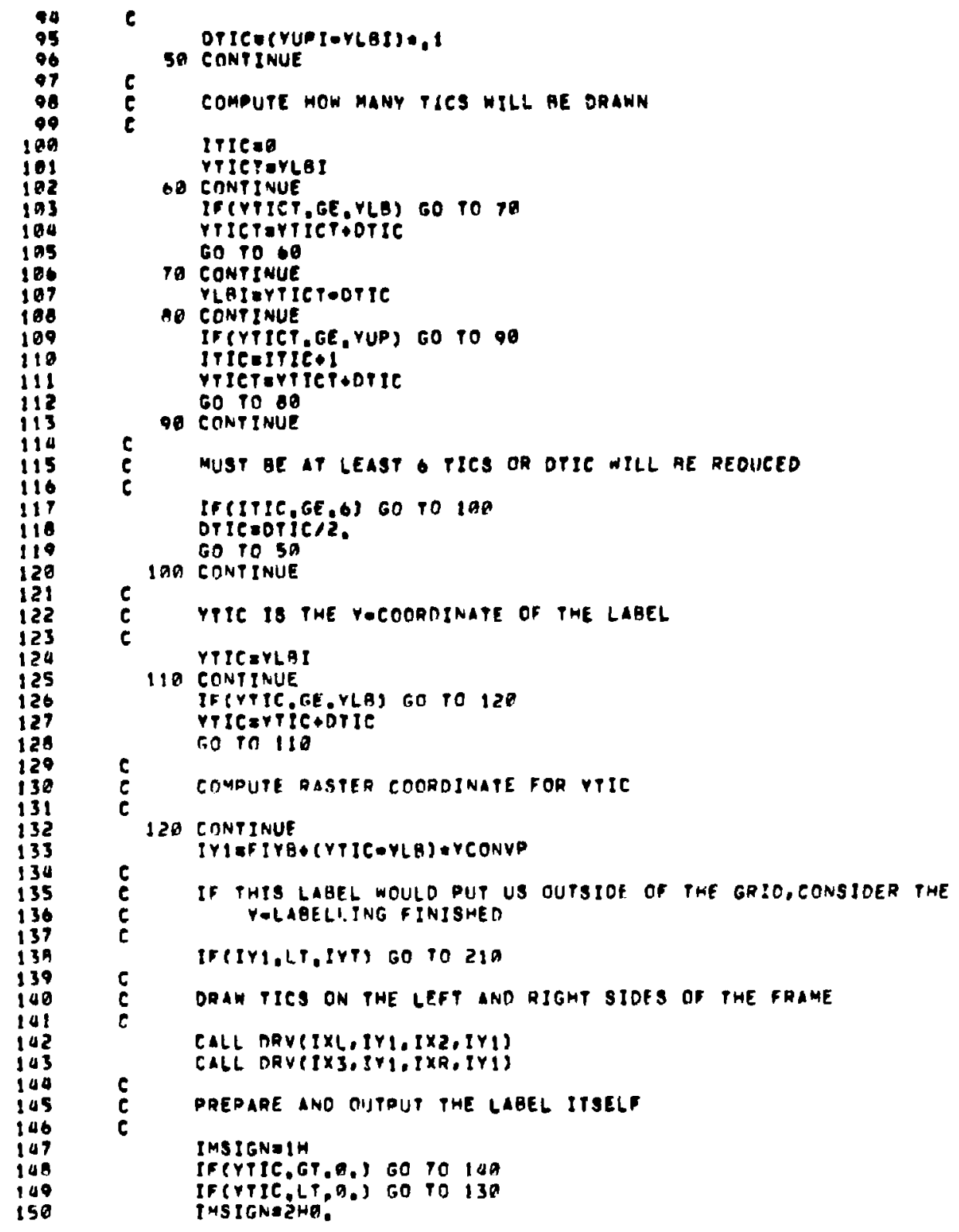




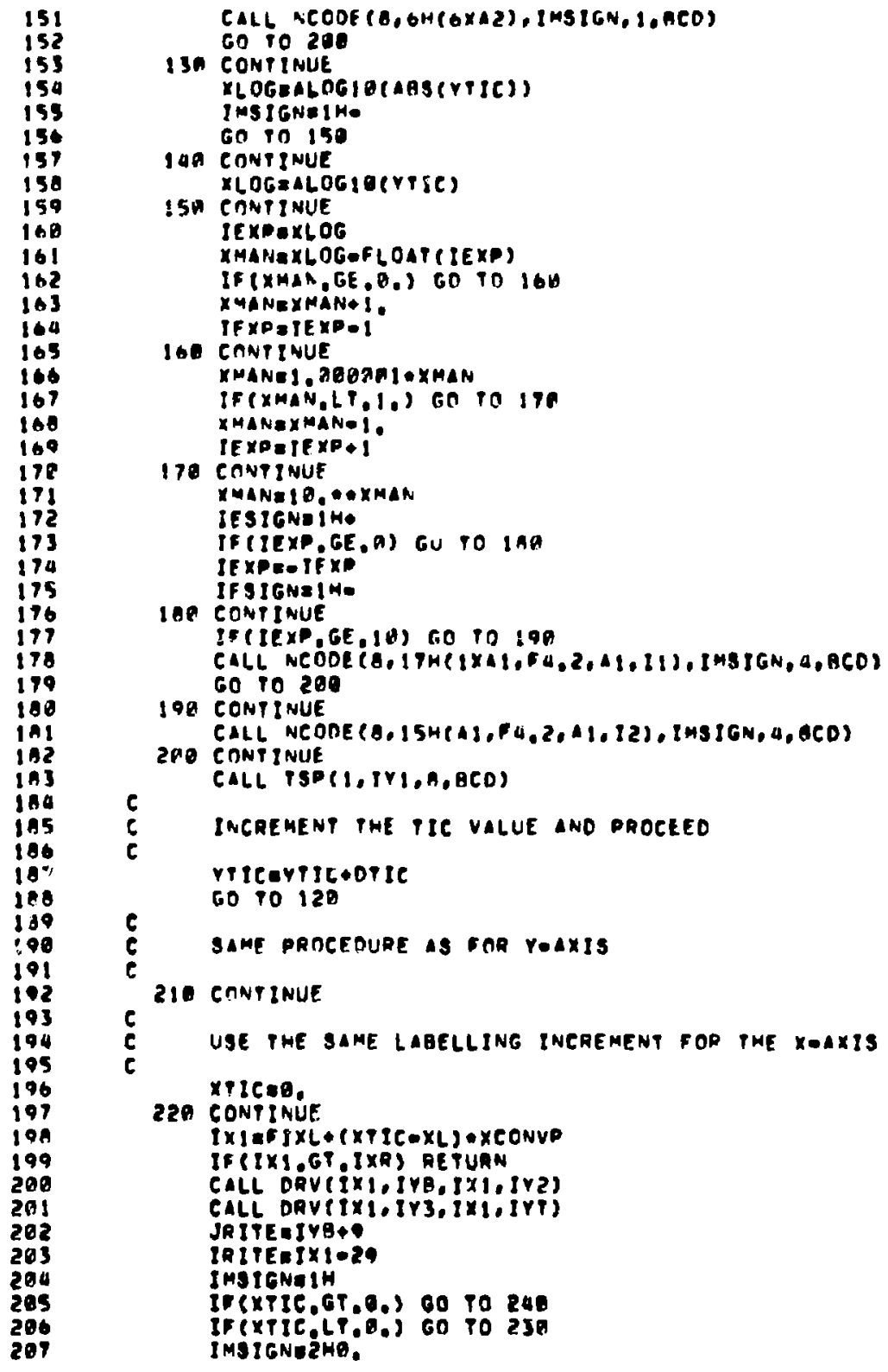




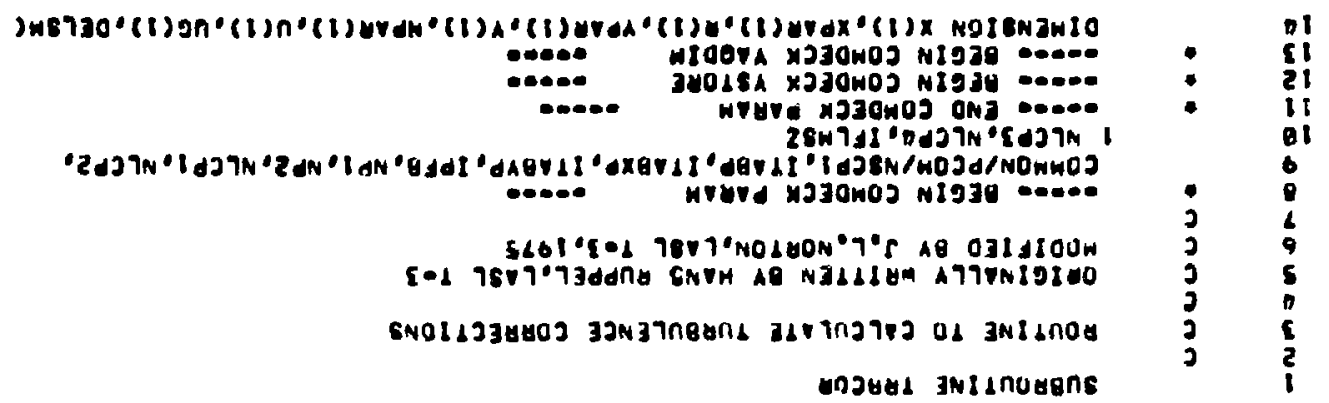

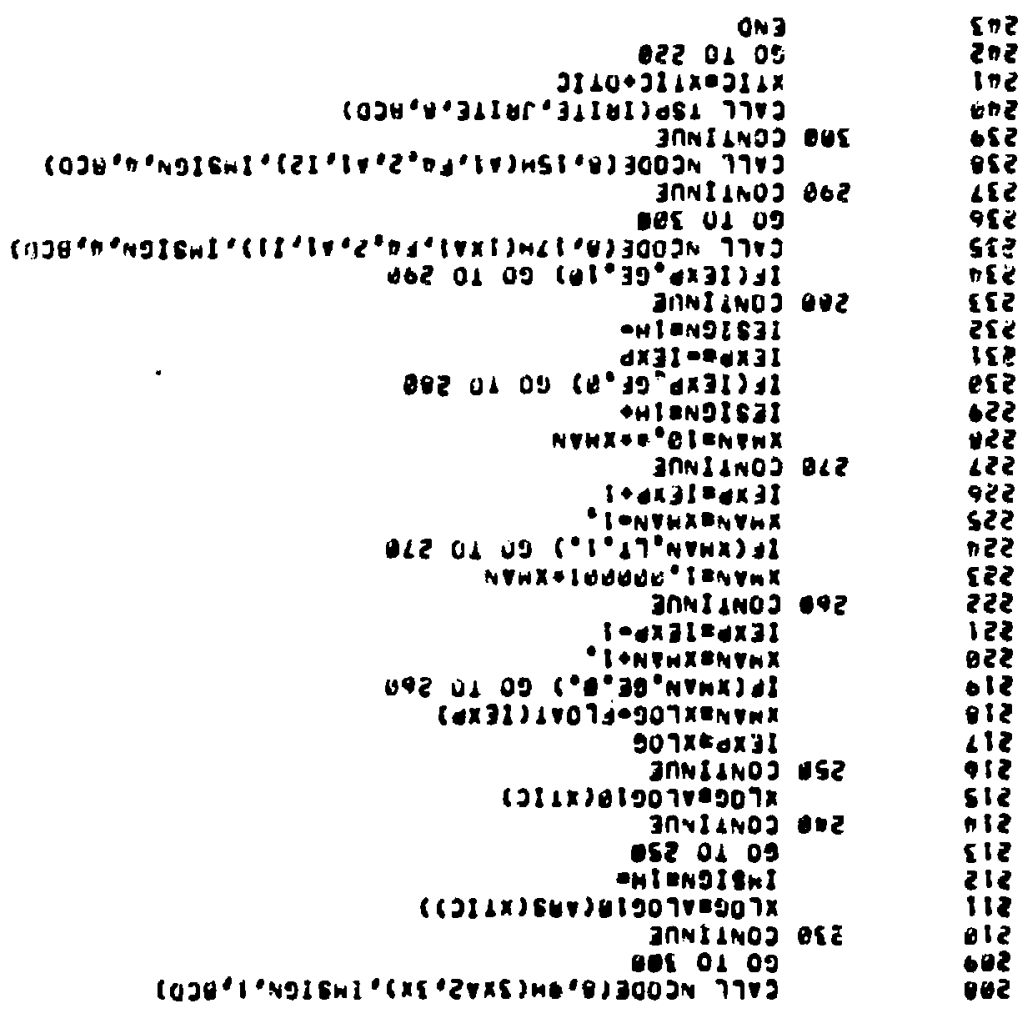




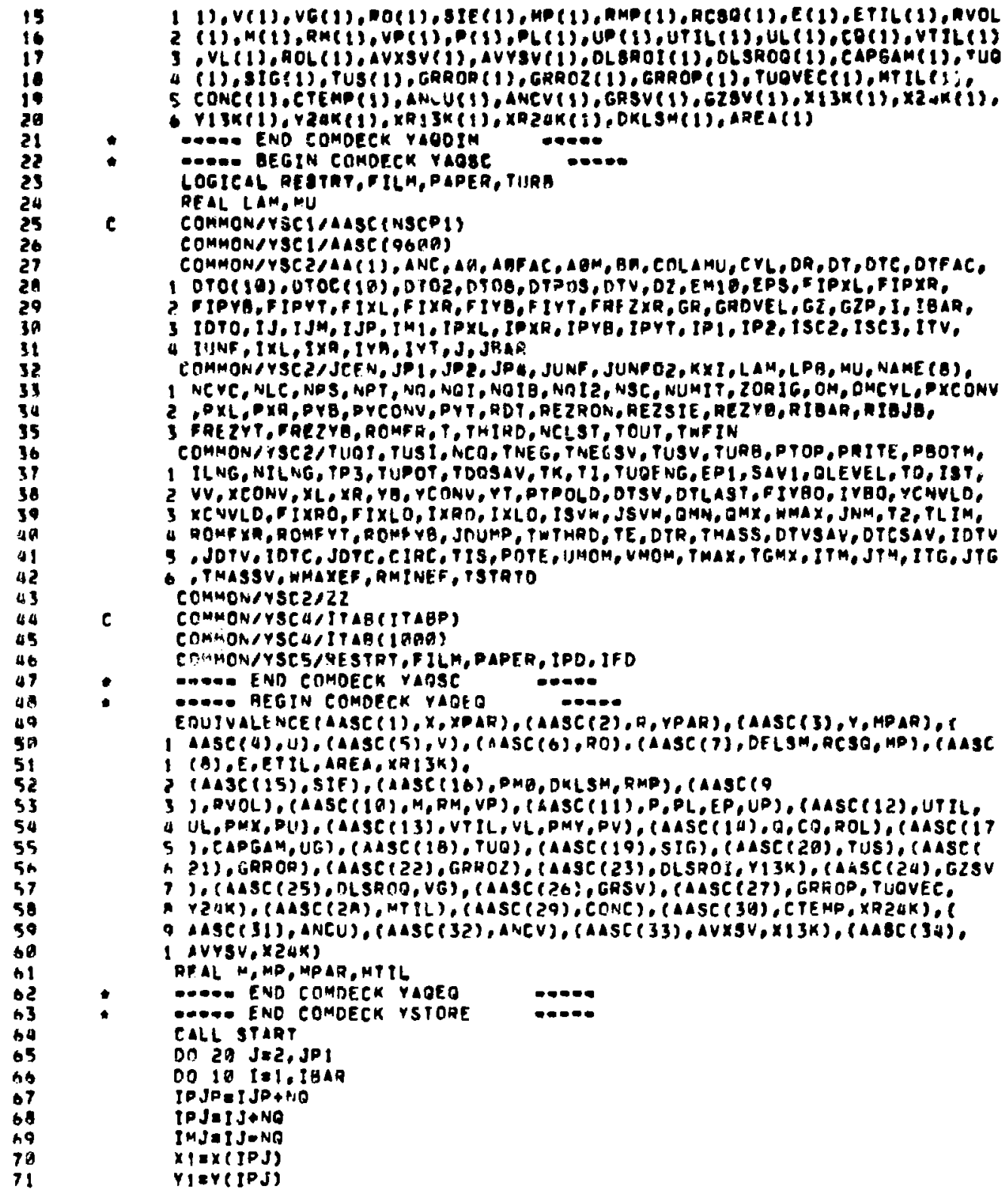




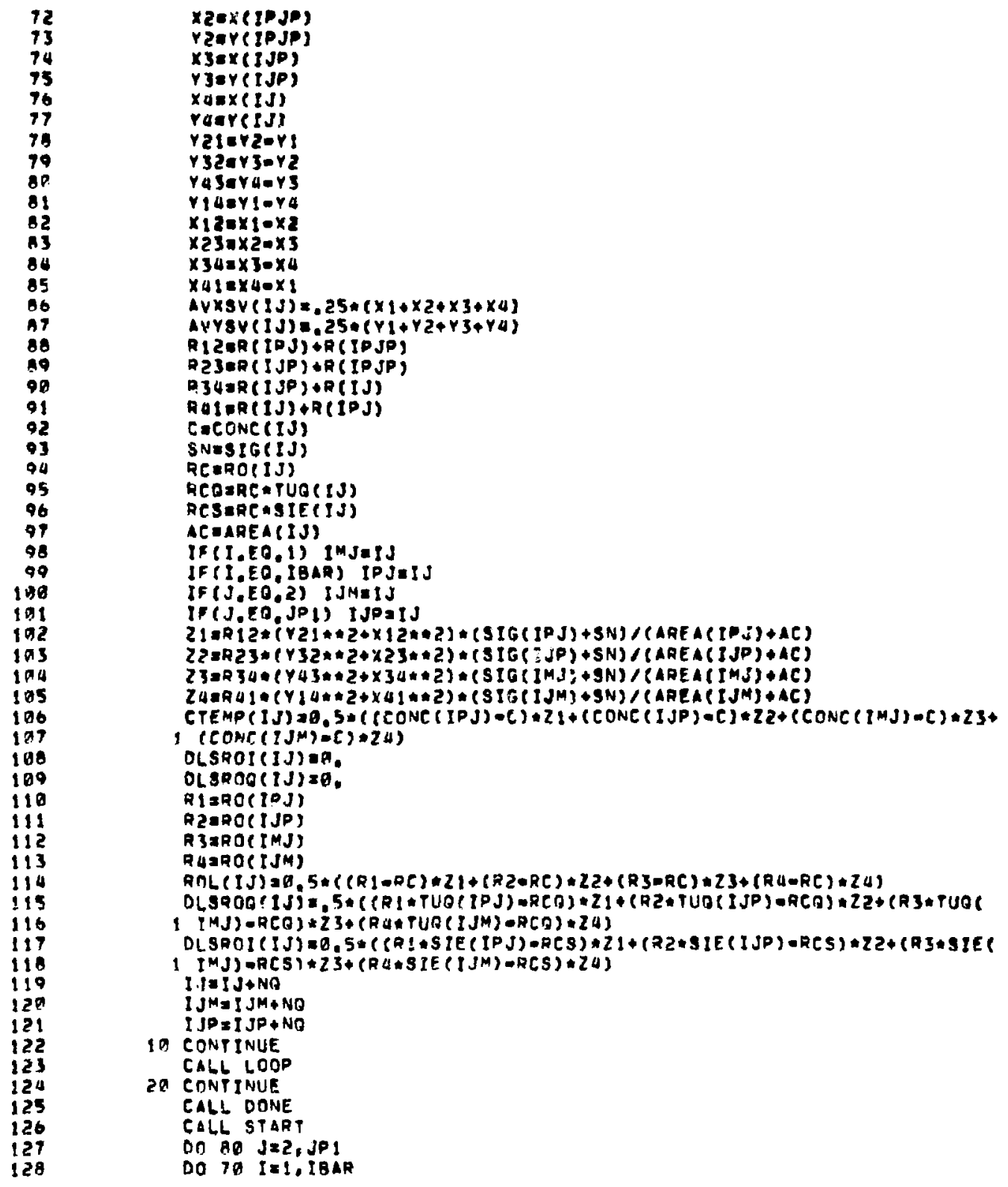




\begin{tabular}{|c|c|c|}
\hline $\begin{array}{l}129 \\
130 \\
131 \\
132 \\
133 \\
134 \\
135 \\
136 \\
139 \\
139 \\
139 \\
140 \\
141 \\
142 \\
143 \\
144 \\
145 \\
146 \\
147 \\
148 \\
149 \\
150 \\
151 \\
152 \\
153 \\
154 \\
155 \\
136 \\
157 \\
150 \\
159 \\
160 \\
161 \\
162 \\
163 \\
164 \\
165 \\
166 \\
167 \\
168 \\
169 \\
170 \\
183 \\
184 \\
185\end{array}$ & 10 & 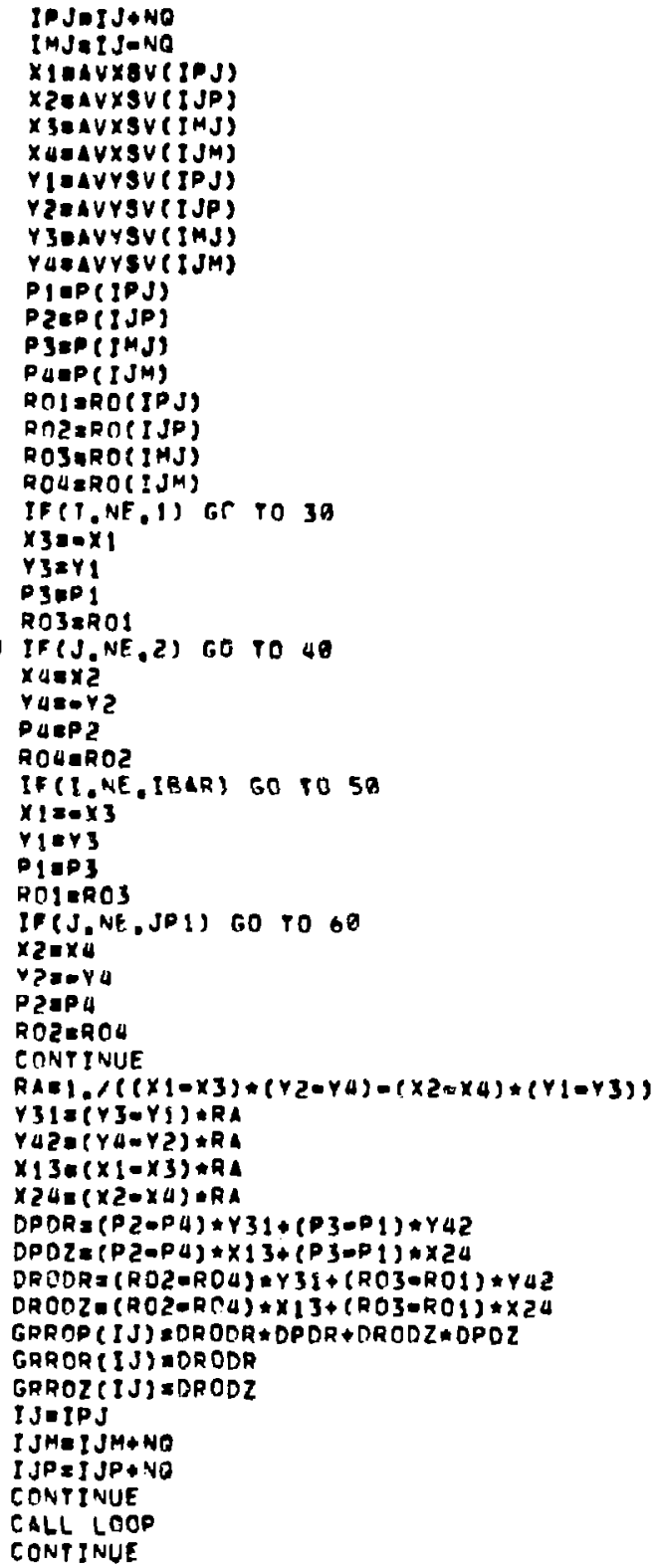 \\
\hline
\end{tabular}




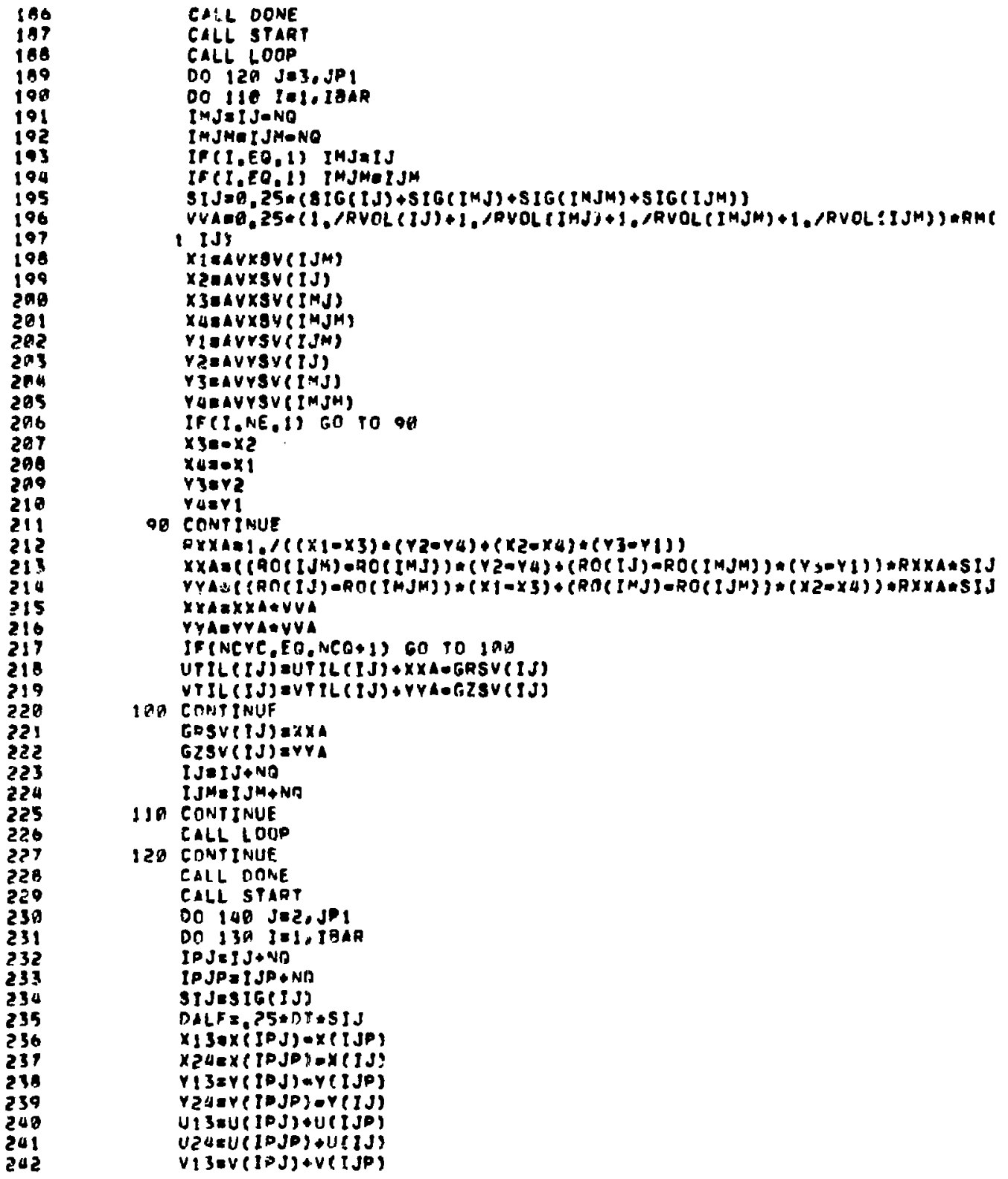




\begin{tabular}{|c|c|c|}
\hline $\begin{array}{l}243 \\
244 \\
245 \\
246 \\
247 \\
248 \\
249 \\
259 \\
251 \\
252 \\
253 \\
254 \\
255 \\
256 \\
257 \\
258 \\
259 \\
268 \\
261 \\
262 \\
263 \\
264 \\
265 \\
266 \\
267\end{array}$ & $\begin{array}{l}130 \\
100\end{array}$ & 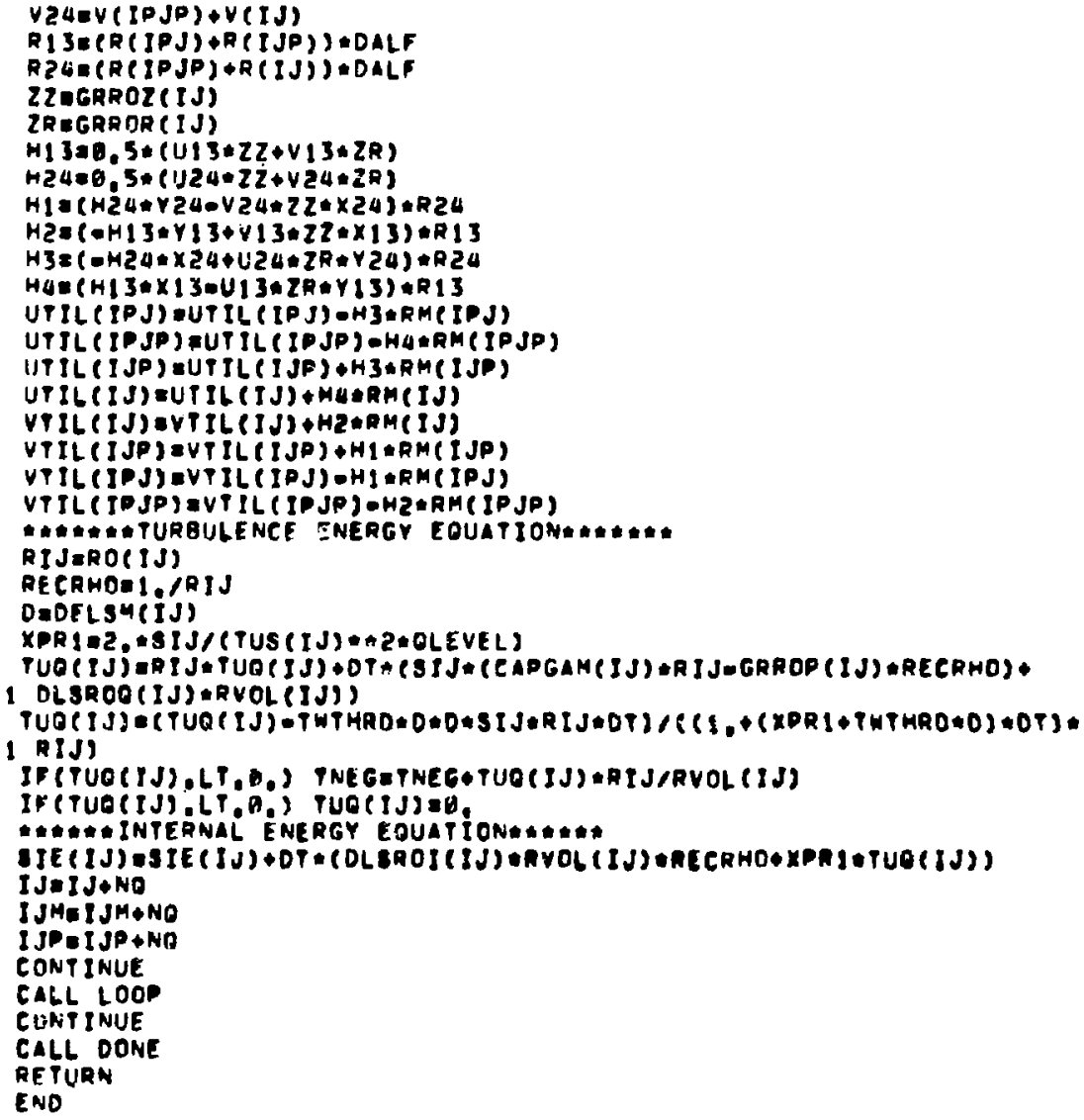 \\
\hline
\end{tabular}

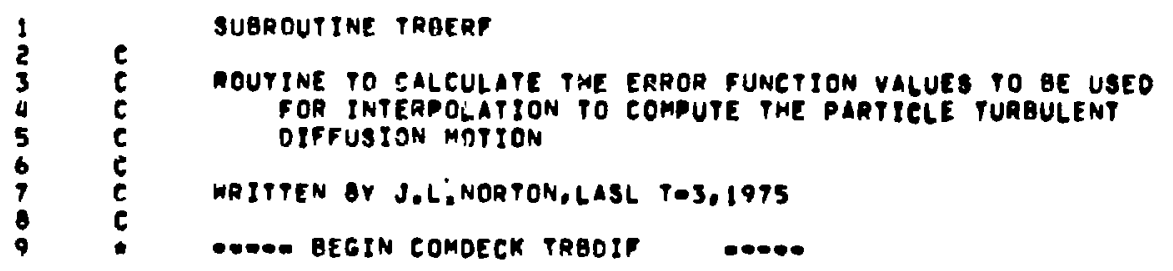




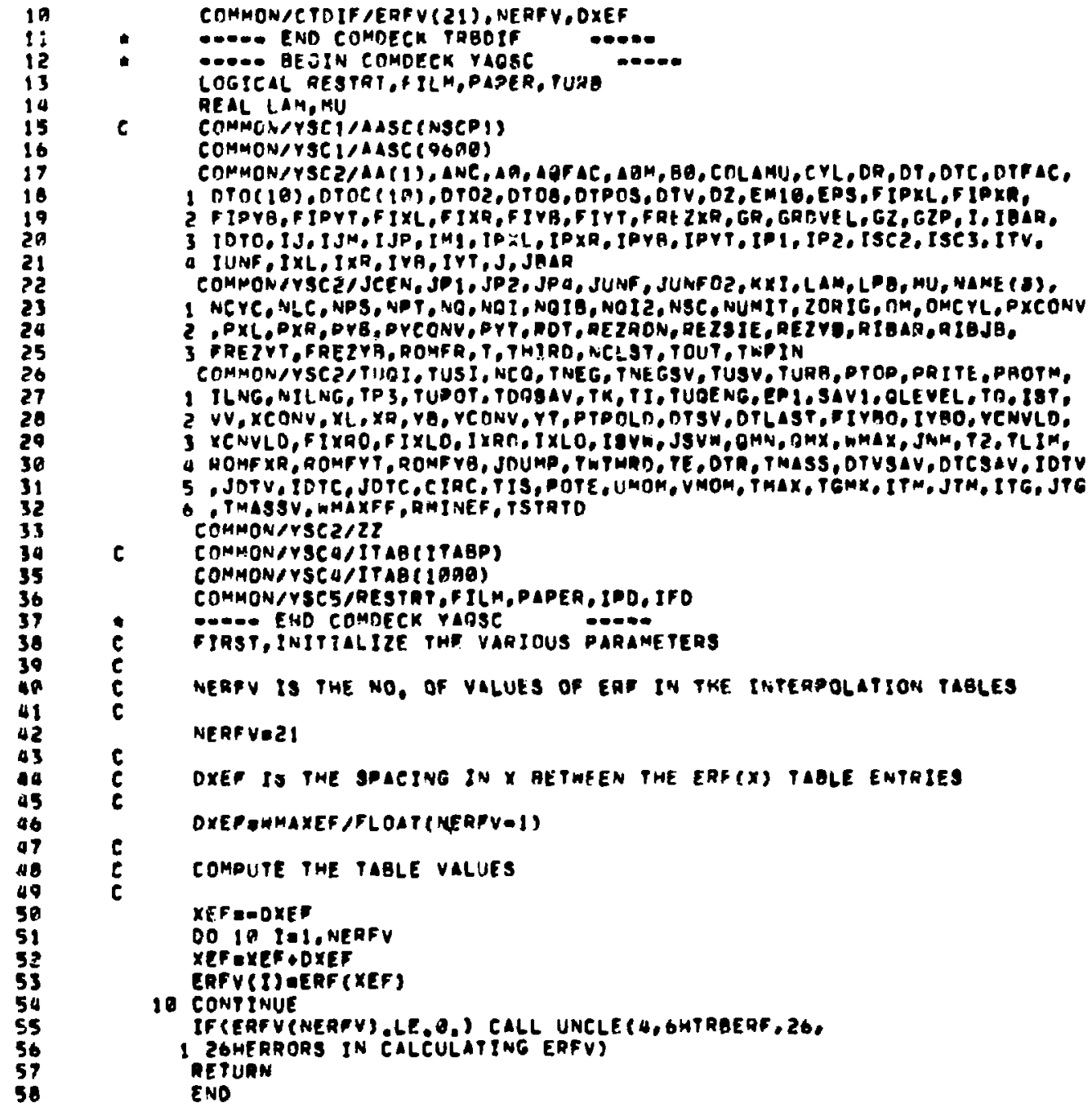




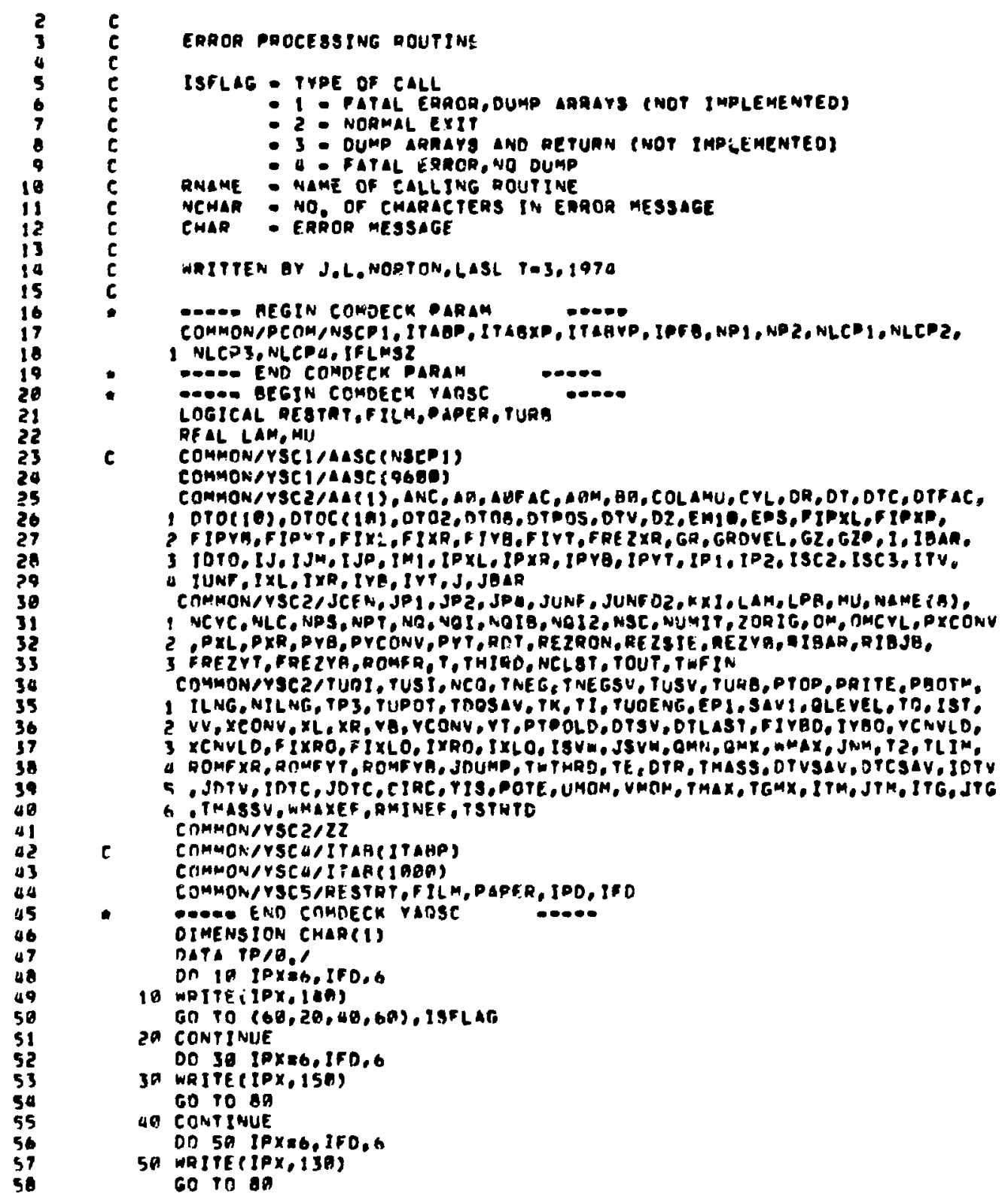


b) CONTINUE Do 70 IDxas. IFo.

10 MAITE(ID $x, 11$,

an CONT INUE

NMOS ENCMAOIIO

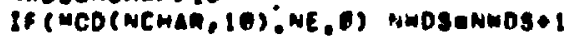

Do 9 IDXa, ITO, O

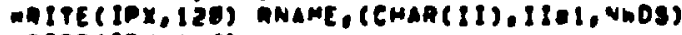

Qp wite (IDX, iad)

CAll secono(to)

maIte(so, 190) TD

IE (ISFLAG,EO, 2) CALL EXIT

if (tsFlaG, $(0,3)$ aetunn

$c$

CaLl ExIT(z)

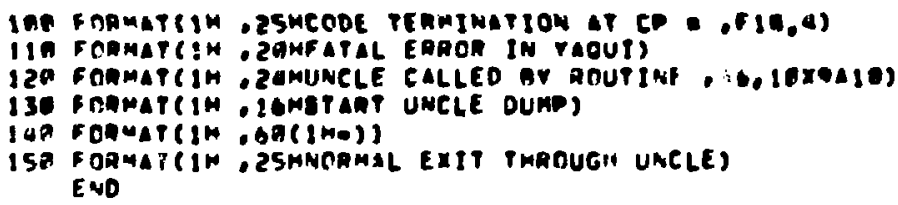

SHOAOUTINE VELPLT(UMAX, IFLAG)

DOUPINE TO DO YELOCITY DLOTS

VMAX IS THE MAXIMUN OE THE VELOCTTY CUARENTL BEING DLOTTED IN ANY ONE DIDECTION.

IFLAG is o Fna clulo velocitr plots scaleo ar umax, it is 1 fon UUSEALED FLUTD VELOCITY PLOTS AND 2 DDA SCALED DELAPIVE VELOCITY PLOTS.

DRIETNALLY MAITTEN AY A.A.AMSDEN.LASL TOJ

MODDTFIEO AND DOCUMENTED BV J.L.NOQTON,LASL P-3,1975

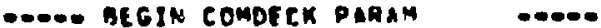

COMHON/PCOH,

1 NLCP3, NLCOA, IFLMSZ

-on end combeck panam Don

-OD- HE GIN COMDECK YSTOAE -OE.

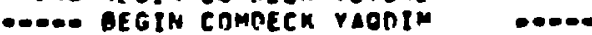

DIMENSION X(1),XPAR(1),R(1), YPAR(1), Y(1), MPAR(1),U(1),UG(1),OELSME

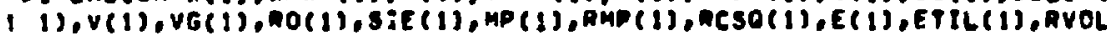

? $(1), M(1), G N(1), V P(1), P(1), P L(1), U P(1), U P(L(1), U L(1), C O(1), V P 1 L(1)$

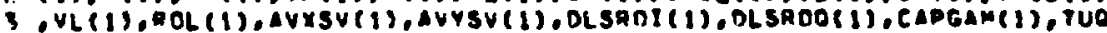

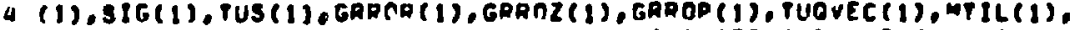

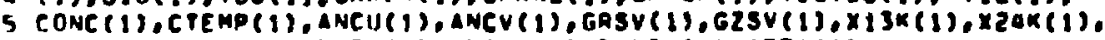

6 YI3K(1), YZaK(1), XA13K(1),XAZAK(1),DKLSM(1), AAEA(1)

DO- ENO COMDECK YABOIM

$00-0$

-OA-0 BESIN COMDECK YAOSC 


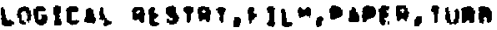

arab LAM, wU

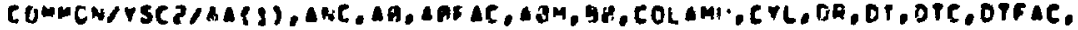

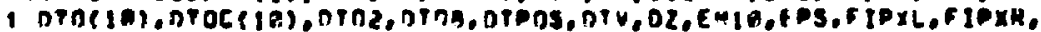

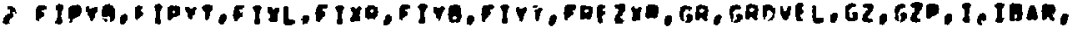

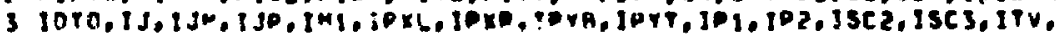

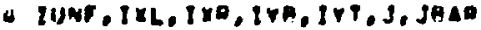

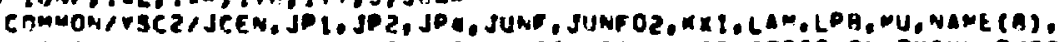

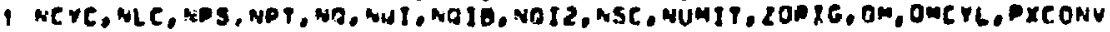

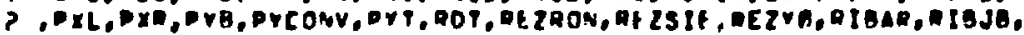

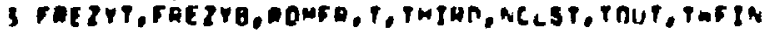

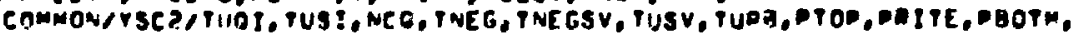

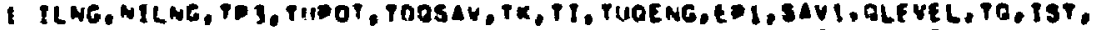

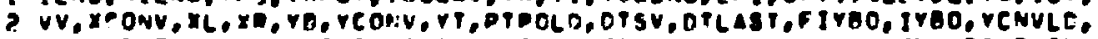

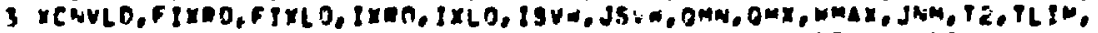

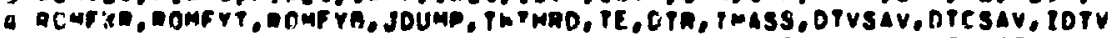

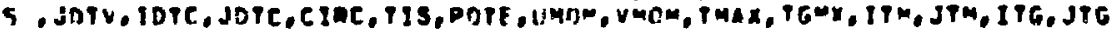

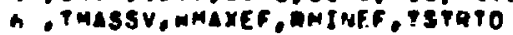

COMMONAYSCZ/Z2

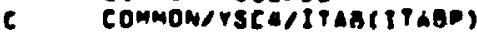

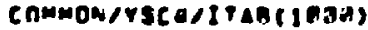

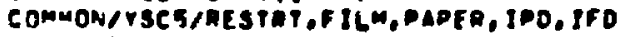

-0-0. HO COMDECK YADSE

- D.0. BEGIN CDMDEeK Yato

000.

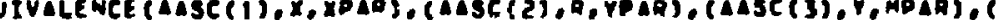

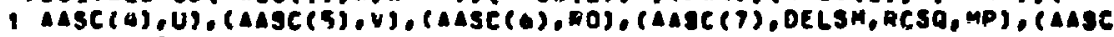

I (B),F,ETIL,AAEA, IAI IK).

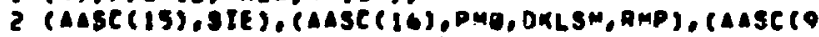

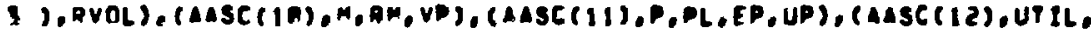

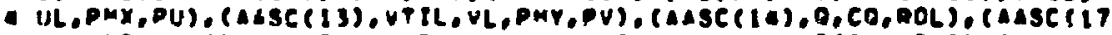

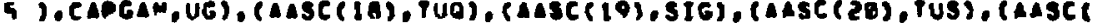

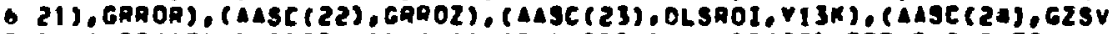

7 I, (AASC (25), DI.SPOO, VG), (AASC (20), GASV), (AASC(27), GAROP, PUOVEC,

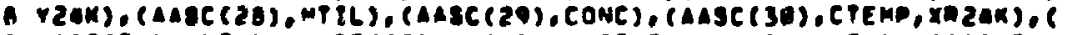

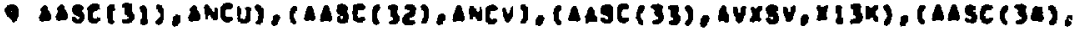

I AVYSV,X2aKs

MEAL M, MP, MPAR, MT I:

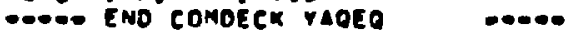

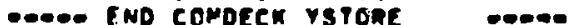

-om. BegIN COMDECK PCAL!

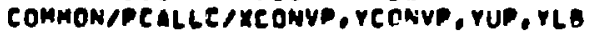

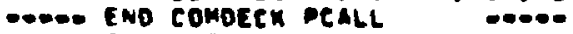

DIAENSION ITITLE $(5,3)$

DINENSION IJL2(S), IJL3(5)

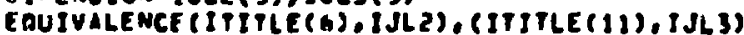

DATA ITITLE /AQHELUIO YELOCITY VECPOAS SCALEO TO MAXIMUM VELOCITY,

data ijlej3inumscalco oluio velgeitr vectoas, in,

DATA IJL3/3anvelocirY of GRID AEL. TO FLUID.

i zan SeAleo ra max. Vel.

SET UP THE VELOCITY VECTOR SCALING FACTOR.

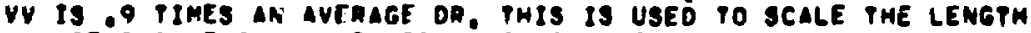
OF PHE VELOCITY VECTOR 30 IT IS NOT LONGEO PHAN THE EXTENT Or AN AVEARE CELL. 


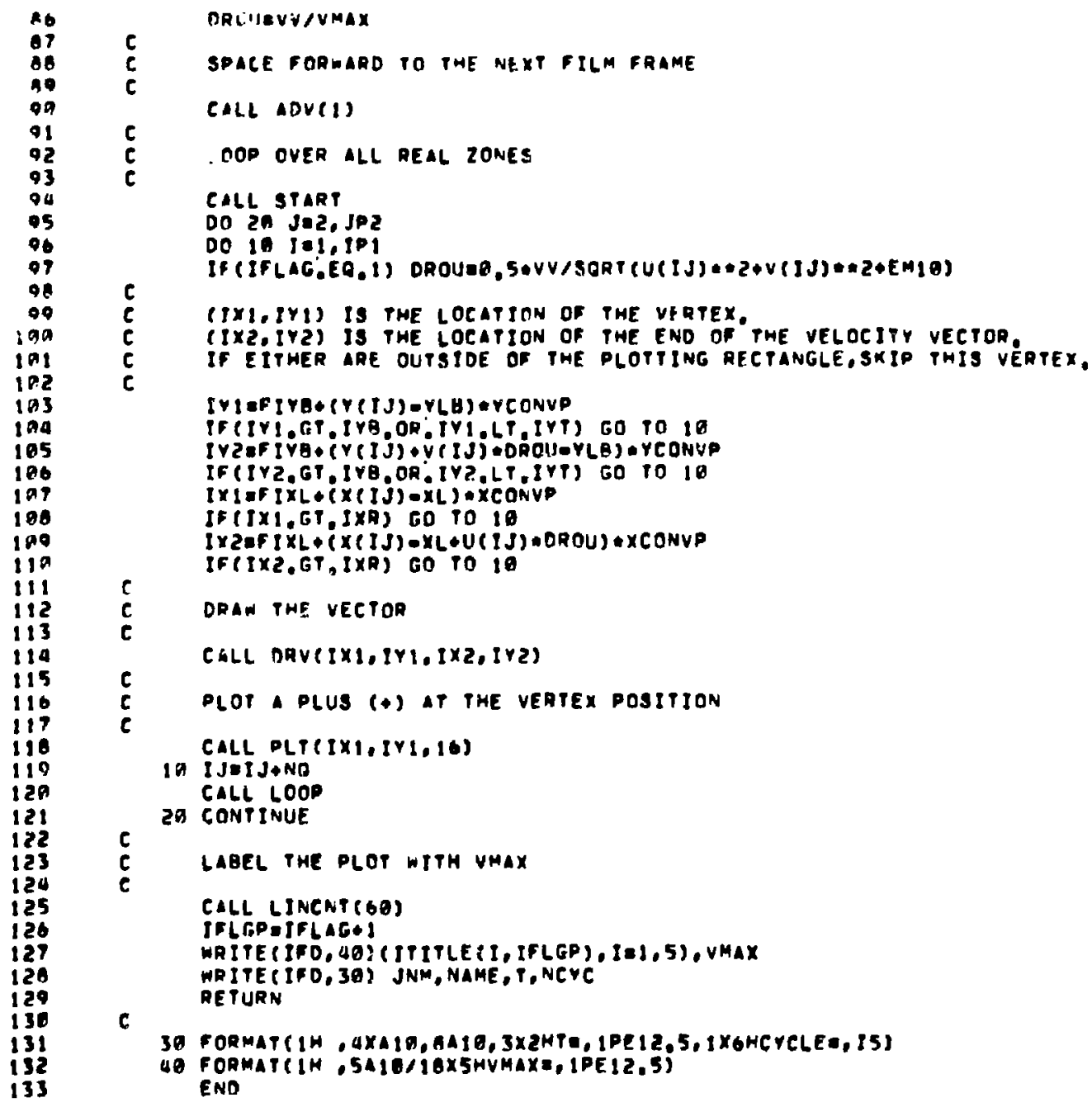

C SUBROUTINE WIROW
2




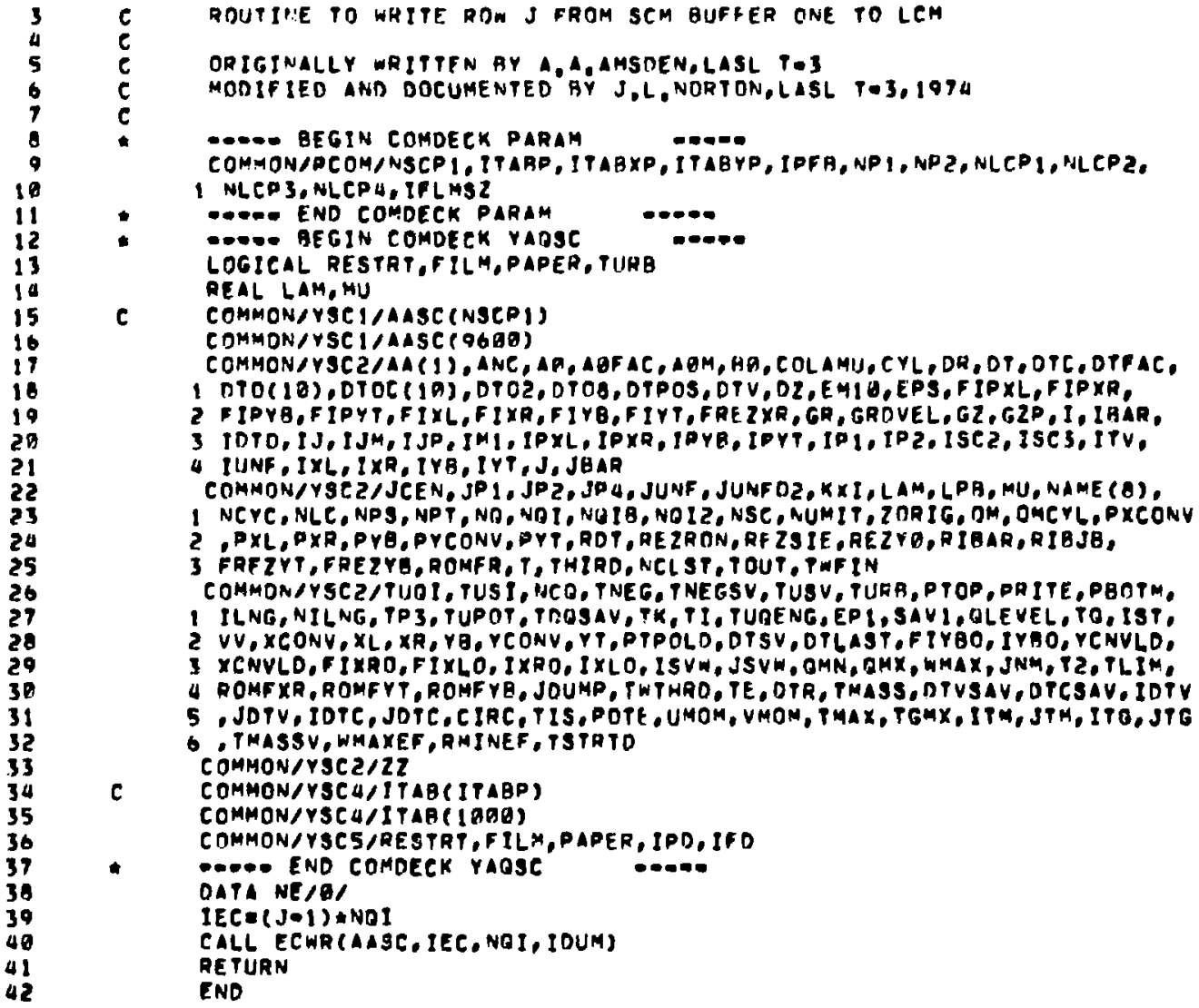

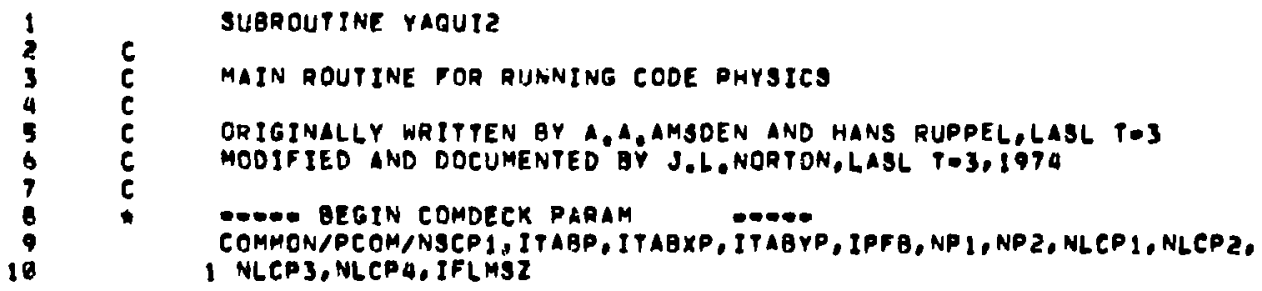




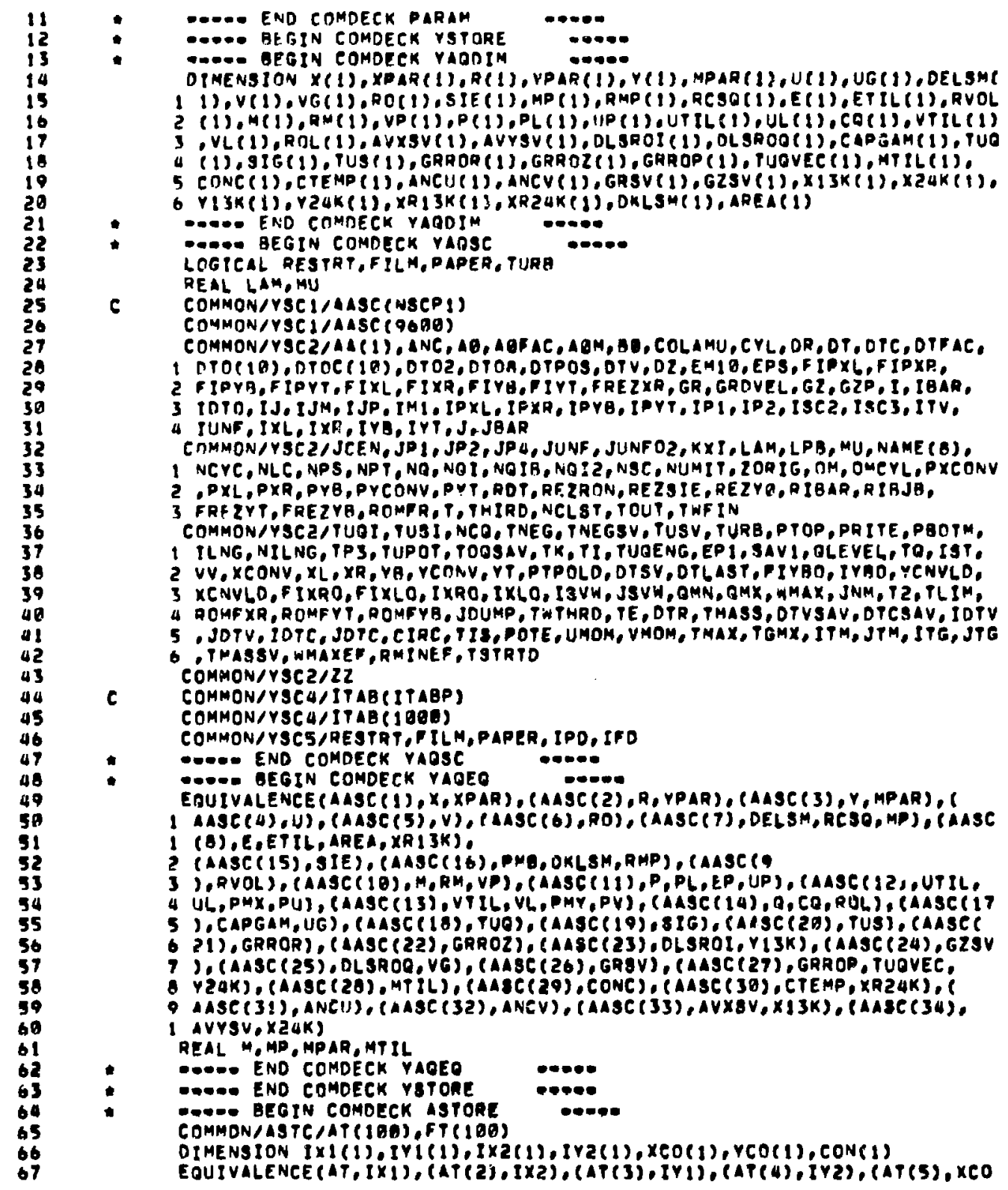




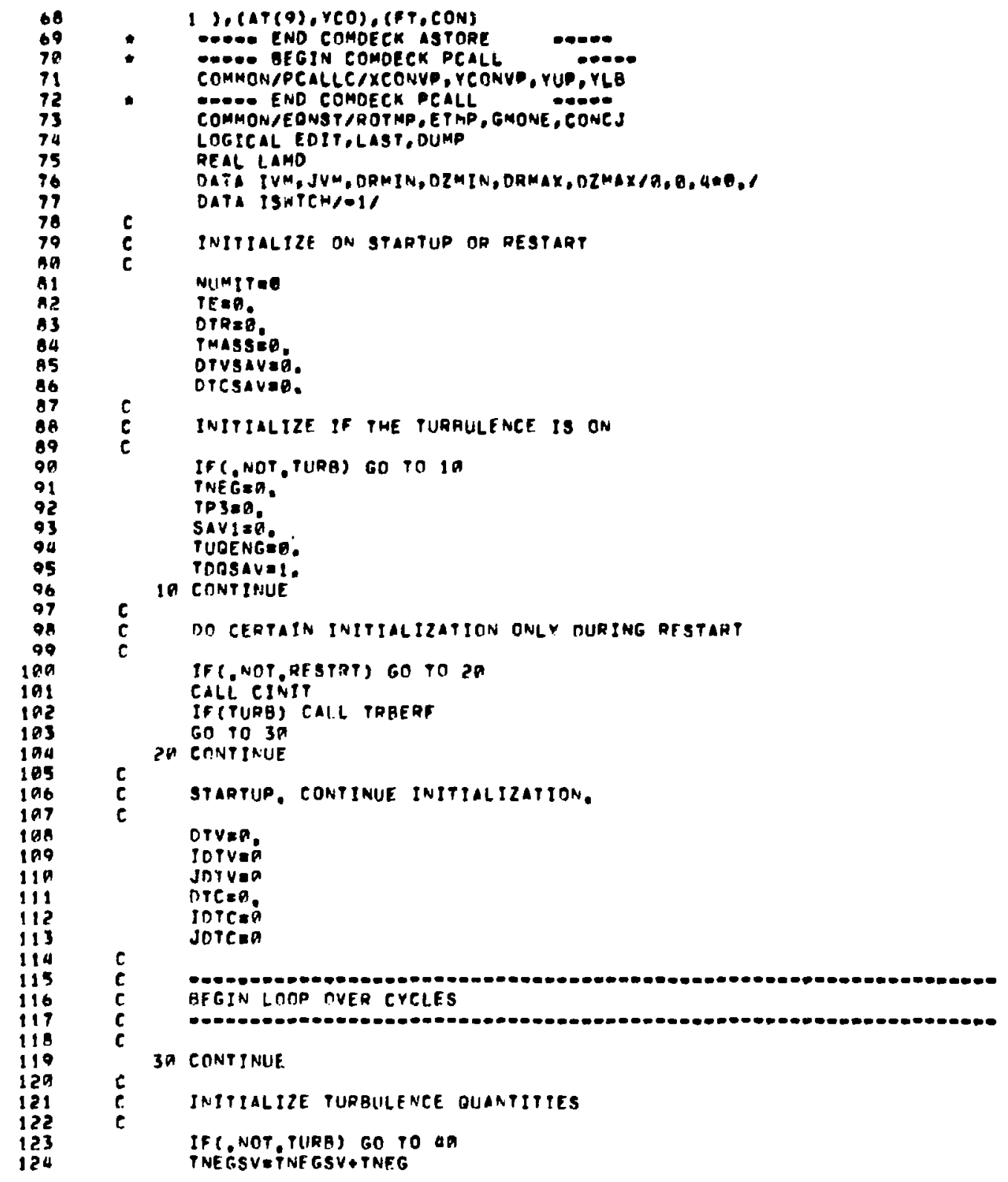




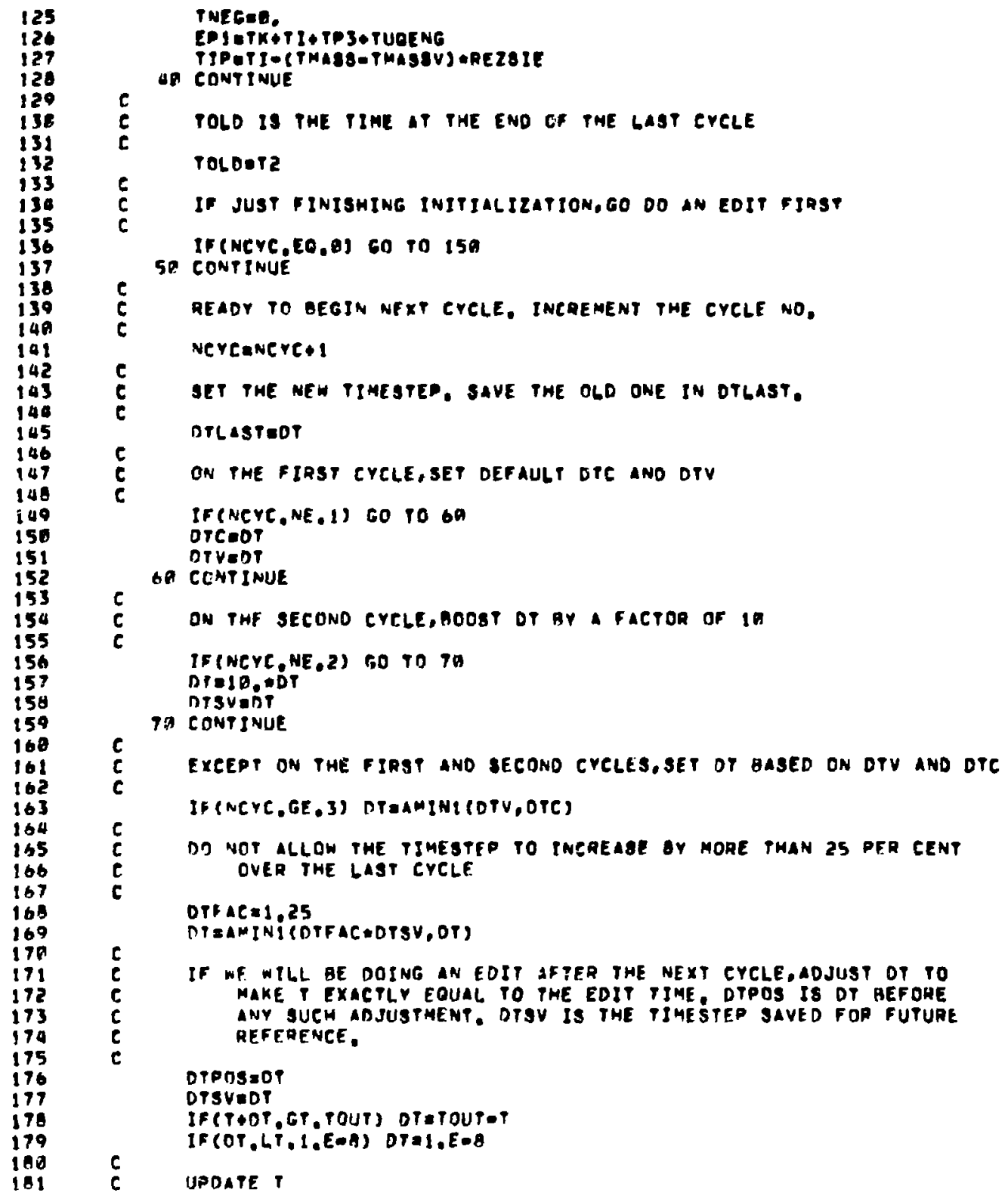




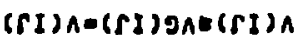

(rI) $n$ - $(5 j)$ onection

idt iet oot od

edrezar als od

d\&V+S 7าง

013*10:RVINA DEj $1: 010$

ounctrazahzs

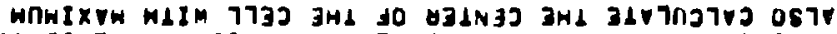

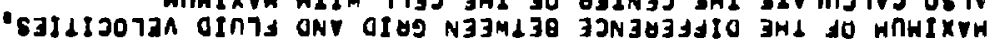

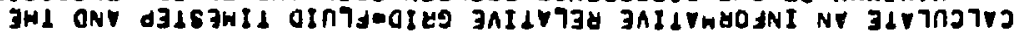

xกาม $77 \% 2$

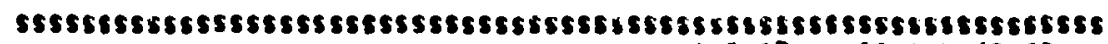

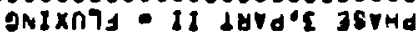

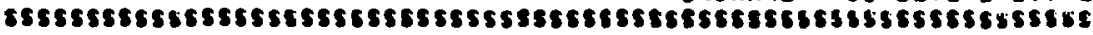

EHdA רาบ

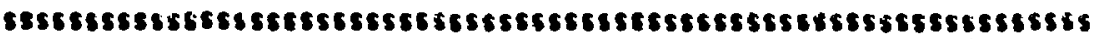

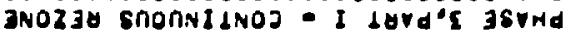

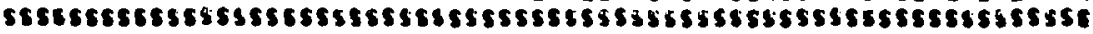

¿mod רาบ

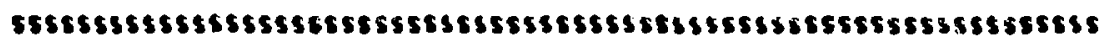

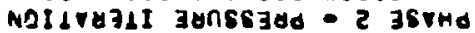

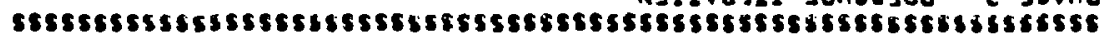

IHAA רาช

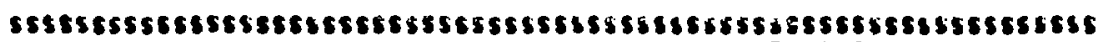

LUVA NVIONTQOV7 DIJITdXJ I JEYHA

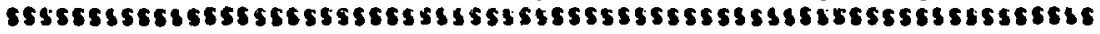

$$
\begin{array}{r}
10+521^{\circ}=80<0 \\
10 \times 5:=2010 \\
101^{\circ} 1=100
\end{array}
$$

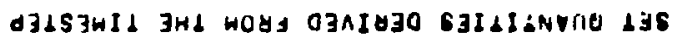

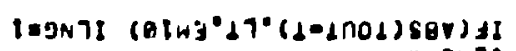
U. TN 7 I

77JAJ 6803 NV SI EIHL II JNO SI IN II

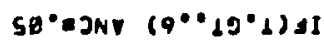

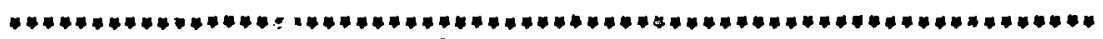

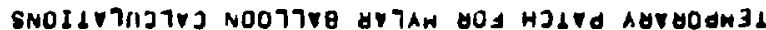

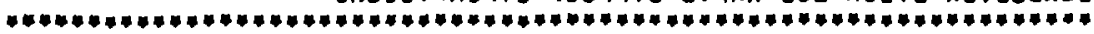

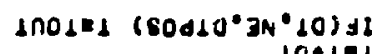

ose

152

952

$\mathbf{5 5 2}$

his

SEL

25

I5?

ors

622

पez

422

922

522

-22

125

222

122

जर

612

ot?

LI

912

5 เ

पI

I 12

212

112

bi2

602

ou?

$\angle B 2$

902

562

DQ2

IUट

202

I0工

oud

061

461

161

961

561

Do 1

[0!

261

101

061

691

091

641

981

501

ก⿻1

รet

J 291 


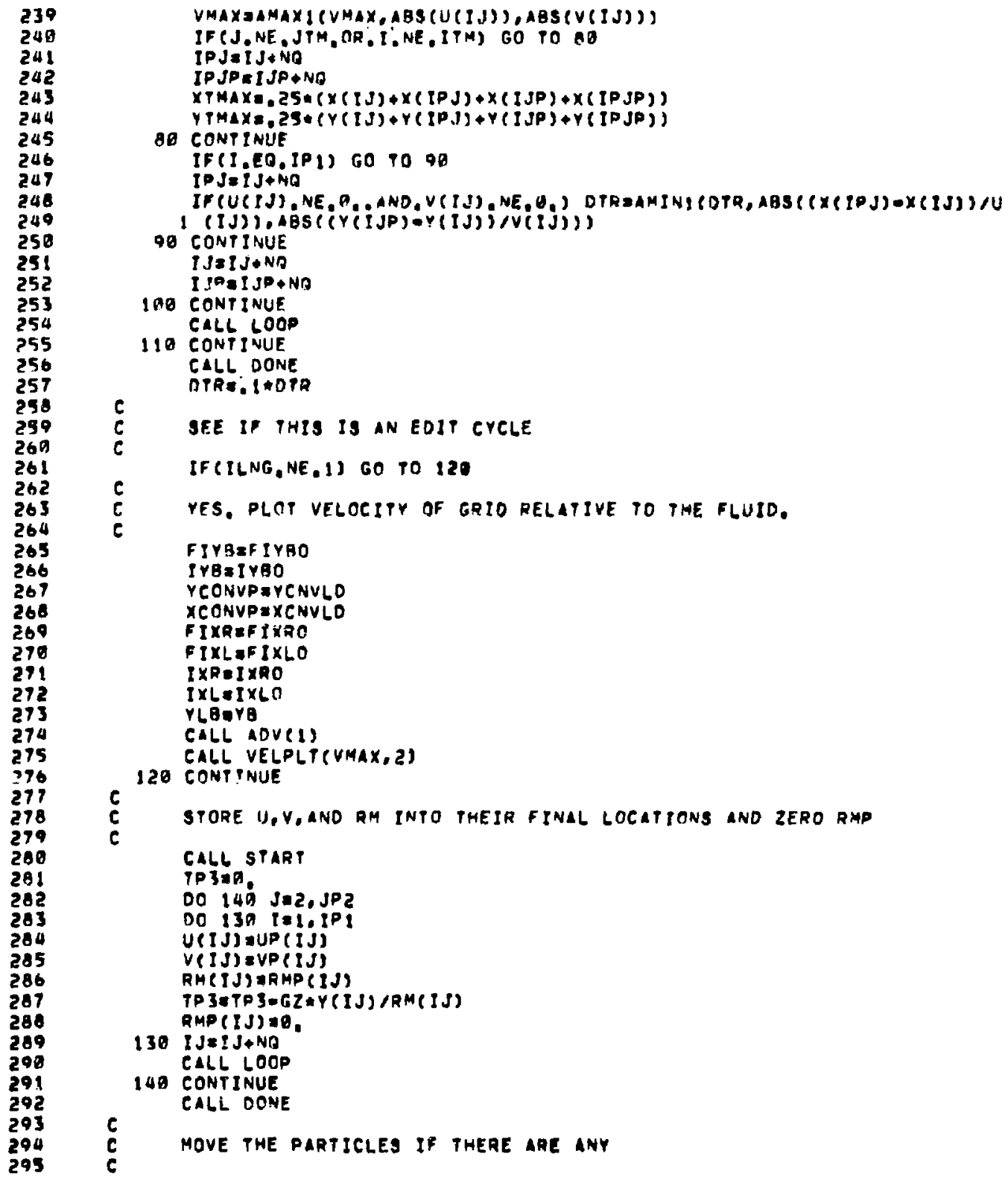




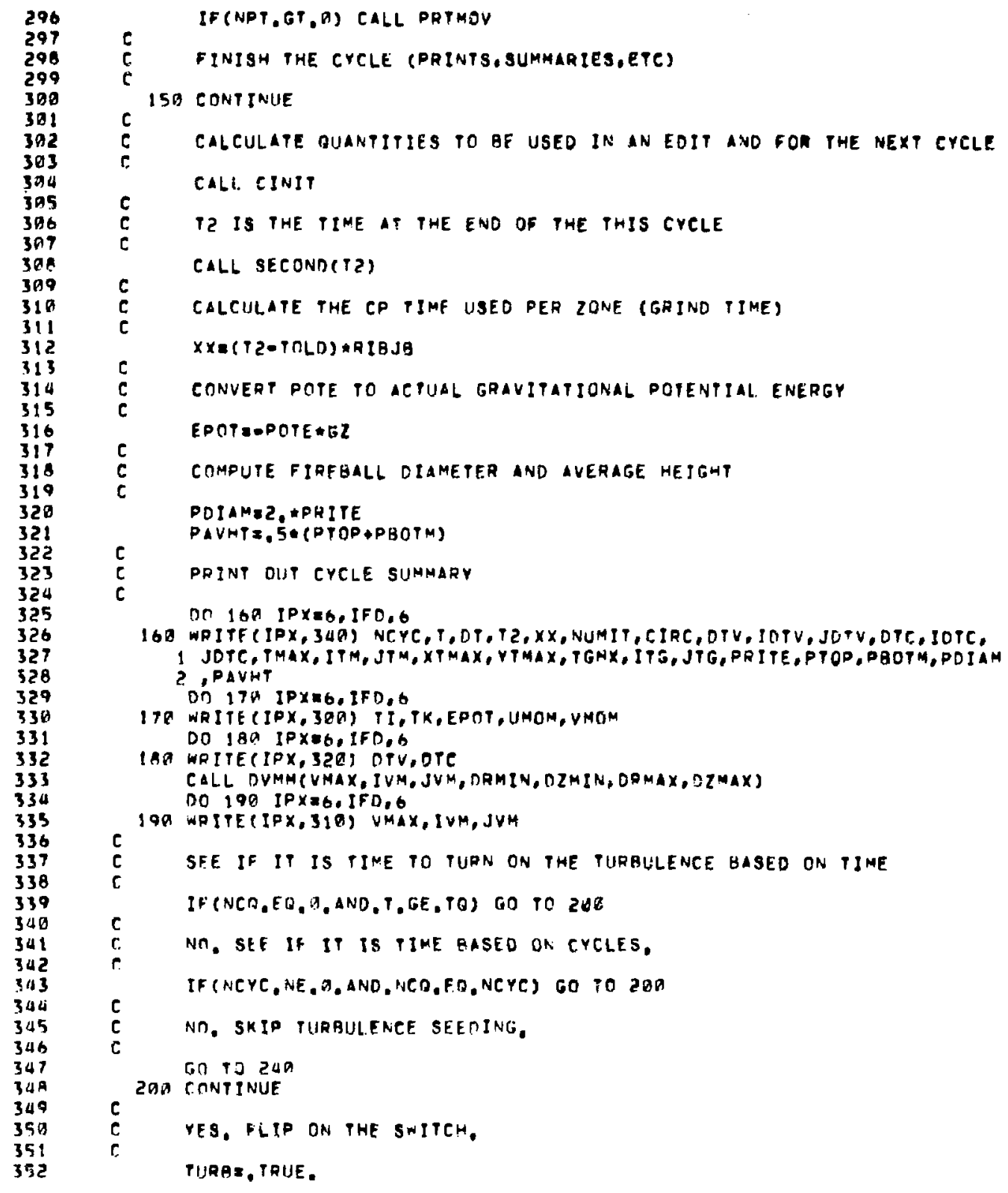




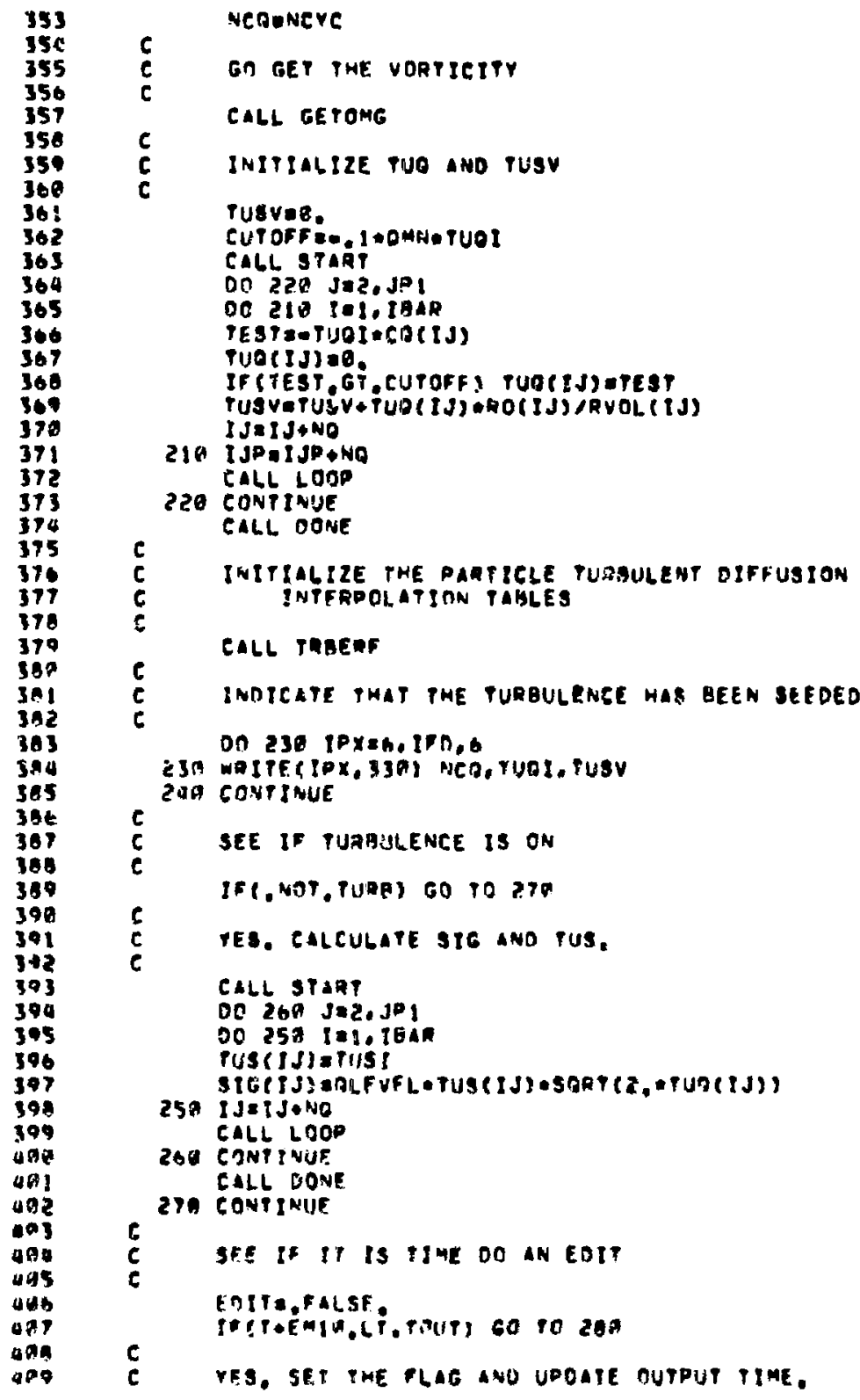




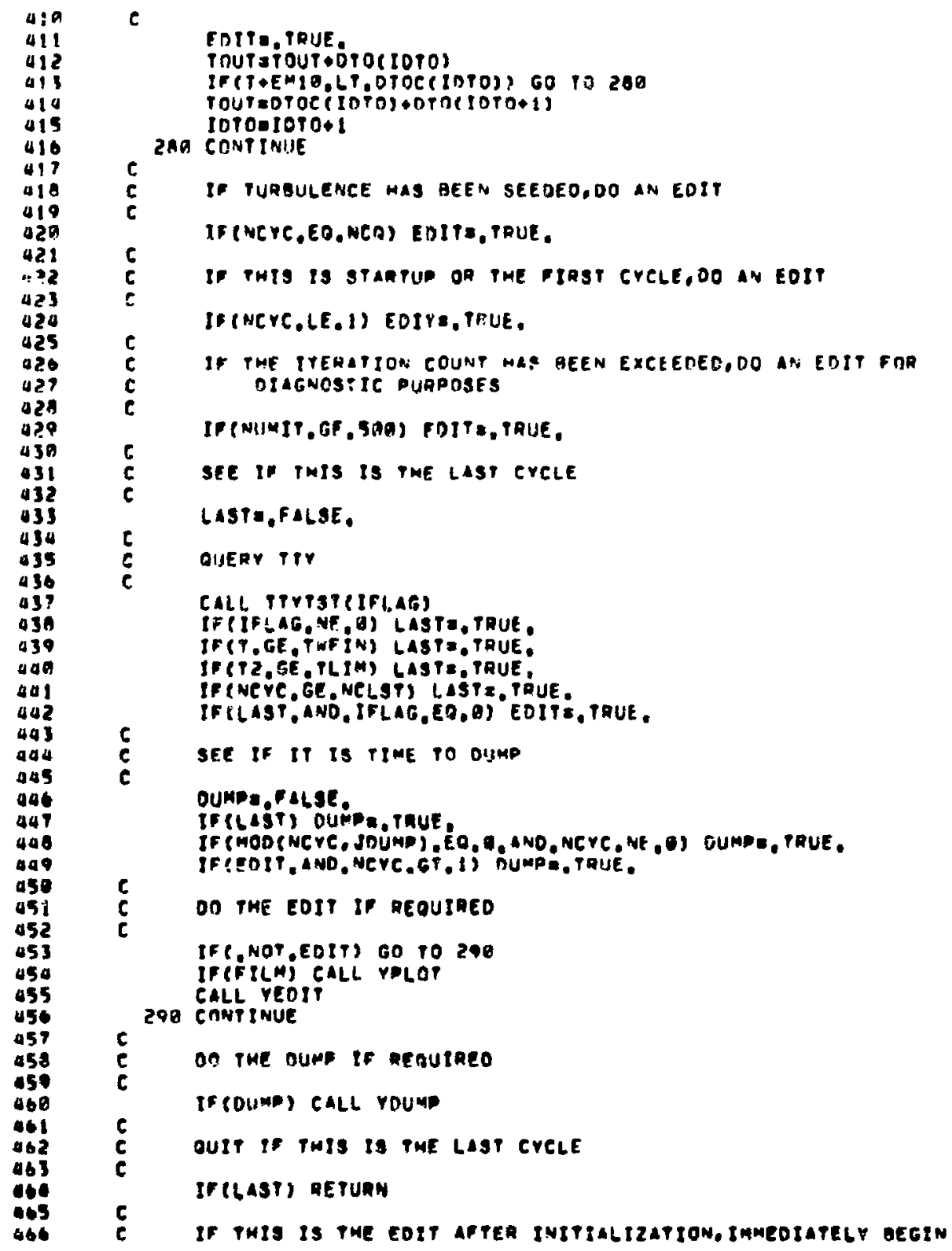




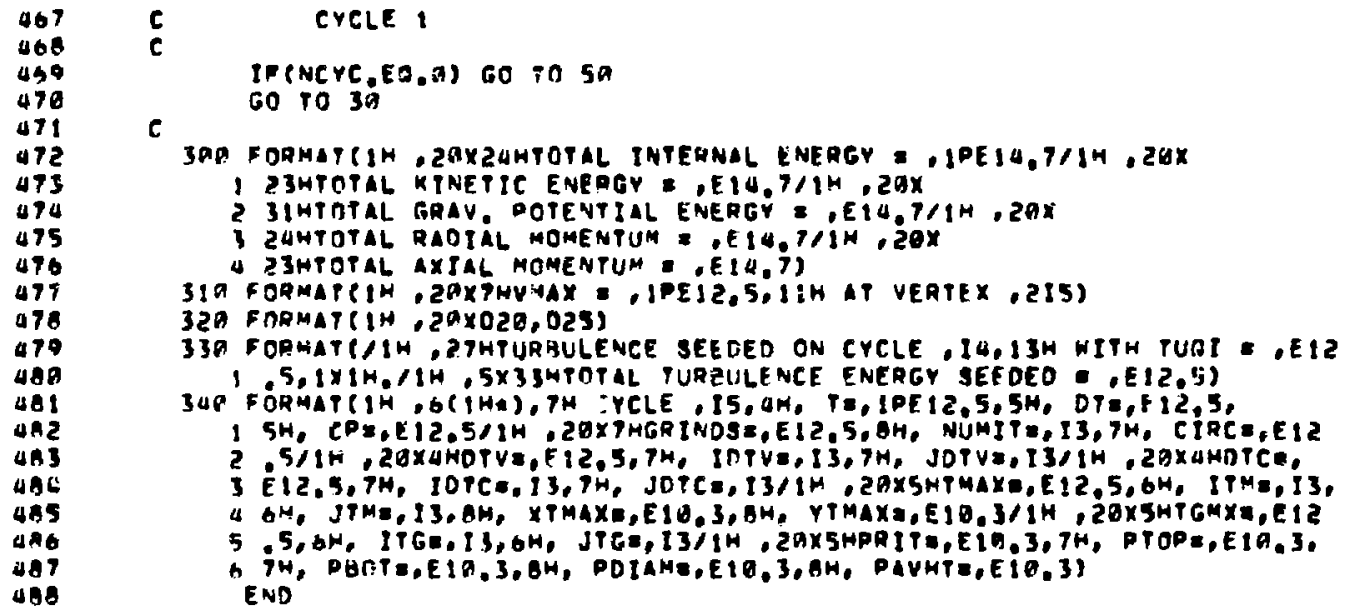


3 IDTO,IJ,IJM, IJP, IMI, IPXL,IPXR,IPY, IPYT,IPI,IPZ,I8C2,ISC3, ITV,

4 IUNF, IXL, IXR, IYB,IYT,J, JBAA

COHMON/YSCZ/JCEN, JP I, JPZ, JPA, JUNF, JUNF OZ, KXI, LAM, LPG, HU, NAME (B), 1 NCYC, NLC, NPS, NPT, NO, NOI, NOIB, NOI2, NSC, NUMIT, 20816 , OM, OMCYL, PXCONV

2 .PXL,PXR, PYB, PYCONY, PYT,RDT, REZRON, REZSIE, REZYG, RIBAR, RIEJB,

3 FRE ZYT, FREZYB, ROMFR, T, THIRD, NCLST, TOUT, TWF IH

COMMON/YSCZ/TUQI, TUSI, NEA, TNEG, TNEGSV, TUSV, TUAB, PTOP, PRITE, PBOTM, I ILNG, NILNG, TP 3, TUPOT, TOOSAV, TK, TI, TUPENG, EPI, SAVI, OLEVEL, TO, IST, 2 VV, XCONV, XL, XA, YA, YCONV, YT, PTPOLD, DTSV, DYLAST, FIYBD, IYBO, YCNVLD, $5 X C N V L D, F I X R O, F I X L D, I X R \cap, I X L O, I S V W, J S V W, D M N$, OHX, WMAX, JNH, T2, TLIH, 4 ROMFXR, ROMFY , ROMFYB, JDUMP, TWPHRD, TE, OTR, TMASS, DTVSAV OTCSAV, IDTV 5 , JOTV, IDTC, JNTC, CIRC, TIS, POTE,UMOH, VMOM, TMAX, TGMX, ITM, JTH, ITG, JTE 6 , TMASSV, WMAXEF, RMINEF, TSTATD COMMON/YSCZ/ZZ

$\tau$ COMMON/YSC $4 /$ ITABC ITABP) COMMON/YSCUIITAB(IOBO) COMMON $Y$ YCS RESTRT, F ILM, PAPER, IPD, IFD 


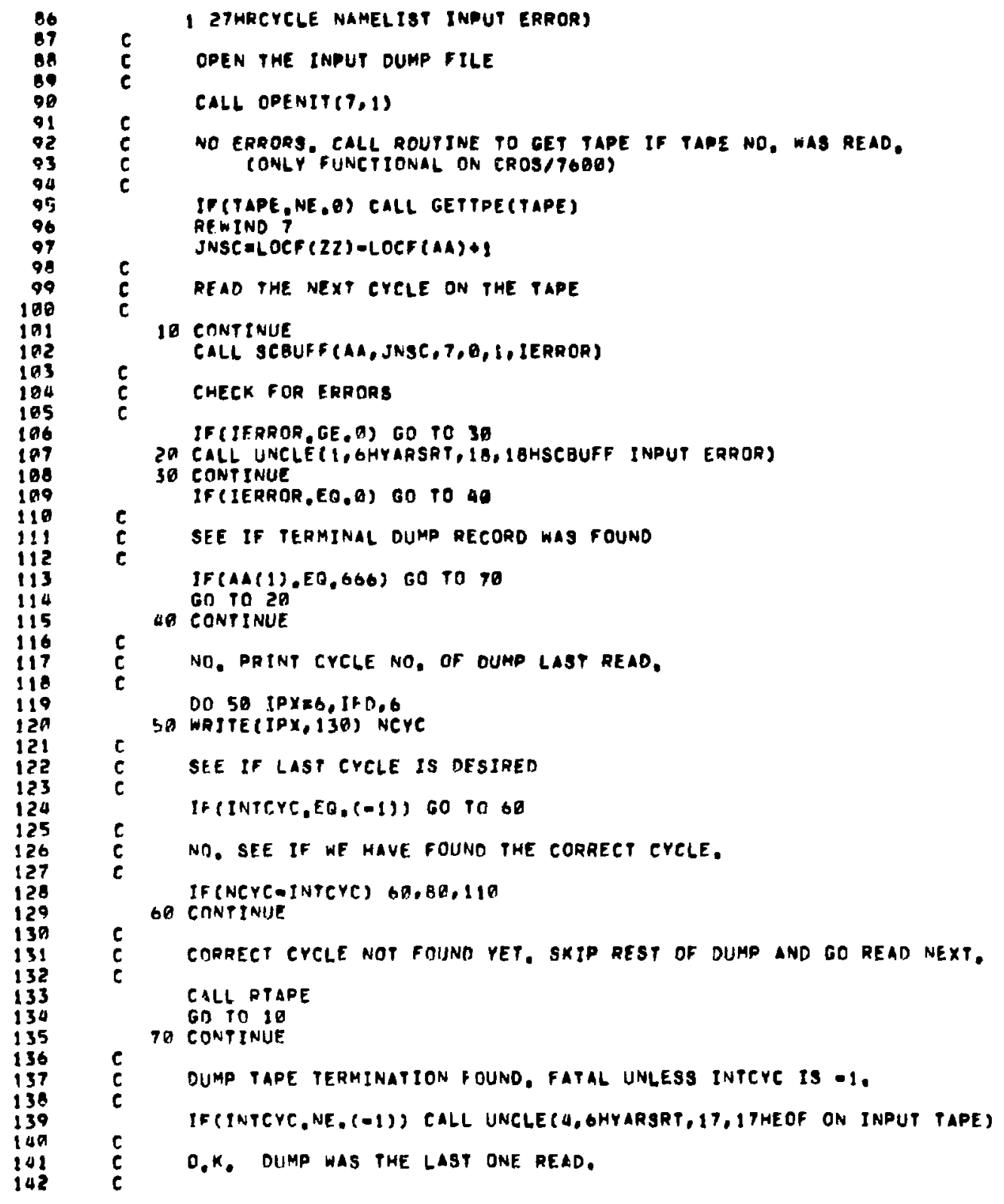


Gก 10 9a

a CONTINUE CALL RTAPE

op continue

C

C PRINT THE CYCLE nO..PROBLEM NAME,AND PRORLEM TIME

C

DO IOA IPX=6,IFD,6

WRITE (IPX, IAPS NCYC

c

190 WRIPE IPX, 15U) NAME,T

c

RESTART COMPLETED. SEE IF THERE AAE CHANGES TO INPUT VARIABLES,

CALL YINPUT

PLIMITLIMBV

C CLOSE THE INPUT OUMP FILE

c

CALL CLOSITCT)

c

REFRESH THE CP TIME

CALL SECOND(TZ)

RETURN

c

C DUMP NOT ON TAPE. FATAL ERROR,

110 CONPINUE

CALL UNCLE ( $4,6 H Y A R S R T, 23,23$ HRESTART CYCLE NOT FOUNDS

120 CONTINUE

C

CALL UNCLECA, GHYARSRT, 36, 36HRCYCLE NAMELIST INITIALIZATION ERROR)

130 FORMAT(1H, GHCYCLE, I5, 6H FOUNO)

140 FORMAT (IM IIHRESTARTING FROH CYCLE, I5J

150 FORMAT(IH, BAIO/IH, 2HTa, IOEI2,5/IH)

END

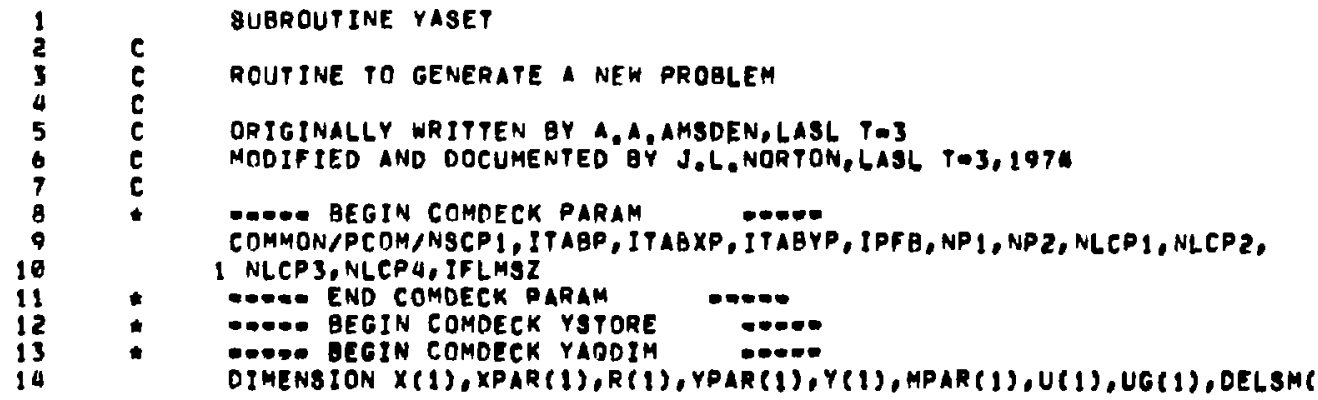




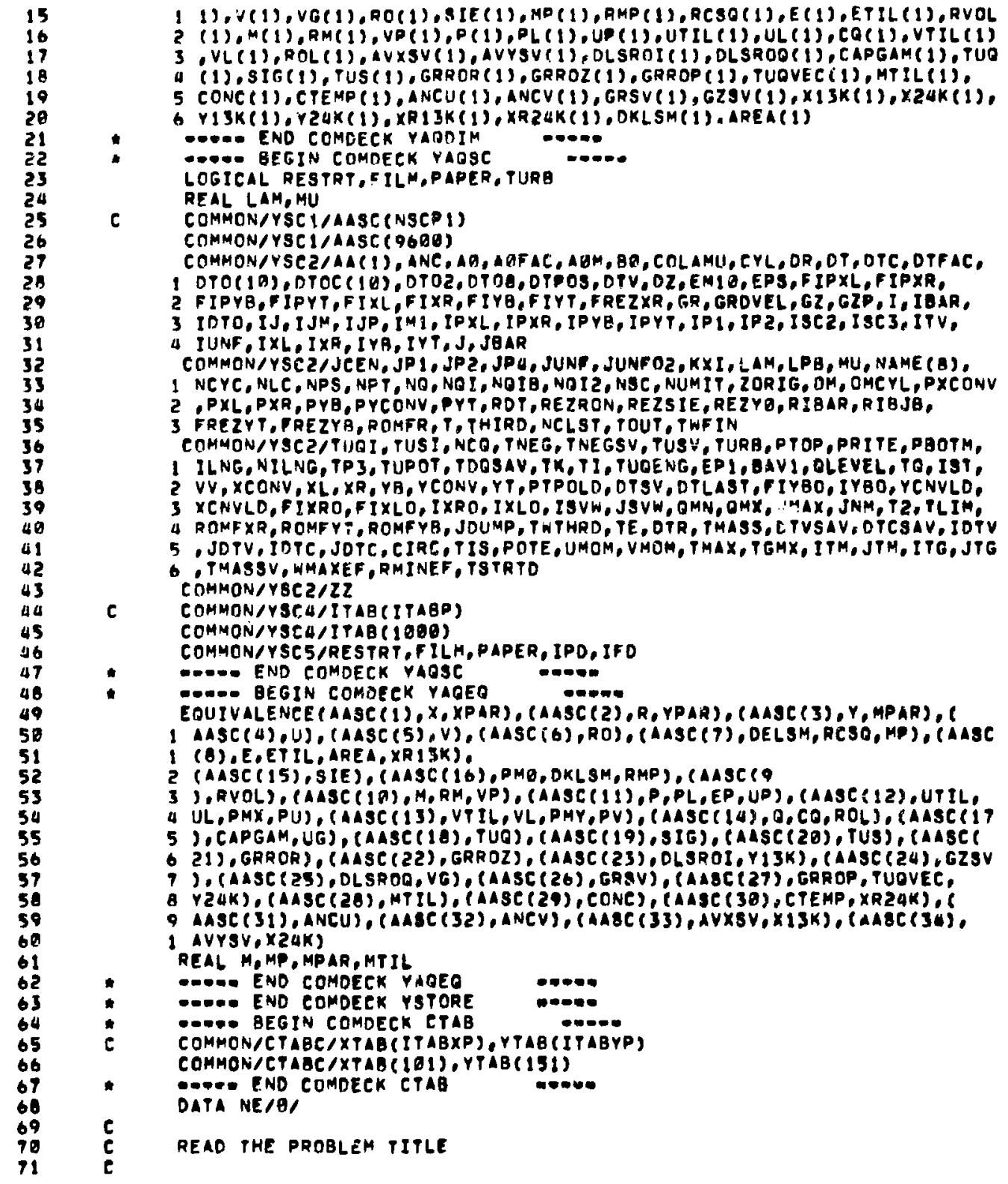




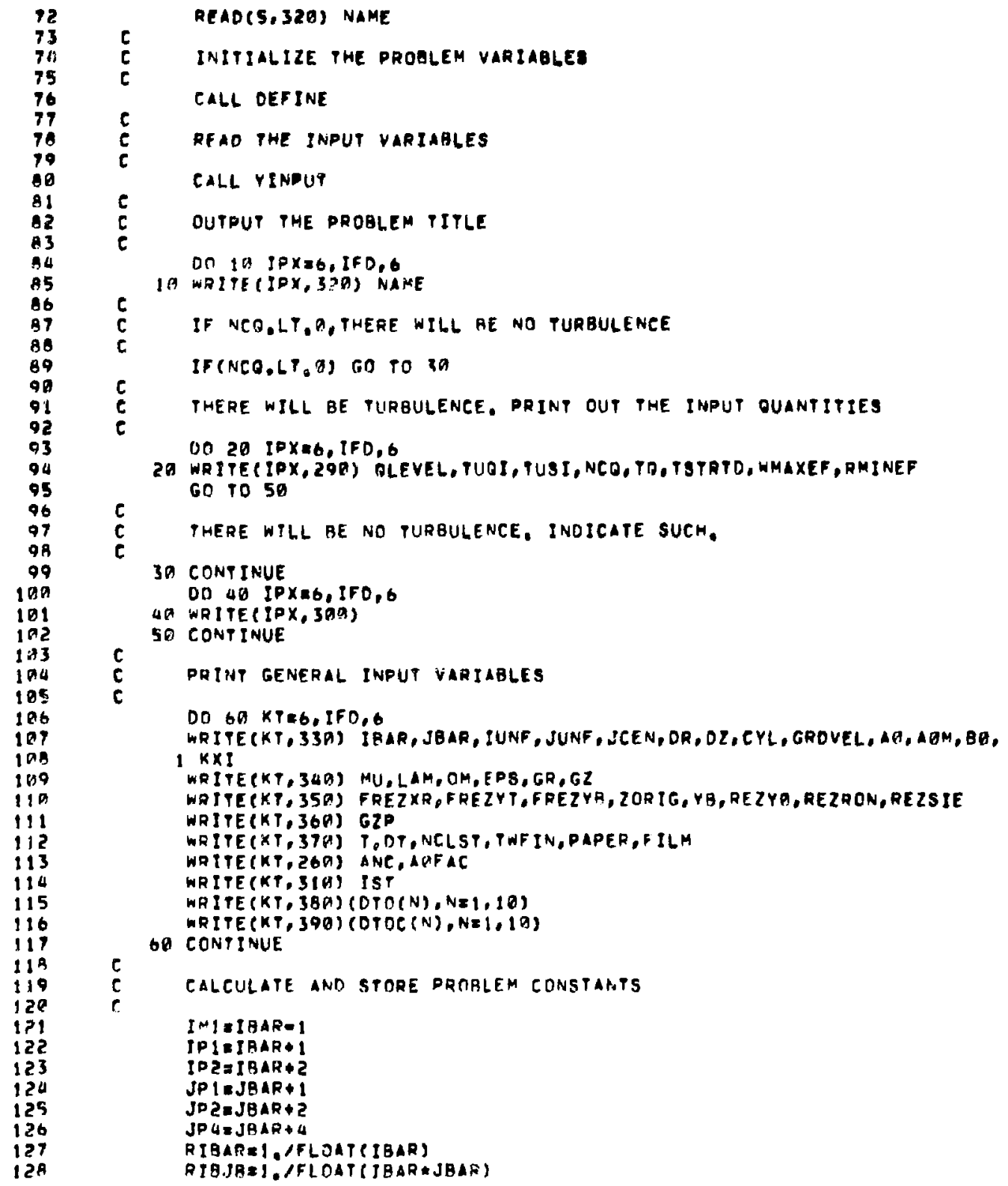




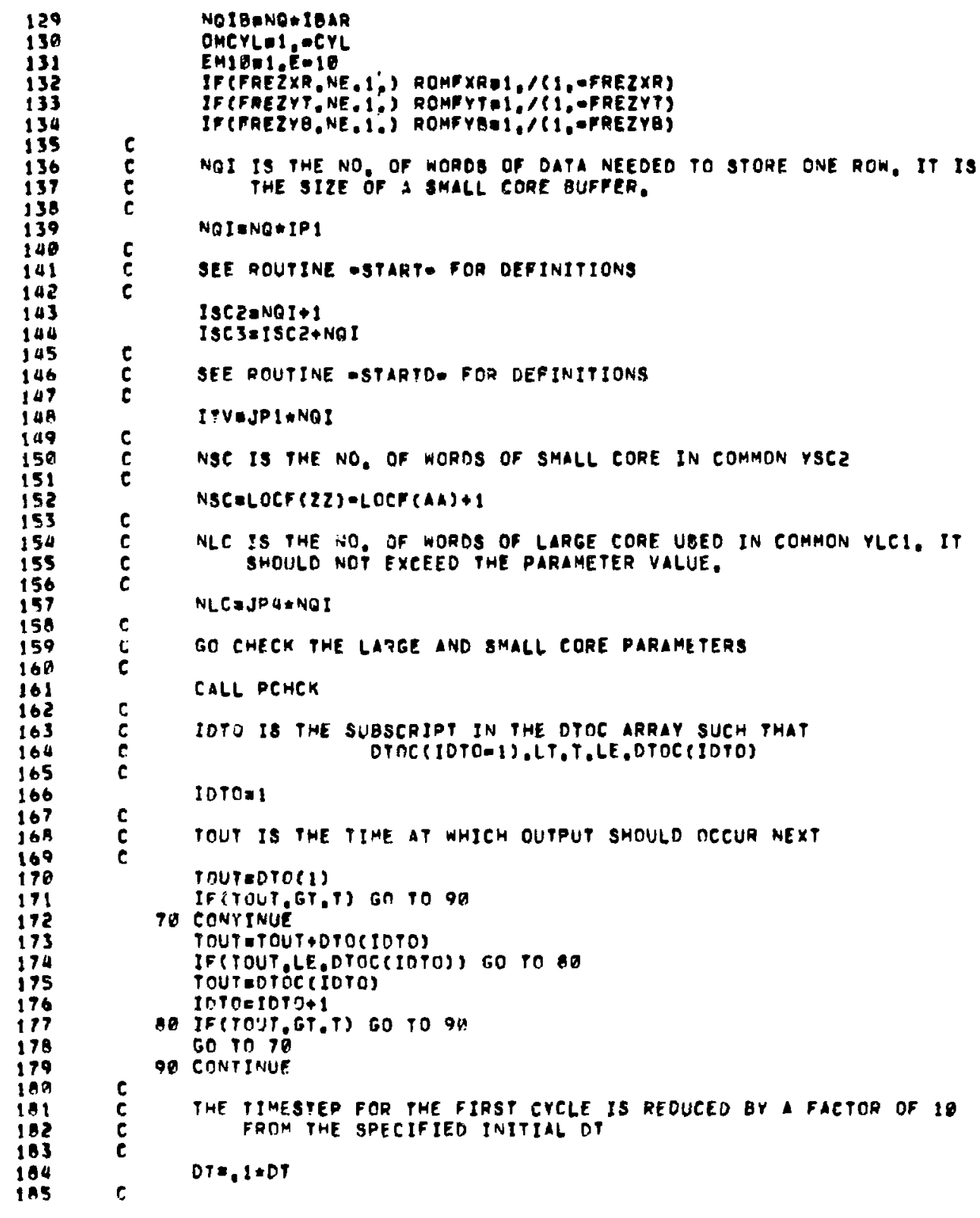




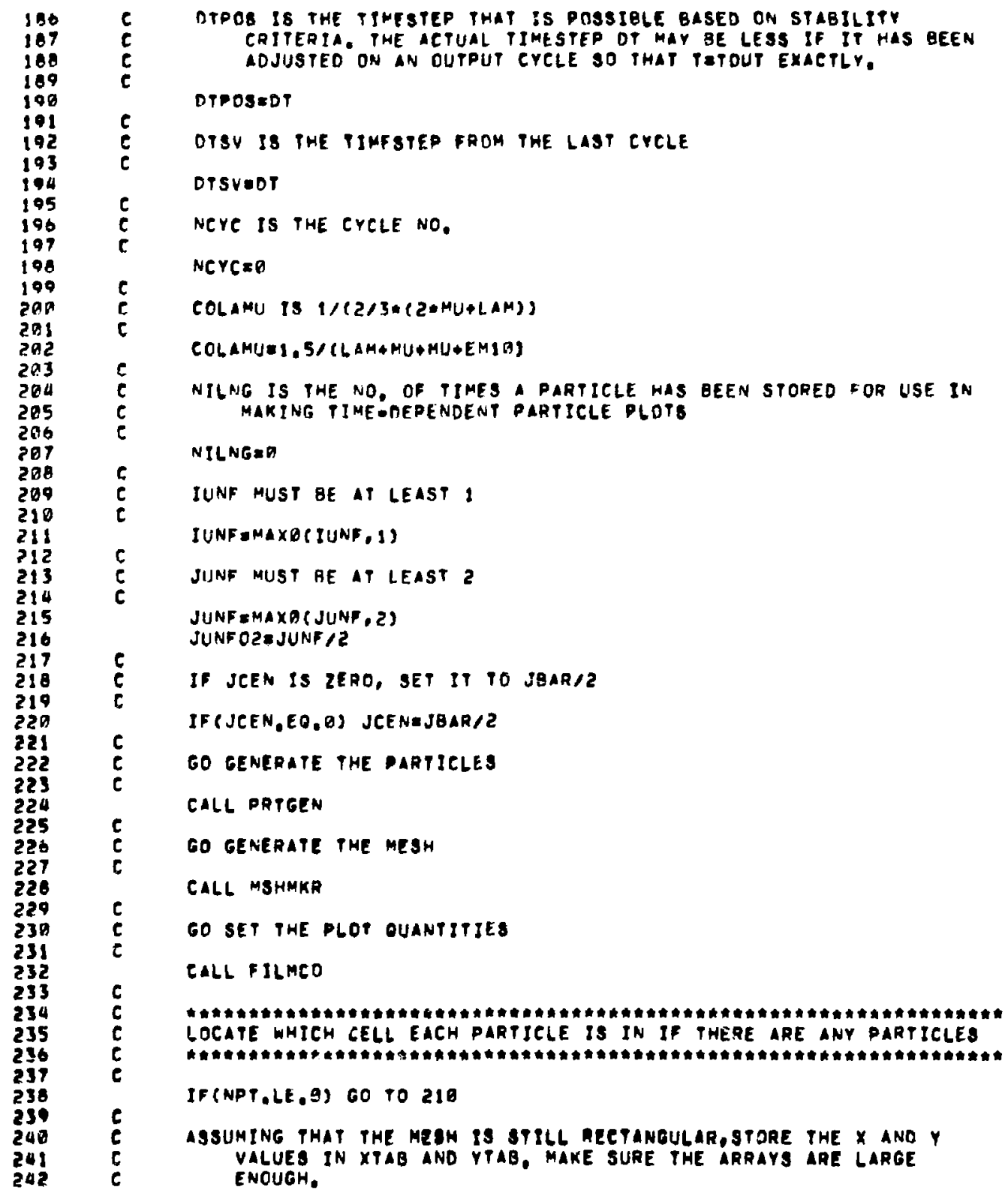




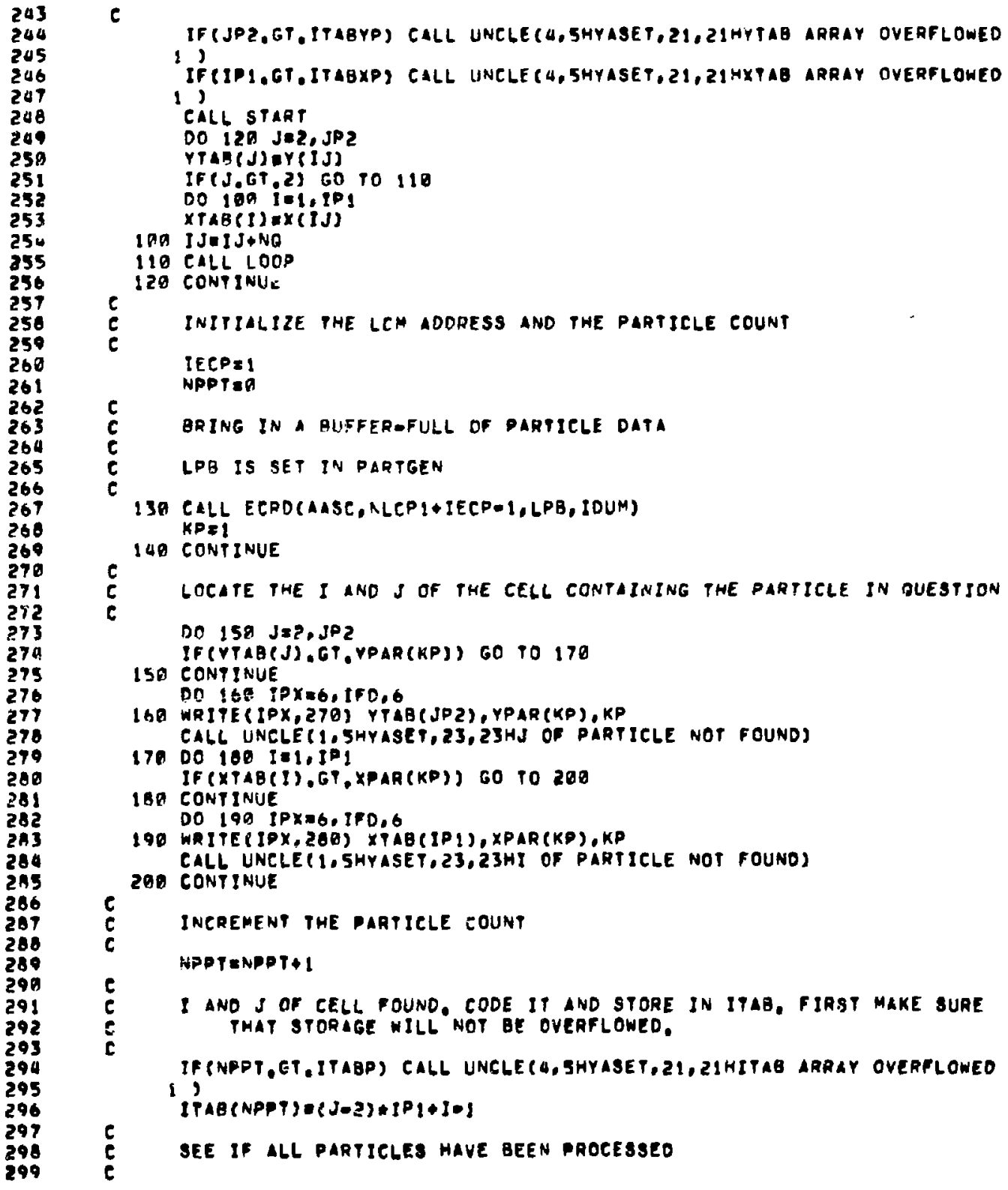




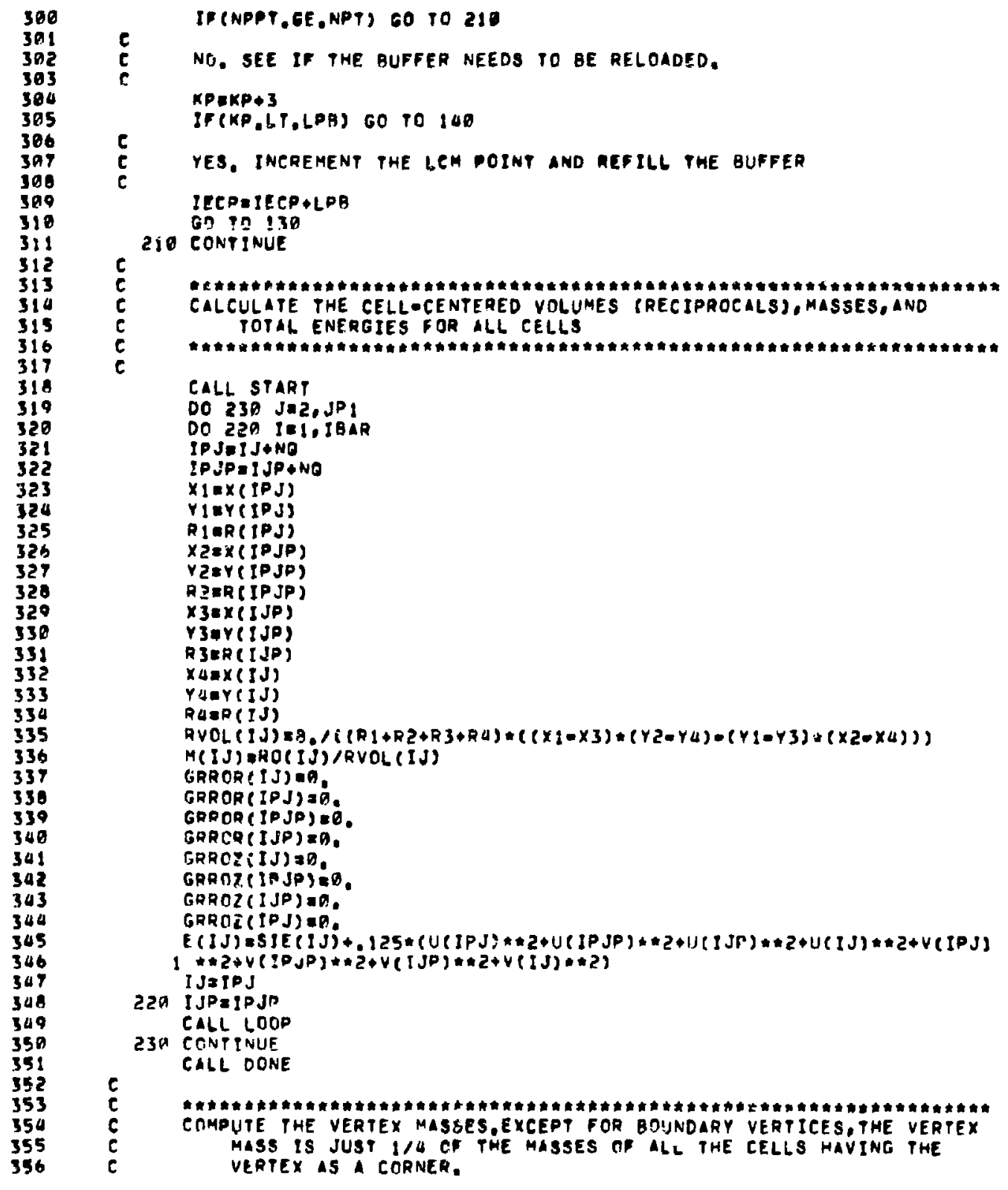




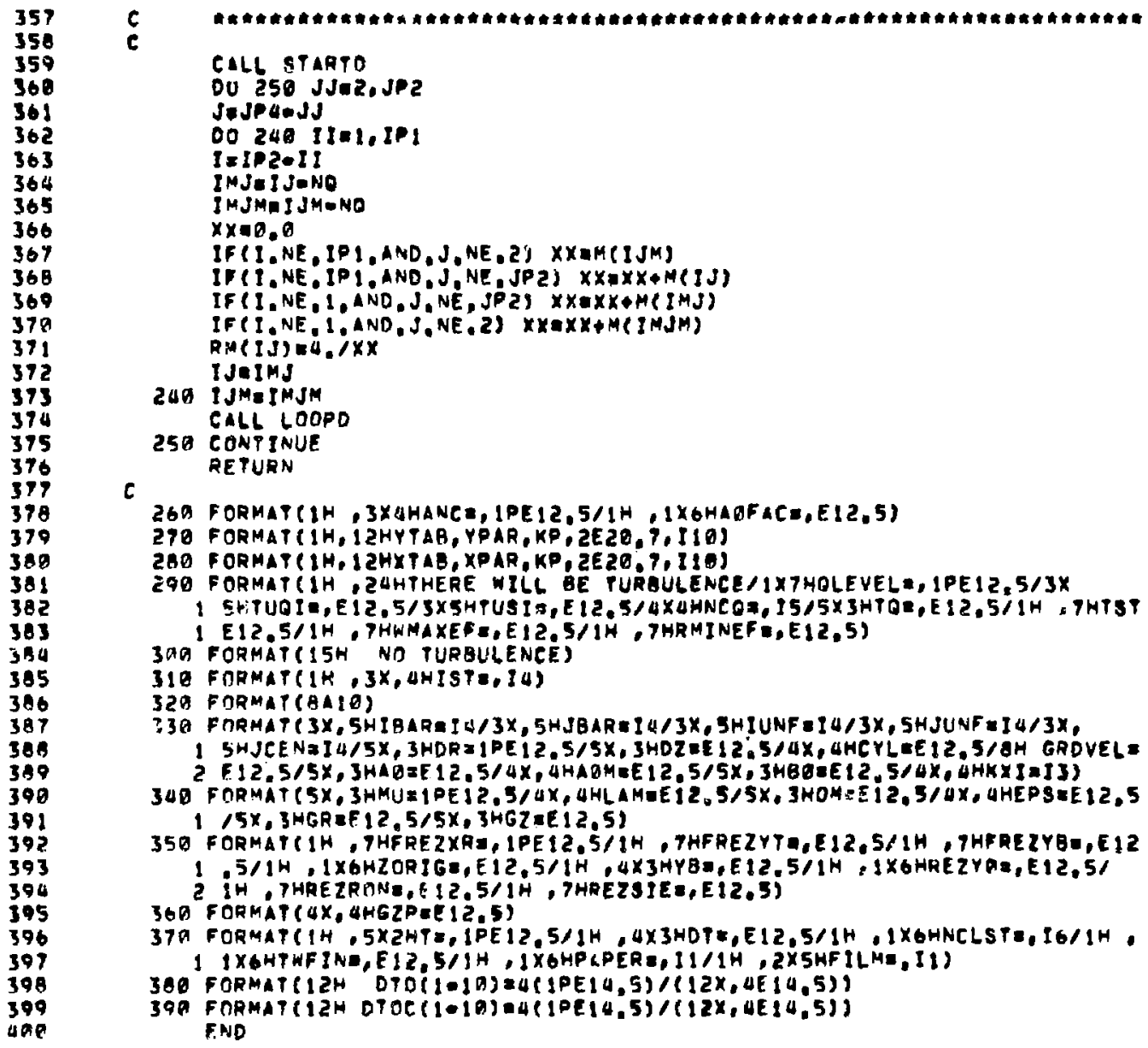

C CALL STAPYO

DU 250 JJar,JP2

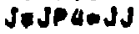

00240 IIII.IPI

$I=I 02-I I$

IMJEI JONO

IMJMIIJMONO

$x \times=0.0$

IF II,NE,IPI, AND,J,NE, 2$\} \quad X X E M(I J M)$

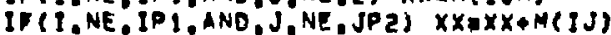

IF (I.NE, I, ND, J,NE, JPIS $X X \times X X \cap M(I M J)$

IF (I. NE. I, AND.J.NE. 2$) \times X a X X+M(I M J M)$

$\operatorname{Rm}(I J)=0 . / \times x$

TJEIMJ

240 IJMEIMJM

CALL LOOPD

250 CONPINUE

RETURN

$c$

269 FORMAT (IH, 3XUHANCE, 1PE $12,5 / 1 \mathrm{H}$, (X6HAOFACE,E12,5)

270 FORMAT(IH, I 2HYTAB, YPAR, KO, 2E20, 7, (10)

280 FORMAT (IH, I LHXTAB, XPAR, KP, $2 E 20,7,110)$

ZQO FORMATIIH, 2UHTHERE WILL BE PURBULENCE/1X7HOLEVELA,IPEIZ,5/3X

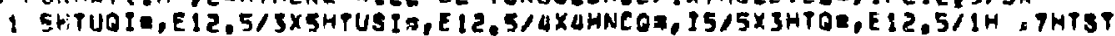

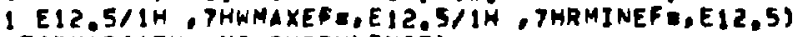

3 GG FORMAT(15H ND TURBLLENEE)

310 FORMAT (IK, 3X, UHISTE, 24)

320 FORMAT (AMIO)

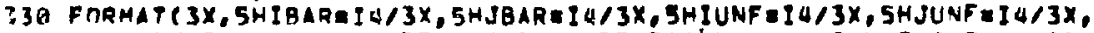

1 SHJCENaI $4 / 5 X$, 3HDR IPE $12,5 / 5 X$, 3HDZ EE $12,5 / 4 X$, 4HCYLEE $12,5 / 9 H$ GRDVELE 2 C $12,5 / 5 x, 3 H A D=E 12,5 / 4 X, 4 H A O M E E 12,5 / 5 X, 3 H 68 E E 12,5 / 4 X, 4 H K X\{A I 3\}$

340 FORMAT $(5 X, 3 H M U=1 D E I 2,5 / 4 X, 4 H L A M E E 12,5 / 5 X$. 3HOMEE $12,5 / 4 X, 4 H E P S=12,5$ $1 / 5 \times, 3 H G R=F 12,5 / 5 x, 3 H G Z=E(2,5)$

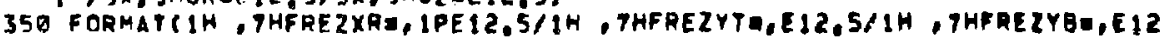

$1,5 / 1 \mathrm{H}, 1 \times 6 H Z O R I 6=, E 12,5 / 1 \mathrm{H}, 4 \times 3 H Y B M, E 12,5 / 1 \mathrm{H}, 1 \times 6 H R E Z Y A=, E 12,5 /$

2 IH, THREZRONE, E $\{2,5 / 1 H, 7 H R E Z S I E=, E\{2,3\}$

36D FORMAT (4X, \&HGZPEE 12,5$)$

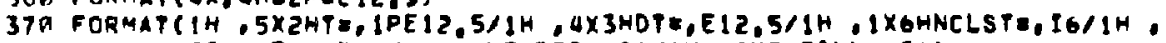

1 IXGHTHF INE, E $12,5 / 1 \mathrm{H}, I \times 6 H P G P E R=, 11 / 1 \mathrm{H}, 2 \times 5 \mathrm{HF}$ (LME, II)

300 FORMAT $(12 H$ DTO $(1-10)=4(1 P E 14,5) /(12 x, 4 E(4,5))$

39A FORMAT(12H DTOC $(1-10)=4(1 P E 14,5) /(12 x, 4 E(4,5))$ F.ND

$\begin{array}{lll}1 & \text { SURROUTINE YDUMP } \\ 2 & c & \\ 3 & e & \text { ROUTINE TO DO A YAOUI DUMP } \\ 4 & \text { C } & \\ 5 & C & \text { WRITTEN BY J.L.NORTON,LASL TE3.1975 } \\ 6 & \text { C } & \end{array}$




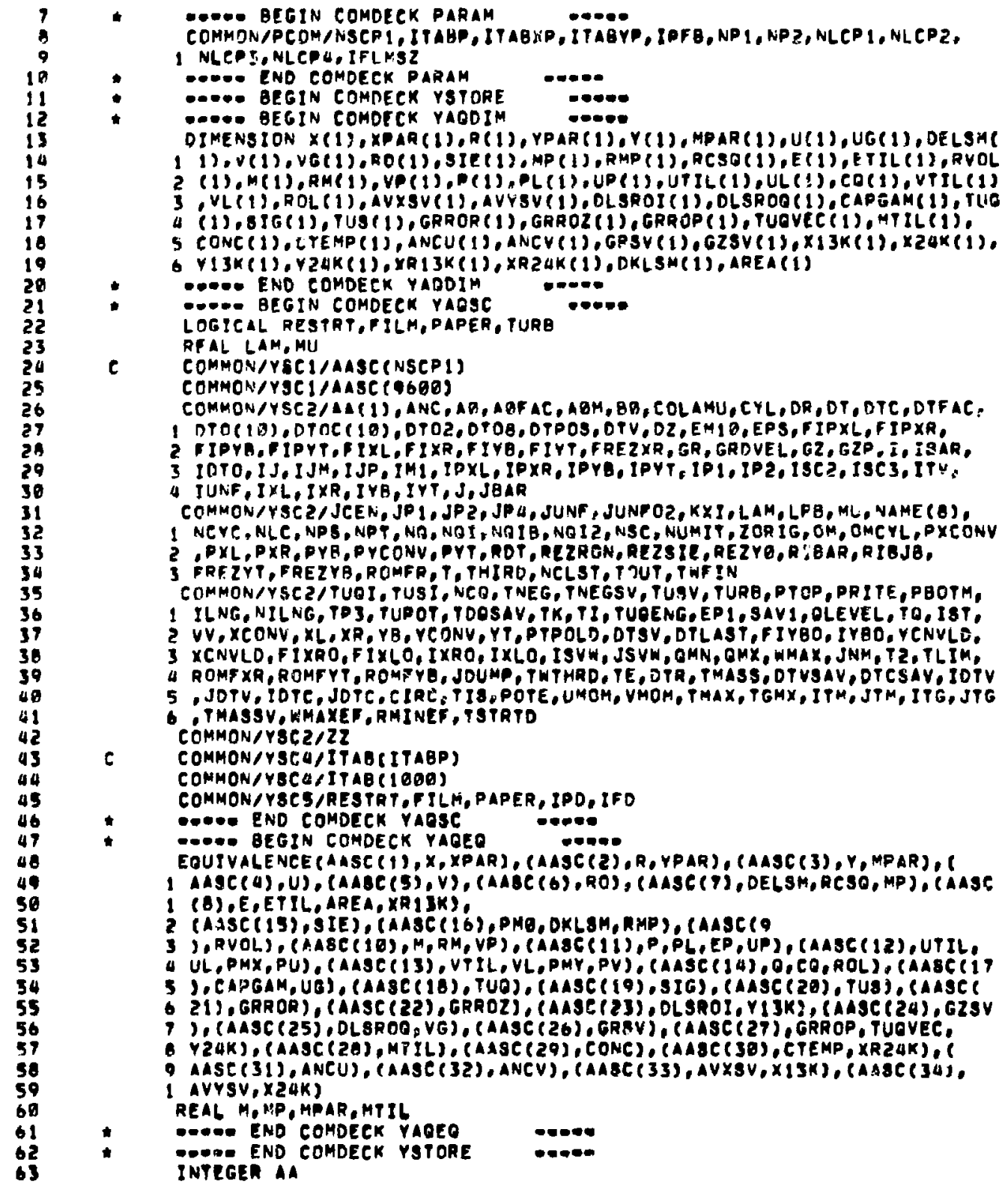




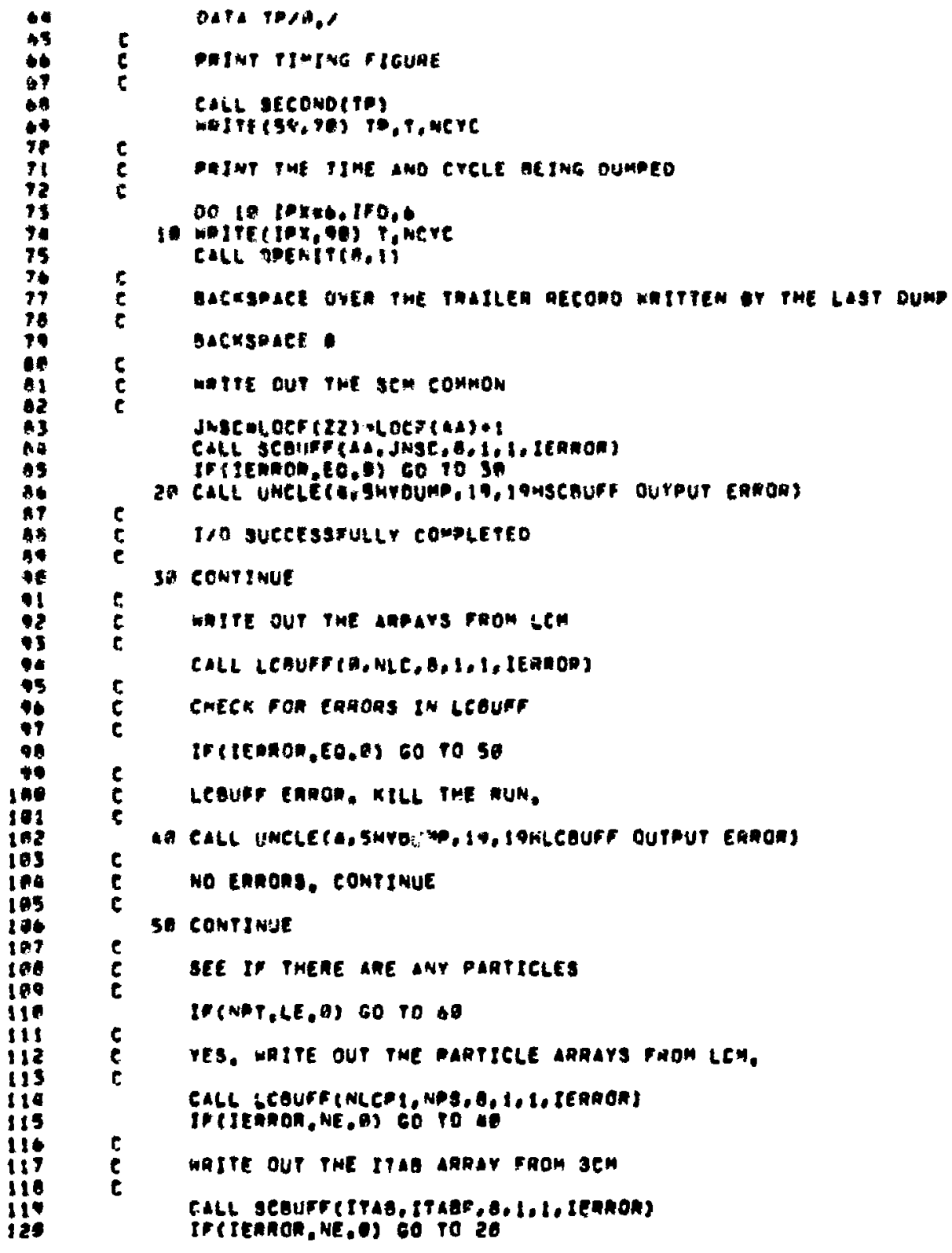




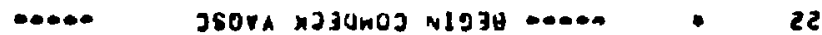

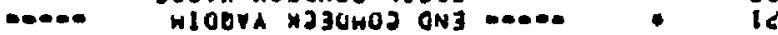

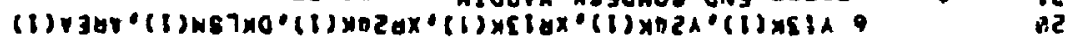

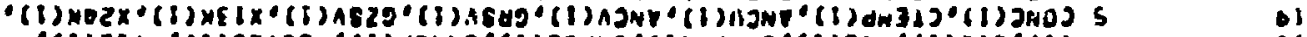

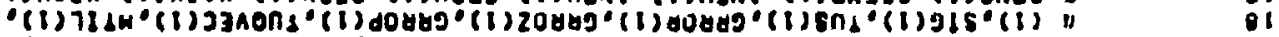

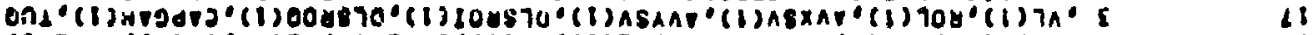

(t) 1 1

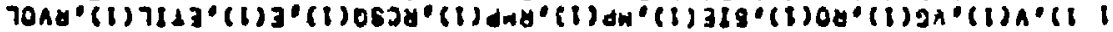

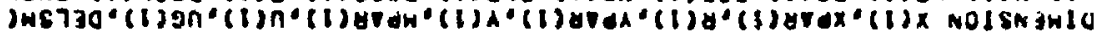

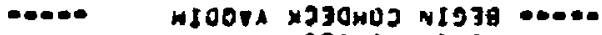

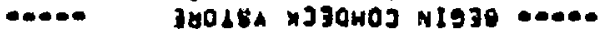

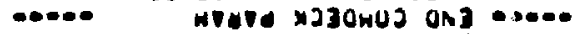

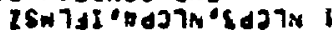

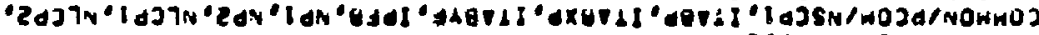

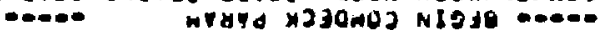

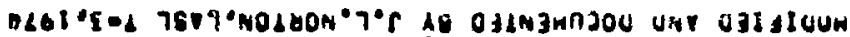

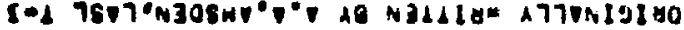

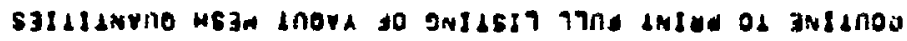

1103A 3nilinougnt

vant3y

at $\left(00^{\circ} \sin 3\right.$ sidun

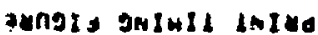

(di) 0 hojas 1782

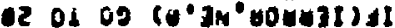

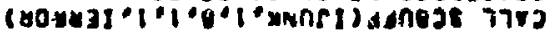

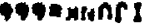

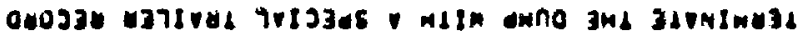

anind 1 NOS 99

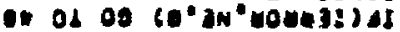

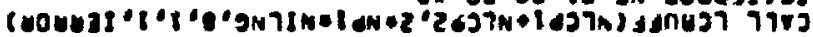

ingr woys ano il jatera caja

0\% $0100\left(9^{*} 37^{\circ}\right.$ ตn $\left.11 \mathrm{~m}\right) \mathrm{dt}$

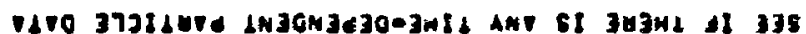

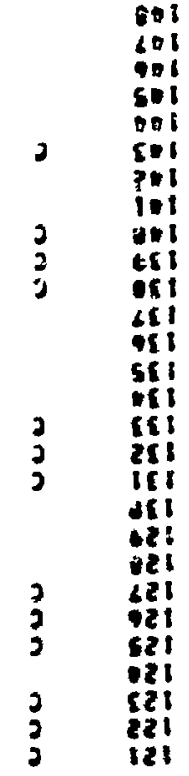


zar. Bes oul o0

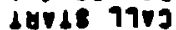

ghoszg 7782 (aund Lon') 18

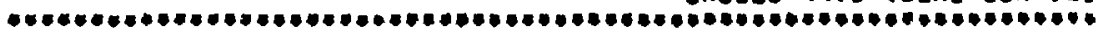

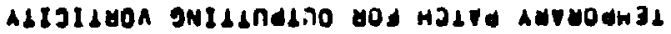

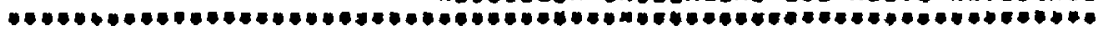
$00853 \times 17$

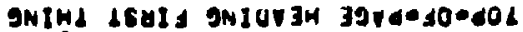

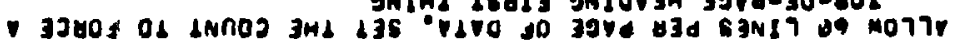

db $(026 \cos ) 31144$

(e) 0 onoj36 7703

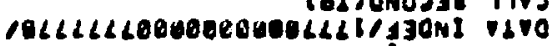
$10 \%$ al 100

(deadt" $1+31$ ) 2 37phinos

e e-e 300LSA nJJONOJ OMJ -

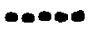

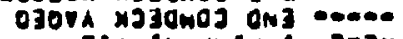
$71 d w^{\circ}$ ovah"dw"w 7v3u trozxonsant

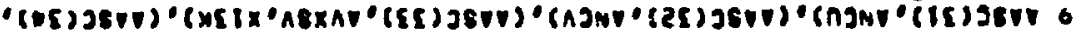

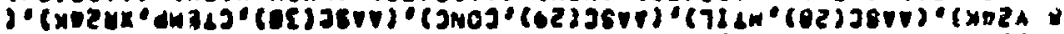

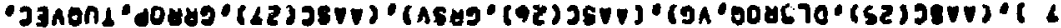

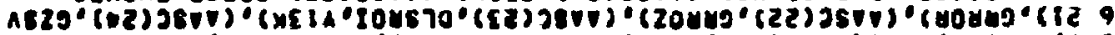

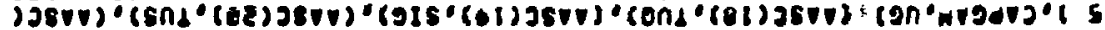

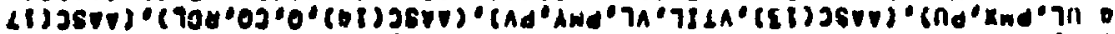

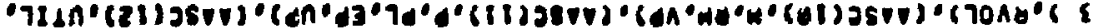

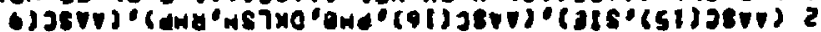

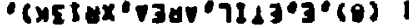

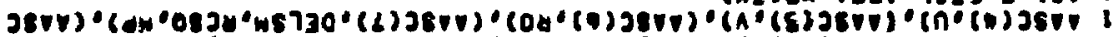

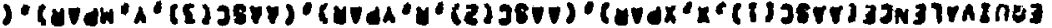
-

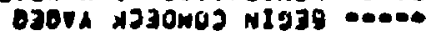

- $9 \cdot 0$

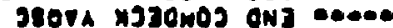

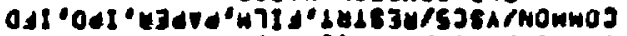

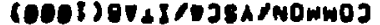

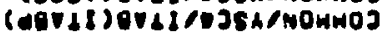
22123 SARMOHHOJ

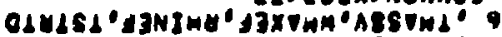

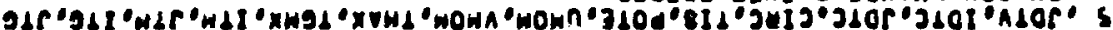

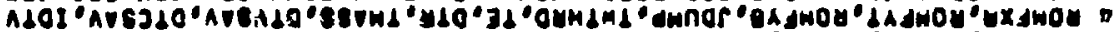

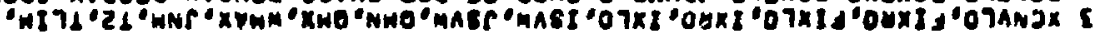

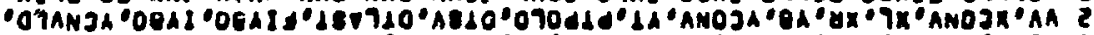

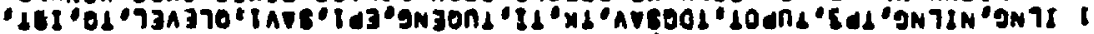

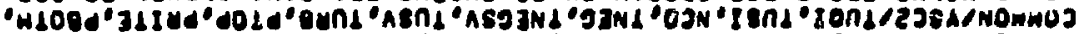

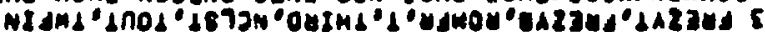

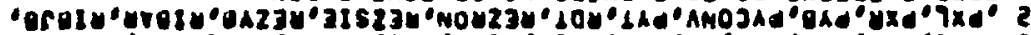

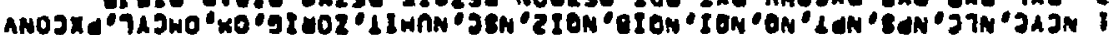

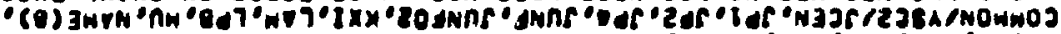

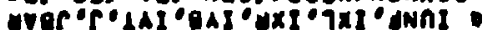

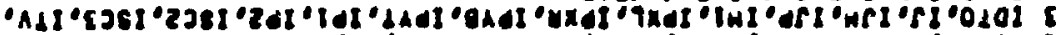

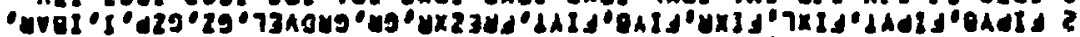

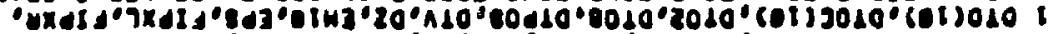

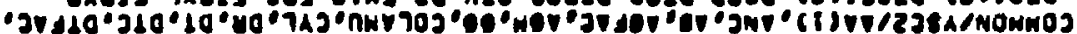

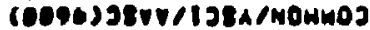

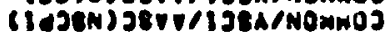

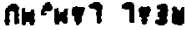

euns.

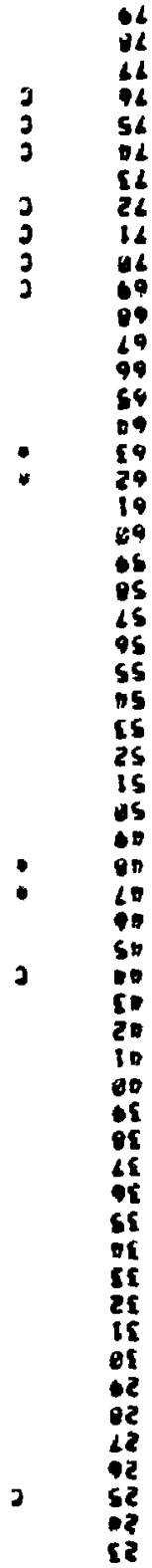




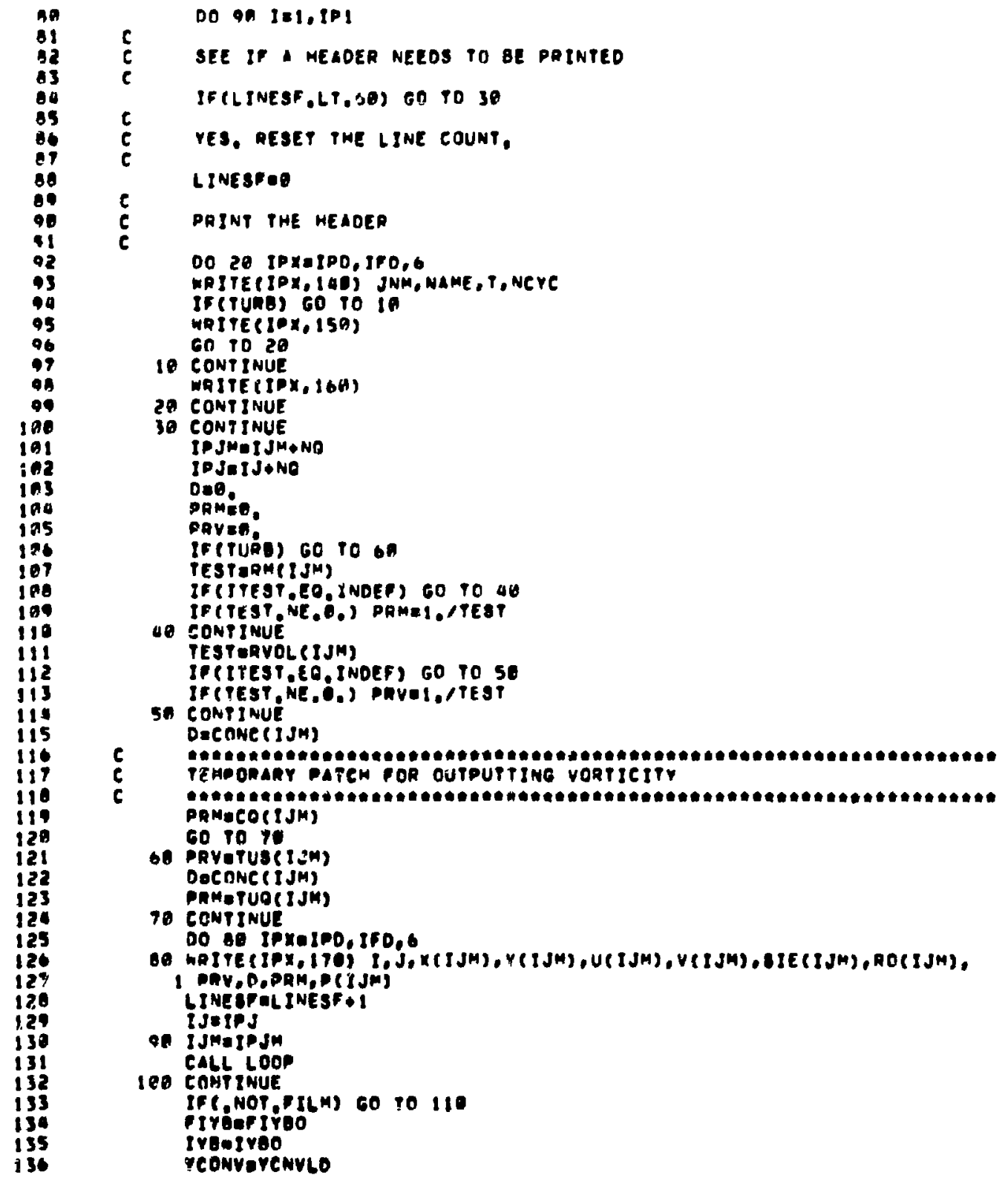




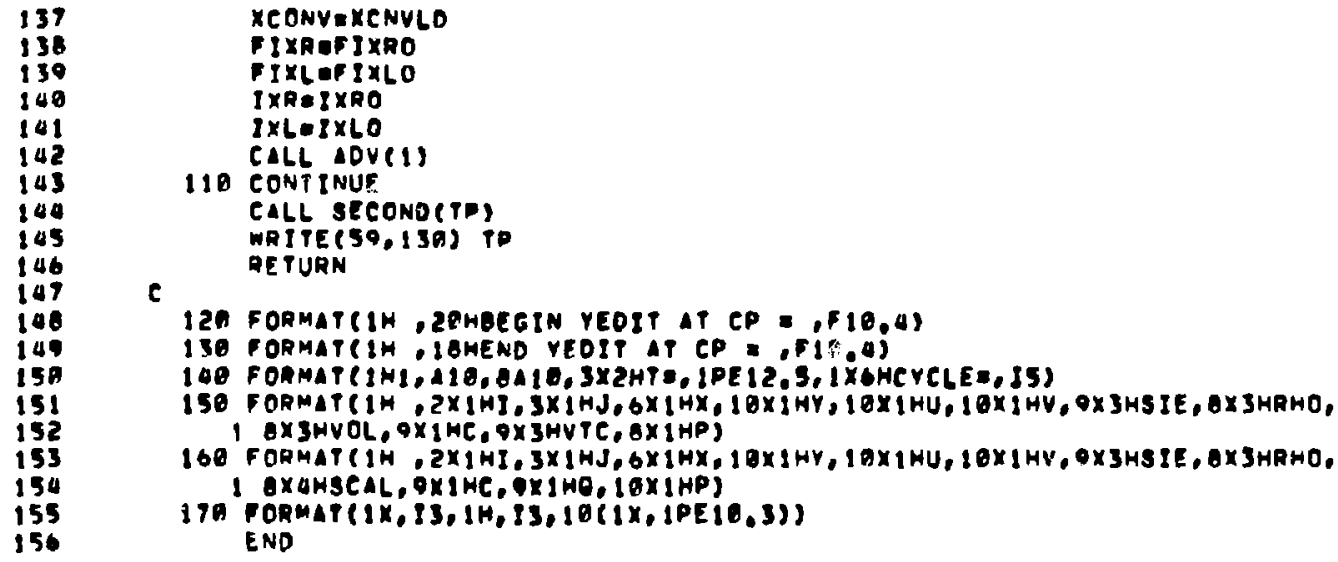

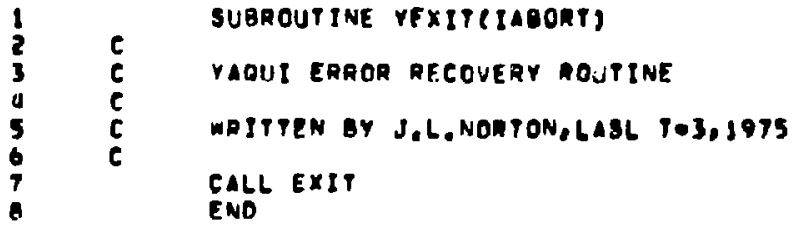

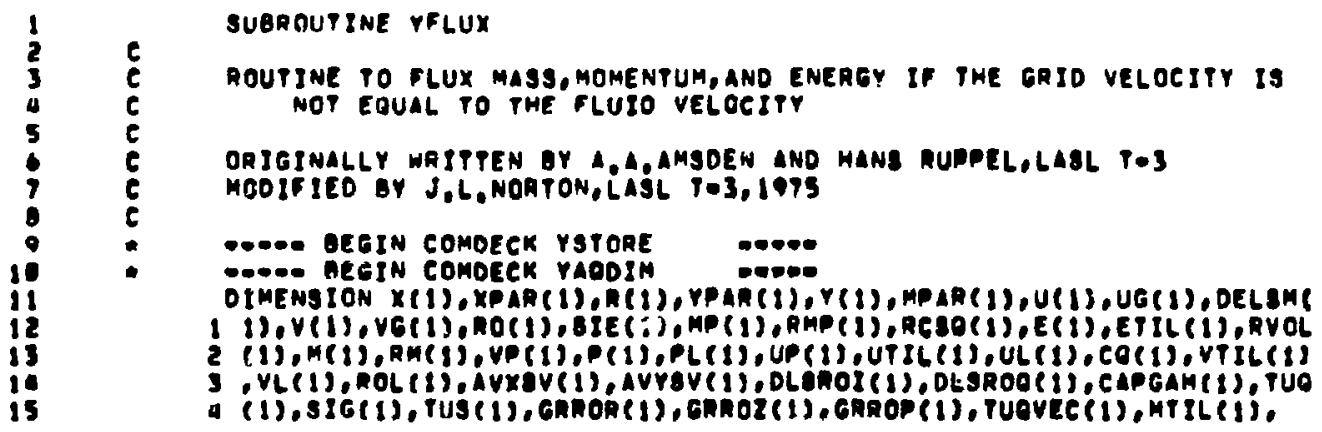


5 CONC(1), CPEMP (1), ANCU(1), ANCV(1), GR8V(1), G2sV(1), XI3K(1), X24K(1),

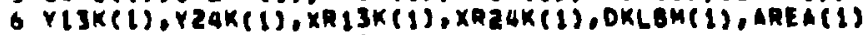

-O.०० END COMDECK YAODIM

C

-oo- oegin comoeck vaOSC

LOGICAL RESTRP, FILM, PAPER, TURE

REAL LAM, MU

COMMON/YSC 1/AASC (NSCP I)

COMMON/YSCI/AASC (\$600)

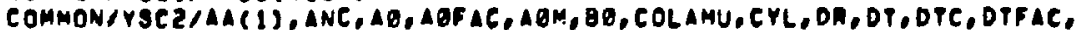

1 OTO(10),DTOC (I0),0T0z,0Y08,DTP0s,0YY,02,EMIO,EPS,FIPXL,FIPXA,

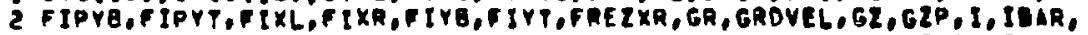

3 IOTO.IJ,IJM,IJP,IMI, IPXL,IPXR,IPY, IPYT,IPI, IPZ,ISCE, ISCS, ITV.

4 IUNF, IXL, IXR, IYB, IYT,J, JBAR

COMMON/YSEZ/JCEN, JP I, JP2, JP 4, JUNF, JUAF OZ, KXI,LAM, LPB, MU, NAME (B)

1 NCYC, NLC, NPS, NPT, NO, NOI, NOIB, NOIZ, NBC, NUMIT, ZORIG, OM, OMCYL, PXCONV

2 -PXL, PXR, PYE, PYCONV, PYT, ROT, REZAON, REZSIE, REZYO, RIBAR, RIOJE,

3 FREZYT, TREZYB, ROMFR, T, THIRD, NCLST, TOUT, THF IN

COMMON/YSCZ/PUOI, TUS I, NCO, PNEG, THEGSV, TUSV, TURB, PYCP, PRITE, PBOTM,

1 ILNG, NILNG, TP 3, TUPOT, PDOSAV, PK, TI, TUAENG, EP I, SAVI, OLEVEL, TO, IST,

2 VV, XCONY, XL, XR, YB, YCONV, YP, PTPOLD, DPSV, DTLAST, FIYBO, IYBO, YCNVLD,

3 XCNVLO, IXRO, FIXLO, IXRO, IXLO, ISVW, JSUW, OMN, OMX, WMAX, JNM, TE, TLIM,

$\triangle$ ROMFXR, ROMFY , ROMFYB, JOUMP, TWTHRD, TE, DTR, TMASS, DTVSAV, OTCSAV, IDTV

5 . JOTV, IOTC, JOTC, CIRE, TIS, POTE, UMOM, VMOM, TMAX, TGAX, ITM, JYM, ITE, JTE

6 . TMASSV, WMAXEF,RMINEF, TSTRTO

COMMON/YSCZ/ZZ

c

COMMON/YSCUAITAB(ITABP)

COMMON/YSCAIITAB (IOOB)

COMMON/YSCS/RESTRT, FILM,PAPER, IPD, IFD

CO- END COMDECK VAOSC

- H. BEgIN COMDECK Yageo

0000

COUIVALENCE (AASC (1), X, XPAR), (AASC (2),R, YPAR), (AASC (3), Y, MPAR) ,

I ASC (4),U),(AASC (5),V), (AASC $(6), R O),(M A S E(T), D E L S M, R C S O, M P)$, (AASC

1 (8),E,ETIL, AREA, XRI3K).

2 (AASC (IS),SIE), (AASC (16),PMO,DKLSM,RMP), (AASC (S

3 ),RVDL), (AASC (iO), M,RM, YP), (AASC (1),P, RL,EP,UP), (AASC (12), UTIL,

a UL,PMX,PU), (AASC (IJ),VPIL,VL,PMY,PV), (AASC(14), Q, CA,ROL), (AASCCIT

5 ), CAPGAM, UG), (AAse (1B), TUO), ( AAsC (19), SIG), (AASC (20), TUS), (AASC

6 21),GRROR), (AASC (22),GRROZ), (AASC (23),OLSROI, Y13K), (AASE(24),GZSV

7 ), (AASC (25), OLSROQ, VG), (AASC (26), GRSV), (AASC (27), GRROP, TUOVEC,

S YZUK), (AASC (28), MTIL), (AASE (29), CONC), (AASC (30),CTEMP, XRZUK),

- AASE (33), ANCU), (AASC (32), ANCV), (AASC (33), AVXSV,XI3K), (AASC (34),

1 AVYSV, X2UK)

REAL M, MP, MPAR, MTIL

-

- 0.0 END COMDEEK YSTORE DEO

- Com aEgIN COMDECK PARAM

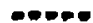

COMMONAPCOM/NSCPI, ITABP, ITABXP, ITAAYP, IPFB, NP I, NP2, NLCP I, NLCP2,

1 NLCP 3, NLCPU, IFLMSZ

-OO. END COMDECK PARAM DOE

- DOE HEGIN COMDECK ASTORE

COMMON/ASTCAT(1OO), FT(1OO)

DIMENSION IXI (1), IYI $(1), I \times 2(1), I Y 2(1), \times C O(1), Y C O(1), C O N(1)$

enUIVALENCE(AT, IXI), (AT (2), IXZ), (AT(3), IYI), (AT(A), IYZ), (ATES),XEO

1 ), (AT (9), YCO), (FT,COH)

- Jo ENO comdeck astoRe

DTC = \&,E 30

CALL START 


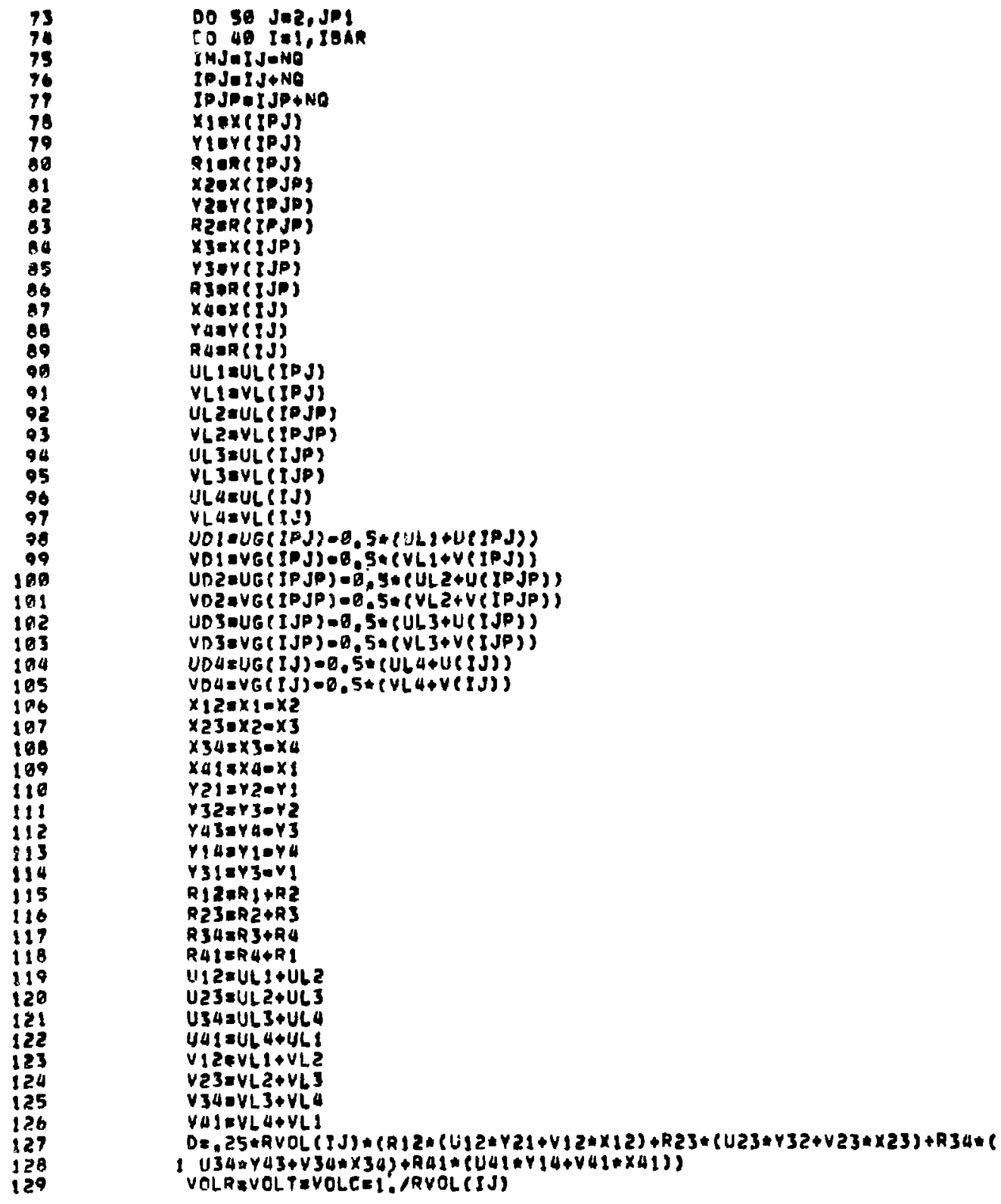




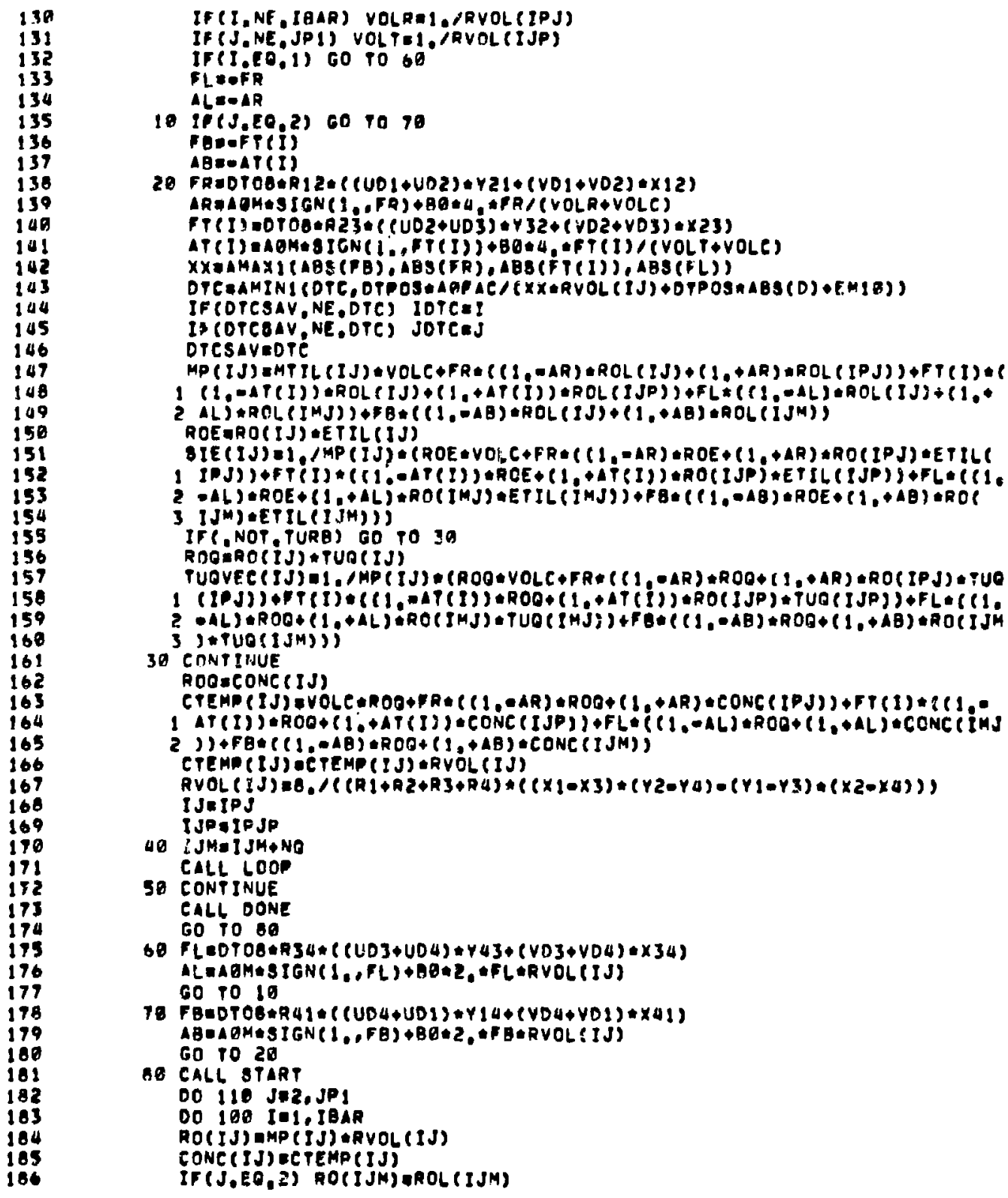




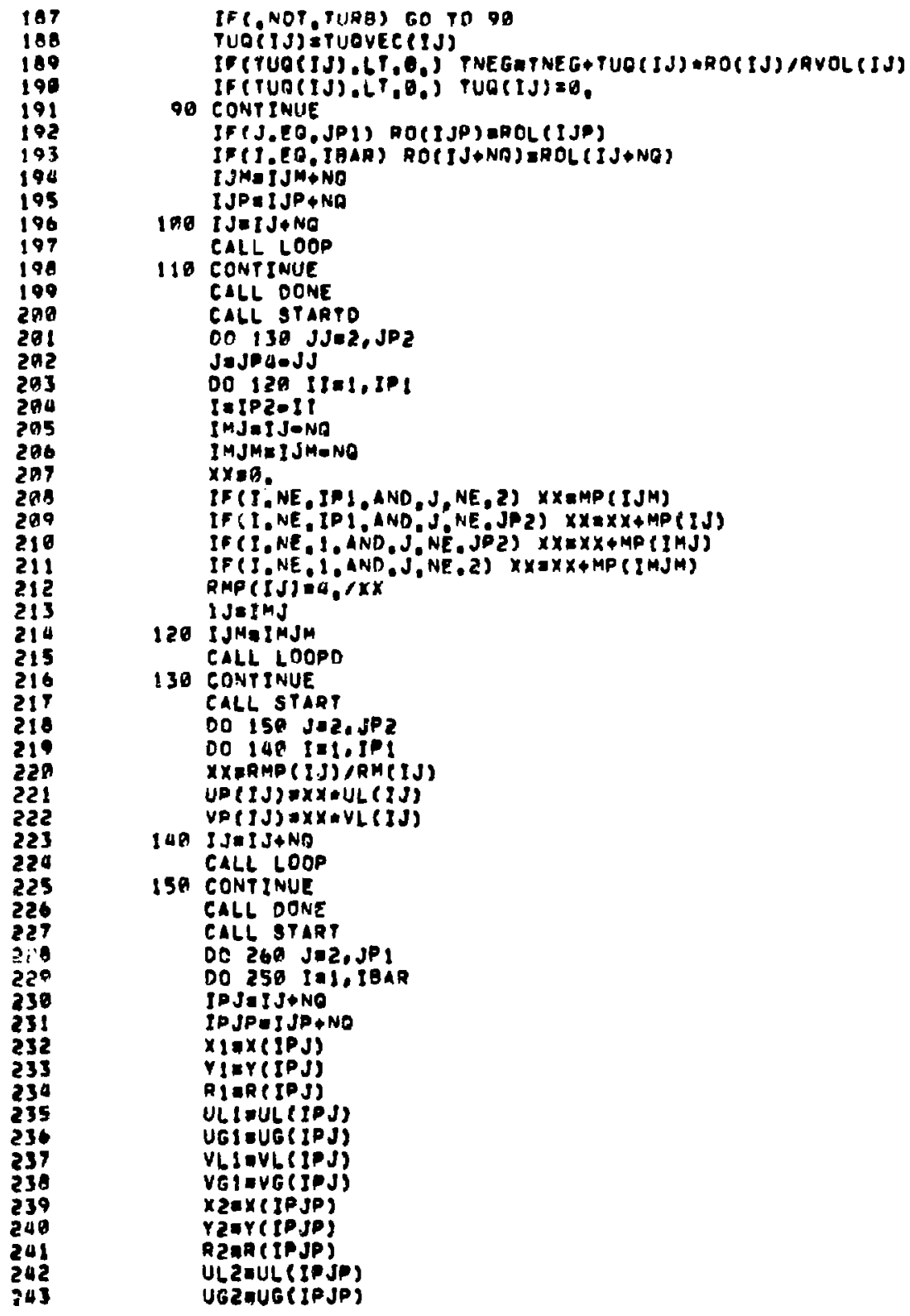




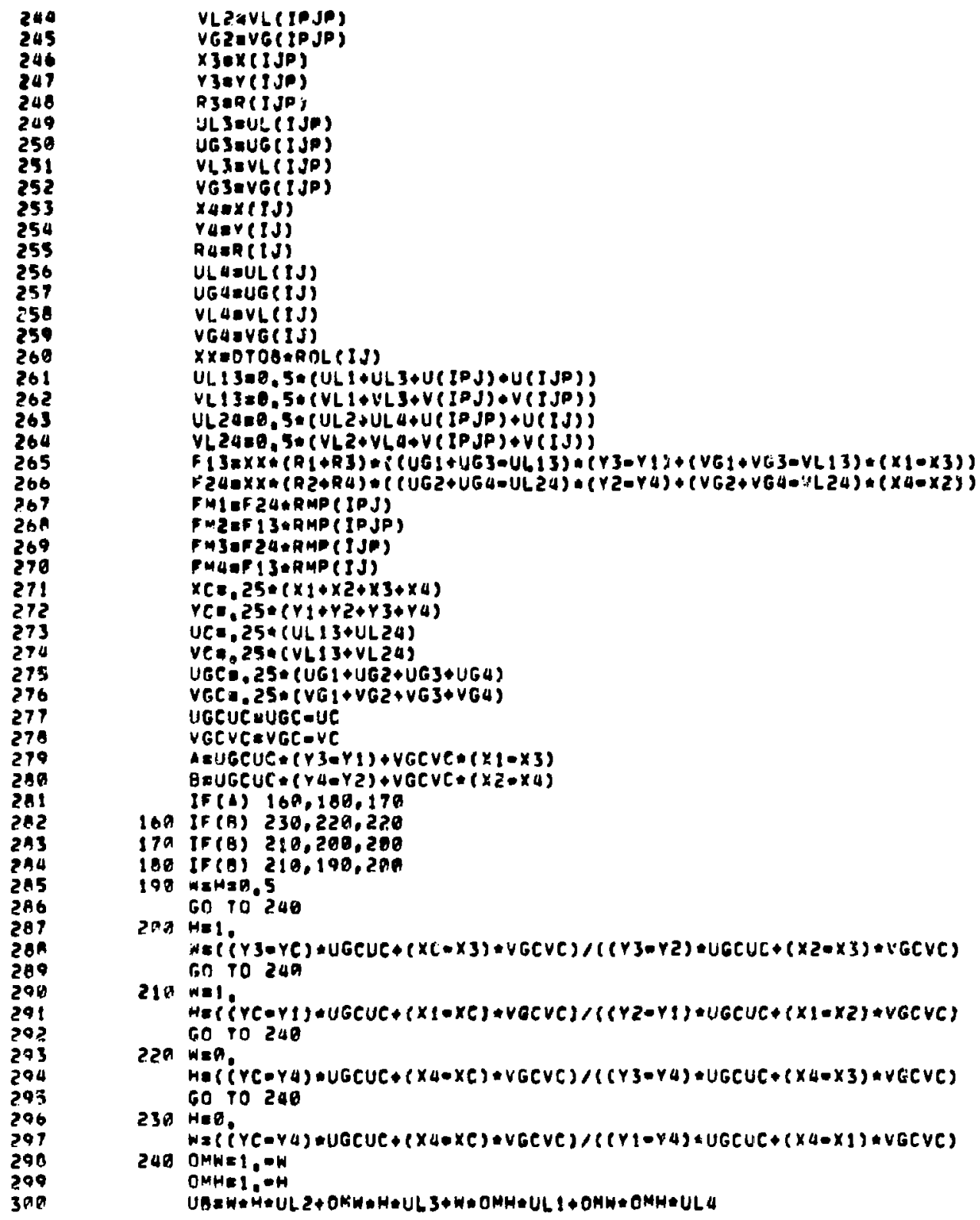

xzex(IJP)

vzer(1jo)

RJaR I ID:

JL seve (1JP)

UEJEUE (IJP)

$V L J=V L($ IJP)

VESaVE( IJP)

$x \in \operatorname{rax}(17)$

ranV(IJ)

AuER(tJ)

ULA =UL (IJ)

UGAUUG(IJ)

VLUDVL(IJ)

VGAJVG(IJ)

$X X=0 T 08$ ROL $(I J)$

$U L$ 1 300.5*(ULI+ULI*U(IPJ)*U(IJP))

$V L I 3=0.5 *(V L I+V L I * V(I P J) \bullet V(I J P))$

$U L 2 a=0.5 *(U L 2+U L a+U(10 J P)+U(1 j))$

$V(24=0,5 *(V L 2+V L 4 * V(I P J P) * V(I J))$

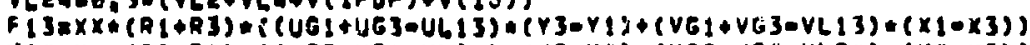

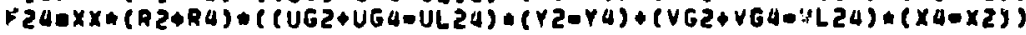

FMIEF $24 \cap R M P$ ( IPJ)

FMCEF 13०RMP (IPJP)

FMJeF $24+A M E(1 J O)$

PMUDFIJ

$X C=.25=\left(X_{1}+X_{Y}+X_{3}+X_{4}\right)$

$Y C=.25 *(Y 1+Y Z+Y 3 * Y 4)$

$U C=.25 \backsim(U L 13+U L 24)$

$V C a, 25 *(V L I 3+V L 24)$

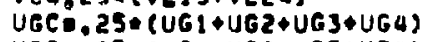

$V G C \cdot .25 *(V G 1+V G 2 * V G 3 * V G 4)$

UGCUCUUGC-UE

VGCVCEVGC-VC

AsugCUe $(Y 3-Y 1)+V G C V E *(X 1-\times 3)$

BEUGCUC $(Y 4-Y 2)+V G C V C *(X Z=\times 4)$

If (1) $169,180,179$

160 IF(B) 230.220 .220

179 IF (B) $2 \& 0.200,200$

180 IF(B) $218,190,299$

190 M 1950.5

6010240

2AB HEl.

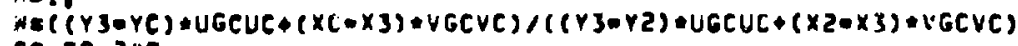
60 To 249

$210 w=1$.

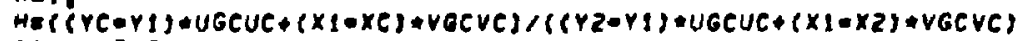
60 To 240

$2.29 \omega=9$.

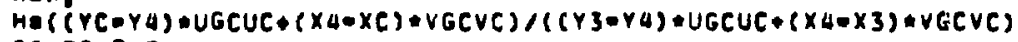
60 To 240

230 Heb.

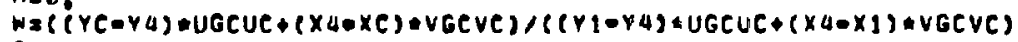

24R OMW $=1,0 \mathrm{~W}$

OMHE I: $: H$

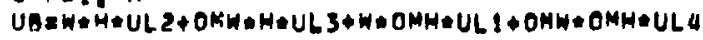



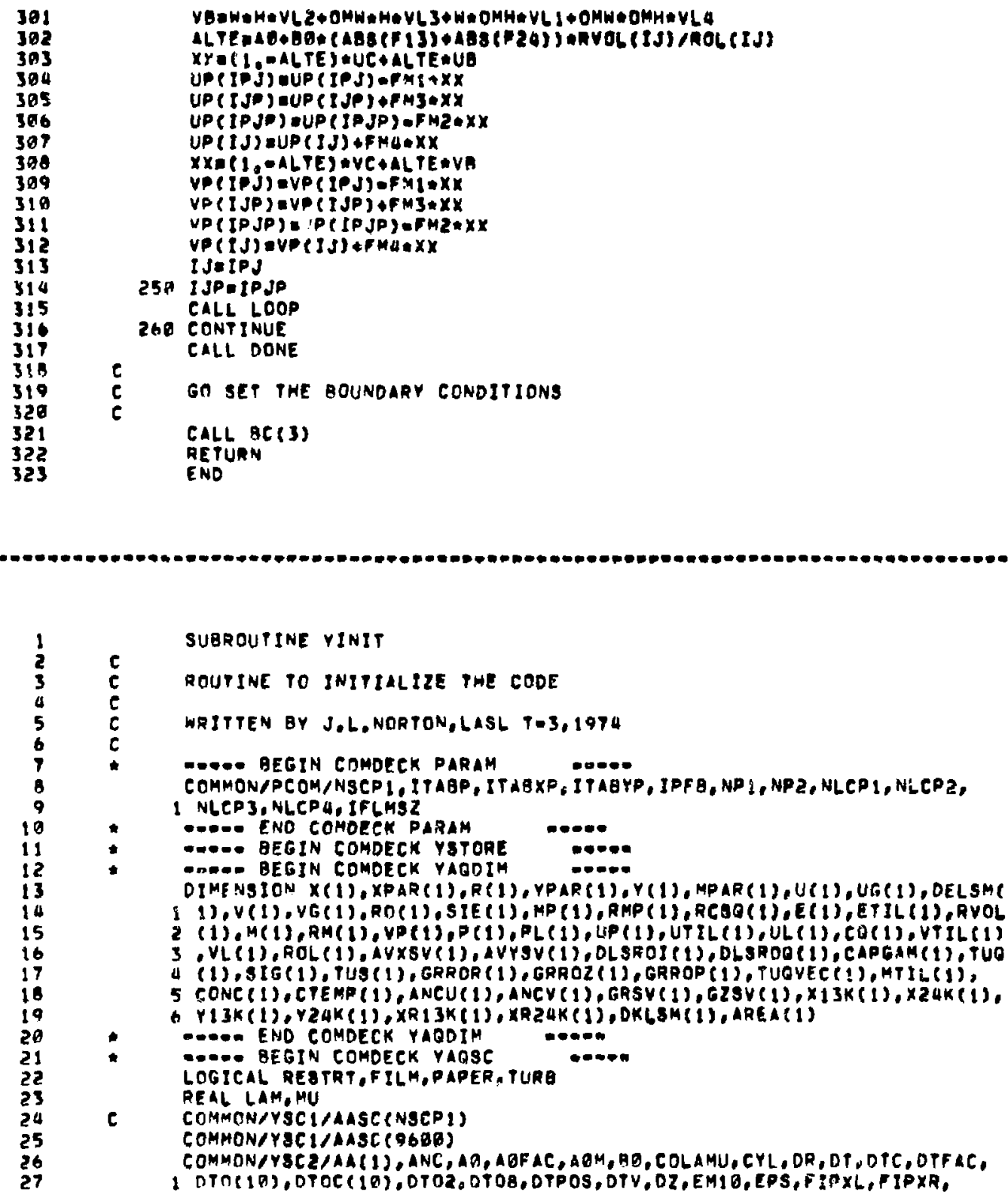


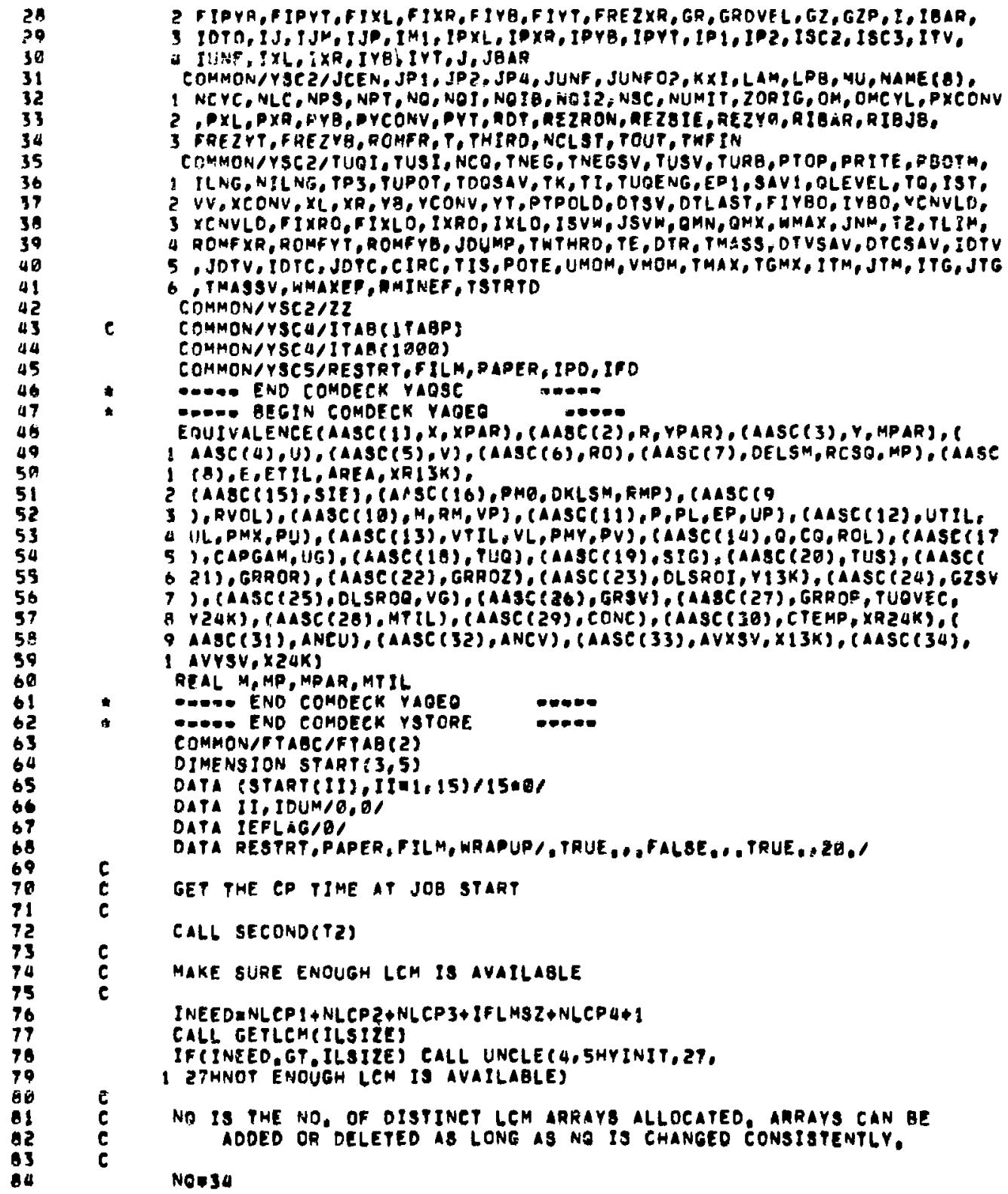




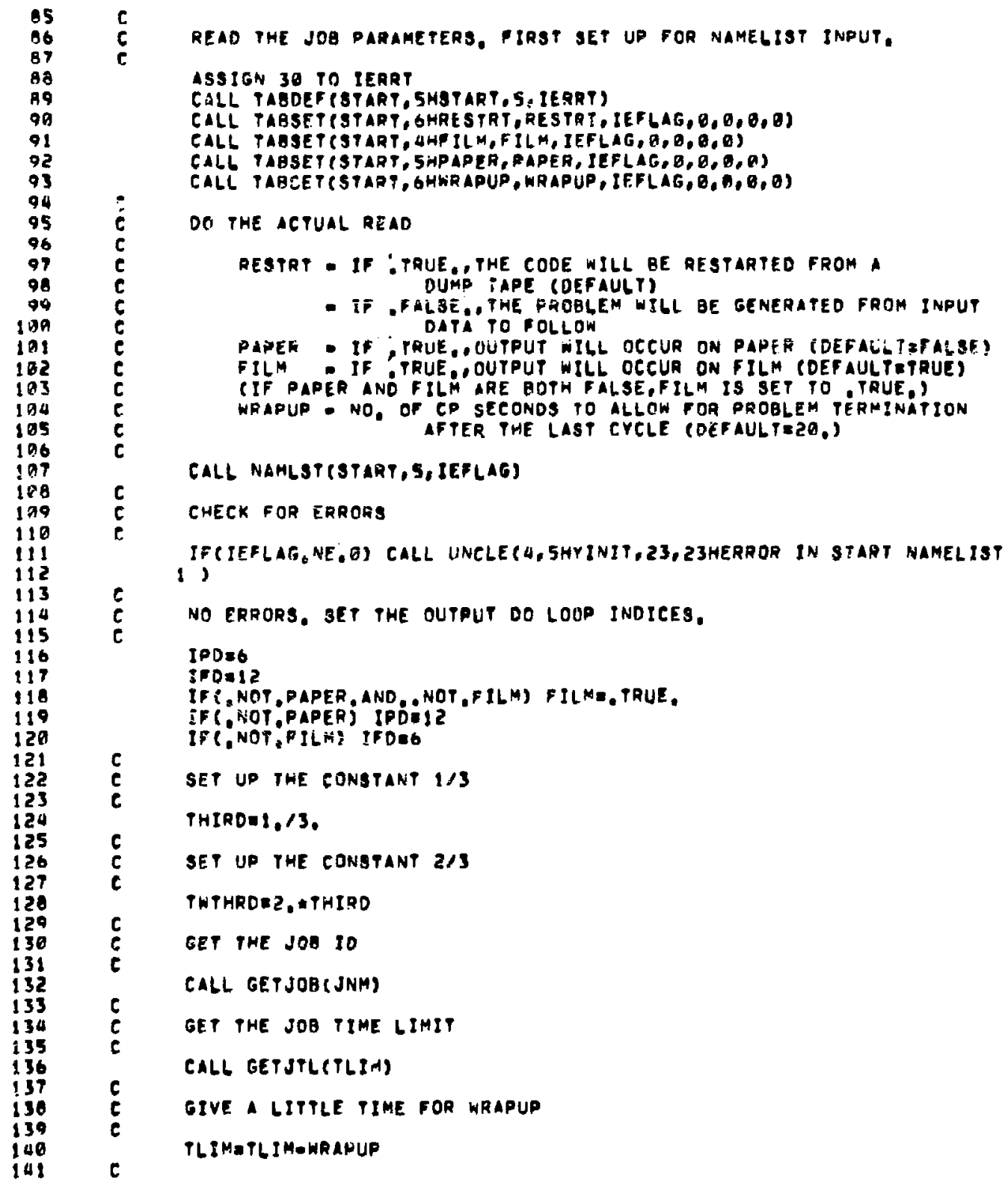




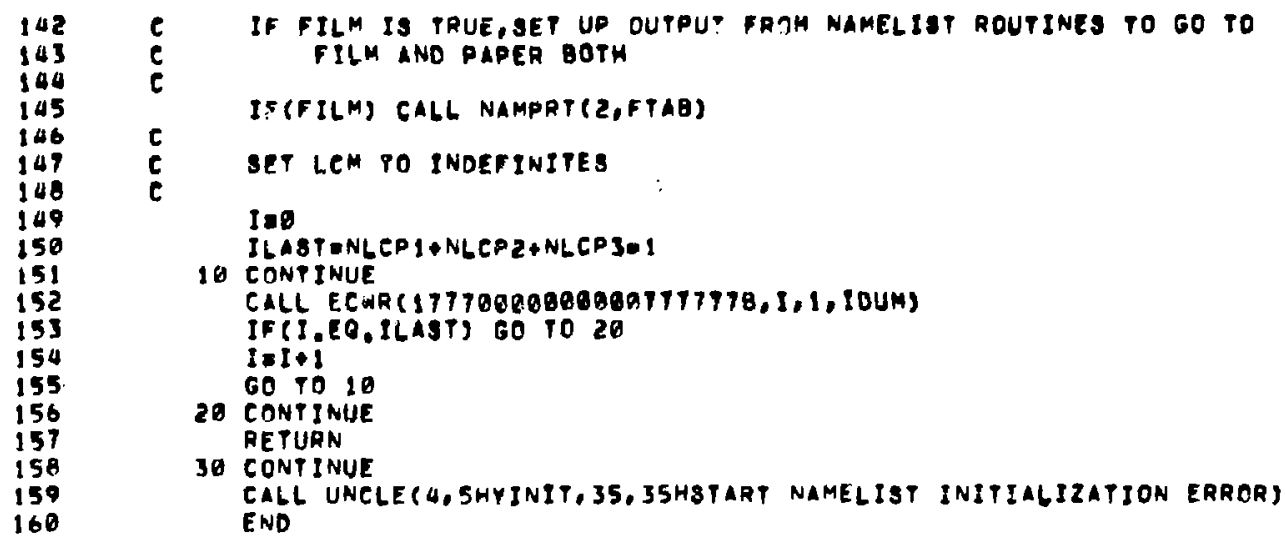

ROUTINE TO READ YLQUI INPUT VARIABLES

WRITTEN BY J.L: NORTON,LASL T-3,1975

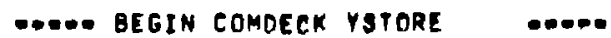


1 ILNG, NILNG, TP 3, TUPOT, TDOSAV, TK, T I, TUOENG,EPI, SAVI, QLEVEL, TO, IST, 2 VV,XCONY,XL,XR, YE, YCONV, YT, PTPOLD,OTSV, DTLAST,FIYOO, IYBO, YCNVLD, 3 XCNVLO,FIXRE, FIXLO, IXRO, IXLO, ISVH, JSVW, OMN, OFX, HHAX, JNM, T2, TLIA, 4 ROMFXR, ROREY , ROMFYB. JDUMF, TWTHRD, TE, DTR, TMASS, DTVSAV, OTCSAV, IDTV 5 . JOTV, IDTC, JDTE, CIAC, TIS, PDTE, UMOH, VMOM, TMAX, TGMX, ITH, JTM, ITG, JTG 6 . TMASSV, WMAXEF, RMINEF, TSTRTD COMMON/YSE $2 / 22$

COMMON/YSCA/ITAB(ITABP) COMAON/YSCAITRAB(1000) COMMON/YSCS/RESTRT OFILM, PAPER, IPD, IFD 


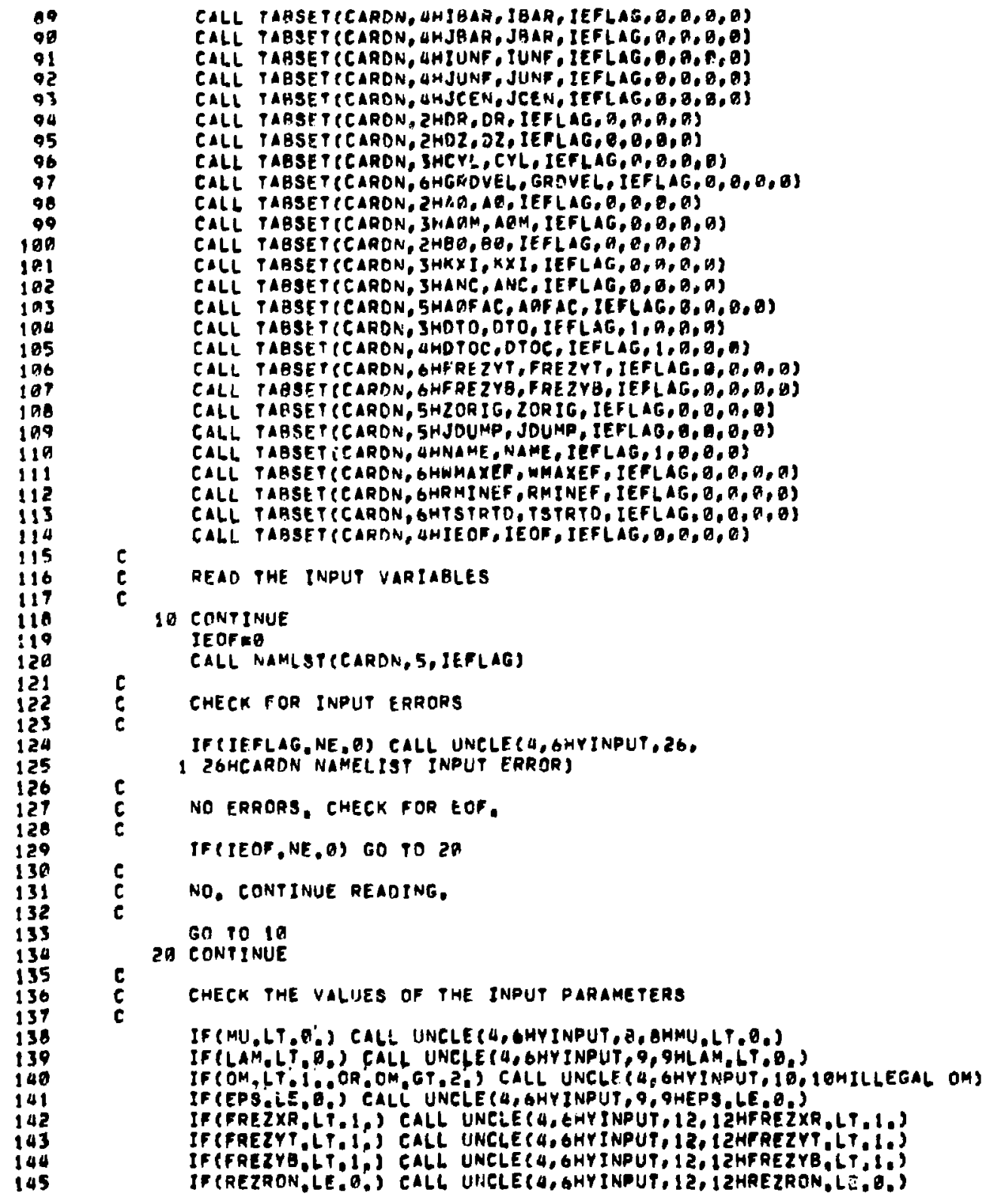




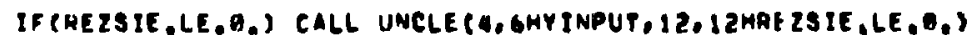

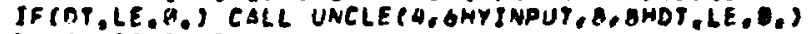

Do 30 II:5, is

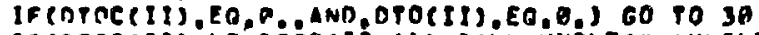

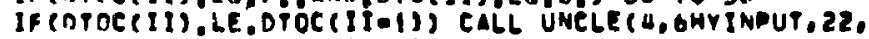

1 2ZHOTOC MUST BE MONOTONIE)

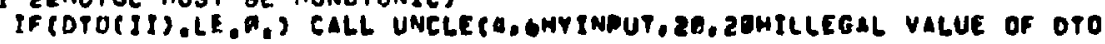
()

30 CONPINUE

IF (IBAR,LE,O) CALL UNCLE (U, GHYINPUT, 9, OHIBAR,LE,G)

IF (JBAR.LE,O) CALL UNCLE (4, GHYIMPUT, 9, OHJBAR,LE, A)

IF (OR,LE,O.) CALL UNCLE (A. GHY TNOUT, B.BHOR,LE, B.)

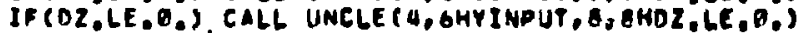

IFICYL, NE, J.AND,EYL.NE,B,) CALL UNCLE (4, GHYINPUT, 20 ,

1 PaHILlegal Valuf of (ri)

TF (GRDVEL. NE, G..AND, GRDVEL, NE, I. AND, GROVEL,NE, R, CALL UNCLE(A,

1 HHINPUT, 23,23 ILLEGAL VALUE OF ERDVEL)

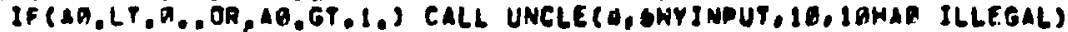

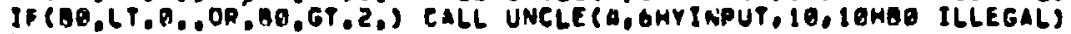

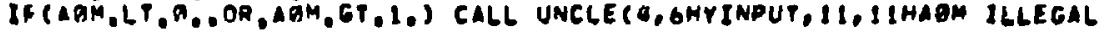

13

IF (KXI,LP, (-1), OR,KYI,GT,1) CALL UNCLEPA, GHYINPUY, II,

I IINKXI ILLEGAL)

IF (ANC.LE,O,) CALL UNCLE (4.GHYINPUT, 9, THANE.6E.0.)

if (AOFAC.LT, F,. OR, AOFAC, GP.1,) CALL UNCLE 4, GHYINPUT, 13.

1 I JHAGFAC ILLEGALS

RFTURN

U) CONTINUE

CALL UNCLE 4, GHYINPUT, 35, 35HCARON NAMELIST INITIALIZATION ERROR) END

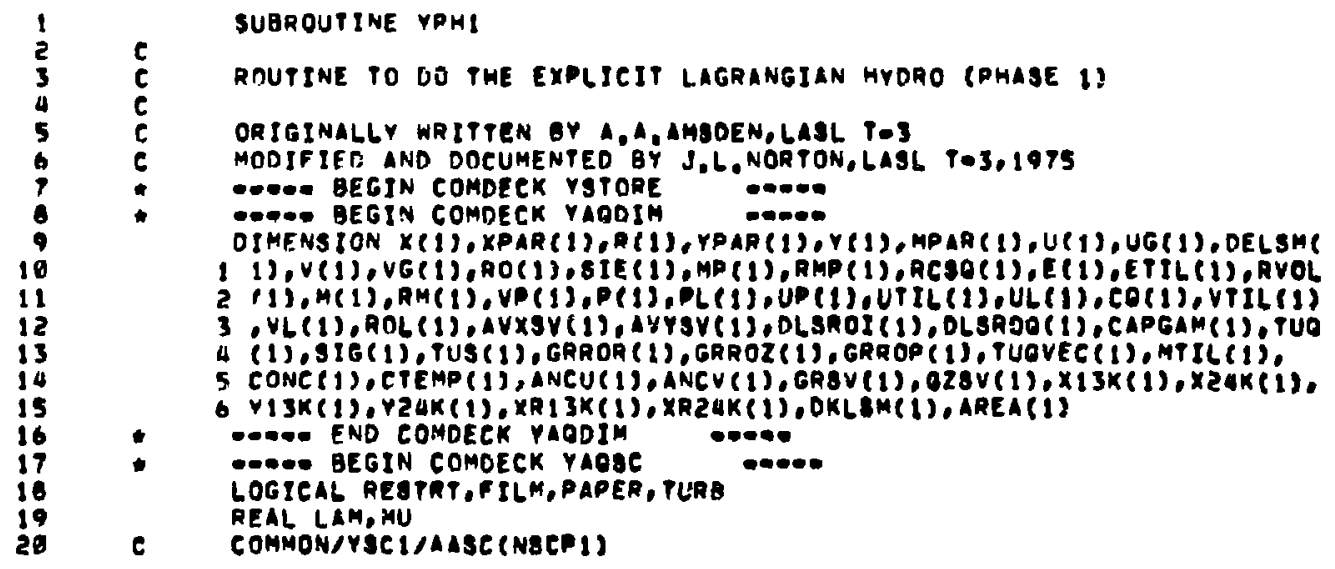




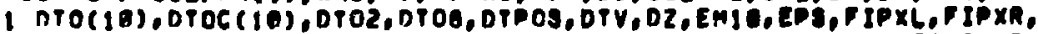

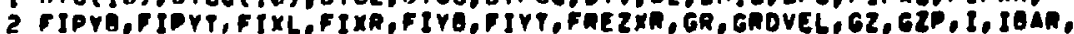

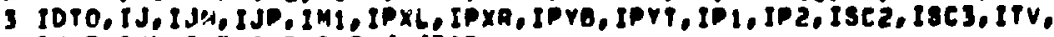

a IUNF, IXL, IXR, IYA, IY , J,JOAR

COMMON/YSCZ/JCEN, JP 1, JP2, JPA, JUNF, JUNF 02, KXI, LAM, LPB, MU, NAME (B),

1 NCYC, $: C$, NPS, NPY, NO, NOI, NOIB, NAIZ, NSC, NUMIT, ZORIG, OM, OMCVL, PXCONV

2 .PRL,OXR, PYE, PYCONY,PYT, RDY, REZRON, REZSIE, REZYO,RIGAT, RIEJH,

3 FREZY , FAEZYG, ROMF, P, PHIRD, NCLST, TOUT. THF IN

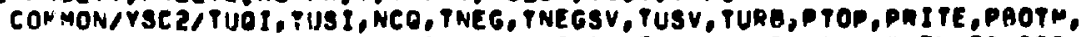

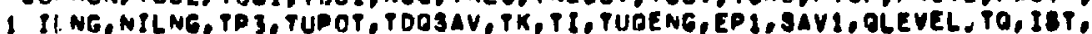

$2 V L, X C O N V, X L, X R, V E$, YCONV, YT, PTPOLD. OTEV, DTLAST, F IYBO, IVBO, YCNVLD.

3 XCNVLD, FIXRO,FIXLO, IXAN, IXLO, ISVW, JSVW, ONN, OMX, AMAX, JNM, TZ, TLIM.

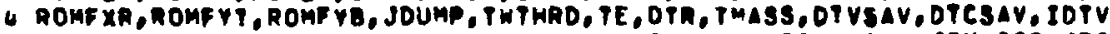

5 . JOTV. IOPC, JDTE, EIHC, TIS, POPE, UMOM, VMOM, TMAX, TGMX, ITH, JTM, ITG.JTG

b. PMASSY, HMAXEF, RMINEF, TSTATd

COMMOHJ TSC2122

COMON/YSCAIITAB(ITABP)

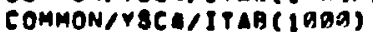

COMMON/YSC5/RESTRT,FILM,PAPER, IPS, IFO

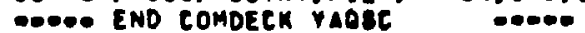

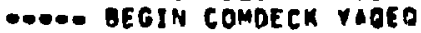

0000

EDUTV HLENEE (AASE $(1), x, X P A R),(A A S C(2), R, V P A R),(A A B C(3), Y, M P A R), C$

I AASC (4),U?, (AASE $(5), V),(A A S C(6), R O),(A A S C(7)$, OELSM,RCSO, MP), (AASC

1 (B),E,ETIL, AREA, XRI3K).

2 (AASE (15),STE), (AASC (16),PMB,OKLSM,AMP), (AASC (Q

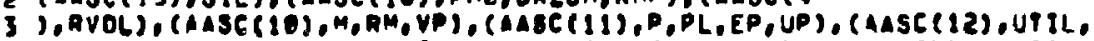

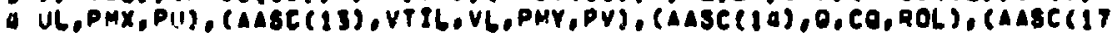

5 ), CAPGAM, llG), (AASC (1Q), TUA), (AASC (19),SIG), (AASC (2B), TUS), (AAsC

- 21), GAROR), (AASC(22), GRAOZ), (AASC (23), CLSHOL, YIJK), (AASC(24),GZSV

7 ). (AASC (25).OLSROO,VG), (AASC (26), GRSV), (AASC (27), GRROP, TUOVEC.

- YZaK), (AASC $(20), 4 P I L),(\triangle A S C(29), C O N C),(A A S C(30), C T E M P, X R 2 O K), C$

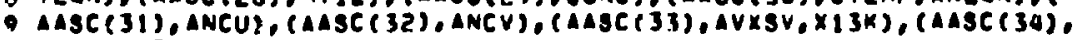

1 AVYSV,X2uKs

REAL. M, MP, MPAR, MPIL

- -OA END COMDECK YAQCo

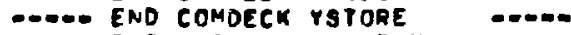

-OE- DEGIN COADECK PARAM

COMMONIPCOMINSCP1, ITARP, I TAPXP, I TABYP, IPFB, NPI, NP 2, NLCP I, NLCPZ,

1 NLCP S, NLCPA, IFLMSZ

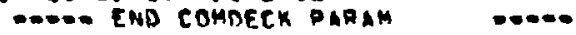

CO. AEGIN COMDECK ASTORE

COMMON/ASTC/AP(100), FT(IDG)

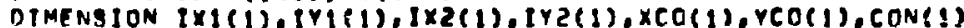

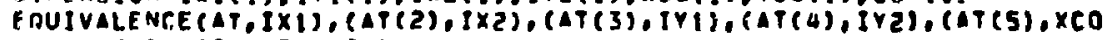

1), (AT Q Q), YEO), (FT,CON)

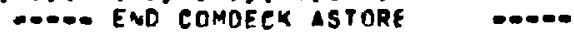

RFIL LAMD, MUOZ

APPLY THE NOOE COUPLEA TO ALL VEATIERS

Call graAt

$Y j=A N C \cap R D T$

on $100 \mathrm{~J}=2 . \mathrm{JPZ}$

on $90 \quad I=1, I \otimes 1$

IMATIJ-ND 


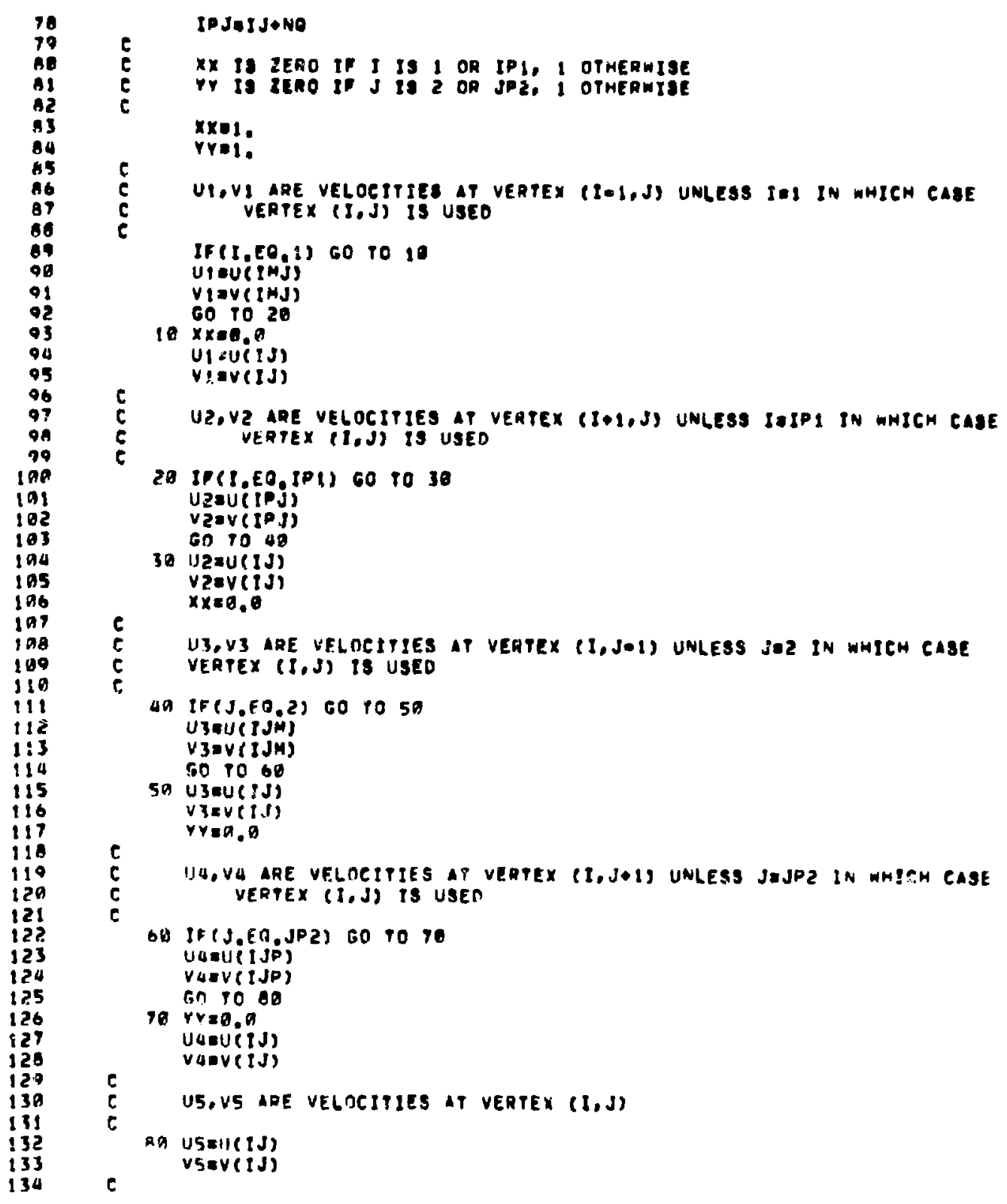




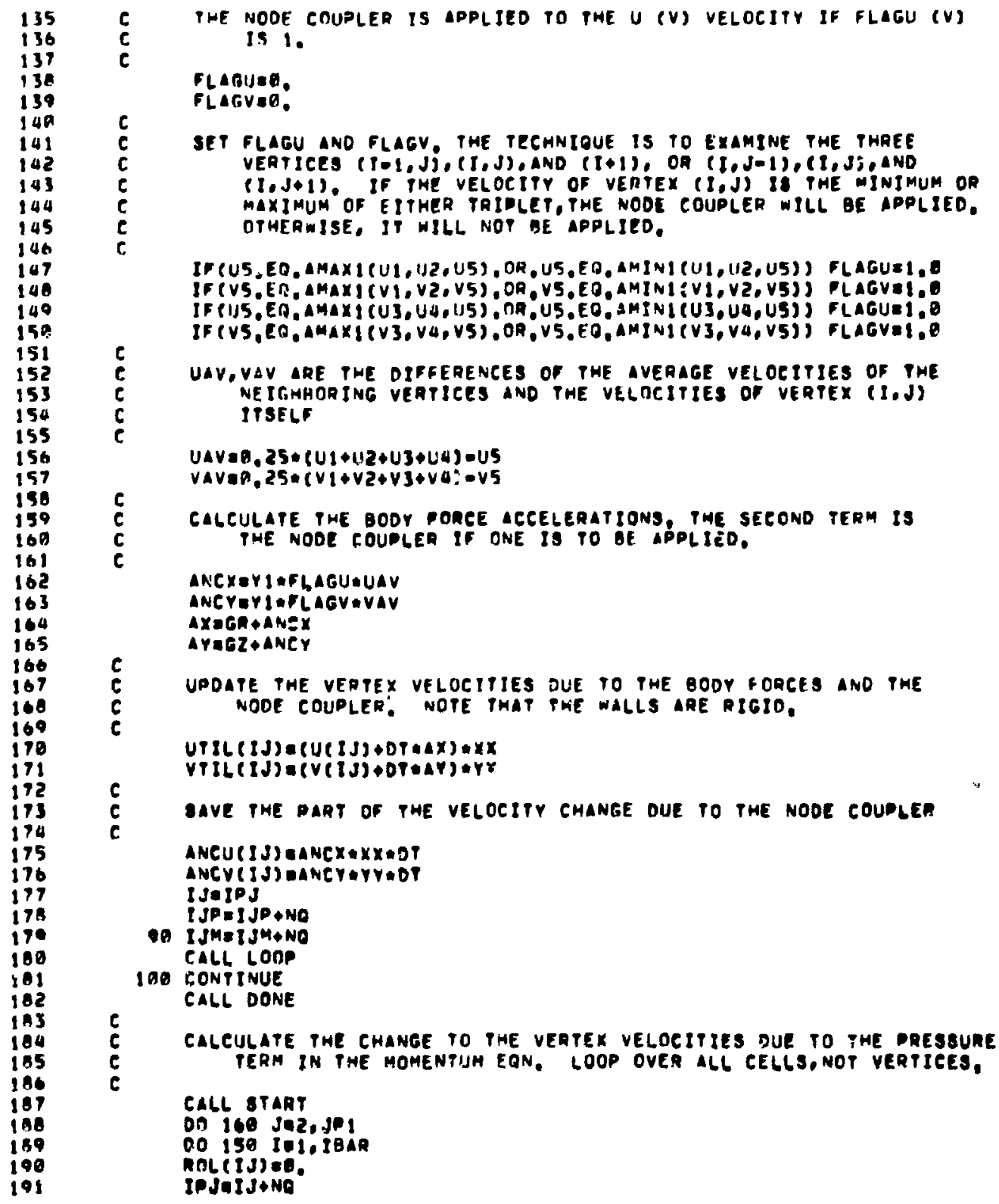




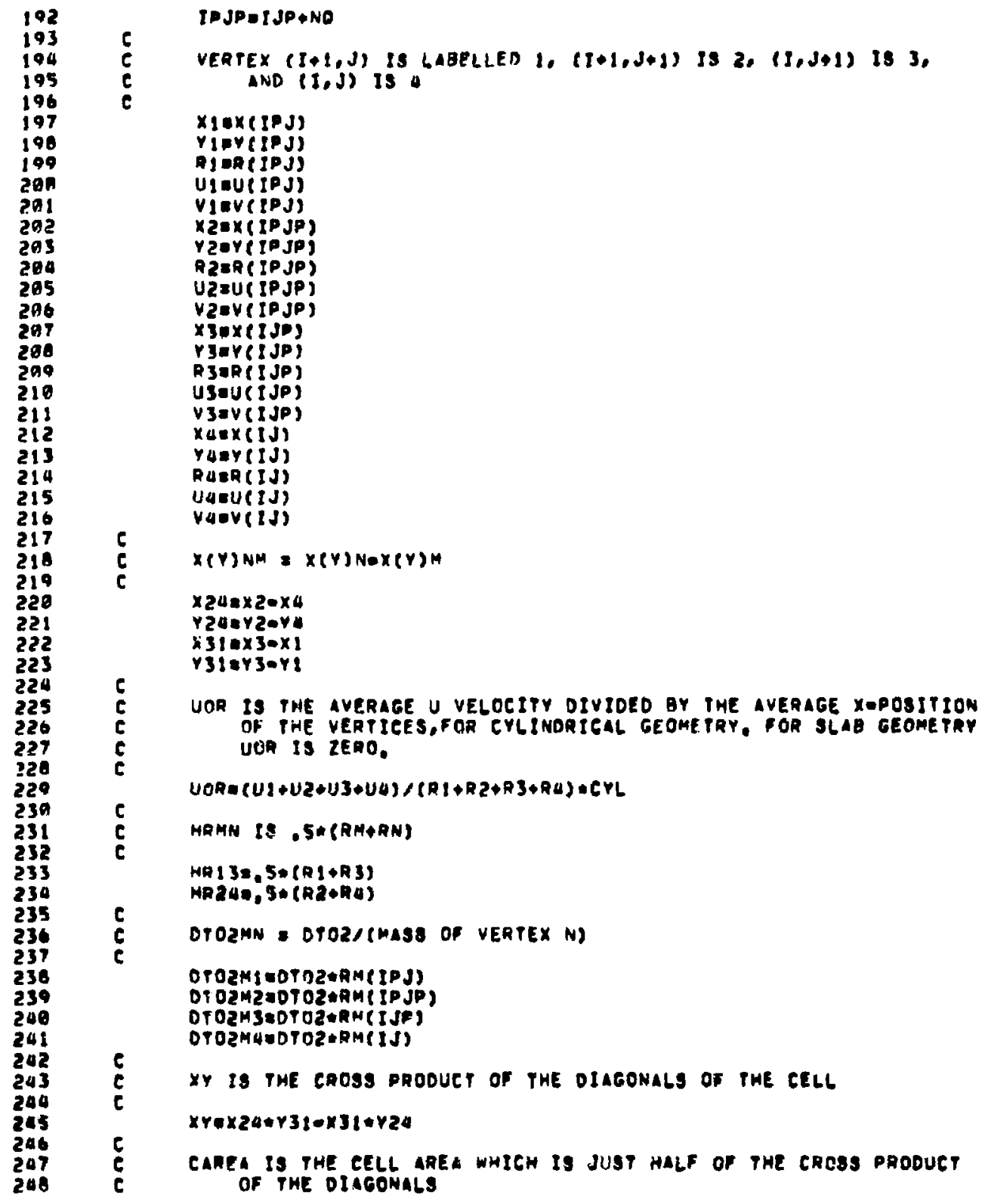




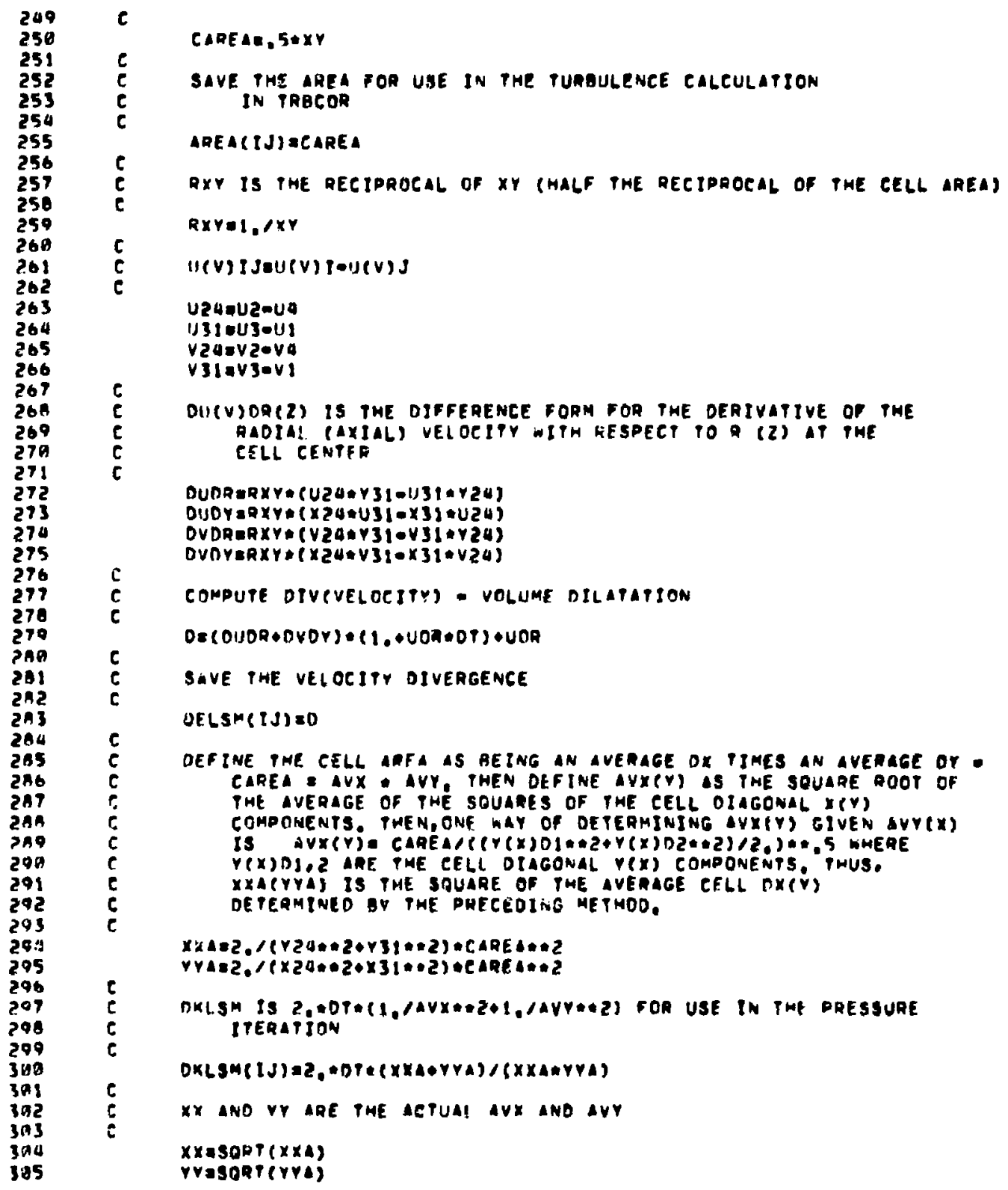




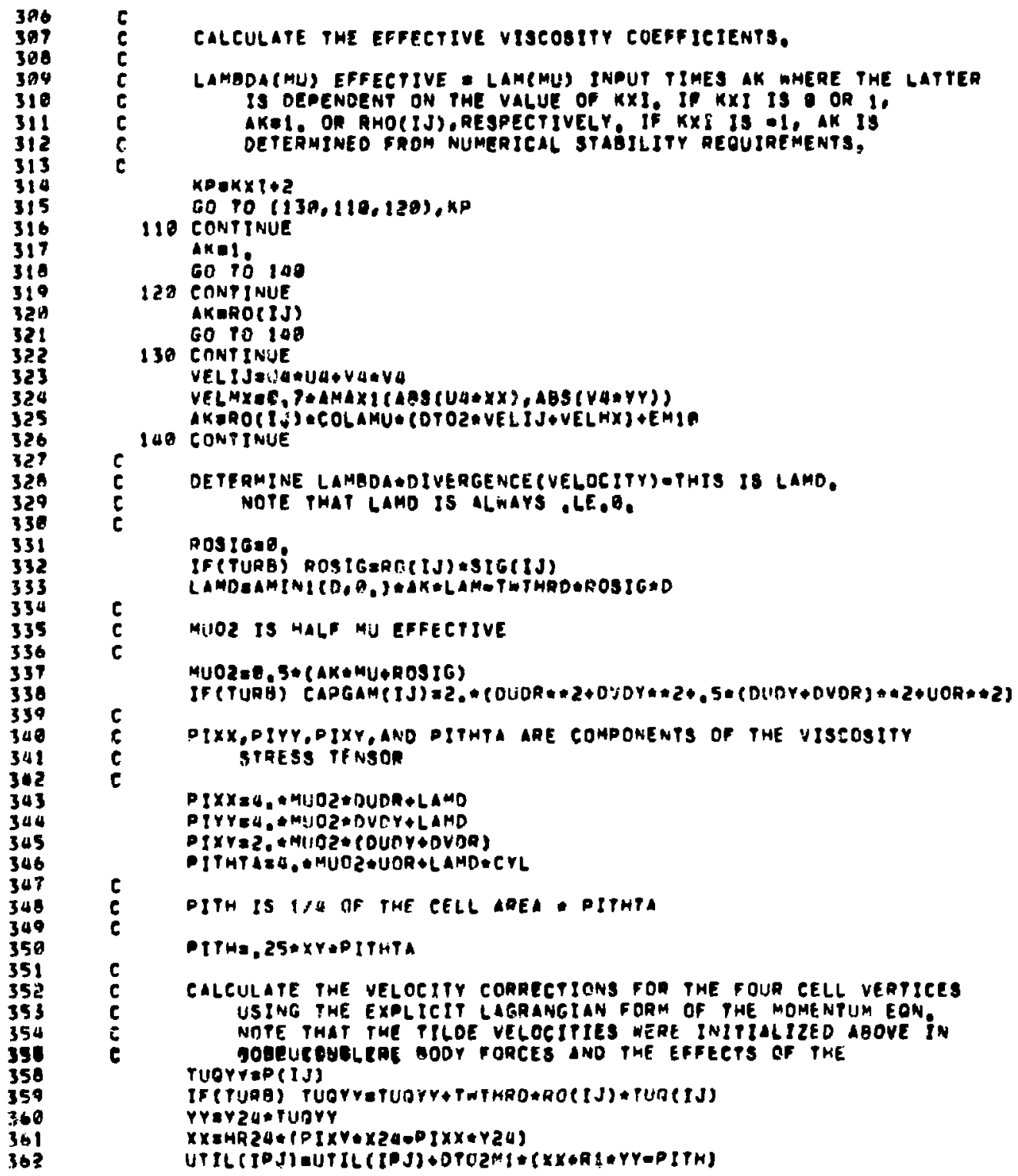



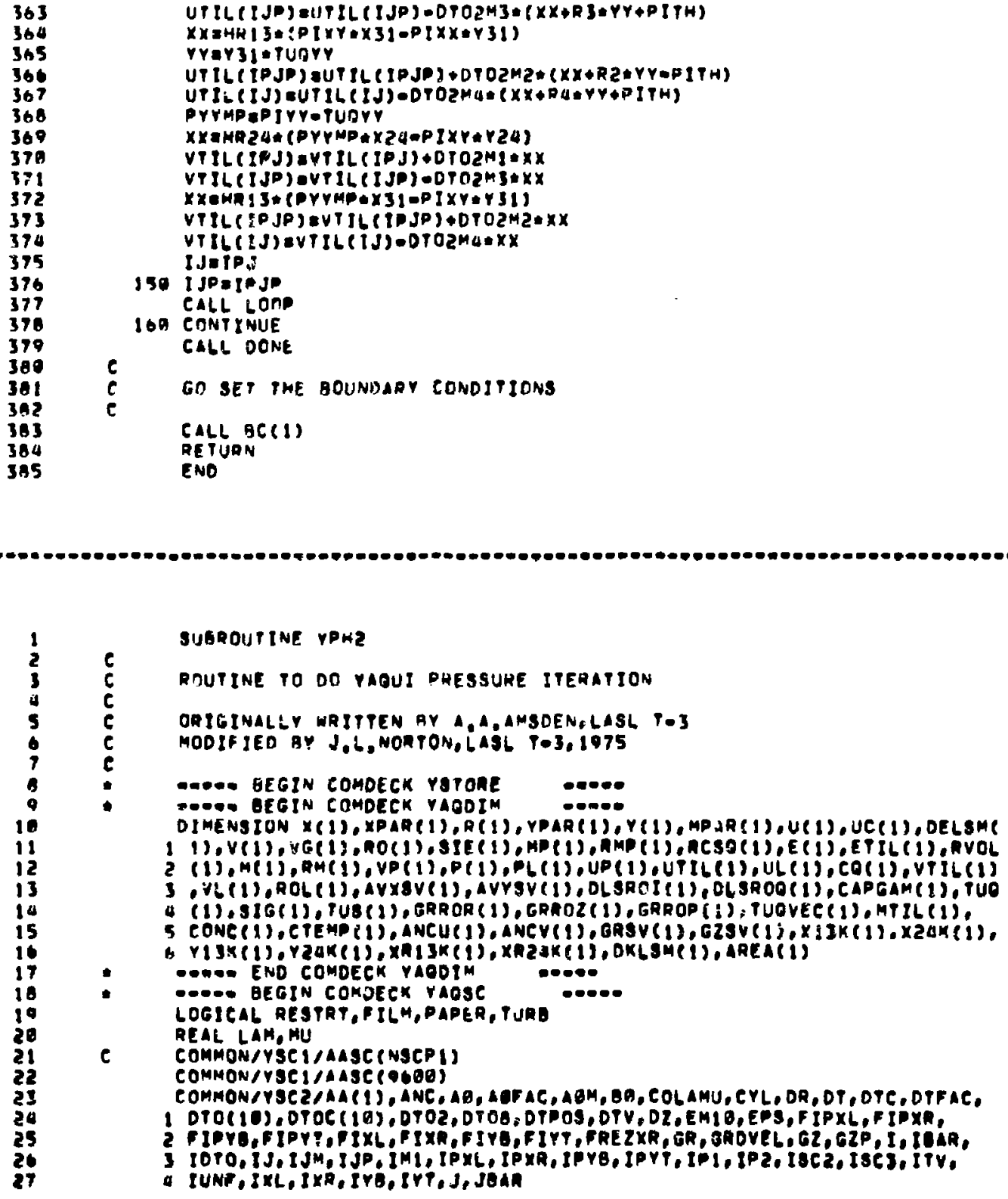


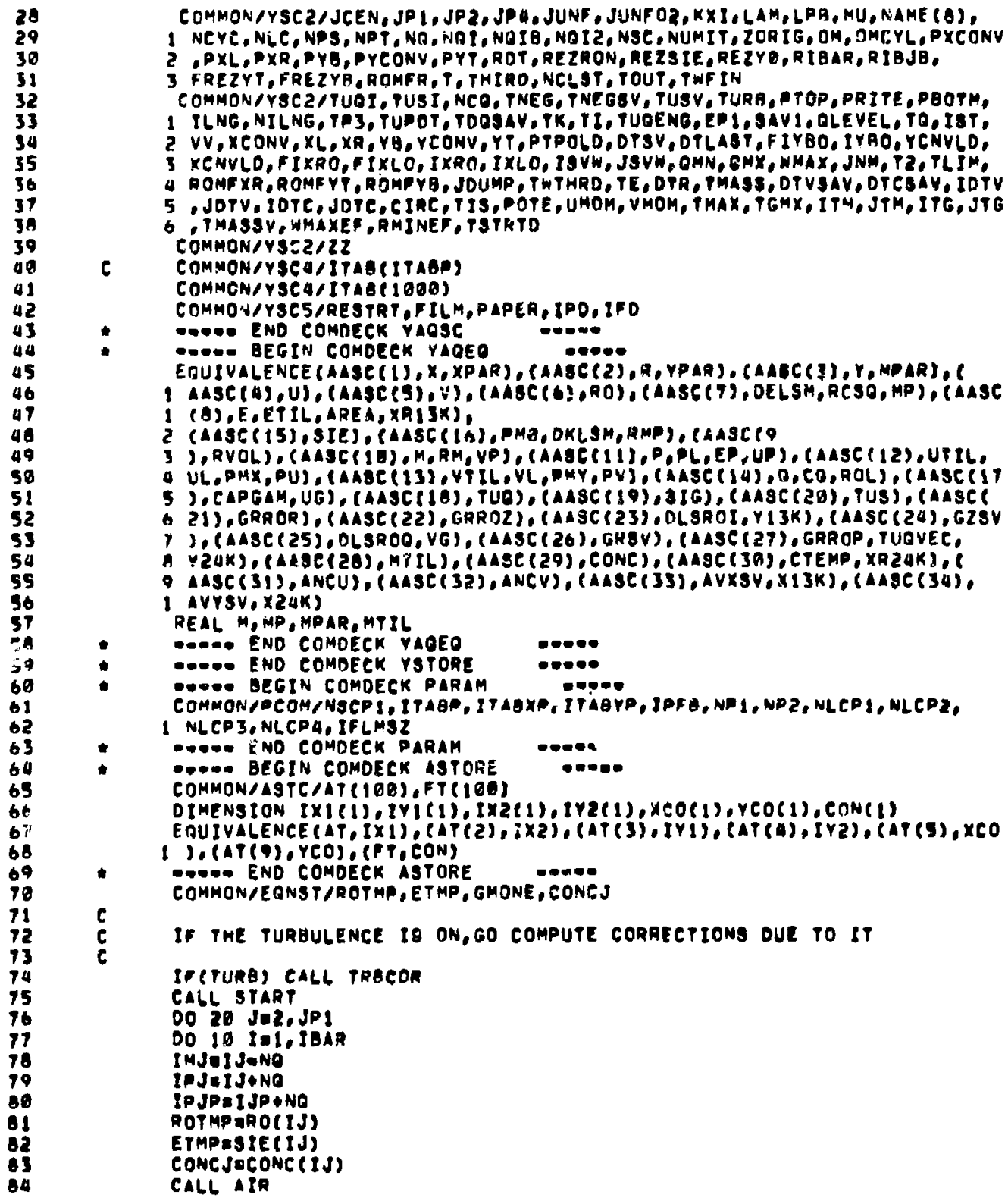




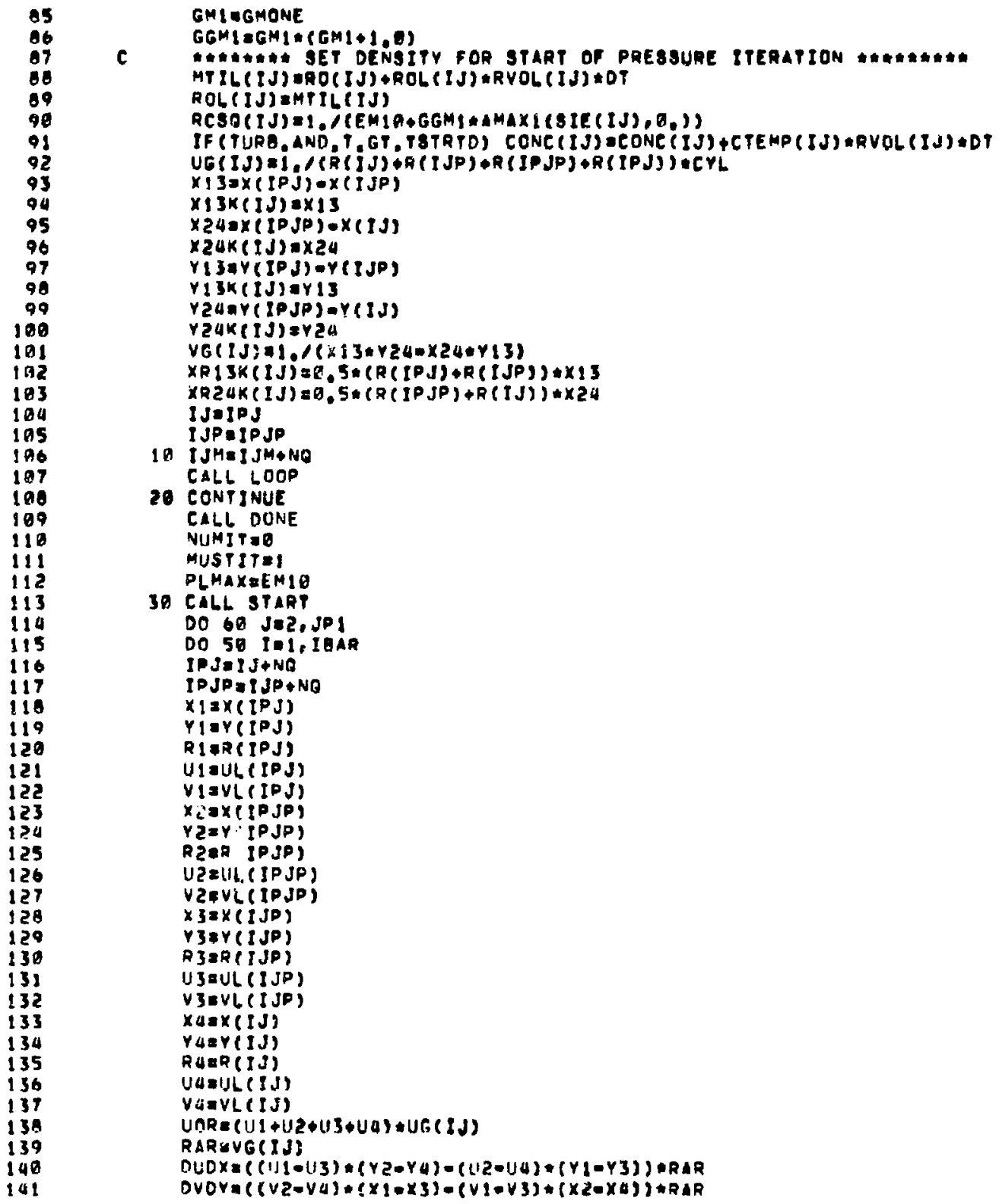




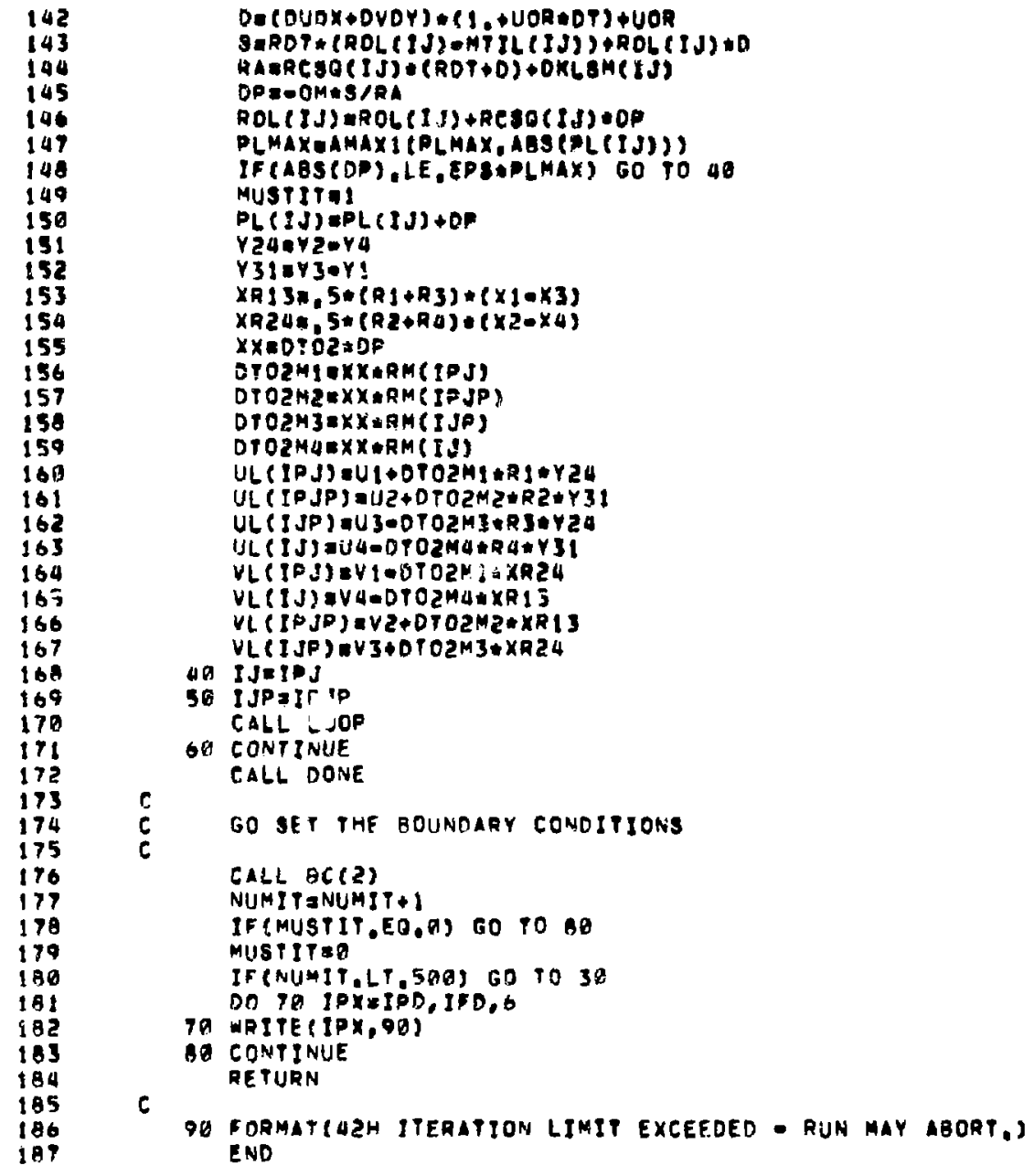

$\begin{array}{lll}1 & \text { SUBROUTINE YPHJ } \\ 2 & C & \text { ROUTINE TO FINISH PHASE I AND CALCULATE GRIO VELOCITIES } \\ 3 & C & \text { C }\end{array}$




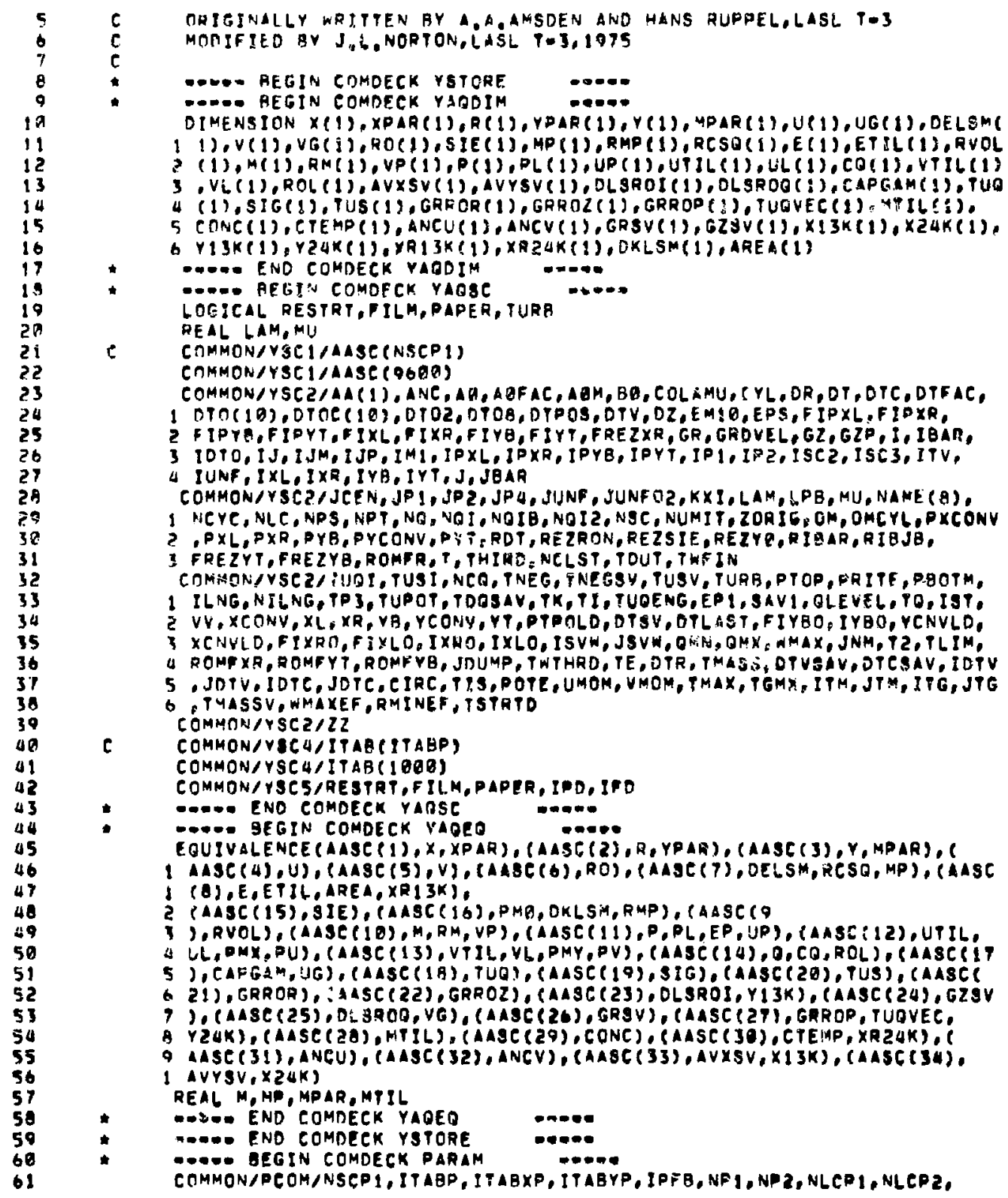




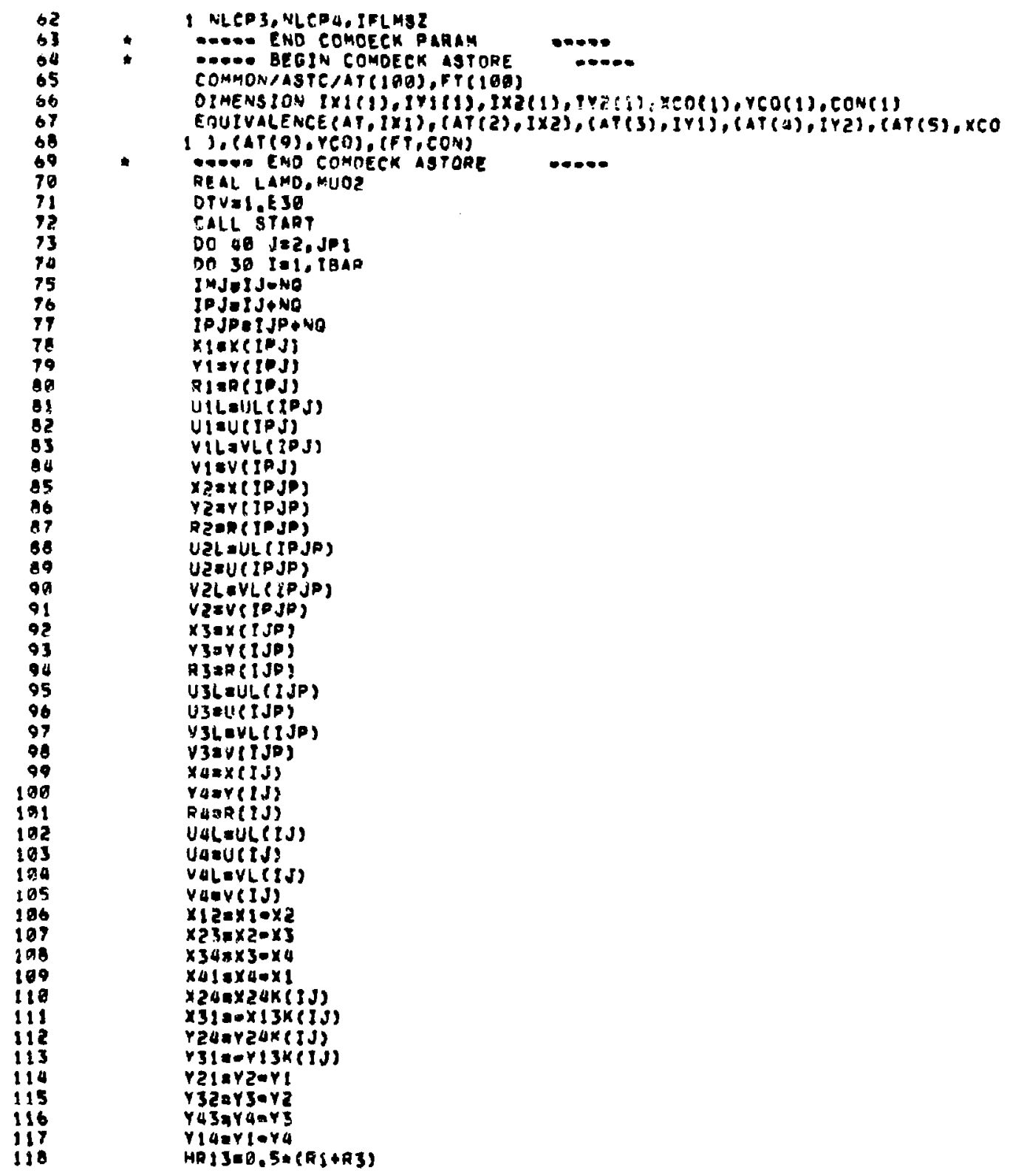




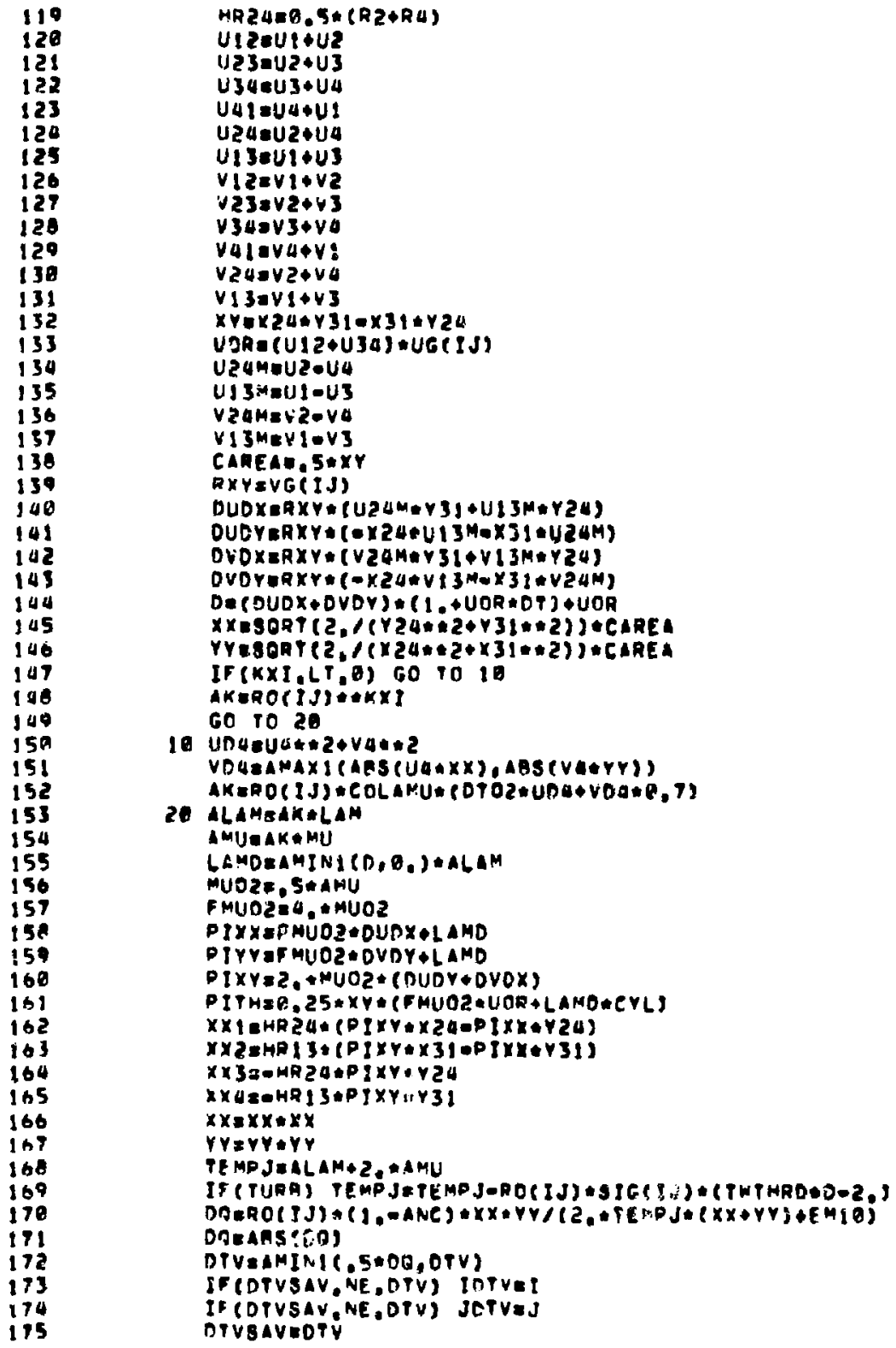

UiReUitu?

U23aU2 ४ 3

U34.U3*U4

U4 I IJ4 U?

U2 4 $42+44$

U13eU1+U3

$v i z=v i+v 2$

$v 23=V 2+63$

V $40 V 3 \leftrightarrow V a$

VALOVA\&V:

$v 24=v 2+v a$

$V 13=V 1+43$

XYEX2UAY $31=\times 31+Y 24$

USA $=(U 12+U 3 a) * U G(I J)$

U24MUUZ०UA

UJ 3intul-U3

$V Z A M E+2-V A$

VIJMEVIOVI

CAREAT.SEXY

RXY $x$ VG (IJ)

DUDXERXY*(U24M०Y3) U1 3M*Y24)

OUbYaRXY* $(0 \times 24 * U 13 M \circ \times 31 * 424 M)$

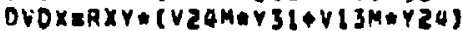

DVOYaAXr* $(-x 24 * V\{3 M 0 \times 3\} * V 24 M)$

$D=(D U D X+O V D Y) *(1 .+U O R * O T)+U O R$

$x \times \operatorname{sog}(2,1(Y 24 * 2 * Y 3) * 2))+C A R E$

YYesogY $(2, f(\times 24 * 2+x 3)-2)) *$ CAREA

IF $(K \times I, L T, B)$, TO TO 10

AKERO(IJ) ERKXI

60 To 20

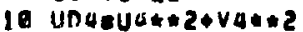

VDUEAmAXI (ARS (UAAXX), ABS (VACYY))

$A K=R O(I J) * C O L A K U *(D T O 2 * U D A+V O A * 0,7)$

20 LLAMBAKALAN

IMUEAKAMU

LGMDEAMINI $\left(D, 0_{0}\right)+A L A M$

MUOZF. S*ANU

F MUOZ:6. MUOZ

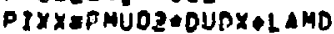

PIYYaFmUOz + DVDY $L A M D$

DIXY $=2 .+M U O Z *$ (DUDY DVOX)

PITHEP. 25*XYM (FMUOZAUOR + LAMDECVL)

$X X I=H R 24 *(D I X Y * X 240 P\{X X \in Y 24)$

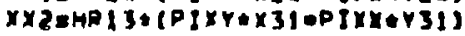

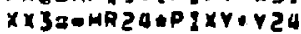

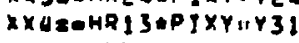

$X X \geq X X+X X$

$Y Y \geq Y Y \oplus Y Y$

TE MPJEALAM+2, MAMU

IF (TURA) TEMPJETEMPJ-AD(IJ) * SIG(D)* (TWTHRDED-2,

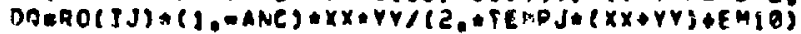

DAR AAs:(iD)

DTVEAMINI $, 5 * 00,0 T V)$

IF (DTVSAV. NE, DTV) IOTVET

IF (DTVSAV, NE, DTV) JETVEJ

DTVBAVEOTY 


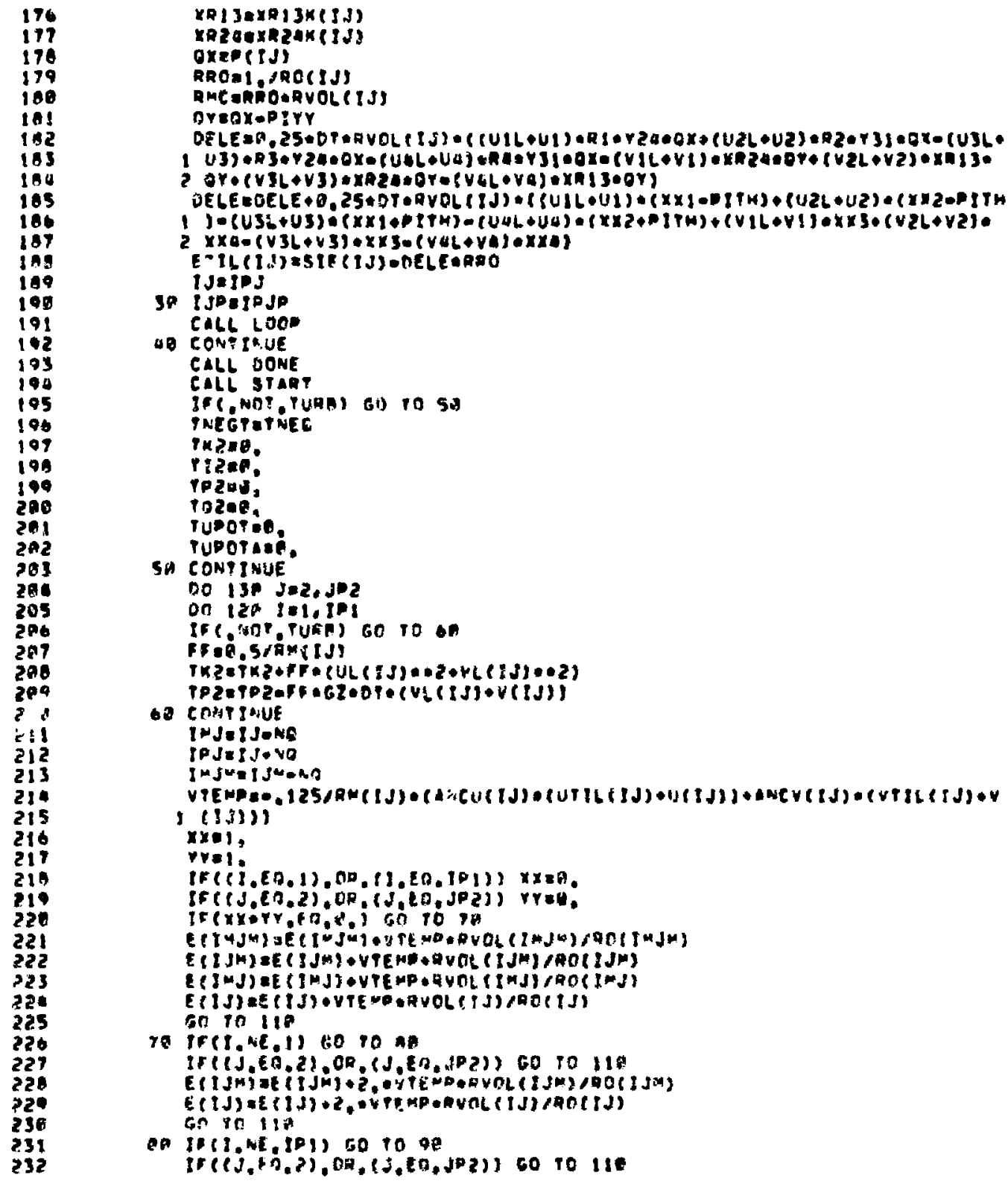




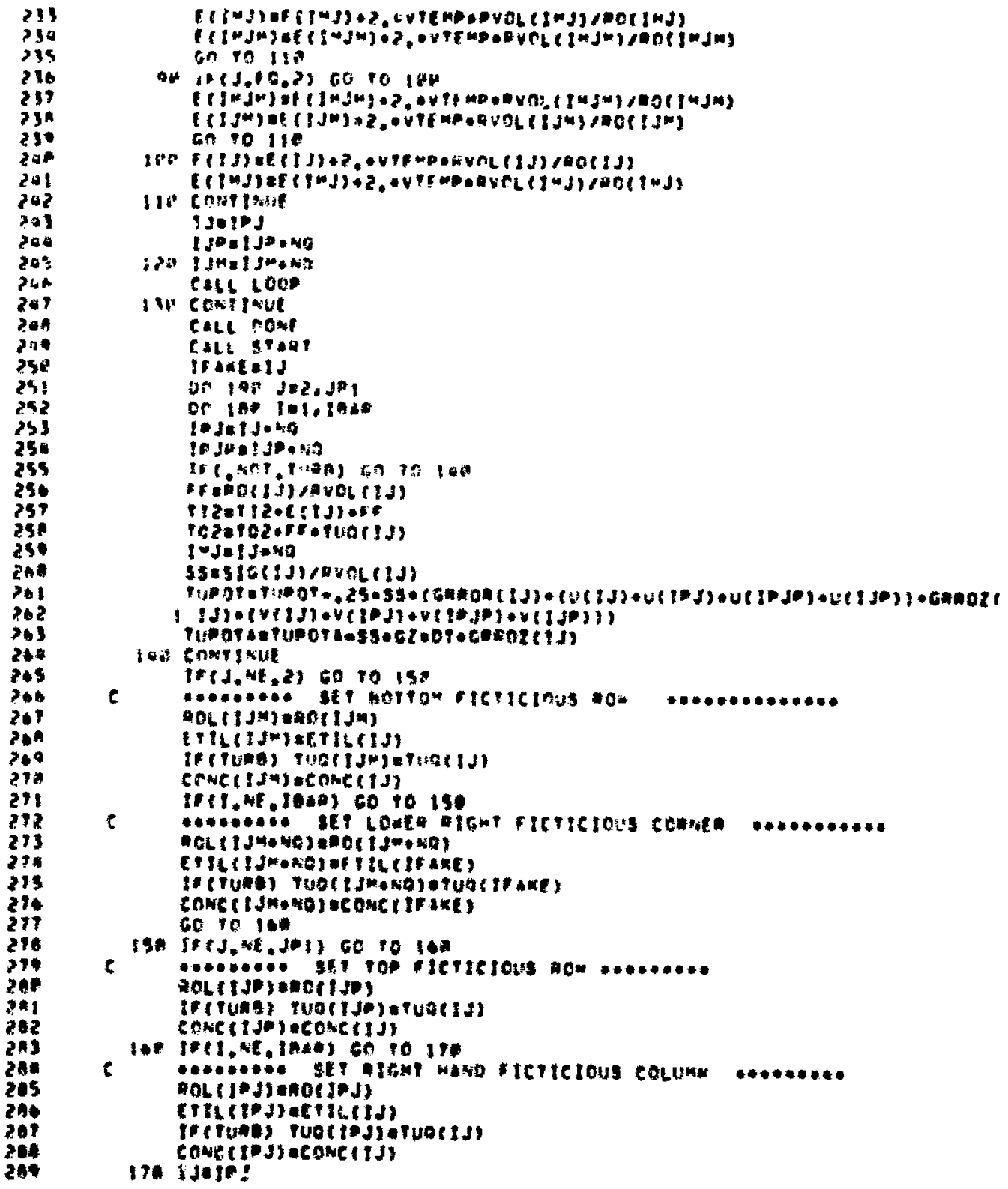




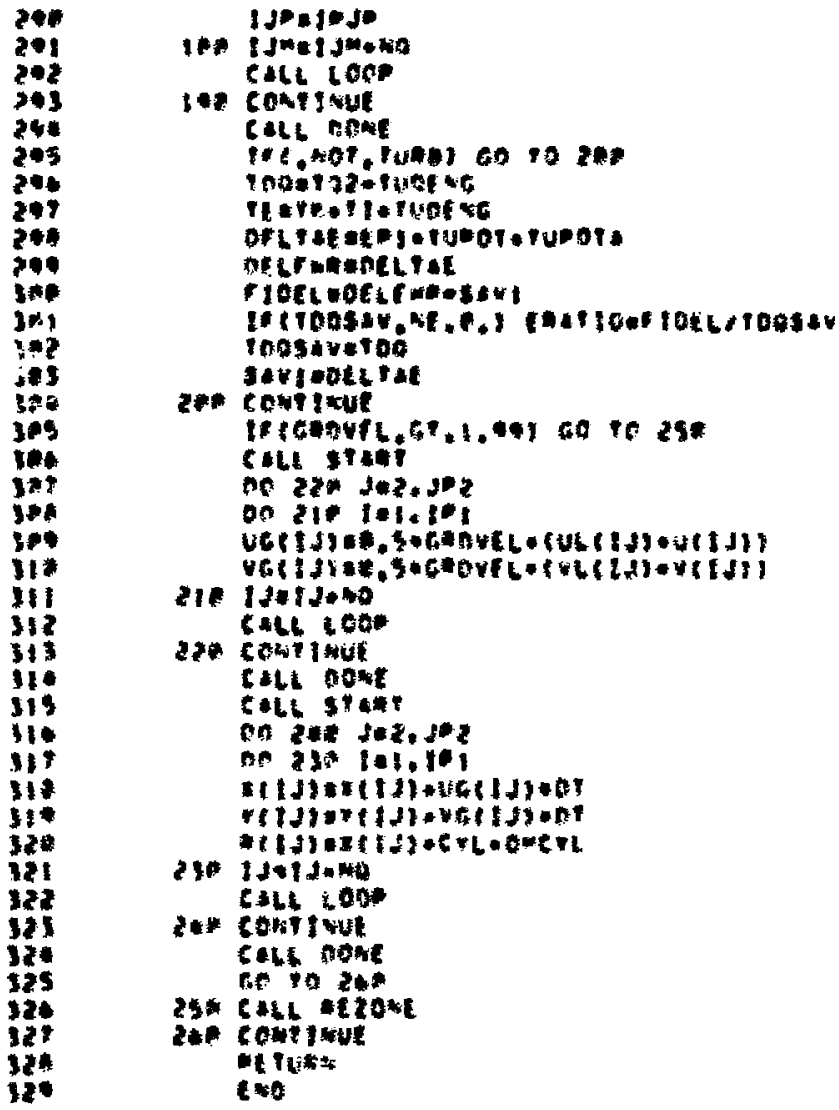

cate tore

149 cont 1 nut

call nowe

14t not Futer at is 200

1 nat $72-1$ the

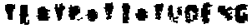

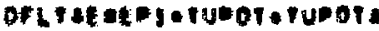

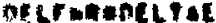

potteofifweot

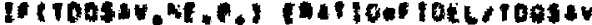

innswetog

$34+5004$ tot

2a) cowiche

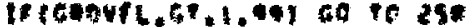

6Lt $\$$ int

no 280 jez.50?

on zit 101.801

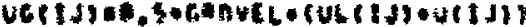

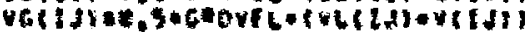

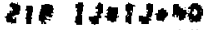

cale tot

ato cont Init

coll tomt

tol stat

an ant toz.tez

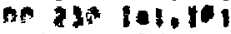

(t)

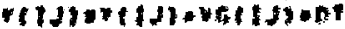

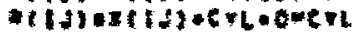

210 15012-40

c4t 200

2.* cont int

GAL not:

for $0 \geq 0$

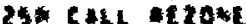

240 coitinte

thits

e*0

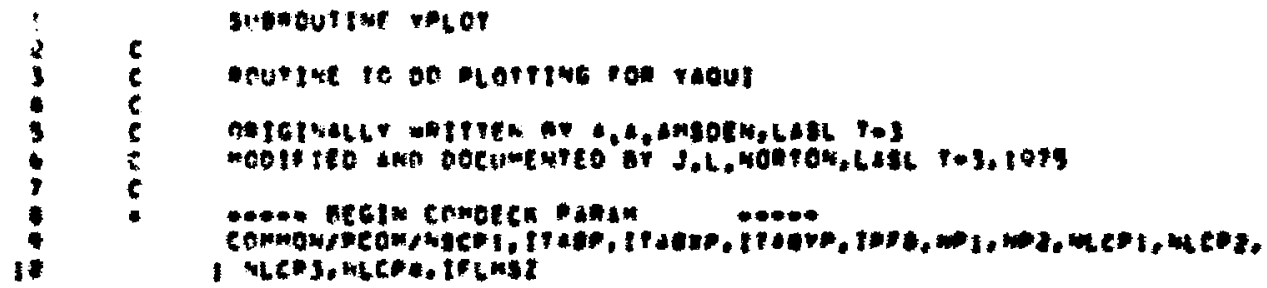




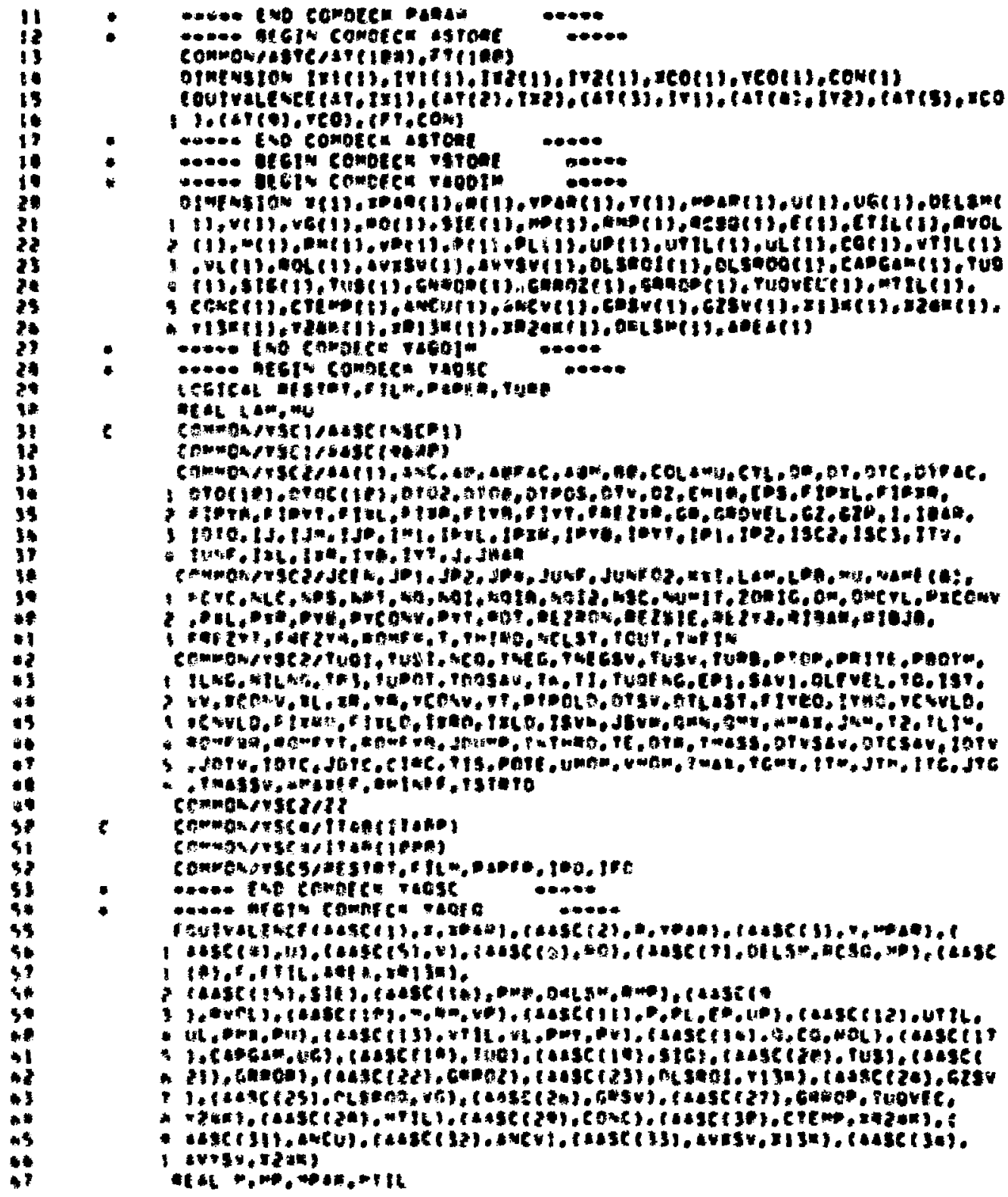




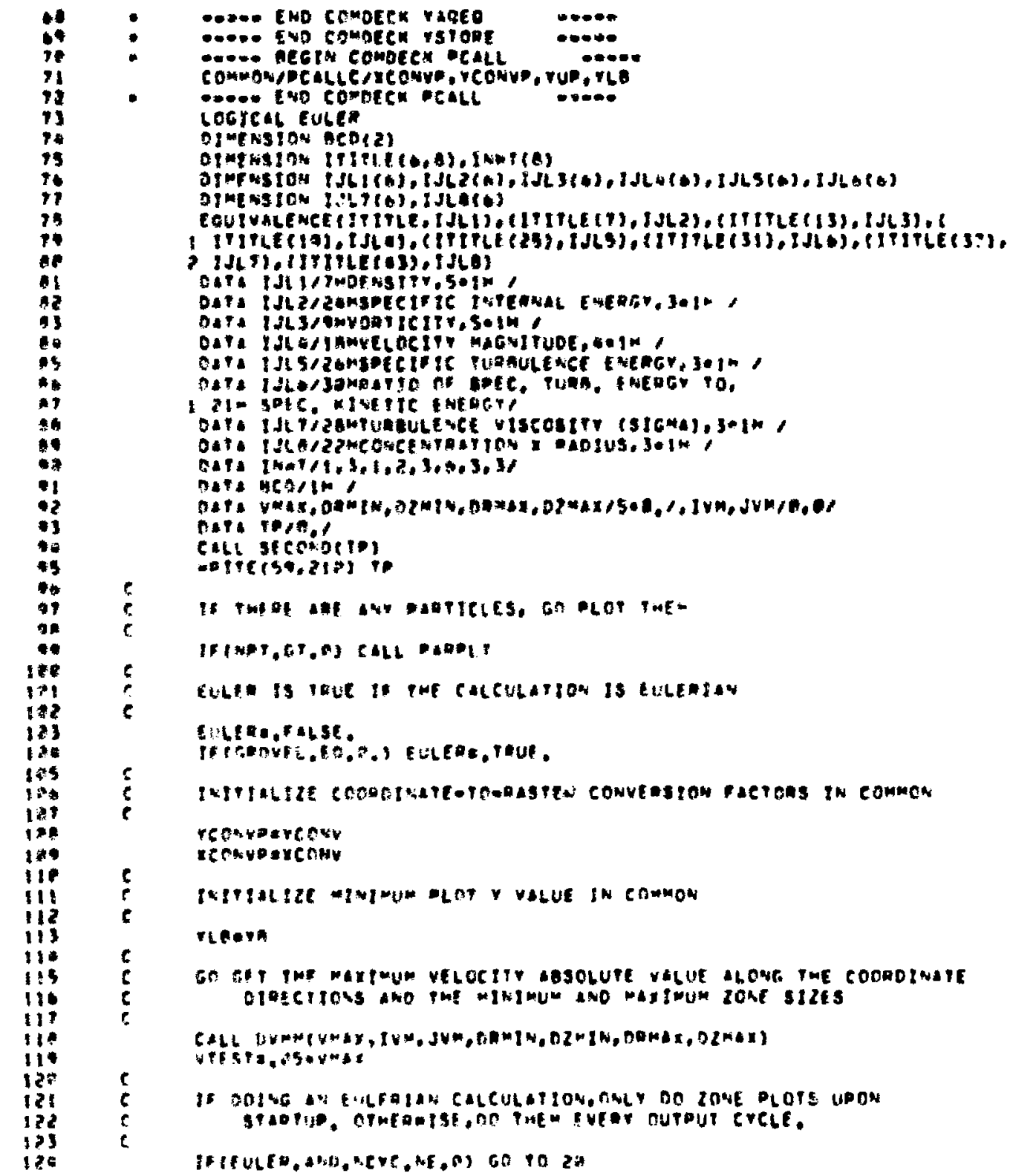




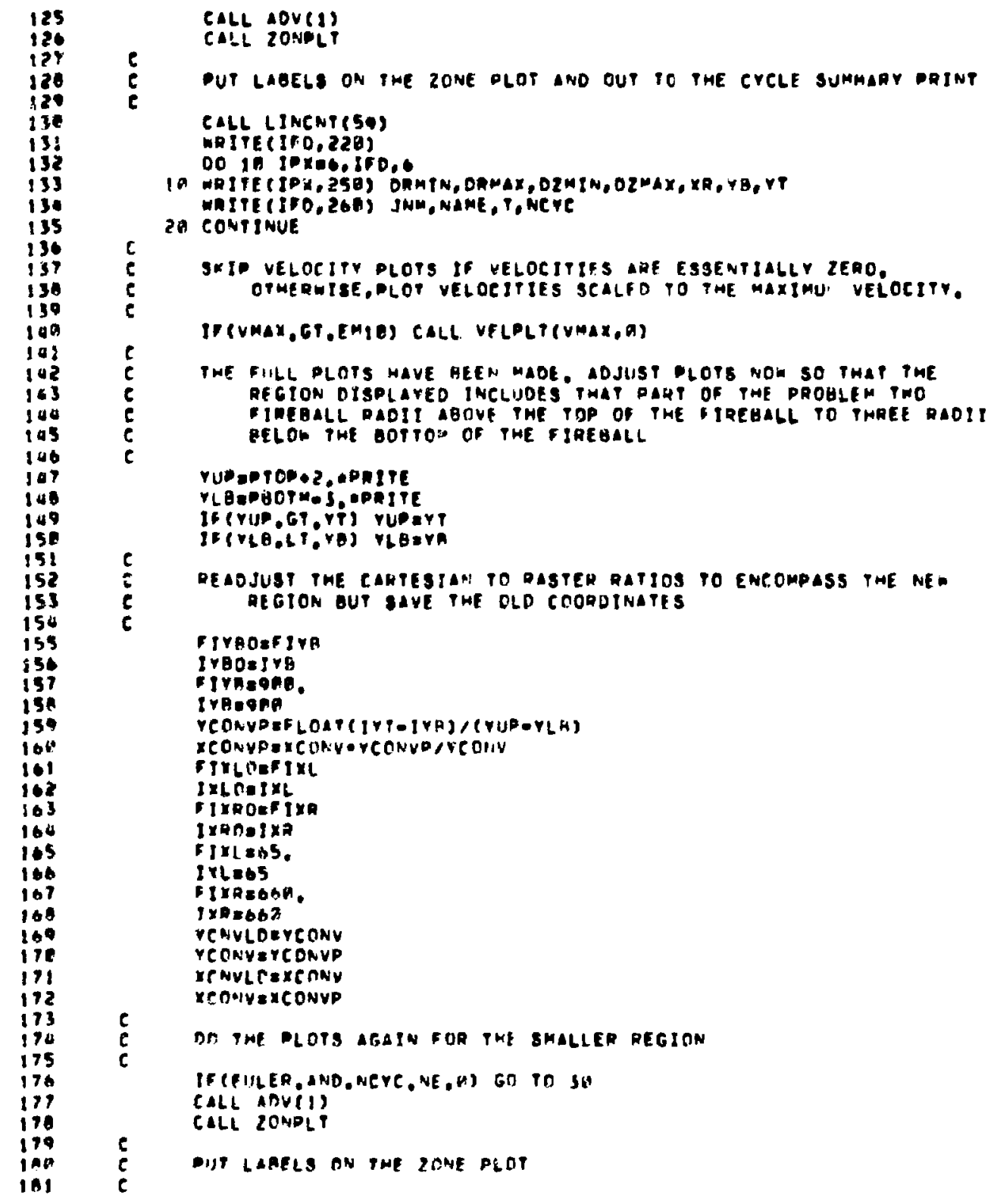




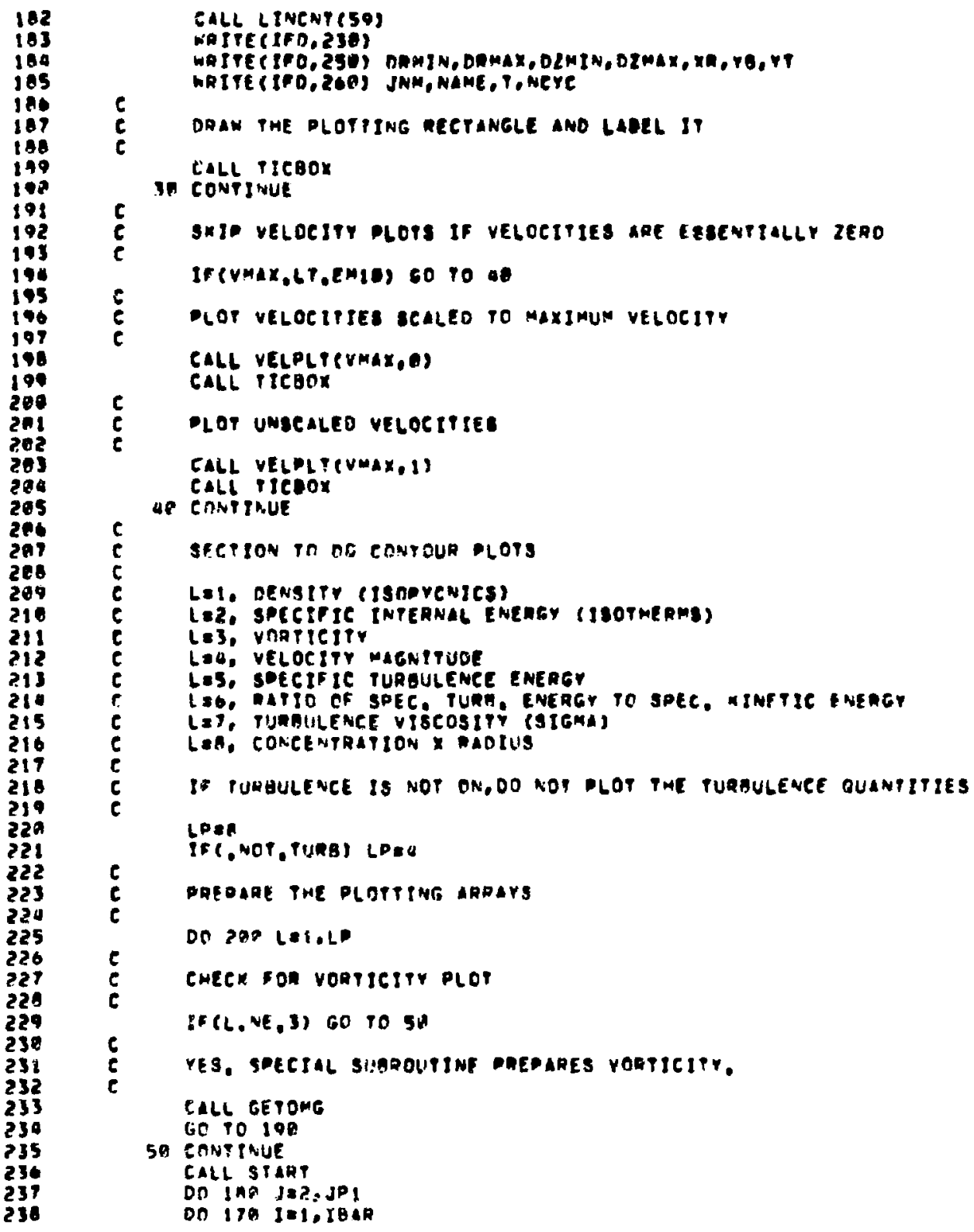




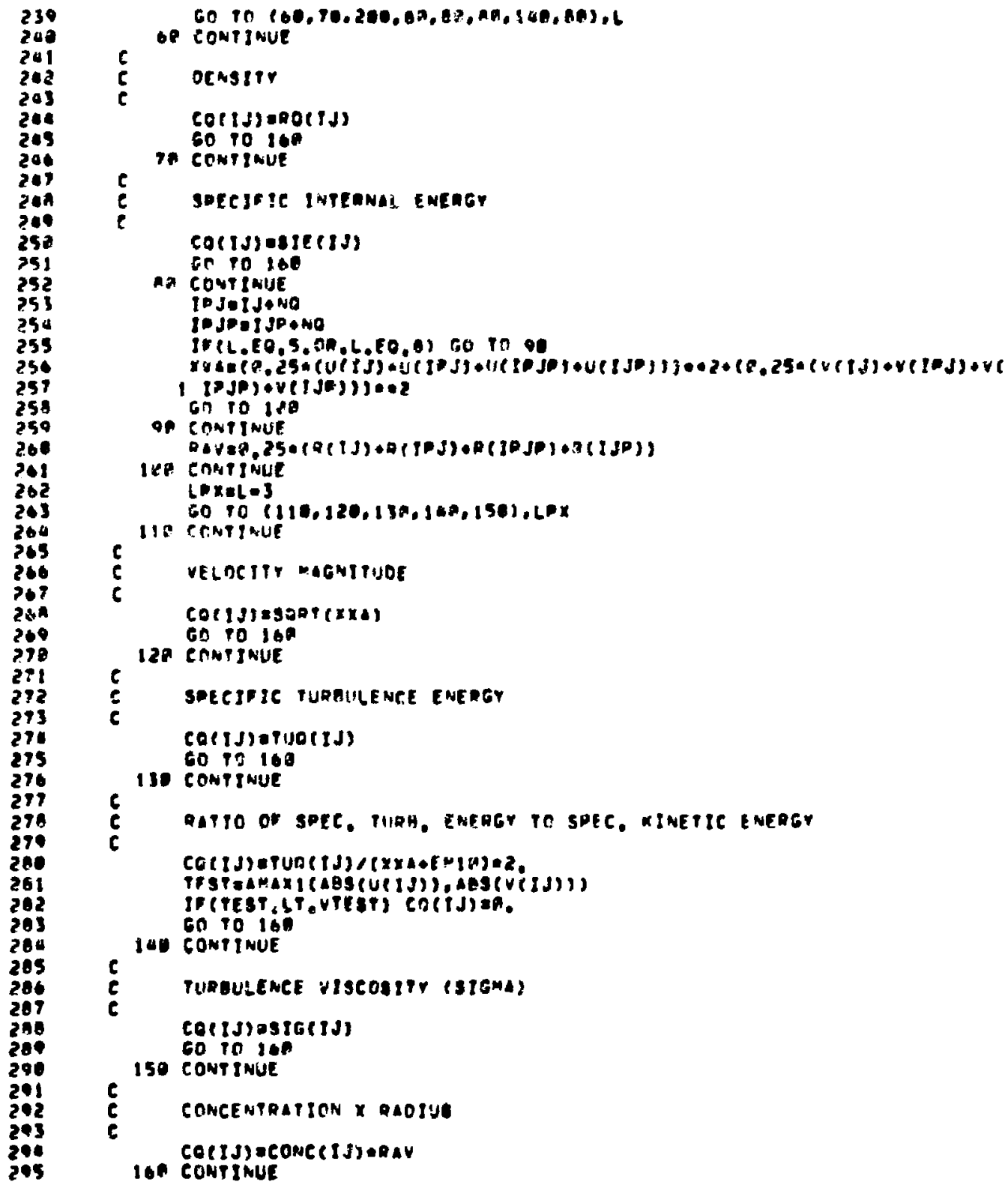




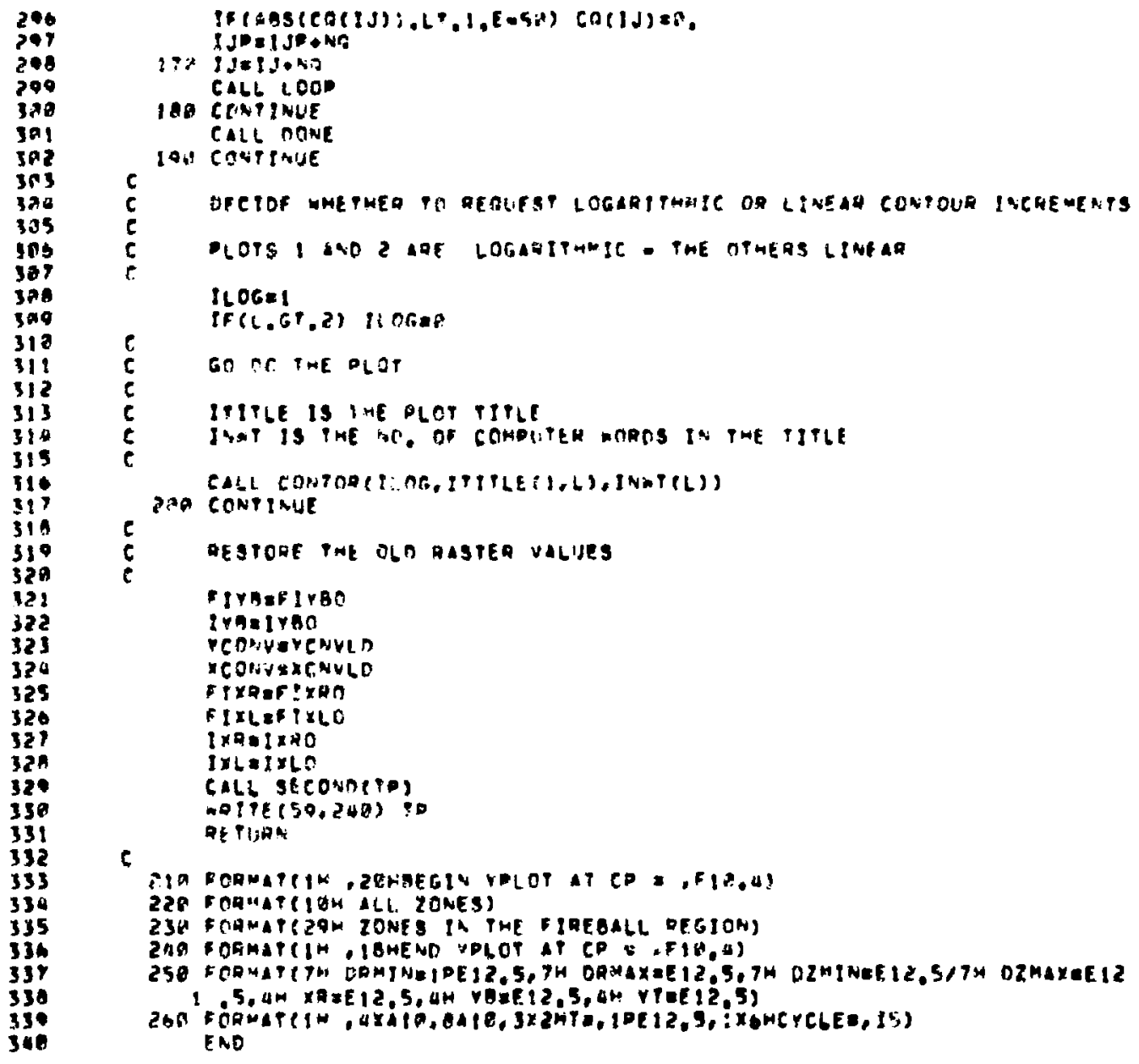

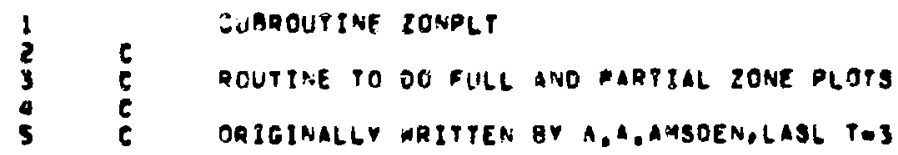




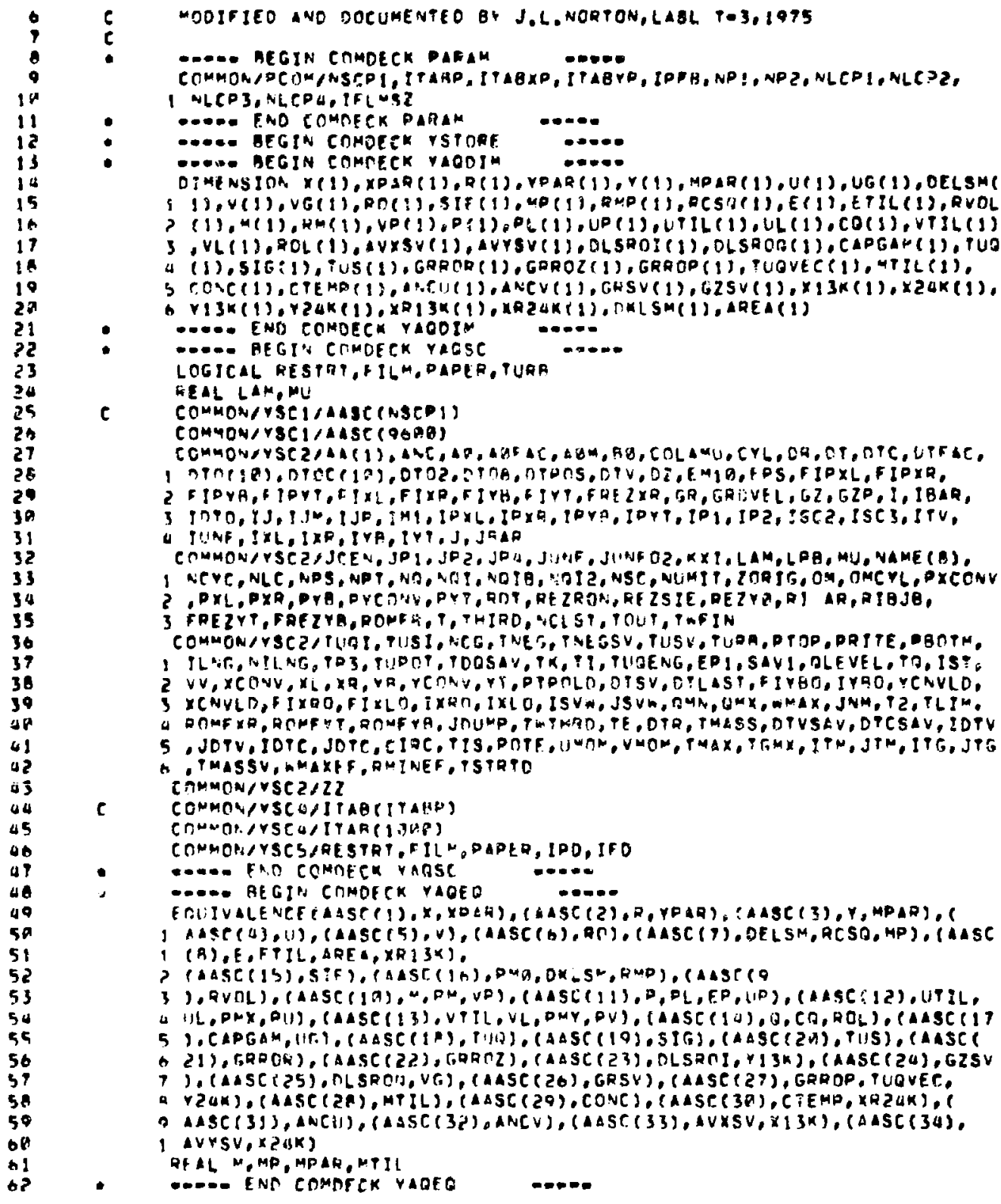




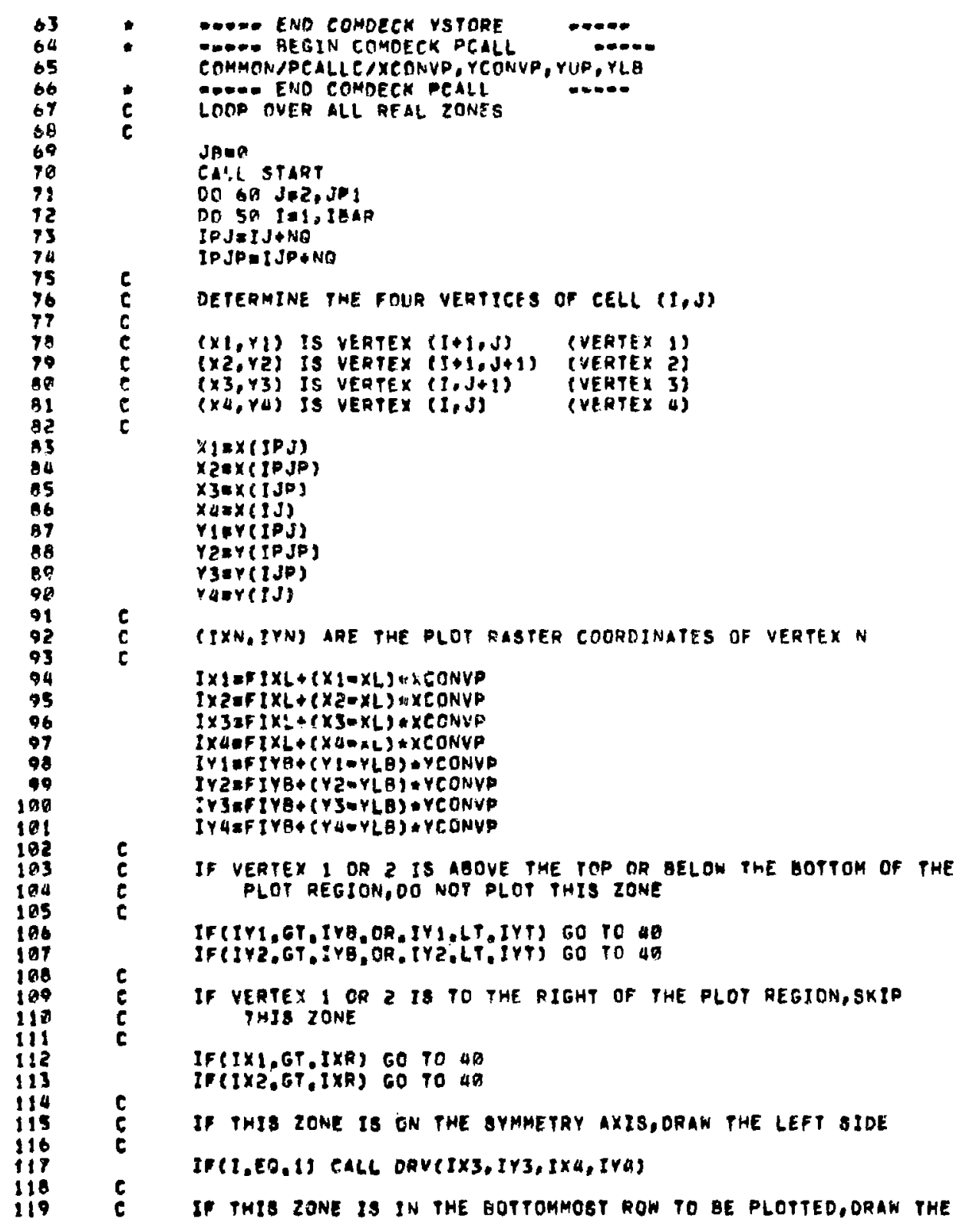




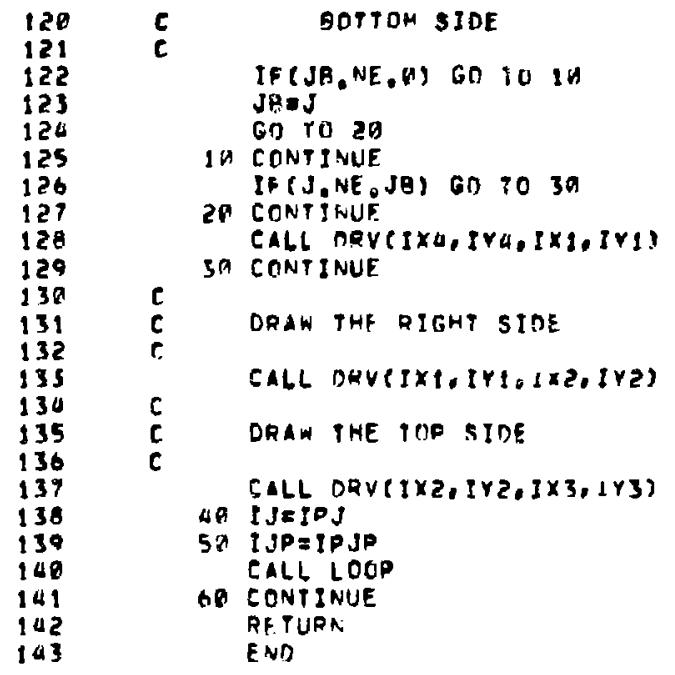

1. F, H. Harlow and A. A. Amsden, "A Numerical Fluid Dynamics Calculation Method for All Flow Speeds," J. Comp. Phys. B, 197 (1971).

2. C, w. Hirt, A. A. Amsden, and J. L. Cook, "Ari Arbitrary Lagrangian-Eulertar Computing Method for A11 Flow Speeds," J. Conp. Phys., 14, 227253 (1974).

3. A. A. Amsden and C. W. Hirt, "YAQUI: An Arbitrary Lagrangian-Eulerian Computer Program for Fluid Flow at All Speeds," Los Alamos Scientific Laboratory report LA-5100 (March 1973).
4. W. E. Pracht, "Calculating Three-Dimensional Fluid Flows at All Speeds with an EulerianLagrangian Computing Mesh," J. Comp. Phys. 17, 132 (1.975).

5. H. M. Ruppe1, R. A. Gentry, and B. J. Daly, "Simulation of Turbulence In Fireballs," Los Alamos Scientific Laboratory report LA-5449-MS (November 1973).

6. H. M. Ruppel and J. I. Norton, "Theoretica: Simulations of the Gas Explosive Simulatio Technique (GEST) Experiments," Los Alamos Scientific Laboratory report LA-6154-MS (December 1975). 